$$
S R / H=-863
$$

\title{
REPORT \\ OF
}

\section{MATERIAL \& EQUIPMENT}

\section{SECTION'S}

ACTIVITIES

AT

NEW YORK SHIPBUILDING CORP. DURING FABRICATION

\author{
OF \\ $\mathrm{AXC} 1671 / 2$ \\ STARTING MAY 18, 1951 \\ PART VII - SECTION III \\ BY: JAMES RAY STEWART
}

APRIL 28, 1954 


\section{DISCLAIMER}

This report was prepared as an account of work sponsored by an agency of the United States Government. Neither the United States Government nor any agency thereof, nor any of their employees, make any warranty, express or implied, or assumes any legal liability or responsibility for the accuracy, completeness, or usefulness of any information, apparatus, product, or process disclosed, or represents that its use would not infringe privately owned rights. Reference herein to any specific commercial product, process, or service by trade name, trademark, manufacturer, or otherwise does not necessarily constitute or imply its endorsement, recommendation, or favoring by the United States Government or any agency thereof. The views and opinions of authors expressed herein do not necessarily state or reflect those of the United States Government or any agency thereof. 


\section{DISCLAIMER}

Portions of this document may be illegible in electronic image products. Images are produced from the best available original document. 

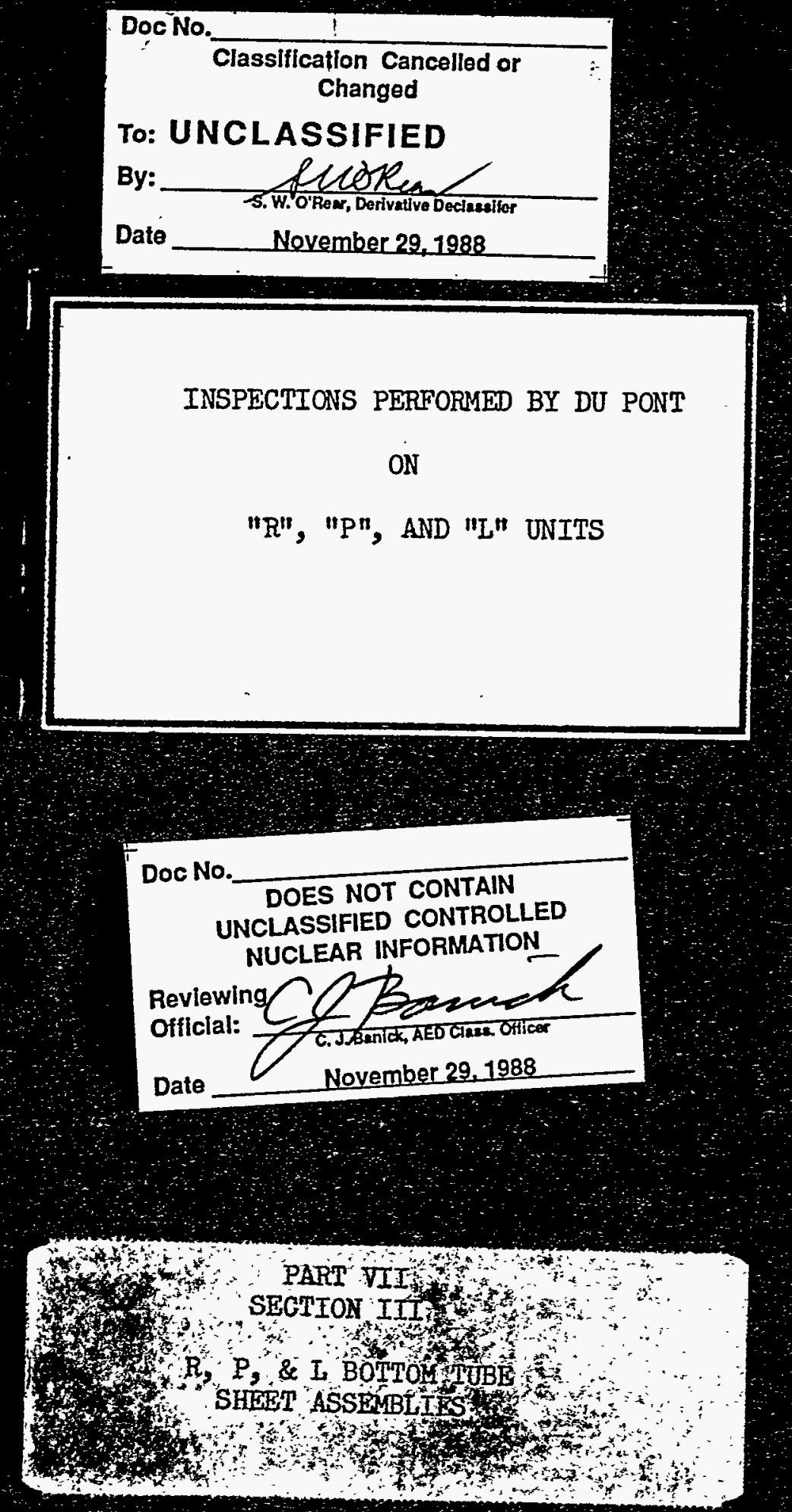
1. Plate Preparation............................

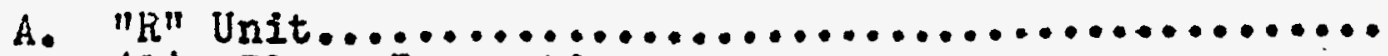

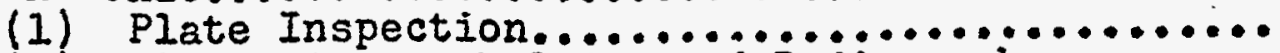

(2) Plate Fit-up, Velding and Radiograph

Inspection...........................

B. "p" Unit...............................

(1) Flate Inspection ......................

(2) Plate Fit-up, Welding and Radiograph

Inspection.

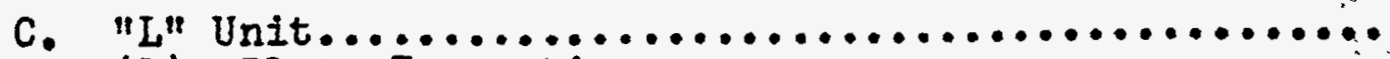

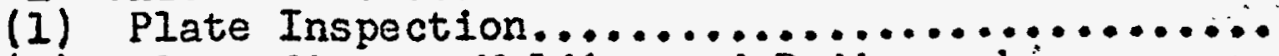

(2) Plate fit-up, Welding and Radiograph

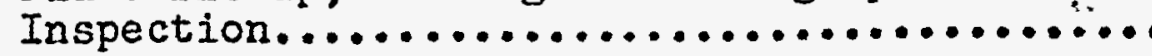

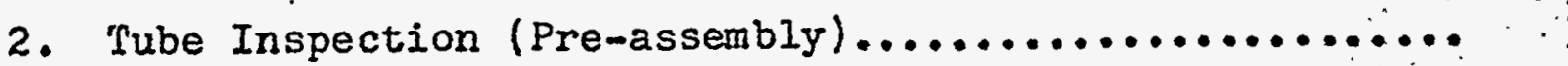

A. ${ }_{\mathrm{h}}{ }^{n}$ Unit $\ldots \ldots \ldots \ldots \ldots \ldots \ldots \ldots \ldots \ldots \ldots \ldots \ldots \ldots \ldots \ldots \ldots$

B. "pn Unit..............................."

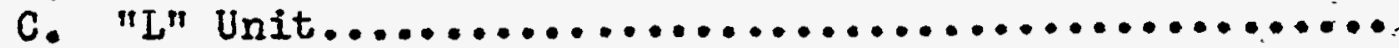

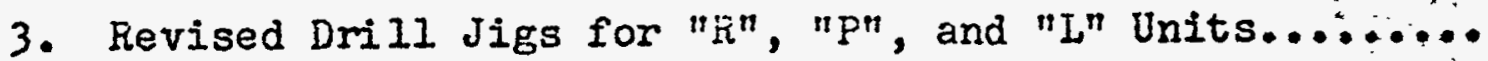

4. Trepanned Bottom Tube Sheet Inspections..............

A. $" \Omega^{1}$ Unit...............................

B. "P" Unit.

C. "L" Unit.

5. Diminsional Check of the Tube Sheet Ligaments and

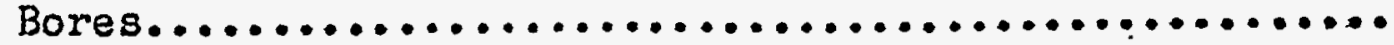

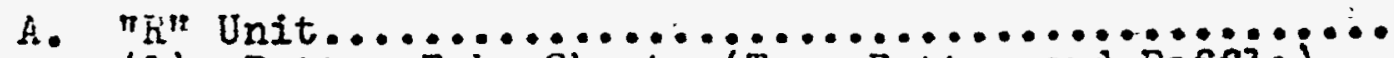
(1) Bottom Tube Sheets (Top, Bottom and Baffle)...

B. "p" Unit................................ (1) Bottom Tube Sheets (Top, Bottom and Baffle)...

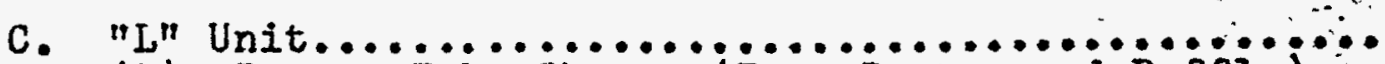
(1) Bottom Tube Sheets (Top, Bottom and Baffle)

6. Inspection of Tube Sheets After Grinding and Acid Washing....................................

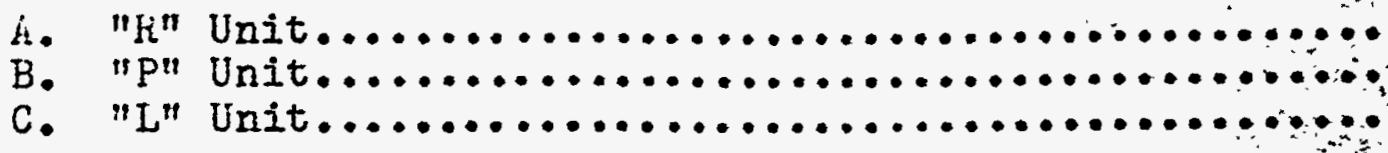

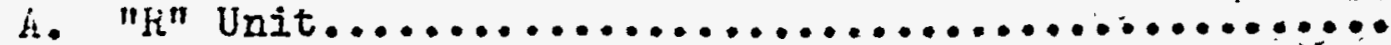

C. "L" Unit。 
7. Assembling of "R", "P", \& "L" Bottom Tube Sheets.......

A. "K" Unit.................................

(I) Gusset Plate Pre-assembiy Inspections..........

(2). Inspections Performed During Assembling of

(3) Baffle Plate Spacers, Sandbiasting, Äid

(4) ishing, and Ferroxyl Testing................

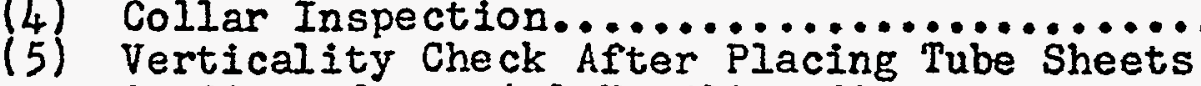
in Circumferential Handling Jig..............

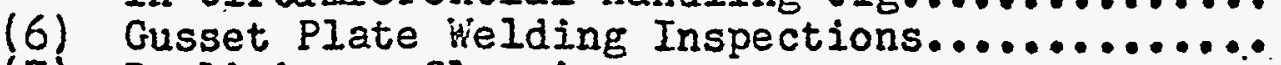

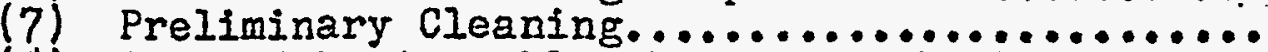

(8) Large Tube Assembly, Instrument iell, and Tack Vielding Inspections..................

(9) Types of Tubes Assembly in "lR" Bottom Tube

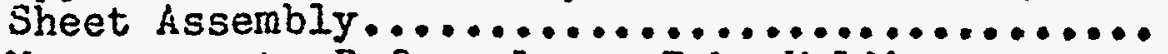

(10) Nieasurements Before Large Tube helding to Determine Unit Shrinkage...................

(11) Measurements After Large Tube Vielding to Determine Unit Shrinkage..................

(12) Visual Inspection and Repair of Tube Velding..

B. "p" Unit..................................

(I) Gusset Plate Pre-assembiy Inspections..........

(2) Inspections Performed During Assembling of

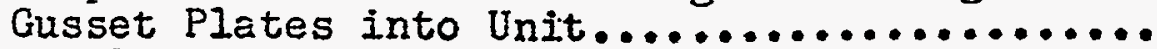

(3) Baffle Plate Spacers, Sandbiasting, Acid

(4) hashing and Ferroxyl Testing................

(4) Collar Inspection..................................

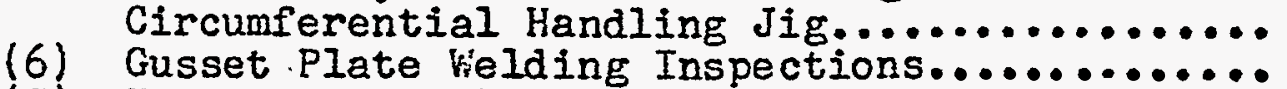

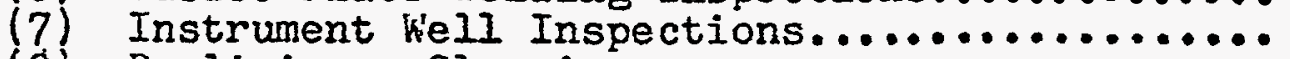

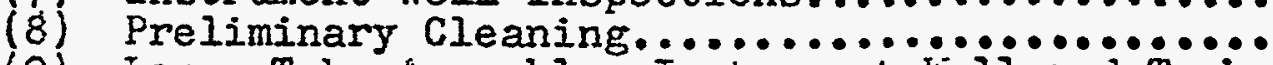

(9) Large Tube Assembly, Instrument heli and Tack

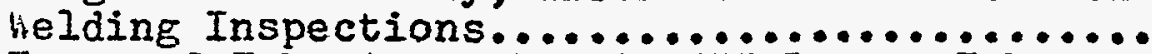

(10) Types of Tube Assembied in "p" Bottom Tube

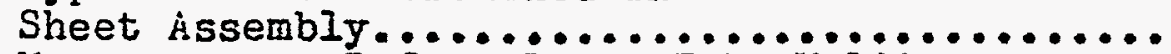

(1I) keasurements Before Large Tube Velding to Determine Unit Shrinkage..................

(12) ireasurements After AII Tubes had been ielded..

(13) Visual Inspection and Repair of Tube Felding..

(14) Replacement of Tubes as a Result of reld Burn Through............................

II

II

11

11

II

II

11

11

12

12

13

13

13

13

13

14

14

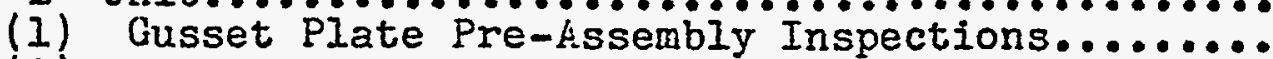

(2) Inspections Performed During Ássembling of Gusset Plates into Unit...................

(3) Baffle Plate Spacers, Sandblasting, Acid

Washing, and Ferroxyl Testing.............. 14

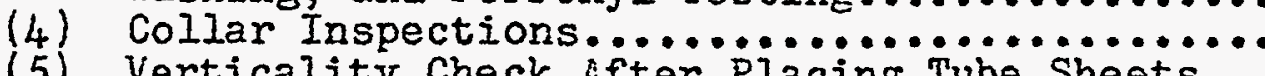

(5) Verticality Check After Placing Tube Sheets in Circumferential Handling Jig..............

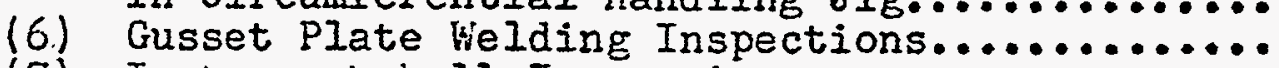

(7) Instrument hell Inspections...................

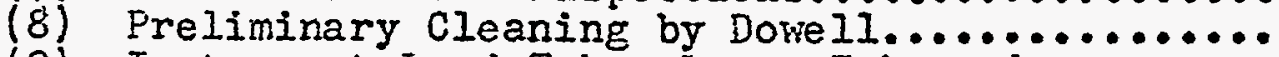

(9) Instrument Lead Tube, Large Tube and

Instrument bell Assembly, and Tack Welding

Inspections............................

14

14

15

15
16 
(10) Types of Tubes Assembled in " $\mathrm{L}^{\text {" Bottom Tube }}$ Sheet Assembly..........................

(11) Veasurements Before Large Tube lielding to Determine Unit Shrinkage..................

(12) Neasurerents After all Tubes had Been Velded..

(13) Visual Inspection and Repair of Tube helding..

(14) Replacement of Tubes As a Result of Held Burn Through.............................. 18

8. Nachining hrapper Plate veld Preparation and Gusset Plate lisiling.................................

A. "R" Unit..................................

B. "P" Unit...................................

C. "L" Unit..................................

9. Fitting Stiffeners to Gusset Plates and Assembling of Inlet and Outlet cups.........................

А. "R" Unit................................

B. "P" Unit................................

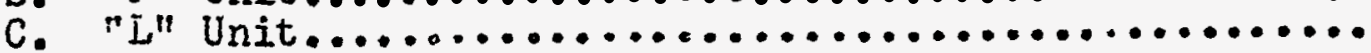

10. Prelininary Cleaning by Dowell Corp................

f. " "il" Unit................................. 20

B. "P" Unit..................................

21

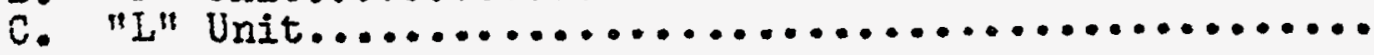

21

11. Cleanliness and Visual Inspection of Hrapper Plates.... 22

A. $" R^{n}$ Unit..............................

B. "P" UnIt................................

C. . "L" Unit................................

12. Hachining of Bottom Tube Sheet Tube Ends, Tube Reaming and Tube Kepair..............................

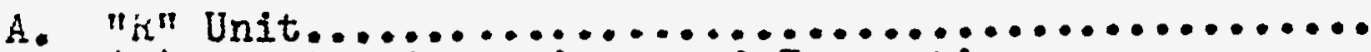
23

(1) Facing Operations and Inspections.............

(2) Tube Reaming Operation.....................

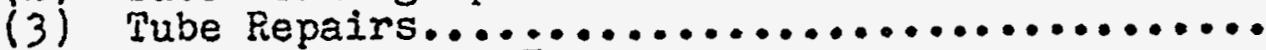

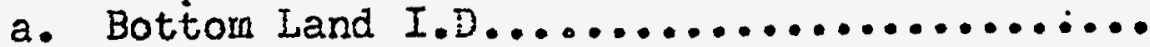

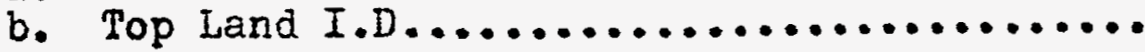

B. "p" Unit..............................

(1) Zy-glo Testing on Top Edges of Tubes on both

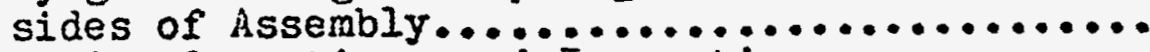

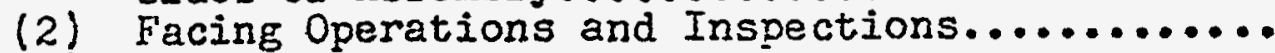

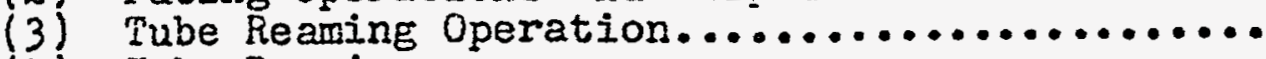

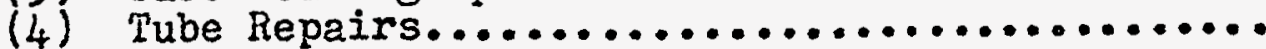

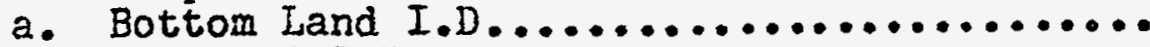

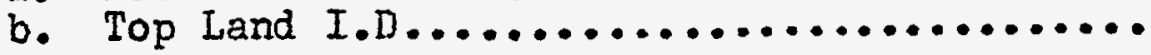

C. "L" Unit..............................

(I) Facing Operations and Inspections............

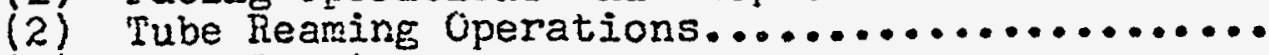

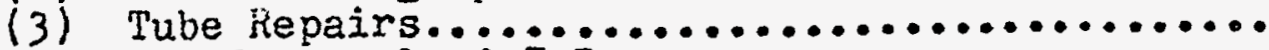

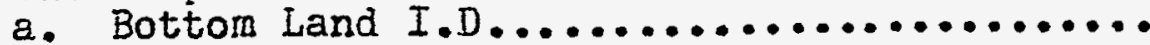

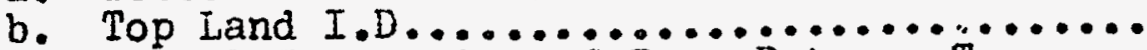
c. Visual Inspection of Bore Between Top 
Page No.

13. Honitor Pin Groove Inspection................... 34

A. "R" Unit.................................

B. "Pn Unit.................................

C. "L" Unit.

14. Preliminary Hydrostatic Test and Bottom Tube Sheet

Testing Program...............................

A. "Kn Unit.

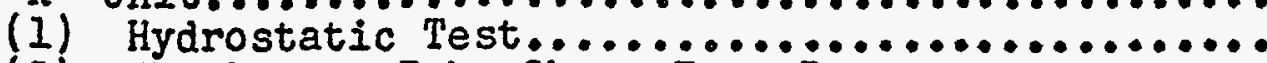

(2) "R" Bottom Tube Sheet Test Program................

(3) "R" Bottom Tube Sheet Test Program and Special Tests Conducted by du Pont Inspectors..........

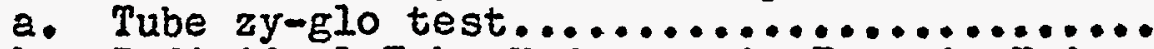
b. Individual Tube Hydrostatic Test in Unit.. c. Removal of Sixteen Defective Tubes..........

d. Sandblasting and Acid Washing (Exterior

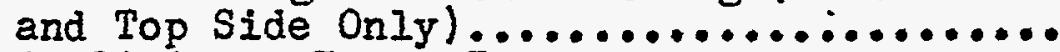

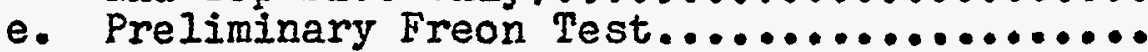

f. Second $z y-g l o$ test on sixteen replacement Tubes and Adjacent Tubes...................

g. Hydrostatic Test of the Sixteen Replacement Tubes and Adjacent Tubes.............

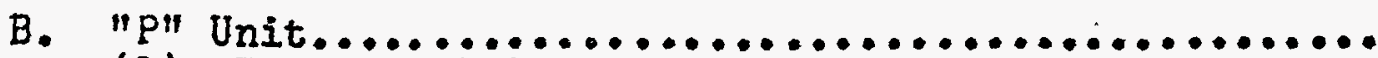

(1) Individuai Tube Hydrostatic Test in Unit......

(2) Summary of Freon Testing on Bottom Tube Sheet

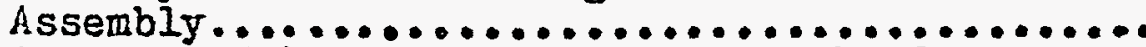

(3) Surmary of Hydrostatic Tests on the Bottom Tube Sheet Assembly........................

c. "L" Unit..................................

(I) Summary of Freon Testing on Bottom Tube Sheet

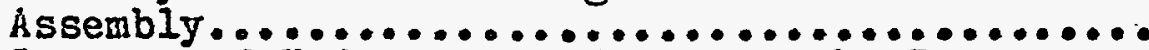

(2) Summary of Hydrostatic Tests on the Bottom

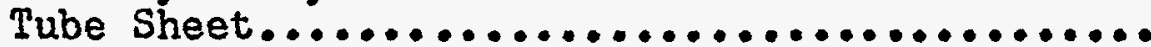
a. Preliminary.........................

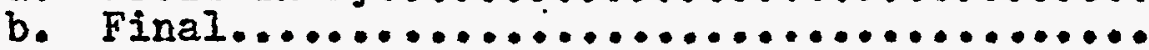

15. Pattern Kieasurements...........................

A. " $K^{n}$ Unit...................................

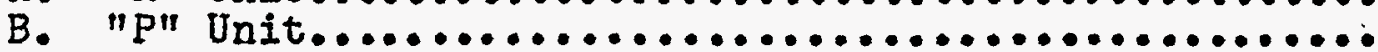

C. "I" Unit................................

16. Final Internal Cleaning by Dowell Inc. and Establishing $X$ and $Y$ Centerlines.............................

A. "R" Unit.................................

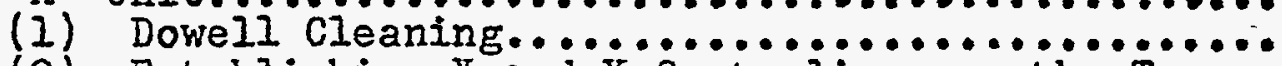

(2) Establishing $X$ and $Y$ Centeriines on the Top

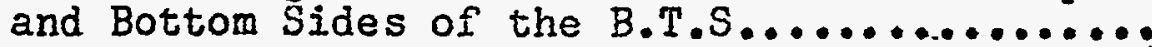

B. "P" Unit..................................

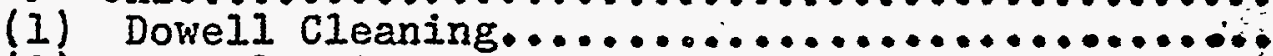

(2) Establishing $X$ and $Y$ Centeriines on the Top

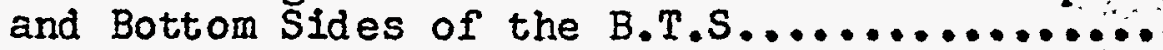

c. "L" Unit.

44

44 
(1) Sandblasting Top Side of Unit and hrapper Plates................................

(2) Establishing $X$ and $Y$ Centeriines on Top and Bottom Sides of Eottom Tube Sheet and Verticality Readings.......................

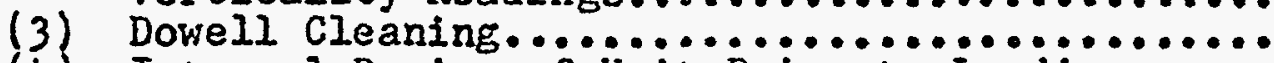

(4) Internal Drying of Unit Prior to Loading

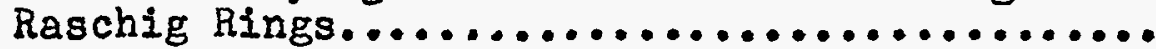

17. Raschig Ring Loading Inspections..................

A. "R" Unit.

C. "L" Unit.

18. Inspection of $8^{n}$ Schedule $10 \mathrm{~S}$ Split Pipe Vielded to Periphery of Bottom Tube Sheet......................

A. $"{ }^{R}{ }^{n}$ Unit...............................

B. "P" Unit................................

C. "L" Unit..................................

(1) Changes in ling $^{2}$ lding Procedure................

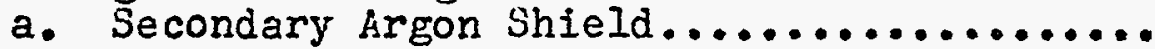
b. Veld Preparation Change From Fillet to

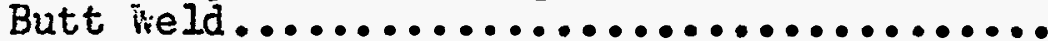
(2) Split Pipe and Half-Tee iail Thickness Check..

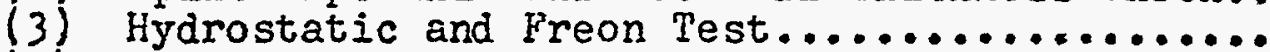

(4) Checking Slope of Split Circumferential Piping and Location of half-Tees with Respect to "Yn

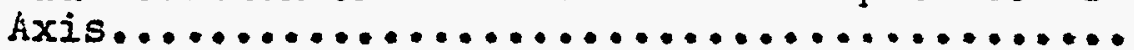

19. Alignment of Tank Bottom Nozzle Assembly on Top Side of Bottom tube Sheet...............................

А. "R" Unit...................................

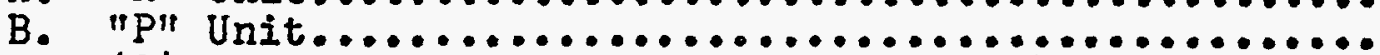

63

B. (1) Keasuring Location of Thermocouple Cilips on

64

(2) the Bottom Tube Sheet Nozzle Assembly..........

(2) Final Inspection to Determine out-of-roundness of Tube Sheet Nozzle Assembly................

(3) Heasuring Height of liozzle Assembly Referencing From Top Ends of Tubes and Circumferential Heasurement.

20. Welding Inspection and $z y-g l o$ Testing of Fillet theld Joining Nozzle Assembly to Bottom Tube Sheet...........

A. "R" Unit.

B. "p" Unjt

Unit.................................

C. "L" Unit................................

21. Mieasurements and Inspections ifter Loading Raschig Rings.and. Velding. Bottom.Tube. Sbeet. Hozzle.4ssembIy.to. Unit..................................

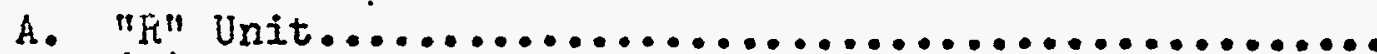

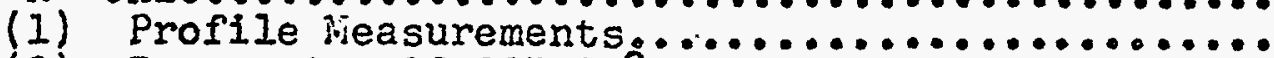

(2) Inspection of $20^{n}-90^{\circ}$ Tank Outiet Nozzle Elbows 
a. Inspections Performed Before Helding to

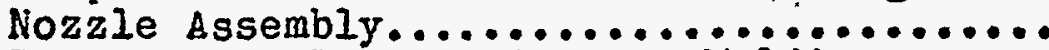

b. Inspections Performed after helding to Bottom Tube Sheet Nozzle Assembly.........

c. Air l'est and Final Freon Test for Detection of Leaks at Tube pields and at Fittet Welds Joining 8" Split Circumferential

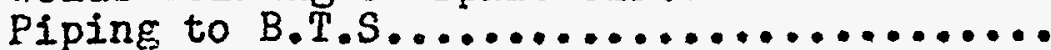

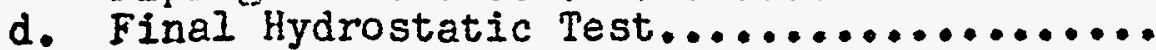

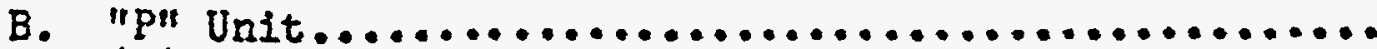

(1) Profile Measurements................... 68

(2) Inspection of $20^{\prime \prime}-90^{\circ}$ Tank Outlet Nozzle

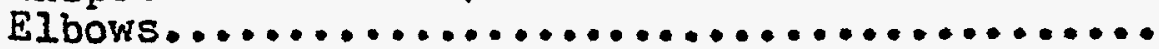

a. Inspections Performed Before kelding to

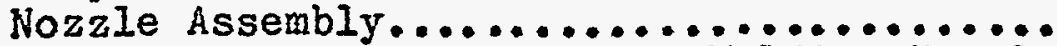

b. Inspections Performed After Welding Nozzles to Bottom Tube Sheet Nozzle Assembly.

(3) Motion . Measurement Pad Inspections.............

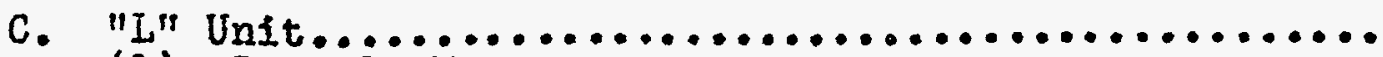

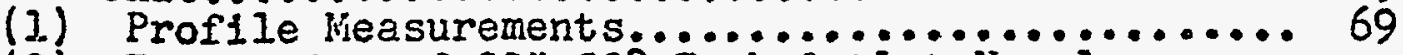

(2) Inspection of $20^{11}-90^{\circ}$ Tank Outlet Nozzle

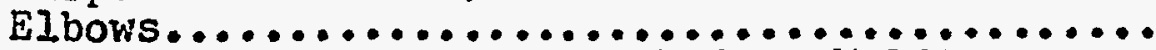

a. Inspections Performed Before helding to

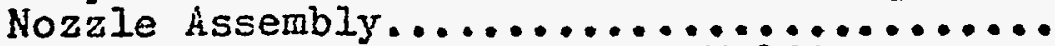

b. Inspections Performed After Kelding to

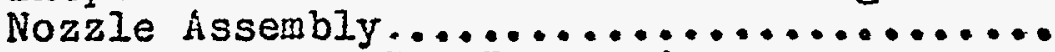

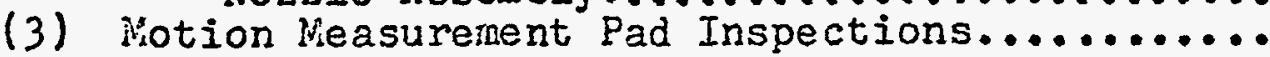

22. Bearing Pad Inspections and Discrepancies.............

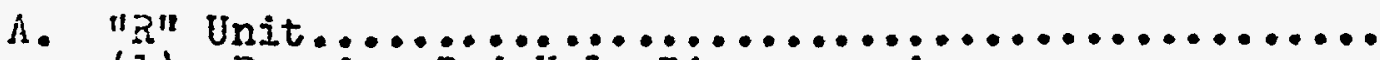

71

(1) Bearing Pad hole Discrepancies.............. 71

(2) Repair of Damaged Bearing Pad Face........... 72

B. "p" Unit.

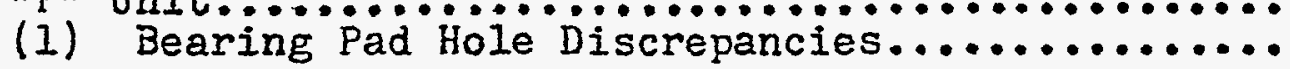

C. "L" Unit.

23. Rod Cups..................................... 74

A. "R" Unit................................

74

B. "p" Unit.............................

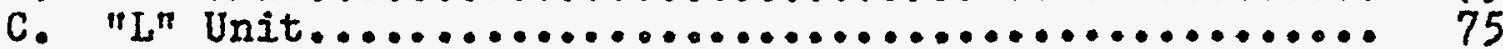

24. Inspection of Split Retaining Rings and Flanges for the Bottom Tube Sheet Large Tubes....................

f. " $\mathrm{fl} \|$ Unit................................

B. "p" Unit...............................

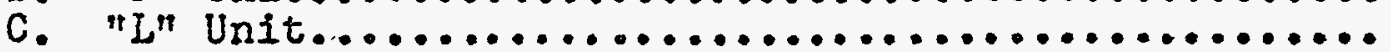

25. Nozzle Wiff Assemblies........................ 77

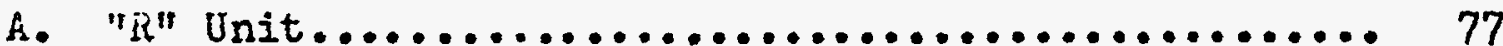

B. $\quad$ pn Unit................................ 78

C. "L" Unit............................... 78 
Page No.

26. Heat Numbering System (AII Units)............... 79

27. Final Inspection of Unit and Shipping Gear

Installation................................ 80

A. " $R^{n}$ Unit................................. 80

B. "P" Unit.............................. 80

C. "L" Unit............................... 80 
1. Photo Serial \#6 - Laying Out Rod Cup Positions on the Top Plate of the pank Bottom "L" Unit

2. DWE. $5-3$

3. DWG. $5-4$

4. Exhibit $\pi 1$

5. Sketch $\frac{\pi}{\# 2}$

6. Sketch 2

7. Siretch $\frac{\| 1}{\pi 3}$

8. Sketch $\frac{1}{4} 4$

9. Ixhibit \#2

20. Sketch $\# 3-A$

11. Sketch ff $4-A$

12. Sketch if

13. Sketch $\$ 6$

14. Exh\{bit $\# 3$

15. Exhibit $\frac{14}{44}$

16. Sketch ff7

17. Sketch if 8

18. Sketch $\# 9$

19. Sketch 10
- Bottor Tube sheet veb plate layout

- Bottom Tuhe Sheet - Thermoo'pl Wells

- Inspection of Weld Penetration at the Two Welded Joints in Ten Instrument Felis

- Initial Shrink Eieasurements Before Tubes Vere Velded on Top Side of Unit (R)

- Initial Shrink Heasurements Before Tubes Vere Helded on Bottom Side of Unit (R)

- Final Shrink lieasurements After Tubes liere Fivelded on Top Side of Unit (II)

- Final Shrink Leasurements After Tubes Here Bielded on Bottom side of unit (B)

- Iypes of Tubes Assembled in "p" Bottom Tube Sheet Assembly

- Initial Shrink jeasurements Before Tubes Here Vielded on Top side of Unit (P)

- Injtial Shrink jeasurements Before Tubes iere welded on Bottom Side of Unit $(P)$

- Final Shrink veasurements After Tubss Viere Welded on Top Side (P)

- Final Shrink ideasurements After Tubes Here Welded on Bottom Side (P)

- Preliminary Cleaning Procedure for "L" Bottom Tube Sheet Assembly Prior to Velding of Vrapper Plateg

- Tube Identification of All Large Tubes in the "I" Bottom Tube Sheet.

- Initial shrink Heasurements Before Tubes Here Welded on Top Side of Unit (I)

- Initial Shrink heasurements Before Tubes Were Helded on Bottom Side of Unit (I)

* Final Shrink lueasurements After Tubes Vere fielded on Bottoln Side (I)

- Final Shrink heasurements After Tubes Were Welded on Top Side (I) 
20. Photo Serial 199

21. Dwg. 5-9

22. Sketoh \#21

23. Exhibit $\mathbb{I} 4-A$

24. Exhibit \#5

25. DW: $2-4$

26. Exhib1t $\frac{H 6}{176}$

27. Sketch 1212

28. Exhibit $\sharp 7$

29. Exhibit $i \neq 8$

30. Fxhibit 19

31. Rrhibit

32. Sketch

33. Exhibit fill

34. Exribit it2

35. Fhoto Serial 杹

36. Photo serial fII9

37. Exhibit 仹3
- Fitting Stiffeners To Gusset Flates

- Bottam Tube Sheet - Strainer Cups

- Verticality deasurements (R)

- Profile Readings on Top side of "R" Buttom Tube Sheet After Machining Tube Inds

- Final Bearing Pad Heasurements and Profile Readings Taken on Bottom side of "R" Bottom Tube sheet After llachining

- Bottoin Tube Sheet - Large Tube

- Results of Top and Bottom Land Bore Diameters in the "R" Bottom Tube sheet

- Verticality Leasurements (P)

- Inspection performed arter NachininE Thube Ends and Trelve Bearine Pads on Botton siae of "p" Bottom rube sheet

- Inspections Perforned After kachining Tube inds on TOp Side of "p" Bottom Tube sheet

- Results or Initial Bottom Land Bore Finishes and Diameters

- Results of Final Bottom Land Bore Finshes and Diameters

- Verticality Heusurernents (I)

- Inspections performed dfter jachinine Tube lnds End 12 Bearing Pads on the Eottom side and tube inds on the Top side

- Final Results of Surface Finishes and Bore Diameters for Top ana Bottor Lands of All Large Tubes in the "I" Bottom Tube Shoot Assembly

- Borescope

- Use of Borescope

- Results of Pattern Coordinates Taken on Top and Bottom Sides of the "R" Bettom Tube Sheet Assembly 
38. Ixhibit \#14

39. Exhibit 15

40. Sketch \#14

41. 'Sketch \#15

42. Dwg. 5-2

43. Skétch 16

44. Hxhibit $\$ 26$

45.Dwg. 5-5

46. Exhiblt \#17

47. DWig. $5-1$

48. Ding. $5-6$

49. Photo Serial fl24

50... Exhibit \#17-A

51. Sketch. \#18

52. Sketch 19

53. Drg. No. 6353-9

54. Drg.' $2-5$

55. Fribit : 18

56. DWB. 5-7

57. Dig. $5-8$
- Results of Pattern Coorainates Taken on Top and Bottori Sides of the "p" Bottom Tube Sheet Assembly

- Resurts of Fattern Coordinates Taken on Top and Bottom Sides of the "L" Bottom Tube Sheet issembly

- Procedure for Transferring Axes From Top of B.T.S. to Bottom of B.T.S.

- Verticality Neasurements (I)

- Section Taru Bottom Tube Sheet

- Split Plpe Meld Preparation

- Checking Slope of Split Circumferential Piping and location of Half-Tees With Respect to "Y" Axis

- Tank Bottom Nozzle Assembly

- Transfer of XI-X2 and YI-X2 Bottom Tube Sheet Axes to the Tank Bottom Nozzle Assembly

- Bottom Tube Sheet

- 20"-90 Tank Outlet Nozzle Elbow

- Dy-cheking Edges of Tank Outlet Nozzle EIbow (P)

- Determine Actual Location Vith Respect Hajor Axes and Verticality of Motion Measurement Pads on Side of Dnit. Inspection of Location and Levelness of Hotion Measurement Pads on Bottom Side of Bottom Tube Sheet

- Br'g Pad - Bottom Tube Sheet "RR"

- Typical set-up for Checking Parallelism of Bearing Pad $5^{\text {" Gude Surfaces }}$

- Measurements on Bearing Fads - "L" B.T.S

- Spist Retaining Ring and Flange

- Inspection of Split Retaining Rings and Flanges for the "I" Bottom Tube sheet

- Mozzle Luff--Bottom Tube Sheet--Bnd Yiey

- Nozzle Muff--Bottom Tube Sheet--Typical for "R" and "P" Units 
GRROLOLOGICAL IIST OF ILIUSTRITIONS (con't)

58. Dwg. $5-10$

- Nozzle Uuff - Bottom Tube Sheet - Typice

59. Photo Serial \#71 -, Leading and Shipment of "R" Unit Bottom Tube sheet Assembly 
The following list covers all du Pont prints pertaining to fabrication released to the $M$ \& $E$ Group located at New York Shipbuilding Corporation.

This list was prepared from existing drawing files at the latter location on February 27, 1954. For reference purposes and convencience, drawings are listed by sub-assembly, drawing number, title, and revision number.

A. "R" Unit

1. Bottom Tube Sheet

Drawing \# Title

Revision \#

Wi-130947 Plan \& Cross Section Arrangt.

W-130948 Sections \& Details - Sheet \#1

10

W-130949 Sections \& Details - Sheet ff Arrangt. 14

Wi-131057 Sections \& Details - Sheet \#3 Arrangt. 17

Hi-131093 Sections \& Details - Sheet H4 $_{4}$

W-131265 Miain Tank Bottom Bearing Plates. 5

D-110129 Vertical Rod Cups. I

D-110149 Instrument Viell. I

D-112637 Split Retaining Ring \& Flange. 3

D-112651 Pre-ikachined Finish of Non-Bearing Tubesid

D-112652 Pre-Nachined Finish of Bearing Tube 2

D-112668 Collars 5

D-114901 Baffle Plate 9

B. "pr Unit

1. Bottom Tube Sheet

W-132760 Tank Bottom Tube Sheet Plan \&

Cross Section 14

ki-13276I Tank Bottom Tube Sheet Section \& Detail Sheet $\frac{113}{13}$ Arrangt.

W-132762 Tank Bottom Tube Sheet Section \& Detail Sheet $\frac{\| 1}{11}$ Arrangt. 
Drawing \#

$W-132763$

$W-132764$

$D-110270$

D-112766

$D-112767$

$D-112845$

$D-112846$

$D-114483$

Tank Bottom Tube Sheet Section \& Detail Sheet \#2 Arrangt.

13

Tank Bottom Tube Sheet Section \& Details Sheet \#4

Tank Bottom Tube Sheet Instrument fiel1

Pre-liachined Finish of Non-Bearing tube in Bottom Tube Sheet

Pre-Nachined Finish of Bearing Tube in Bottom Tube Sheet

Tank Bottom Tube Sheet Collars

Split Retaining Ring \& Flange $\mathrm{tor}$ Tank Bottom Tube Sheet

Tank Bottom Tube Sheet Baffle plate

c. "L" Unit

1. Bottom Tube Sheet Drawing \#

Titie

W131395 Tank Bottom Tube Sheet plán \& Cross Section Arrangt

W-131396 Tank Bottom Tube Sheet Sections \& Detalls - Sheet H2

bi-131400 Tank Bottom Tube Sheet Sections \& Details - Sheet \#I:

W-132416 Tank Bottom Tube Sheet Sections \& Details - Sheet \#3.

V-131433 Tank Bottom Tube Sheet Sections and Details - Sheet 74

D-110152. Vertical Rod Cûp for Tank Bottomitube Sheet

D-110168 Tank Bottom Tube Sheet Instrument WeI1

D-112667 Pre-Machined Finish of Non-Bebring pube in Tank Bottom Tube Sheet

D-112672 Pre-liachined Finish of Bearing hube, 1 Tank Bottom Tube Sheet

D-112687. Split Retaining Ring \& Fange iforthak Bottom Tube Sheet

D-II2689 Tank Bottom lube Sheet Cóllars 
PART VII - SECTION III BOTTOM TUBE SHEET

INSPECTIONS PERFORMED BI DU PONT ON "R", "P" AND "L" UNITS

\section{Plate Preparation}

A. "R" Unit

(1) Plate Inspection

The Type 304 stainless steel plate material for the top, bottom, and baffle tube sheets was inspected in a similar manner to that discussed in Part II-A, Section 1-a. All inspections were satisfactory.

(2) Plate Fit-up, welding and Radiograph Inspection

After the material for the top and bottom tube sheets and baffle plate was inspected for thickness, surface cracks, laminations, and other mechanical defects, each of the three plates that make up a tube sheet blank were laid out to drawing dimensions with excess material on the O.D. to allow for tube weld shrinkage. After laying out baffle and tube sheet plates, they were placed on a flat slab and checked for levelness and then straightened where necessary using a 150 ton deep throat press. Next, each of the three plates that form a tube sheet blank were planned square on an edge planer and beveled on both sides for welding. The angle of bevel was checked by inspectors at random on each plate using an adjustable angle square and found satisfactory.

The three plates were then laid on a flat slab and butts mated until they were flush. After the plates were properly fitted, the two joints were tack welded with i" tack spaced approximately $10^{\text {" }}$ on center. The weld tacks were wire brushed and defects ground out. These operations were witnessed by a du Pont inspector.

Next, the tube plate edges were clamped to a slab and an aircomatic track welding machine and tracks were set up for welding the joint. Suitable weights were placed on the tube plate blank at established locations to minimize weld buckle. Both joints of the tube plate blank were welded using the established welding procedure adapted for this job.

After all welding was completed, the welds were ground flush. (See Part II-A, Section I, photo serial \#4 for view of grinding operation) Welding was then inspected for undercutting, cracks, and other mechanical defects. Necessary repairs were made, re-inspected and released for x-raying. 
The top and bottom tube sheets and the baffle plate welds were then $x$-rayed 100\%. Radiographs were examined in accordance with the non-destructive test as specified in paragraph $U-58$ (h) (2) to (10) inclusive of the A.S.M.E. Code for Unfired Vessels, 1949 Edition. Unacceptable defects were repaired and re-x-rayed.

After all $x$-ray work was completed, each tube sheet blank was set up on suitable supports for burning the outside diameters. The top and bottom tube plates were then burned using a stainless steel cutting torch and flux approximately four inches oversize. The baffle plate was cut approximately two inches oversize. Tube sheets had to be left full in diameter due to welding shrinkage which had been established from experience on the NYX unit. Since no additional welding was ever done on the baffle plate after trepanning and assembling into the unit, it did not reguire as much excess material for fabrication. After burning the plates to the required diameter, the tube sheet edges were straightened on a 350 ton press. Weld joints were straightened on a 70 ton deep throat press. The above fabrication operations were witnessed by a du Pont inspector.

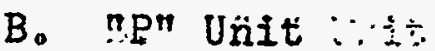

\section{(1) Plate Inspection}

This inspection was performed in a similar manner to those performed on the "R" unit as described above in Section $1 \mathrm{~A}-(1)$. AII inspections were satisfactory.

(2) Plate Fit-up, helding and Radiograph Inspections

These inspections were performed in a similar manner to those performed on the "R" unit as described above in Section $1 A-(2)$. All inspections were satisfactory.

C. "I" Unit

(1) Plate Inspection

This inspection was performed in a mimilar manner to those performed on the "R" unit as described above in Section $1 \hat{A}-(1)$.

(2) Plate Fit-up, Felding and Radiograph Inspections

These inspections were performed in a similar manner to those performed on the "R" unit as discussed above in Section $1 A-(2)$, except as follows: It was requested by the du Pont Inspection Department that New York Ship stencil $x$-ray identification numbers on the outside of all tube sheets on " $L$ " and subsequent units in such a manner that they would stay there. 
Heretofore, $x$-ray numbers on tube sheets were stenciled on the outside of all tube plates. In some cases, after assembling of a unit, $x$-ray numbers on tube plates were In the inside of the unit and there was no way to match the radiograph with the weld seam. New York Ship complied with request on "L" and subsequent units and put $\mathrm{x}$-ray numbers on the outside.

Finel grain $x-r a y$ film was used in lieu of coarse grain film on this unit. This change was a result of difficulty in reading $x$-rays on "P" unit expansion joint. All $x$-ray film for this unit (" $L "$ ) was interpreted according to the revised $x-r a y$ reading technique discussed in "p" unit expansion ring inspections. (Part VII, Section IV)

2. Tube Inspection (Pre-Assembly)

A. "R" Unit

Inspection of pre-machined bottom tube sheet tubes was performed in an identical manner to that described in Part VII, Section I, item $2 \mathrm{~A}$.

B. "p" Unit

Inspection of pre-machined bottom tube sheet tubes was performed in a similar manner to that described in Part VII, Section I, item $2 B$, except as follows:

As a result of a fabrication meeting held between du Pont Design Division, du Pont Inspection Department and Nlew York Ship, it was concluded that the following design change be incorporated into the pre-machining of large tubes for the "P" bottom tube sheet:

1. Those tubes for the bottom tube sheet of the "P" unit which have not yet been premachined in outside vendors' shops be completed with an additional .040" on diameter in the smallest bore. This decreased the size of the bore from 3.250" diameter to $3.210^{\prime \prime}$ diameter. Revise du Pont drawings D-112667 and D 112672 cover this change.

2. Those tubes for the bottom tube sheet of "p" unit which the smallest bore has already been finished to the originally specified $3.250^{\circ}$ diameter were completed, accepted and shipped to New York Ship as planned.

Additional material was desirable in the small bores of the bottom tube sheet tubes since experience with NYX has indicated that the tube-welding operation tends to "bell-mouth" the outer extremity of this bore, and hence more stock was required to allow for line reaming.

C. "L" Unit

Inspection of pre-machined bottom tube sheet tubes was performed in an identical manner to that described in Part VII, Section I, item 2 . 
3. Revised Drill Jigs for "R", "P" and "L" Units

The discussion for "R" plenum chamber drill jigs included the "Rn bottom tube sheet. Refer to Part VII, Section I, item $3 \mathrm{~A}$ for a detailed analysis of the problems confronted with and the steps taken to solve the problems.

4. Trepanned Bottom Tube Sheet Inspections

A: : : "R" Unit

$\because \therefore \quad$ The method used for inspecting the top and bottom plates and baffle plate for the "R" bottom tube sheet assembly has been discussed in Part VII, Section I, item 4A. Sketches \#6 and-4f.7 show the ligament measurements for both the top and bottom tube sheets of the "R" bottom tube sheet. The baffle plate, was also measured in an identical manner. Measurements were not corrected for temperature.

B. "pu Unit

The method used for inspecting the top and bottom plates and baffle plate has been discussed in Part VII, Section I, item $4 B_{1}$. Sketches $\# 12$ and $\# 13$ show the ligament measurements for both the top and bottom tube sheets of the " $k$ " bottom

tube sheet. The baffle plate was also measured in an identical manner. Neasurements were not corrected for temperature.

cint

The method used for inspecting the top and bottom plates and baffle plate has been discussed in Part VII, Section I, Item 40 sketches \#18 and \#19 show the ligament measurements for both the top and bottom tube sheets of the "L" bottom tube sheet... The baffle plate was measured in an identical manner leasurements were not corrected for temperature.

Demerisional Check of Tube Sheet Ligaments and Bores

A. " "Rnit

(1) Bottom Tube Sheets (top, bottom and baffle)

$\therefore$ Iigament measurements on the top, bottom and baffle plates for the bottom tube sheet assembly were obtained in a similar manner to that described in Part VII, Section $I$, item $5 \mathrm{~A}-(1)$.

npn Unit

(1) Bottom Tube Sheets (top, bottom and baffle)

Ligament measurements on the top, bottom and baffle plates for the bottom tube sheet assembly were obtained in" a similar manner to that described in Part VII, section I; Item $5 \mathrm{~B}-(1)$. 
C. "L" Unit

(1) Bottom Tube Sheets (top, bottom and baffle)

Ligament measurements on the top, bottom and baffle plates for the bottom tube sheet assembly were obtained in a similar manner to that described in Part VII, Section I, item 5C-(I), except as follows: On the top plate of the "L" bottom tube sheet, it was requested by the du Pont Inspection Department that New York Ship locate and layout rod cup positions. Typical layout for locating rod cups on the top plate of the bottom tube sheet can be seen by referring to du Pont drawing $W-132760$, Detail "V". Also, see du Pont drawing W-132762, detail " $Z^{n}$ for "as welded" position of rod cups. helding of rod cups to the top plate was done in the field. Photograph serial \#6, presented herewith, illustrates pictorially how layout lines were established by New Iork Ship layout men.

6. Inspection of Tube Sheets after Grinding and Acid Washing

A. "R" Unit

This inspection was performed in a similar manner to that discussed in Part VII, Section I, item 6A.

B. "p" Unit

This inspection was performed in a similar manner to that discussed in Part VII, Section I, item 6B.

c. "L" Unit

This inspection was performed in a similar manner to that discussed in Part VII, Section I, item 6C.

7. Assembling of "R", "P" and "L" Bottom Tube Sheets

A. "K" Unit

(1) Gusset Plate Pre-assembly Inspections

The design of gusset plates was altered slightly on the " $R$ " bottom tube sheet assembly. In addition to the minor changes in the gusset plates, twelve short "T" gussets were added to the unit. Du Pont drawing shows where these were located.

Thirty gusset plates were laid out; twelve off-set, six straight and twelve short "T" gussets. All gusset plates were burned to layout and then the burned edges were chipped and dressed to parent metal. ilext, the gussets were planed to height and then beveled for weld preparation. The twelve off set gusset plates were then bent to conform to a template layout. Stiffener bars were planed to length, beveled for weld preparation, and 


\section{PROJECT 8980 - SAVANNAH RIVER PLANT}

This view shows the laying out of the rod cup positions on the top plate of the Tank Bottom "L" Unit.

Layout of rod cup positions is done in the shop and welding of the rod cups to the top sheet is done in the field.

The layout man is using a circular layout tool set to one-half the pitch of a ligament. Using each tube hole (3) surrounding the rod cup position, three lines are scribed, thus locating the center of the ligaments with respect to the three tube holes. Using this point as the center, two circles are scribed. Layout for positioning rod cup is now complete. On the right is a view of the rod cup that will be welded in the field. 


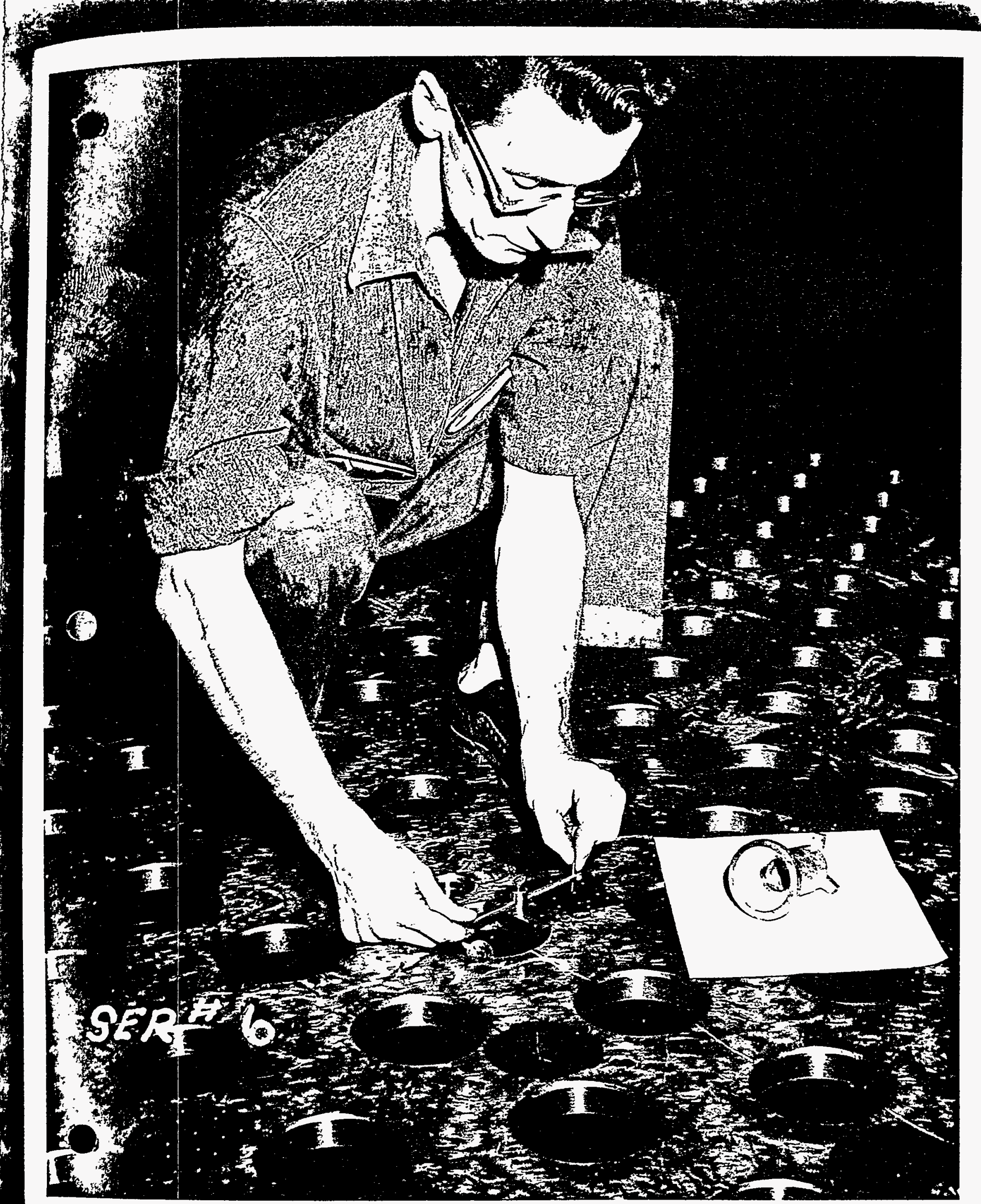


then dressed and fitted to the twelve offset and six gusset plates. Two stiffener plates were then tacked and fully welded to each of the above gusset plates. After welding, straightening, and dressing stiffeners joined to the twelve offset and six straight gusset plates, all welding was visually inspected by du Pont inspectors for porosity, cracks, undercutting and other mechanical defects. Necessary repairs were made; reinspected and found satisfactory.

Next, the twelve short "in" gussets were fit, tacked, welded, dressed, straightened and inspected in a similar manner to that described above.

End stiffening bars were laid out, planed to length, beveled for weld preparation, and pieces dressed.

The thirty gusset plates were then sandblasted, acid washed, ferroxyl tested and accepted for assembling into the bottom tube sheet.

(2) Inspections Performed During Assembling of Gusset Plates into Unit.

The top tube plate was placed with the top side down on a level platen and gusset plates positioned and tack welded. (In the bottom tube sheet assembly, location of the baffle requires building of the bundle in an inverted position). (See photo serial fil29 \& 130 in Part II-B-4a). The relative position of the gussets with respect to the $X$ and $Y$ axis was checked. This was done by placing the baffle sheet on top of the top tube plate and checking gusset layout against slots cut in the baffle plate. After the $X$ and $Y$ centerlines on the baffle plate were matched to the $X$ and $Y$ centerlines of the top tube sheet, measurements were taken around the outer edges of the two plates to determine if the baffle plate was centered over the top tube plate, and at the same time measurement were also taken again between baffle plate slots and the upright tack welded gusset plates to determine if sufficient clearance was being maintained between baffle slots and gusset plates. ffter fully welding all gusset plates (or web plates) to the bottom side of the top tube plate, welding was visually inspected for cracks, undercutting, porosity and other mechanical defects and necessary repairs made. See dwg. 5-3 for bottom tube sheet gusset plate (or web) layout.

(3) Baffle Plate Spacers, Sandblasting, Acid Washing and Ferroxyl Testing

The baffle plate was removed from the partially built assembly and made ready for welding 30-1" thick support blocks (See du Pont dwg. D-114901). The se support blocks were located symmetrically around the outer portion of the baffle plate. After fitting support blocks to layout and tacking, they were fully welded using a manual "aircomatic" welding machine. lield splatter was removed from the baffle plate and ther the 


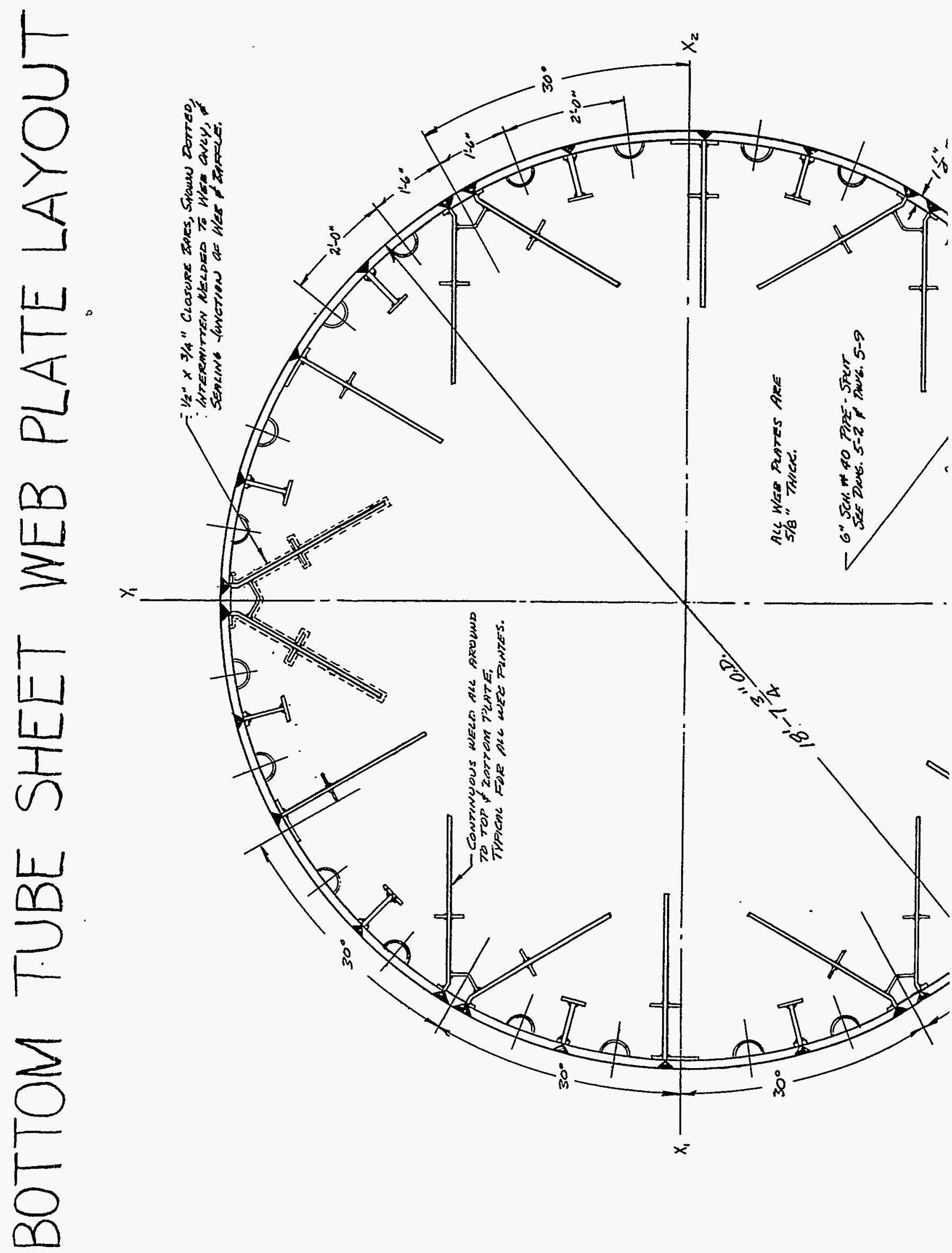




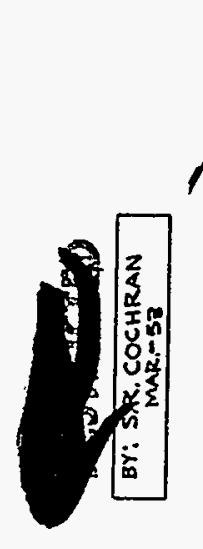


welding was dressed. After this all welding was visually inspected for porosity, undercutting cracks and other mechanical defects. Repairs were made, reinspected and approved.

Next, the baffle plate was sandblasted, acid washed, ferroxyl tested and accepted for assembling into the unit.

(4) Collar Inspection

The large tube collars for spacing the baffle plate on the inside of the bottom tube sheet assembly were checked for thickness only. This was necessary to insure that a level plane would be maintained when the baffle plate was bolted in place. The required thickness of all tube collars was $1^{\prime \prime}$. This was measured using $0-1^{\prime \prime}$ outside micrometer.

Next, the large tube, instrument well and instrument lead collars were acid washed and then ferroxyl tested. Photo serial $\$ 84$ in Part II illustrates pictorially acid washing of large tube collars.

The large tube collars were then fitted and tack welded to the bottom side of the top tube plate. Since shoulder tubes hold their collars firm against the tube plate, they were not fitted at this time. (see du Pont. drawing $n-130948)$. Shoulder tube collars were later set in place with shoulder tubes holding them firmly in position during preliminary assembly operations. Ten instrument well collars were tack welded in place with a smali tack on each of the three legs. (See du Pont drawing D-112668-H). Instrument lead tube collars were identical to rod tube collars used in the top tube sheet assembly. These were fit and tack welded to the bottom side of the top plate. Du Pont drawing $W-131093$ shows where the different type collars were located and the number required. All of the above assembly operations were witnessed by a du Pont inspector.

(5) Verticality Check After Placing Tube Sheets in Circumferential: Handling Jig.

This inspection was performed in a similar manner to. that discussed in Part II-A, section 4, except as follows: During tube sheet layout, the $X$ and $Y$ axis were extended to the edges of both tube sheets. After aligning the sis top and bottom tube sheets in the circumferential handing jig to the best verticality, these extended axes or match marks were checked for vertical alignment with surface gage and box level by New York Ship me chanics and witnessed by du Pont inspectors (See photo serial \#323 in Part VII section $7 \mathrm{~A}-(1)$

(6) Gusset Plate Welding Inspections

After the top and bottom tube plates were mated for best verticality, the bottom edge of each gusset plate was tack welded and then fully welded. Ali welding was dressed and then visually inspected for porosity, cracks, 


\section{Page 8}

undercutting and other mechanical defects. Repairs were made, re-inspected and approved.

Sealing bars were then laid out, cut to length, and cutouts machined in the bar sides so as to clear large tube outside diameters. These bars were used to seal off the opening between the baffle plate and gusset plate. Sealing bars were then dressed, acid washed, ferroxyl tested and accepted for fitting and welding into the bottom tube sheet assembly. End sealing bars for gusset plate and stiffeners were cut, fit and tacked as a small assembly. When the unit was ready, sealing bars and end assemblies were acid washed again, fit and tacked to the gusset plate to seal off openings around baffle slots. All tack welding was dressed by grinding and then inspected. Sealing bars near the outer periphery of the unit were left out until the unit was turned and the end stiffeners welded in position to the bottom side of the top tube plate. The remaining seal bars were fit, welded, dressed, and then cleaned with SAFE-TEE SOLVENT F. 0. 128 (Fine Organics). A visual inspection was made by du Pont inspectors for cleanliness and weld defects. Necessary repairs were made, re-inspected and passed as being, satisfactory.

The tube holes near the vicinity of the gusset plates were distorted by welding of the gusset plates to the top and bottom tube plates. Portable drills were set up and holes were again reamed to original size in order to pass large tubes freely.

\section{(7) Preliminary Cleaning}

Before inserting and tacking large tubes, the unit was given a preliminary cleaning externally and internally to remove dirt, oil, and other foreign material which had collected during fabrication. This was done by first air jetting the unit at approximately $100 \mathrm{psi}$ to remove all loose material. After this, the top and bottom sides of each tube sheet, gusset plates, and all other accessible areas were wiped clean using a clean cloth saturated in CCI4. After cleaning, the unit was inspected, accepted and released for further fabrication.

(8) Large Tube Assembly, Instrument Well and Tack Welding Inspections

Starting in the center of the unit and working out, large tubes were progressively cleaned with $\mathrm{CCl}_{4}$, inserted in the unit, and tack welded to the inside of the bottom tube plate. Tack welding was visually inspected for undercutting, cleanliness and necessary repairs made. Tube assembly was witnessed by du Pont inspectors.

As shown on drawing 5-4, ten (10) instrument wells were required for the "R" bottom tube sheet. (There were none in the NYX unit). New York Ship fabricated the required number of instrument wells from type 304 


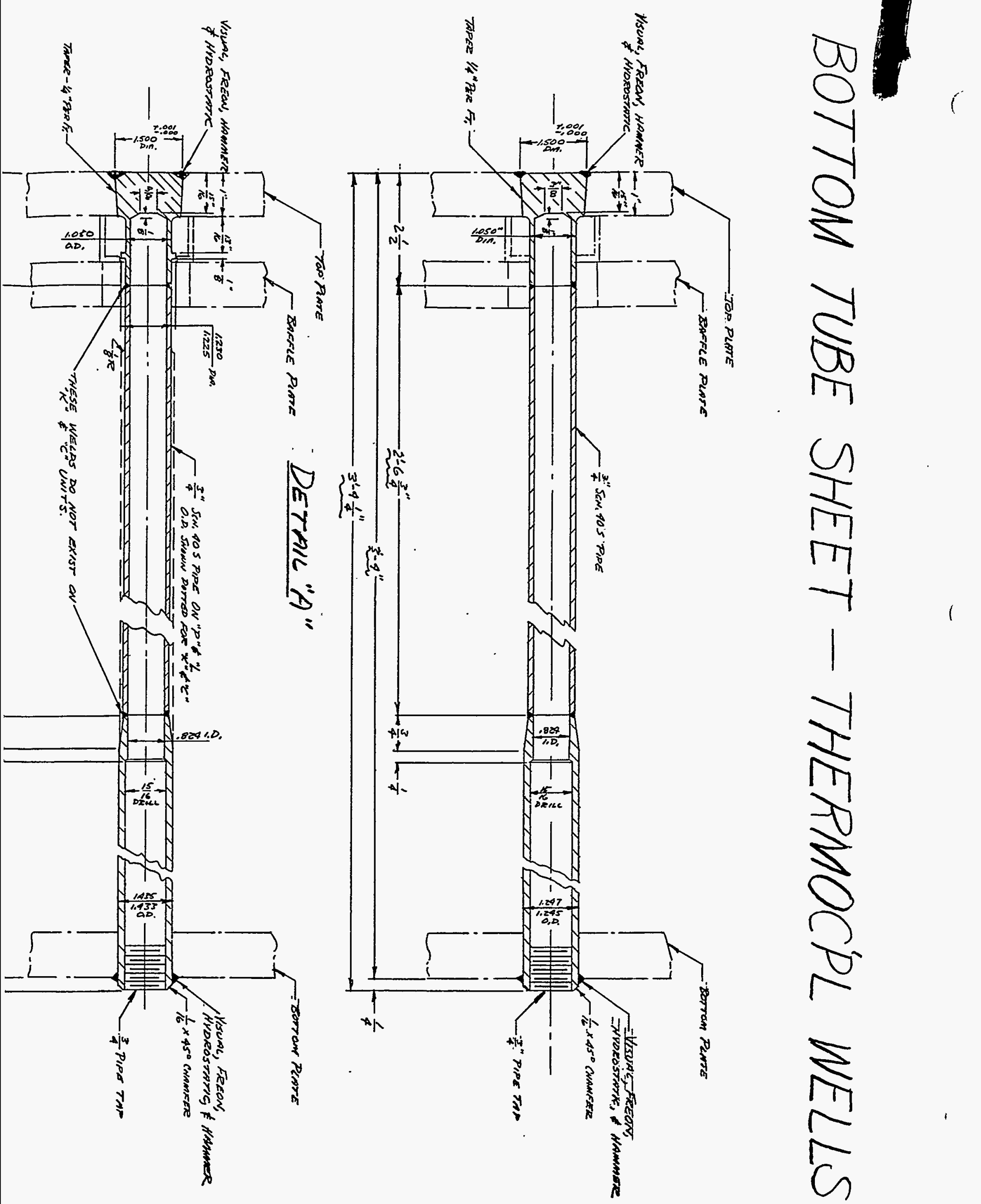


stainless steel bar stock and pipe. Referring to the above mentioned drawing, each instrument well was fabricated in three sections and then the pieces butt welded at two joints to form the instrument well. The top section of the well was machined from bar stock of suitable size with a $1 / 4^{\text {" }}$ taper/foot on the out side diameter. A male and female taper gauge was machined to fit the pieces and to check the hole diameters. A special taper reamer was made for reaming the top tube sheet (in unit) for receiving the top part of the tapered well section. The centering section of the well was a piece of $3 / 4^{n}$ sch. $40 \mathrm{~S}$ pipe cut to the required length with both ends beveled for weld preparation. The lower piece of the well was a piece of bar stock, bored, turned, threaded and beveled for welding as shown on drawing 5-4.

After the three sections that form a instrument well were butt welded, they were dressed and then visually and dimensionally inspected by the du Pont Inspection Department. Visual inspection of the bore in some of the wells indicated the presence of weld splatter. This was removed by passing a reamer through the bore of the well. A small functional gage $\left(.824^{\prime \prime}\right.$ diameter) was used to gage all ten instrument wells. They all passed the functional gage freely. AIl other dimensions were checked using a $6^{\circ}$ steel tape, $1-2^{n}$ outside micrometers and a taper gauge.

Next, the ten instrument wells were hydrostatically tested at 2000 psi for ten minutes. Several leaks were found and repaired. Wells that were repaired were retested and found satisfactory.

The ten instrument wells were assembled and welded into the bottom tube sheet assembly. Felding at the top and bottom ends joining the wells to the top and bottom tube sheet was visually inspected for defects and passed as being satisfactory.

After the bottom tube sheet assembly was accepted at New York Ship and shipped to the field, it was discovered that the butt welds on the inside bore of the instrument wells had not been visually inspected at the vendor's plant for weld penetration. Therefore, a du Pont inspector from New York Ship was sent to the Savannah River Plant to perform this inspection. Results of this inspection revealed that all ten instrument wells were satisfactory. For a resume covering the manner in which this inspection was carried out in the field, see Exhibit \#I.

(9) Types of Tubes Assembled in " $R$ " Bottom Tube Sheet Assembly

The approximate number of each of the various types of 3-15/16" O.D. tubes assembled in the "R" bottom tube sheet was as follows:

Type of Tube

Seamless

Cast

Welded
Number of Each Assembled in Unit 106 


\section{EXHIBIT 步I}

INSPECTION OF WELD PENETRATION

AT THE TWO GELDED JOINTS IN TEN

INSTRUNENT WELIS 
I. DU.PONT DE NEMOURS \& $60 . \%$ INC. Otruction Division

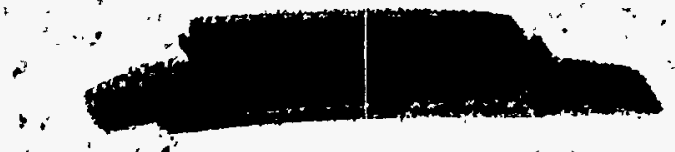

ind

TO Q. J. VEITH - M \& E FILE

FROM R. H. Potte

EIELD INSPECTOR'S REPORT

PROJRCT NO. 8980 PLANT Savanneh River DATE October: 5,1952

October 7,1952

New York Shtip - Camden, Nod.
CC: H. H. Cosney. F.P.M.

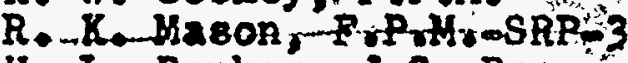
H. I. Bunker -J.G. Brewer
J. G. Brewer
H. B. Gage.
F. C. Breuninger
R. D. Bradway (NZS)
R. H. Potts: (2)
J. B. Johnson o File

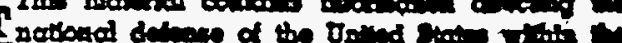

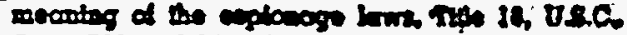

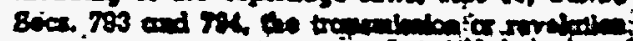

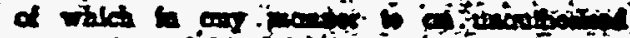

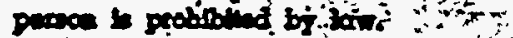

BQOIPMBNT Instrument Wells-Bottom Tube Shiset EQ:PC.NO 153-R

O wrino nos. D-110149 JOB RATING

WHOR New York Shipbullding Corporation LOCATION Camiden, N. J.

Scope:". To visually inspect the butt welds (inside.bore) in "R" unit tank bottom instrument wells. This inspection was made at the Savannah RIver Plant s1te on October 1, 1952.

Procodure: Using 2 5/8n 0.D. borescope the 10 inetrument wells in the subject unit were inspected for weld penetration in 2 butt Joints on I.D. of wells.

Results:

Instrument Hell Number I-5.6. $\mathrm{Y}-44$

I-3.3: $7-47$

$x=44: 1-7$

$x-34:-20$

$x-31$ 261

I-2Z: $: 178$

T-25: $1-35$

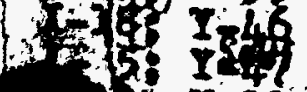

$\rightarrow|l|-11$

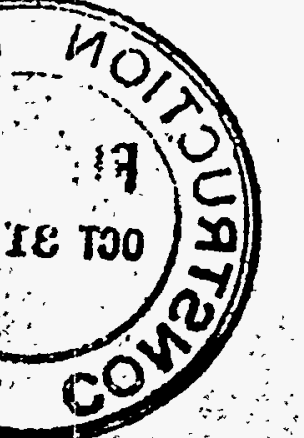

Per cent penetration

Top Butt Bottom Butt

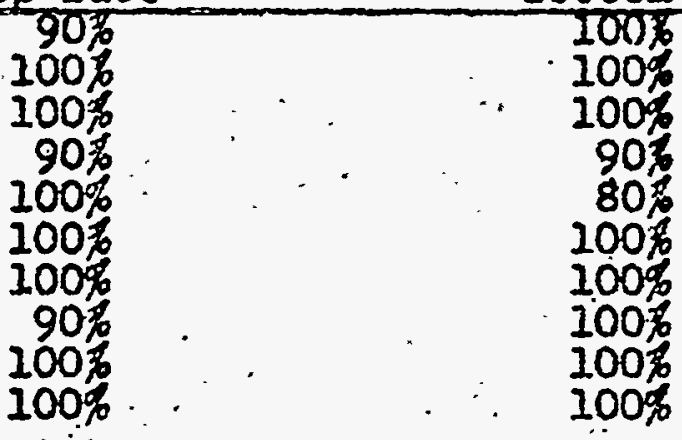


TELD INSPECTOR'S REPORT

ax:

94:

Note:

\section{$E x+2$}

Report Number 288-R

Page 2 of 2

Attach.

The por cent of penetration refers to the per cent of circumference that is fully penetrated.

In the case of relds listed as 80 per cent or 90 per cent penotration, the weld on the remaining percentage of circumference showed in all cases at least 80 per cent of full penetration.

By lssuing of this report the subject instrument wells are accepted.

Report Number 252-R is now vold.

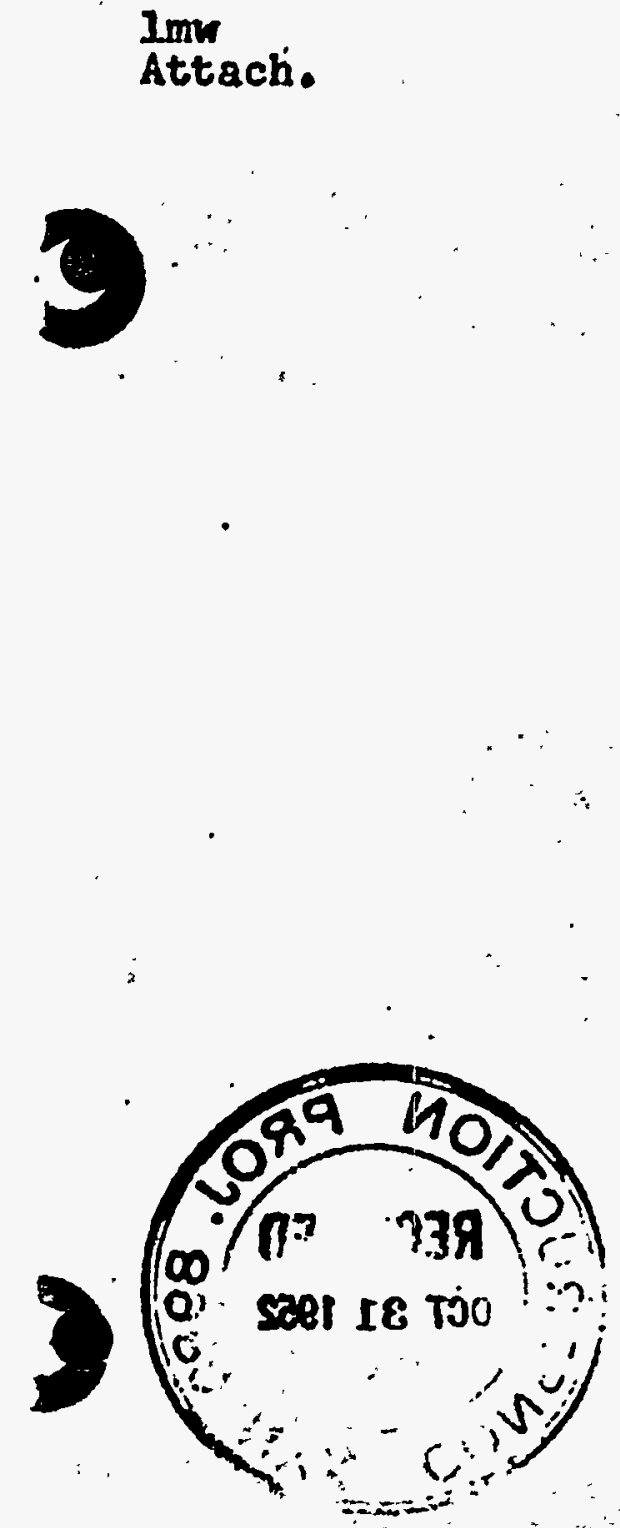


D

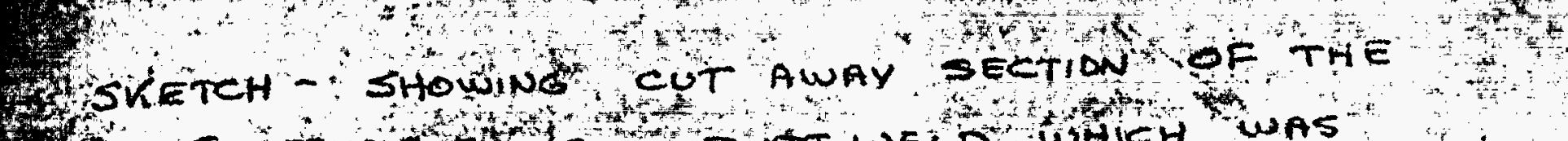

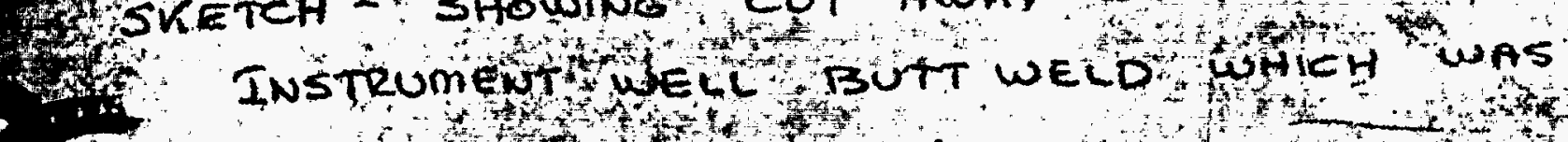

$\infty$

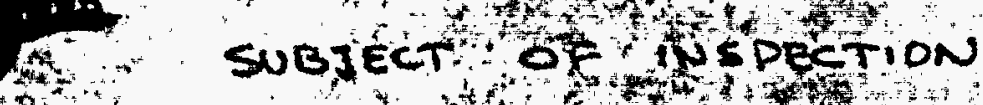

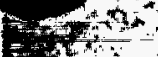

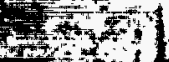

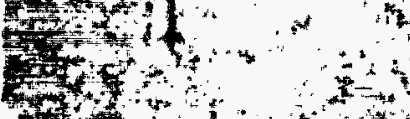

$+1$

$\operatorname{tin}$

6. SnAvi SPOT ON T.D.

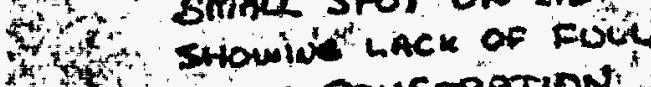
No WELS PENETRPTIBN"
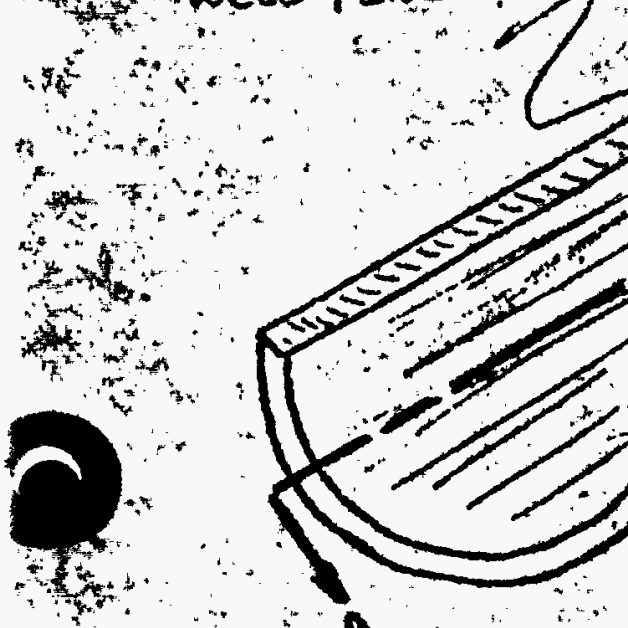

SECTION :A-A

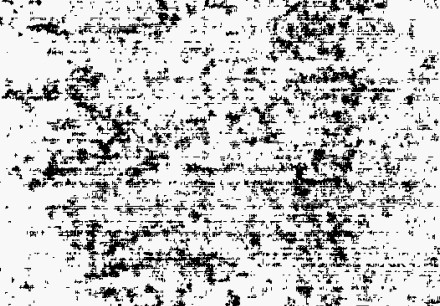

and
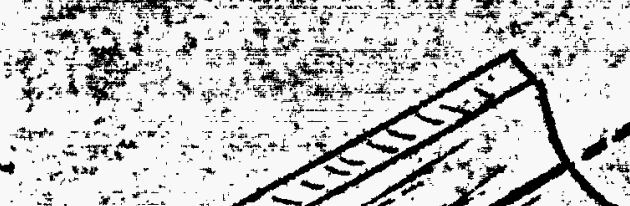
These figures which are only approximate were obtained from existing shipping records, records of defective tubes subsequentiy replaced lafter assembling of unit) and other such records not necessarily kept for this purpose.

The locations of these different tube types in the tube sheet assembly could not be determined since such records were not previously made, and no pre-determined method of assembling the tubes as to type was followed.

(10) Neasurements Before Large Tube Welding to Determine Unit Shrinkage

After all large tubes had been inserted into the unit, aligned and tack welded, initialishrink measurements were taken across three major diameters. Part II-A, section 5-c, describes the method incorporated to take these measurements. Results of these measurements (before welding large tubes) for the top and bottom sides are shown In sketches $\# 1$ and $\# 2$.

2. The average measurement for the top side was calculated to be $182.271^{17}$. The average measurement for the bottom side was calculated to be $182.300^{n}$ (AII measurements bore to bore)

(11) Measurements After All Tubes Had Been Welded

A1l large tubes were welded in this unit using the same procedure díscussed in Part II-A, section 5-d.

After al1 large tube welding was completed, measurements were ago in taken using the procedure discussed in paragraph (10) above Results of these measurements for the top and bottom sides are shown in sketches $\$ 3$ and \#4. The average measurements for the top side was calculated to be $181.95^{\circ}$ or The average neasurements for the bottom side was calculated to be $182.003^{n}$.

Since Design bivision specified that the top and bottom side measurements (after welding) had to be within $0.0321^{\text {n }}$ of each other or less, $1 \mathrm{t}$ can be seen by analyzing the results that the measurements were within the specified limit loe.s.

$$
\begin{aligned}
& \text { Bottom side } \frac{182.003 \mathrm{n}}{181.985^{\mathrm{n}}} \\
& \text { Top spde } \\
& 0.018^{\mathrm{n}} \text { offference }
\end{aligned}
$$

Therefore, no addittonal shrink welding was necessary, and the unit was released for further fabrication.

(12) Visual Inspection and Repair of tube helding

A After all large tube welding was completed, weld pâsses around the tubes on top and bottom sides of the unit were visually inspected with the aid of a flashlight for porosity, crater cracks, undercutting, and other me chanical defects. Defective welds were marked 


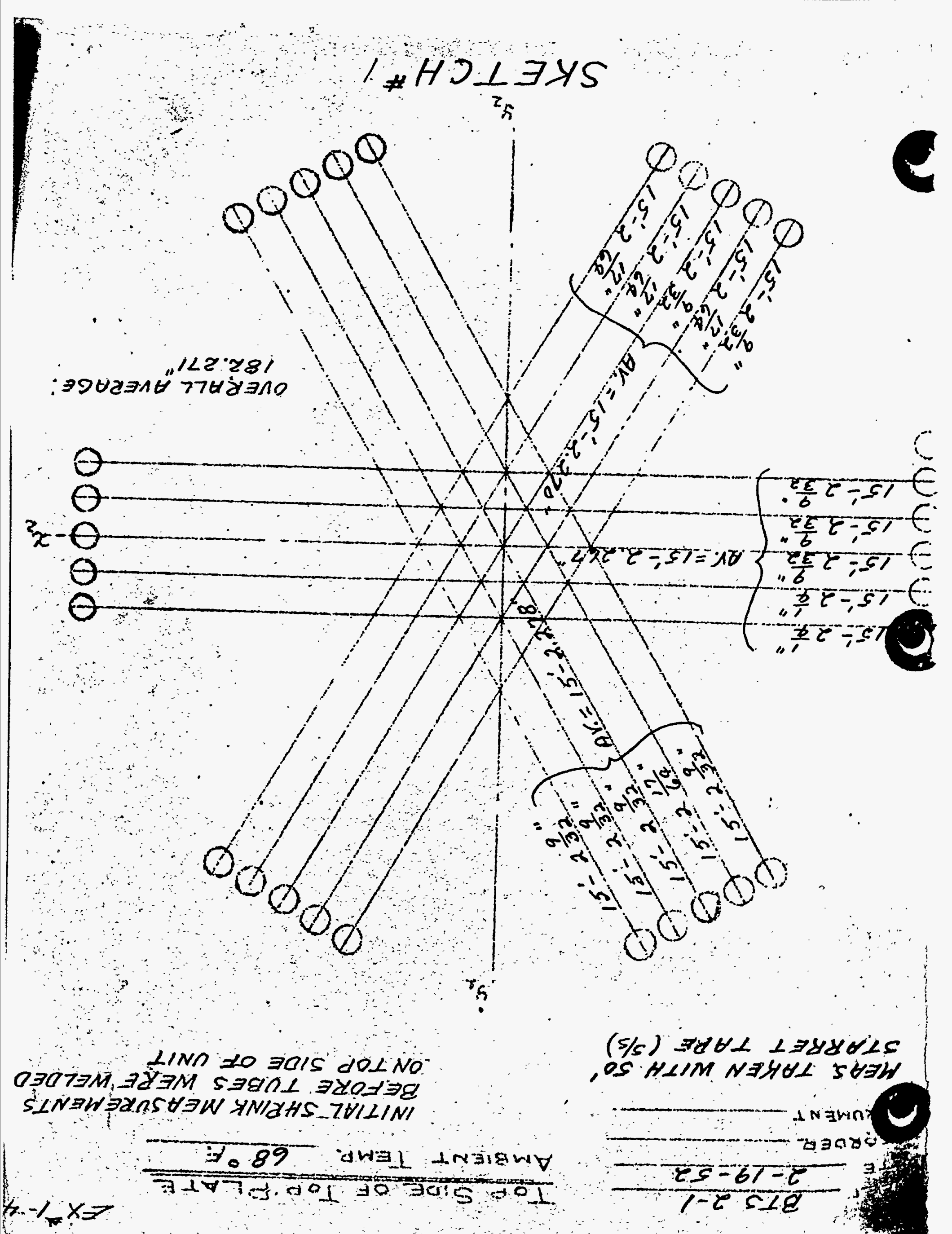




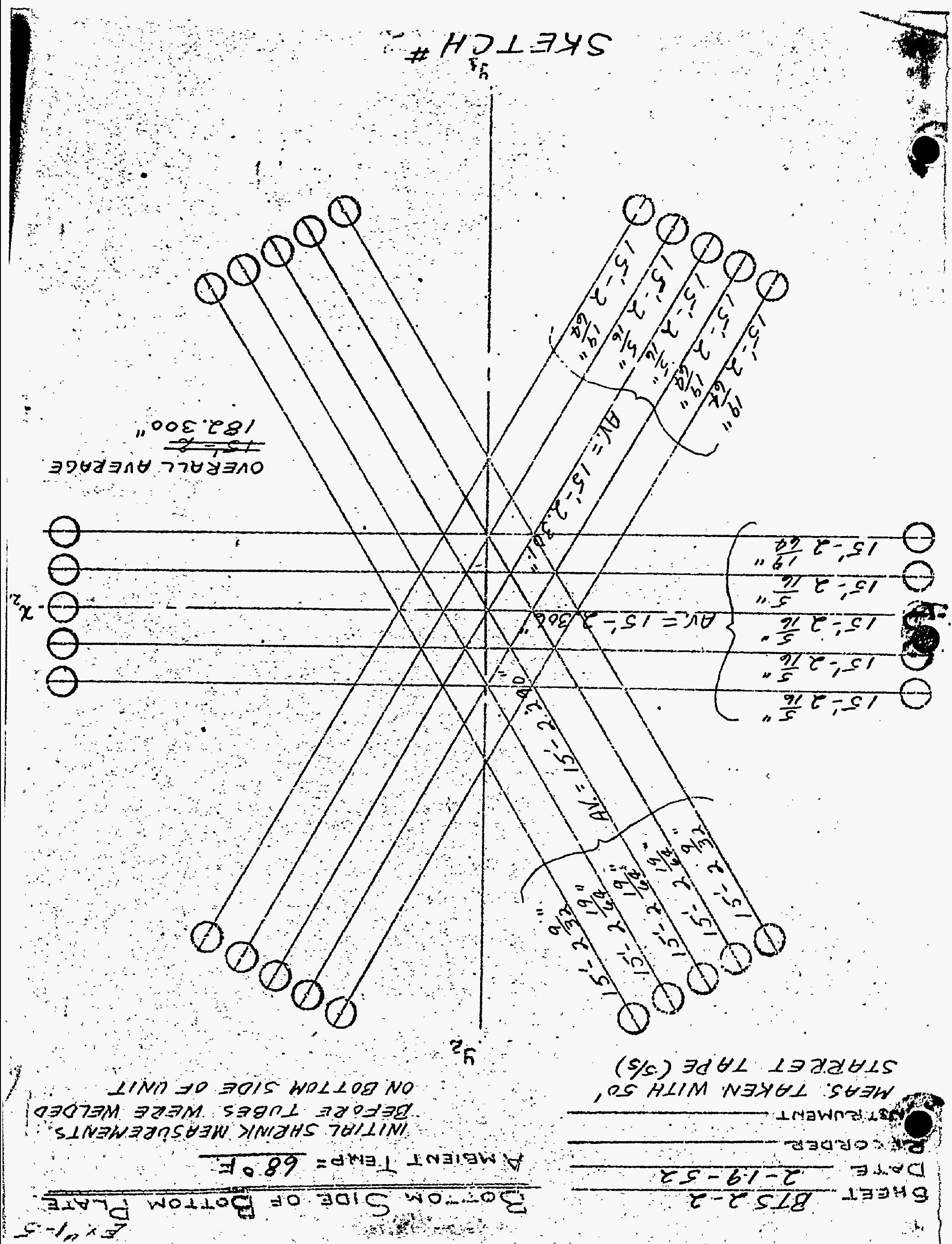


EHEET BTS2-1

D.०TE $2-25-52$

POCRER

CUMERT

MEAS. TAKEN WITH 50'
S/S STARRET TAPE.

MEAS. TAKEN WITH 50'
S/5 STARRET TAPE.
Top SIPE of ToP PLATE AIMBIENT TEMP: $68^{\circ} \mathrm{F}$

FFINAL SHRINK MEASUREMENTS AFTER TUBES WERE WELDEO ONTOP SIDE OF UNIT -

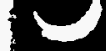

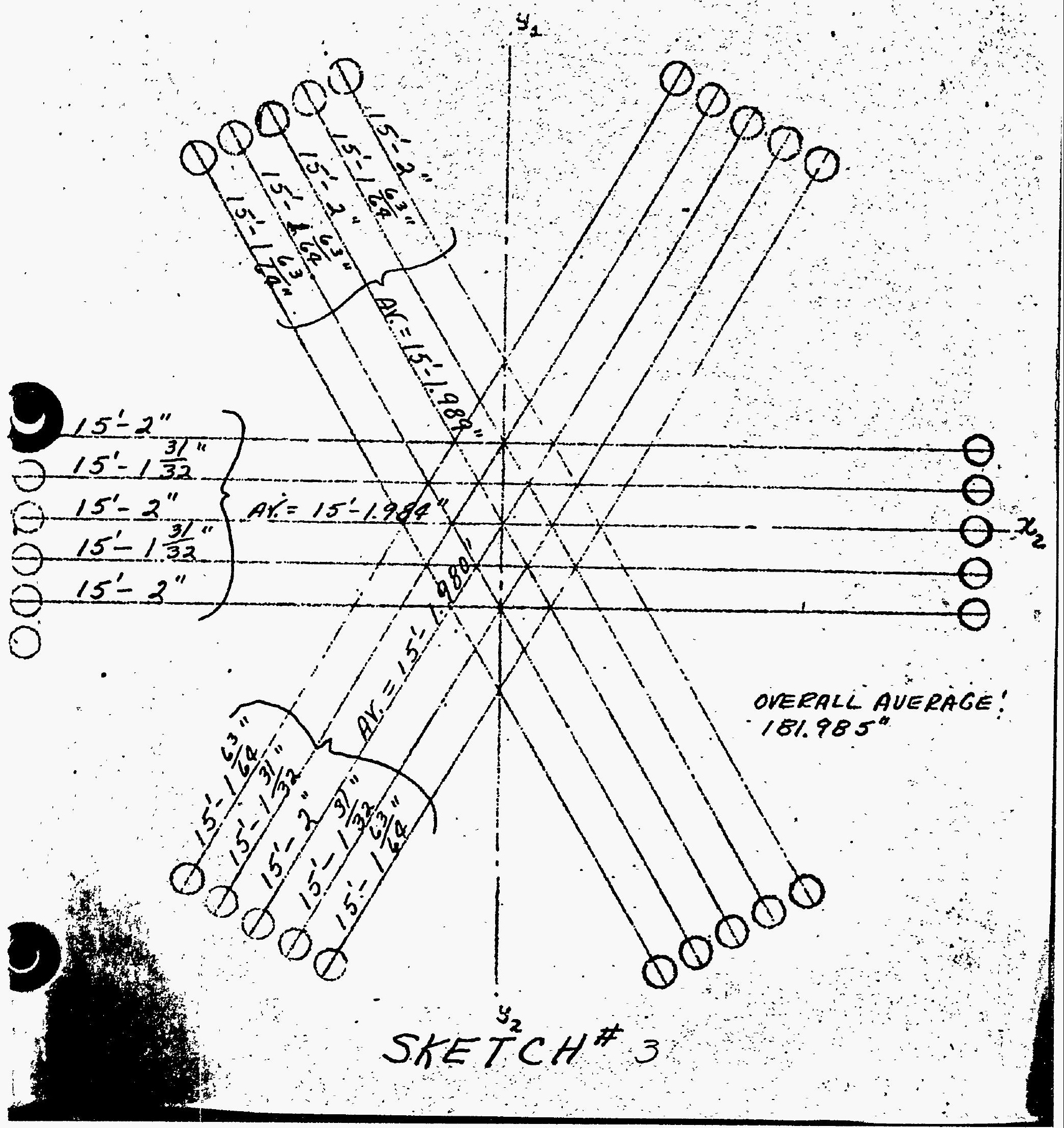




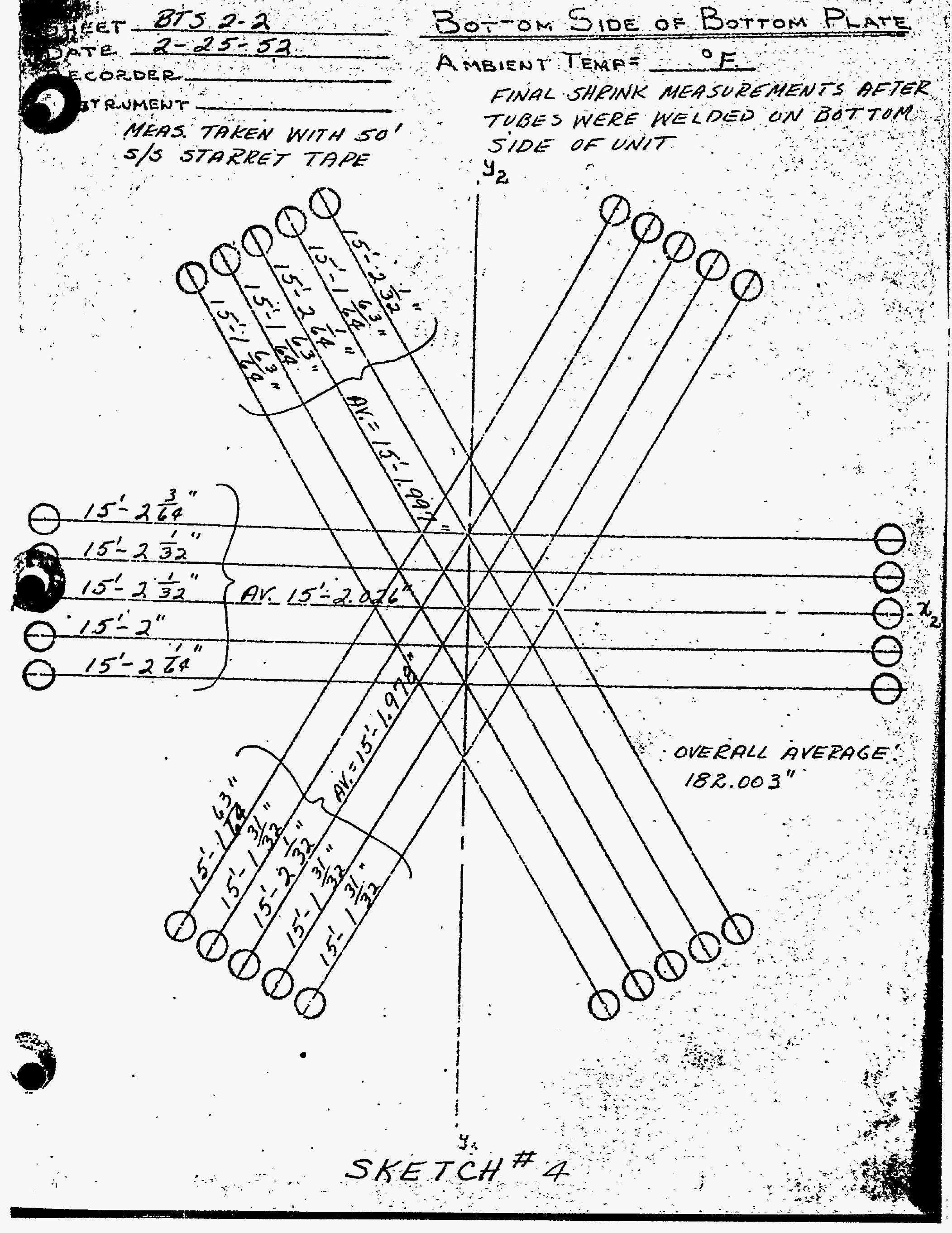


and necessary repairs made by chipping, grinding and re-welding (if necessary).

7. Assembling of "R", "P" and "L" Bottom Tube Sheets

B. "pn Unit

(1) Gusset Plate Pre-assembly Inspections

Inspections were performed in a similar manner to that discussed in Section $7 \mathrm{~A}-(I)$ of this manual:

(2) Inspections performed during Assembiing of Gusset plates into Unit

Inspections were performed in a similar maner to that discussed in Section $7 A-(2)$ of this manual.

(3) Baffle plate Spacers, Sandblasting, Acid Washing and Ferroxyl Testing

Inspections were performed in a similar manner to that discussed in section $7 A-(3)$ of this manual.

(4) Collar Inspection

W Inspection of tube collars was performed in a similar manner to that discussed $1 n^{2}$ Section $7 \AA-(4)$ of this manual.

(5) Vertcality check After placing Tube Sheets in circumder entifai Handing jig

rhis inspection was perforied in a similar maniento that discussed in section $\mathrm{A}-(5)$ of this manual, except as follows The Wild target was used to level the tube sheets clamped in the circumferential handing jig prior to taking verticality readings. For use of the wid NIII level in leveling of units see Part III section II-J.

(6) Gusset piate Welding Inspections

Wobese inspections were performed in a simslar manner

to that described in section $7 \mathrm{~A}-(6)$ of. this manual.

(7) Instrument Weil Inspections

Whs shown in drawing $5-10$ (section $7 \mathrm{~A}-(8)$ of thls manuall, ten instrument wells were required for tho $\mathrm{mp}$ bottom tube sheet 1 Hew York Ship fabricated the reguired number of instruitent wells from type 304 stainless steel bar stock and pipe. Aleferring to the above mentiones drawing, each instrument well was fabricated in three sections and then the three pieces butt welded at $\mathrm{t}_{\mathrm{w}}$ points to form, the instrument well. The top section of weil was machined from bar stock of suitable size dith a $1 / 4^{n}$ taper $/$ foot on the outside diameter. A male $a n d$ female taper gauge was machined to fit the pieces and to check the hole diameters. A special taper reamer was 
made for reaming the top tube sheet (in unit) for receiving the top part of the tapered well section. The center section of the well was a piece of $3 / 4^{n}$ schedule $40 \mathrm{~S}$ pipe cut to the required length with both ends beveled for weld preparation. The lower piece of the well was a piece of bar stock, bored, turned, threaded and beveled for welding as shown in drawing 5-4.

After the three sections that form a instrument well were butt welded, they were dressed and then visually and dimensionally inspected by the du Pont Inspection Department. (Visual inspection on side of well bore vas not done at this time). As small functional gage $\left(.824^{\prime \prime}\right.$ in diameter) was used to gage all ten instrument wells. They all passed the functional gage freely. All other dimensions were checked using a $6^{2}$ steel tape, 1-2" out-: side micrometer and a taper gage. The above inspections were satisfactory and the wells were released for testing.

Next, the ten instrument wells were hydrostatically tested at 2000 psi for ten minutes. Several leaks were found, repaired, re-tested and found satisfactory.

Finally, the instrument wells were freon tested, Each was individualily connected to a freon bottle and tested at a bottlenof approximately $100 \mathrm{psi}$ ). The instrument vells were subjected to this pressure for approximately. I5 minutes and then the two butt welded joints were checked for leaks using a General Electric type "H" Hallde Leak Detector. In addition, all other areas on the wells. were checked for possible leaks. None were found and the ten instrument wells were released for assembling and welding into the bottom tube sheet assembly. Instrument wells were welded in the unit during final welding of gusset plates to tube sheets discussed above in Section $7 \mathrm{k}-(6)$.

(8) Preliminary Cleaning

Before inserting and tacking large tubes, the unit was given a preliminary cleaning externally and internally to remove dirt, oil, and other foreign material which had collected during fabrication. This was done by first air jetting the unit at approximate 100 psi to remove all loose material. ifter this, the top and bottom sides of each tube sheet, gusset plates, and all other.'. accessible areas were wiped clean using a clean cloth saturated in F.0. 128. (Fine Organcs Safe-Tee Solvent). After cleaning, the unit was inspected, accepted and released for further fagrication.

(9) Large Tube Assembly and Tack Helding Inspections

Starting in the center of the unit and working out large tubes were progressively cleaned with F.0. 128 inserted in the unit, and tack welded to the inside of the bottom tube plate. Tack welding was visually inspected for undercutting, cleanliness, and necessary repalrs made. Tube assembly was witnessed by du Pont inspectors. 
(10) Types of Tubes Assembled in "Pn Bottom Tube Sheet Assembly

As a result of the problems encountered in the use of welded tubes in "R" bottom tube Sheet (See Section $14 \mathrm{~A}-(3)$ of this manual), Design Division requested that only cast and seamless tubes be assembled and welded into the "Pn bottom tube sheet. For location of seamless and cast tubes in the "P" B.T.S., see Exhibit $\frac{\|}{\# 2}$ presented herewith.

(11) Measurements before Large Tube Welding to Determine Unit Shrinkage

After all large tubes had been inserted into the unit, aligned and tack welded, initial shrink measurements were taken across three major diameters. Part II-A, Section 5-c, describes the method incorporated to take these measurements. Results of these measurements (before welding large tubes) for the top and bottom sides are shown in Sketches $\left.\#\right|_{2}$ and $\# 4-a$. The average measurement for the bottom side was calculated to be 182.309". (AIl measurements bore to bore). This average measurement for the top side was calculated to be $182.288^{\prime \prime}$.

(12) Measurements After AII Tubes had been Welded

All large tubes were welded in this unit using the same procedure discussed in Part II-A, Section 5-d.

After all large tube welding was completed, measurements were again taken using the procedure discussed in paragraph (II) above. Results of these measurements for the top and bottom sides are shown in Sketches $\frac{41}{45}$ and \#6. The average measurement for the top side was calculated to be $181.995^{\prime \prime}$. The average me asurement for the bottom side was calculated to be $182.018^{\prime \prime}$

Since Design Division specified that the top and bottom side measurements (after welding tubes) had to be within $0.0321^{\text {" }}$ of each other or less, it can be seen by analzying the results that the measurements were within the specified limit, e.i.,

$$
\begin{array}{ll}
\text { Bottom Side } & \begin{array}{l}
182.018^{n} \\
\text { Top Side }
\end{array} \frac{181.995^{n}}{0.023^{n}} \text { Difference }
\end{array}
$$

Therefore, no additional shrink welding was necessary, and the unit was rele ased for further fabrication.

(13) Visual Inspection and Repair of Tube Welding

This inspection was performed in a similar manner to that described in Section $7 \mathrm{~A}-(12)$ of this manual.

(14) Replacement of Tubes as a Result of Wield Burn Through

At various stages during the fabrication of this assembly, it was necessary to remove the following tubes: 


\section{EXHIBIT \#2}

TYPES OF TUBES ASSEMBLED IN "P" BOTTON TUBE SHEET ASSEMBLY 


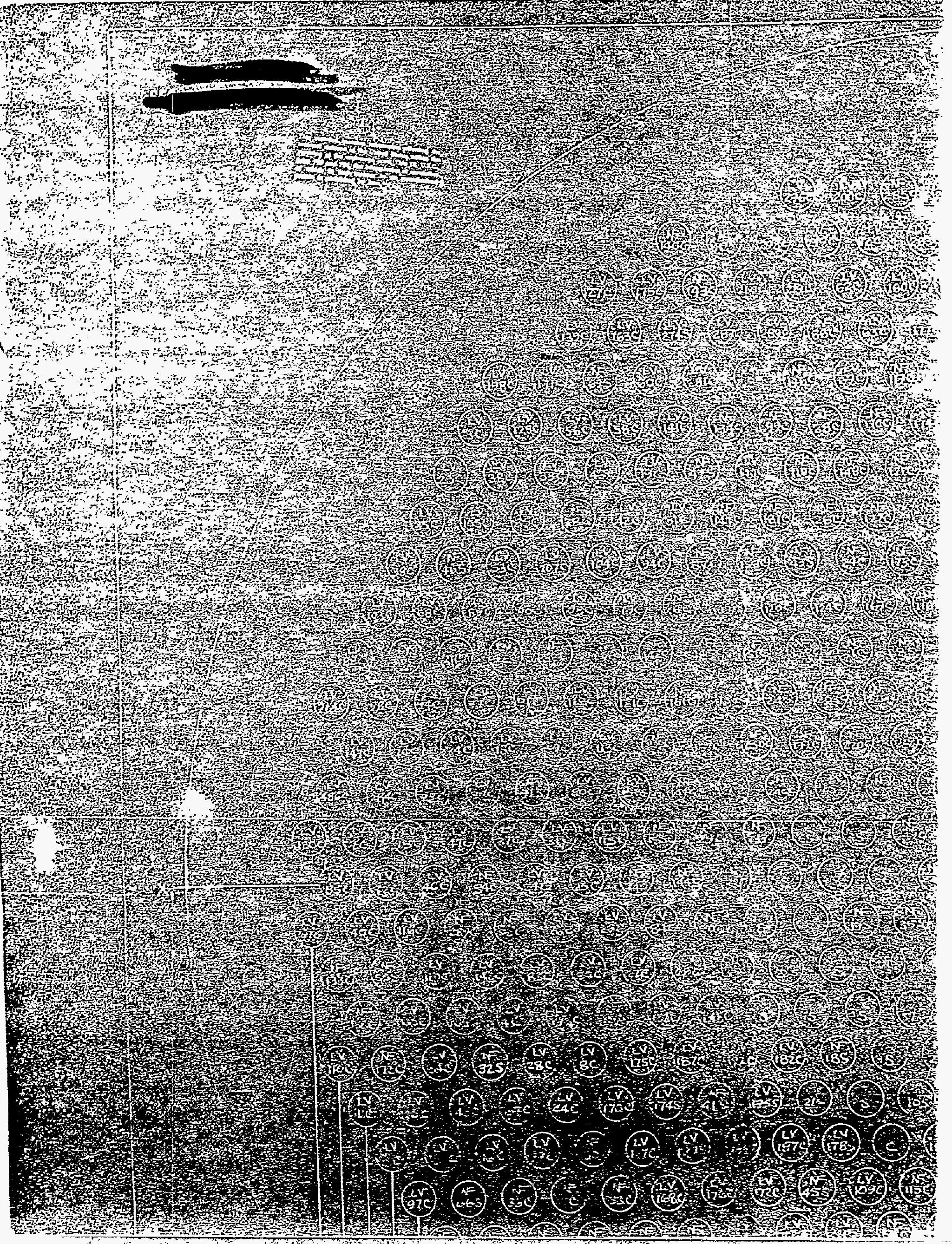


PF,

and

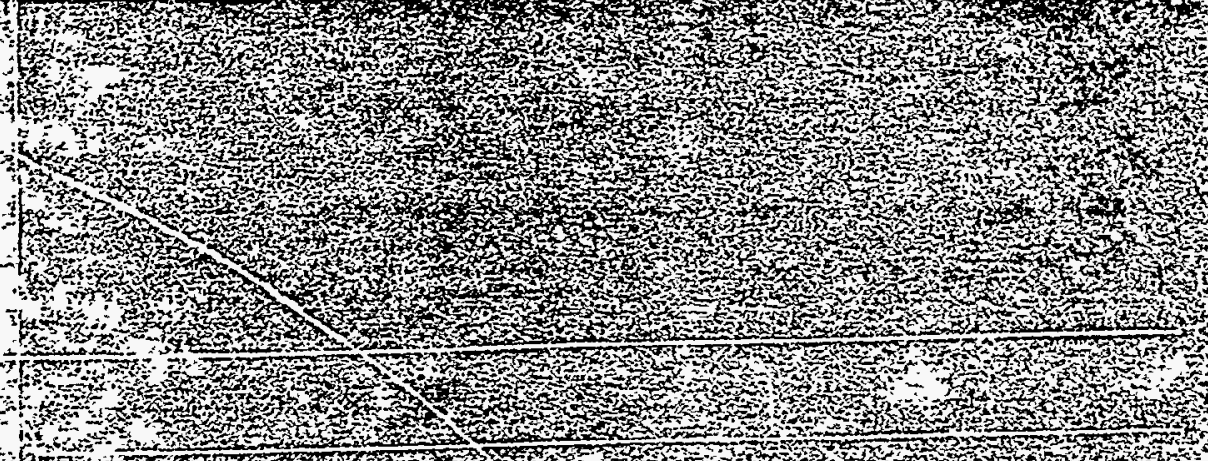

Hot

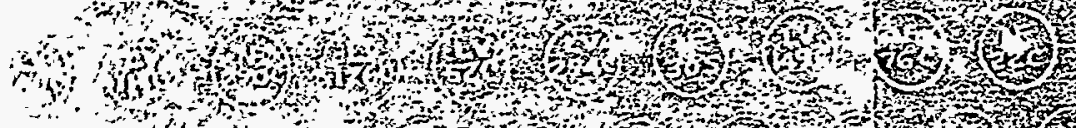

(1)

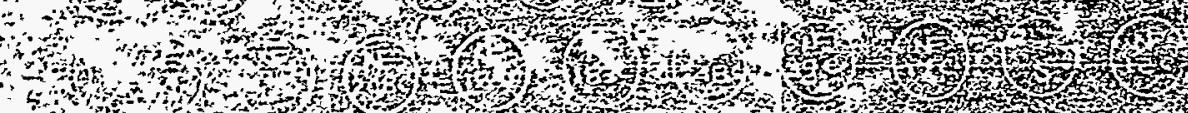

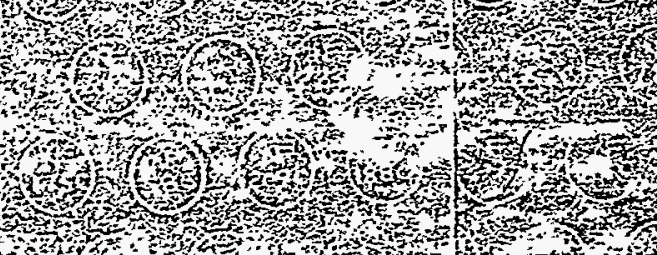

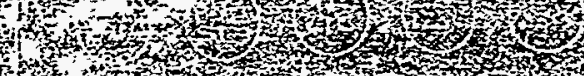

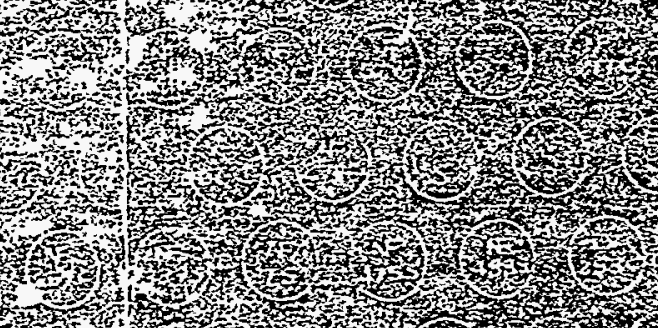

1

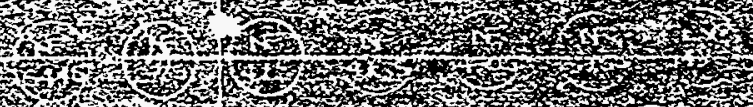

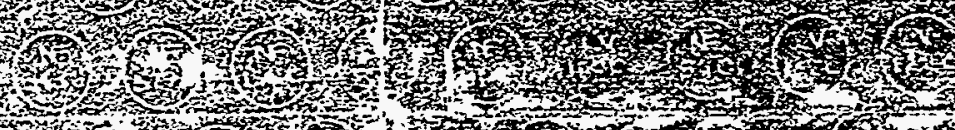

2.

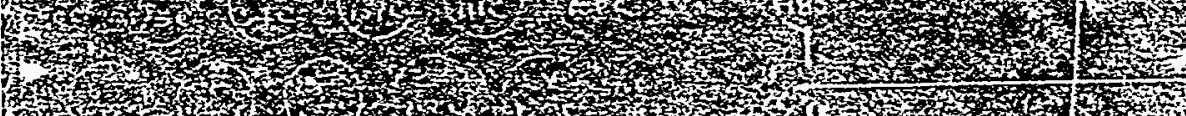

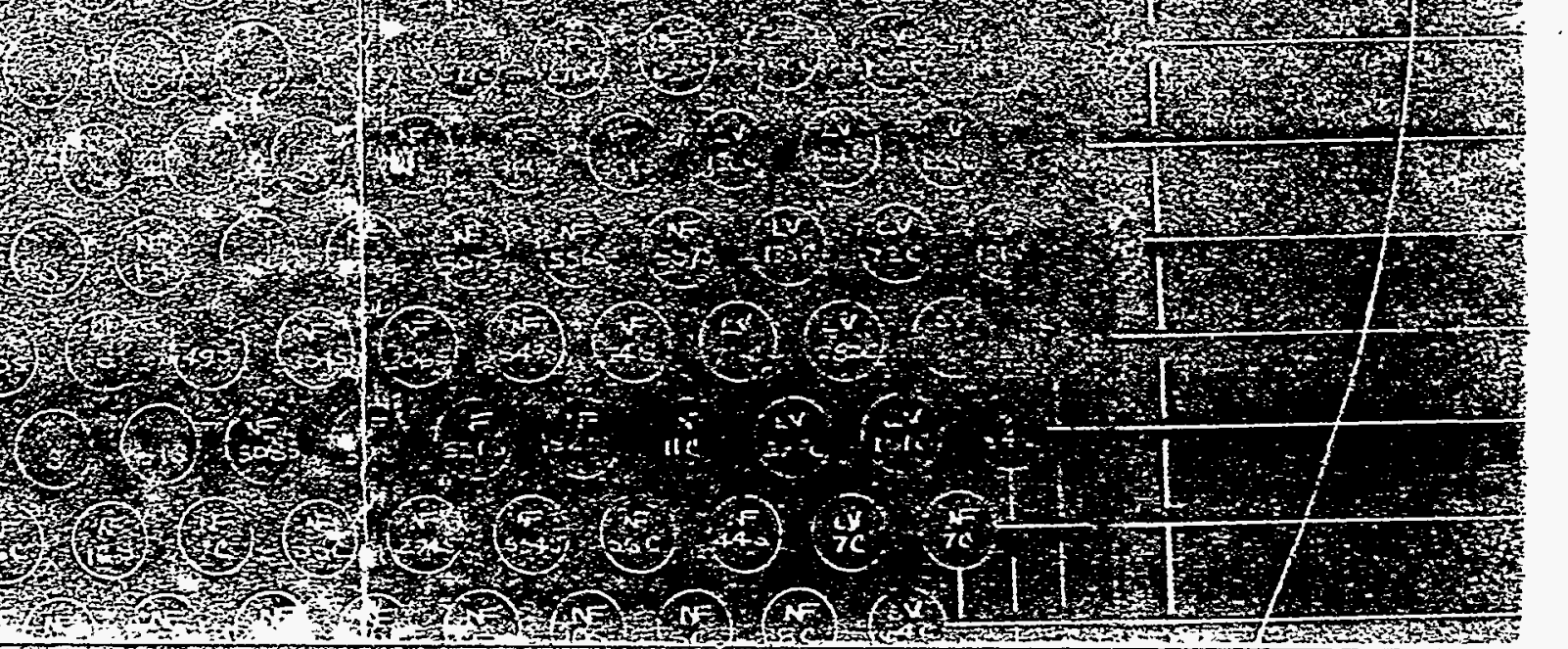




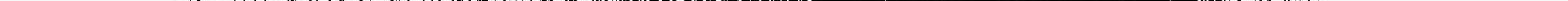


tos

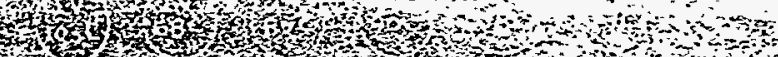

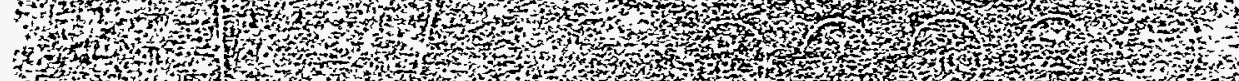

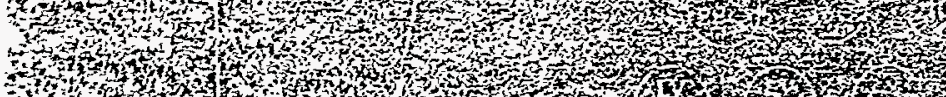

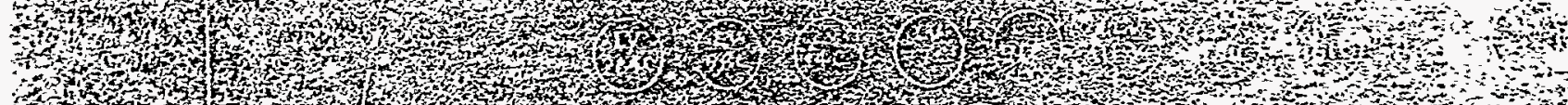

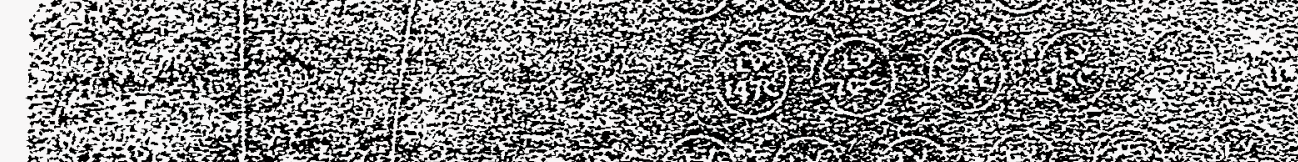

Hot.

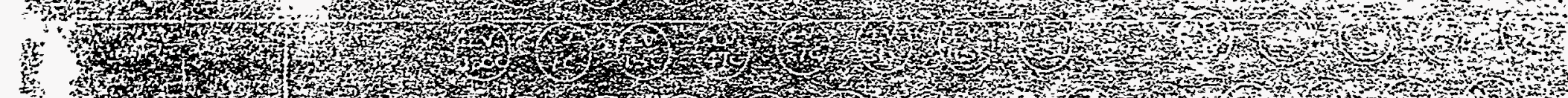

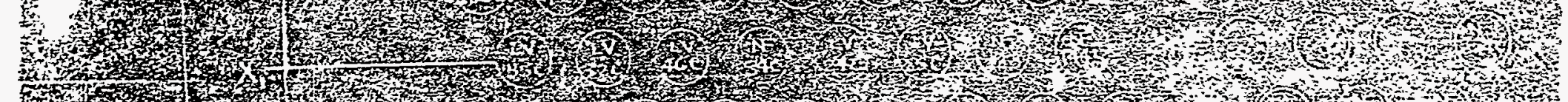

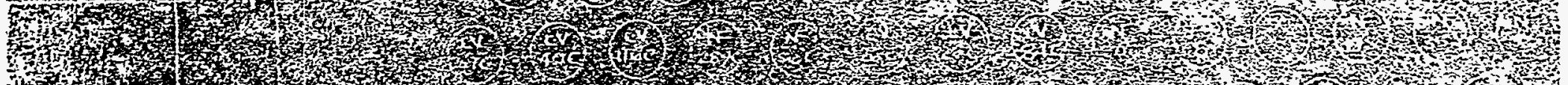

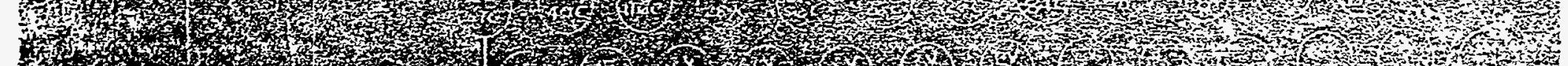
1.

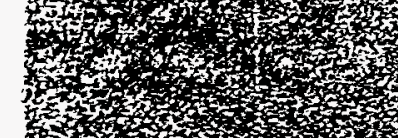

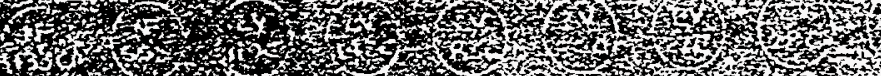

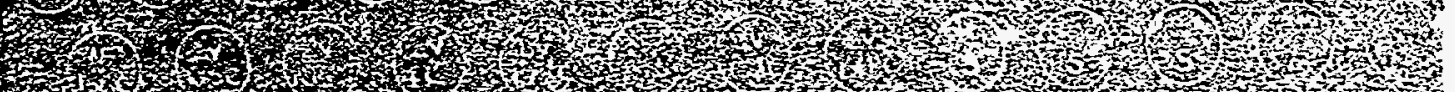

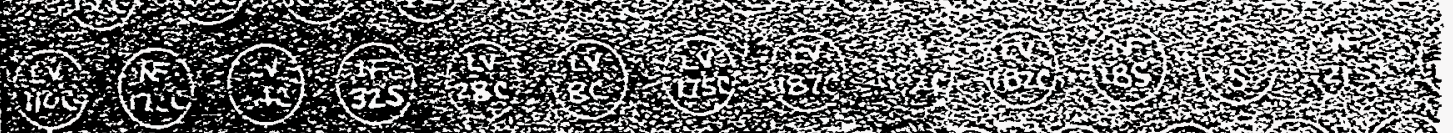
(1)

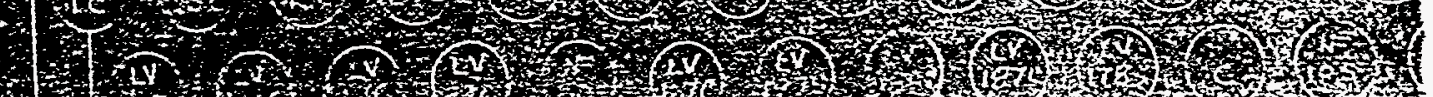

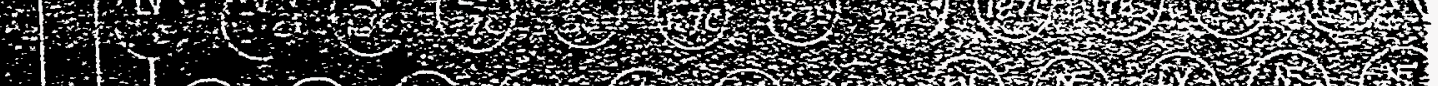

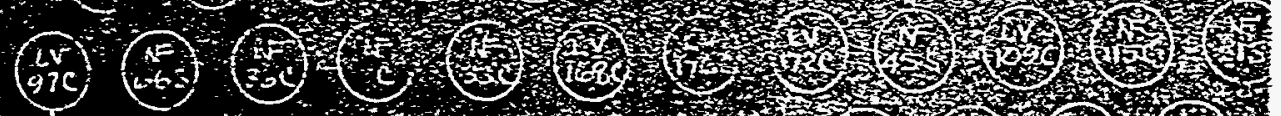

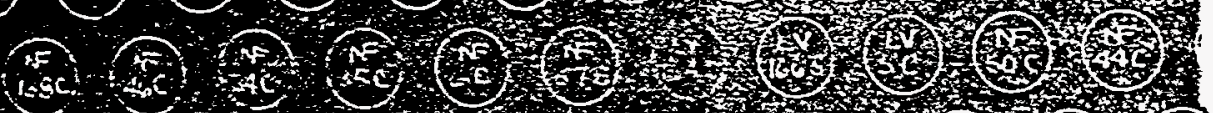

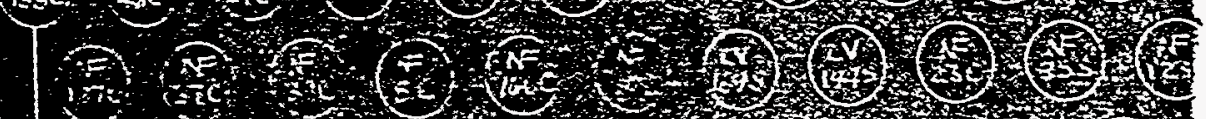
(1)

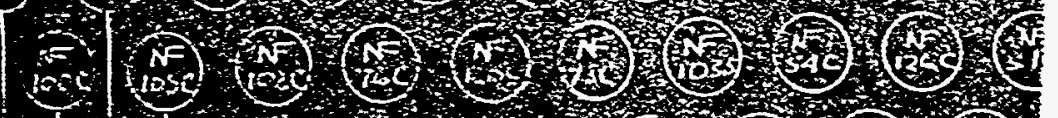

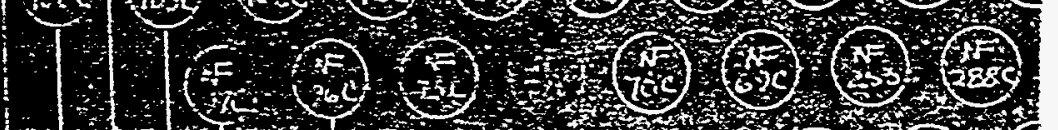

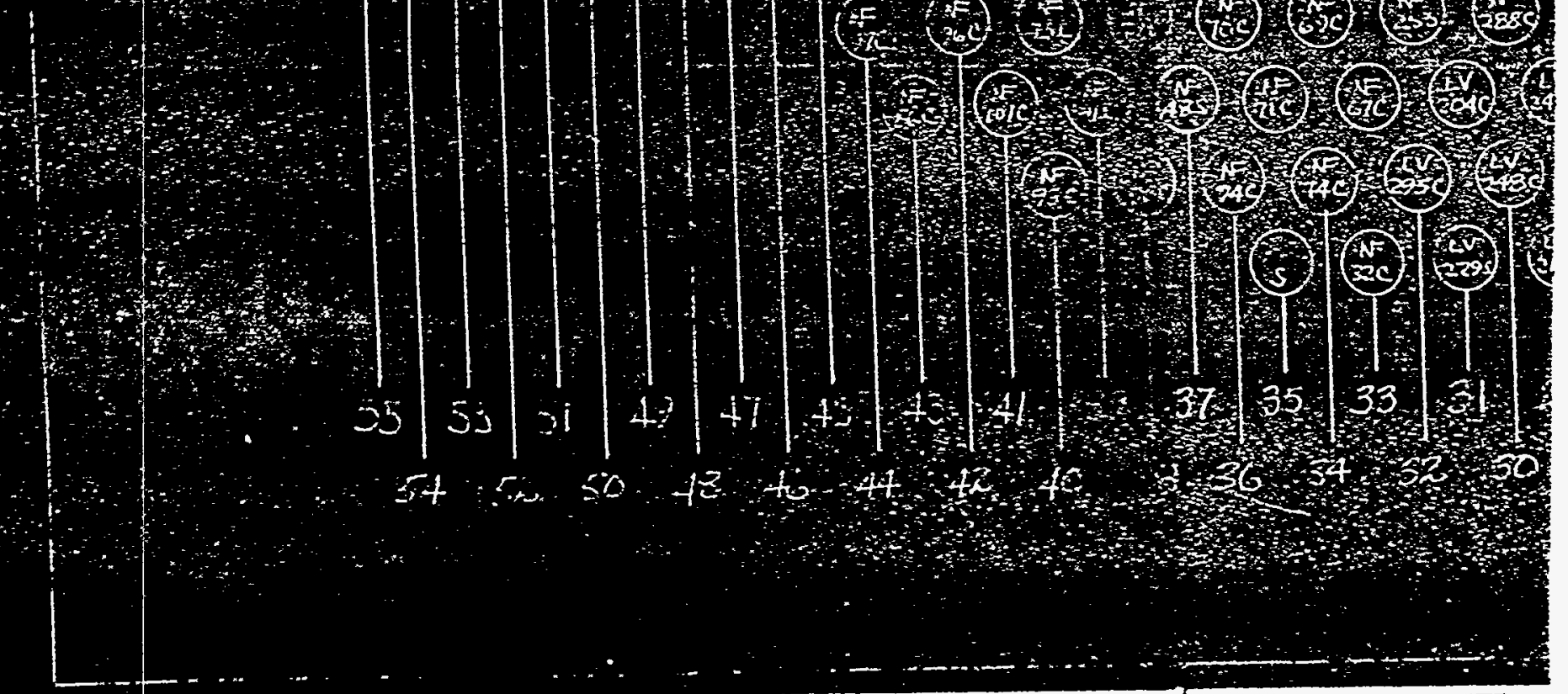




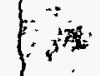

WEET $\frac{B T S 3-1(P)}{6-6-52}$

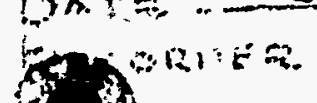

A.UNE IT:

WIASUREMENTS TAKEN WITA 50'5/3 STARRET TAPE

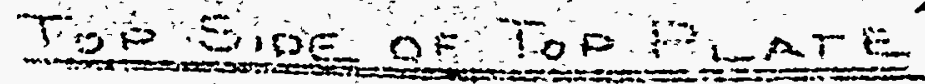

AMBERAT TeMP $80=$

INITIAL JHRINK MEASURENEENTS BEFORE TUBES WERE WELDED ON TOP SIDE OFUNT

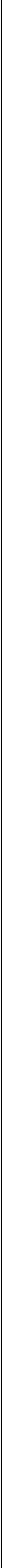

SKETCH ${ }^{*}$-A: 
40 SHEET

DATE

$\frac{3.5 \cdot 2}{6-6-52}$

ECORDER

HTRUMENT

EGES. TAKEN WITH $100 ' 5 / 5$ STALRET

TAPE-N.B.S. 9677 . UUPONT TAPEA/

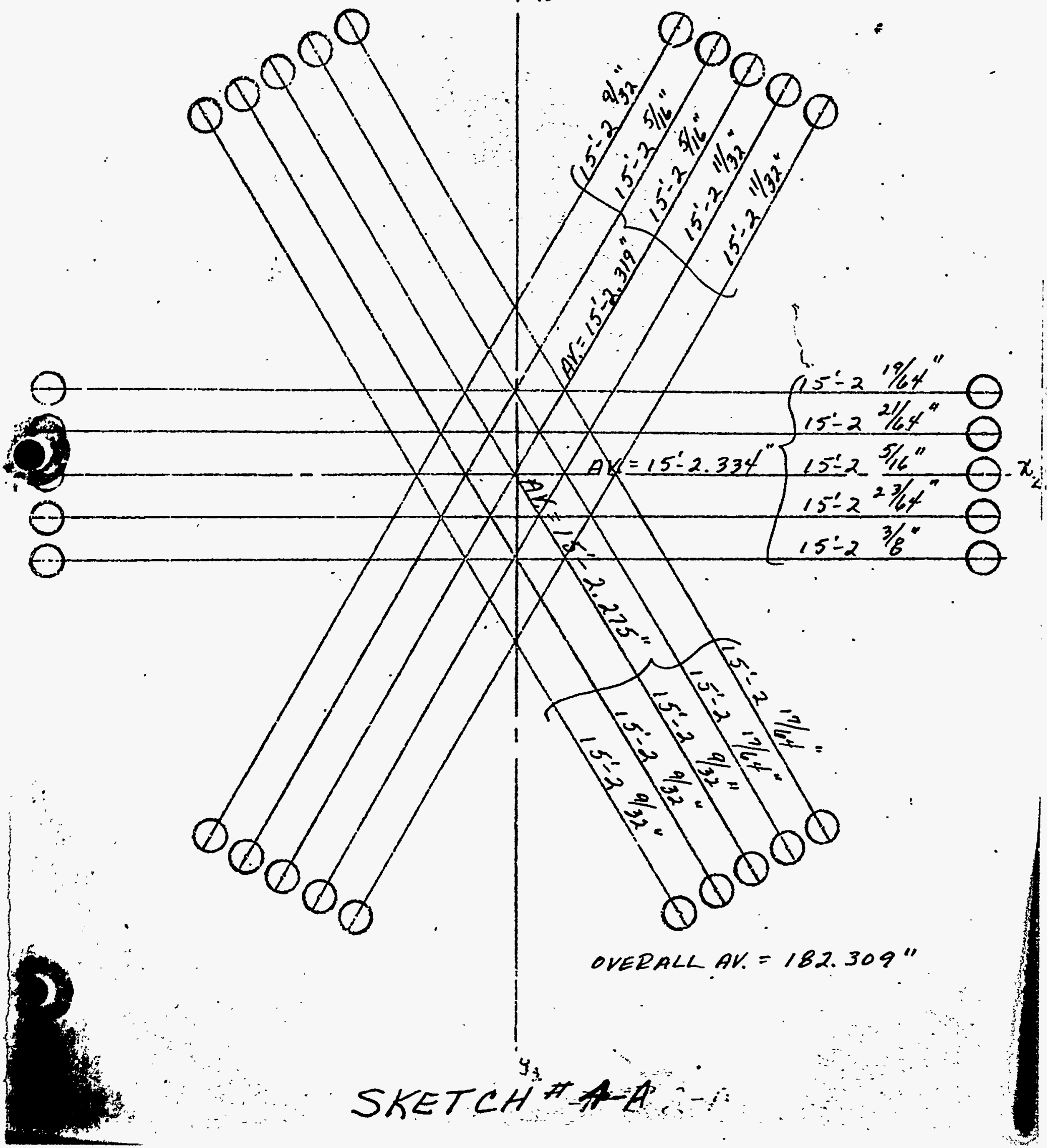

AMBIENT TEMP $=Q 00^{\circ} \mathrm{F}$

INITIAL SHRINK MEASUREMENTS BEFORE TUBES WERE WEZDED ON BOTTOM SIDE OF UNIT

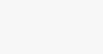

$y_{2}$ 


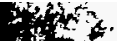

$\frac{3 . T}{6-1.2-53}+(P)$

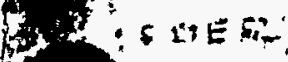

$M E N T$

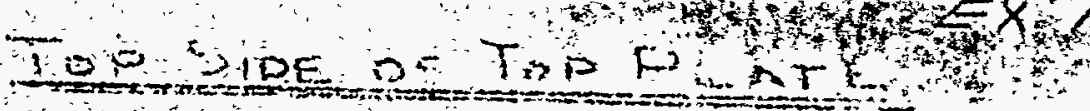
AMBIENT TEMP Q00

FINAL SHRINK MEASUREMENTS AFTER TUBES WERE WELDED ON TOP SIDE

MEAS. TAKEN WITH $100^{\circ} \mathrm{S} / \mathrm{S}$ STARRET TARE

N.B.S, 9677 - dUPONT THPE\#I

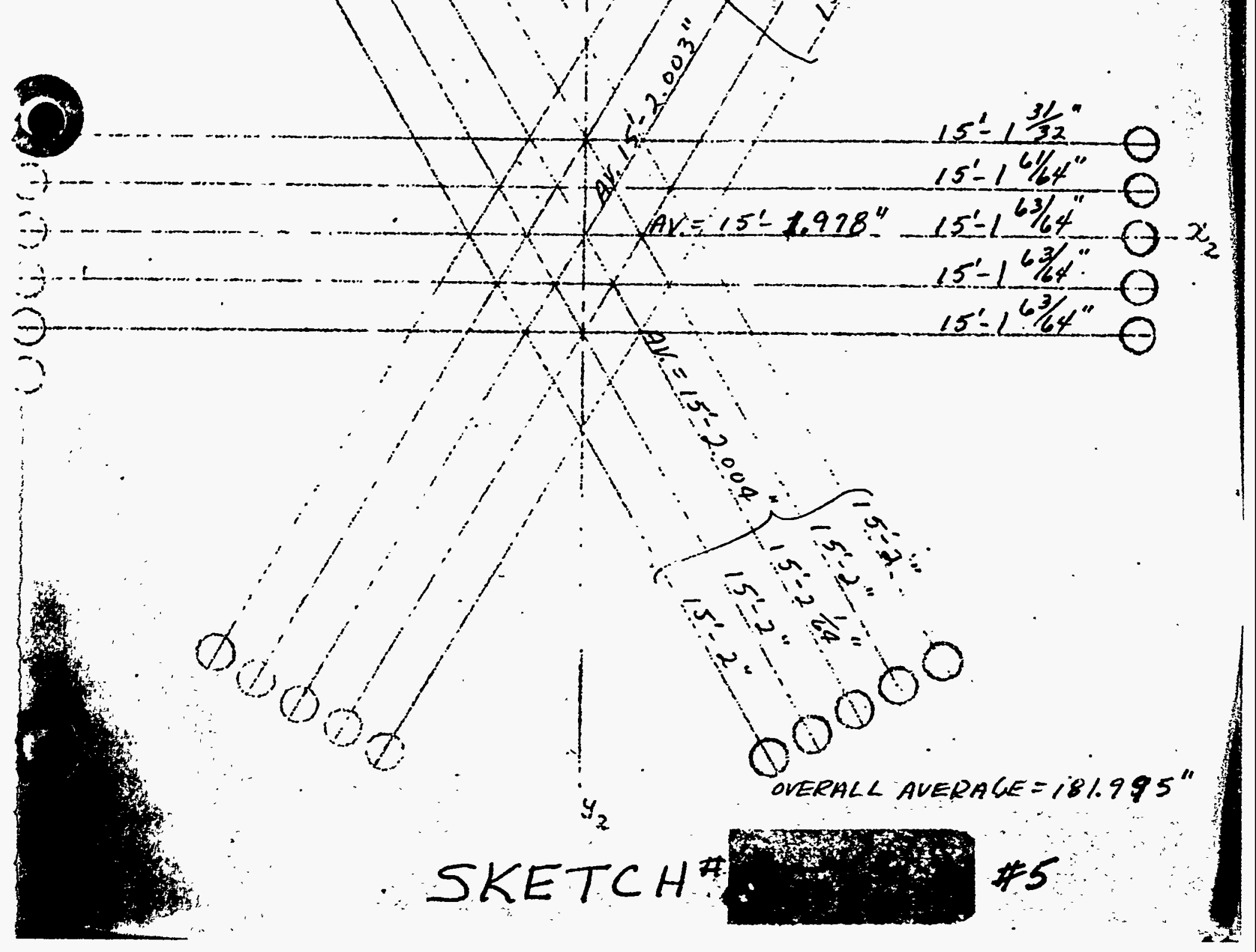


SHEET B.T.S $3-2$

DATE: $6-16-53$

WETORDER

tis

ST R.NAELT

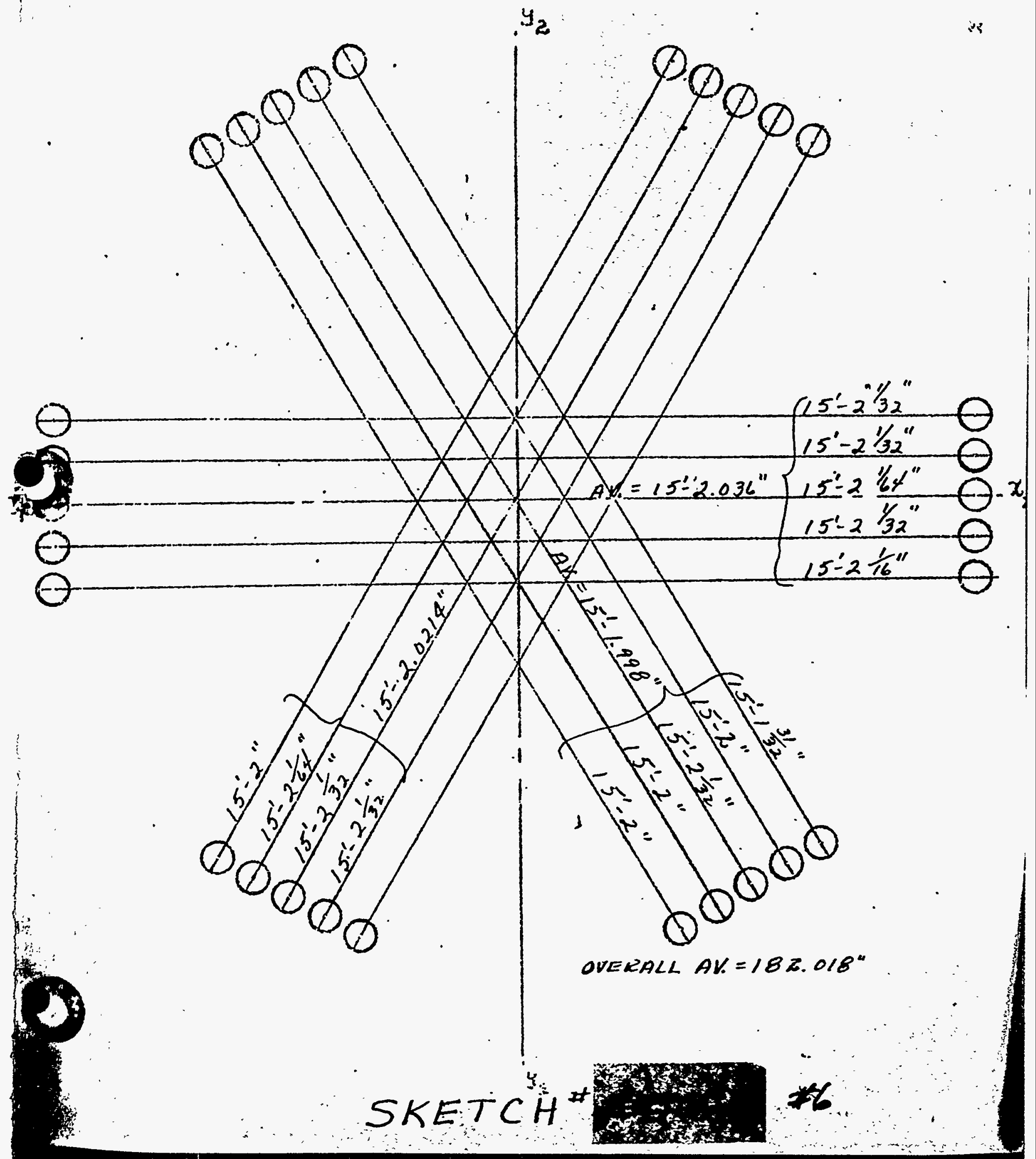


Tube Position

$\times 35-13$

$\times 37-Y 57$

$X 31-Y 81$

$X 27-Y 45$

$\times 37-739$

$\mathrm{XII}-\mathrm{Y} 75$

\section{$\mathrm{X} 22-16$}

$\bar{X} 34-Y 90$
Reason for Removing

Iaminations and weld burn through

Weld burn through

Vield burn through

Weld burn through

WeId burn through

When original weld joining tube to bottom plate was found defective and cut out, inspection of tube revealed a weld burn on $0 . D$. It was thought that re-welding would burn through tube:

Record incomplete.

Record incomplete

After the above tubes were replaced, welded and tube weld overlay ground, all welding was visually inspected by du Pont inspectors for cracks, craters, undercutting, weld burn through, and porosity. Minor defects were removed by grinding. Tube welds were re-inspected and approved.

A shrinkage pattern was again taken by du Pont inspectors to determine if additional welding on replacement tubes distorted the tube pattern. Measurements were repeated in a similar manner described in Section $7.8-(12)$ of this manual. Final results indicated the tube pattern on the top and bottom sldes was still within Design's specified limit: The unit was acepted and released for further fabrication.

c. "L" Unit

(I) Gusset Plate Pre-assembly Inspections

Inspections were performed in a similar manner to that discussed in Section $7 \mathrm{~A}-(1)$ of this manual.

(2) Inspections Berformed During Assembling of Gusset Plates into Unit

Inspections were performe in a similar manner to that discussed in section $7 \mathrm{~A}-(2)$ of this manual.

(3) Baffle plate Spacers, sandblasting, Acid Washing and Ferroxyl Testing

Inspections we re performea in a similar manner to that discussed in section $7 A-(3)$ of this manual.

(4) Collar Inspection

Inspection of tube collars was performed in a similar manner to that discussed in Section $7 \mathrm{~A}-(4)$ of this manual.

(5) Verticality Check After Placing Tube Sheets in Circumferential Handling $\mathrm{Jig}$.

This inspection was performed in a similar manner to 
that described in Section $7 \mathrm{~A}-(5)$ of this manual, except as follows: During tube assembling operations, du Pont inspectors recorded the location of all tubes and the type. Large tubes were identified by a serial number stenciled near one of the tube ends. Prior to assembling of tubes into this unit, inspections performed on the tubes were recorded for each using the newly adopted tube numbering system, thereby tying in tubes welded in the unit with their pre-assembly inspection me asurements. This new numbering system was necessary since there was no method used in the past for comparing tubes in the assembly with pre-assembly inspection results. In addition, incoming field complaints pertaining to tube discrepancies could not be readily compared with those taken at New York Ship which further necessitated the adoption of a tube numbering system.

\section{(6) Gusset Plate Welding Inspections}

The se inspections vere performed in a similar manner to that described in Section $7 \mathrm{~A}-(6)$ of this manual.

(7) Instrument Well Inspections

As shown on Dwg. 5-4 (Section 7A-(8), Detail "B" of this nual), ten instrument wells were required for the "L" bottom tube sheet assembly. Prior to assembling and welding wells in the bottom tube sheet, the following inspections were made:

a. Each of the ten instrument wells were visually inspected by inserting a six foot long $x 1 / 2^{\prime \prime}$ Rd. Lico Borescope into the well and slowly rotating it until the entire circumferential welded butt joints vere inspected for amount of weld penetration. Both butt welds in each instrument well showed full weld penetration and were accepted.

b. The I.D. of each well was checked with a $0.824^{n}$ diameter plug gage. All wells accepted the gage freely and were accepted.

c. Each well was connected to a cyclinder of freon 12 and the gas was allowed to enter the well at approximately 100 psi pressure. A General Electric, type "H" Leak Detector was used for detecting any leaks in the instrument wells. Gas was retained in the well for a ten minute period. No leaks were detected.

d. Each well was connected to a hydrostatic testing fixture and water was pumped into the well until 2000 psi gage pressure was attained. After holding pressure for 15 minutes, a visual inspection was made for leaks. None were found.

The above pre-assembly inspections were satisfactory, and the ten instrument wells were released for fabricating into the " $L "$ bottom tube sheet assembly. 
(8) Preliminary Cleaning by Dowell, Inc.

During the initial stages of fabricating "L" iunit internal cleanliness of the various sub-assemblies became a major problem. This came about as a result of the establishing of strict cleaning specifications by plant site personnel. Heretofore; minor complaints hä been received from the field pertalning to the cleanliness of " $R$ " and "P" units which prompted the du Pont Inspection Department to take immediate steps to better clean inters nally all future sub-assemblies.

Steps were immediately taken by du pont Inspect on Department to develop and write preliminary cleaning procedures for the various sub-assemblies st111 1 nothe early stages of fabrication A prellminary cleaping procedure was written for internally cleaning tho nit bottom tube sheet prior to assembling and welding of wrapper plates. This procedure is presented herewth as Exhibit \#3.

The preliminary cleaning procedure was carried out in its entirefy by the Dowell Corporation and witnessed by a du Pont inspector.

After cleaning the unit was visualiy inspected on the

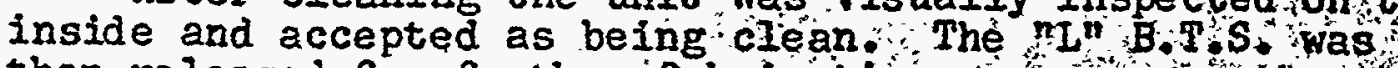
then released for further fabrication.

Instrument Lead Tube, Large Tube and Tnstrument ifeli Assembly and Tack Welding Inspections

As shown on du Pont drawing 132764 , seven $(7)$ additional tubes were added to the unit these tubes wers rod tubes used in the top tube sheet but here fabricated into this unit to serve as instrument lead tubes. These. seven tubes were the first to be ivelded into the unt The seven tubes were set to their properthelght and then tack welded to the inside of the bottom tube plate Tack welding was visually inspected by du Pont Inspectors for undercutting, melt downs and other mechanical jefects All tack welds were then cleaned to repove weld smoke oxides and other foreign material-using a stainless steet wire brush. Wire brushing of tube tack welds was requested by the du Pont Inspection Departinent as a clebr liness preventive measure, and also to make for a better unit insofar as internal cleanisness of the unit wes
concerned.

After al1 instrument lead tubes were tack wejded inspected and approved, they were fully lded using the th automatic aircomatic tube welding process

Starting in the center of the unit and working ont pre-inspected large tubes were progressively insertedinto the unit and tack welded to the inside of the bottomtube plate. AlI large tubes were identified by a symboly designating the vendor and serial number section $70-15$ of this manual explains why this identification systep 
EXHIBIT \#3

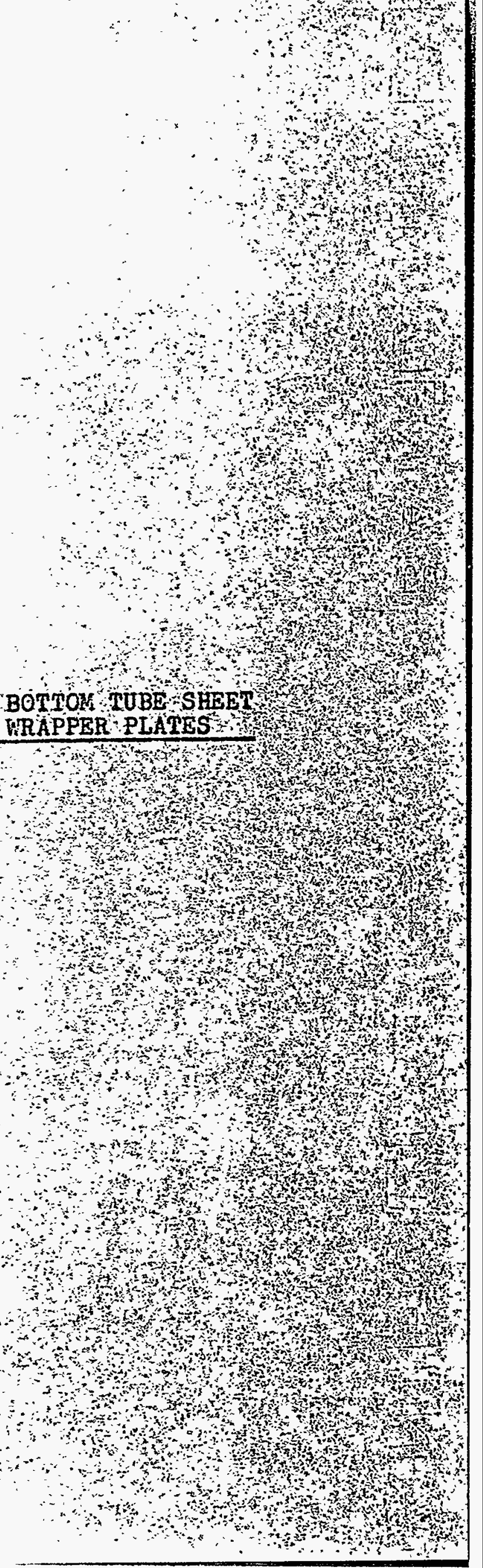


B. I. DU⿴ PONT DE NEMOURS \& CO., INC. ponstruction Division

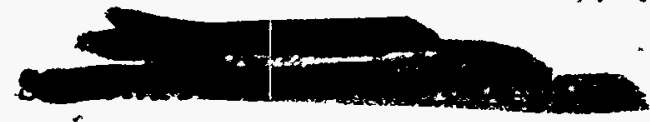

Serial Number 219

CC: H. W. Gosney, F.P.M. (2)

R. K. Mason, F.P.M.-SRP (3)

H. I. Bunker - J. G. Brewer

H. B. Gage

J. A. Colins

c. J. Veith

L. H. Arning

J. F. Elliot

Dowell Inc: (2)

S. R. Cochran (2)

J. B. Johnson - File:

July 7,1953

Now York Ship - Camden, N. J.

\section{MEMORANDUM}

TO: : - R. H. BARTO - J. W. REID (5) NEW YORK SHIPBUILDING CORP. CAMDEN, NEW JERSEY

FROM: J. B. JOHNSON - R. V. GRAHAM

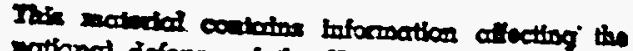

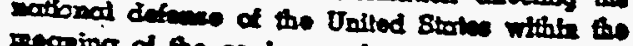
sece 799 of the explonoge law, Iith 18, OSC.

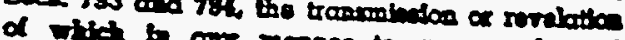

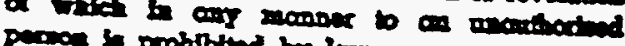
perion in prohiblud by law.
\end{abstract}

an following procedure supersedes the cleaning procedure on the same subject serial number 206 and is essentially the same with a few additions and. corrections.

Inatall raschig ring loading cradle.

Set up vertically.

cleaning solution will be by weight:

$0.1 \%$ Deterger

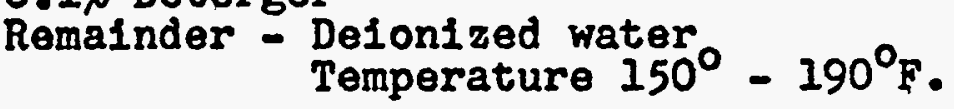

Jet using stainless steel nozzle upper $60^{\circ}$ for 15 minutes.

Ringe with manual hose using hot delonized or distilled water, upper $60^{\circ}$ for 15 minutes.

Jet additional $120^{\circ}$ each side with cleaning solution for 1 hour keeping hot rifise water hose on upper $60^{\circ}$.
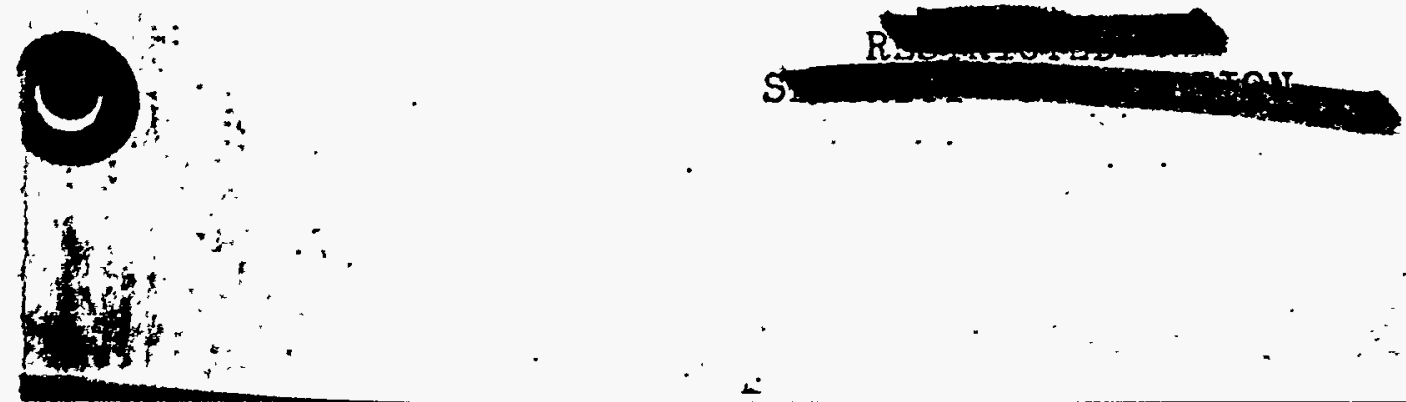
Inie additional $120^{\circ}$ each side with hot delonized or distilled water keaplas mainuli hose on upper $60^{\circ}$ for 1 hour.

Rotate assembly $60^{\circ}$ ither way, Jet with detergent, original bottom $60^{\circ}$ for 15 minutes and minse same area for 15 minutes.

Time: 8 hours.

Durlng all jetting be sure to cover area between top sheet and baffle as woll as baffle and bottom sheet area. 
was incorporated on this unit. Exhibit $\$ 4$ presented herevith shows the location of all tubes. After each large tube was inserted in the unit and tack welded, the weld was wire brushed to remove oxides and weld smoke. Du Pont inspectors witnessed this operation and visuaily inspected each tack weld for cleanliness, undercutting and melt down.

The ten instrument wells repuired for this unit were installed and fully welded. Velding was visually inspected for porosity, cracks, undercutting and other mechanical defects. Hecessary repairs were made, re-inspected, and instrument well welding accepted.

The remainder of fabrication and inspection performed during and after large tube assembly is similar to that discussed in sections $7 A-(6)$ of this manual.

(10) Types of Tubes Assembled in "I" Bottom Tube Sheet Assembly

Al1 $3-15 / 16$ " O.D. tubes assembled into the "I" bottom tube sheet were seamless tubes.

(11) Neasurements Before Large Tube Helding to Determine Unit Shrinkage

After all large tubes had been inserted into the unit, aligned and tack welded, initial shrink measurements were taken across three major diameters. Part II-A, Section 5-C, describes the method incorporated to take these measurements. Results of these measurements (before welding large tubes) for the top and bottom sides are shown in Sketches $\$ 7$ and 78 . The average measurement for the top side was calculated to be $182.275^{n}$. The average measurement for the bottom side was calculated to be $182.317 "$. (AII measurements bore to bore).

(12) Measurements After AII Tubes Had Been Helded

AII large tubes were welded in this unit using the same procedure discussed in Part II-A, Section 5-d.

After all large tube welding was completed, measurements were again taken using the procedure discussed in paragraph (II) above. Results of these measurements for the top and bottom sides are shown in Sketches \#9 and \#10. The average measurements for the top side was calculated to be 181.995". The everage measurement for the bottom side was calculated to be $182.046^{\prime \prime}$.

Since Design Division specified that the top and bottom side measurements (after welding tubes) had to be within $0.0321^{\prime \prime}$ of each other or less, it can be seen by analyzing the results that the difference lay outside the specified limit, i.e.,

$$
\begin{array}{ll}
\text { Bottom Side } & 182.046^{n} \\
\text { Top Side } & \frac{181.995^{n}}{.041^{n}}
\end{array}
$$


EXHIBIT 144

TUBE IDERTIFICATICN OF ALI LARGE TUBES IN THE "L" BOTTOR TUBE SHEET

6 


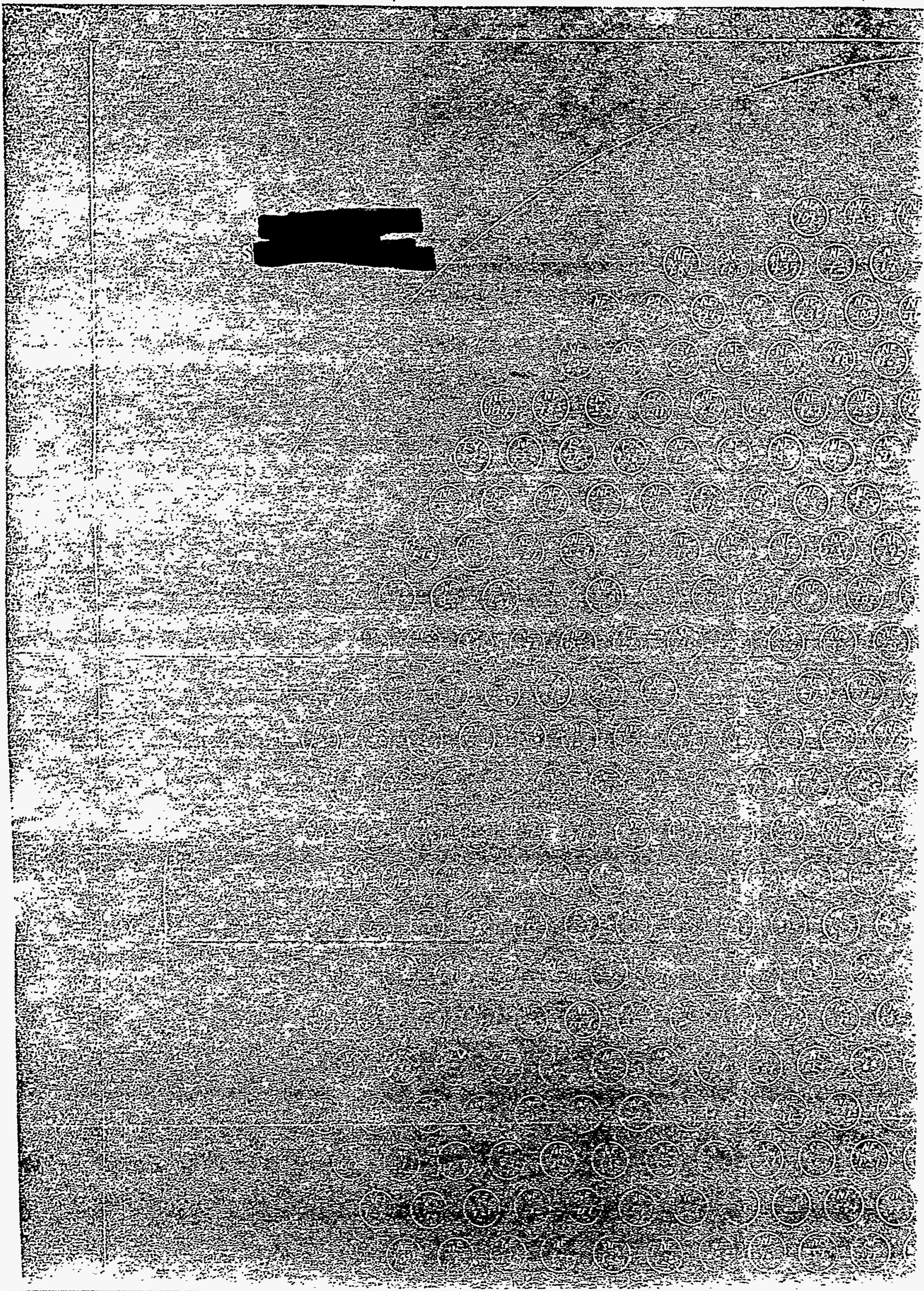




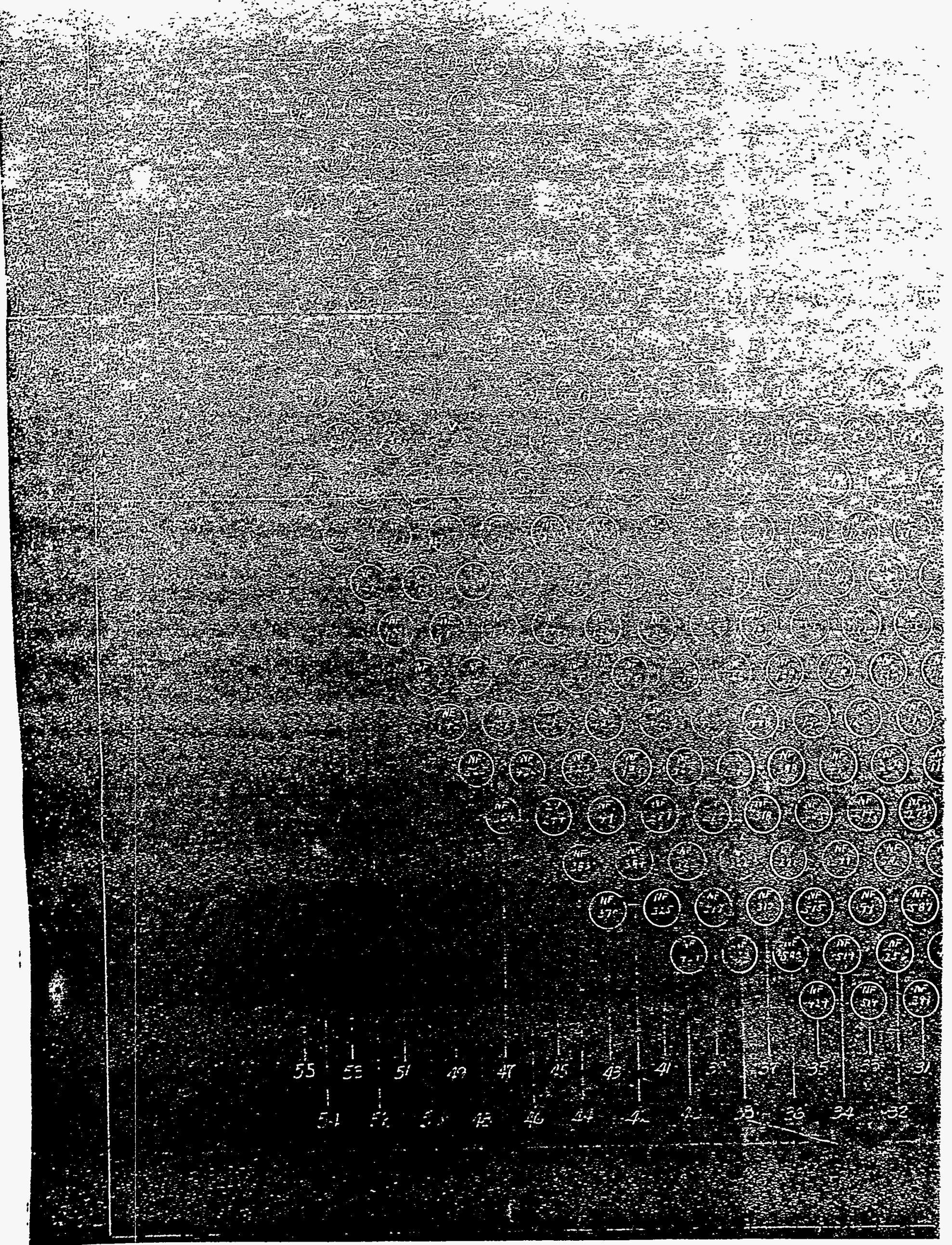




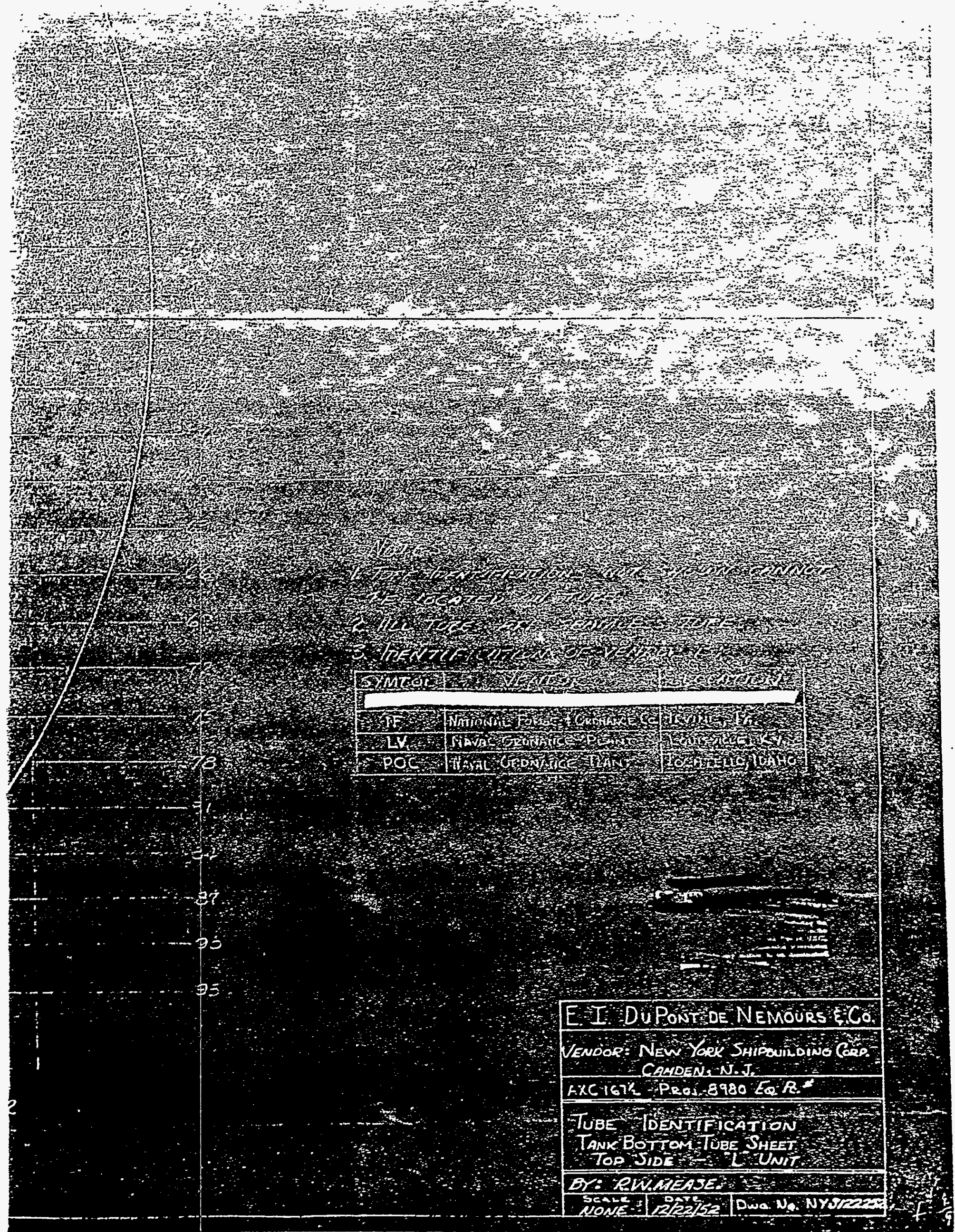


TEET B.T.S. $L-L(L)$

$=r E-10-8-52$

MOKJER.

JMEN $T$

MEAS. TAKEN WITH dUPONT

- INITIAL SNRINK MEASUREMEMTS, BEFORE TUBES WERE WELDED ONTOP SIDE OF UNT
ToP SIDE OF TOP PLATE

AMEIEAT TEMP. 570 TAPE FE (100's/5 TAPE) 
HEET B.T. $S .4-L(L)$ कI

DOU JER.

IMEH $T$

MEAS. TAKEN WITN dUPONT TAPE TE (100'S/S TAPE) (1)
TUBES WERE WELDED ONTOP SIDE OF UNIT

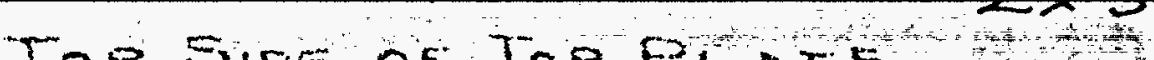

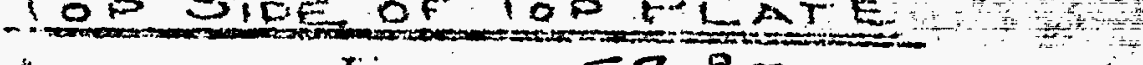
FMElEnT" TEMP. 570

\section{- INITIAL SNRINK MEASUREMENTS DEFORG}

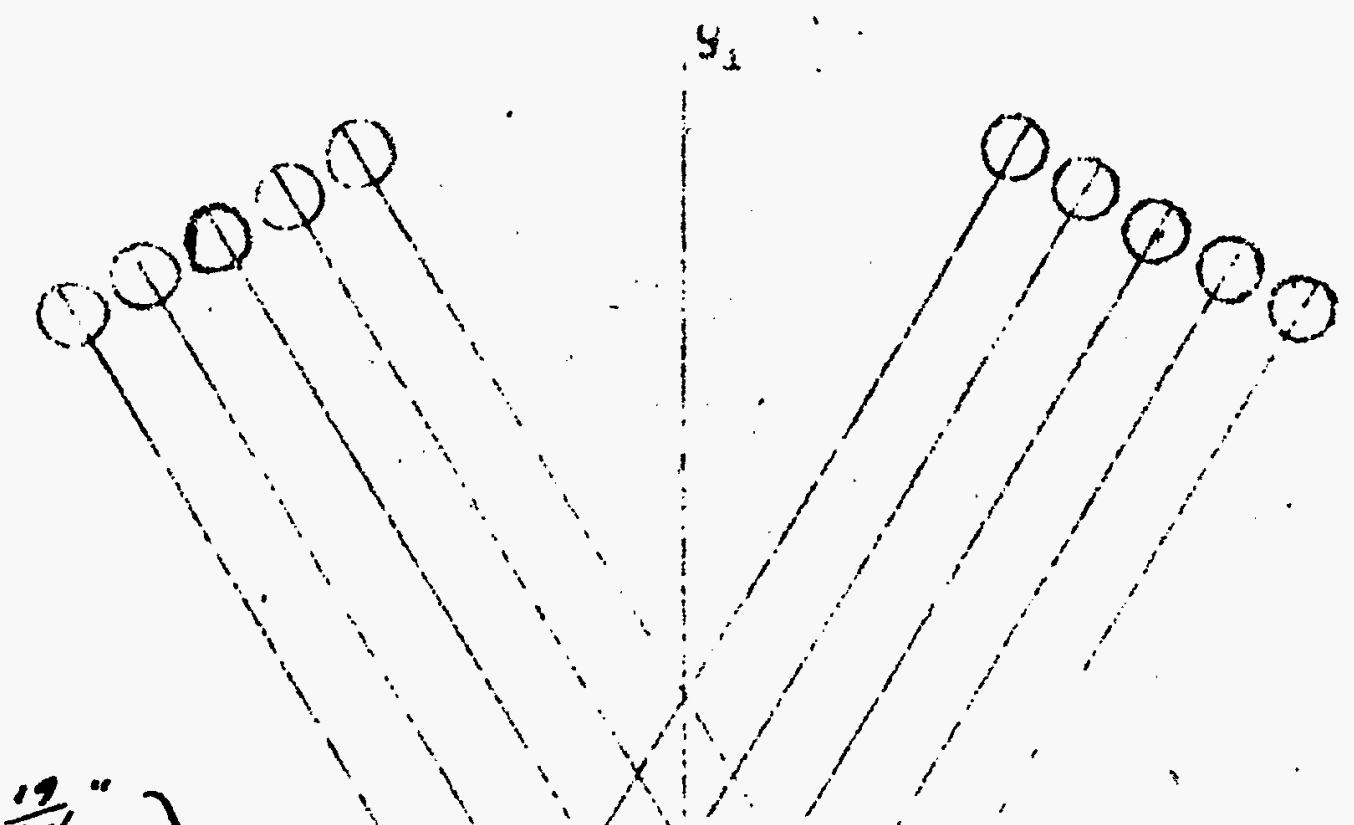

$15^{\prime}-2 \frac{19}{64} "$
$+15-2 . \frac{19}{64} "$

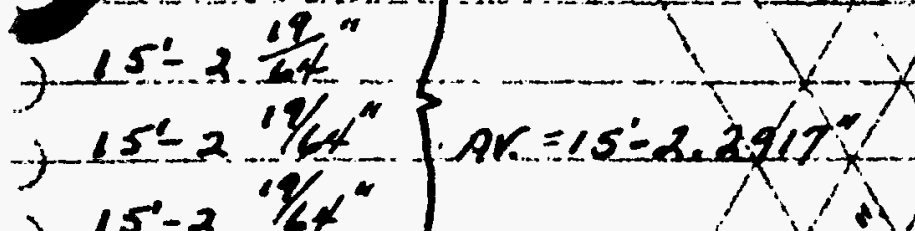

$-15^{\circ}-29 / 64^{\circ}$
$+15^{\circ}-2932^{\circ}$

)

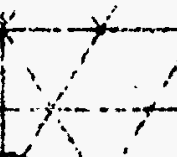

$\therefore$

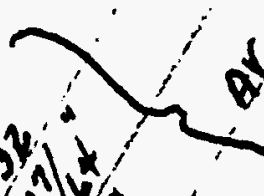

$x+$

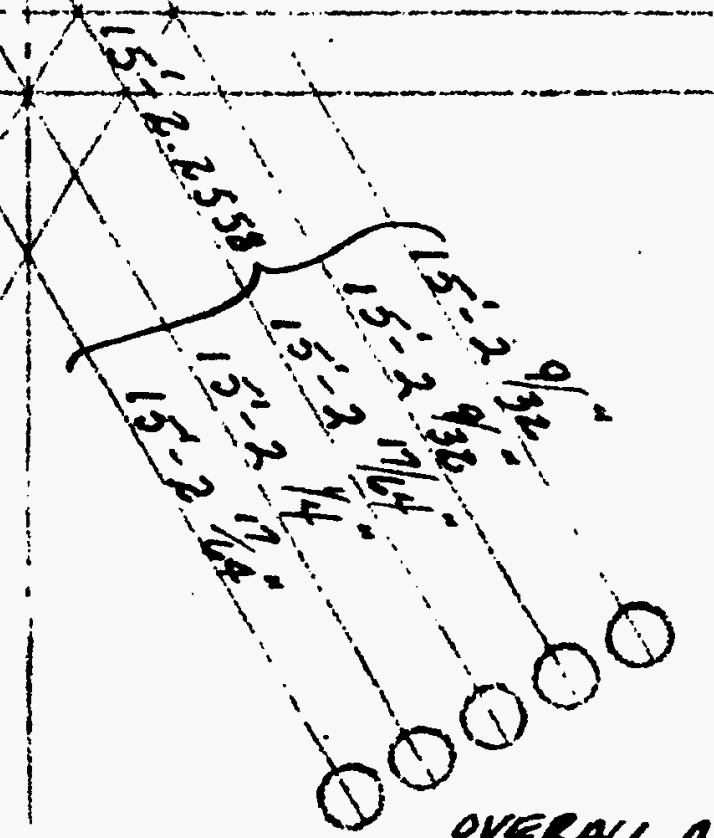

$y_{2}$

OVERACL AY $=182.275^{\prime \prime}$

SKETCH 7 


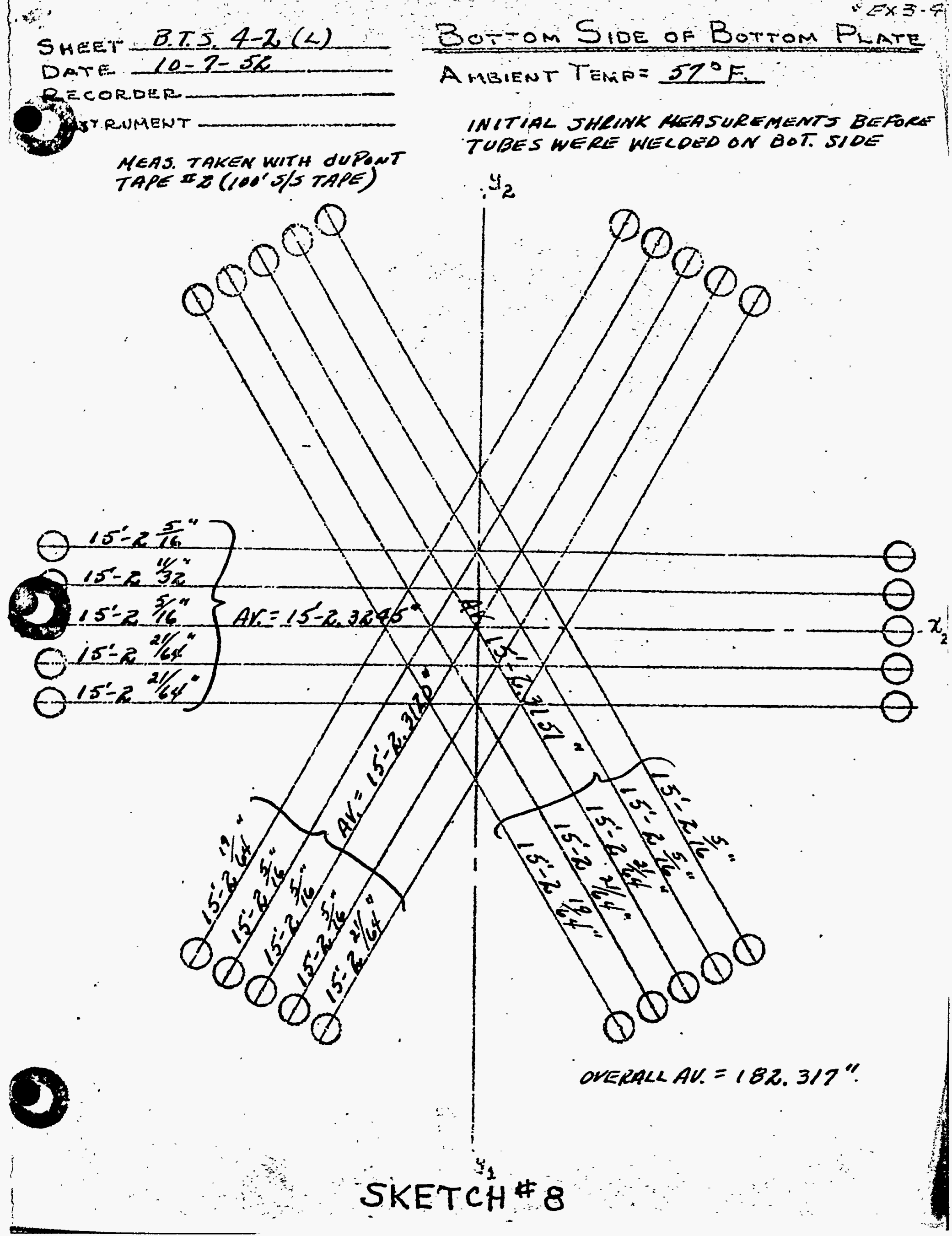




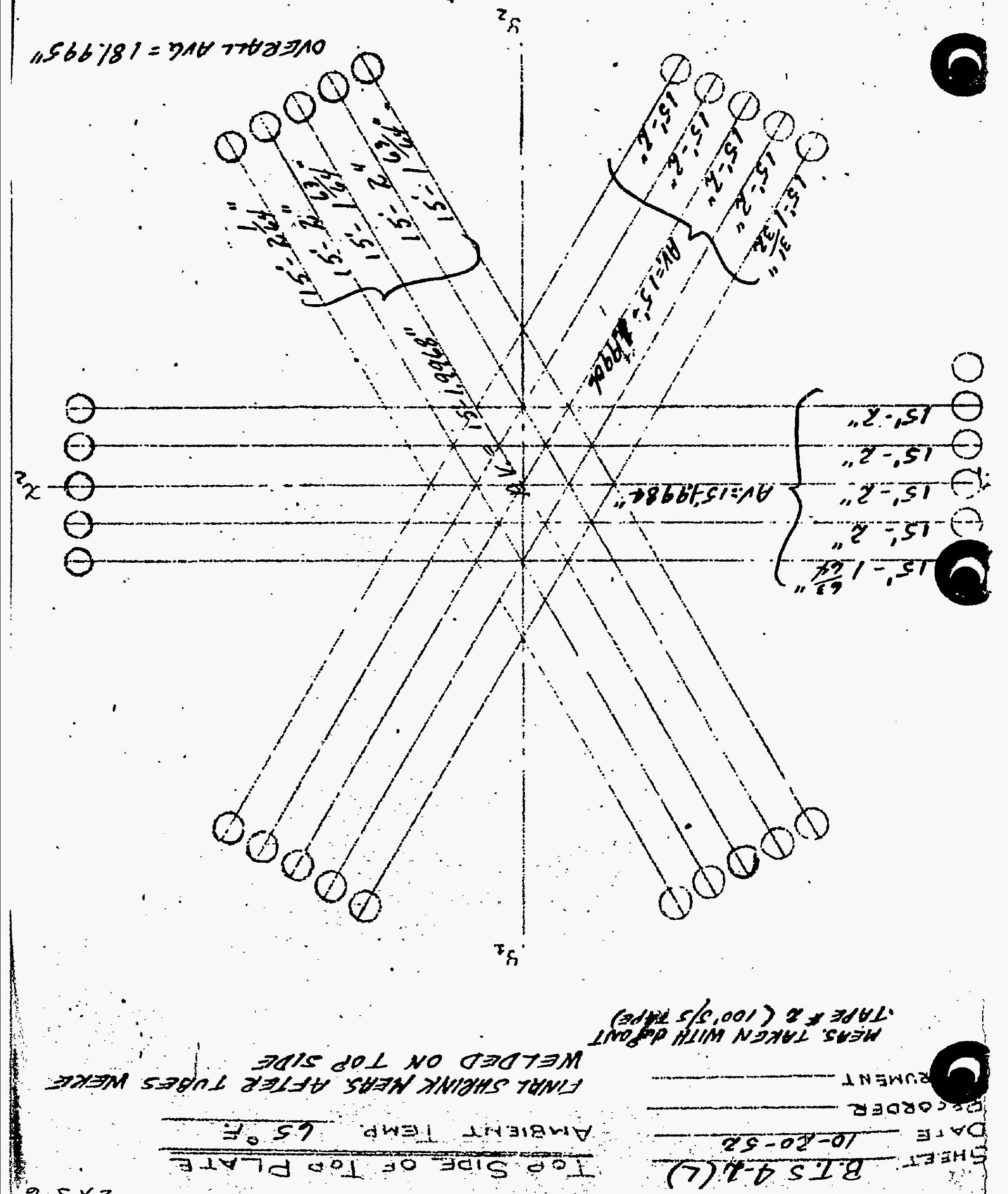


However, when the above figures were reported to Design, they accepted the difference as being satisfactory, thereby eliminating additional shrink welding on the bottom tube sheet assembly in order to bring the top and bottom side within the desired tolerance.

(13) Visual Inspection and Repair of Tube Welding

Inspection of tube welding on this unit was performed in a similar manner to that described in Section $7 \mathrm{~A}-$ (12) of this manual. For a detail discussion on tube weld inspection technique and how it developed; see Part VII, Section I, item $7 \mathrm{~B}-(2) f$.

(14) Replacement of Large Tubes as a Result of Weld Burn Through

Visual inspection of all large tube bores revealed that the following tubes had weld melt throughs:

$\begin{array}{ll}X 32-Y 12 & X 44-Y 30 \\ X 36-Y 18 & X 39-Y 33 \\ X 17-Y 21 & X Y 8-Y 36 \\ X 21-Y 27 & X 24-Y 42 \\ X 35-Y 27 & X 35-Y 51 \\ X 30-Y 30 & X 17-Y 75\end{array}$

A meeting was held between the du Pont Inspection Department and Design Division to discuss the disposition of the above If sted tubes. As a result of this conference it was decided that the following inspections would be performed to determine whether or not the tubes would be cut out and replaced.

$\therefore$ (a) Grind out melt through and ream out weld neck

(b) Inspect with borescope

(c) Hydrostatle test (a) 2000 psi for thirty ininutes

(d) Inspect again with borescope

The above Inspections were performed and all tubes were found satisfactory, except tube number XII-Y7.5. Laminations were noted at the weld melt through line after the bore was reamed to size. This tube was cutout and replaced with another pre-inspected seamless tube. Re inspection of tube after replacing Indicated all tube welding was satisfactory and the unit was released for further fabrication

8. Hachining Wrapper Pläte held Preparation and Gusset Plate Wiling A. "R" Unit

After tube welding on both sides of the unithad been inspected and repaired, the bottom tube sheet assembly was set up on a 12 , open mill: Tube sheet dia meters were machined to size and then beveled for weld preparation. After this, the mill was stopped and two portable horizontal mills were set up next. to the unt 
for milling gusset plate edges to size. Gusset plates were milled to size and then preparations were made to move the unit to a open platen for further fabrication. During this time tube plates were machined to size and beveled for weld preparation and while gusset plates were being milled to size, a du Pont Inspector was present checking on the progress and quality of work. No other measurements were taken at this time.

B. "P" Unit

This operation was performed in a similar manner to that described in Section $8 \mathrm{~A}$ of this manual.

C. "In Unit

This operation was performed in a similar manner to that described in section $8 \mathrm{~A}$ of this manual.

9. Fitting End Stiffeners to Gusset Plates and Assembling of Inlet and Outlet Cups.

A. "R" Unit

The bottom tube sheet assembly was removed from the $12^{\prime}$ open mill and placed on a platen for further fabrication. Gusset plate edges were laid out and beveled for weld preparation. End stiffeners were cut, fit, and tack welded to gusset plates. (See photo serial \#99. This is a view of fitting stiffeners to top tube sheet gusset plates; however, this same fabrication operation is performed on the bottom tube sheet.) Concurrent inspection by du Pont Inspectors revealed that gusset plate edges showed evidence of burned metal. During fabricating of gusset plates, the edges were flame cut on the end next to the wrapper plates. The burned gusset plate edges were milled to size as stated in paragraph ( $8 \mathrm{~A}$ ) above; however, in some cases all burned metal was not removed by mililing. To correct this, the gusset plate edges (where required) were chipped back to parent metal, dressed and then ferroxyl tested by the du Pont Inspection Department.

To prevent a reoccurrence of the above situation on subsequent units ( $P, L, K$, and $C$ ), it was requested by the du Pont Inspection Department that all gusset plate edges be machined or chipped $1 / 4^{\prime \prime}$ in from the burned edges. This applied not only to gusset plates but to all stainless steel material that was flame cut with a cutting torch and flux. New York Ship complied fully with this request and no further trouble was encountered with this problem.

After all stiffeners had been fitted, welded, straightened and dressed, du Pont inspectors visually inspected all welding for evidences of porosity, cracks, undercutting and other mechanical defects. Repairs were made; re-inspected and the job approved. 
Serial Number 99

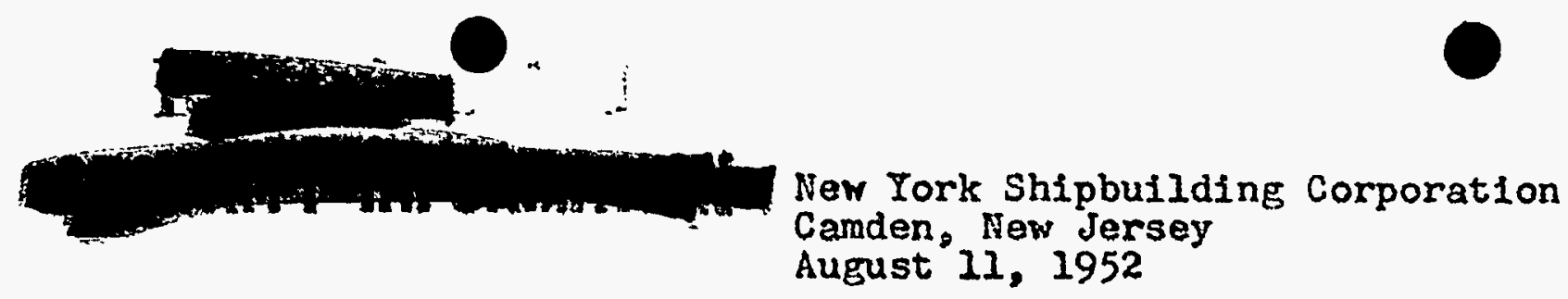

PROJECT 3980 - SAVANNAH RIVER PLANT

This view shows the fltting of stiffeners to the outer ends of the gusset plate on the Top Spectal Assembly "pn Unit. The stiffeners are clamped in place and welded with an A1rcomatic Helding Machine. All welding is ground flugh and stiffeners straightened (caused by welding) before closing unit with wrapper plates.
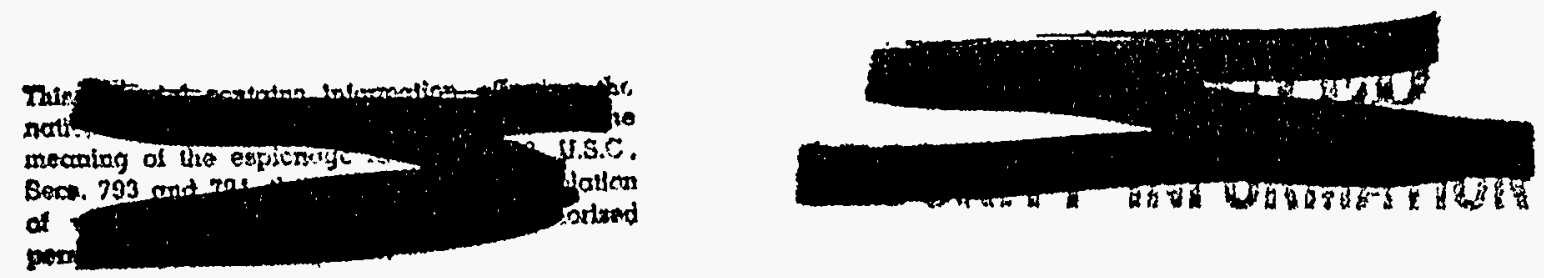


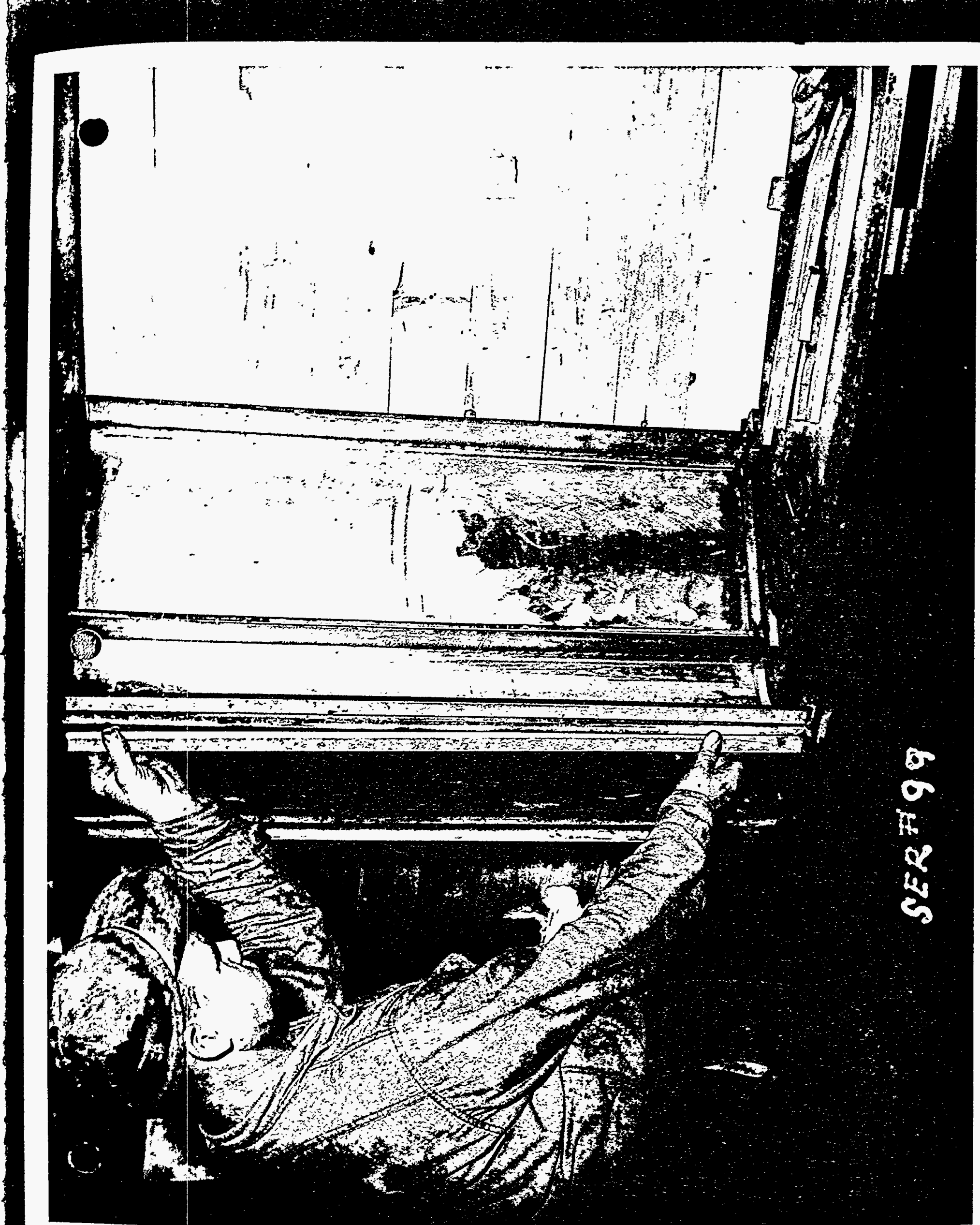


Concurrent with fitting and welding of end stiffeners, inlet and outlet cups were fitted and welded into the bottom tube sheet assembly. Extra inlet and outlet cups fabricated for the NYX bottom tube sheet were salvaged and used in the " $\mathrm{H}$ " bottom tube sheet. (see drawing 5-9). A grand total of forty-eight (48) inlet and outlet cups were assembled and welded into this assembly. Trientyfour (24) outlet cups were fit and welded to the top, middle end of those wrapper plates which were in line with outlet cup location in the baffle plate. The other twenty-four inlet cups vere fit and welded to the unit directly under the outlet cups.

A11 inlet cups were acid washed and ferroxyl tested before assembling into the unit. Since outlet cups were welded to the wrapper plates, these were acid washed and ferroxyl tested after subjecting the wrapper plates to this same cleaning operation.

Before proceeding with any further fabrication of the unit, it was decided by the du Pont Inspection Department to have the Dowell Corp. internally clean the unit. This cleaning operation is covered in Section (10) $-A$ of this manual.

B. "p" Unit

Inspection of fitting and welding end stiffeners to gusset plates and assembling of inlet and outlet cups was performed in a similar manner to that described in Section $9 A$ of this manual.

c. "I" Unit

Inspection of fitting and welding end stiffeners to gusset plates and assembling of inlet and outlet cups was performed in a similar manner to that described in Section $9 \mathrm{~A}$ of this manual.

10. Preliminary Cleaning by Dowell Corp.

A. "fin" init

Before welding wrapper plates to the bottom tube sheet, it was decided by the du Pont Inspection Department to internally clean the unit to remove dirt, oil, and other foreign material that had collected on the inside during fabrication. It was postulated that this preliminary cleaning bould make for a cleaner unit internally when the time carne for final cleaning. The problem as to how and what to use to clean the unit was of great concern. At this time no preliminary cleaning procedure had been developed and written for the preliminary cleaning of bottom tube sheet sub-assemblies. From the experience gained in the cleaning of the NYX sub-assemblies by the Dowell Corp., it was decided to turn the problem over to them. 


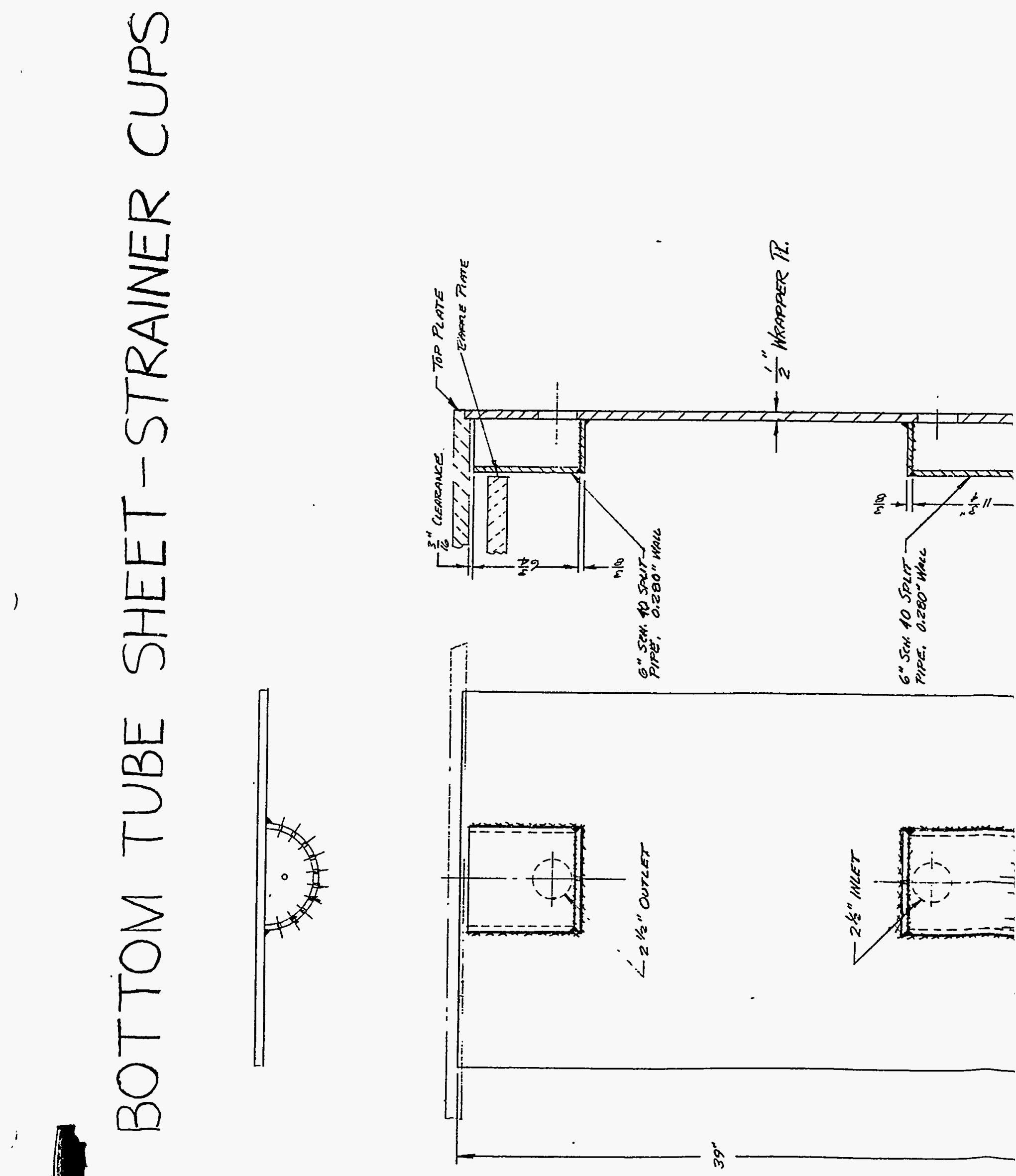



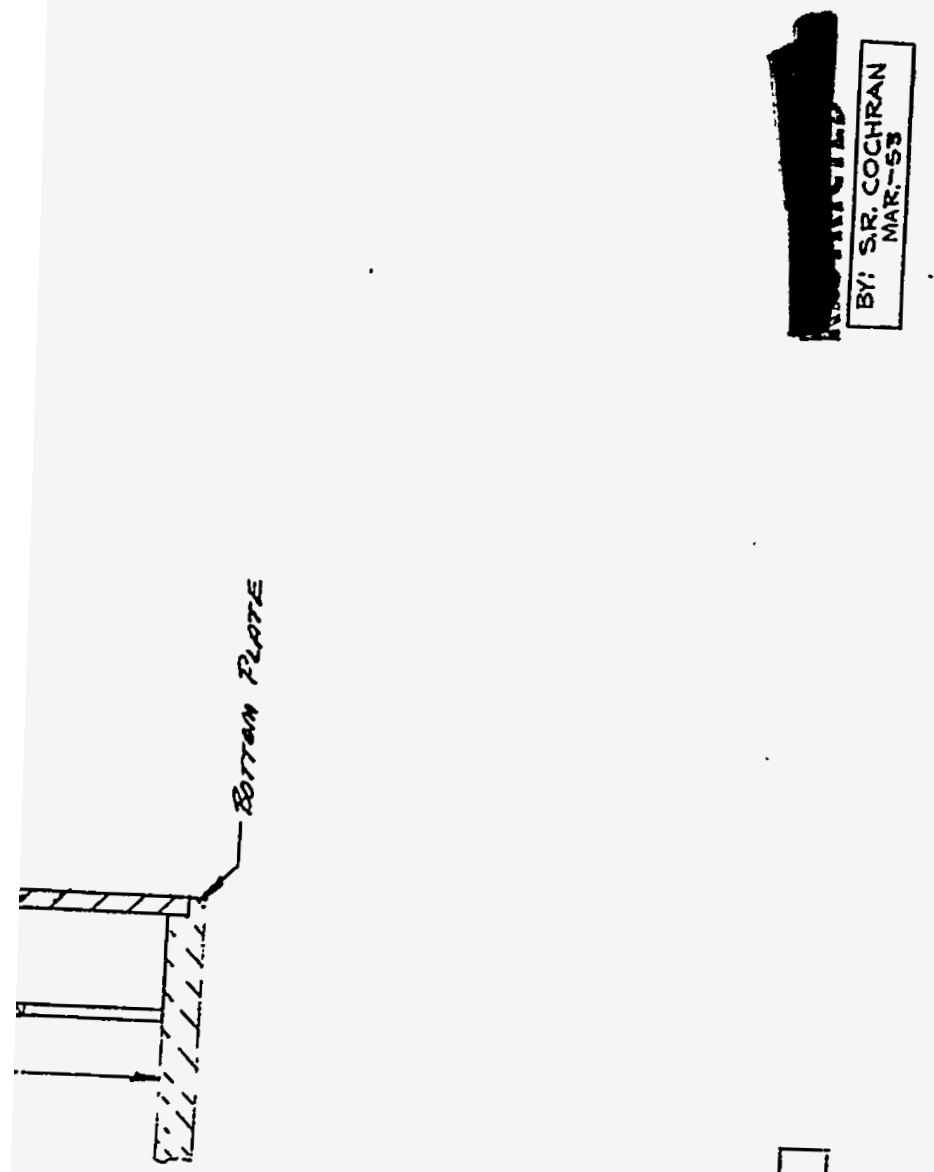

$\left[\begin{array}{l}0 \\ 1 \\ 0 \\ 0 \\ 3 \\ 0\end{array}\right]$

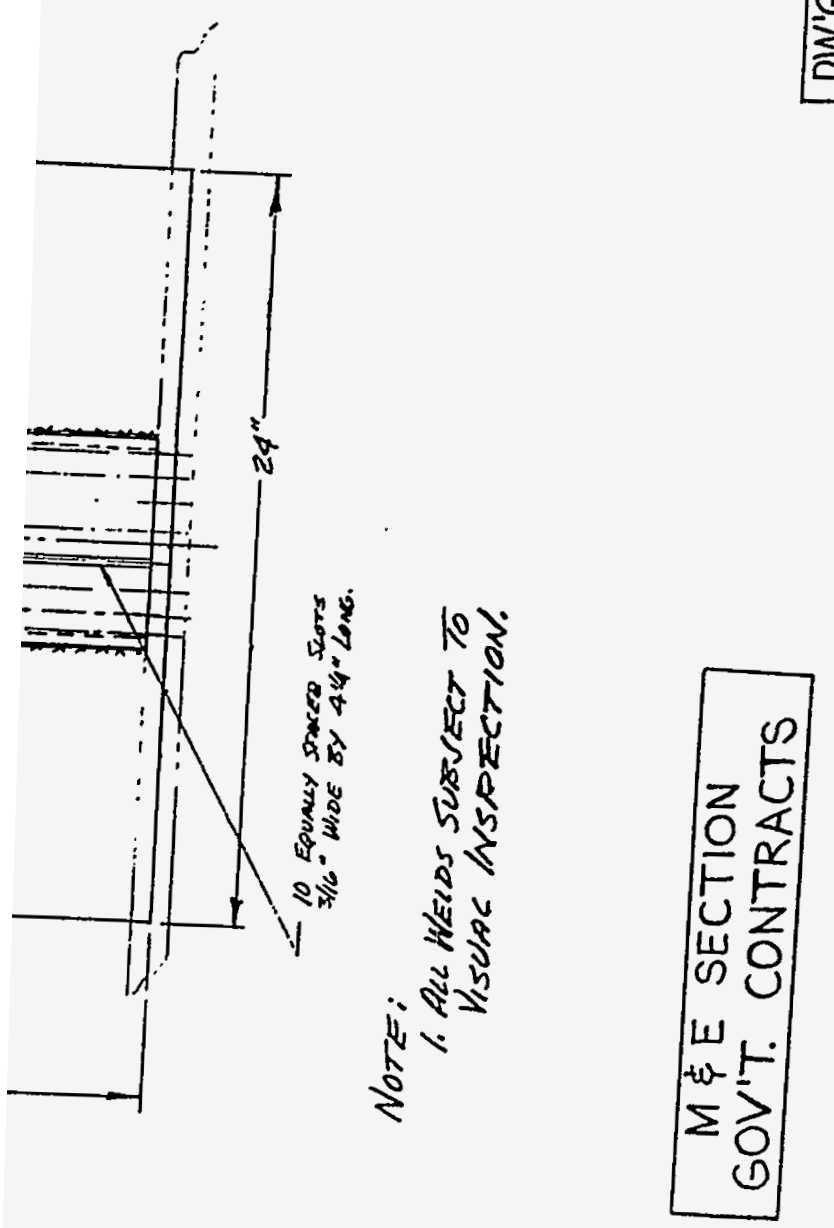


Dowell Corp. was contracted to internally wash the unit prior to assembling of wrapper sheets. The following method was used by them to clean the unit: The unit was placed in a washing pit top side up and slightly inclined to provide drainage. Dowell's high pressure car unit was used for supplying the high pressure jetting action. The solution first used to clean the unit was a wetting agent $(F-29)$. This wetting agent was jetted into the unit using a long $1 / 2^{n}$ open end galvanized pipe working from all sides of the unit. The unit was internally jetted with the wetting agent for several hours. After this the interior of the unit was jetted with high pressure distilled water to provide additional cleansing action and to remove the wetting agent. This rinsing was done over a period of several hours, and then the unit was visually inspected by du Pont inspectors and accepted.

B. "p" Unit

Preliminary cleaning by Dowell Corp., was not performed on this unit. However, the following cleaning steps were performed by New York Ship.

(1) Bottom side of unit was acid washed. Top side was not.

(2) Tube bores were swabbed with F.0. 128 .

(3) All exterior surfaces on gusset plates, top and bottom tube plates, large tubes, baffle plates, etc., inside the B.T.S. Were wiped clean manualiy with the aid of F.O. 128 SafeTee solvent. Clean, white cloths were attached to a long wood stick for cleaning those surfaces not readily accessible by hand. This cleaning was considered adequate after all interior surfaces of the bottom tube sheet had been visually inspected.

c. "L" Unit

During the initial stages of fabricating the "L" unit, internal cleanliness of the various sub-assemblies became a major problem. This came about as a result of the establishing of strict cleaning specifications by plant site technical personnel. Heretofore, minor complaints had been received from the field pertaining to the internal cleanliness of "Rn and "Pn units which prompted the du Pont Inspection Department to take immediate steps to better clean the "L" sub-assemblies.

For the " $L "$ bottom tube sheet, a method to internally clean the unit before installing wrapper plates was studied. AII data and methods of cleaning used on previous units was analyzed. As a result of this, a revised preliminary internal cleaning procedure was written and followed for cleaning the "L" bottom tube sheet. 
The step by step procedure developed and used far internaliy cleaning the "In bottom tube sheet was as follows:

(I) Install raschig ring loading cradle to perphery of unit.

(2) Set unit in vertical position and place on loading cradle bed located next to a washing pit.

(3) Cleaning solution will be by weight:

$0.1 \%$ Deterger

Remainder - Delonized water

Temperature $150^{\circ}-1900 \mathrm{E}$

(4) Jet using stainless steel nozzle upper $600^{\circ}-$ for 15 minutes.

(5) Rinse with manual hose using hot delonized or distilled water, upper $60^{\circ}$ for 15 minutes.

(6) Jet additional $120^{\circ}$ each side with cleaning solution for one hour keeping hot rinse water hose on upper $60^{\circ}$.

(7) Rinse additional $120^{\circ}$ each side with hot delonized or distilled water keeping manual hose on upper $60^{\circ}$ for one hour.

(8) Rotaté assembly $60^{\circ}$ either way jet with detergent, original botton $60^{\circ}$ for " 15 minutes" and rinse same area for 15 minutes

Time 8 hours - During all jetting be sure to cover area between top sheet : $\therefore$ and baffle as well as baffle w and bottom sheet areà

The above procedure was carried out in its entirety by Dowell Inc. Upon completion of preliminary cleaning; the unit was visually inspected by du Pont inspectors and accepted.

11. Cleanliness and Visual Inspection of Wrapper Plates. A. "R" Unit

After Dowell cleanjng, the bottom tube sheet was set up for fitting and tacking wrapper plates. However, before this took place, the du Pont. Inspection Department requested that New York Ship wipe the inter ior and exterior of the unit with acid solution in. further attempt to remove any oil dirt or free iron that may not have been removed during preliminary. Dowell cleaning. A1I âd cleaning vas done at room temperatures using the following solution. 
Acid washing was done by swabbing the solution on the surface to be cleaned and then following up with a water rinse. After the unit had been cleaned, various spots were ferroxyl tested to determine if any free iron was present. This test along with a visual inspection proved satisfactory and the unit was released for welding wrapper plates.

All wrapper plates were acid washed and ferroxy.l tested as previously discussed in section $9-A$, and then fit and tack welded to the circumference of the unit. Next, the unit was placed on a welding positioner for downhand work while welding the circumferential joints. (See photo serial "IDO in Part II-B section $40 \%$ Due to inaccessibility, circumferential welding could not be $x$-rayed. After removing the unit from the welding positioner, butt welded wrapper plates were dressed and then visually inspected for porosity, undercutting, cracks and other mechanical defects and necessary repairs.

B. "P" Unit

All wrapper plates were acid washed and ferroxyl tested as previously discussed in Section $9 \mathrm{~A}$ of this manual, except on this unit (P) and "I" wrapper plates were sandblasted and then acid washed. The plates were then fit and tack welded to the circumference of the unit. Next, the unit was placed on a welding positioner for downhand work while welding the circumferential Joints. (See photo serial HIOO in Part II-B, section 4d). Due to inaccessibility, circumferential welding could not be $x$-rayed. After removing the unit from the welding positioner, butt welded wrapper plates were dressed and then visually inspected for porosity, undercutting, cracks, and other mechanical defects and necessary repairs made.

c. "L" Unit

Cleanliness and visual inspection of wrapper plates for this unit was performed in a similar manner to that discussed in sections $I I A$ and $I I B$ of this manual.

\section{Machining of Bottom Tube Sheet Tube Ends, Tube Reaming and Tube Repair.}

A. "R" Unit

(1) Facing Operation and Inspections.

The bottom tube sheet assembly was set up and leveled bottom side up under three radial drill presses by New York Ship mechanics and checked by du Pont inspectors using the WIId NIII Precision level and target. Next, preparations were made to ream all "spider. web tubes" at the top and botton weld necks in the bore. This reaming was necessary in order that the "hour glass effect" (shrinkage) at the weld line (caused from welding tube to tube sheet) on the I:D. of the tubes could be reamed to original dimensions, allowing the bottom tube 
sheet verticality gage to pass through when the unit was top side up on the $20{ }^{\prime}$ mill table. No other tubes were to be reamed other than the "spider web tubes" in this operation; however, since the $20^{\prime} \mathrm{mill}$ was not available, 211 tubes were neck reamed at the bottom neck weld in order to save time. (See Part II-A, section 3-a for location of "spider web tubes"). The top ends of the remaining tubes were reamed at a later date. During the reaming operation, du Pont Inspectors inspected finished reamed tubes for evidence of any machined steps in the bore, and also bore diameters were checked at the weld line using a standard dial indicator bore gage and ring gage. This was necessary to determine whether or not bores were being reamed to original sizes.

During the above reaming operation, the bottom side of the bottom tube sheet was laid out for the 12 bearing pads. The bearing pads were fit, set, tack welded to layout, fully welded, dressed and welding inspected and accepted.

When the $20^{\prime}$ mill was cleared of other work, the bottom tube sheet assembly was placed on the mili (top side upl and preparations made for machining tube ends and the 12 bearing pads.

First, the unit was set to the best verticality using the spider web tubes" for verticality readings. (see Part III, section II-L for use of verticality gage) This optimum position was obtained by shimming the unit to the required amount as indicated by previous sets of verticality readings. Results of these final readings are shown in Sketch \#11.

After verticality of the unit was taken and accepted (with the unit clamped to the mill table), level readings were taken on five reference tubes. These level readings were taken with the lild NIII Precision level and target. The five reference tubes were: (1) X54-Y48 (2) X2-Y48 (3) X15-Y9 (5) X15-Y87 (5) $\times 28-148$. These level readings or bench marks were given to New York Ship's machinist for final set-up for machining the tube ends.

The top ends of the tubes vere machined to finished size and then deburred, inspected and found satisfactory. Before turning the unit bottom side up to machine the bottom tube ends and twelve bearing pads, profile readings in the $X$ and $\bar{Y}$ directions were taken using $a 18^{\prime}$ straight edge and feeler gages. Results of this inspection are shown in Exhibit f4A. These measurements were satisfactory and the unit was turned over and the bottom ends of the tubes and twelve bearing pads were machined to size. (See photo serial \#142, Part II-C, section 5) Before the unit was removed from the $20^{\prime}$ mill, the following measurements were made by du Pont inspectors:

(I) Profile readings in the $X$ \& $Y$ direction (Bottom Side) 
NOTE: READIHGS ARE IN . OOO" PER FOOT.

RECORDER LELAND

INSTRUMENT LELAND

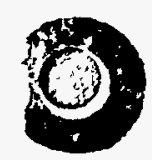

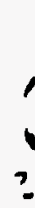

$\Xi$

.
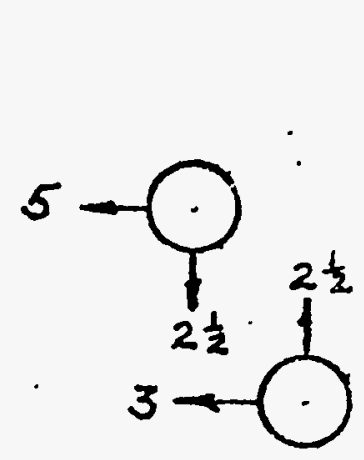<smiles>COCCO</smiles><smiles>COCCO</smiles>

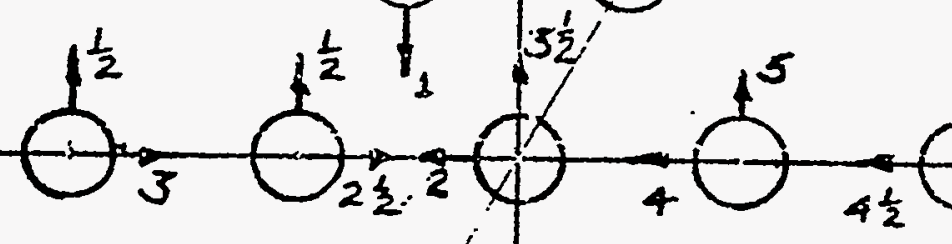
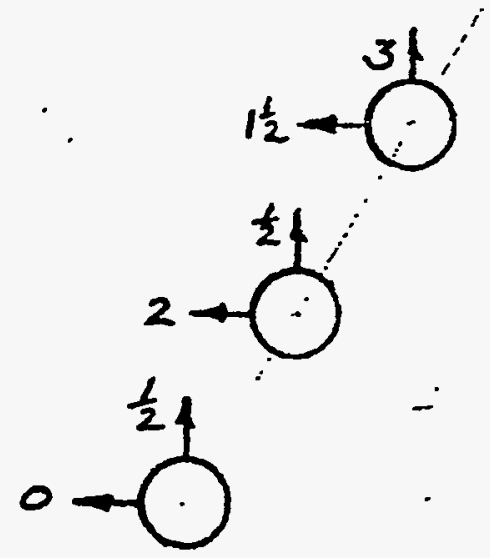

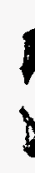

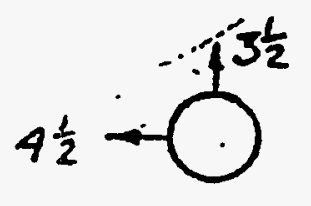<smiles>[Y2]c1cccc(C=C)c1CCC</smiles>

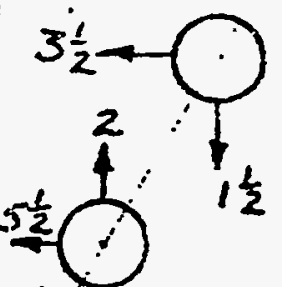<smiles>[Y]C1CCCCC1C</smiles>

35 


\section{EXHIBIT $\# 4-A$}

PROFILE READINGS ON TOP SIDE OF

"R" BOTTON: TUBE SHEET AFTER MACHINING TUBE ENDS 
E. I. DU PONT DE NEMOURS \&C CO., INC。 truction Division

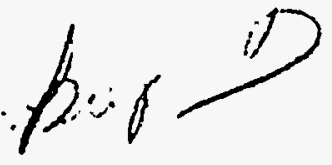

Report Number $177-R$

CC: C. E。 Buckley, F.P.M.

R. R. Mason, F.P.M. -SRP (3)

H. I. Bunker - J.G. Brewer

J. G. Brewer

H. B. Gage

F. C. Breuninger

A. H. Hughes

R. H. Potts (4)

C. W. Dunn -- Filo

August 8, 1952

New York ShIp - Camden, NJ

42

FIELD INSPECTOR:S REPORT

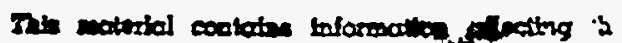

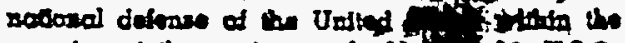

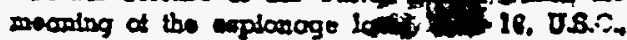

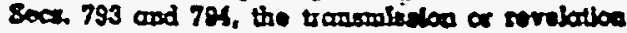

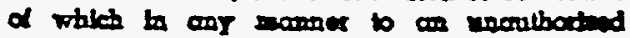
pervos is probiblud by low.

TO C. J. VEITH - M \& E FILE

FROM D. Jo Smathers - Ro Baker

DATE August 8, 1952

PROJECT NO. 8980 PLANT Savannah River

ROUIPMENT Bottom Tube Sheet

ORDER NO.

AXC-167i

QING nos. $W-130947$ EQ.P.C.NO. 153-R

VEHDOR_New York Shipbullding Corporation JOB RATING

Scope:

Procedure:

Results:
Results of measurement of clearance bëtween tube ind surfaces and stralght edge placed on these surfaces. (This report covers only top side of bottom tube sheet). These measurements were made to determine if tube ends were in a level plane. (This work performed on 4-2-52.)

After tube ends had been faced on 20' boring mill, a straight edge was placed on the ond surfaces of tubes located along X1-X2 axis. The clearances between the tube end surfaces and the straight edge were then determined by inserting foeler gages between them.

This procedure was then repeated with straight edge placed on tubes located on YI-YZ axis.

See attached sket.ch。 
HePTon TUEe SHECT TOP SIDE- "R" UNIT

CHECK TO DETERMINE VIF

$1+2-52$ tuie endos are. in same PLAN AFtER MACMINING.

O KER-" SMATHERS
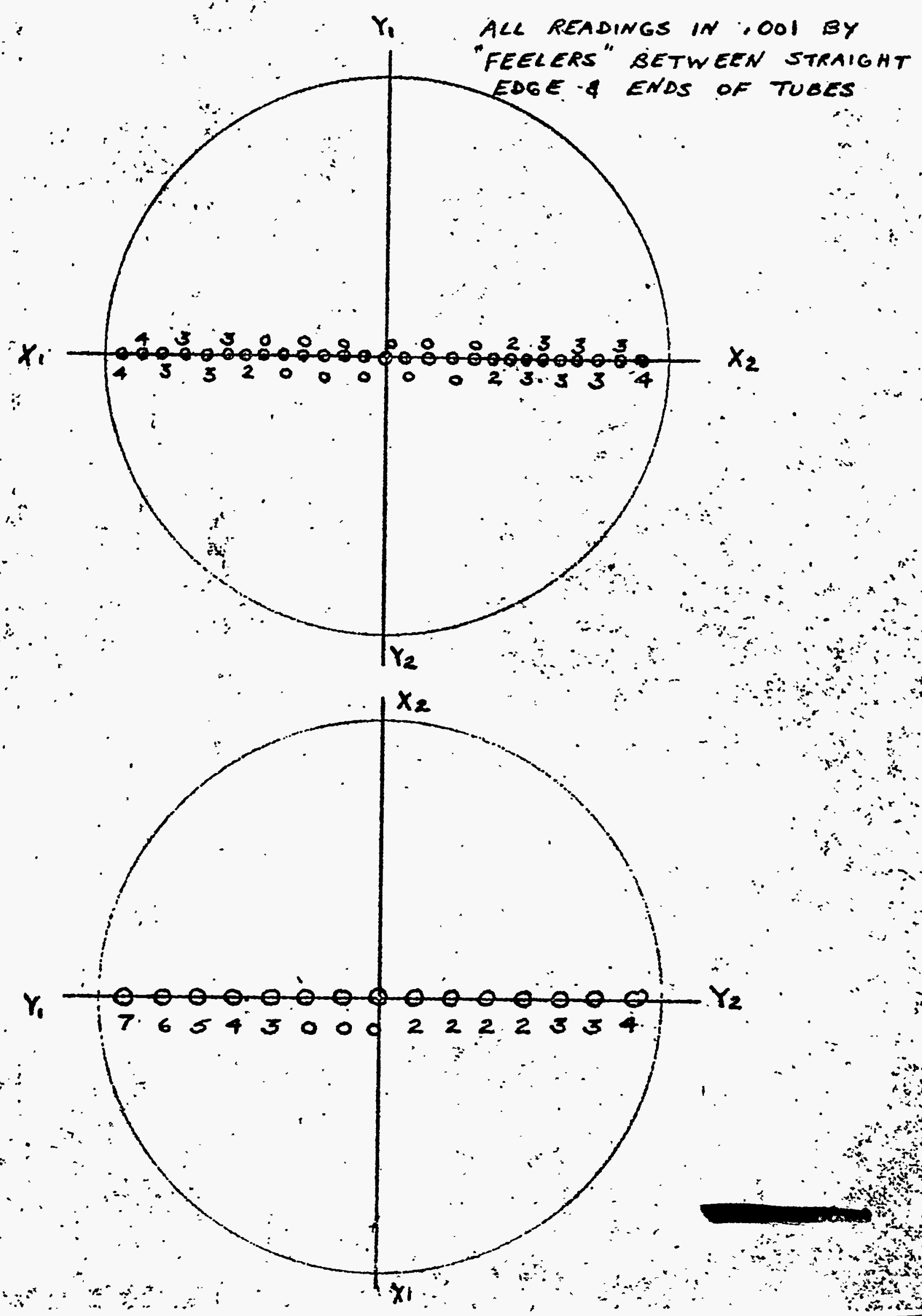
(2) Distances from the bottom side of each bearing pad to the tube ends on the top side of the unit.

(3) Overall length of tubes.

The results and method used for taking the above measurements are covered in Exhibit $\$ 5$. All final measurements were satisfactory and the job was approved.

\section{(2) Tube Reaming Operation}

The bottom tube sheet assembly was removed from the $20^{\prime}$ mill and set up under three radial drills (bottom side up) to ream out the "hour glass effect" (shrinkage) at the weld line. (Caused from welding tube to tube sheet). It was necessary to place the unit bottom side up because the top land pre-machined dimension $\left(3.210^{\prime \prime}-3.217^{\prime \prime}\right)$ was smaller than the tube bore finish machined dimension. Hence, working from: the bottom side of the unit, it was only necessary to change the large reamer (used for reaming out "hour glass effect" nearest bottom end of tube to a smaller reamer to remove the same condition in the top land, and also to finish ream the latter to size.

As stated in Section 10-A (I) above, the hour glass effect nearest the bottom end of the tube had all: ready been removed, and hence it was only necessary to ream the top land to required finished dimensions. Dwg. 2-4 presented herewith shows where the two lands were located, and the required finish machined dimensions.

As a result of facing tube ends and reaming tubes, many of them were damaged. The se descrepancies were found through concurrent inspection during machining operations and are treated in section (3) below.

(3) Tube Kepairs

a. Bottom Land I.D.

Visual inspection of tube ends on the bottom side of the bottom tube sheet after facing and reaming tubes revealed that approximately fifteen tubes had been distorted or "caved in" on the bottom end tube wall. This condition resulted from: feeding the cutting tool too deep during facing of : the bottom tube ends. As shown in Dwg. 2-4, the large tube bottom land I.D. was machined to finished dimensions prior to assembling and welding into the unit. Since tube bottom lands were to finished size, it was decided to repair the tubes rather than replace them with new ones. New York Ship attempted to swage the bottom lands to original dimensions, and in doing so, seven of the tubes were swaged oversize. This method was discontinued because swaging resulted in "belling" of the tube: end. To bring the tube bores within tolerance; the 
EXHIBIT \#5

FINAL BEARING PAD MEASURENENTS AND

PROFILE READIKGS TAKEN ON BOTTOM SIDE

OF "R" BOTTON TUBE SHEET AFTER RACHINING 


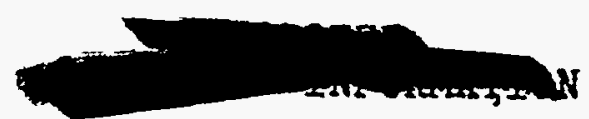

I. DU PONT DE NEMOURS \& $C O$. , INC. WILINATON, DELAWARE

CC: C. E. Buckley, F.P.M.

Construction DIvision
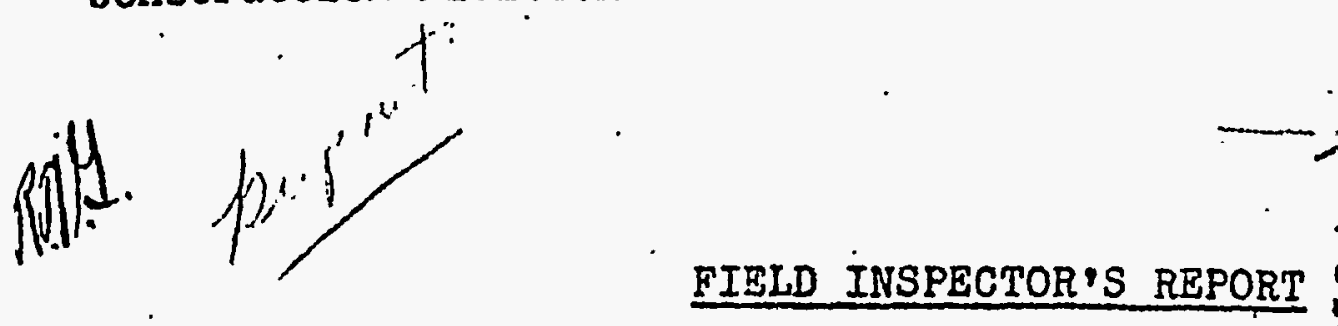

TO C.J. VEITH - M \& E PILE

FROM S.R. COCHRAN-C。H.HEIST-H.H.SCHOLES

R. K. Mason, F。P M. $-S R P(3)$

B. L. Bunker - J.G.Brewer (2)

H. B. Gage

F. C. Breuninger

A. H. Hughes

C.-Ho-Dunn-File

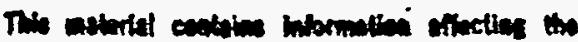

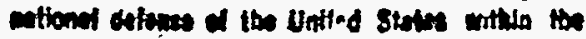

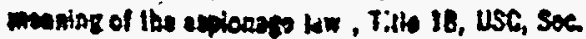
703 and 794, ths tranciestion of miniation at

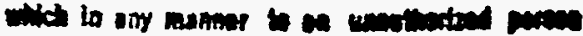

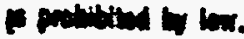

PROJECT NO。 $8980 \quad$ PLANT SAVANNAH RIVER DATE APRIL 10, 1952

EQUIPMENT TANK BOTTOM TUBE SHEET ORDER NO. AXC-1672 DRAWING NOS H H-130947\& W-130948 EQ.PC.NO. "R" UNIT DRAWING NOS。 W-130947\&W-130948 JOB RATING VENDOR NEW TORK SHIPBUILDING CORP. LOCATION CAMDEN, N.J.

following report pertains to the measurements made on the "R" unit tank tom tube sheet with the tube bundle in a bottom side up position on a vertical boring mili table fust after the finish "facing" operation. .

\section{Exh1b1t "A"}

With the tube bundie clamped to the mill table in a bottom side up position and the whole rotated such that the $X_{1}-I_{2}$ axis was parallei with the cutting rall, a straight edge was placed on the end surfaces of the tubes. "Feeler" gages were inserted between the straight edge and end surfaces of the tubes. The clearances measured are shown on the sketch on Page 30

Exhibit "B"

The measurements determined for Exhlbit" $B^{n}$ were obtained by the same procedure as in Exhibit "A" with the exception of the straight edge being placed on the $Y_{2}-I_{2}$ axis.' The results are shown on the sketch on Page 3 .

Following the completion of the procedures of Exhibits " $\mathrm{A}$ " and "Bn the tube bundle was checked for levelness. This was done by placing a level on the stralght edge while same was resting on the $Z_{1}-X_{2}$ and $Y_{1}-Y_{2}$ axes respectively. The results indicated the overall tube bundle to be level fithin $.005^{n}$ per foot.

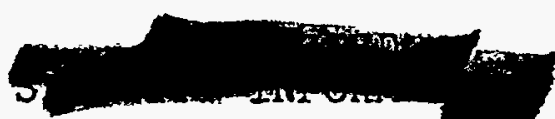


is Cochran/Heist/Scholes

Apri1 10, 1952

Exhibit "C"

The dimensions shown on the sketch on Page 4 are maximum and minimum dimensions pertaining to all 12 bearing pads and tubes adjacent to bearing pads.

The overall tube length was determined by means of a pin gage set at $49.4375 "$ and "neeler" gages. These dimensions are observed to bé from $.0025^{n}$ to $.005^{n}$ greater than the tolerance of $49.4375^{n}=.030^{n}$. This was passed as being satisfactory by $\mathrm{Mr}$. A. H. Hughes.

The distances from tube tops to bearing pads are observed as being $41.513^{n}$ to $41.514^{\prime \prime}$ which is within the tolerance of $41.500^{\prime \prime} \pm .015^{n}$. These dimenstons were determined by means of a pin gage set at $41.500^{\text {" and }}$ "feeler" gages. 
$4 / 10 / 52$

$2 \times 3-3$

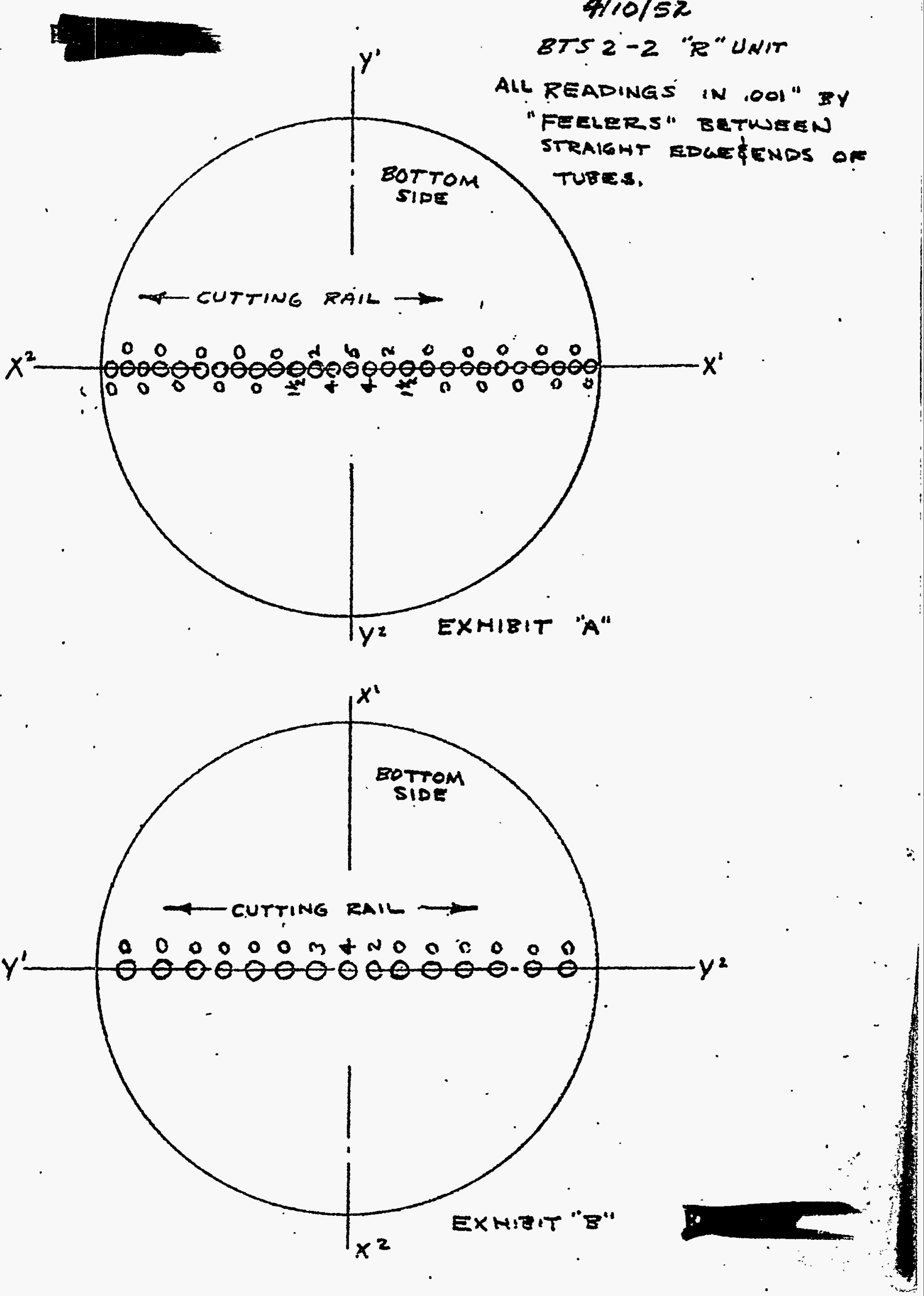


Pase top i $2 \times 5.4$ $\therefore / 10 / 52$

$8 T 52-i$
$8 \pi 5 i 5-21 R$ NNIT

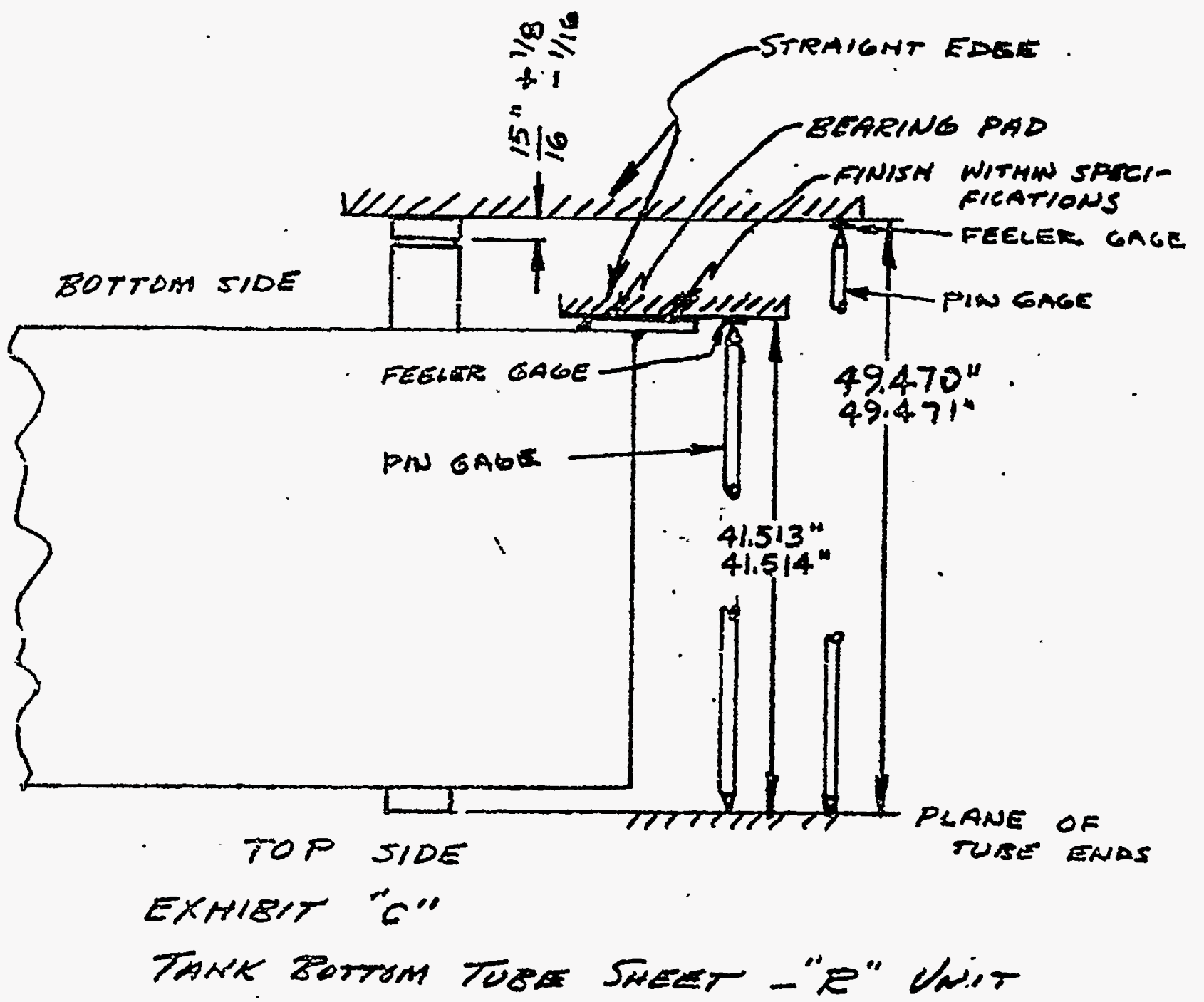

$j$ 

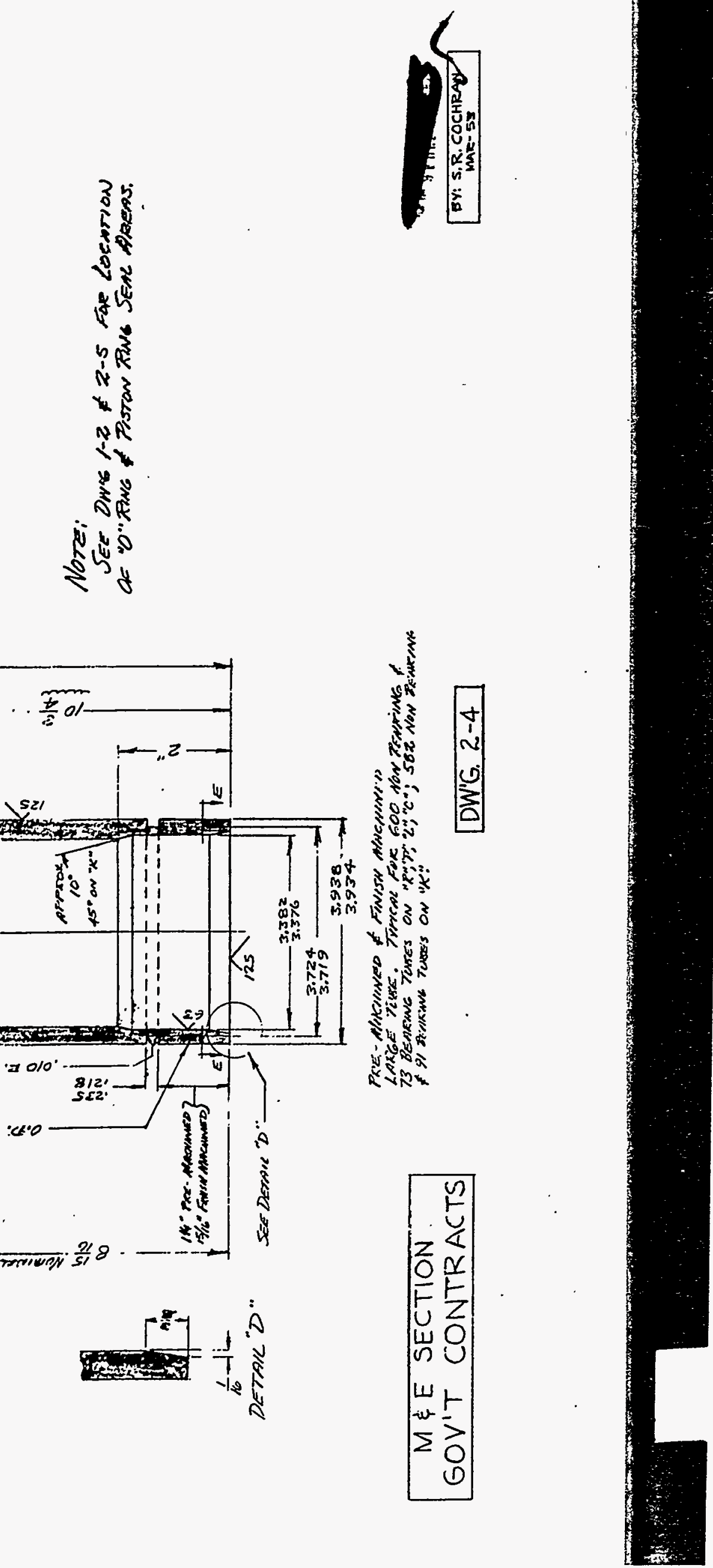


\section{EXIBIT}

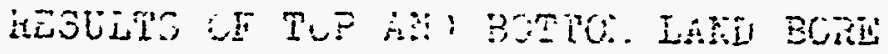

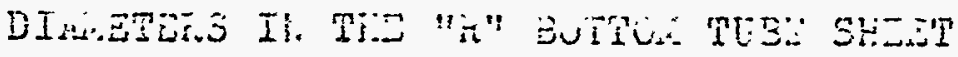
ASSEIEYY.

O 


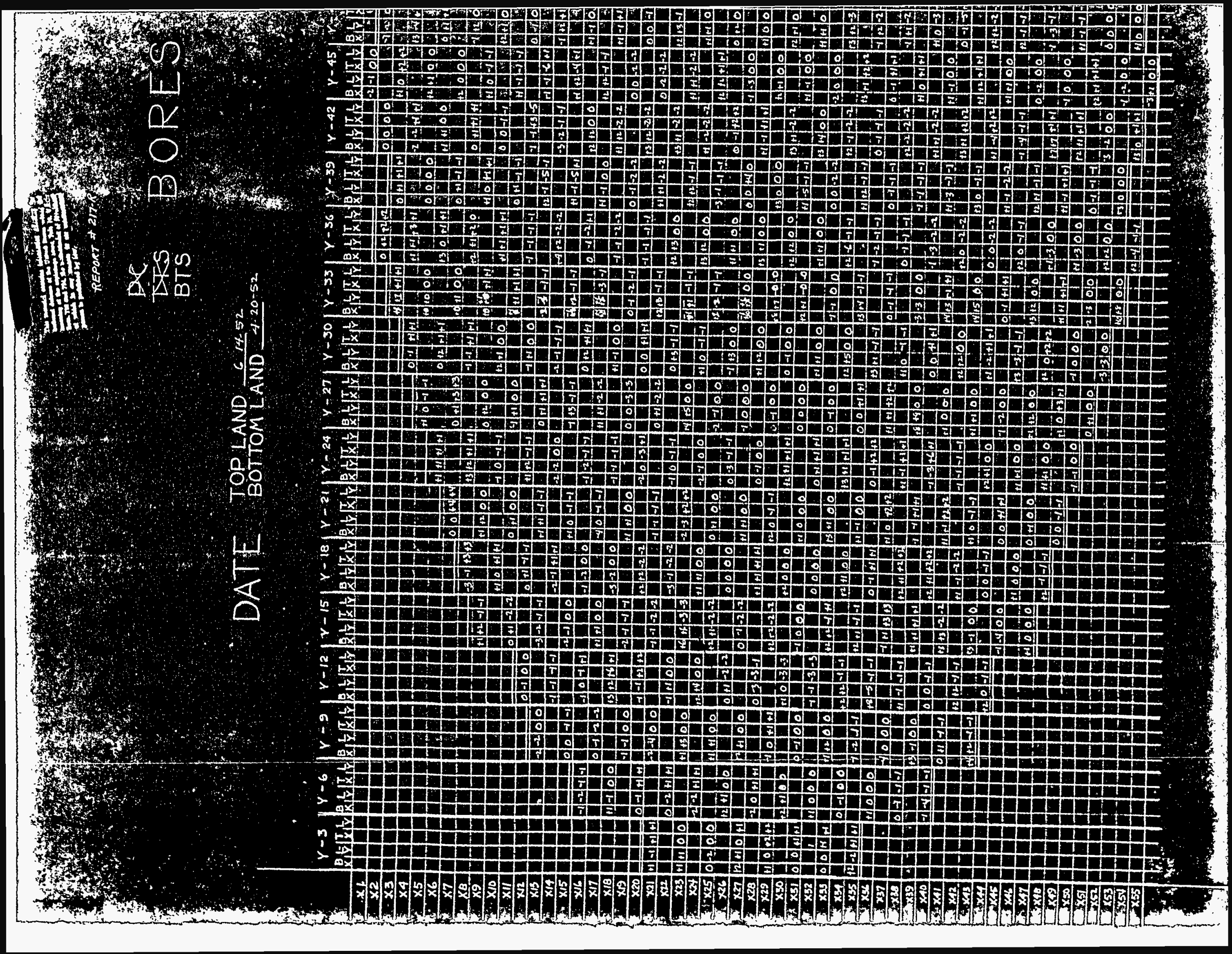




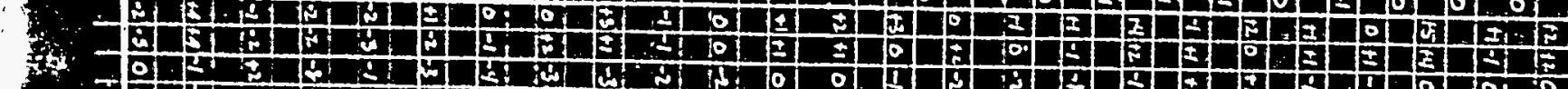

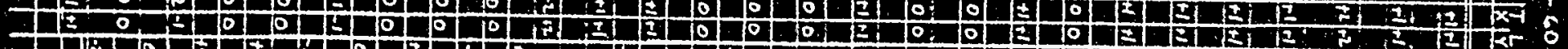

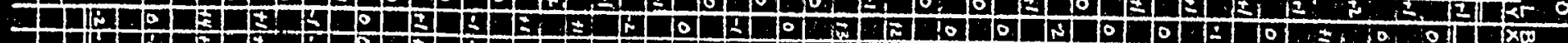

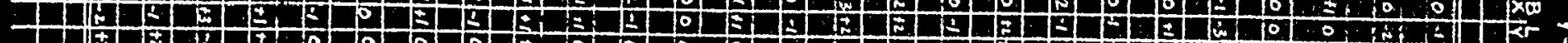

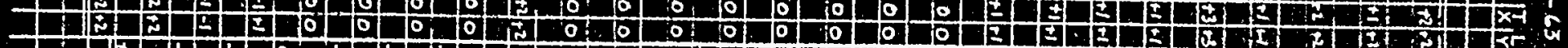

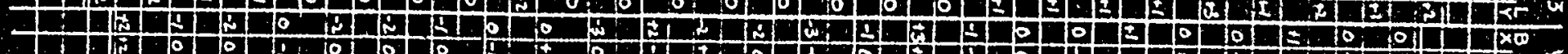

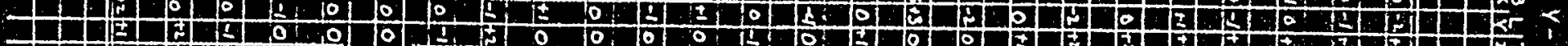

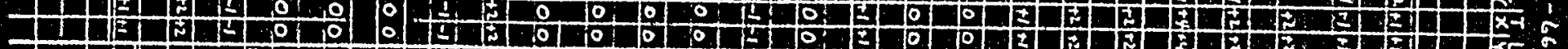

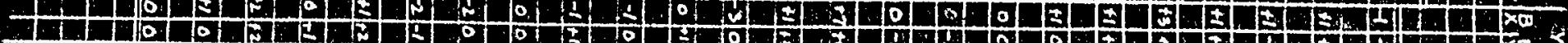

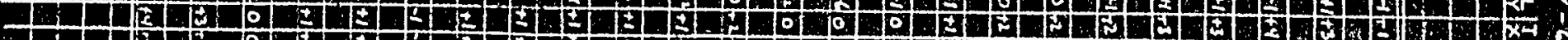

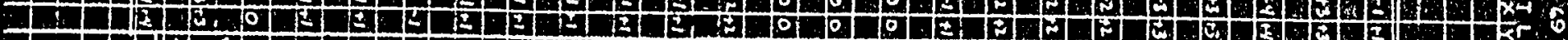
- L L a a

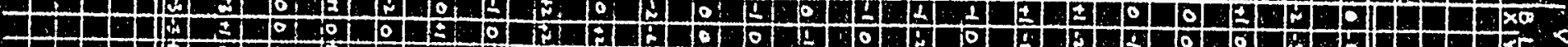

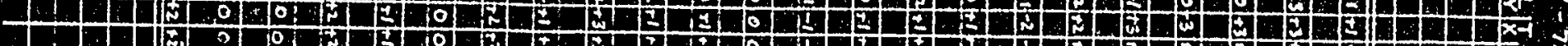

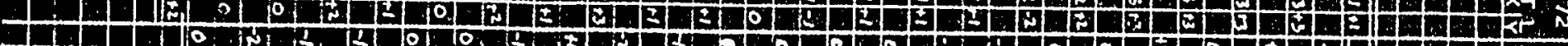

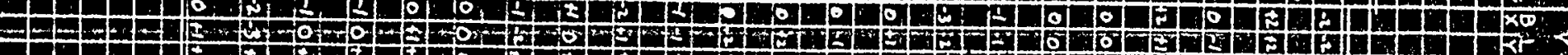

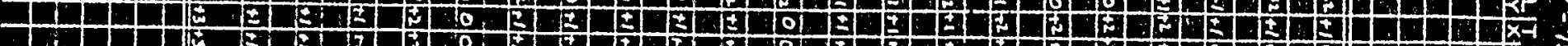

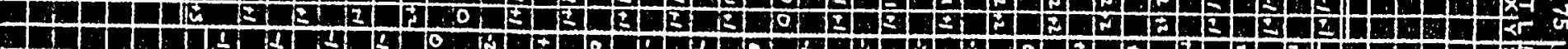

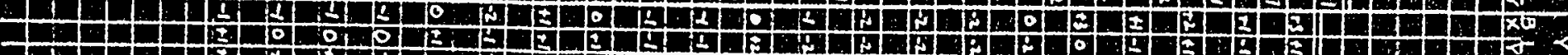

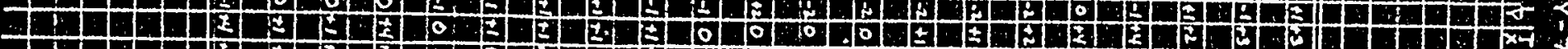

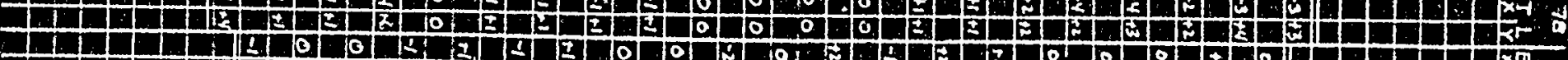

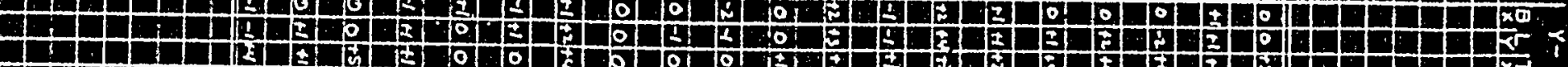

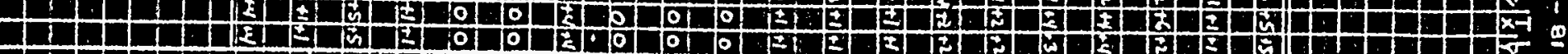

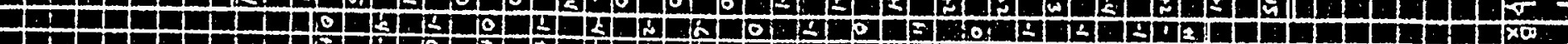

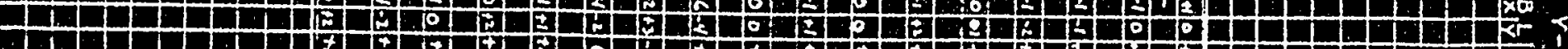

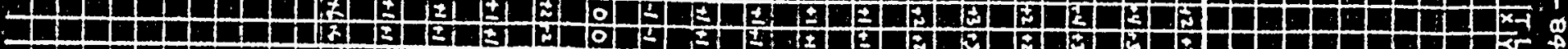

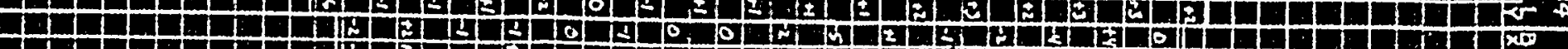

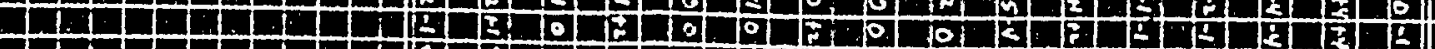

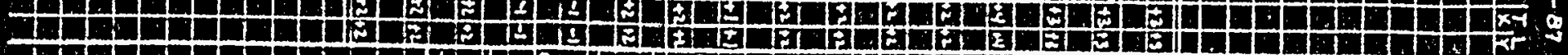

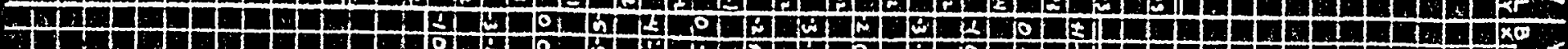

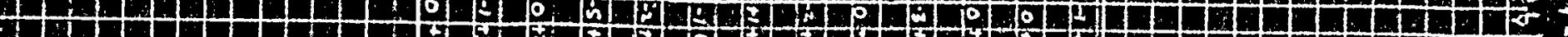

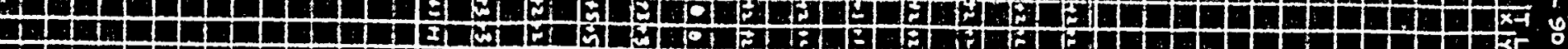
il 112 T

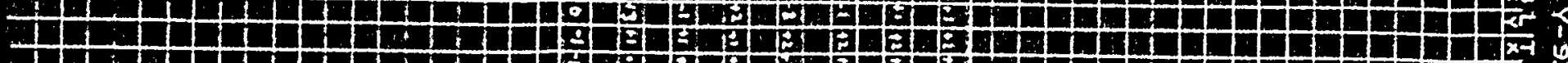

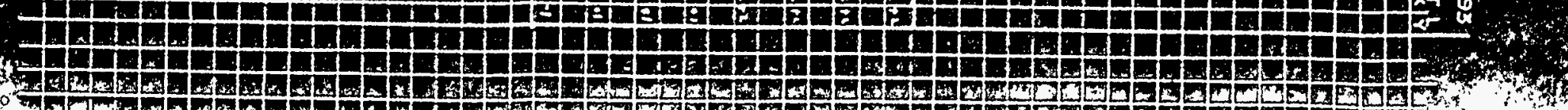

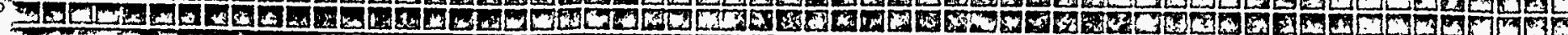
7

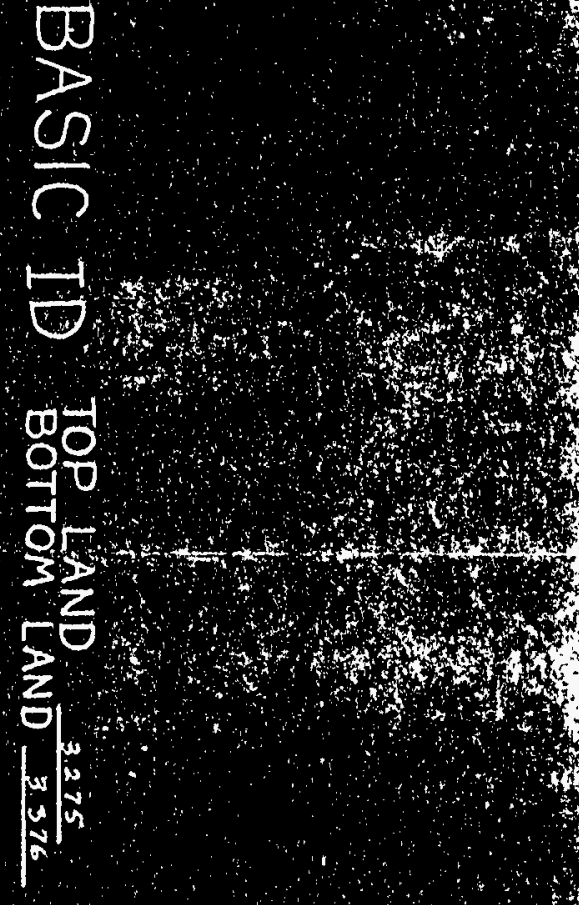


seven tubes vere shrunk by welding a series of beads around the bottom U.j. of the tube. Heliarc welding without íller metal was used to shrink all seven tubes. irfter strirking the bottom land bore was hored to $3.377^{\circ}$. Tubes vere then inspected for finish and bore size and found within tolcrance.

liext, the bottom land firish was checked usine a profiloneter. The specified finish was 63 :. micro-irches. of the 673 tubes checked, timenty-ore (21) were found to have finishes ranging from 100 KiS to 400 HiS. All others vere 100 Kis or less. The twenty-one tubes wit- bore finishes ranging from $100 \mathrm{Ki}$ :S to 400 RH:is were honed to inprove th:e finist, and in cases where the $3.382^{\prime \prime}$ maximum diameter was exceeded, the tube was shrunk (heli-arc method without filier metal) and re-honed to the specified dianeter and finist. however, the specified bore finish ( 63 Fis) was relexed by the Design Division to 100 FIES. This relaxation in specification was necessary sirce the finish machined bottom land bores were not within drawing specifications upon receipt at ler: York Ship. ilso, there was a shortage of tubes and what ras on hand at the time had to be used to expedite the completion of the i.Y. Program, and in addition, further honing to improve bore finishes to 63 Pin resulted in tube bores going out-of-round and cversize.

Based on the above relaxed finish specifications, all bottom land bores were either honed or cloverleafed to acceptable finishes. Bore diameters were measured using a standard dial indicator bore gage and ring gage. Bores were massured in two directions, parallel to the $X X$ axis and paralled to the $Y Y$ axis. "Heasurements were taken down approximately $1^{\text {" from }}$ the bottom end of the tube. Ixhibit 136 presented herewith lists the final bore diameter measurements. Tolerance on bortor land I.D. ranged between $3.376^{\circ}$ and $3.382^{\prime \prime}$. All measurements were satisiactory and approved by the du Pont Inspection Eepertrent.

ifter the "is" bottom tube shett assembly was received at the plant site, a sub-standird condition was found to exist in the bottom land of tube $x_{4} 5-Y$ El 1 . This condition was discovered during the course of field cleaning the bottom tube sheet tubes preparatory to sonitor pin installation. Photographs were taken of the tlioe and forwarded to the du Pont Inspection Department. These pictures showed an overlepping crescert effedt in the internal bore of the tube. In adition, field measurements vere taken in the botton land 0 -ring sealing area and vere as follows: $X_{X}$ axis $-3.382^{\prime \prime}$, YY axis 3.3 co" $^{\prime \prime}$. These measurements taken by field persornel, indicated that the YY axis was .007" over the design tolerarce and that an outof-round condition of the same magnitude existed. 
In reply to the field's complaint, the overlapping crescent effect in the internal bore of the tube (which was estimated by the Inspection Group at K.Y.S. Erom the photos to be $2-2 \frac{1}{2} "$ from the face of the tube) was in an area where it could be tolerated as confirmed by Design. The inspection report issued by the du Pont Inspection Department at New York Ship, winch covered the final bore measurements in the bottom 1-11/16" counter-bore, accepted all bores as being within tolerances. The subject tube $\mathrm{X}_{4} 5-\mathrm{Y} 81$ was recorded as $\mathrm{X}-3.376^{n}$ and $\mathrm{Y}-3.377^{\prime \prime}$ which was within tolerance. The manner in which inspectors checked these bores at New York. Ship before accepting was as follows: (1) precision ring gage (3.375" dia.) was used to set a dial indicator bore gage. (2) AII measurements were taken $1^{\prime \prime}$ from tube end. (3). Results were recorded. It was suggested to the field that they used this method and re-inspect tube $\times 45-Y 81$. Nieasurements re-taken by the field in the tube bore indicated that it conformed closely with the official NYX measurements. (NYX measurements: $X X-3.376^{\prime \prime}, Y Y-3.377^{\prime \prime} ;$ Field revised measurements: $\left.X X-3.3755^{\prime \prime}, Y^{\prime}-3.3775^{\prime \prime}\right)$ The substandard bore was then checked by the field to determine if the o-ring could be inserted without damage. The check was performed without apparent damage to the ring, and no other problems were encountered in this tube.

b. Top Land I.D.

$\therefore$ After line reaming the top land of all bottom tube sheet large tubes, the following inspections were made:

1. Bore diameter measurements in $X$ \& $\Psi$ direction taken $1^{n}$ below top ends of tubes. The se measurements were taken with a standard dial indicator bore gage and ring gage (final results are shown in Exhibit \#6\}.

2. Finish in pus micro-inches using a profilometer.

3. Visual inspection for burrs, scratches, steps, and other mechanical defects that might be present in top land bore.

As stated in (i) above, bore measurements were taken in the top land to determine if bores were within tolerance During this inspection tube number $X_{44}-Y 18$ was measured in the $X$ \& $Y$ direction and found oversize and out-of-round. Measurements were: XX direction $-3.280^{\prime \prime}$, IX direction $3.292 "$. Specified bore size ranged from $3.270^{\prime \prime}$ to $3.277^{\prime \prime}$. This tube diameter was reamed $.015^{\mathrm{n}}$ oversize and. $.012^{\text {hi }}$ out-of-round. In view of this discrepancy, the du Pont Inspection Department requested this tube be cut out and repleced. Tube was replaced, inspected and accepted. All other tubes were within tolerance and accepted. 
Next, the finish in the top land of all tubes were checked using a profilometer. Hany of the tubes were found to have finishes greater than the specified 63 RMS. These tubes were either honed or clover-leafed until the bore finish was satisfactory.

A final visual inspection was made on the top land to determine if any scratches, burrs, tool steps or any other mechanical defects were present. Any found were removed by one of the three following methods: (1) honing (2) cloverleafing (3) smoothing out defect with crocus cloth. After minor repairs were made, 211 top land bores were approved as being satisfactory.

B. "p" Unit

(1) Zy-glo testing on Top Edges of Tubes on Both Sides of Assembly.

As a result of finding laminations, cracks and other mechanical defects in the large tubes. in the " $\mathrm{R}^{\text {" }}$ bottom tube sheet, covered in Section $14 \mathrm{~A}-(3)$ of this manual, it was decided to zy-glo the ends and bores of all large tubes in the "pn unit bottom tube sheet to determine their final disposition.

The $z y-g 10$ process was followed in its entirety (See section $14 \mathrm{~A}-(3)$ of this manual for procedure) and al1 of the 673 tubes were tested on top edges and bores for determining presence of laminations or cracks. All were found to be satisfactory. However, a crack $1-3 / 8^{\prime \prime}$ long vas found in the top side of top plate $\frac{1}{4}$ " from the fillet weld on tube $X 11-Y 75$. This cracked area was chipped to 2 size of $2 \frac{1}{2}$ "long $\times 3 / 8^{n}$ wide $\times 5 / 32^{n}$ deep, ground smooth, zy-gloed, and then welded. After welding, it was ground smooth and $z y-g l o e d$, and accepted as being satisfactory.

\section{(2) Facing Operation and Inspections}

The bottom tube sheet assembly was set up and leveled bottom side up under three radial drill. presses by New York Ship mechanics and checked by du Pont inspectors using the tiild NIII Precision level and target. Next, preparations were made to ream all "spider web tubes" at the top and bottom weld necks in the bores. This reaming was necessary in order that the "hour glass effect" (shrinkage) at the weld line (caused from welding tube to tube sheet) on the I.D. of the tubes could be reamed to original dimensions, allowing the bottom tube sheet verticality gage to pass through when the unit was bottom side up on the $20^{\prime}$ mill table. No other tubes were reamed other than the spider web tubes" in this operation.

During the above tube reaming operation, the bottom side of the bottom tube sheet was laid out for the 12 bearing pads. (See du Pont drawing li-131564 for location 
and specifications). The 12 bearing pads were fit, set, tack welded to layout, fully welded, dressed and welds dy-cheked and accepted.

The bottom tube sheet assembly was placed on a $20^{\prime}$ mill (bottom side up) and preparations made for machining tube ends and the 12 bearing pads. First, the unit was set to the best verticality using the "spider web tubes" for verticality readings. (See Part III, Section II-I for use of verticality gage). This optimum position was obtained by shimming the unit to the required amount as indicated by previous sets of verticality readings. kesults of these final readings are shown in Sketch $\# 12$.

After verticality of the unit was taken and accepted. (with unit now clamped to the mill table), level readings were taken on five reference tubes. These level readings were taken with the WiId NIII Precision Level and target. The five reference tubes were: (1) $X-54-Y 48$ (2) X15-Y9 (3) X2-Y48 (4) X15-Y87 and (5) X28-Y48. These 1eve1:. readings or bench marks were given to New York Ship's machinist for final set-up for machining the tube ends.

The bottom ends of the large tubes and 12 bearing pads were finished machined to drawing sizes, then deburred, inspected and found satisfactory. Exhibit $\| 77$ presented herewith covers all inspections made on bottom side of this unit.

After the bottom side was inspected and accepted, the unit was turned top side up for machining tube ends on this side to finish size. The top ends of all large tubes were machined to drawing size, tubes deburred and then inspected. Exhibit "f 8 presented herewith covers all inspections made on the top side of this unit.

\section{(3) Tube Reaming Operation.}

This operation was performed in a similar manner to that described in Section $12 \mathrm{~A}-(2)$ of this manual.

(4) Tube Repairs

a. Bottom Land I.D.

Visual inspection of tube ends on the bottom side of the bottom tube sheet after facing and reaming tubes revealed that eight tubes had been distorted or "caved in" on the bottom end tube wall. This condition resulted from feeding the cutting tool too deep during facing of the bottom tube ends. As shown in drawing 2-4, the large tube bottom land $I . D$. was machined to finished dimensions prior to assembling and welding into the unit. Since tube bottom lands were to finish size, it was decided to repair the tubes rather than replace them with new ones. To bring the tube bores within tolerance, the eight $(8)$ tubes 


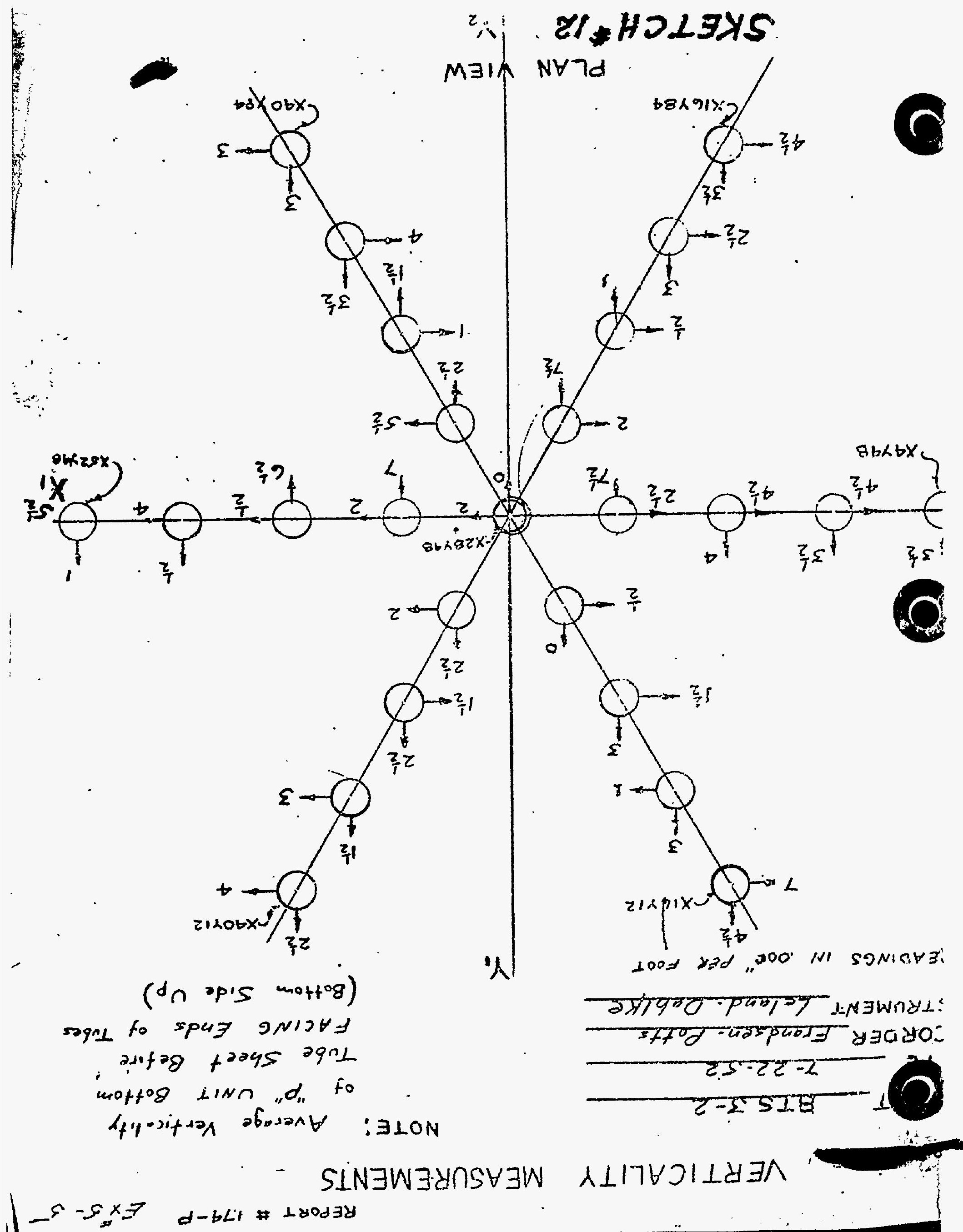


$\therefore \because \cdots$

EXHIBIT \#7

INSPECTIONS PERFORMED AFTER WA CHINING TUBE

ENDS AND TUELVE BEARING PADS ON BOTTOM SIDE

OF "P" BOTTOM TUBE SHEET ASSEMBLY -

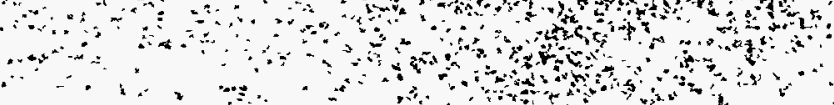


E. I: DO PONT DE NEBOURS \& CO \&, INC. inir,

onstruction DIvision

4

tip

TO

. C. J. VEITH $M$ \& E E FILE $K_{0} E_{0}$ Chaney, $R_{0} W_{0}$ Hease, $R_{0} R_{0}$ Baker

FROM C. H. Heist, D. Jo Smathers

\section{EIELD INSPECTOR'S REPORT}

PROJECT NO. 8980 PLANT Savannah River

EQUIPMENT Bottom Tube Sheet DRAWING NOS. $W-131395 \& W-131400$
Report Number 163-P

CC: C, 5: Buckley, F,P,N.

R. K. Mason, F,P.M. SRP-3

H. L. Bunker -J.G.Brewer

J. G. Brewer

H. B。 Gage

F. C. Breuninger

A. Ho Hughos

R. H. Potts (4)

C. Wo Dunn - File

August 6,1952

New York Ship o Camoien, NoJ.

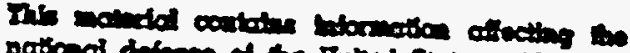

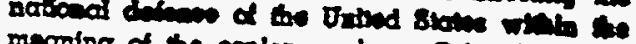
meconing of the eplonoge lawn, Tith 18, U8.C.

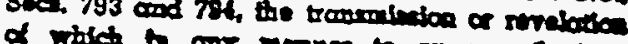

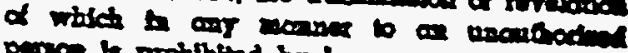

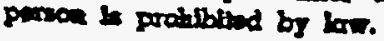
DATE. JulY 28, 1952

Scope: Measurements made on the following after machining bottom ends of tubes and bottom surfaces of 12 bearing pads.

1. Bottom ends of tubes in rows $X-28 \&$. Y-48 to determine deviations, if any, of end surfaces of tubes frorn a-plane.

2. Bottom surface of 12 bearing pads.

A. To determine deviations, if any, of bottom surfaces of bearing pacis from a plane.

Bo To determine surface finish in $r . m . s$. micro inches of bottom surfaces of bearing pada.

3. Tube ends and bottom surface of bearing pacs to deternine if plane of tube ends and plane of bottom surface of bearing pads are parallel.

Procedure:

1. With tube sheet clamped to tbe mill table in a bottom side up position, a straight edge was placed on the X1-X2 axis (row $Y-48$ )。 Measurements were obtalned by inserting. "feelern gages between the tube ends and stralght edge. Above procedure repeated for $Y 1-Y 2$ axis (row $X-28$ ).

2a. With a dial indicator clamped to the tool post of the boring mill at an elevation such that the bottom surfacea of the bearing pads could be indicated, readings were taken on each of the 12 bearing pads by revolving tha tübe sheet with the mill table.

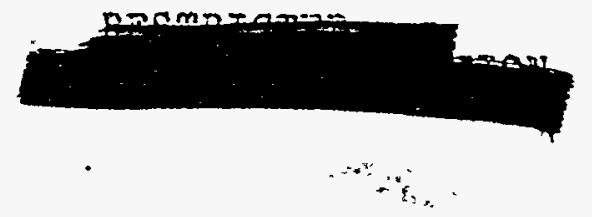


Resuits:

$$
F x^{*} 7-2
$$

(2)

(2)

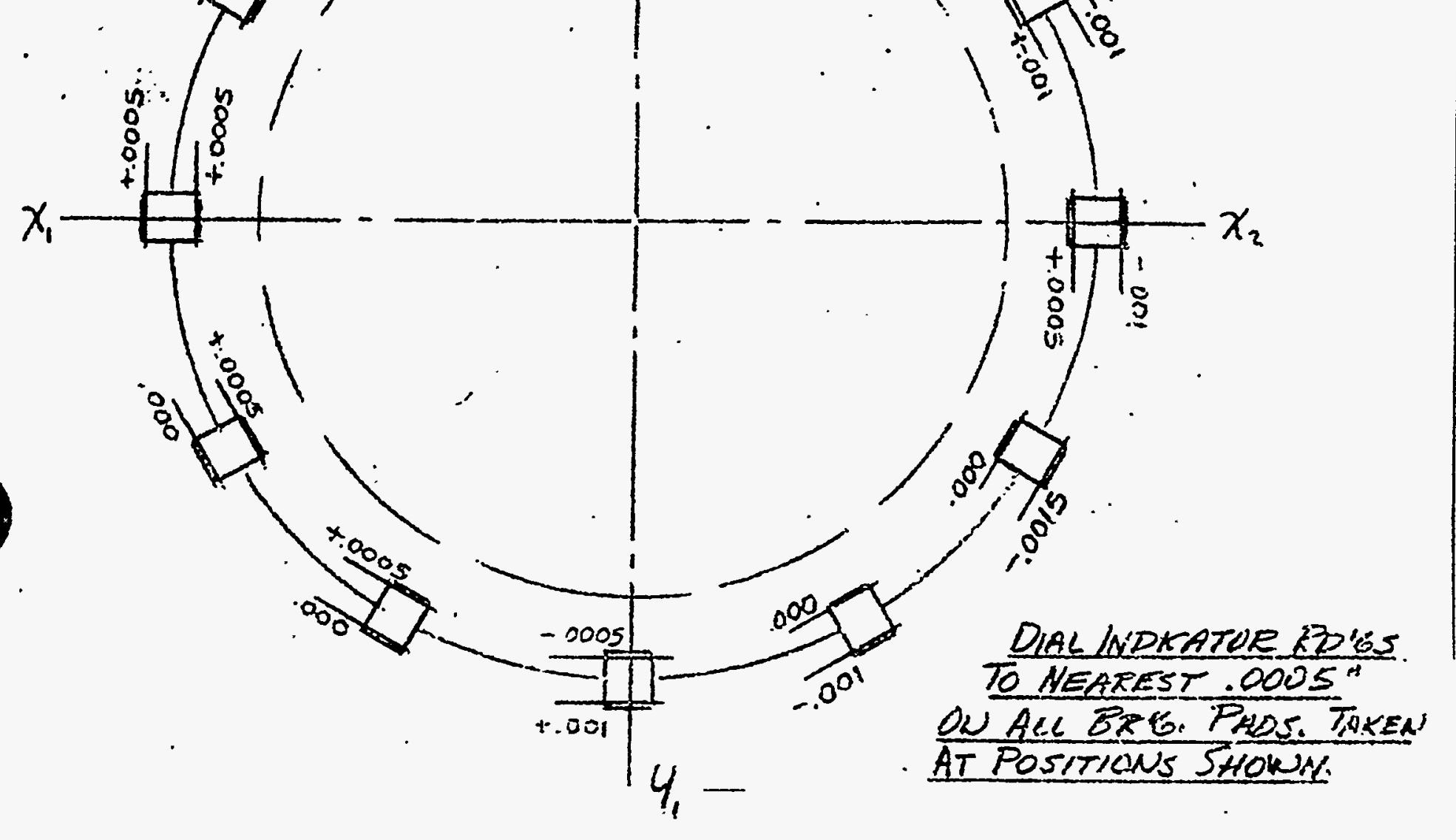

TANK BOTTOM TUBE SHEET-BÓTTOM YIEN: (PART ZA.)

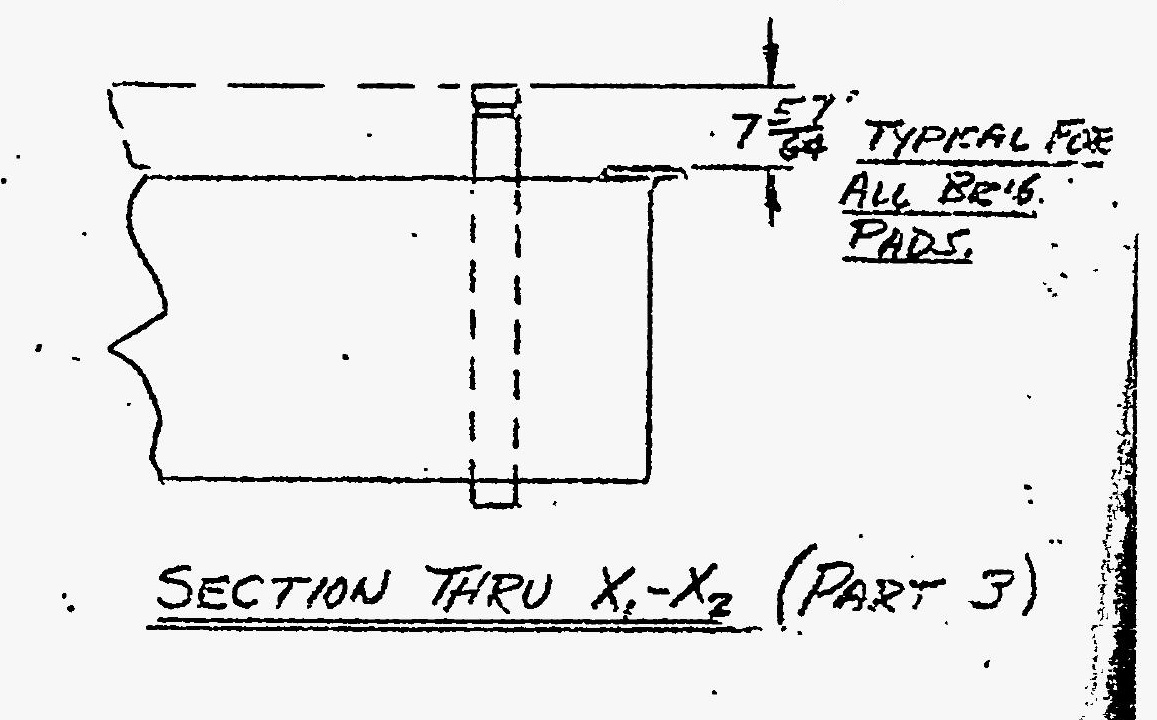


Results: 1. Plane of thbe ends Inspectors: Chaney, Mease, Baker;

2b. Surface finich of bearing pads determinea by moans of a profllometer.

*:3. Parallel check of 2 planes, (plane of tube ends atro plane of boarling pads), by measuring distance from bottom surface of beering pady to end surface of tubes.

Tube

$X+54, Y-48$

$\begin{array}{ll}50 & n \\ 48 & n \\ 46 & n \\ 42 & n \\ 38 & n \\ 34 & n \\ 30 & \therefore n \\ 26 & n \\ 22 & n \\ 18 & n \\ 14 & n \\ 10 & n \\ 6 & n\end{array}$

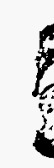

$\begin{array}{rr}34 & n \\ 30 & : n \\ 26 & n \\ 22 & n \\ 18 & n \\ 14 & n \\ 10 & n \\ 6 & n\end{array}$

Clearance:
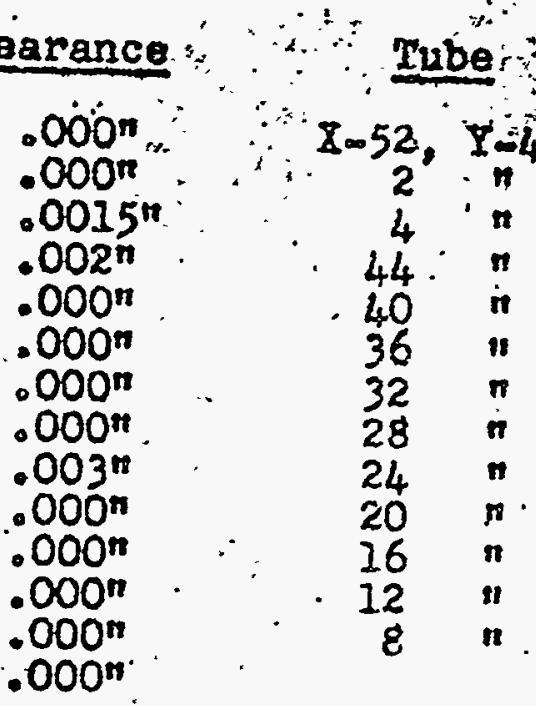
$-52, Y=48$
2
4 .
$44 . n$
40
36
32
28
24
20
16
12
8

$.000^{n}$

Clearance
$.000^{n}$
$.000^{n}$
$.000^{n}$
$.002^{n}$
$.002^{n}$
$.000^{n}$
$.000^{n}$
$.004^{n}$
$.000^{n}$
$.000^{n}$
$.000^{n}$
$.000^{n}$
$.000^{n}$

2a. See attached sketch.

b. .50 r.m.s. micro inches surface finish.

$2 \mathrm{~mW}$ 
$\because \because+\cdots$

EXHIBIT

INSEECTICKS PEHFOR̈LD AFTER YHACHIHING TUBE ENDS ON TOP SIDE OF "PI BOTTON TUBE SHEET ASSENBLY. 
L. DU PONT DE NEROURS \& Construction Division

Raport Number 195-P

CC: C. E. Buckley, F.P.M.

R. Ko Mason, F.P.M, -SRP (3)

H. L. Bunker - J. Go Brever.

J. G. Brewer

H. B. Gage

F. C. Breuninger

A. H. Hughes

R. Ho. Potes fut in

$\Rightarrow$ C.W. Dunn. - F118

August 22, 19.52

Hew York Ship - Camden, N. J.

. $17^{7}$

TO

C. J. VEITH - M \& E FILE

H. H. Scholes

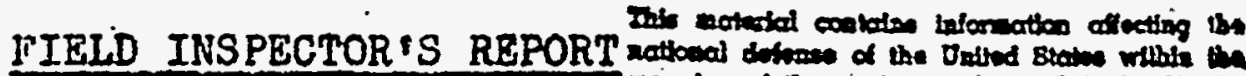

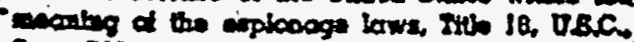

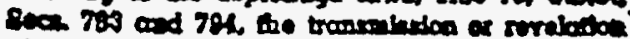

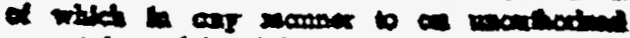
pencel in problbind by lew.

EROM LoW. Mergenthaier. I.R.Lovder, W.J.Laughin DATE August 18,1952

YROJECT NO._8980. PLANT_Savannah River ORDER NO. AXC-167)

EQUIPMENT Bottom Tube Sheet EQ.PC.NO. 153-P

DRAWING NOS. W-131395 JOB RATING

VBKDOR Nar York Shipbuilding Corporation LOCATION_Camden, He J.

Scope:

1. To determine if tube ends $(3-25 / 16 " 0 . D$. Tubes) on top side of tube sheet are located in same plane.

2. To determine if bearing pads are located in same plane.

3. To determine if plane of tube ends and plane of bearing pads are parallel.

Re eults:

Seo attached sheets

Inw

A.ttach. 2

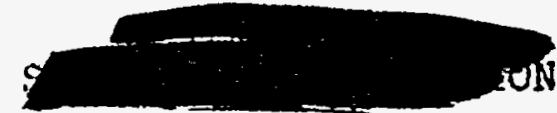


PUNT BOTTOM TUBE SHEET

Report No $195-\mathrm{P}^{2}$ MeTA UEED TO CHECK TUBE LENGTHS
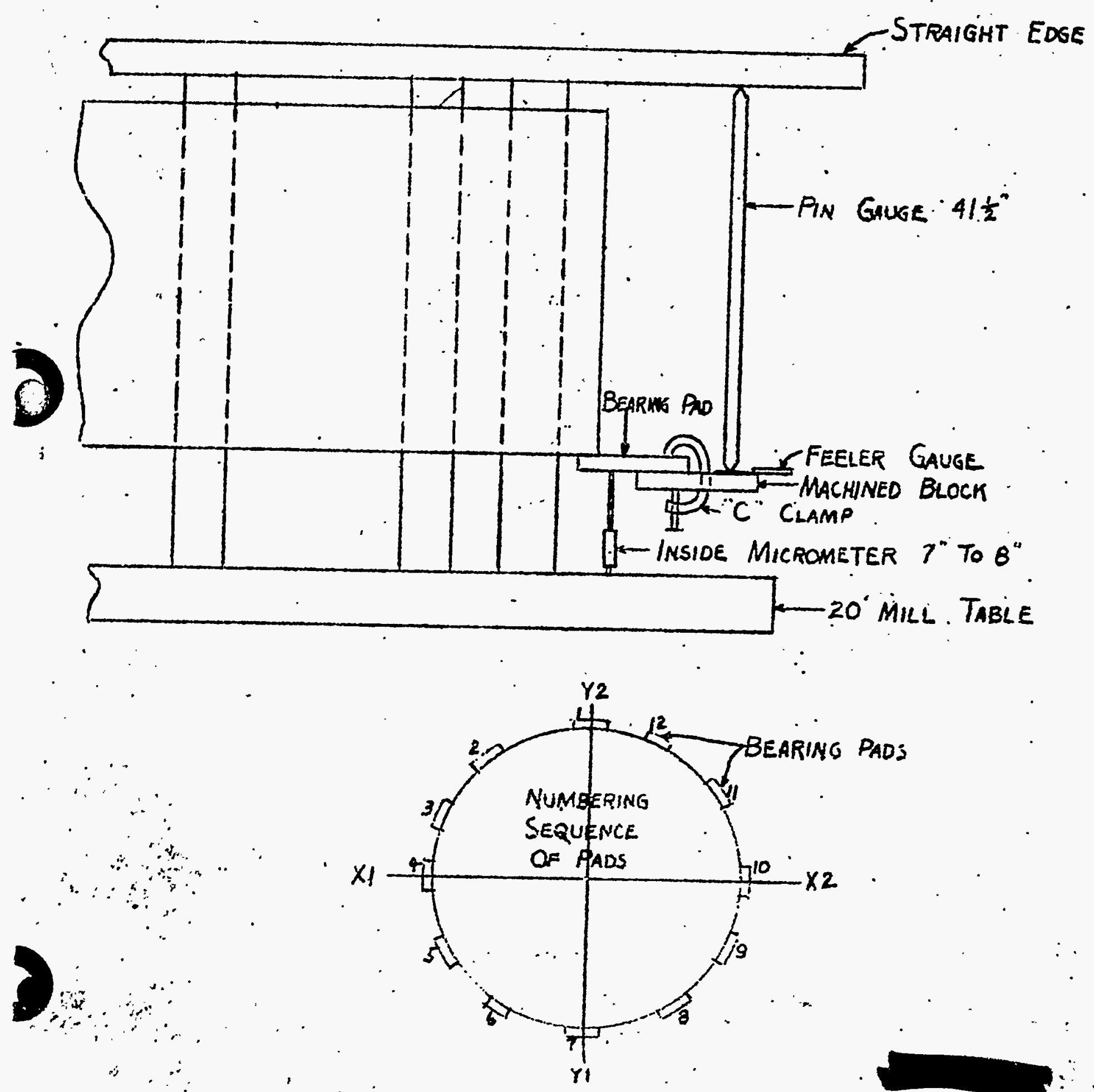
were shrunk by welding a series of beads around the bottom $0 . D$. of the tube. Heli-arc relding without filler metal was used to shrink all eight tubes. After shrinking the bottom land bore was reamed to drawing size $\left(3.376^{\prime \prime}-3.282^{\prime \prime}\right)$ and honed. The tubes were then inspected for bore size and finish. Results of this inspection was as follows:

BORE DIAPETER

Tube Number

$\mathrm{X}$

X21-19

$X 9-Y 51$

$\mathrm{X} 13-\mathrm{Y} 51$

$X I 1-Y 57$

$X 21-Y 81$

$\times 18-184$

$X 50-154$

$\times 35-145$

3.378
3.380
3.380
3.376
3.379
3.378
3.382
3.378

$Y$

RINS

All of the above tubes were within drawing tolerance except tube number $\times 50-154$ which was $0.002^{n}$ oversize in the $Y$ direction; nevertheless, this tube was accepted. The finish of all tube bores vere well within the specifled 63 RIKS microinch as noted in the above table.

Next, the bottom land finish and bore diameters were checked. The specifled finish was 63 RUS micro-inches. The bottom land finish was checked using a profilometer. The specified bore diameters were measured using a standard dial indicator bore gage and ring gage. Bores were measured in two directions - parallel to the $X X$ axis and parallel to the II axis. Measurements were taken down approximately $1^{n}$ from the bottom end of the tube. For results of this inspection, see Exhibit $\# 9$. By examining this exhibit, it can be seen that many of the bottom land bores did not meet the required finish specifications of 63 RiSS micro-inches, and in addition, many of the bore diameters were oversize. To correct the above discrepancy, it was necessary to improve the finishes of three tubes that required it by one of two methods; namely, (1) cloverleafing (2) improve finish in spots using crocus cloth. In some cases it was necessary. to "heli-arc". shrink the $0 . D$. of the tube'to: provide sufficient metal in the bores for cloverleafing or honing to the repuired finish and at the same time, maintain the specified bore diameter. Bore diameters that were oversize were "heli-are" shrunk until the diameters were within the specified range as determined by measuring with a bore gage and ring gage. After all tube repair work was completed, finishes and bore diameters were rechecked in a similar manner described above. All 


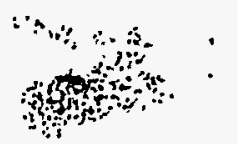

\section{EXHIBIT \#9}

RESULTS CF INITIAL BOTTOH LEND BORE FINISHES AND DIAIETERS. 
I. DU PONT DE NEMOURS \& CO., INC.

Report Number idg-P

struction Division

CC: C. B. Buckley, F.P.M.

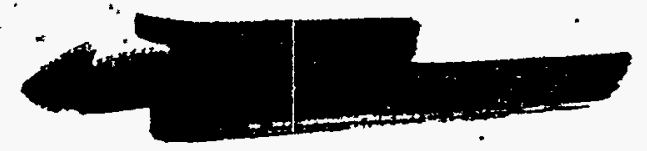

R. X. Mason, PJM - -SRP - (3)

H. L. Bunker - I: Go: Brewer

J. G. Brewer

H. B. Gage

F. C. Breuninger

\section{$\Rightarrow$ A. H. Kughes (4) \\ C. W. Dunn - File}

August 18,1952

New York Ship - Camden, N. J. .,

FIELD IMSPECTOR'S REPORT

TO C. Jo VEITH - M \& E EILE

FROM R. H. Graham

PRO JECT NO. 8980 PLANT Savannah River Tank Bottom Tube Sheot W-130947

(3) WIFAR Nos.

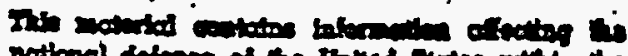

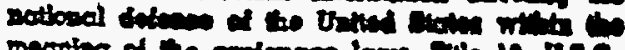

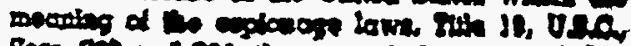

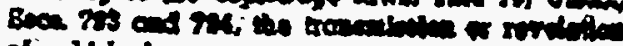

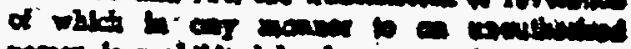
parion of grethind by law.

DATE August 1421952 BQ.PC.NO. $153-P$

VENDOR New York Shipbuilding Corporation YOCATION Camden, $\mathrm{H}$. J.

Scope:

Results:

The bottom bore of all tubes in the subject tube sheet was checked for diameter and finish. The following is a $118 \mathrm{st}$ of tubes that do not mest drawing speciflcations. AiBo included is the pus finish as deterwined wth a profilometer and two bore measurements for each tubo.

See attached sheets.

Note: Specified bore is $3.376 n$ to $3.382^{n}$. Zero Bore gage setting was $3.375^{n}$ and mossurements are recorded as - .000n of this basic dotuinga.

Imw

Attach。 4 


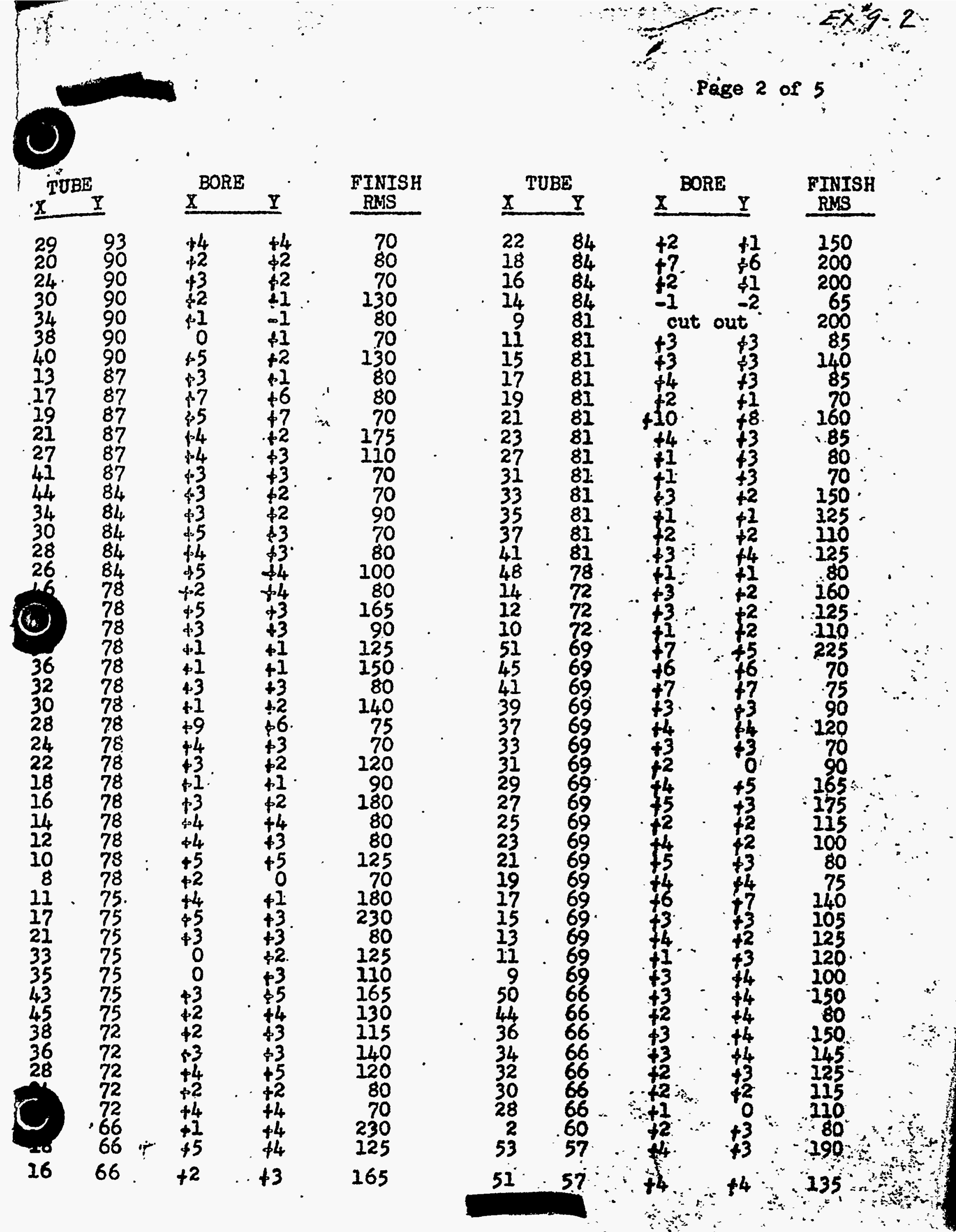




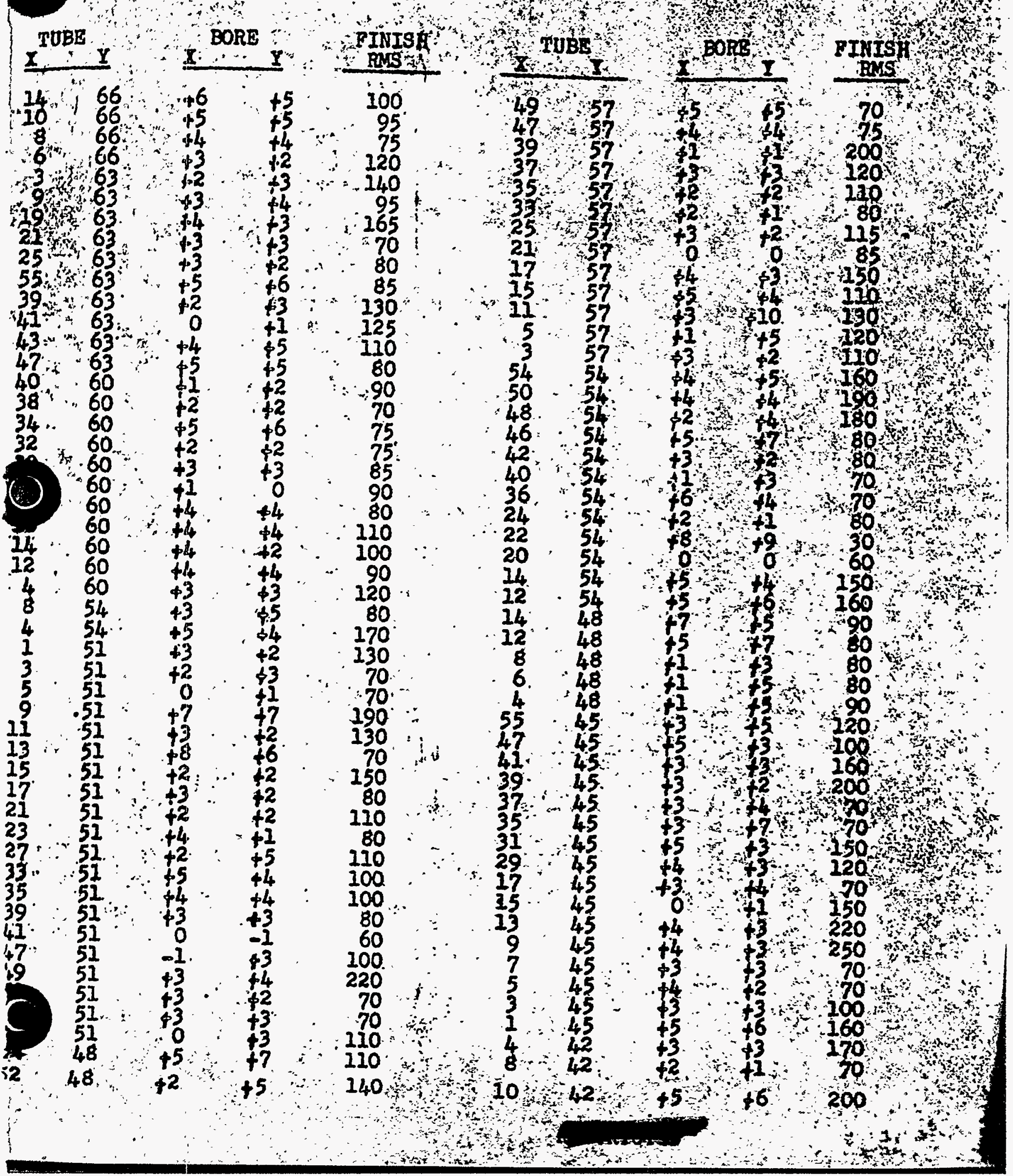


(

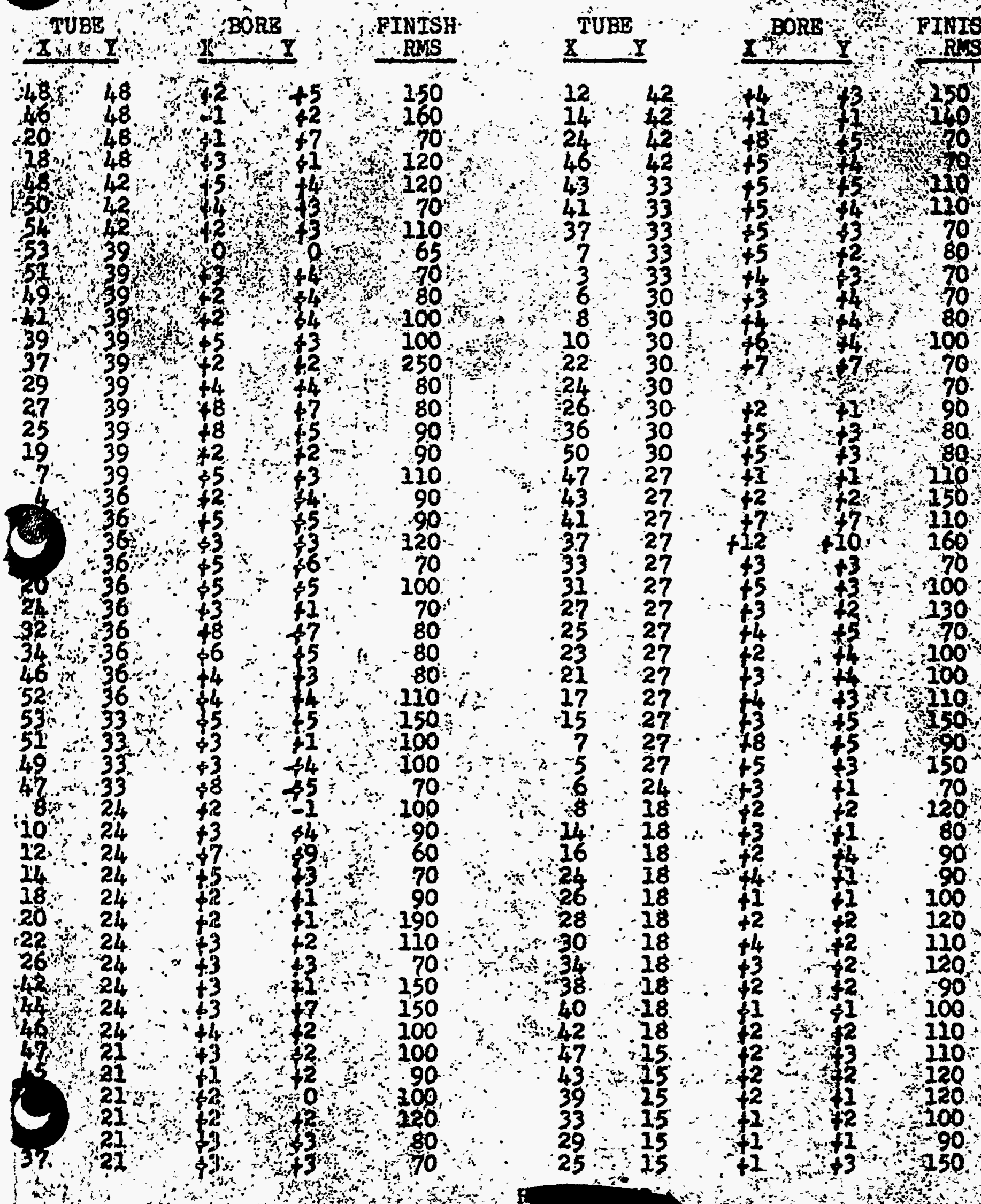

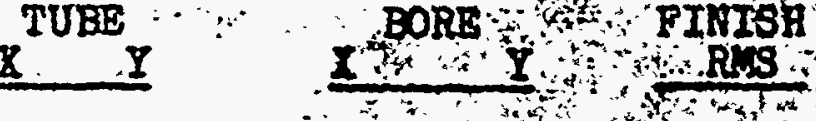

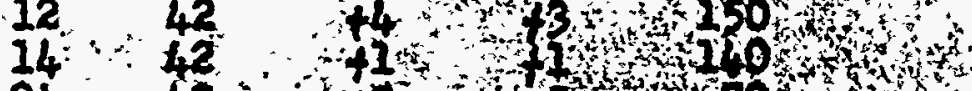

$46 \cdots 42$

$43 \ldots 33$

$37 \quad 33$

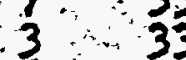

$8 \% 30$

$22 \ldots 30$

26.30

$36 \cdot 30$

$47 \therefore 27$

43. 27

42

33

25

23

$37 \ldots 27$

$15 \div 27$

$-5 \div 27$

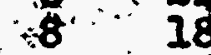

$\frac{14}{16} \cdot \frac{18}{18}$

$26 \cdot 18$

$28 \quad-18$

34.18

38.18
$40 \therefore 18$

$42 \therefore \quad 18$

$47 \therefore 3.15$

$39 \quad 25$

$33: \because 15$

$29=15$

s. 
Page 5 of 5

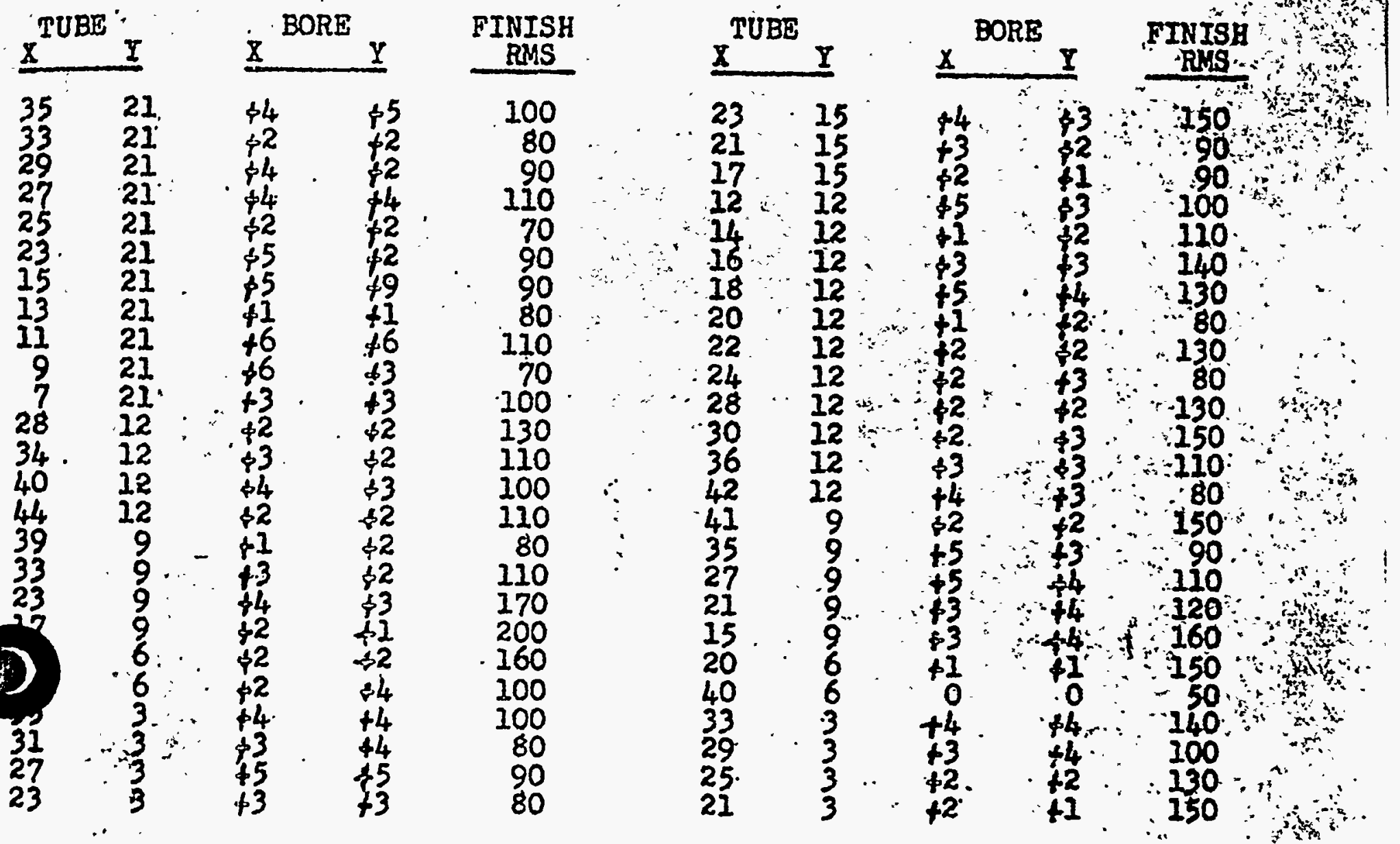


Inspections were satisfactory and approved by the du Pont Inspection Department. For final results of these inspections, see exhibit $k 10$.

b. Top Land I.D.

Inspection and repair of the top Iand I.D. of large tubes in the "p" bottom tube sheet was performed in a similar manner to that described in Section $12 A-(3) \mathrm{b}$ of this manual. Fesults of this final inspection are covered in Exhibit \#10.

c. "L" Unit

(I) Facing Operation and Inspections.

The bottom tube sheet was set up and leveled bottom side up under three radial drills presses by New York Ship mechanics and checked by du Pont inspectors using the Wild NIII Presision Level and target. Next, preparations were made to ream all "spider web tubes" at the top and bottom weld necks in the bores. This reaming was necessary in order that the "hour glass effect" (shrinkage) at the weld line (caused from welding tube to tube sheet) on the I.D. of the tubes could be reamed to original dimensions, allowing the bottom tube sheet verticality gage to pass through when the unit was bottom side up on the 20 mill table. No other tubes were reamed other than the "spider web tubes" in this operation.

During the above tube reaming operation, the bottom side of the bottom tube sheet was laid out for the 12 bearing pads. (see du Pont Drawing W-133138 for location and specifications) (For a detail discussion of " $L^{\text {" unit }}$ bearing pad revisions and additional inspections, see section 220 of this manual.) The 12 bearing pads vere fit, set and tack welded to zayout, fully welded, dressed, and welds dy-cheked and approved.

The bottom tube sheet assembly was placed on a $20^{\prime}$ mill (bottom side up) and preparations were made for machining tube ends and the 12 bearing pads. First, the unit was set to the best verticality readings. (See Part III, section II-I for use of verticality gage). The unit was resting on four blocks while on the mill. The bottom tube sheet assembly was shimmed at these blocks until a satisfactory verticality pattern was obtained. Results of these final readings are shown in Sketch \#i3.

After verticality of the unit was taken and accepted (with unit now clamped to mill table), the vild level was used to establish the elevation of tube ends on the extremities of the $X$ and $Y$ axes and the middle tube. These five reference tubes were: (1) $\times 54-Y 48$ (2) $\times 15-Y 9$ (3) $X 2-Y 48$ (4) X15-Y87 and (5) X28-Y48 (middle tube in unit). The mill table was then rotated to each reference tube with a dial indicator affixed to the mill's cutting arm which registered to tube tops. The elevations that 


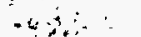

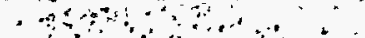

and

$4 x^{2}+a$

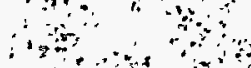

$\therefore a$ o o

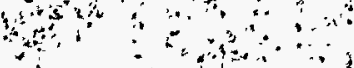

$\therefore \%$

and

and

$4 y$

10

tit

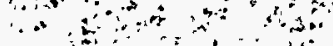

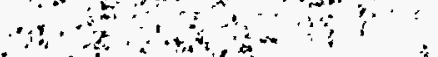

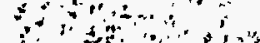

0

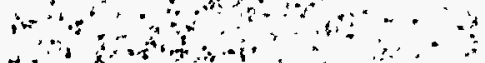

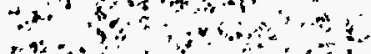

a

-

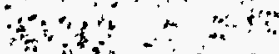

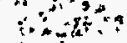

thon

and and

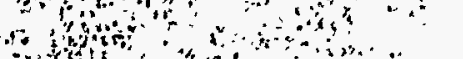

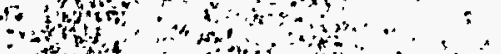

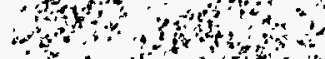

is

to 4 and

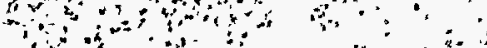

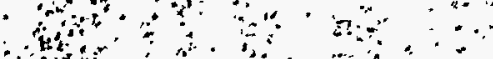

$0 \quad \therefore \quad 4 \quad \therefore$

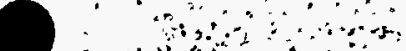

a d a

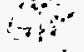

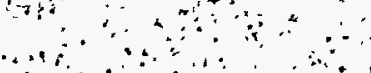

$\therefore 4$

RESULTS OF FINAL BOTTOA LAND BORE FINISHES

AND DIAMETERS.

EXHIBIT 410 


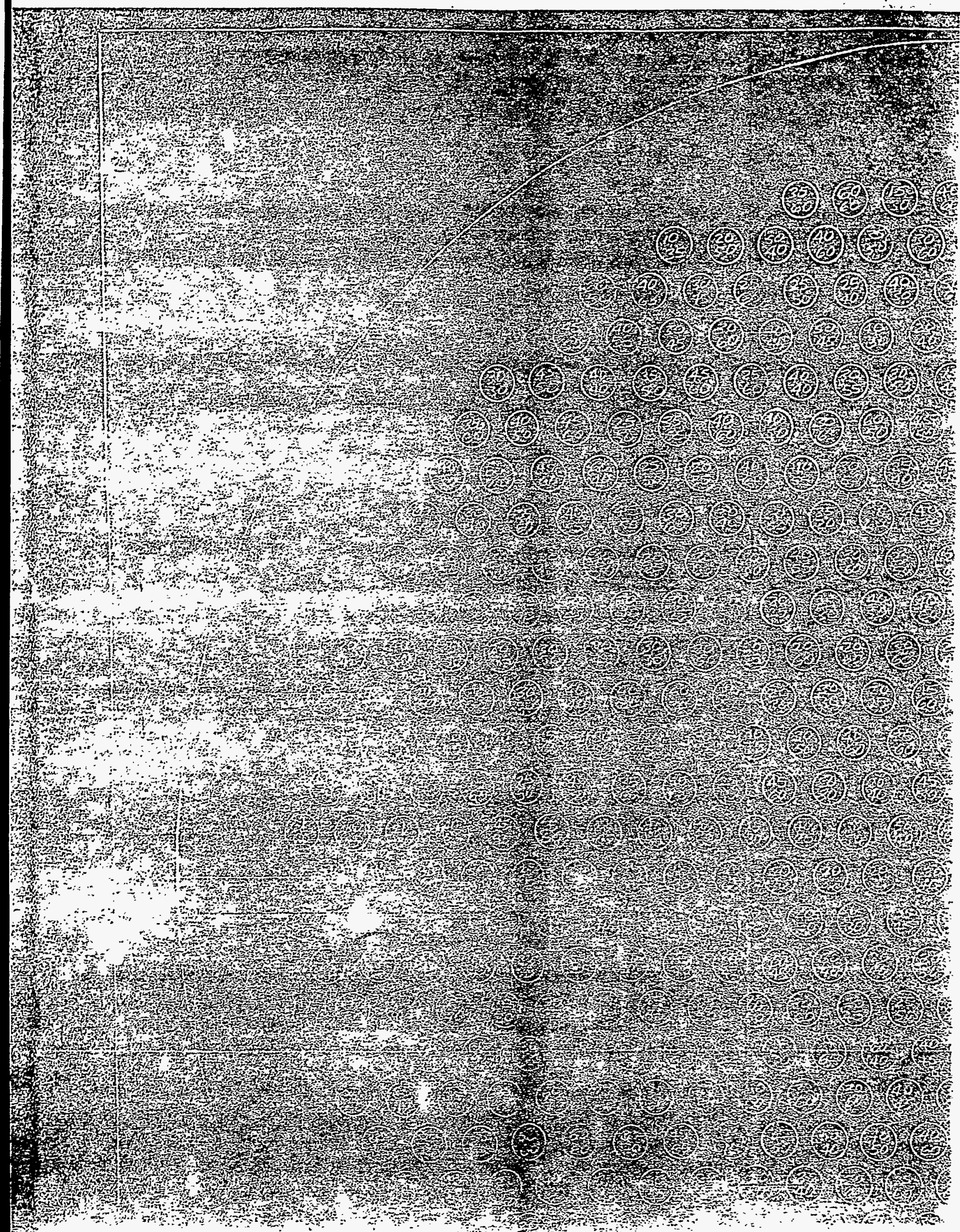




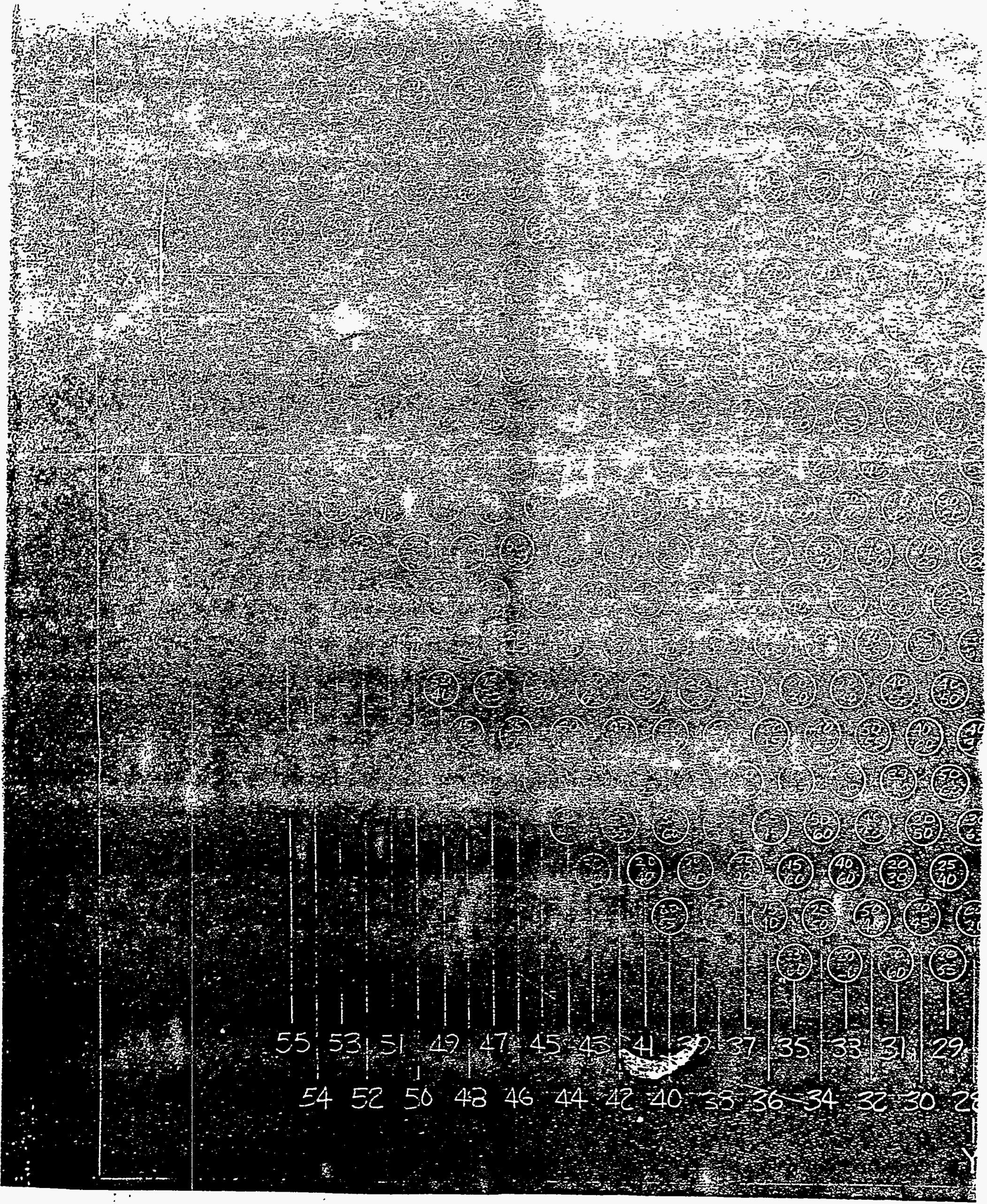




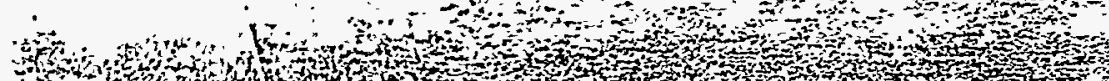

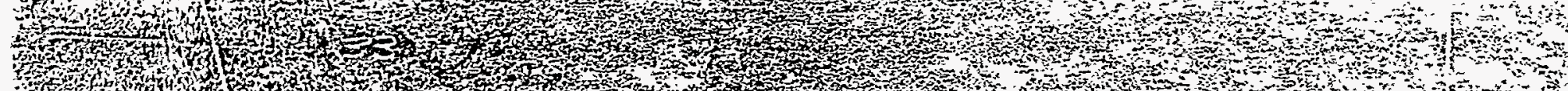

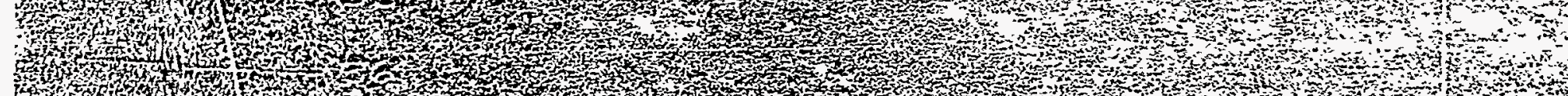

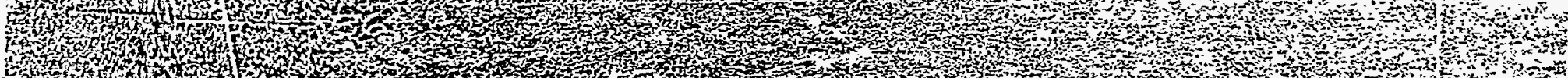

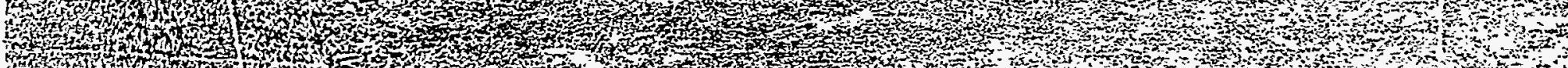

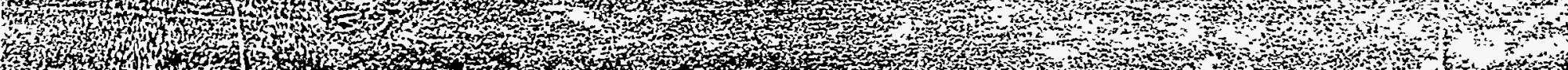

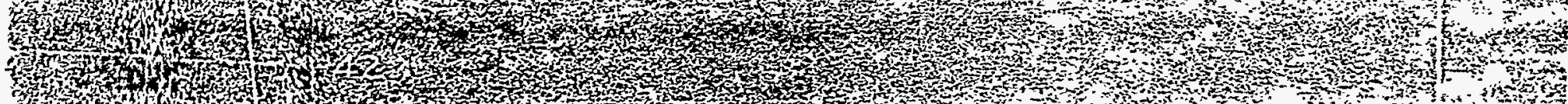


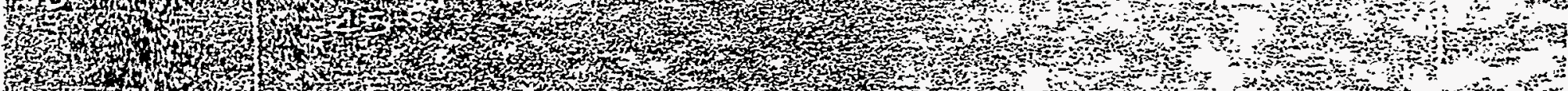

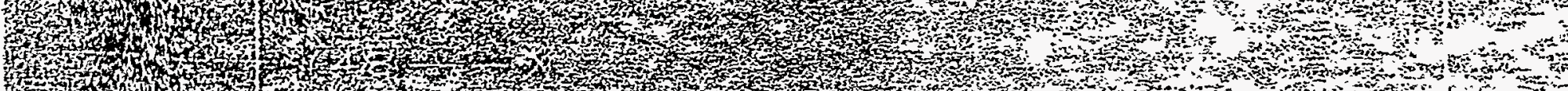

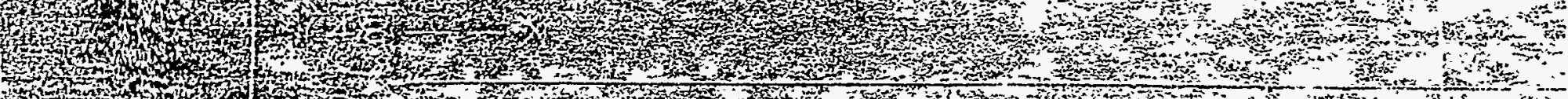

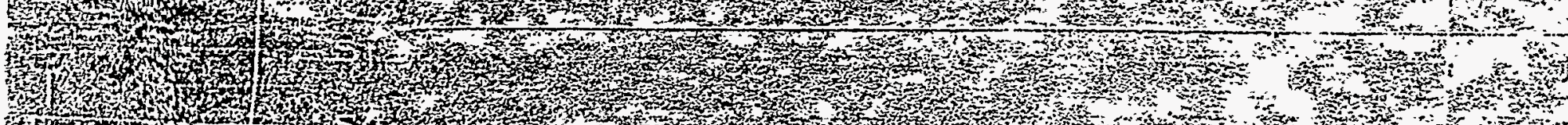

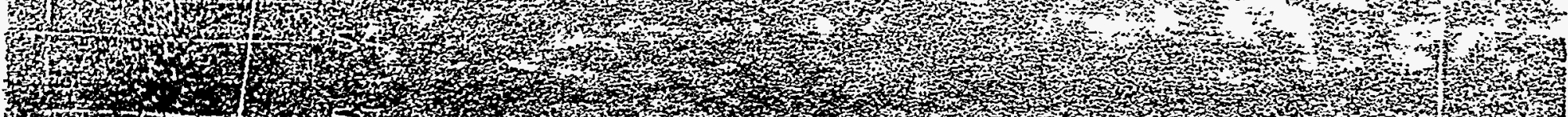
(3)

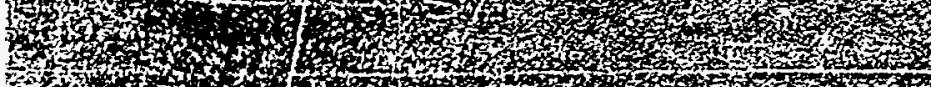

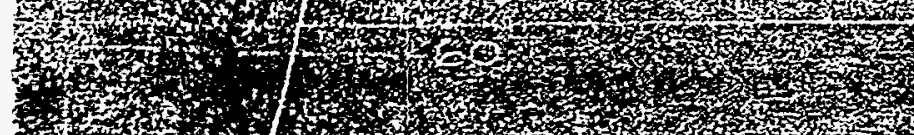

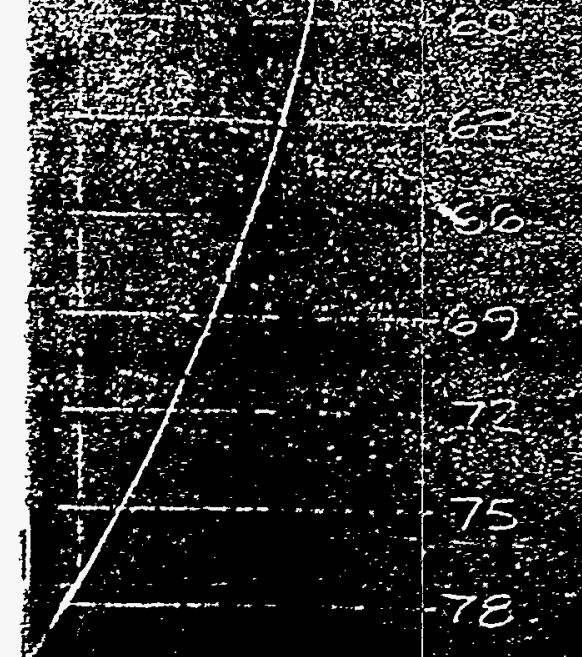
El
$\varepsilon 4$
$\$ 7$
ijot:

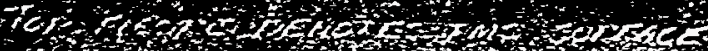

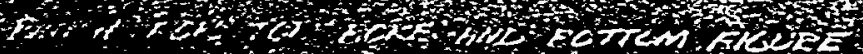

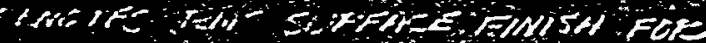

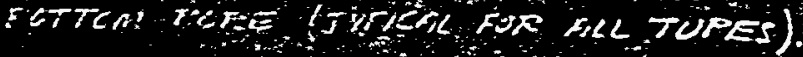

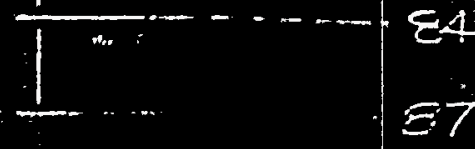

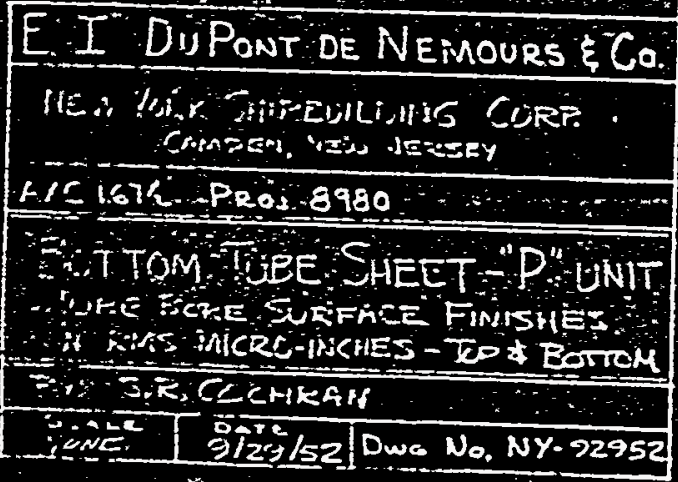


were established on the tubes were then duplicated by shimming the unit under the cutting arm as noted on the dial indicator. In this manner the twist in the mill table was compensated for so that the established verticalities would be duplicated when the unit placed in a level plane. The unit was then released to the machinist for facing tube ends and bearing pads.

The bottom ends of the large tubes and 12 bearing pads were finished machined to drawing sizes, then deburred, inspected and found satisfactory. Exhibit \#1 presented herewith covers all inspections made on the bottom side of this unit.

After the bottom side was inspected and accepted, the unit was turned top side up for machining tube ends on this side to finish size. The top ends of all large tubes were machined to drawing size, tubes deburred and then inspected. Exhibit \#11 covers all inspections and results taken on the top side of the unit.

(2) Tube Reaming Operation

This operation was performed in a similar manner to that described in Section 12A-(2) of this manual.

(3) Tube Repairs

a. Bottom Land I.D.

While the bottom tube sheet was bottom side up and after: (I) reaming the top land bore to finish size (3.270" to $\left.3.277^{\prime \prime}\right)$ and (2) removing the "hour glass effect" (caused from welding tube to bottom tube plate) by reaming the bottom end of tubes to original size (3.312" to $\left.3.328^{n}\right)$, du Pont inspectors checked the bottom land bore diameters using a standard dial indicator bore gage and ring gage. In addition, all bottom land finishes were checked using a profilometer. Many tubes were found to have finishes greater than the required 63 RMS. These tubes were honed until the required finish was obtained; being careful not to exceed the bottom land bore tolerance $\left(3.376^{\prime \prime}\right.$ to $\left.3.38^{\prime \prime}\right)$.

During the honing operation, one tube (X49-Y27) was honed $0.027^{\prime \prime}$ out-of-round. To correct this it was necessary to "heli-arc shrink" (without filler metal) the O.D. of the tube surrounding the bottom land bore to provide sufficient metal in the bore for honing to size. The bore was re-honed, inspected and accepted.

After all repairs were made, a preliminary reinspection of bore sizes and finishes proved satisfactory. The unit was released for drilling dowell pin grooves in the bottom land bores of all large tubes. Section 130 covers this inspection, the problems encountered and how they were handled. Final results of bore diameters and finishes on the bottom lands are also covered in this section. 


\section{EXHIBIT \#II}

IRSPECTIONS PERFOR AFD AFTER MACHINING TUBE EIDS AND 12 BEARING PADS ON THE BOTTOK SIDE AND TUBE ENDS ON THE TOP SIDE. 
5. I. DU PONT DE NEMOURS tCO., INC. apitriction Division

Report Number 409-L

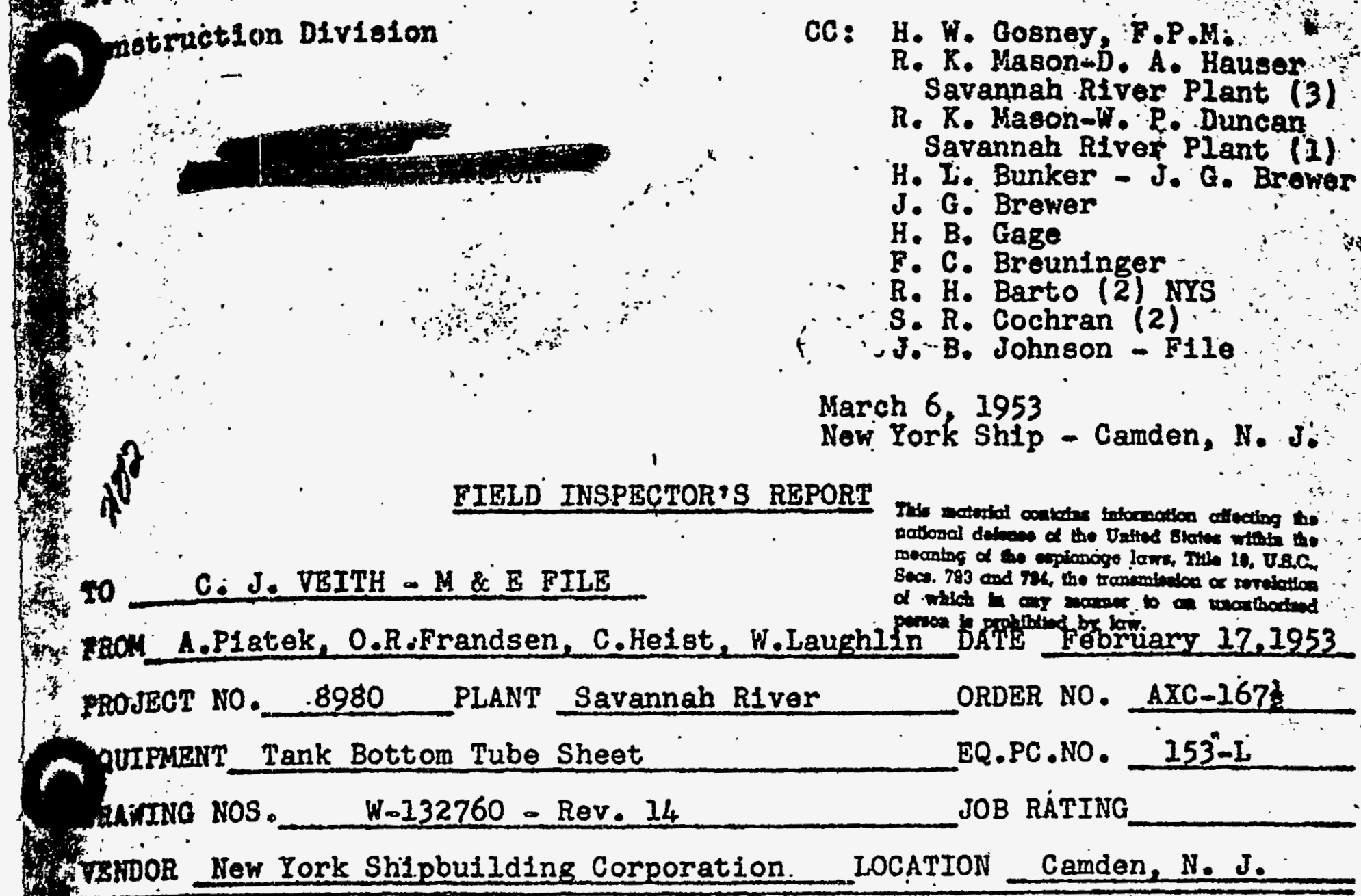

Th1s is a report on the measurements taken on top and bottom 81de of the unit after the tubes and bearing pads were faced off on the $20 \mathrm{ft}$." boring m111. In'spection started February 5, 1953 and completed 2/7/53.

A. Profiles of tops and bottoms of tubes were taken with a $18 \mathrm{ft}$. straight edge and feeler gages.

(1) Top Side:

The straight edge was placed on the row of tubes on the X1-X2 and Y1-Y2 axes. Feeler gages were then inserted between the streight edge and top of tubes to determine clearance between the straight edge and the top of tubes. See attached sketch.

(2) Bottom Side:

Same procedure was used as on the top side. 


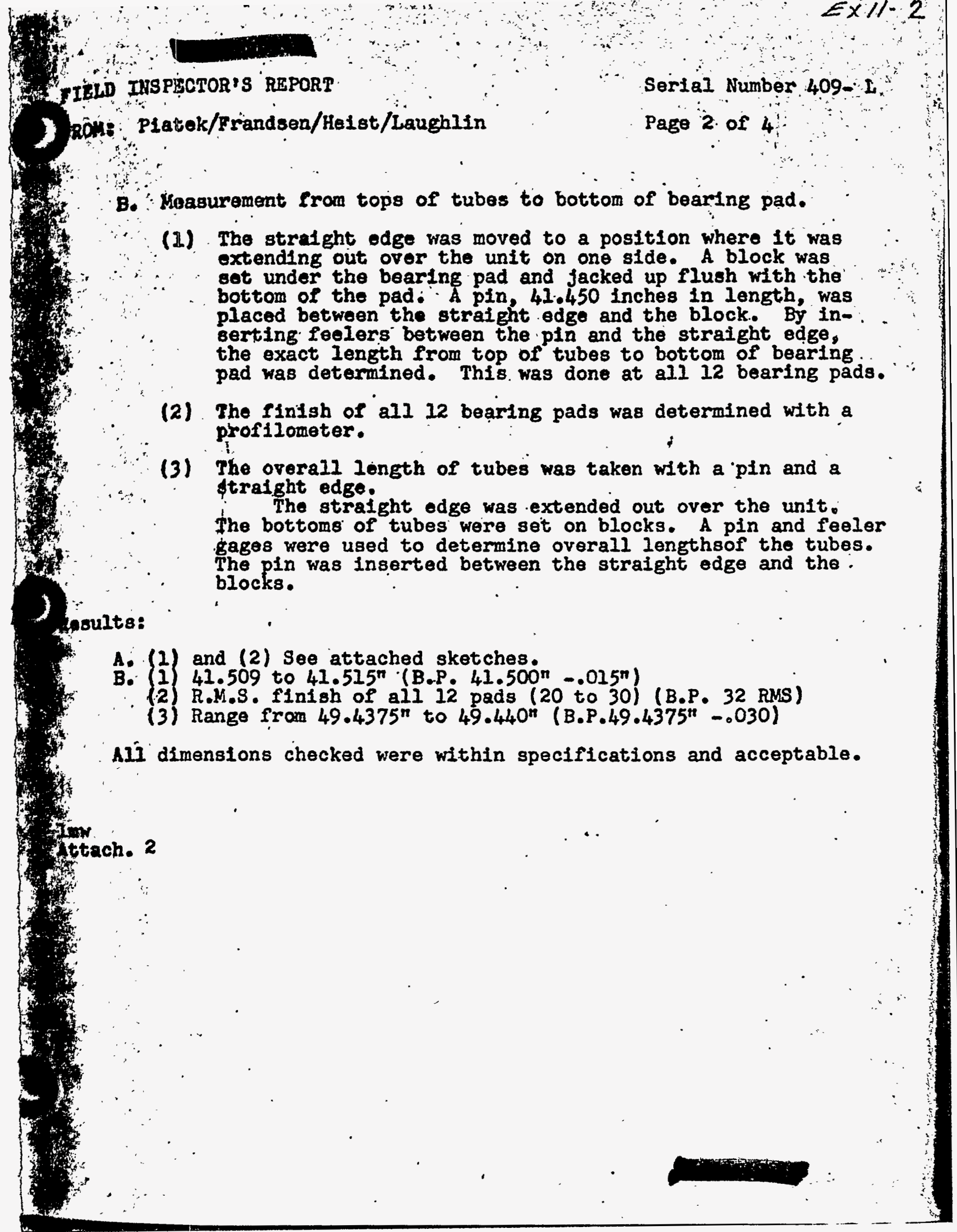




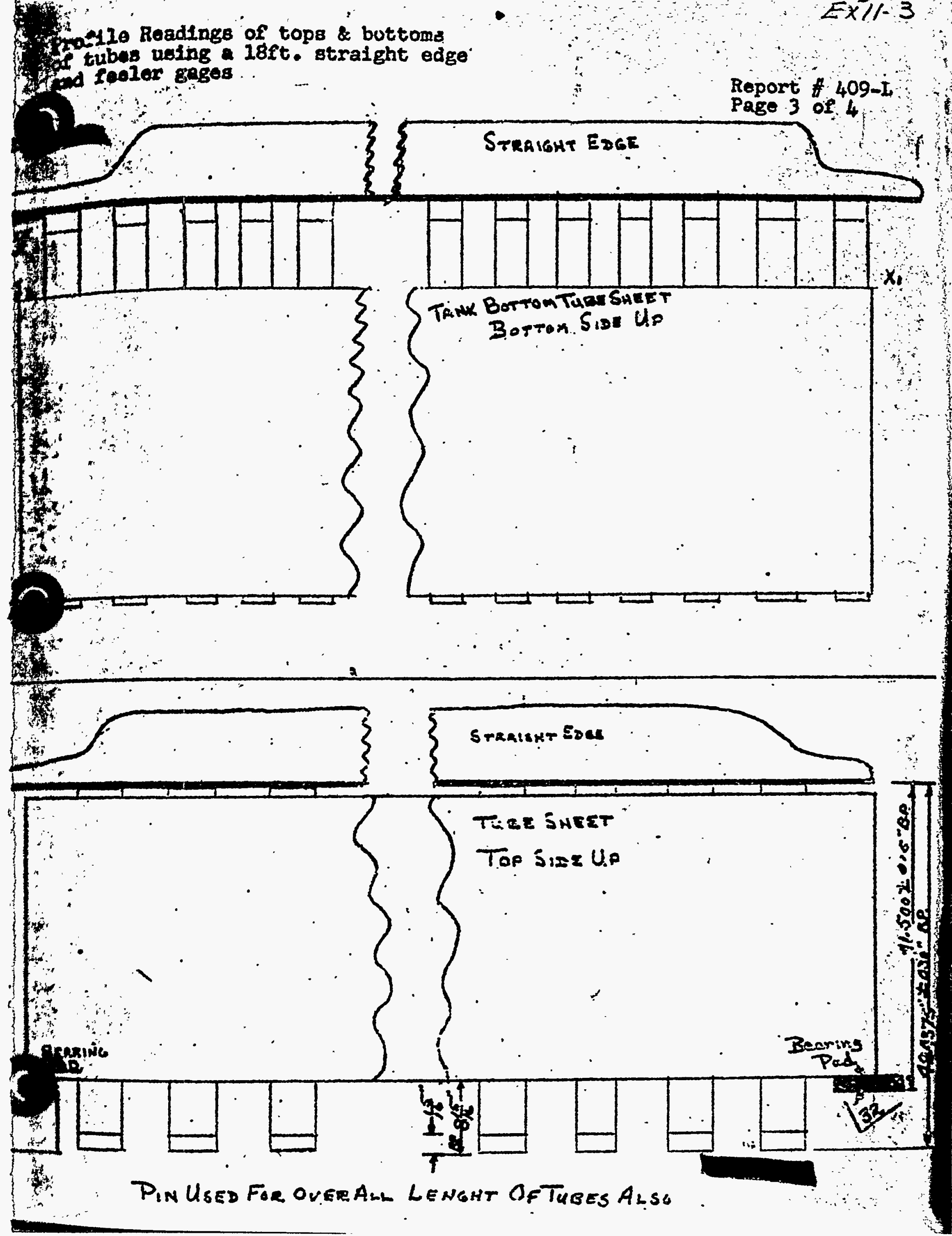




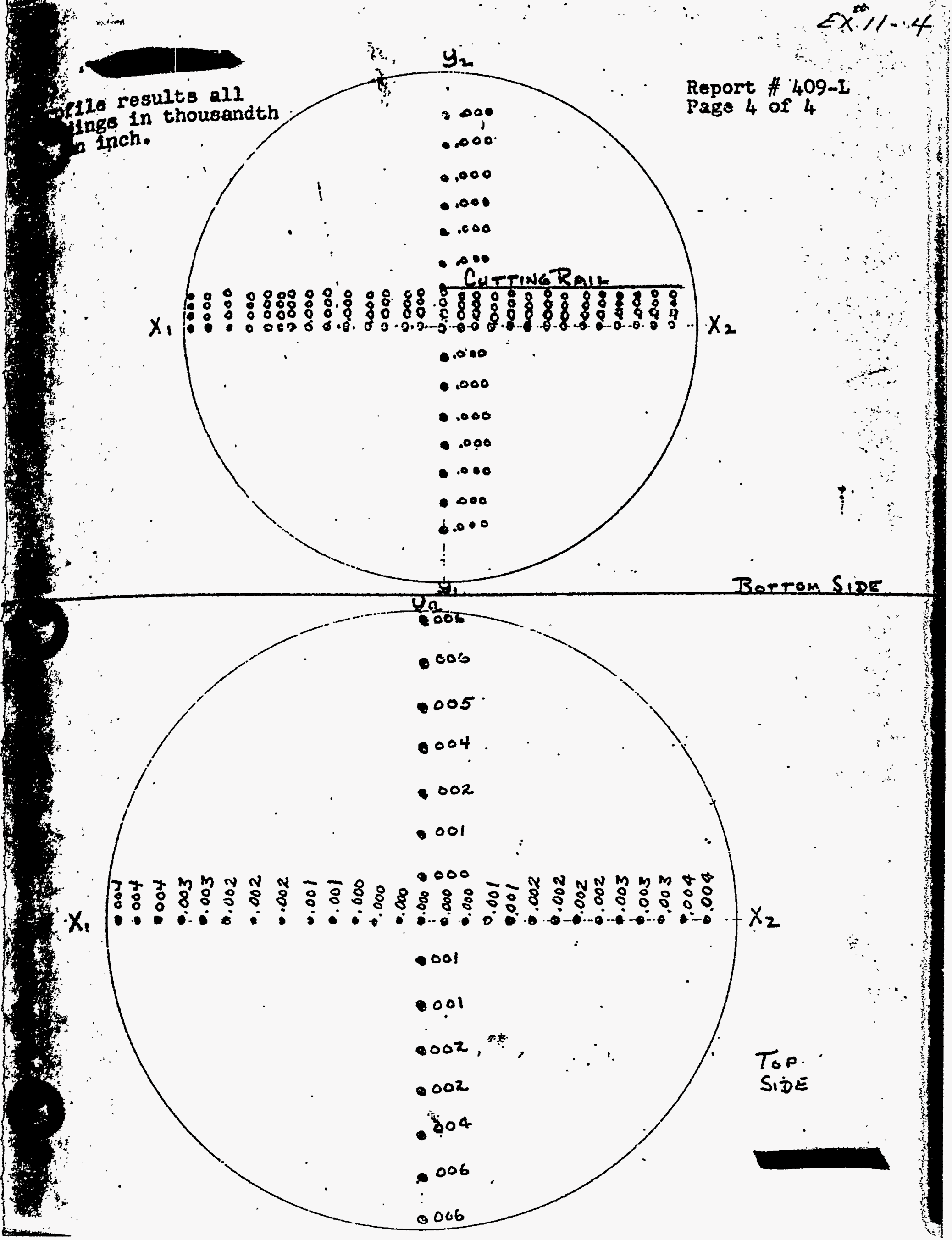




\section{b. Top Land I.D.}

After line reaming the top land of all bottom tube sheet large tubes, the following inspections were made:

(1) Bore diameter measurements in $X$ and $I$ direction taken $1^{n}$ below top ends of tubes.

(2) Finish in RMS micro-inches using a profilometer.

(3) Visual inspection for burrs, scratches, steps, and other mechenical defects that might be present in top land bore.

As stated in (1) above, bore diameters were taken in the top land to determine if bores were within tolerance $\left(3.270^{n}\right.$ to $\left.3.277^{n}\right)$. Heasurements were taken with a standard dial indicator bore gage and ring gage. Bore diameters found undersize were honed to size or cloverleafed, depending on how much metal had to be removed before bores were within the specified tolerance. All repair work was observed by du Pont inspectors. At the completion of all necessary work, bore diameters were re-measured in a similar manner to that described above and accepted. For results of this inspection, see Exhibit fl2 in Section 130 of this manual.

Concurrent with the honing of tubes to required size, finishes of the top land were measured using $a$ profilometer. Many of the tubes were found to have finishes greater than the specified 63 RMS. These tubes were either honed or cloverleafed until the bore finish was satisfactory; taking care not to exceed bore tolerances on those tubes that were all ready within tolerance, but requiring additional honing to improve the finish.

A final visual inspection was then made on the top land to determine if any scratches, burrs, tool steps, or any other mechanical defects were present. Any found were removed by one of the three following methods: (1) honing (2) cloverleafing (3) smoothing out defect with crocus cloth. After minor repairs, al1 top land bores were approved as being satisfactory. For final bore diameter and finish measurements, see Exhibit \#12 in Section $13 \mathrm{C}$ of this manual. For pictorial views of the top land, see Part VII, Section I, drawing $1-2$ and Section III, drawing $2-4$.

c. Visual Inspection of Bore Between Top and Bottom Lands

As large tube bore work neared completion, a visual inspection for nicks, burrs and other mechanical defects were made between the top and bottom lands. To aid in the $v$ isual inspection of bores, $a$ drop cord with a socket wired to one end and 260 watt lamp screwed into the latter was lowered into each 
tube to make for a better inspection of the tube wall I.D. Any defects noted were removed either by grinding or cloverleafing. Bore sizes (mid-length bore tolerance $3.312^{\prime \prime}$ ) were checked at random using a standard dial indicator bore gage and ring gage. After all repair work was completed, re-inspection of tube bores by du Pont inspectors was passed as being satisfactory. For view of mid-length bore between top and bottom lands, see Part VII, Section III, drawing 2-4.

\section{Monitor Pin Groove Inspection}

\section{A. "R" Unit}

New York Ship drilled three monitor pin grooves in the bottom land of each large tube in the bottom tube sheet assembly. For location and specifications of the dowell pin grooves, see du Pont drawing W-130948, section "M-M".

After monitor pin grooves had been drilled in the bottom ends of all large tubes, du Pont Inspectors spot checked the depth of the slots using a 6" scale and visually inspected them for evidences of any burrs. Also, a 100\% visual inspection was de to determine if the three monitor pin grooves were drilled on the $X 2$ side of the tube. All inspections were satisfactory and the job was approved.

After the bottom tube sheet assembly was received at the Savannah River Project, fleld personnel inspected the bottom land of large tubes before inserting monitor pins and the following conditions were found and reported to the du Pont Inspection Department at New York Ship:

(1) Scratches in the $3-3 / 8^{n}$ diameter counter-bore in the lower end of tubes.

(2) Depth of half-round orienting grooves too shallow to permit entry of some monitor pins. Depthehere refers to the dimension perpendicular to the centerline of a tube.

(3) Length of orienting grooves (in a direction parallel to tube centerline) too great, thus violating the o-ring seating zone, or too short, thus preventing complete entry of monitor pins.

(4) Edges of half-round grooves and crown of chamfer sufficiently sharp to endanger 0-ring during insertion.

To prevent occurzence of similar conditions on $" L n$ and subsequent units, the du Pont Inspection Department took immediate steps to improve the situation encountered on the "R" bottom tube sheet as noted by the fleld. The revised. method of inspecting monitor pin grooves in " $\mathrm{L}^{n}$ and subsequent units is covered in the "L" bottom tube sheet history discussed in this manual. 
B. "p" Unit

The inspection of monitor pin grooves in the bottom land of eech large tube in the "pn bottom tube sheet was performed in a similar manner discussed in Section 13-A of this manual. Complaints received from the field on this unit were similar to the ones received for "R" B.T.S. These discripancies are covered in the above referenced section. AIso, see Part III, II-E, for further information concerning field complaints and steps taken by the du Pont Inspection Department at New York Ship to improve the monitor pin groove problem on "L" and "K" units.

c. "nin: Unit

Three monitor pin grooves were drilled in the bottom land of each large tube of the "I". bottom tube sheet in a similar manner to that performed on the "R" and "pn units. (Sections $13 \mathrm{~A} \& \mathrm{~B}$ of this manuel). However, due to complaints received from the field pertaining to the finish (RISS) condition of large tube bottom land and the monitor pin grooves on "R" and "p" units (discussed in Sections 13A $\& B$ of this manual and Part III, II-E), the steps taken on "I" to prevent such conditions from re-occuring will be reiterated to describe the method of inspection and repairs necessary to render all tubes acceptable.

As pointed out in Part III-II-E, numerous discrepancies were reported from the field pertaining to monitor pin grooves and condition of the bottom lands. To prevent occurrence of similar conditions in the "I" bottom tube sheet and later units, it was requested by Design Division that the Inspection Department's inspection procedure for all tube bores on "I" unit be reviewed for adequacy. In addition to checking confirmation with all drawing speciflcations, such as dimensions, finish and freedom from sharp edges, each bore was requested to be independentiy examined as to its suitability for O-rings. This examination was to include a close visual inspection and running thehand over the surfaces involved.

In response to the above field complaints and in compliance with Design that 211 bottom lands in "I" unit be reviewed for adequacy, the du Pont Inspection Department immediately investigated and inspected the jig and drills used to chine monitor pin grooves, The jig itself. was found satisfactory; however, $3 / 16^{\prime \prime}$ drills used were not of the proper size to produce the required depth of the half-round orienting grooves. (Depth refers to the dimension perpendicular to centerline of a tube.) The $3 / 16^{n}$ drills originally used were replaced by a $3 / 8^{n}$ drili ground to $7 / 32^{\prime \prime} 0 . D$. pilot for $1 / 2^{n}$. Bushings in the jig were linewise replaced with proper sizes to receive the new type drill.

After the above situation was corrected, all bottom lands in the "I" bottom tube sheet were visually inspected For finish and scratches. Where scratches were found tubes were cloverleafed until scratches were blended in. After the original check, it was found that twenty-five 
(25) tubes were badly marked in the "o" ring seating area and 9 tubes were badly marked but not in the "o"-ring area. (Marks consisted of deep scratches, grind marks, gouges and tool marks). All defective tubes are listed below. Fifteen (15) other tubes (not listed) had burr marks upon the tube bore which were ground out. Since the bore sizes were up to maximum $(3.382)$ on the twenty-five (25) tubes with omring area defects, it was decided by a member of Design to have plastic molds of the defects taken to determine the depth of defects. This was done and after consultation between members of Design and Construction Division, It was decided that the tolerance of $3.382^{\text {th }}$ be increased to $3.385^{\prime \prime}$ in en attempt to clean up as many as possible of the defective tubes. This method of repair left six tubes (11sted below): with defects impossible to clean up and the decision to move the o-ring seating area in the field on such tubes was reached at the aforementioned consultation.

The dowel pin functional gage and plug gage were used to check orientation of the dowel pin grooves. This gage checked location and radial depth of slots with respect to the $X_{1}-X_{2}$ axis. Irength of grooves was checked with stainless steel $6^{n}$ scale. The up-flow cooling pin functional gage with a $0.220 "$ O-ring was used to check the grooves for sharp edges. It was found after the first inspection that all groove edges cut the 0-ring. All edges were ground smooth, and all tubes re-checked. This operation was the cause of ruch concern because of marks left on the tube land in or near the o-ring seating area. A protector, covering the land entirely, with the exception of the grooves, was devised and fabricated from gasket material so that the land would not be scratched by the grinding tool. In this manner the sharp edges from all the dowel pin grooves were removed. For use of all gages employed in the inspection of bottom lands in the "L" bottom tube sheet, see Part III-II-E.

The list of twenty-five (25) tubes of wich plastic molds were taken follows:

$\begin{array}{llll}X 41-Y 81 & X 16-Y 60 & X 9-Y 21 & X 48-Y 54 \\ X 24-Y 72 & X 18-Y 60 & X 21-Y 3 & X 54-Y 54 \\ X 10-Y 72 & X 22-Y 60 & X 29-Y 87 & X 49-Y 27 \\ X 21-Y 75 & X 38-Y 60 & X 34-Y 72 & X 47-Y 21 \\ X 21-Y 69 & X 18-Y 60 & X 19-Y 69 & X 27-Y 69 \\ X 30-Y 54 & X 15-Y 63 & X 37-Y 69 & X 25-Y 27 \\ X 19-Y 57 & & & \end{array}$

The following is the list of tubes in which the o-ring area had to be moved. (Defects all In O-ring area)

$$
\begin{array}{lll}
X 21-Y 69 & X 24-Y 72 & X 22-Y 66 \\
X 19-Y 57 & X 25-Y 27 & X 18-Y 60
\end{array}
$$

Upon final visual inspection, many tubes were found to have scratches or tool marks which were not located in the 0 -raing area and did not cut the 0 -ring after the functional gage check. 
After all scratches and sharp edges were removed from the bottom land bores, final bore diameters and bore finishes were taken. All bore diameters were measured at the 0-ring seating zone using a standard dial indicator gage and ring gage. Final bore finishes were recorded in RMS micro-inch values using a profilometer to obtain readings. For final results of bore diameters (bottom land and top land) and Iinishes, see Exhibit " 12 presented herewith.

14. Preliminary Hydrostatic Test and Bottom Tube Sheet Testing Program A. "R" Unit

\section{(1) Hydrostatic Test}

The bottom tube sheet was set up and prepared for preliminary hydrostatic testing. After sealing off all openings and filling with de-ionized water, pressure was applied to the unit. While applying pressure to the unit, $a$ leak occurred in the reld seam of tube number $\times 36-190$ at approximately 22 psi. This was a welded tube. when the internal test pressure reached $52 \frac{1}{2}$ psi, all tube welding and tube bores were visually checked for leaks after the unit was under pressure one hour. Three leaks were found on the top side and one leak was found on the bottom side. These leaks occurred around tube welds.

The unit was drained and tube number $X 36-190$ was cut out of the unit and replaced with a seamless tube. The tube was line reamed and then the ends faced to the required plane. The top and bottom land bores were inspected in a similar manner described in section $12 \mathrm{~A}-(3)$ of this manual and found satisfactory. The three leaks on the bottom side and one leak on the top side were repaired by chipping out the defective area in the tube weld and re-welding. Repaired welds were dressed by grinding and then visualiy inspected and approved.

The assembly was again prepared for hydrostatic testing and tested in 2 similar manner described in paragraph I above. However, during this test another welded tube was found to be leaking in its seam. The welded tube number was $\mathrm{X} 42-\mathrm{Y} 42$. The second preliminary hydrostatic test was discontinued and this tube replaced in a similar manner described in paragraph 2 above.

Since there were over four hundred welded type tubes in this unit, it was decided jointly by the \& E Section, Design Division and New York Ship to discontinue the preliminary hydrostatic test (until later) and to outline a test program to thoroughly evaluate the extent of the unsatisfactory quality of welded tubes in the " $R$ " bottom tube sheet.

(2) "R" Bottom Tube Sheet Test Program

First, alpreliminary review was held by members from the $K$ \& $E$. Section, Design Division and New York ship to discuss problems incident to the unsatisfactory quality of the welded tubes in the " $R$ " bottom tube sheet. 


\section{EXHIBIT \#12}

FINAL RESULTS OF SURFACE FINISHES AND BORE DIANETERS FOR TOP AND BOTTOH LANDS OF ALI LARGE TUZES IN THE "L" BOTTOM TUBE SHEET ASSEMBIY.

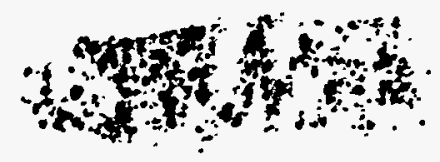


E. ${ }^{3}$. DU PUNI DE NBHOURS \& 60 , INC.

Report Number 495 L L

Construction Division

GG: H. W. Gosney, F.P.M.

R. R. Mason-D.A.Hauser-SRP

R. K. Yason-W.P.Duncan-SRP

H. I. Bunker -J. G. Brewer

J. G. Brewer

H. B. Gage

F. G. Breuninger

S. R. Cochran (2)

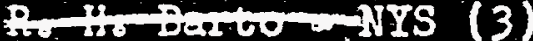

-J.B. Johnson - File

June 2, 1953

New York Ship - Camden, N. J.

af

FIELD INSPECTOR'S REPORT

TO

C. J. VEITH - M \& E TILE

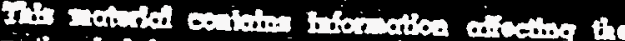
national dofons of the Uniled States whing the meaning of the espionage lent, TIHe 18, US.C. Secas. 793 and 784, the tranminilos or jovolotion

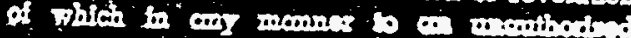

FROM S. R. Cochran DAYY

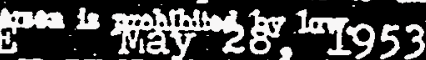

PROJECT NO. 8980 PLANT Savannah River ORDER NO. AXC-167?

EQUIPMENT

Botton Tube Sheet

BQ.PC .NÓ.

$153-\mathrm{L}$

DRAWING NOS.

$W-132760-R .18$ JOB RATING

VENDOR

New York Shipbuilding Corp.

LOCATION Camden, No J.

Finishes of Tube Bores

The attached drawing no. NY 52853 is a record of surface finishes in rms.. micro inches of the top and bottom bores of all tubes.

Surface finishes were taken with a profllometer in an axtal direction with the tube bore. All finishes are 65 Rll or better and acceptable. (Drawing specifies finish of 63 Ris.)

Note: Tubes X21-Y69, X22-Y66, X19-Y57, X24-Y72, X16-Y60, and X-12have scratches in the "o" ring seating area. Finish readings for these tubes as shown on attached drawing are not indicative of

- scratches.

$1 \mathrm{mw}$

attach。 


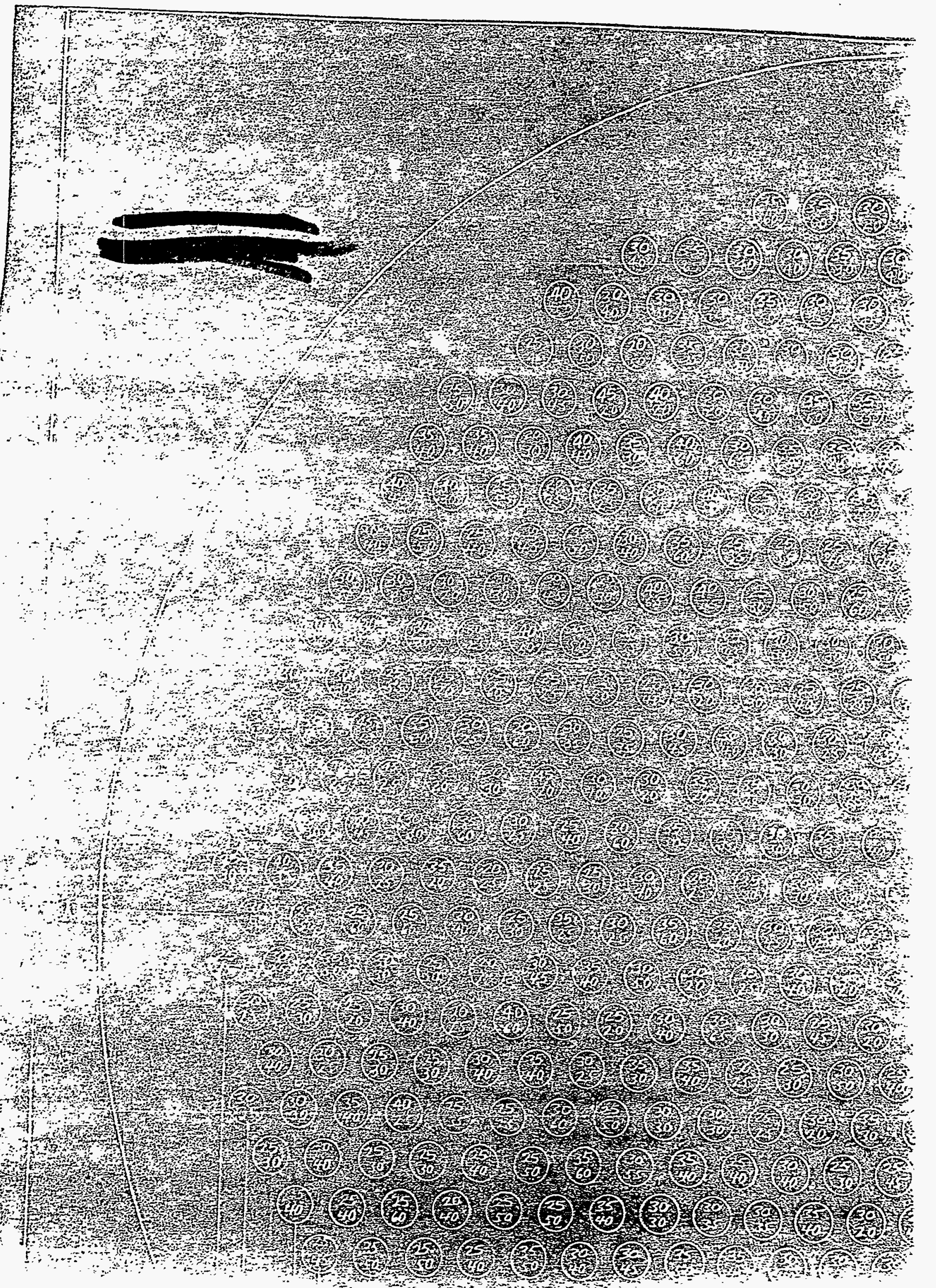




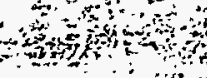




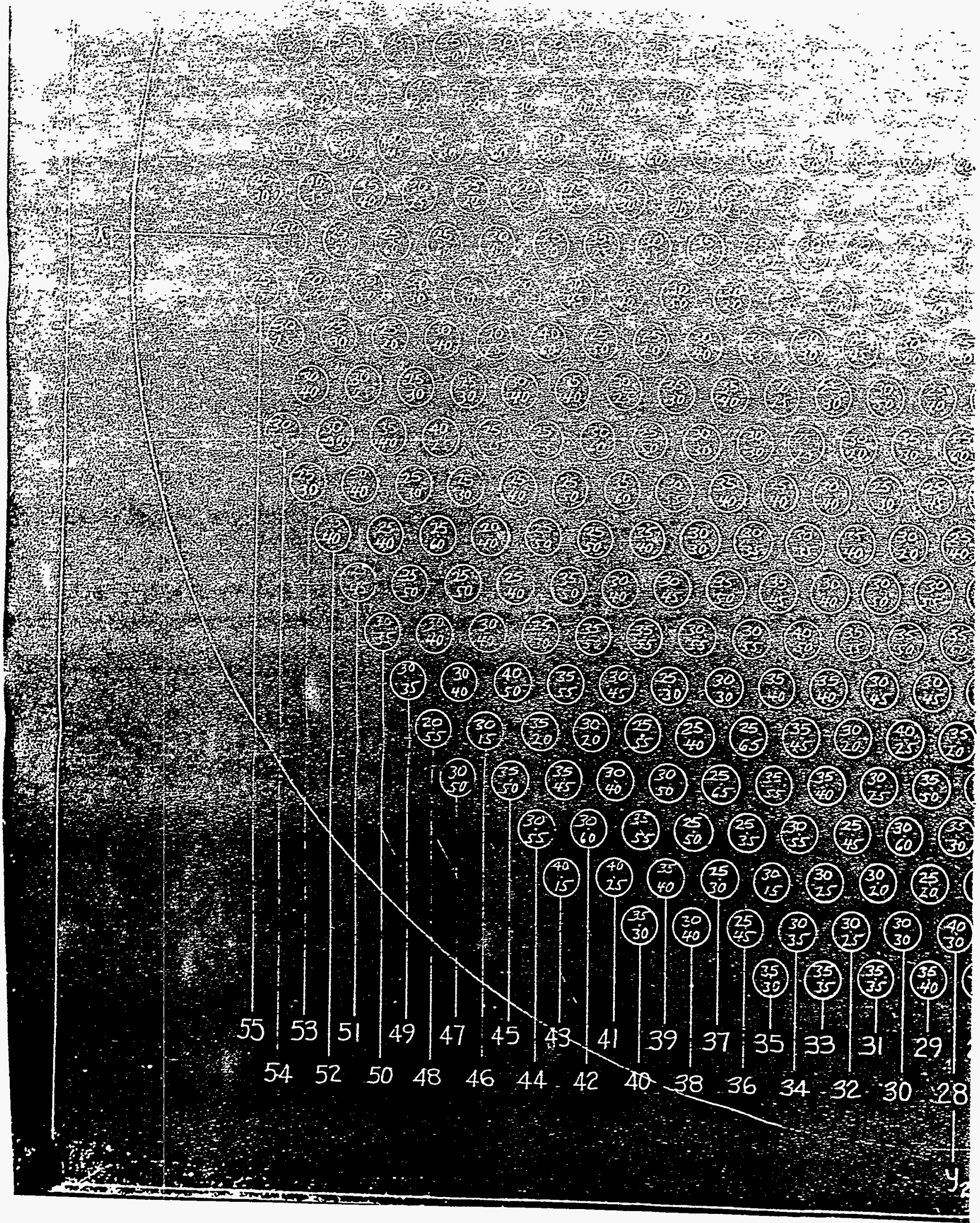


W. I. DU PONY DE NEMOURS \& CO,, INC. Gonstruction Division and

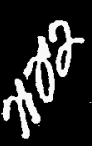

Report Number 493-L

CO: H. Wo Gosney, F.P.M

R. Ko Mason-D.A.Hauser-SRP

R. Ko Nason-W.P.Duncan-SRP

H. I. Bunker-d.G.Brewer (6)

J. G. Brever

H. B. Gage

B. O. Brauninger

S. R. Gochran (2)

R. H. Barto - NIS (3)

J._Bo-Johnson - F11e

June 2, 1953

New Yoris Ship - Camden, No Jo

\section{FIEAT INSPEGTOR'S REPORT}

To

C. J VEITH $-U$ \& E FIIE

FROM R. We Mease

DATE Mar 27. 1953

PROJECT NO. 8980 PLANT

Savannah River ORDER NO. AXC.167?

EQUIPNENT Botton Tube sheet BQ.PC.NO. $153-2$

DRAWING NOS. Wo-132762, Rols JOB RATING

VENDOR New York Shipbuilaling Corpo LOGATION Gamden, N. J.

Subject: I.D. of $3-15 / 16^{n}$ 0.D. Bottom Tube Sheet Tubes

Attached is a record of the final I.D. of all $3-15 / 16^{n}$ O.D. tubes in the botton tube sheet. This list includes the bore measurement at both top and bottom of tube at approximately one inch from end in each case. Bores were measured in two directions parallel to the $\bar{X}-\bar{X}$ axis and parallel to the IoI axis.

Measurements were made with a standard dial indicator bore gage and all readings on attached sheet are in $.001^{n}$ and show deviations from basic bores.

Note: On bottom bores, measurements of tubes Iisted at bottom of attached dwg. were taken at maximum and minimum bore rather than in $X$ and $Y$ directions.

$1 \mathrm{mw}$

attach. 


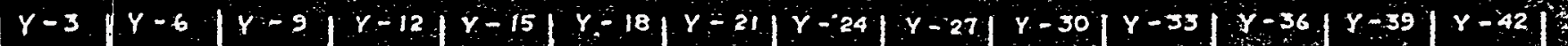

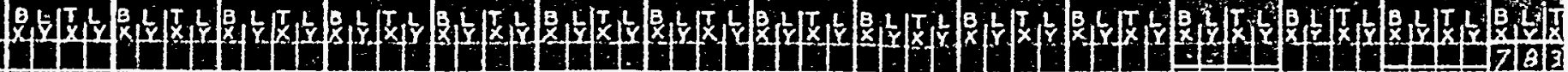


Before outlining the test program, the following information was considered pertinent. Twenty-two tubes of the approximately 450 installed inachine welded tubes were known to be questionable after, both ends of the tubes had been examined by the $z y-g l o$ technique (procedure for $z y-g l o$ testing is discussed later). Full length examination of each tube was in progress at this time. Twelve of the trenty-two tubes inspected by the $z y$-glo process were found to have defects in the ends of tubes extending through the top tube plate of the bottom tube sheet. Ten of the twenty-two tubes were found to have defects on the lower ends of the tubes. The difficulty encounter d was apparently due to the lack of fusion in the welded path of the tubes seam.

After reviewing and analyzing all current problems pertaining to defective welded tubes this far found, the following test program was set-up.

I. Test Program for "F" Bottom Tube Sheet as a Unit

a. $2 y-g l o$ test all welded tubes in unit.

b. Freon test unit at 35 psi. Freon to be applied to shell side of tubes.

c. Hydrostatically test each tube in unit.

d. Repeat freon test at 35 psi in the shell side.

e. Repeat $z y-g l o$ test on all tubes.

II. Test Program for Individual Tube Evaluation (Testing of Centrifugally Cast Tubes To Be Given Preference)

a. Tubes required for test

(1) 46 sigma welded bottom tube sheet tubes

(2) 5 seamless bottom tube sheet tubes

(3) 10 centrifugally cast bottom tube sheet tubes

(4) 10 extruded bottom tube shect tubes

(5) 10 hand welded top tube sheet tubes

b. Tests at New York Ship

(I) X-ray all welded tubes at the veld section

(2) Completely $x$-ray all centrifugally cast and seamless tubes

(3) Zy-glo all tubes I.D. and O.D.

(4) Ship to Engineering Research Laboratory two of each type tube. Only tubes passing $x-r a y$ are to be included on item (I), (3) and $(5)$ in section "a" above. 
(5) Ship to ERL two of each items (1), (3) and (5) in section "a" above.

(6) Ship to ERL two sigma welded tubes for cyclic pressure test. One tube $O K$ by $x-r \triangleq y$ examination, the other two show cracks.

(7) Test balance of tubes as outlined in I above.

The above test program was carried out in its entirety by all groups concerned; however, the discussion of the above testing procedure to foilow will deal only with the part that the du Pont inspectors played in evaluating the " $R$ " bottom tube sheet.

(3) "R" Bottom Tube Sheet Test Program and Special Tests Conducted by du Pont Inspectors.

a. Tube Zy-glo Test

AIl tubes were prepared for $z y-g l o$ testing by New York Ship personnel. For positive identification of welded tubes, the tube ends were etched, and then the welded tubes were prepared for zy-gloing from end to end. At this time it vas also decided to zy-glo all tubes (welded, cast, and seamless) since the probability of cracks and laminations being present in cast and seamless tubes was not known.

The overall purpose of the zy-glo test was to determine the location of cracks, laminations and other mechanical defects that may be present in tube ends and bores. The zy-glo testing of tubes was performed in the following manner:

(1) All tube bores were swabbed clean with $\mathrm{CCl}_{4}$

(2) $Z y-g l o$ penetrate oil (Type $Z L-1$ ) was swabbed on tube ends and tube bores and allowed one hour to penetrate.

(3) Swabbed surfaces were then washed off with water and dried.

(4) The top ends and bores of tubes nere dusted with developing powder (Type $2 F-2$ ) and allowed ore hour to develop.

(5) Excess powder yas removed by air jetting.

(6) The ends and bores of tubes were then visually inspected for cracks and laminations using a lamp rit with a self-contained Ceneral Electric 15 watt black iluorescent lamo developed by a du Pont Inspector. The lamp was used to direct rays to the areas under test. Any defect noted (crack or lamination) appeared as a yellow Elow. iffer locating the defect, a $3 / 4^{\prime \prime}$ borescope was used to 


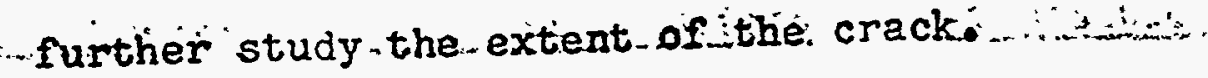

All tubes were inspecte jointly by du Pont and

Sew York Ship personnel A total of thirty (30) tubes vere found to have defects of varying nature. The majority of the defects found appeared to be lack of fusion in the : velded seam of the tube. These tubes. were marked and results sent to WIInington for their final disposition

The test of tubes submitted, and their noted defects along with Wilmington!s. final decision was as follows:

Tube Number

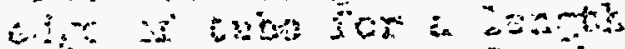
X5-Y69 Lack of fusion starting at inside edge of tube for a length of $10^{H}$. Bottom side of tube.

16-Y72 Lack of fusion starting at inside edge of tube for a length of $B^{\prime \prime}$. Iop side of tube.

XI1-Y81 Lack of fusion starting Remove $\therefore$ 'ti- ? $^{n}$ from inside odge of tube for a length of $100:-5:$

Top side of tube, $=5 \%$

X9-Y63 Lack of fusion starting $4^{\mathrm{n}}$ "Retain i. $y$ from inside edge of tube $t j$. for a length of 3 n $^{n}$ Bottom $\cdots=$ side of tube $\because[\because$ r.j.

X13-Y69 Lack of fusion starting at Retain $\therefore$ inside edges of tube for a

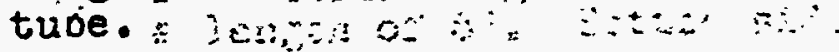

X18-Y84 Lack of fusion starting at Retain

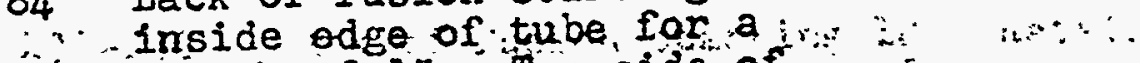
length of in : Top side of , $: 2$.

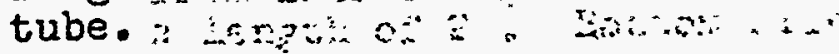

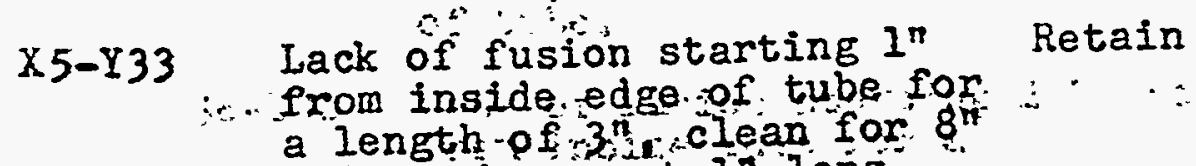
and another spot In long. : s: Top side of tube.

XI0-Y30, Crack outside area of tube, Remove $\because \because$ Botton side of tube t.

X14-Y24 Lack of fusion starting : Remove $3 / 4^{n}$ from inside edge of $\therefore \because$ tube for la length of 18 .

Top side of tube. 


\section{Page 41}

Tube liumber

Analysis of Defect

Disposition

$X 27-Y 69$

Crack startirg $3^{\prime \prime}$ from

Remove inside edge of tubes for a length of $1 \frac{1}{2} \%$. Bottom side of tube.

X33-187 Lack of fusion starting at inside edge of tube for

Remove a length of $5^{\prime \prime}$. Bottom side of tube.

X16-Y12 Crack starting from inside Remove edge of tube for a length of $2 \frac{1}{2} "$. Top side of tube.

x27-Y39 Crack inside top edge and outside surface for a length of $3 / 4^{\prime \prime}$. Bottom side of tube.

$\mathrm{X} 27-\mathrm{Y} 33$

Lack of fusion starting at inside edge of tube for a length of $2 \frac{1}{2}$. Spotty. Top side of tube.

X31-145 False showing.

Retain

X40-Y72 Crack starting at inside

Remove of $1^{\prime \prime}$, also top surface of tube. Top side of tube.

X43-Y75 Lack of fusion starting $3^{\prime \prime}$ Retain from inside edge of tube for a length of $6^{\prime \prime}$. Spotty. Top side of tube.

X44-Y54 Irack of fusion starting $I_{2}^{1}$ " Remove from inside edge of tube for a length of $8^{\prime \prime}$. Bottom side of tube.

X38-136 Lack of fusion starting $18^{\prime \prime}$ Retain from inside edge of tube for a length of $2^{n}$. Bottom side of tube.

X38-Y 30 Lack of fusion starting $2 \frac{1}{2}$ " Remove from inside edge for a length of $8^{1:}$. Bottom side of tube.

X35-Y2I Lack of fusion starting at Remove inside edge of tube for a length of $2 \frac{1}{2}$ ". Bottom side of tube.

X39-Y21 Lack of fusion starting $4^{\prime \prime}$ Retain 
Tube Number

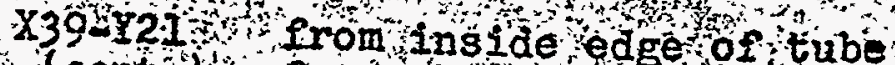

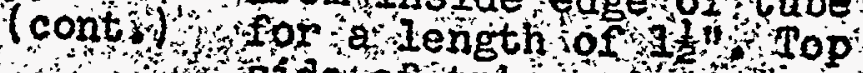
sidelof tube.

$\mathrm{x} 47-739$, tack of fusion stanting 3

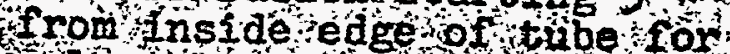

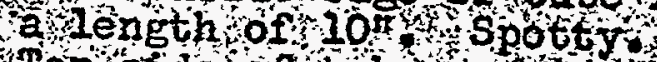

Retäin Top side of tube

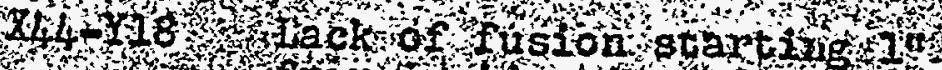

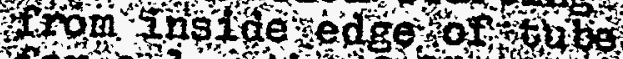
torianienth of

Rènove Qidde.

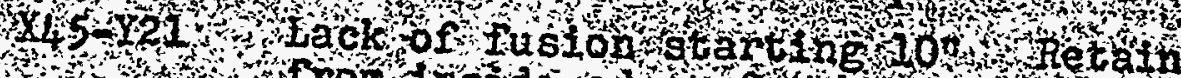
Irom Inside ede of tube for

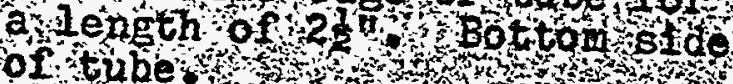
in 1 or tube

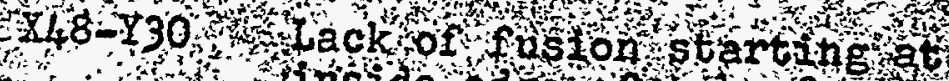
inside eage of tube for

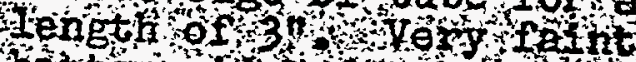
bottom sioe of tube.

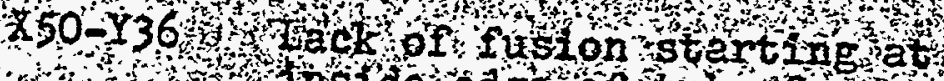

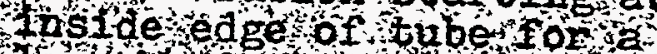

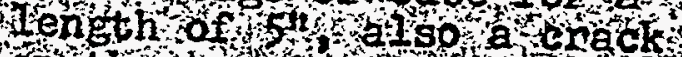
onthe to phs ha poge of thing

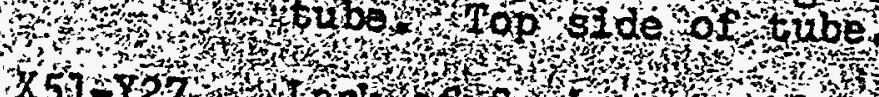

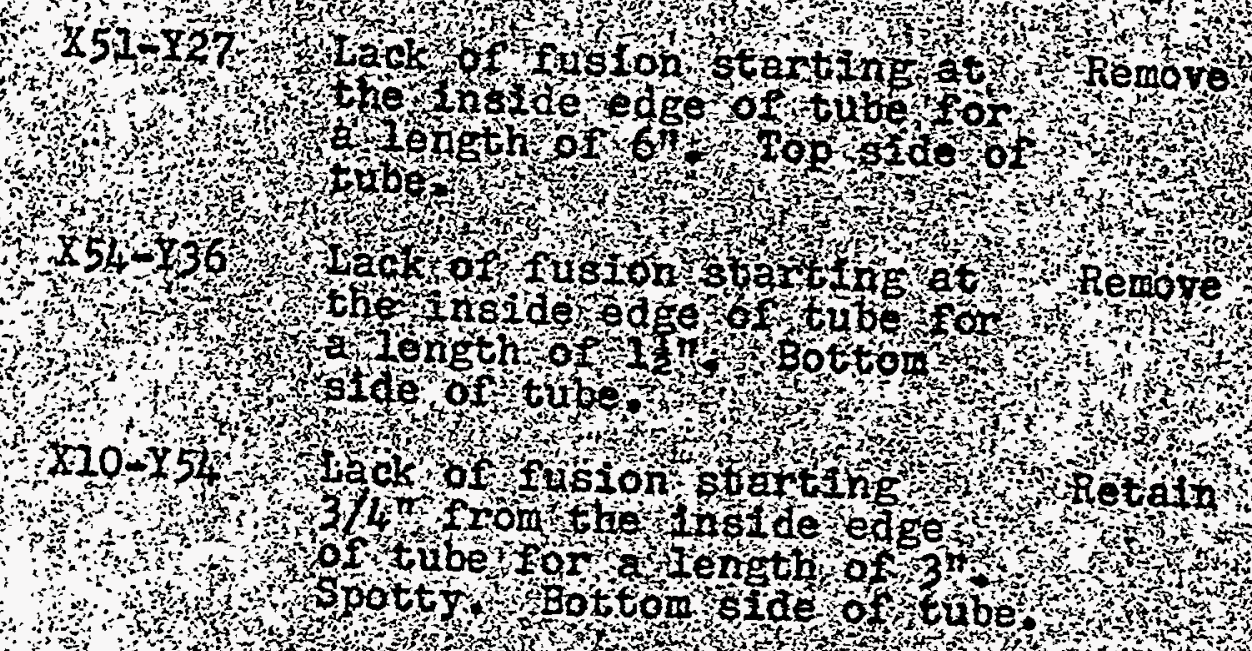

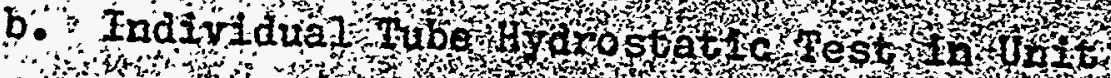

Regove

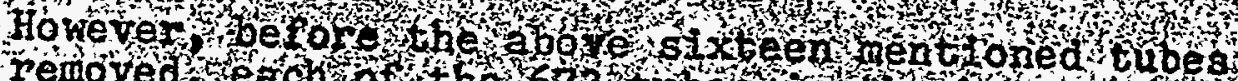

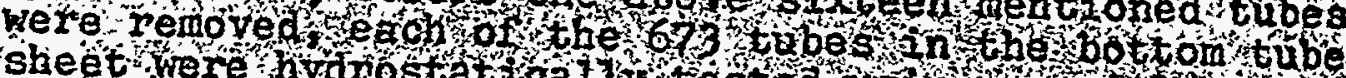

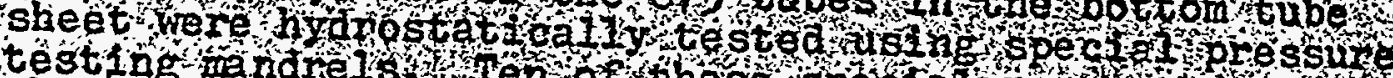

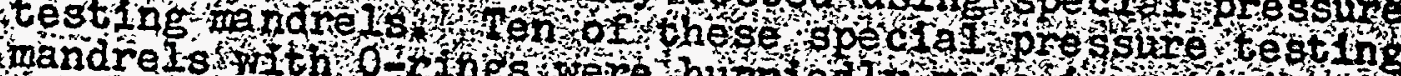

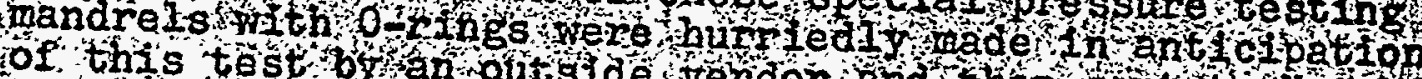
Tork Shio to

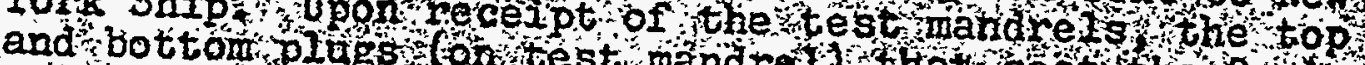

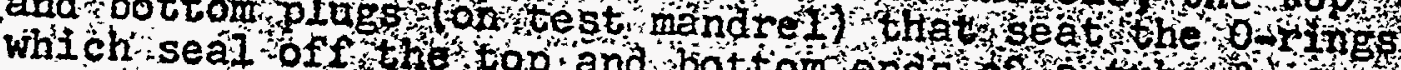
testing were fon top and botton enas of a thbe on

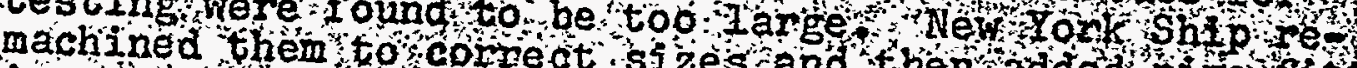

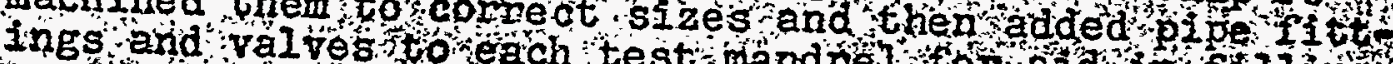


and draining water during the hydrostatic test. The ten randrels were installed in tuoes to a workable pattern. Each test mandre was connected up to a low pressure water line and filled with city water. Air trapped in the mandrel was vented through the top end by means of a $3 / 4^{\prime \prime}$ valve. After the tube was full of water, this valve was closed and each of the tubes were individually connected up to a hand pressure pump. Pressure was built up to 1000 psi and held at this pressure for a period of fifteen (15) minutes. Du Pont Inspectors checked time and pressure for each tube and recorded all data. Any drop in pressure (as noted on pressure gage) indicated a leaking tube; however, none were found in this test. The sixteen tubes that were to be removed were by-passed in this test. Some trouble was experienced with the o-ring seals leaking; however, this was eliminated by periodically changing 0 -rings at regular intervals.

\section{c. Femoval of Sixteen Defective Tubes}

After the hydrostatic testing of tubes in the bottom tube sheet, preparations were made for removing the sixteen defective tubes listed in (3)-a above. AII replacement tubes were either cast or seamless. Also, at this time, the Design Division requested that no welded tubes be used in any subsequent sub-assembly ( $P, I$ and $C$ ).

The assembly was set top side up under three radial drills and condemned tubes bored through (from top side) and tube holes in the top plate recountersunk. The unit was turned bottom side up and the tube fillet weld was machined from the condemned tubes using a special tool designed for this purpose.

The assembly was removed from the radial drill setup and turned top side up for installing sixteen new tubes, which had been previously inspected by du Pont and approved. First, the old tubes were removed from the unit, tube holes cleaned and dressed and new tubes installed. Then, the unit was moved and set up under the automatic aircomatic tube welding machines and new tubes welded on both sides.

After welding of tubes the unft was set up under the three radial drills for facing tube ends to the required plane and reaming the top and bottom tube ends to remove the "hour glass effect" in the bore caused from weld shrinkage. During the reaming operation, one of the sixteen replaced tubes was damaged beyond repair. This tube was removed and replaced in a similar manner described above. The sixteen new tubes were then chamfered on the bottom ends, dressed, monitor pin grooves drilled am dressed and then inspected by du Pont Inspectors and found satisfactory.

Before procedding with further work on the bottom tube sheet, it was necessary to take a final shrinkage pattern since the welding of the sixteen new tubes 
caused additional shrinkage. These measurements were taken in a similar manner discussed in Section $7 A-(10)$ of this manual.

The final shrinkage measurements taken after welding all 673 tubes in the bottom tube sheet were used as initial measurements for determining final shrinkage after replacement and welding of the sixteen defective tubes.

Before Helding

Top side Bottom Side 182.003"

Difference $\quad-0.018^{n}$
After bielding Top Side 181.970" Bottom Side 181.969"

Difference $\quad 0.001^{\prime \prime}$

Total Shrinkage of Top and Bottom Plates After All Welding on Tube Sheets

Initial trepanned plate dia.... $\frac{\text { Top Plate }}{182.350^{\prime \prime}} \quad \frac{\text { Bottom Plate }}{182.358^{\prime \prime}}$
Final center to center of
tube bores after welding 16
replacement tubes............ $\frac{181.970^{n}}{0.380^{\prime \prime}}$

The difference between the top and plates after replacing and welding sixteen defective tubes was still within the specified limits designated by Design Division (See Section $7 \mathrm{~A}-(10)$, and therefore the shrinkage pattern was considered satisfactory by the du Pont Inspection Department.

d. Sandblasting and Acid Viashing (Exterior \& Top Side Only)

Before proceeding with the bottom tube sheet test program, it was decided to sandblast and acid wash the top side of the unit. All tubes on both ends were capped with wooden plugs to prevent damaging of the tube bore "and finished machined tube ends during the sandblasting operation. The unit was filled with approximately 30 psi of air, placed on a railroad flat cer, and pulled outside the building and sandblasted.

After sandblasting the top side was acid washed using a solution of nitric acid, hydrofluric acid and water nixed in proper proportions for this jok.

The above two cleaning operations were witnessed by a du Pont Inspector. After all cleaning was completed, a visual inspection was made by a du Pont Inspector and passed as being șatisfactory.

e. Preliminary Freon Test

As called for in the bottom tube sheet test program, the assembly was to be subjected to a preliminary freon 
test. The purpose of this test was to determine if any leaks occurred in tube welds around the sixteen replaced tubes and also in the replaced tubes themself. The unit was prepared for freon testing by closing off all openings and then introducing 20 \# of freon (by weight) into the unit and raising the internal pressure to 35 psi using air. However, during the freon test inspection, a instrument well located adjacent to tube number $\times 37-147$ was found to be leaking. The leakage of freon from the defective instrument well was of such a quanity that it contaminated the entire atmosphere surrounding the unit rendering it impossible to use the General Electric halid leak detectors with any accuracy. The freon test was temporarily discontinued and the faulty instrument we 11 machined out and replaced with a new one that had been hydrostatically and freon tested under the same conditions as the unit and accepted.

A second freon test was then performed on the unit for purposes as discussed in the above paragraph. However, during the second test another instrument well was found leaking. This instrument well was located $X 18$ and $X 20$ on the $Y-Y 2$ axis. The freon test was interrupted again to replace this instrument well with another that had been hydrostatically and freon tested under the same conditions as the unit and accepted.

After all leaking instrument welds had been replaced with new ones, a third freon test was started. Again, the unit was filled with $20 \%$ of freon (by weight) and brought up with air to a pressure of 35 psi. Using three General Electric Halid Leak Detectors, all tube fillet welding around the sixteen replaced tubes and the six tubes surrounding each and the instrument well welding was checked for leaks. No leaks were detected. around the sixteen replaced tubes and tro replaced instrument wells. Also, no leakage was detected around the tubes adjacent to each of the replaced tubes. The freon test was consiuered satisfactory and the repair work previously done was approved.

f. Second $2 y-g l o$ Test on Sixteen Tube Feplacements and Adjacent Tubes

As a final check on the quality of tubes used, and based on the " $R$ " bottom tube sheet test program, all sixteen (16) replaced tubes and those adjacent were zyglo tested in a similar manner described in Section $14-(3)$ a of this manual. No defects were found in the tubes that

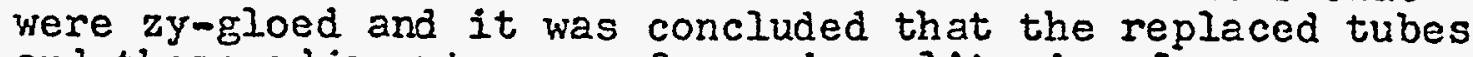
and those adjacent were of sound quality insofar as visual inspection was concerned.

g. Hydrostatic Test of the Sixteen Replacement Tubes and Adjacent Tubes

To further insure the quality of the replaced sixteen tubes, a final hydrostatic test of each individual. tube and those adjacent to the replaced ones was conducted. These tubes were hydrostatically tested in a similar 


\section{Page 46}

manner described in Section $14-(3) \mathrm{b}$ of this manual and found satisfactory.

B. "pn Unit

(1) Individual Tube Hydrostatic Test in Unit

Since the probability of cracks and laminations being present in cast and seamless tubes (the two types assembled in "P" B.T.S.) was not known, and as a direct result of welded tubes in the "R" B.T.S. leaking, it was decided to hydrostatic test each tube in the "P" B.T.S. in an identical manner to that performed on "R". Following the testing procedure outlined in Section $14 \mathrm{~A}-(3) \mathrm{b}$ of this manual, all of the 673 large tubes in the "P" B.T.S. were hydrostatically tested. Final results of this test indicated that no leaks were present in the tube walls. The unit accepted and released for further fabrication.

(2) Summary of Freon Testing on Bottom Tube Sheet Assembly

The following resume sunmarizes all froon test and major reairs made on the "p" bottom tube sheet assembly. For alI tests performed, twenty (20) pounds (by weight) of freon was introduced into the interior of assembly and pressure was raised to 35 psi with air. General Electric Type "H" Leak Detectors, set at medium sensitivity, were then used to examine assembly for indication of leaks.

The first freon test performed on the unit revealed leaks between top plate and large tubes $\$ 26-148$ and X16-Y18 and between bottom plate and instrument well $\mathrm{X} 25-\mathrm{Y} 35$.

The above leaks were repaired and another freon test revealed leaks in weld between bottom plate and instrument welis X34-Y32; X37-Y47; X S2-Y44 and X44-Y74, and a leak in instrument weII X5-Y47. After necessary repairs were made, the unit was again subjected to a freon test and no leaks were detected. (See du Pont drawing D110168-A).

Borescope inspection of instrument wells then indicated poor penetration of butt welds on the I.D., and it was necessary to replace the following wells: (See photo serial numbers 218 \& 119 )

Tube Number

$\%$ ireld Penetration Ioop Butt iield Bottom Butt

$30 \%$
$90 \%$
$10 \%$
$0 \%$
$20 \%$
$20 \%$
$90 \%$
$20 \%$

$40 \%$
$10 \%$
$30 \%$
$20 \%$
$40 \%$
$50 \%$
$10 \%$

Quality of Rield

Poor

Very Poor

Poor

Very Poor

Fair

Fair

Very Poor 


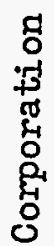

总

造嵒

口.

嵒

次

है क्ष

엉ㅌㅀ

芯哥号

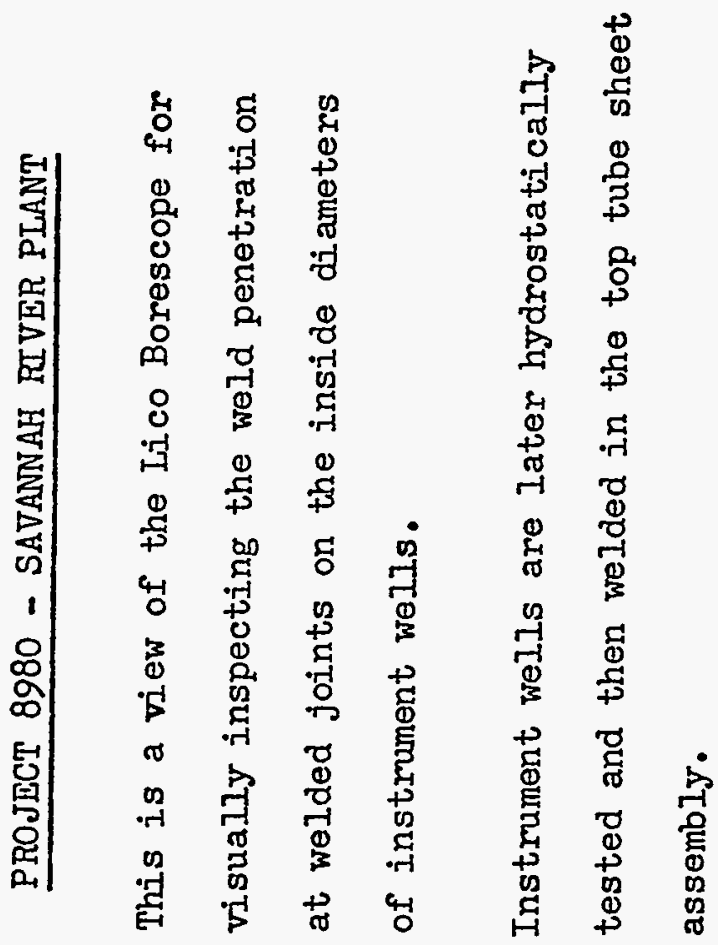

$\stackrel{\infty}{7}$

兽

तु 


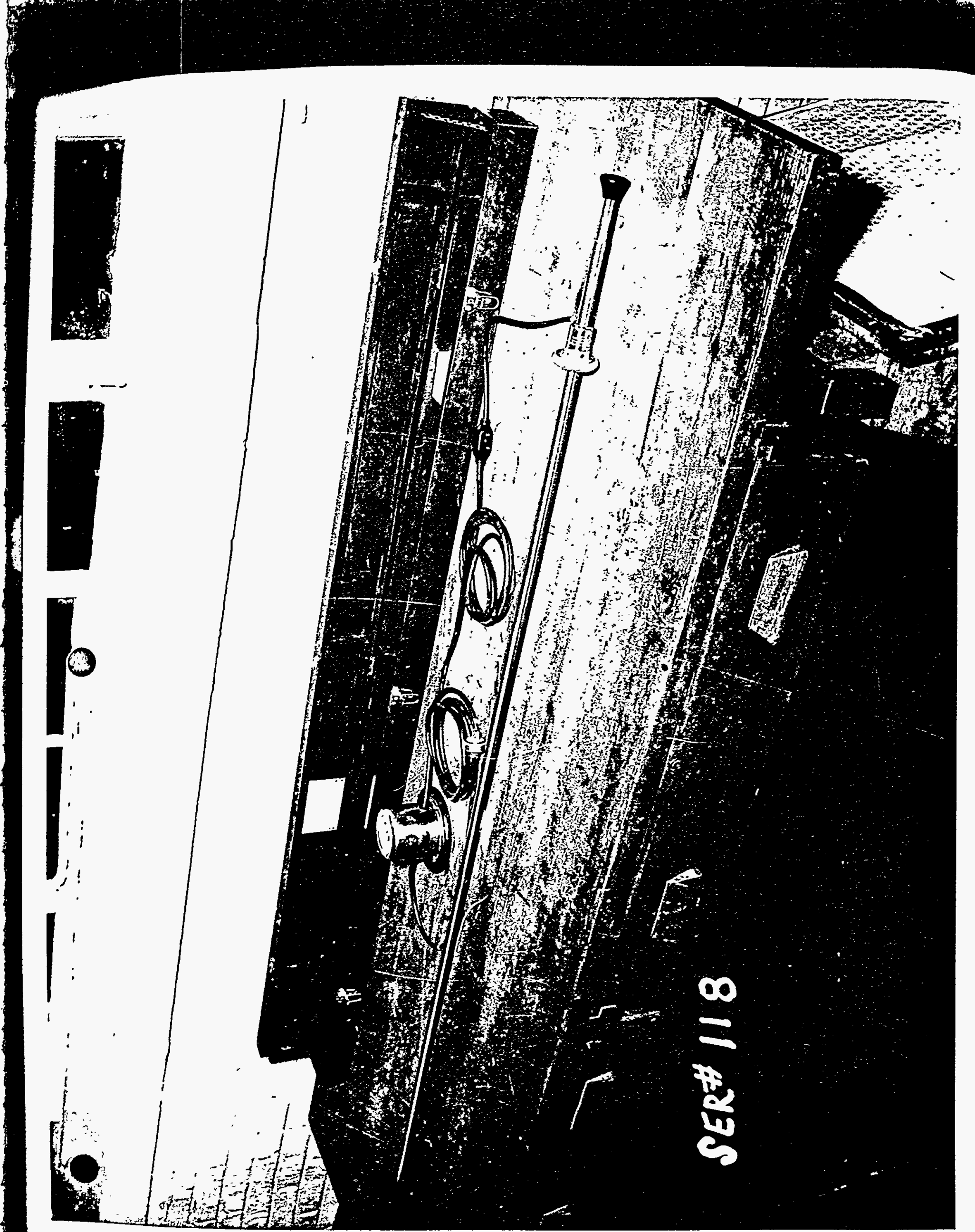




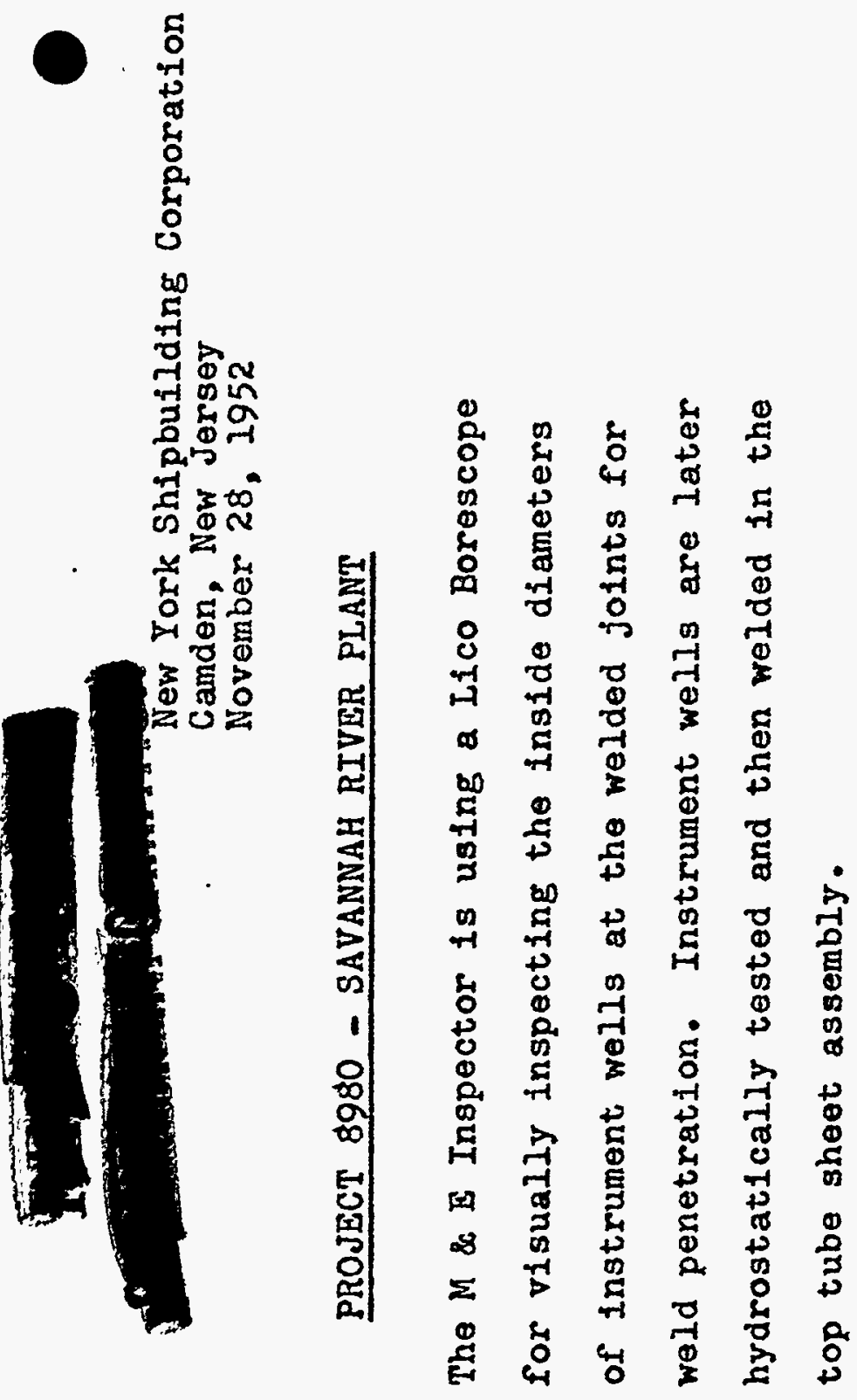

न्-

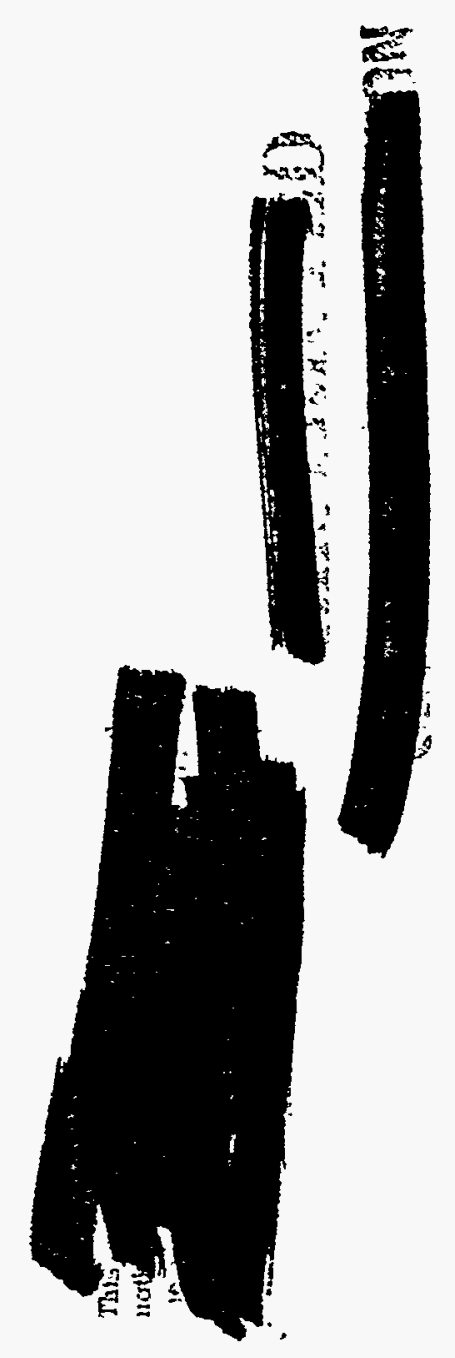




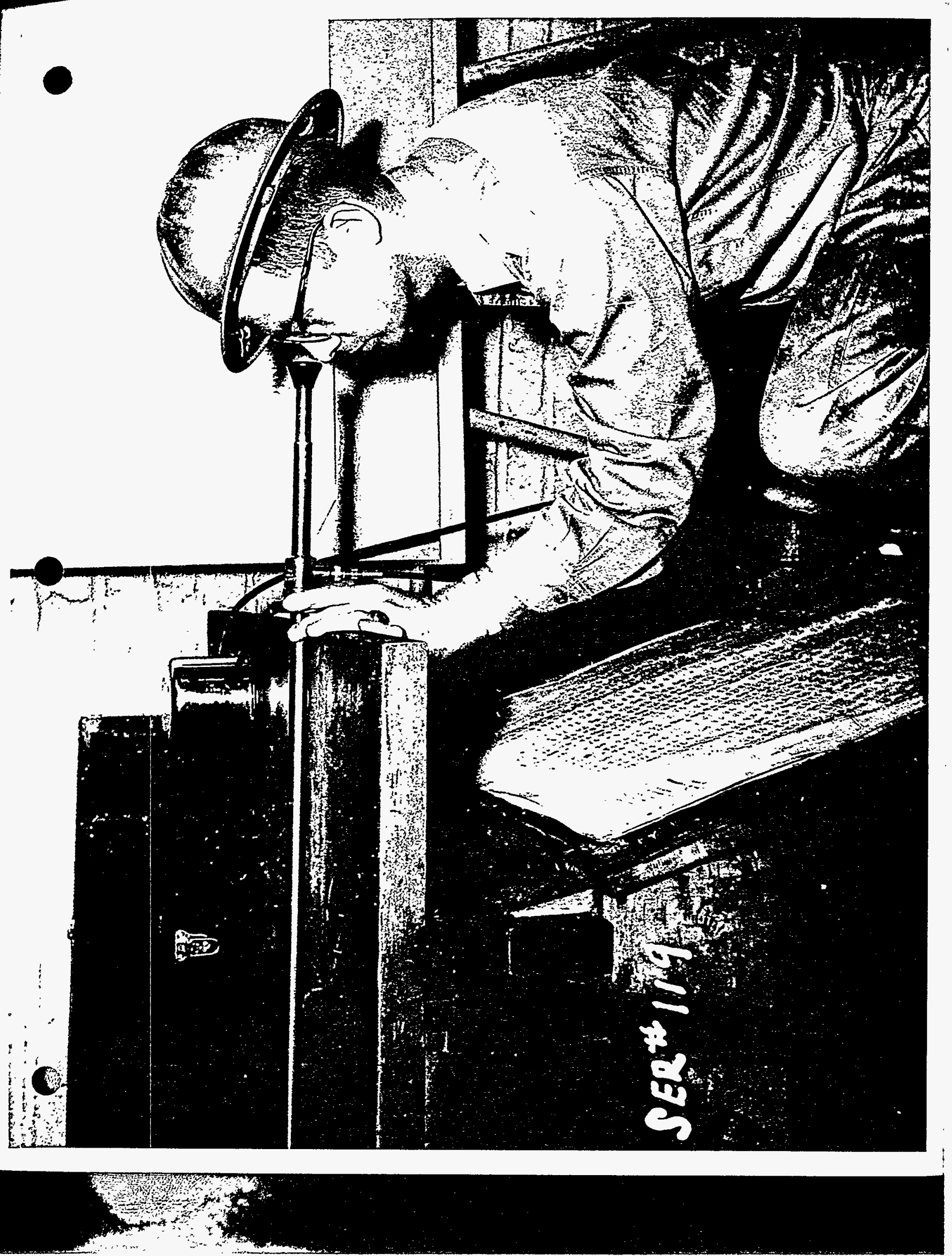


The replacement wells were individually freon tested and hydrostatically tested in the following manner;

(a) Each thermocouple well was connected to a cylinder of freon 12 and the gas was allowed to enter the well at approximately 100 psi pressure. A General Electric, "ype "h" Leak Detector was used for detecting any leaks in the thermocouple wells. Gas was retained in the well for a ten-minute period. No leaks were detected.

(b) Each the rmocouple well was connected to a hydrostatic testing fixture and water was pumped into the well until 2000 psi gage pressure was attained. After holding pressure for 15 minutes, a visual inspection was made for le aks. None were found.

Detaid IBH on DHE $5=4$ (Section $7 A$ of this manual) Detail 1 B: On DWE
represents seven (7) of the replacement wells installed
in "p" bottom tube sheet. It was necessary to alter the design of the original (Detail "A" on DWg. 5-4) instrument wells in order that the new ones fit the holes in the bottom tube plate which were enlarged while cutting out the defective wells. Also, it was necessary to machine a flanged ne ck near the top end on the replace-

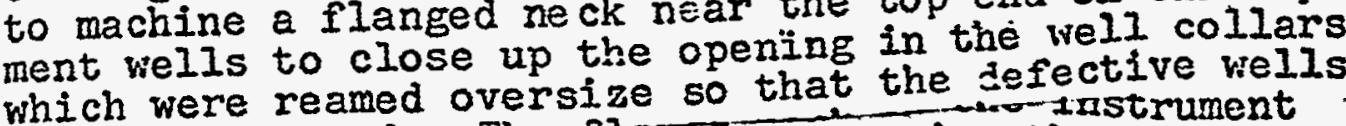

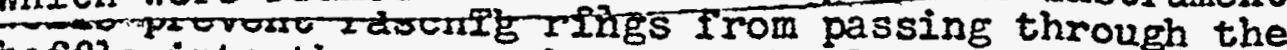
baffle into the space between the latter and top tube plate. Du Pont drawing D-110168 covers the above instrument well design change.

Before installing the seven instrument wells in the assembly, it was decided to sandblast the top side and wrapper plates. The unit was placed on a railroad flat car, (top side up) and pulled outside the building for sandblasting. After this; the top and sides of the assembly were acid washed, ferroxyl tested, inspected for cleanliness and accepted as being satisfactory.

Next, the seven defective instrument wells were cut out of the unit and replaced with the seven new ones described above. (See du Pont drawing D110168-A). After welding of these instrument wells into the assembly, it was again freon tested in an identical manner described in this section. All wells and welds joining them to tube sheet plates were carefully inspected. Ieaks were found in veld joining top plate and well $\times 37-Y 47$ and in weld joining bottom plate and well X31-161. These welds were then repaired and freon tested satisfactory.

All of the above tests were made prior to filling unit with raschig rings and installation of $\delta^{\prime \prime}$ split circumferential pipe.

After loading of raschig rings and installation of $8^{n}$ split pipe, another freon test revealed the following leaks: 
(a) In weld joining a "B" port between $X 2$ and $Y 1$ to wrapper plate (Third port from II toward X2 starting at port located on YI).

(b) In weld (two leaks) joining underside of gn" spilt pipe to wrapper.

(c) In weld joining temporary sealing cover to water outlet at $Y 2$

Necessary repairs were made and the 81 "pipe and ail ports re-freon tested, inspected and accepted.

Extensive minor weld repairs were then made on wrapper and the entire assembly (except tube welds which had already been satisfactorily checked) was again freon tested and no leaks were detected.

(3) Sumary of Hydrostatic Tests on the Botton Tube Sheet Assembly

For all tests performed the testing procedure used was the same. To prepare the bottom tube sheet assembly for the hydrostatic test, it was placed an cast iron pedestals six feet high with the top side up. A spectal threaded pipe with two hydro-type pressure gages attached was screwed into one of the ports. Next, a Watson-Stiliman hand pump was connected to the outlet side of the de-1on-t. ized water tank and the inlet side of the bottom tube sheet. The unit was filled with water from the de-jonized water tank. The hand pump was used to bring about asfew pounds of pressure inside the unit as indicated on the pressure gages. The pumping was stopped and the trapped air inside the bottom tube sheet assembly was vented thioung removing the pipe plugs located near the top of the assem bIy. It was realized that any trapped alr not bled from the unit would prevent an adequate hydro test. $\because$ After Essembly had been vented, the pipe plugs were re-used to wsoal off the unit. The iatson-Stiliman pump was used to ralse

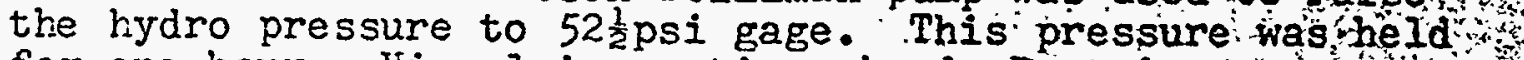
for one hour. Visual inspections by du Pont inspectors. were ther made with the aid of a flashlight on both sldes of the unit. The "P" B.T.S. assembly was hydro tested with the top side up at all times.

The following resume summarizes all hydrostatictests and repairs actually made on the "Pn bottom tube sheet assembly while at New York Ship. During the first hydro test performed on this unit, a leak was found in the top weld of instrument well X31-Y61. After th1 s wela was repaired, assembly was again tested, re-inspected now found satisfactory. After the above tests borescopenspetion of 211 bottom tube sheet instrument weils indicated poor veld penetration on $I . D$. butt welds of the fólowing yseven tubes: X25-Y33; X13-Y11; XI9-Y46;X34-Y32; X37-Y47; X441.74; X52-Y44. These were replaced (See section (2) above)

After replacement wells had beenwelded into the tube sheet, another hydrostatic test was put on the unit and all wells and welds joining them to tube sheet plates were 
visually checked. No leaks were found.

Eollowing extensive minor weld repairs on wrapper plate and after installation of $8^{\prime \prime}$ split circumferential pipe, the entire assembly was satisfactorily tested. The entire bottom tube sheet assembly including the split pipe was inspected during this final test.

Hydrostatic testing of the assembly was acceptable.

C. "L" Unit

(1) Summary of Freon Testing on Bottom Tube Sheet Assembly

The following resume summarizes all freon tests and major repalrs made on the "L" bottom tube sheet. The 1 . The ive of inférior welding and defective parent metal five times. All freon tests were performed on this unit after internal drying. The drying procedure preceding freon testing of the "L" bottom tube sheet is discussed in Part VII, Section I, item $16 C-(2)$.

For each test twenty pounds (by weight) of freonias introduced into the interior of the tube sheet and pres-i sure was increased to 35 psi with air. General Electrid "Type "H" leak detectors set at medium sensitivity were then used to check the entire assembly Special atteriton was given to each of the exterior or pressure welds:

Three tests were put on the assembly prior to fining raschig rings and prior to welding $8^{n}$ half-round pipe tot the wrapper plate circumference. Four leaks were located during the first test. There was one leak in each weld joining tubes $X_{4} 8-172, Y 35-Y 18$, and $X_{4}-Y 54$ to the bottom plate. One leak was in the weld joining tube X15-Y51 to the top plate. ifter necessary repairs were made, the assembly was arain tested.

During the secont test, leaks were detected In tho weld between the bottor plate of the assembly and tubes X15-Y39 and X7- 69 . These two welds were repaired andi the assembly was subjected to another test. No leaks were detected in this third test.

After the tube sheet had been loaded with filier and the split circumferential pipe had been welded to the wrop per, the assembly was again freon tested The forth test revealed one small leak on the weld joining bottom side fol the inlet pipe between $Y 1$ and $Y 2$ to the wrapper and one leak in an inspection port weld between X2 and Y Y2.

The above welds were repaired and the entire assembiy was again tested and insoected for the fifth time No leaks were detected in this final test and the unit was: accepted.

(2) Summary of hydrostatic Tests on the Bottom Tube Sheet 


\section{a. Preliminary Test}

To prepare the bottom tube sheet assembly for the hydrostatic test, it was placed on cast iron pedestals six feet high with the bottom side up. A speclal threaded pipe with two hydro-type pressure gages attached was screwed into one of the ports. liext, a Watson-Stiliman hand pump was connected to the outlet side of the de-ionized water tank and the inlet side of the bottom tube sheet. The unit was filled with de-ionized water from the de-ionized water tank. The hand pump was used to bring about a few pounds of pressure inside the unit as indicated on the pressure gages. The pumping was stopped and the trapped air inside the unit was vented through removing the pipe plugs located near the top of the assembly. It was realized that any trapped air not bled from the unit would prevent an adequate hydro test. After the assembly had been vented, the pipe plugs were re-used to seal off the unit. The biatson-stiliman pump was used to raise the hydro pressure to 45 psi for hammer testing. A drop hammer was then used at approximately five inch intervals on the bottom side to hammer test the unit. The impact force of the drop hammer on the unit was equal to a swinging blow of $a$ ten (10) pound hammer. After the hammer test was completed at 45 psi, the unit was relieved of its pressure and some water was drained out of the unit. (hater level about $2^{\text {n }}$ below tube platel. A complete hammer test was again performed on this side in a similar manner to that described above. After the second hammer test was coupleted, the unit was filled completely with water and the internal pressure raised to $52 \frac{1}{2}$ psi. The unit was allowed to stand two hours and then it was visually inspected for possible leaks around tube welded wrapper plete welding and tube sheet welding. Ko leaks were found. The unit was then drained of the water and turned top side up.

The above hammer testing procedure was repeated on the top side. During this test wrapper plate velding was hammered using a six (6) pound hammer with a sharp striking blow adjacent to the welding. No leaks were found on the top side of the uritt.

\section{(b) Final Test}

a. After the unit was properly vented and filled with de-ionized water, the pressure was built up to 44 psi.

b. The unit was then allowed to sit for one (1) hour; pressure being maintained at 44 psi.

c. The hammer test was then parformed on the wrapper plates at distances 6" apart between the half rounds and below the botton half-rourid. All welds on the : wrapper plates were then inspected.

i.

d. Pressure on the unit was then built up to $52 \frac{1}{2}$ psi and the entire unit was again visually inspacted for leaks 
with the aid of flashlights. No leaks were found and the unit vas accepted.

NOT: : During freon and hydrostatic tests on both top and bottom tube sheet assemblies, three additional steps were employed in the checking of instrument wells for possible leakage. These were:

(a) Clean wells with $25 \%$ solution of nitric acid. Sniff each instrument well with G.E. leak detector after cleaning.

(b) During all freon tests on unit, remove plugs from welis and sniff with leak detector. Replace plugs after testing.

(c) During all hydrostatic tests, remove plugs from wells and lover a clean, dry rag attached to a S/S wire into wells to determine presence of water in well by. blotting action of rag.

15. Pattern Heasurements

A. "En" Unit

After all machining and repair work had been completed on large tubes, final pattern measurements were taken to show the position of each tube center from the $X$ and $Y$ centerlines. Patterns were taker on both the top and bottom sides of the unit using ligament gages. Part II-A, section 13-a, describes how the $X$ and $Y$ centerlines on the top and bottom were established. Pattern coordinates were later computed and referenced from these axes. For results of pattern measurements taken on the top and bottom sides of the " $\vec{r}$ " bottom tube sheet, see Exhibit $; 13$.

B. "p" Urit

This inspection was performed in a similar manner to that described above in Section 15A. For results of pattern measure ments taken on the top and bottom sides of the "p" bottom tube sheet, see Exhibit

C. "IL" Unit

This inspection was performed in a similar manner to that described above in section $15 \dot{\mu}$. For results of pattern measure ments taken on the top and bottom sides of the "L" bottom tube. sheet, see Exhibit

16. Final Internal Cleaning by Dowell Inc, and Establisheng $X$ and $Y$ Centerlines.

A. "R" Unit

(I) Dowell Cleaning

Prior to loading raschig rings in the bottom tube sheet, Dowell Inc. of Filmington, De Isware, chemically $\therefore \rightarrow$

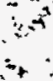




\section{EXHIBIT 13}

RESULTS OF PATTERA COORDINATES TEKEN ON TOP

AND BOTTOH SIDES OF THE "R" BOTTOR TUBE SHEET ASSENBLY. 
1)

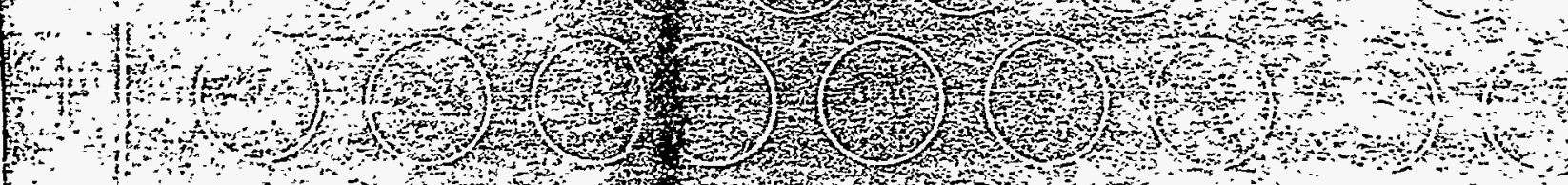

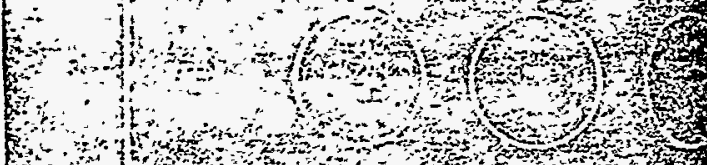
1.:

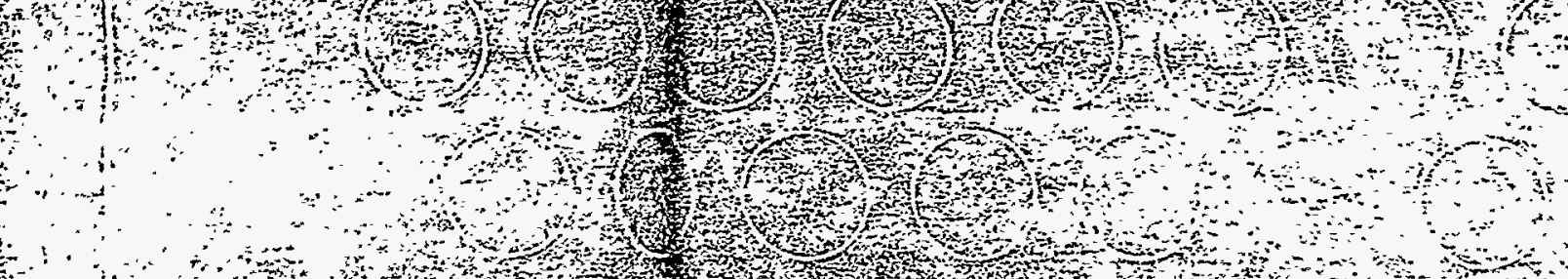
40
W
4. 013

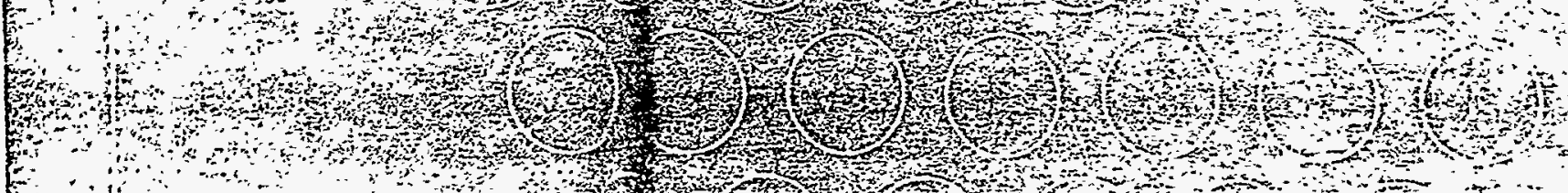

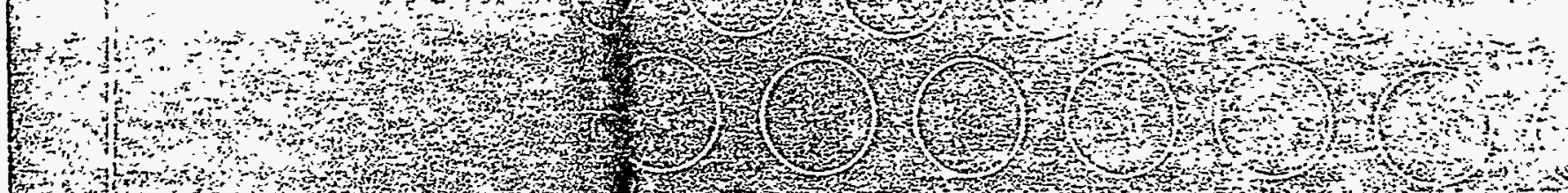

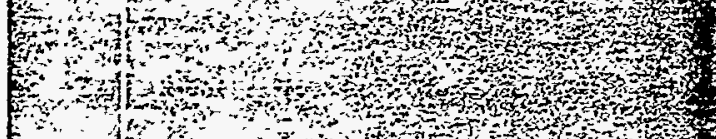

焉

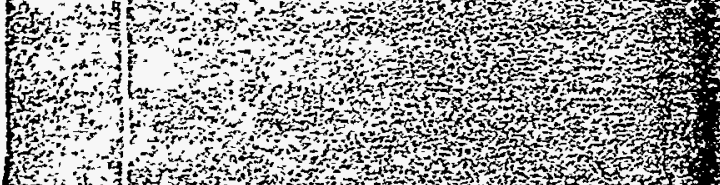

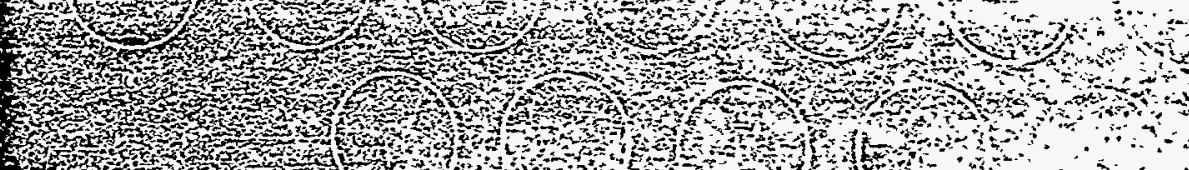

4
5

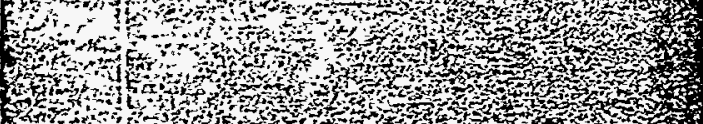

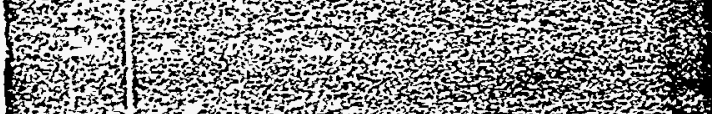

.

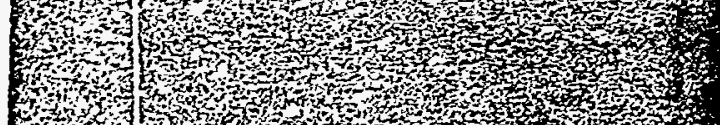

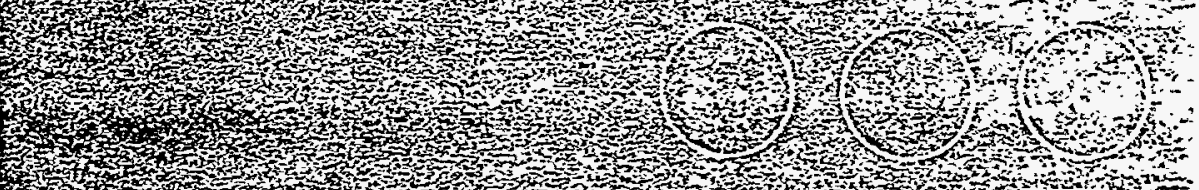

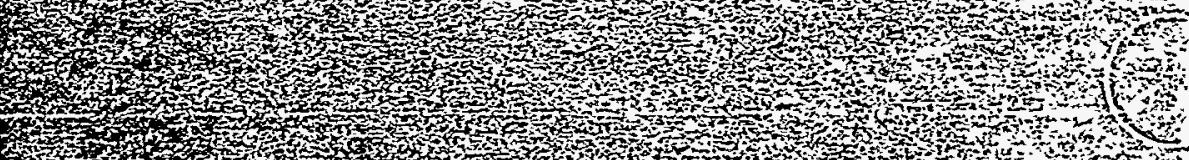

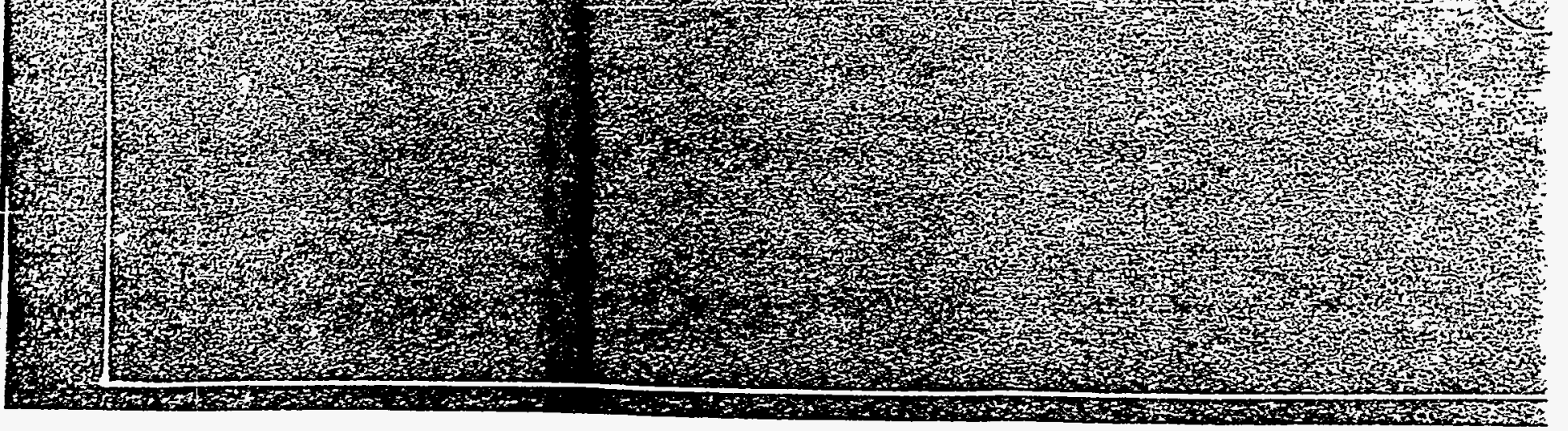


W 2.

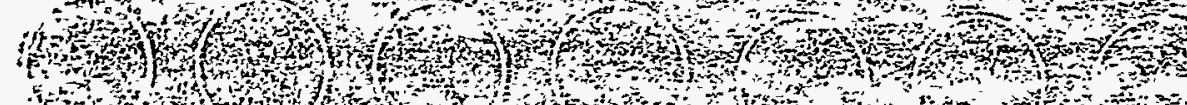
Fof

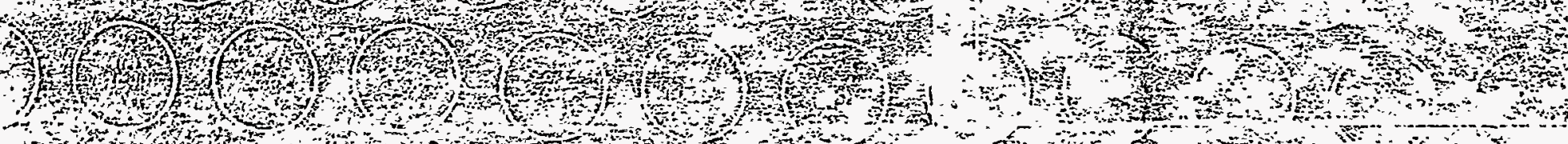
年,

(2)

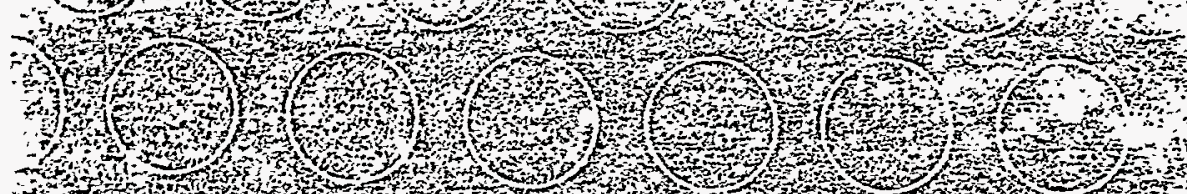
2. (2) (2) (2) 政

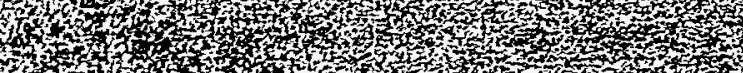

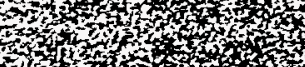

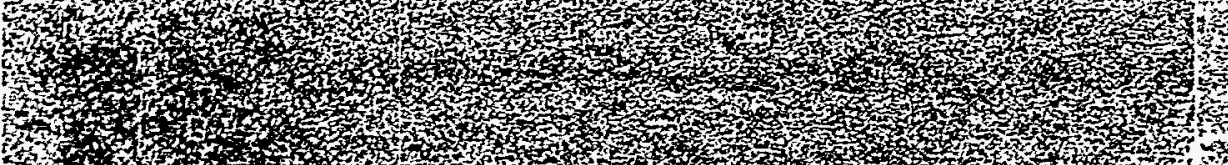
T. (5)

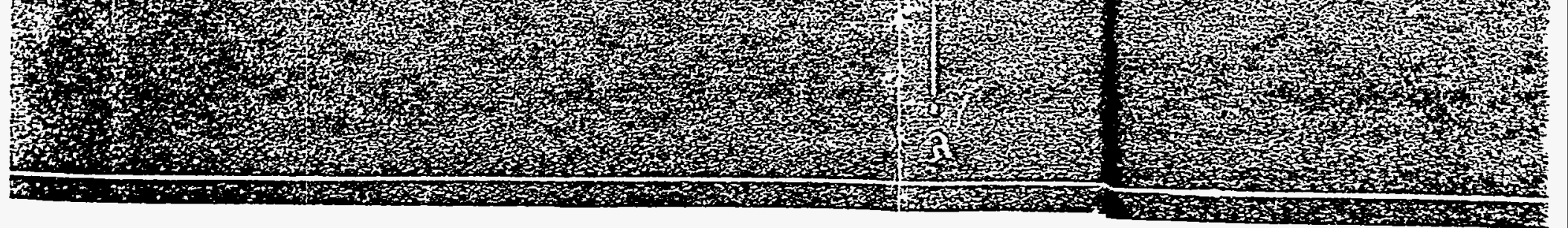


20 (2)

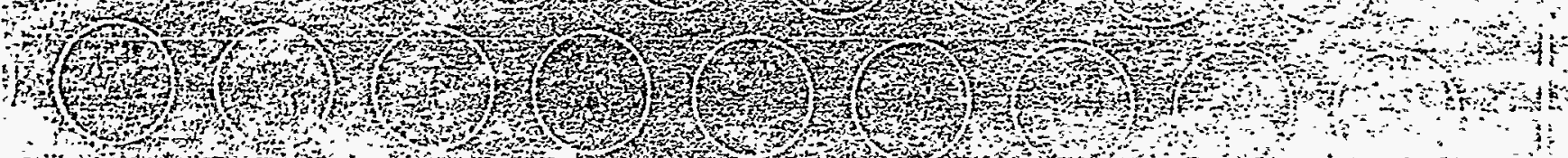

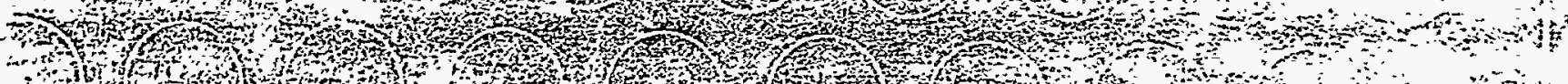

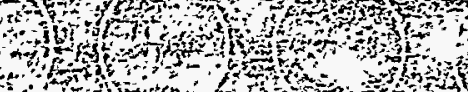

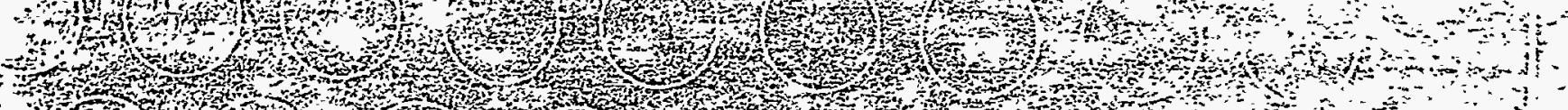

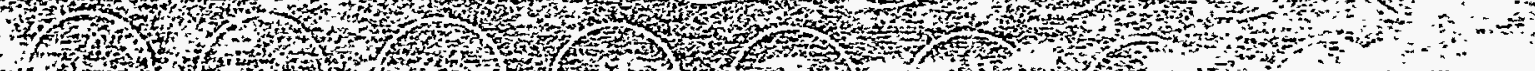

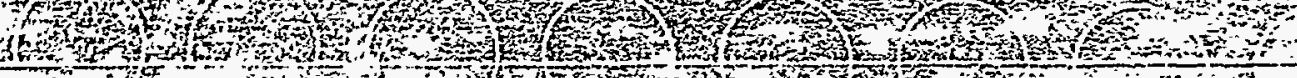

tans

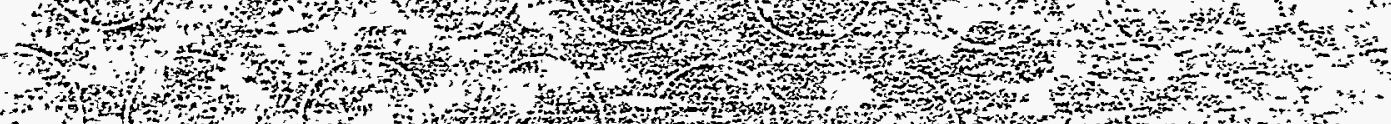

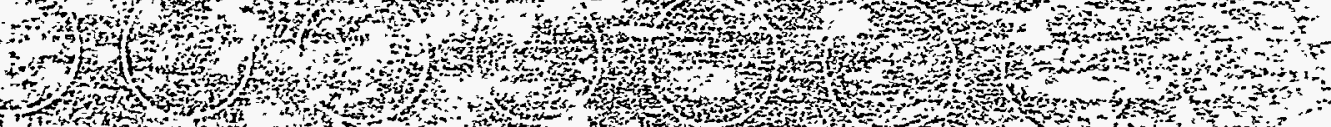

(3)

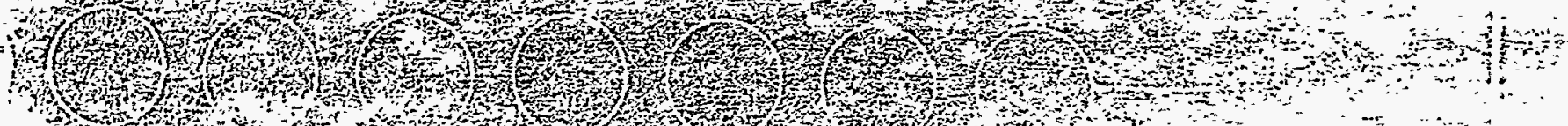

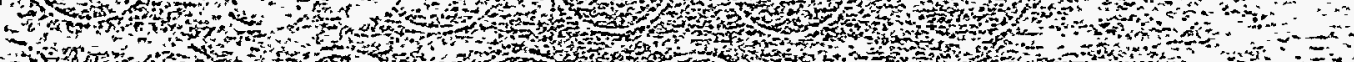

1)

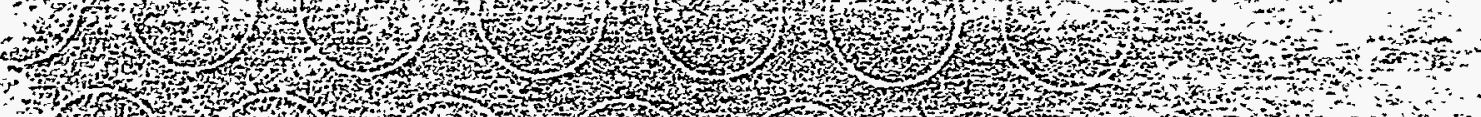

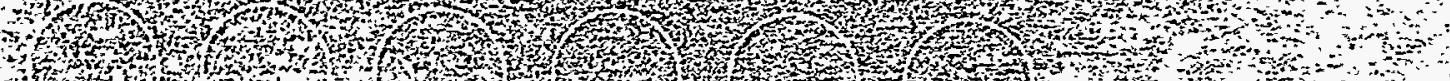

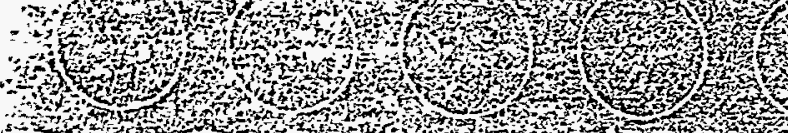

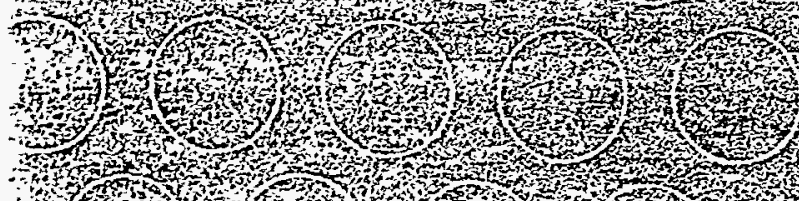

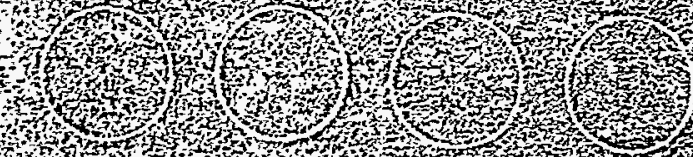

3
7

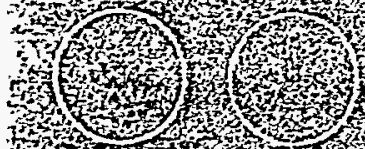

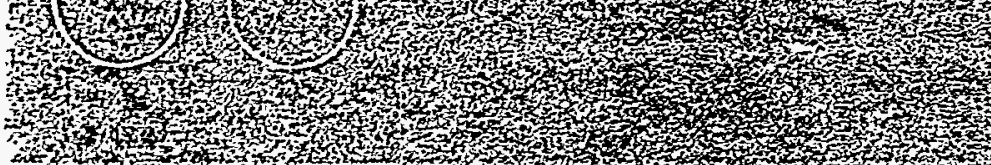

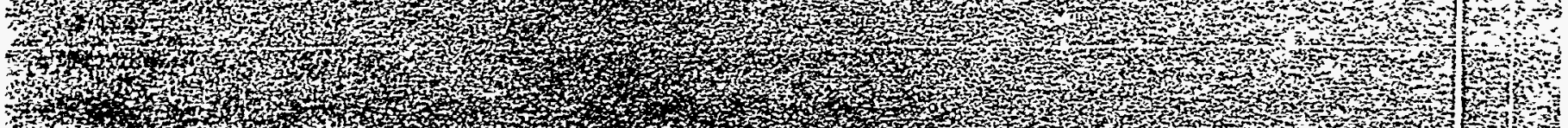
3
$\gamma_{1}$

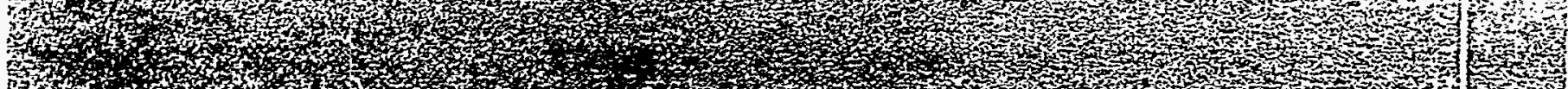

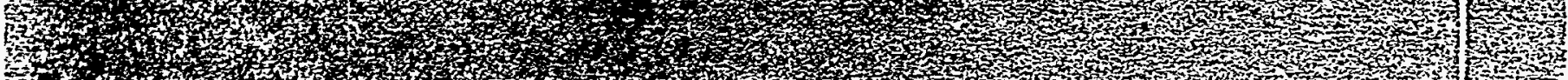

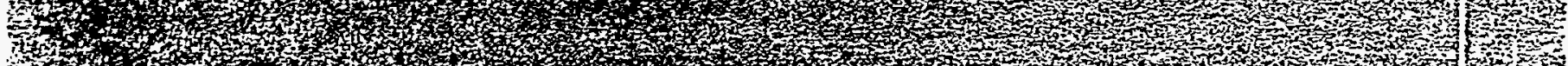

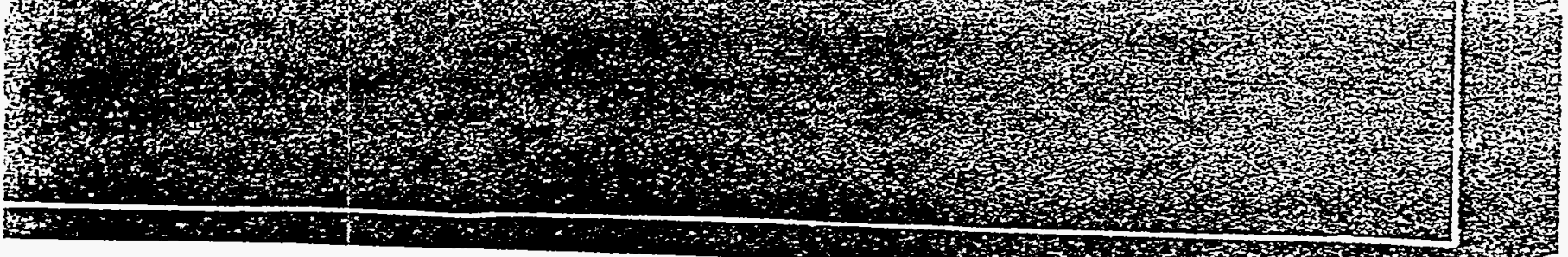




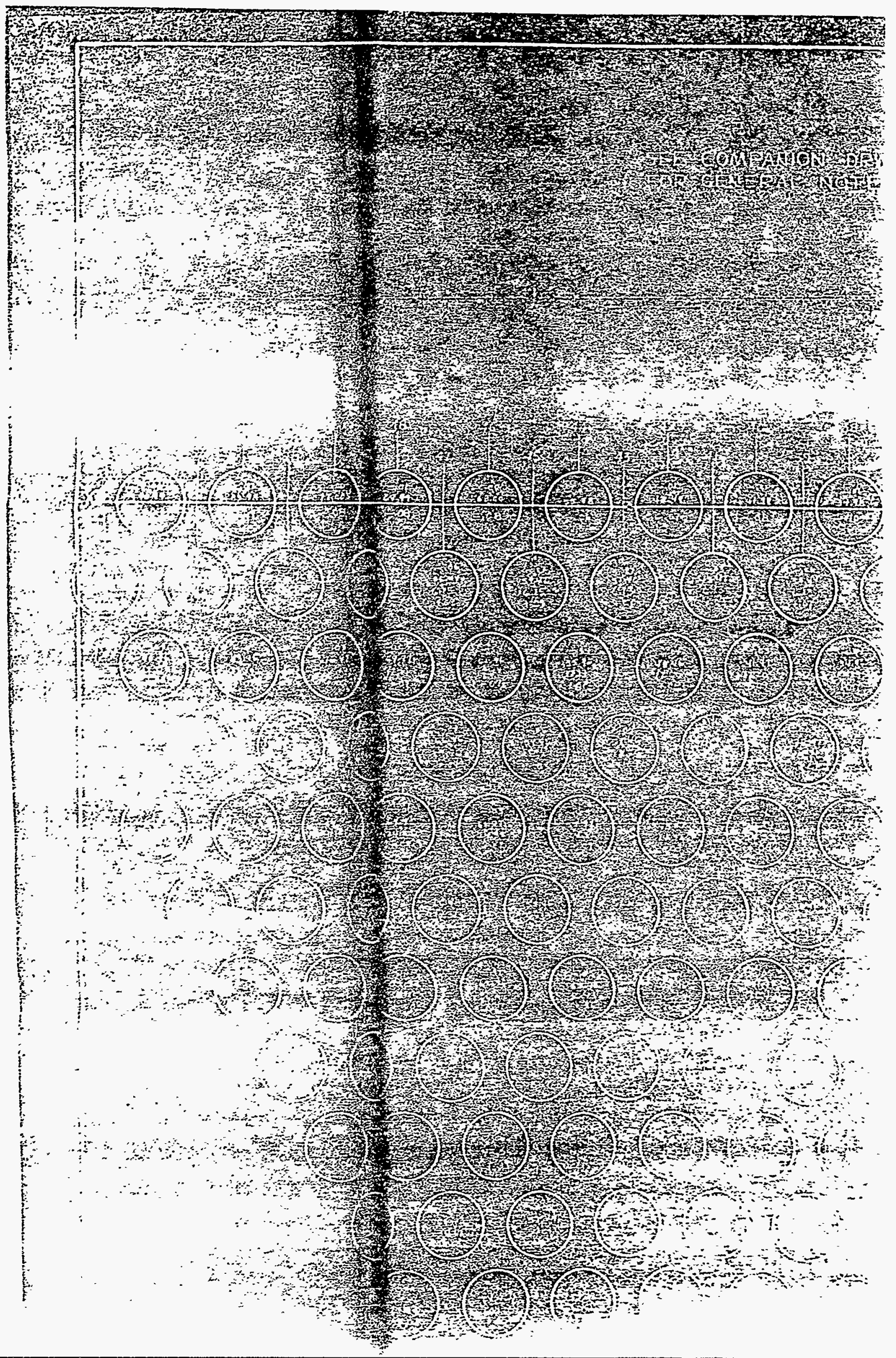




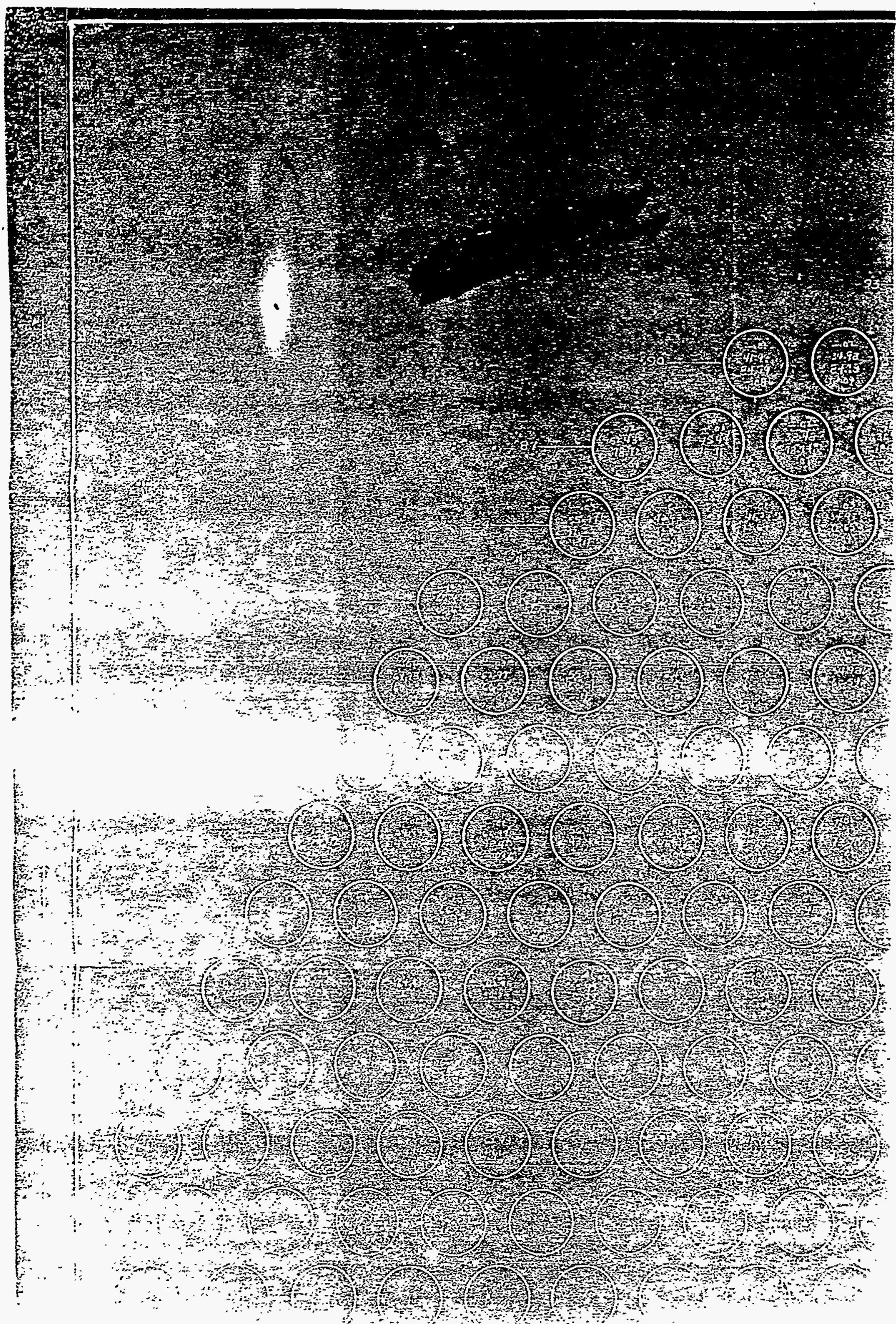




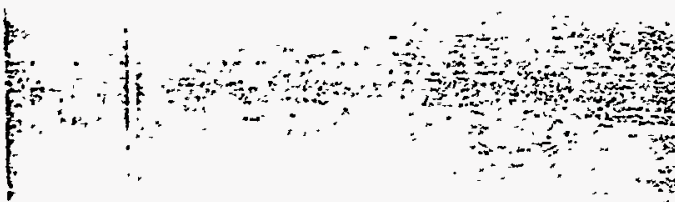

P)

$-$

1) Whe

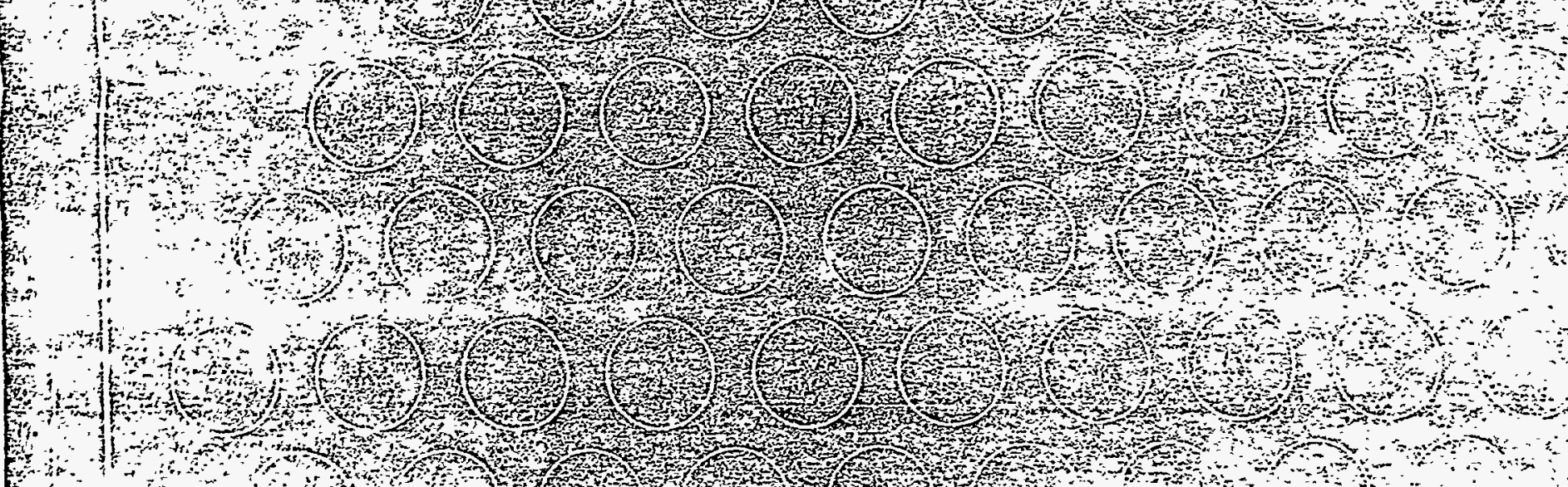

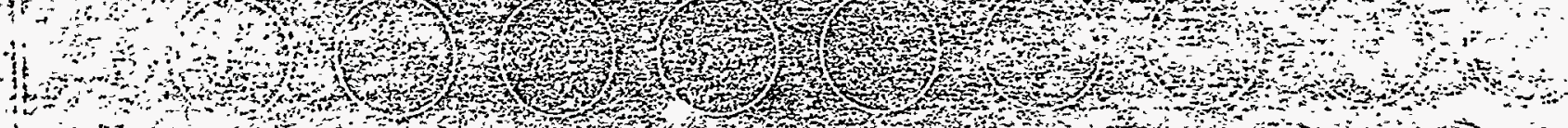

(n) (5)

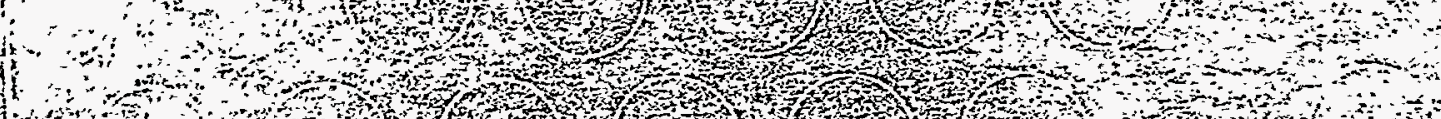

19.

3 (1)

2
0
0

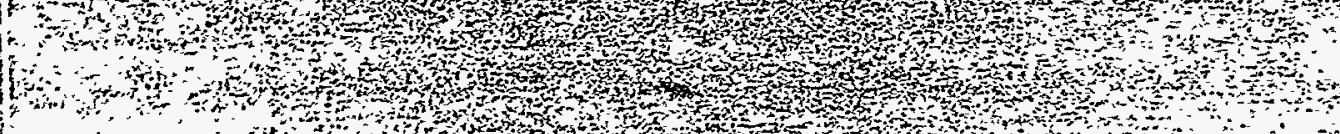

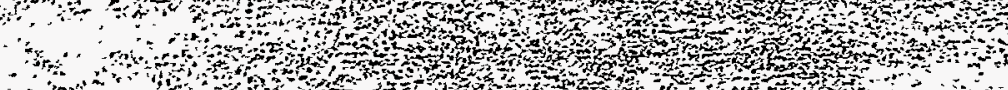

and

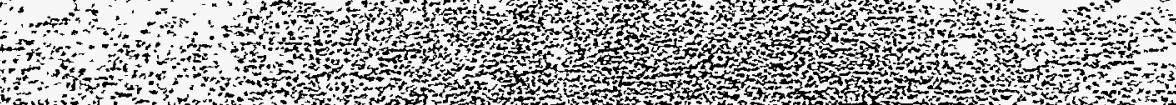

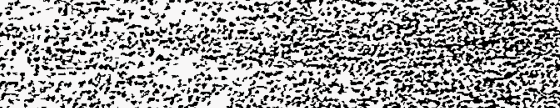

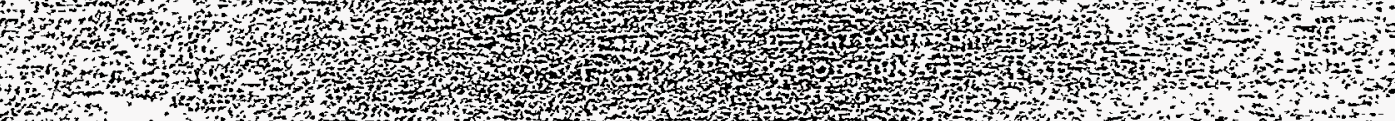

F,

1
1

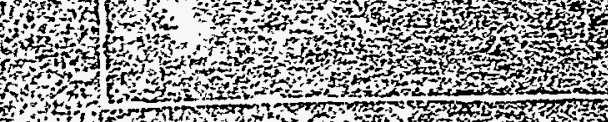


H) H: (1)

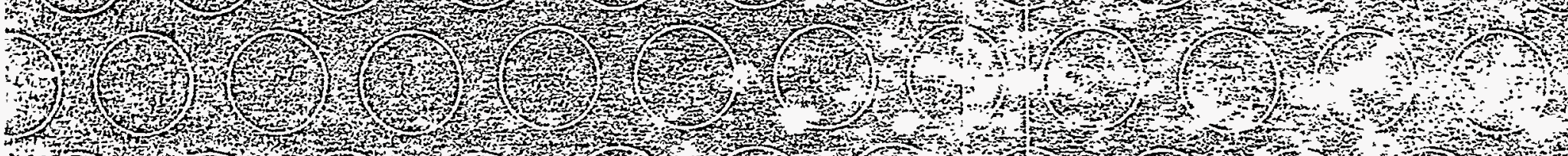

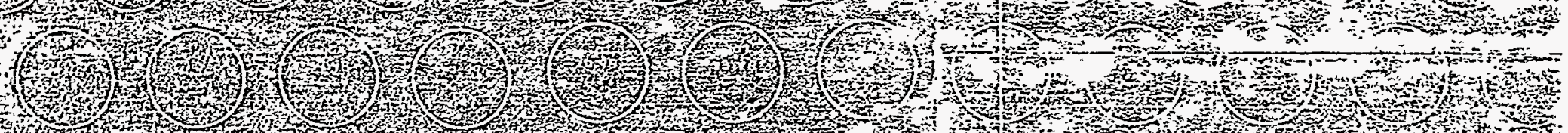

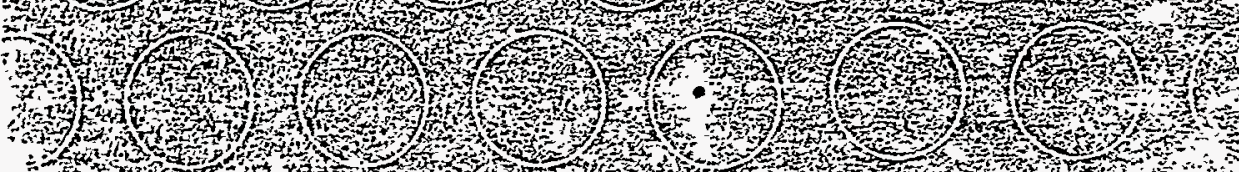

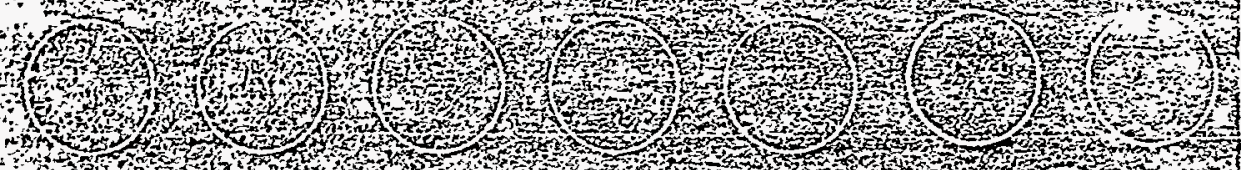

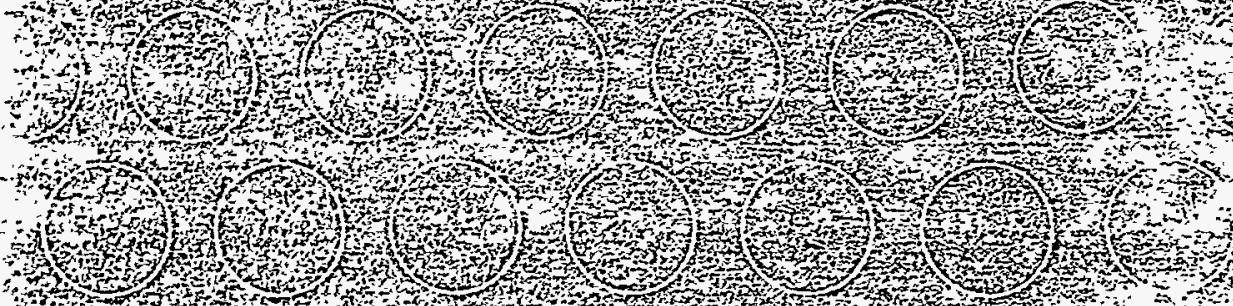

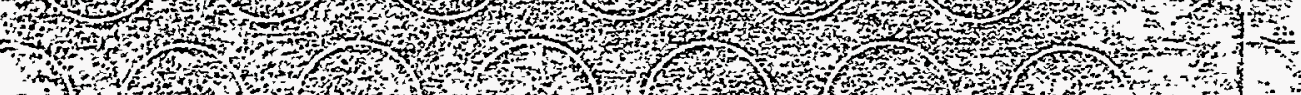
(n)

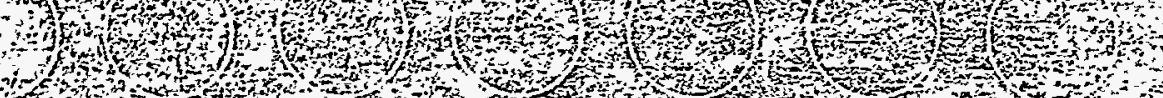

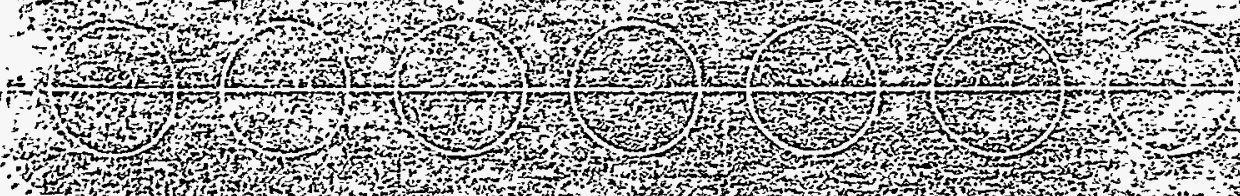

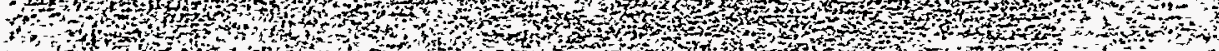

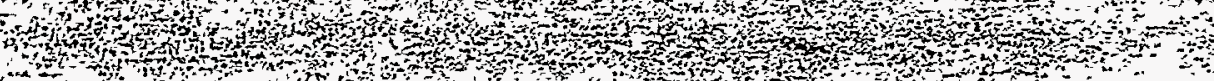

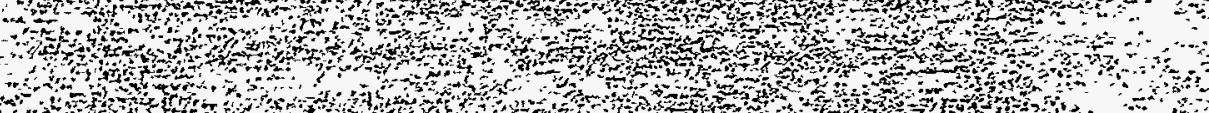

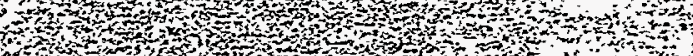

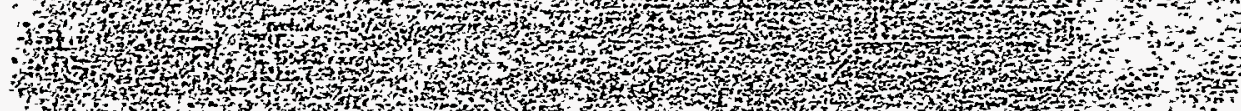
, W

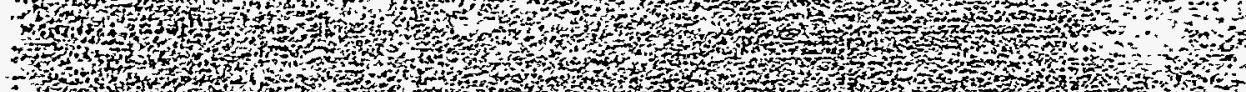

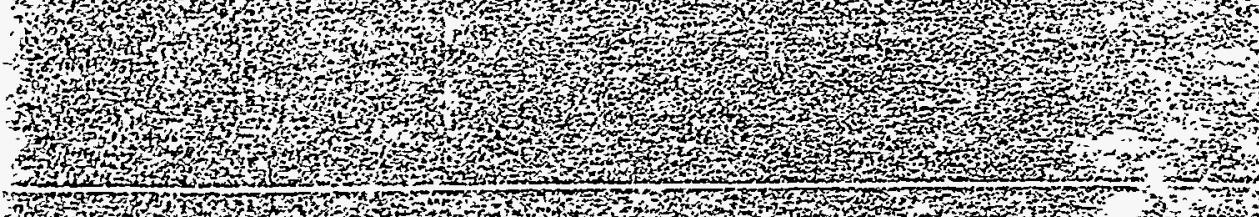




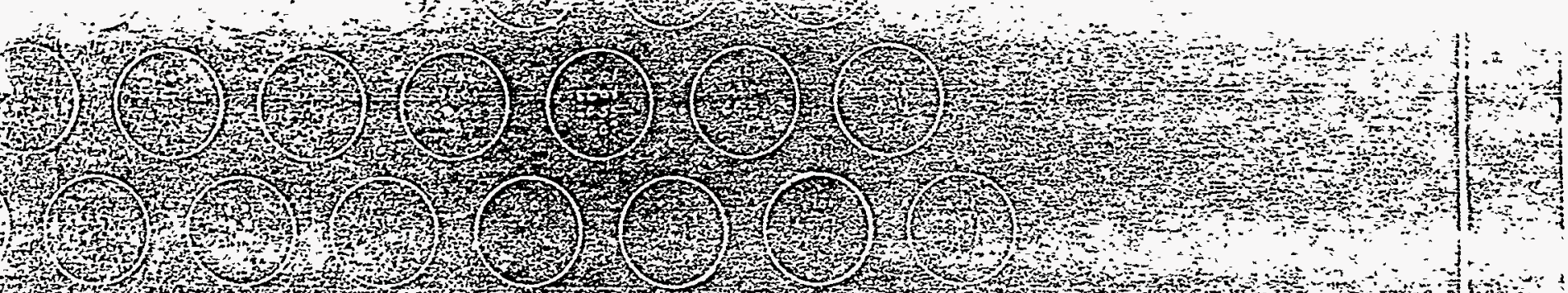

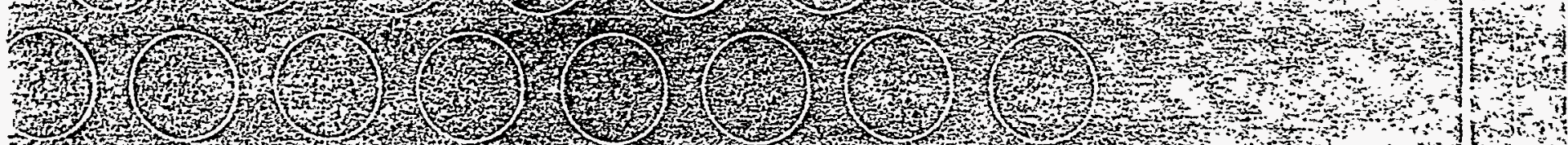

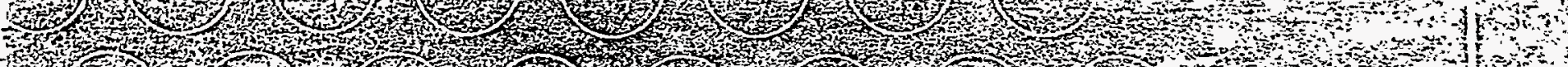

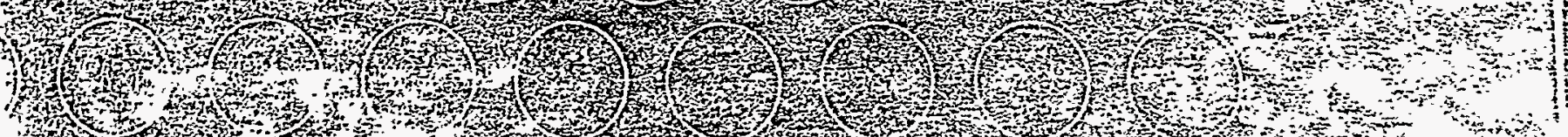

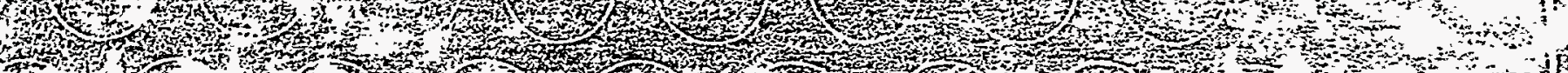
F, (1)

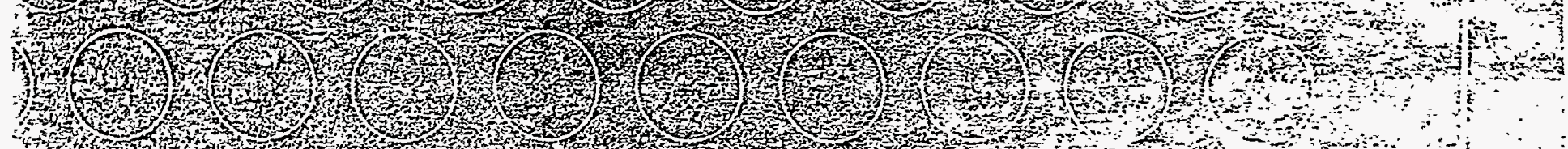

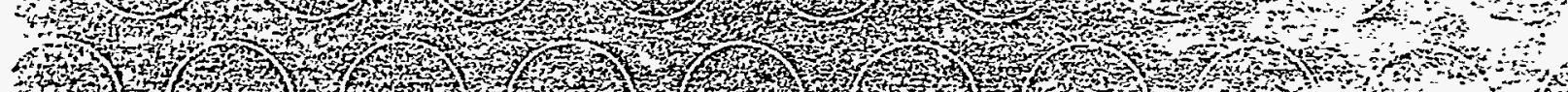

4
4

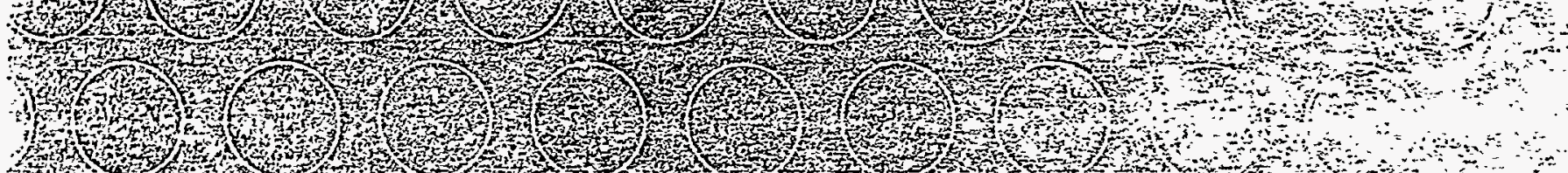
,

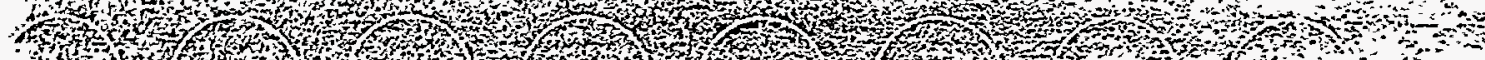

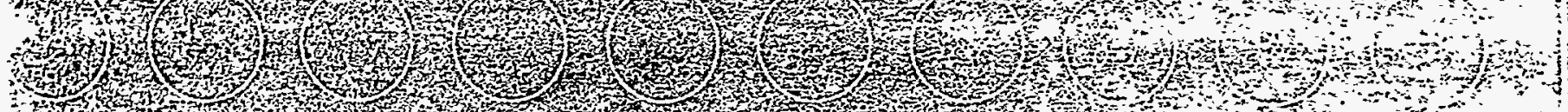

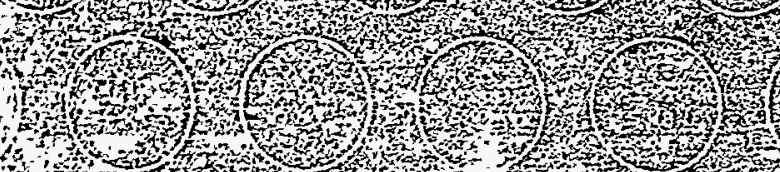

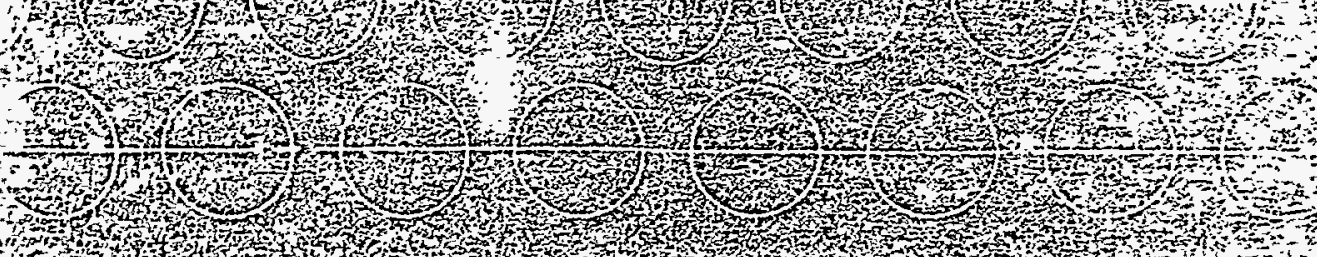

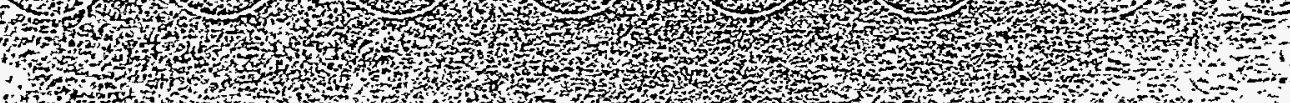
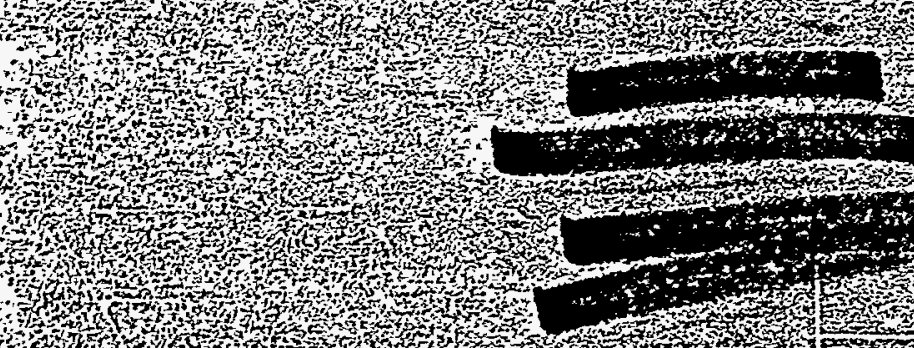
3.t. 政

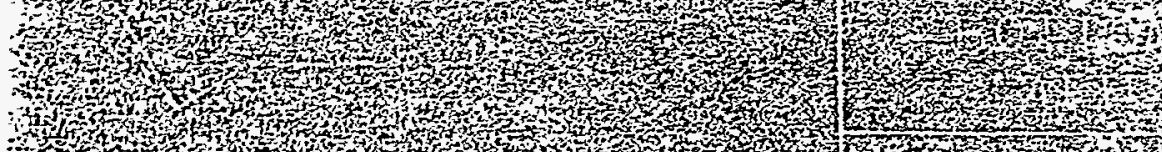

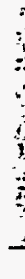




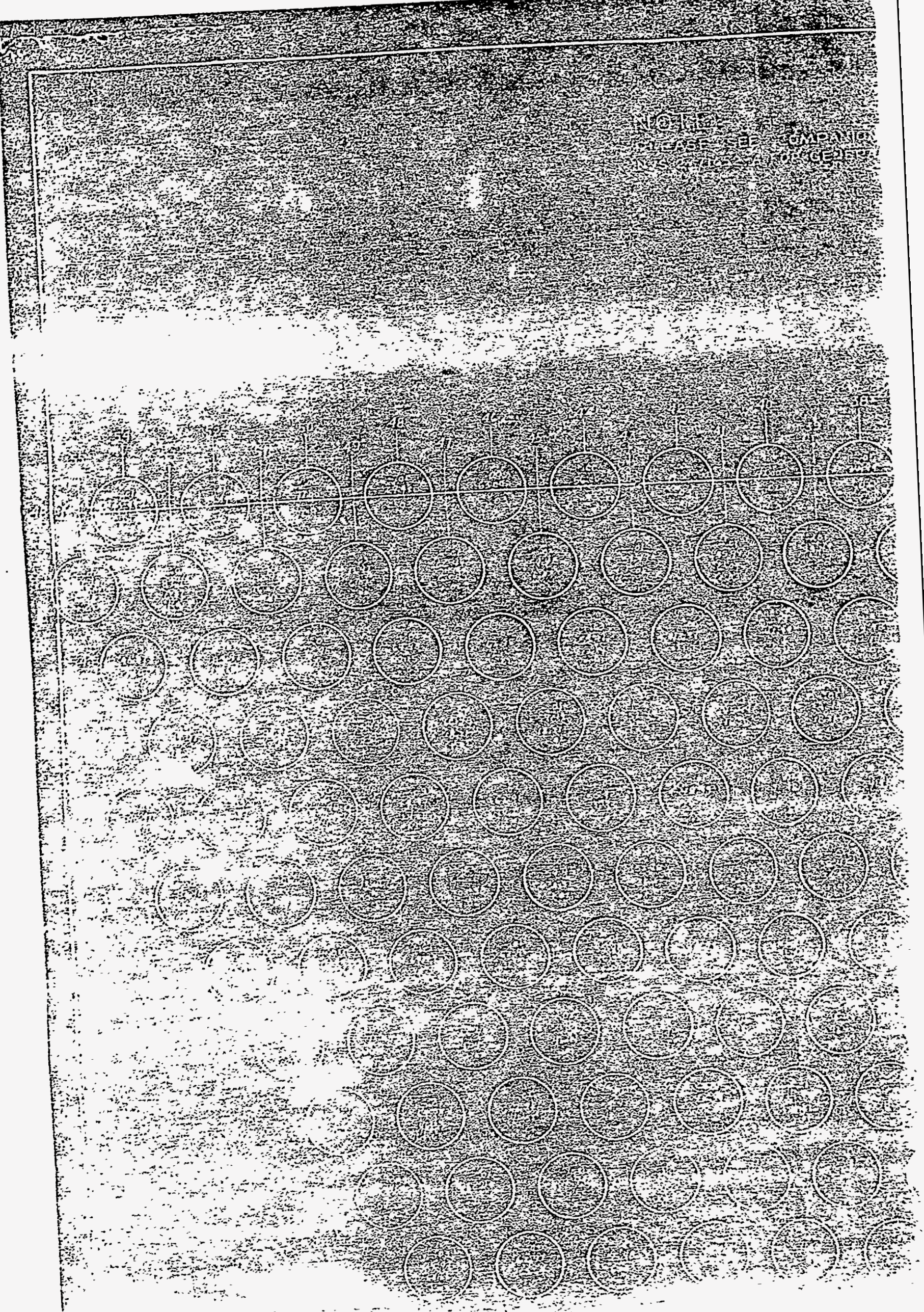




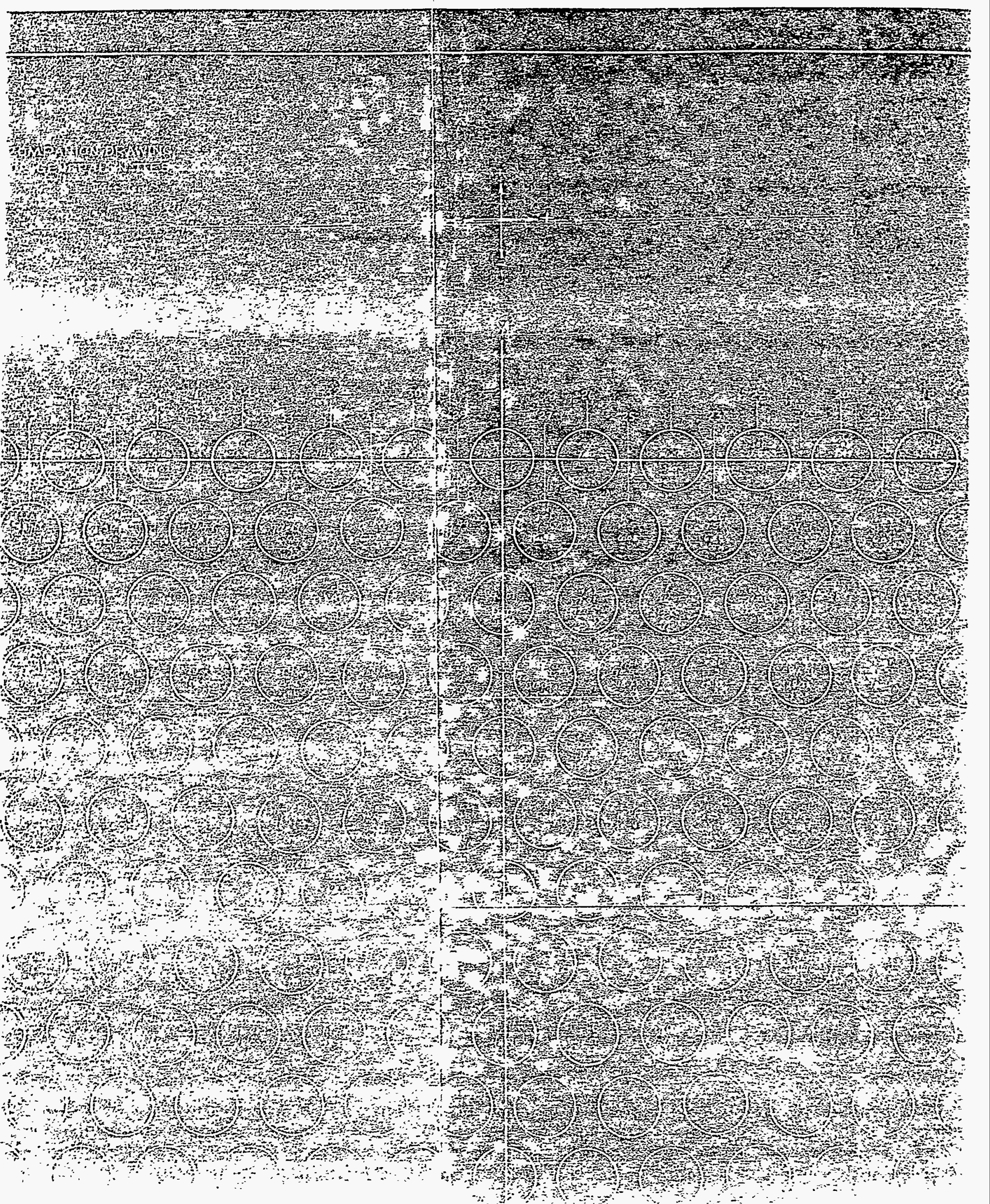




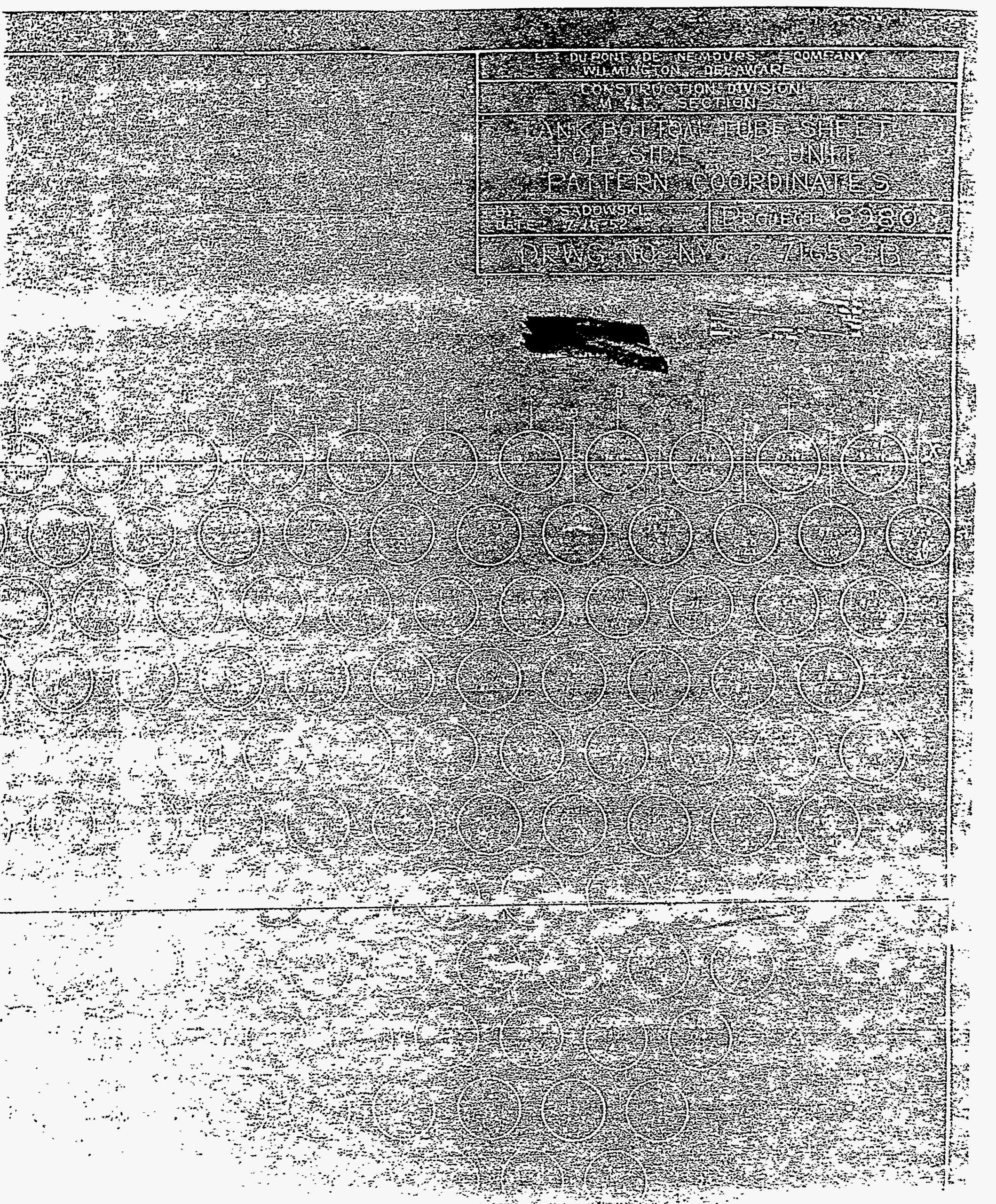




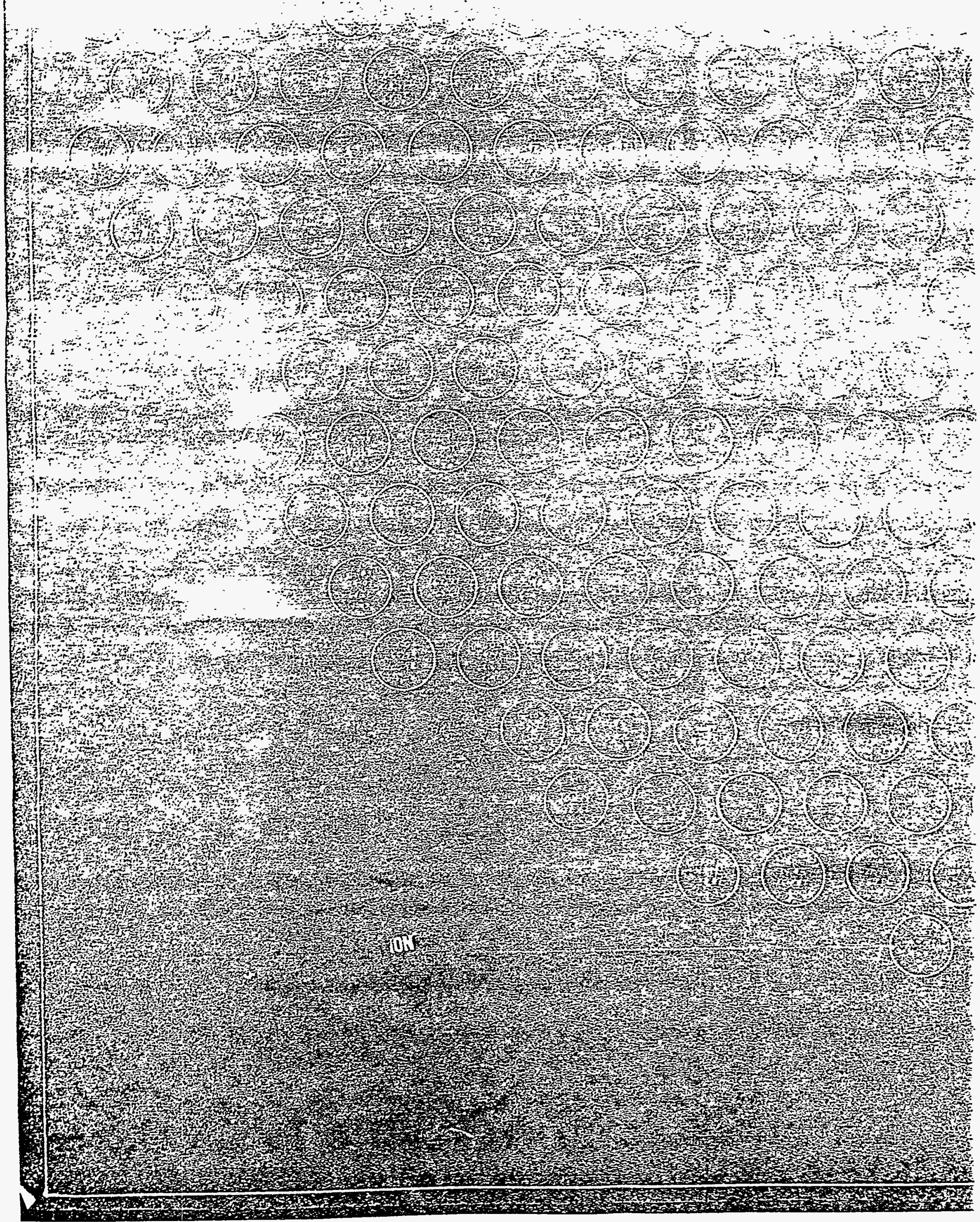


(2)

3ix

(1)

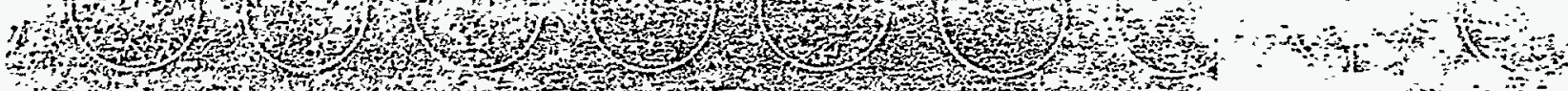

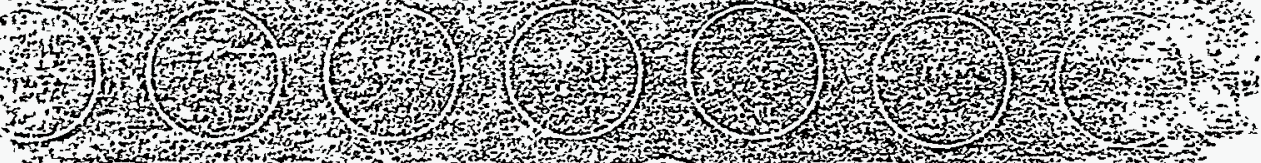

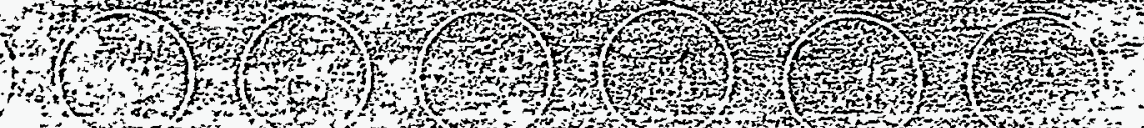

xis

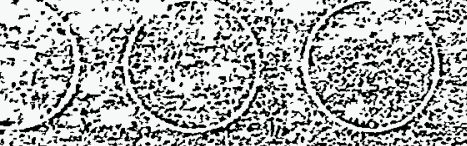

(2)

(5)

(5)

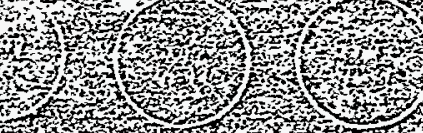

(c)

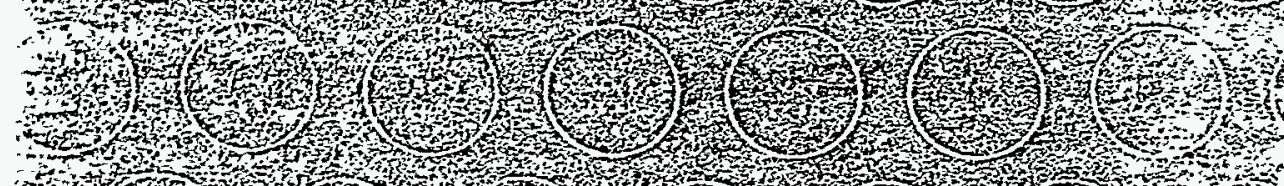

(3) (-)

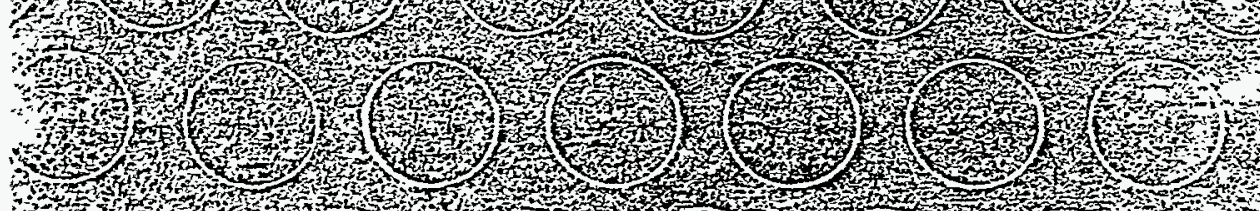

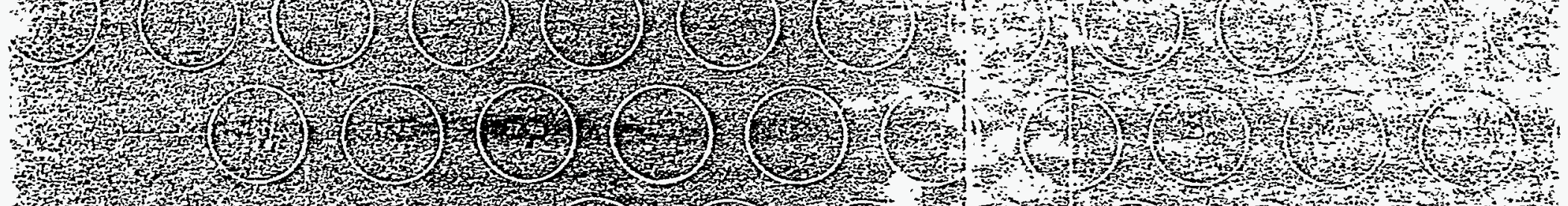

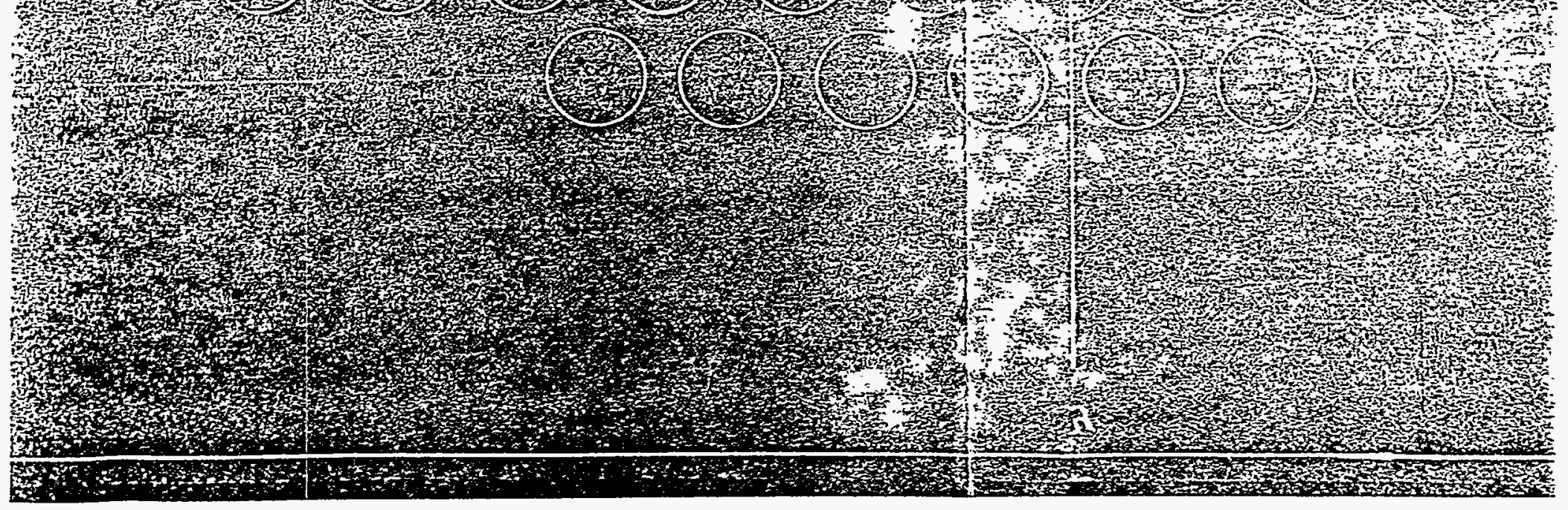


(1)

(2)

(t)

Fin

(1)

(n)

(2) -

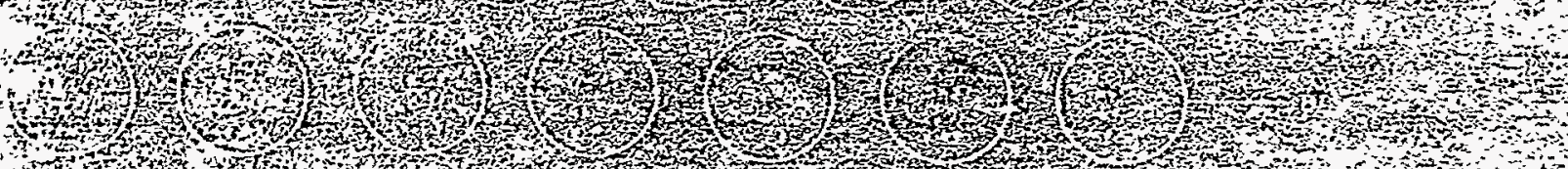

W(2)

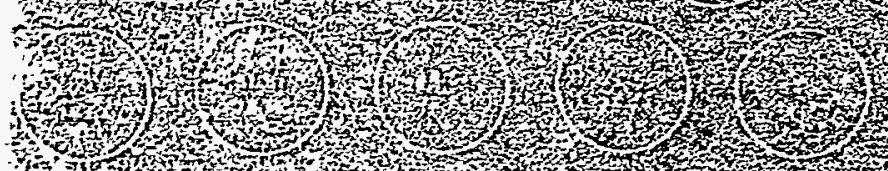

N(5)

(1).

(25)

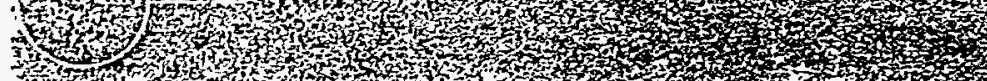

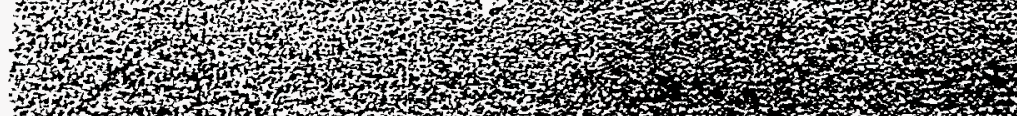
17,

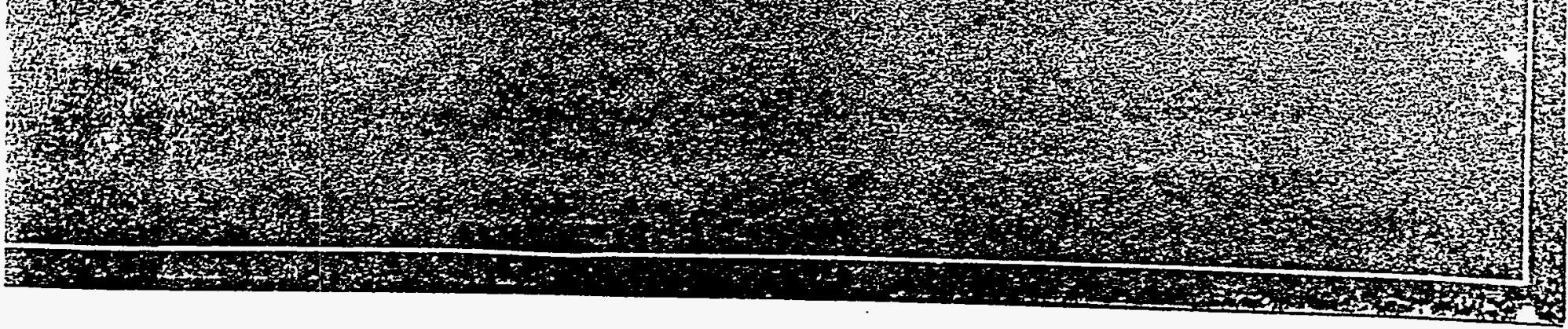




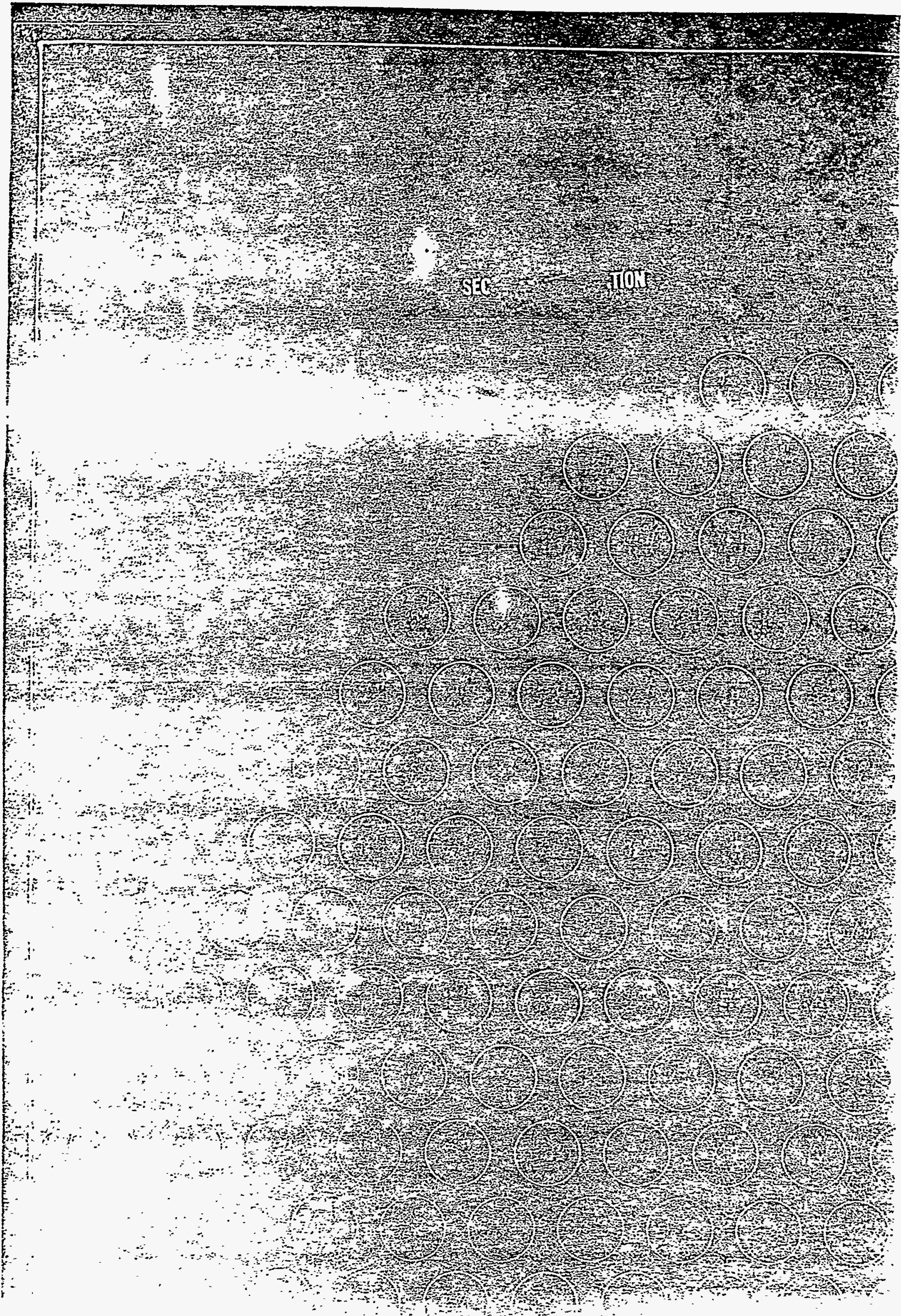




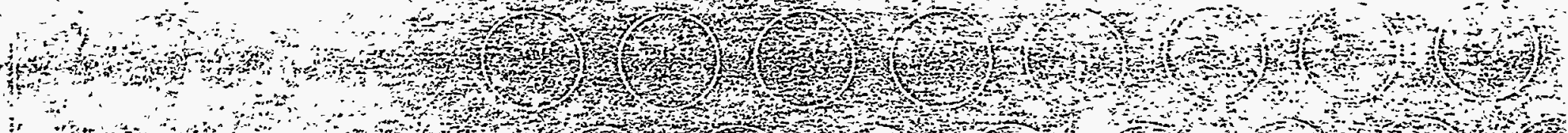

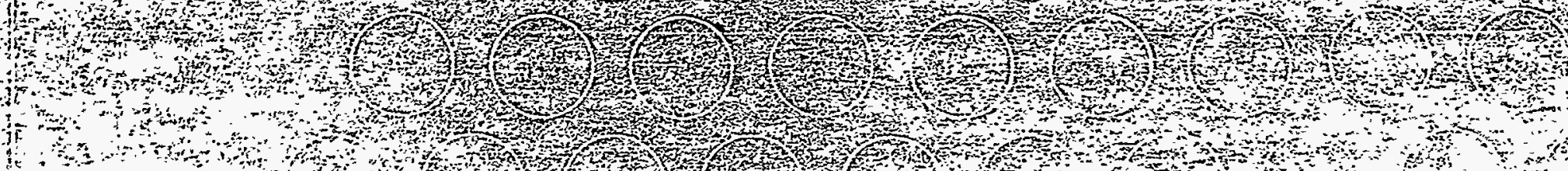

and

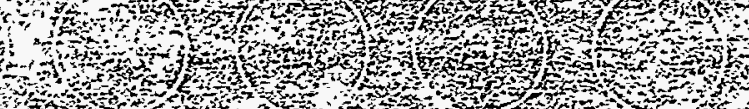
in $\rightarrow$ Now

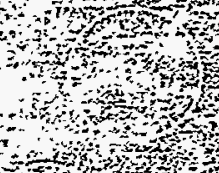

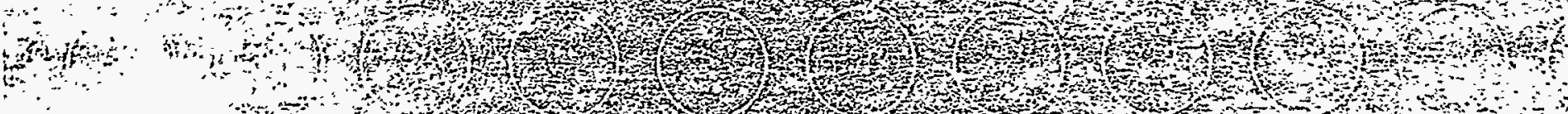
10

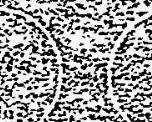
15 ton Fis.s.

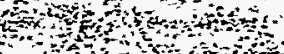

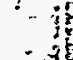

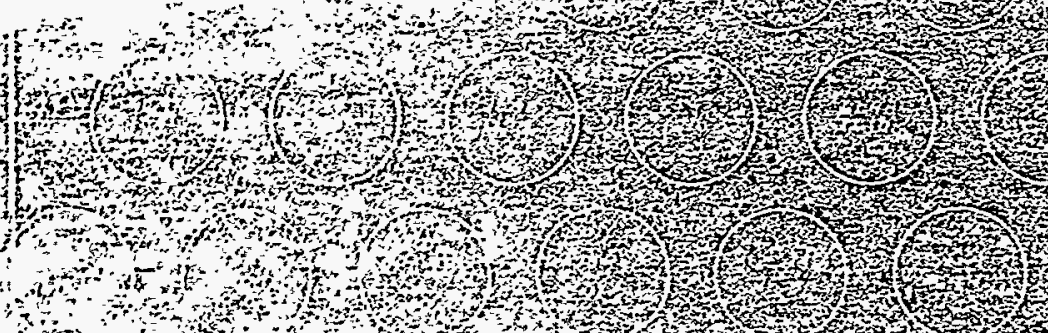

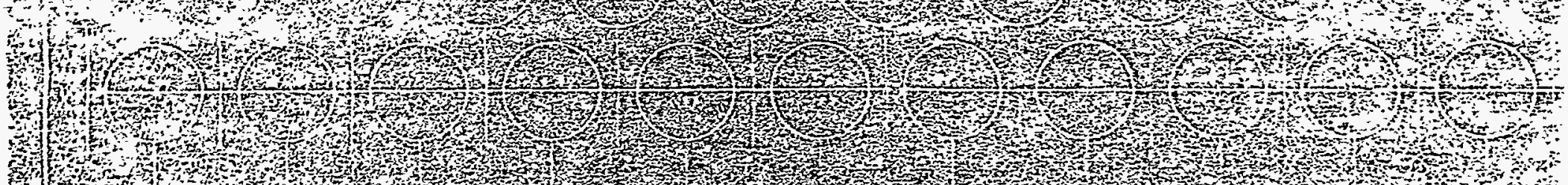

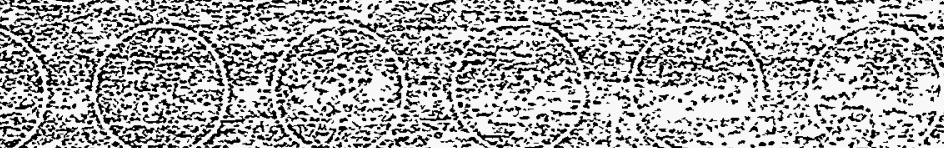
a

W 篓

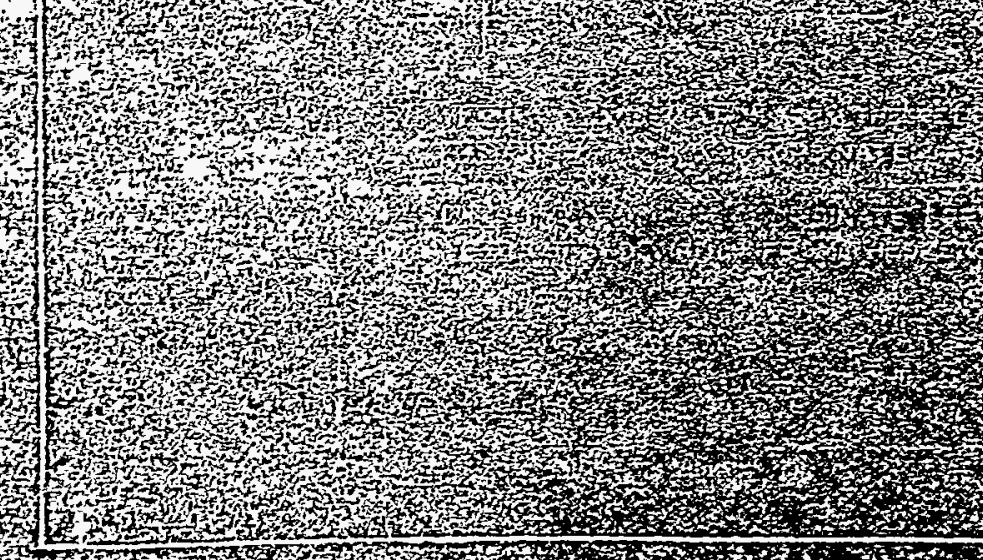


3) (1)

Hontros

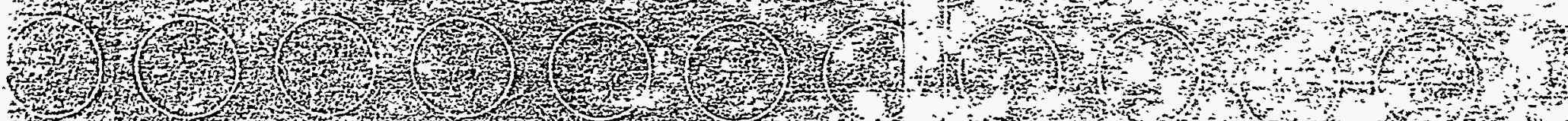

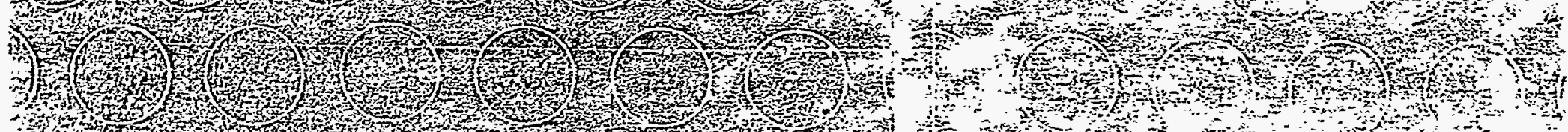
Tht:

(a)

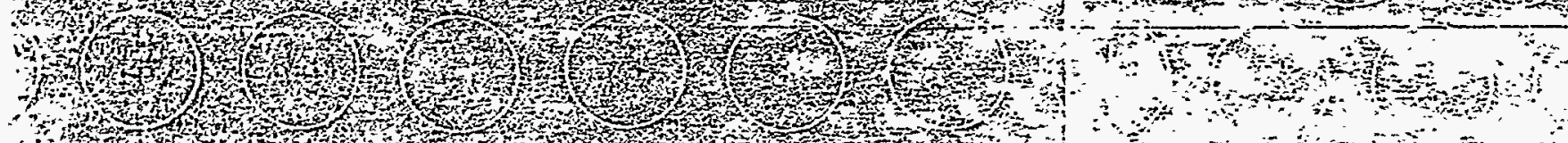

(2)

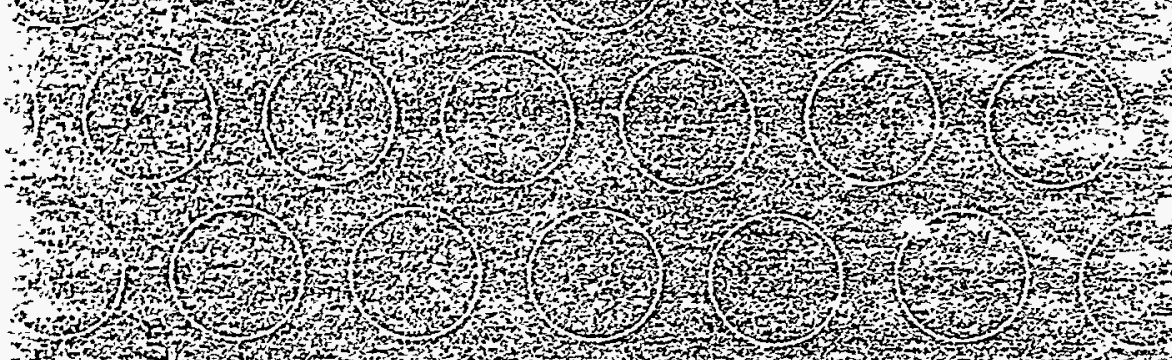
(3)

\section{(2)}

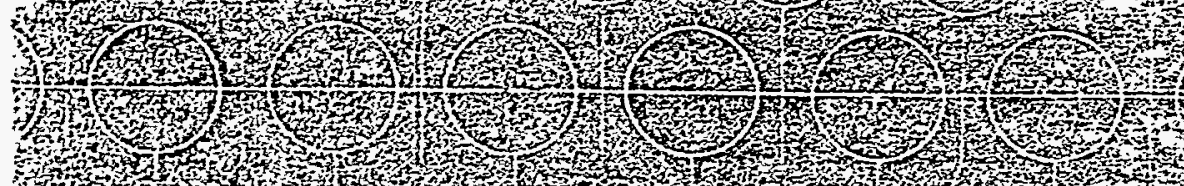

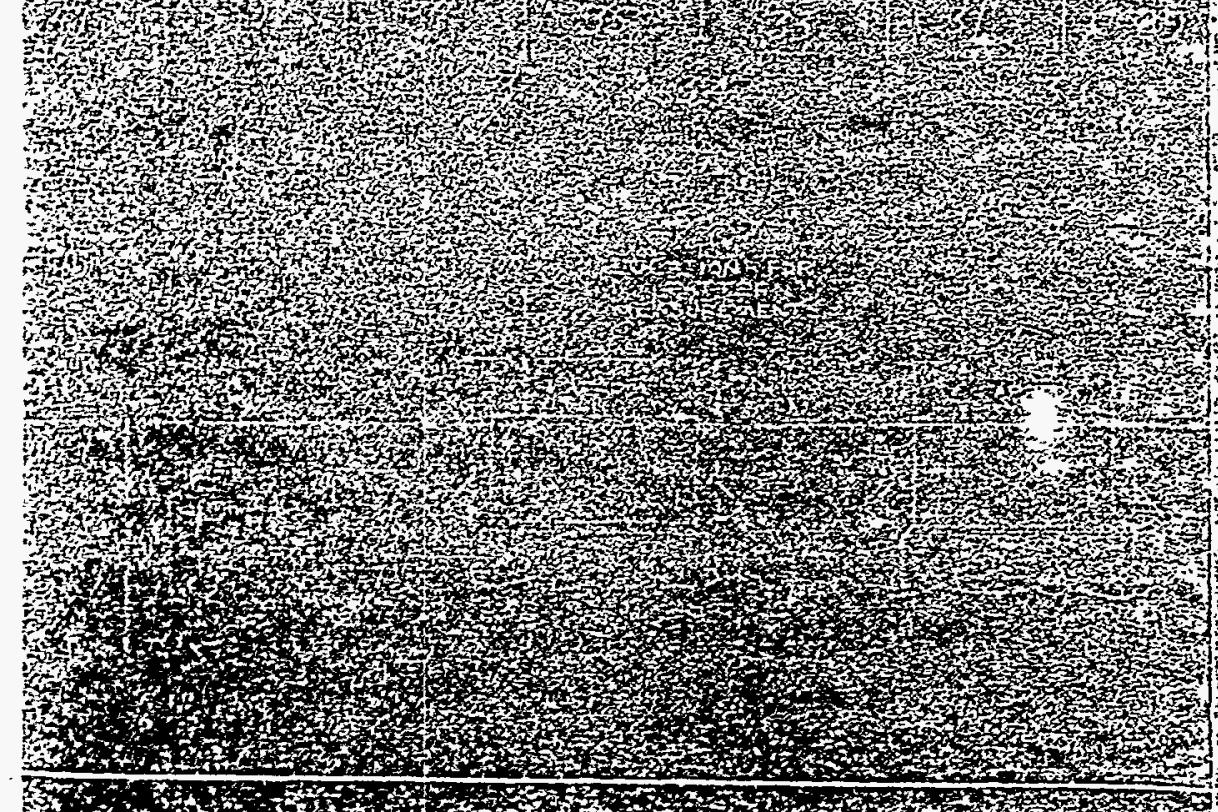

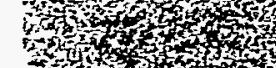

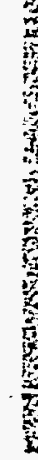




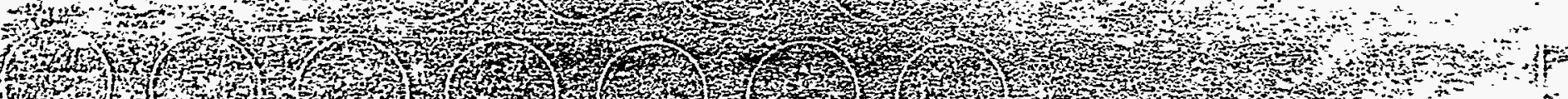

(6)

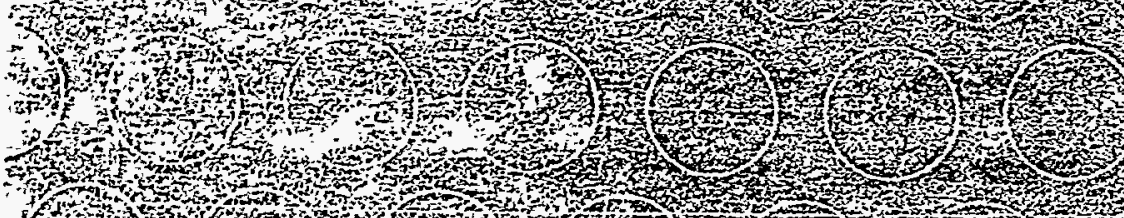

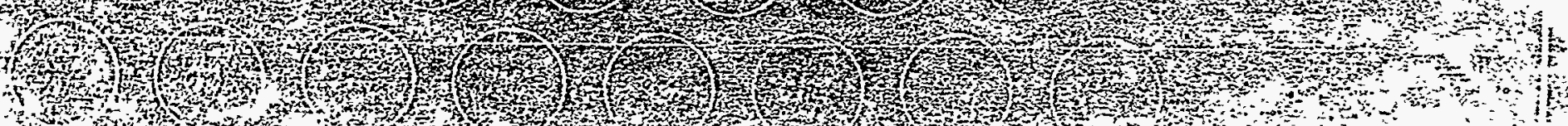

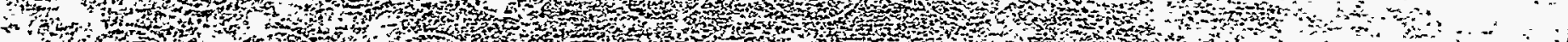

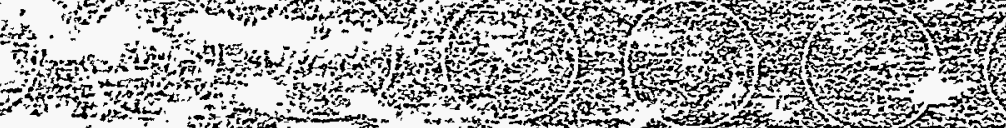

(19)

H.

M.

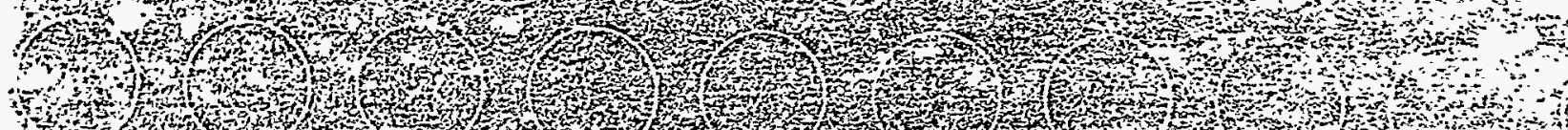

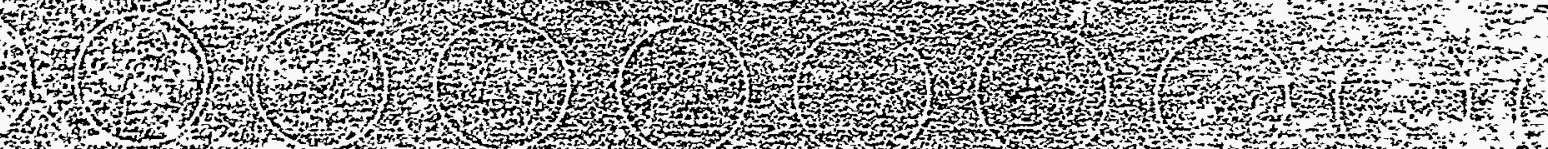

$\begin{array}{lllllll}3 & 3\end{array}$

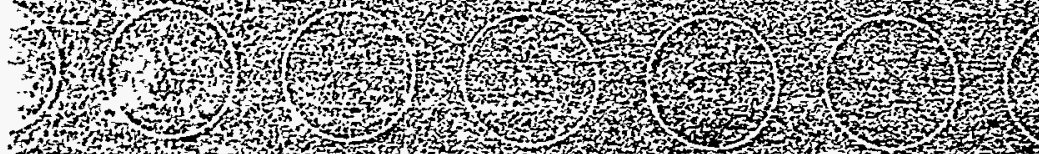

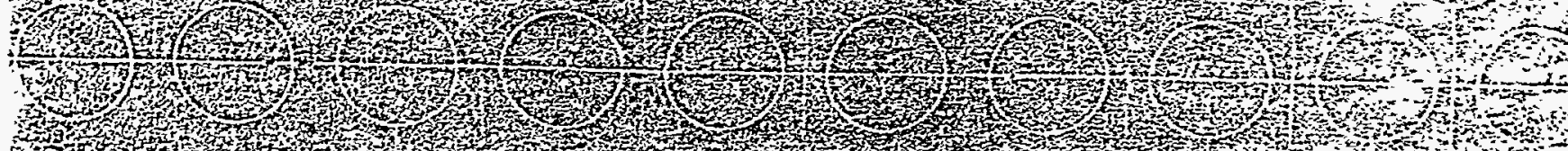

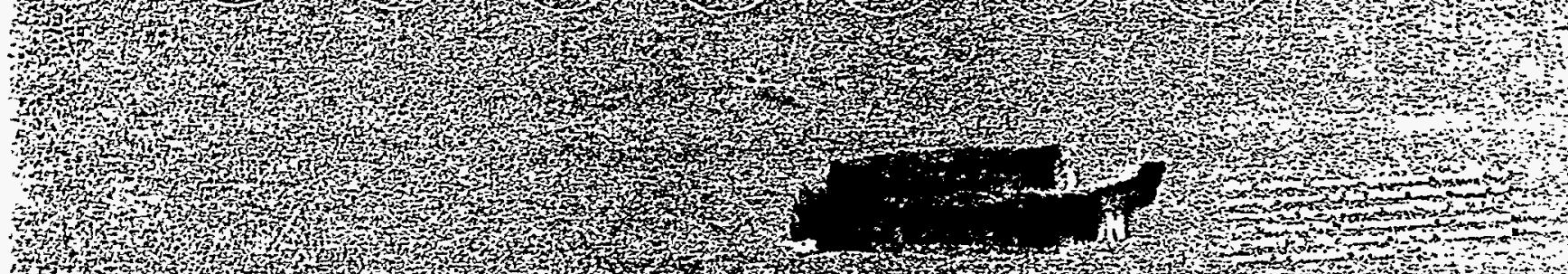

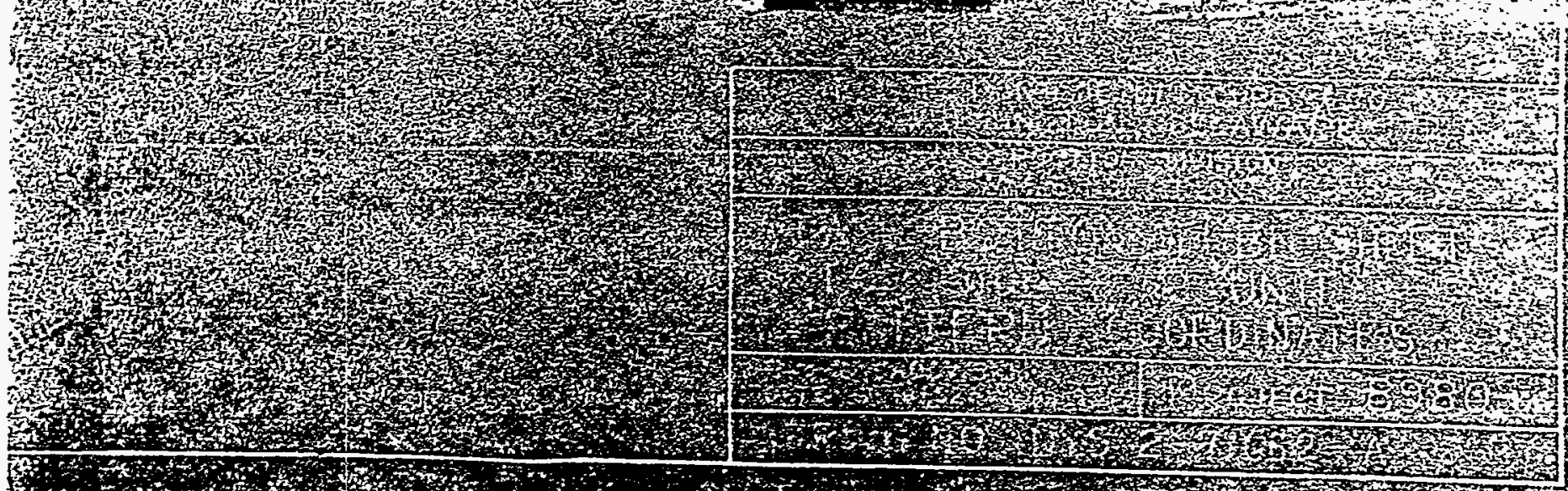




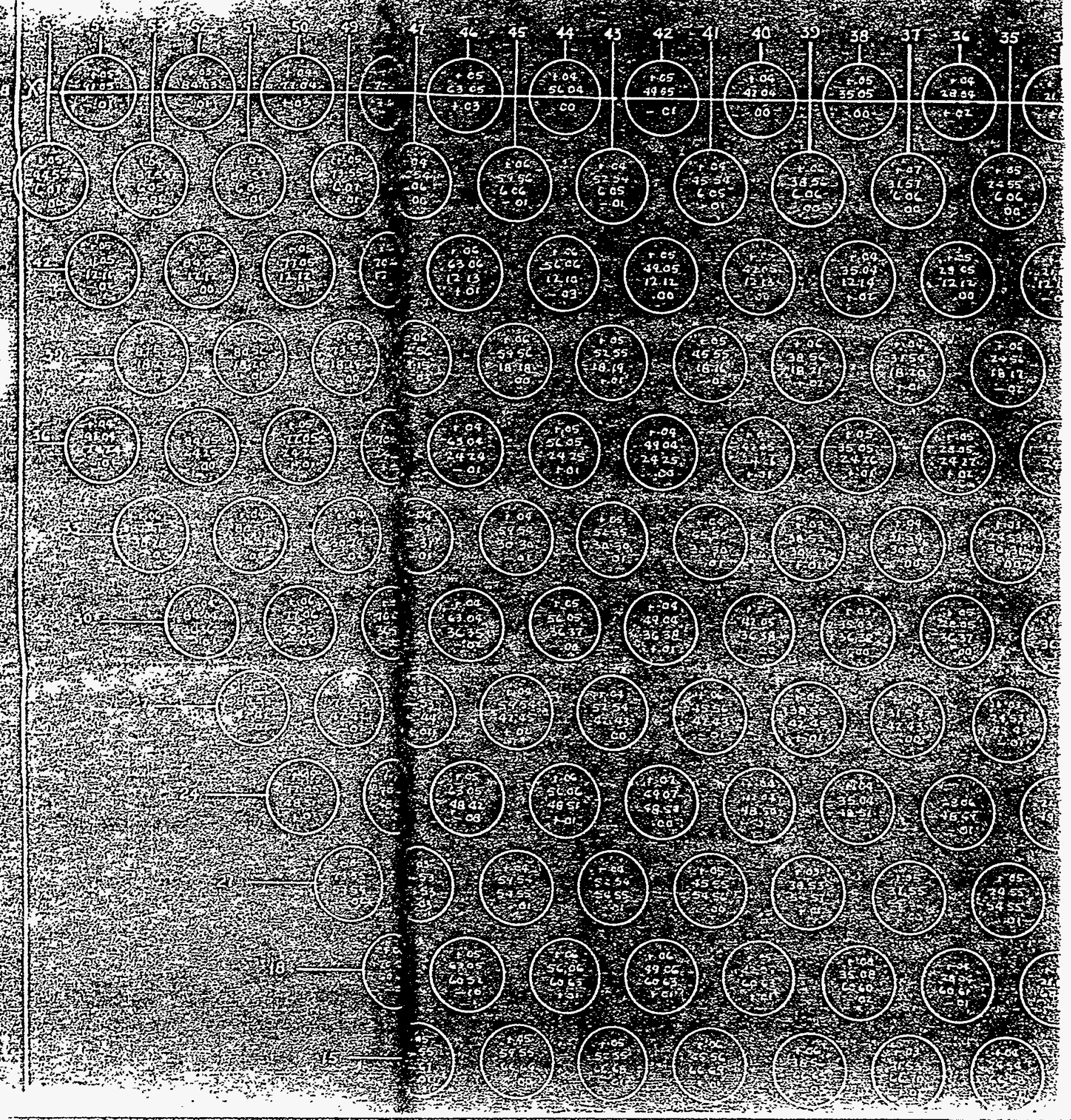


OMPANIONDOWG NYS 3/OOS2-A

ENERAL NOT ES 


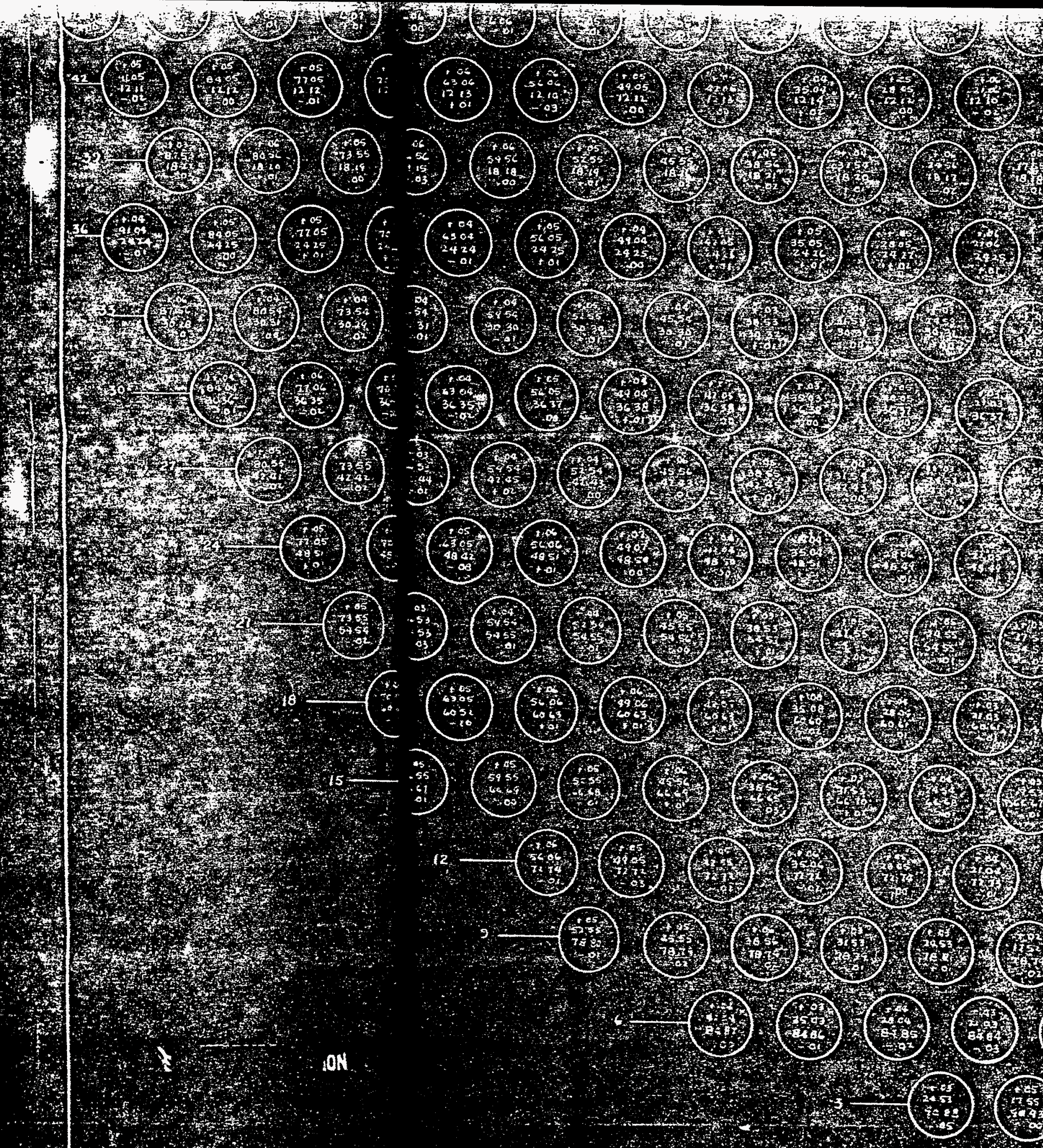




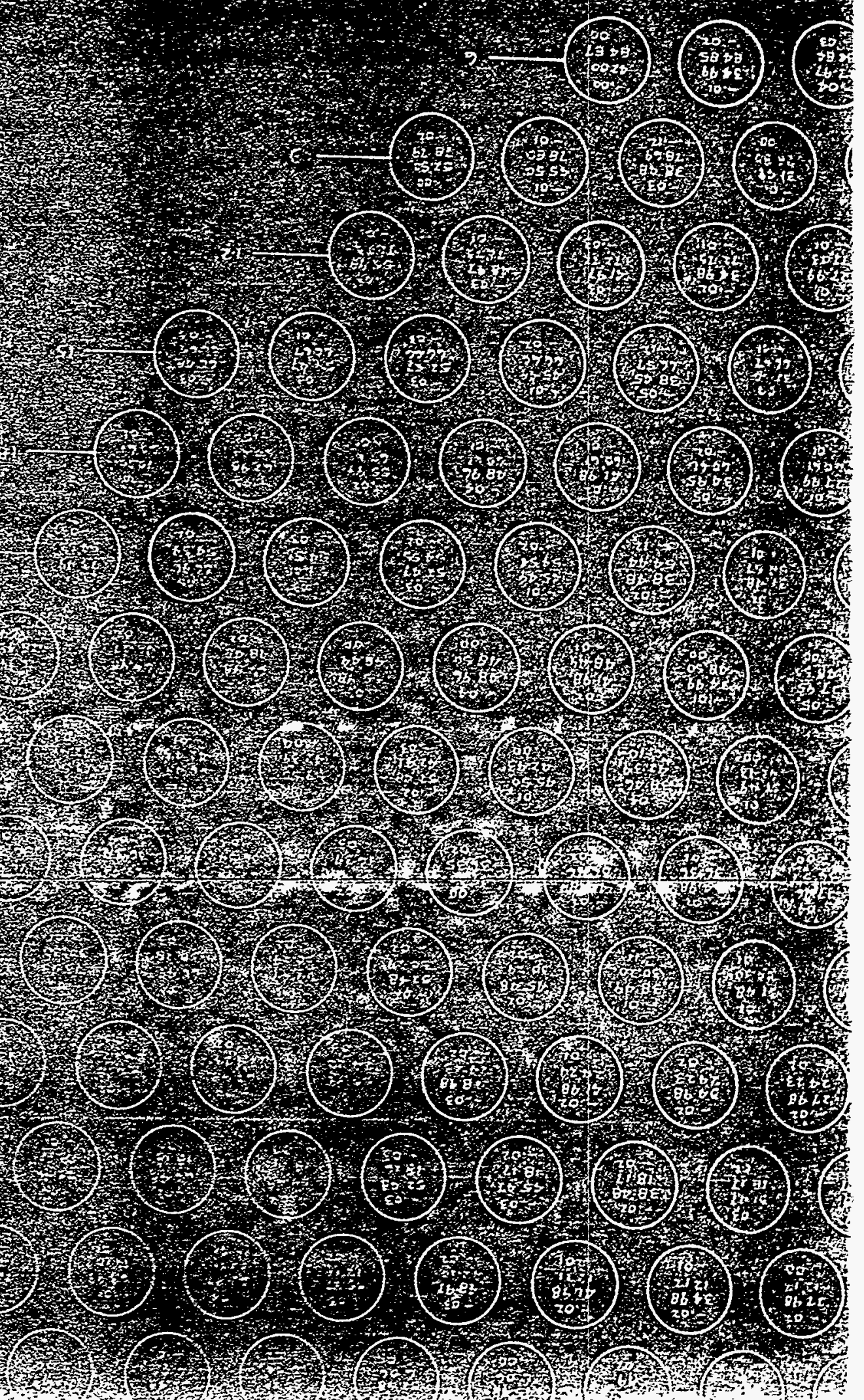




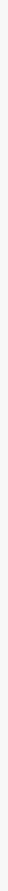
(2) (2)

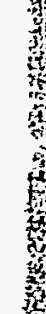

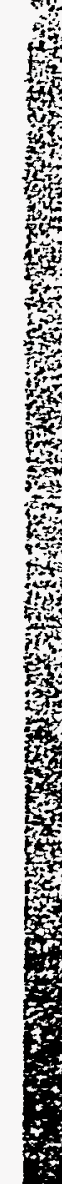

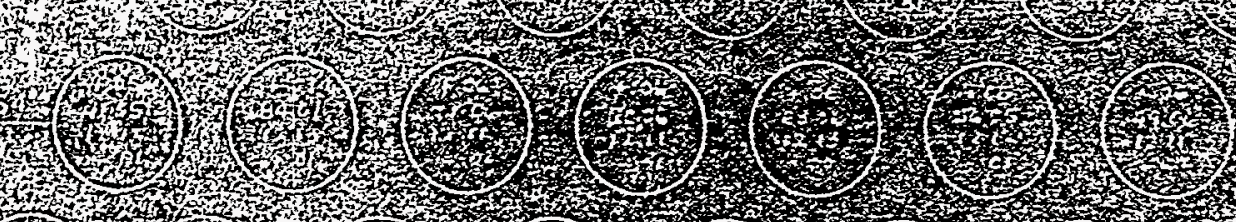
(2) (3)

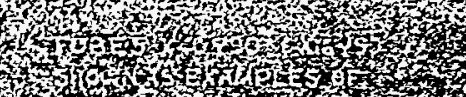

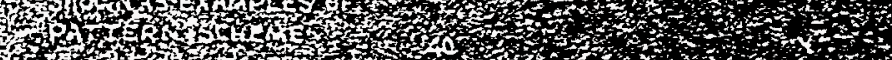

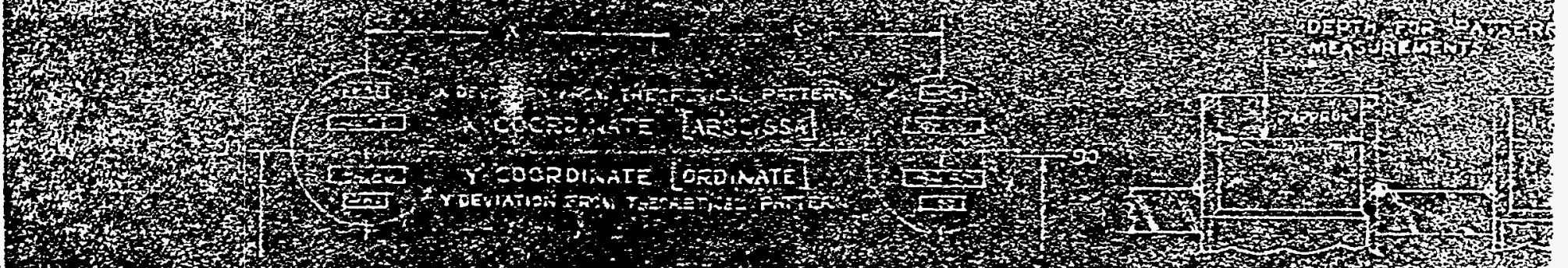

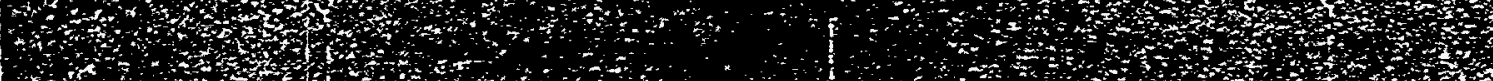




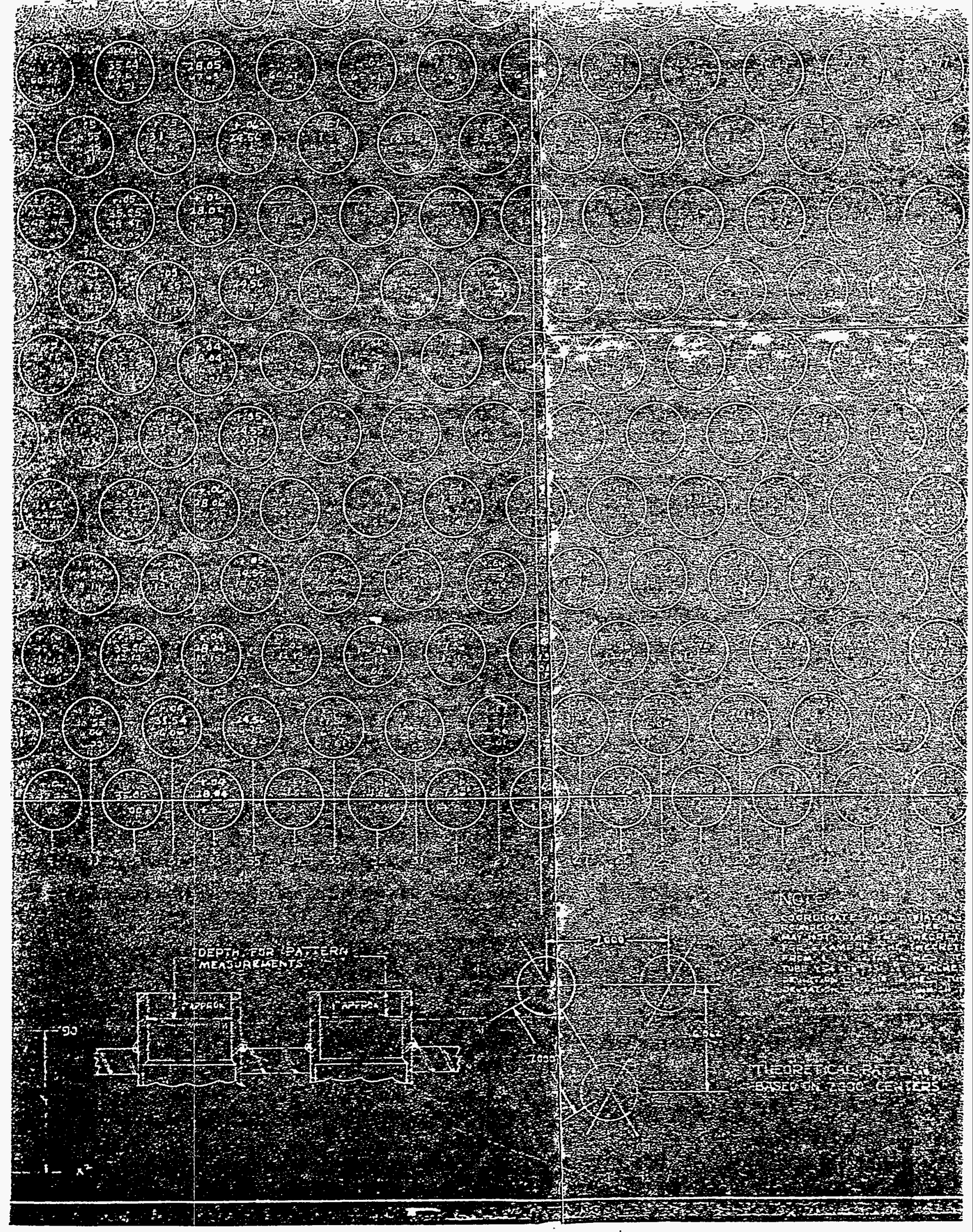




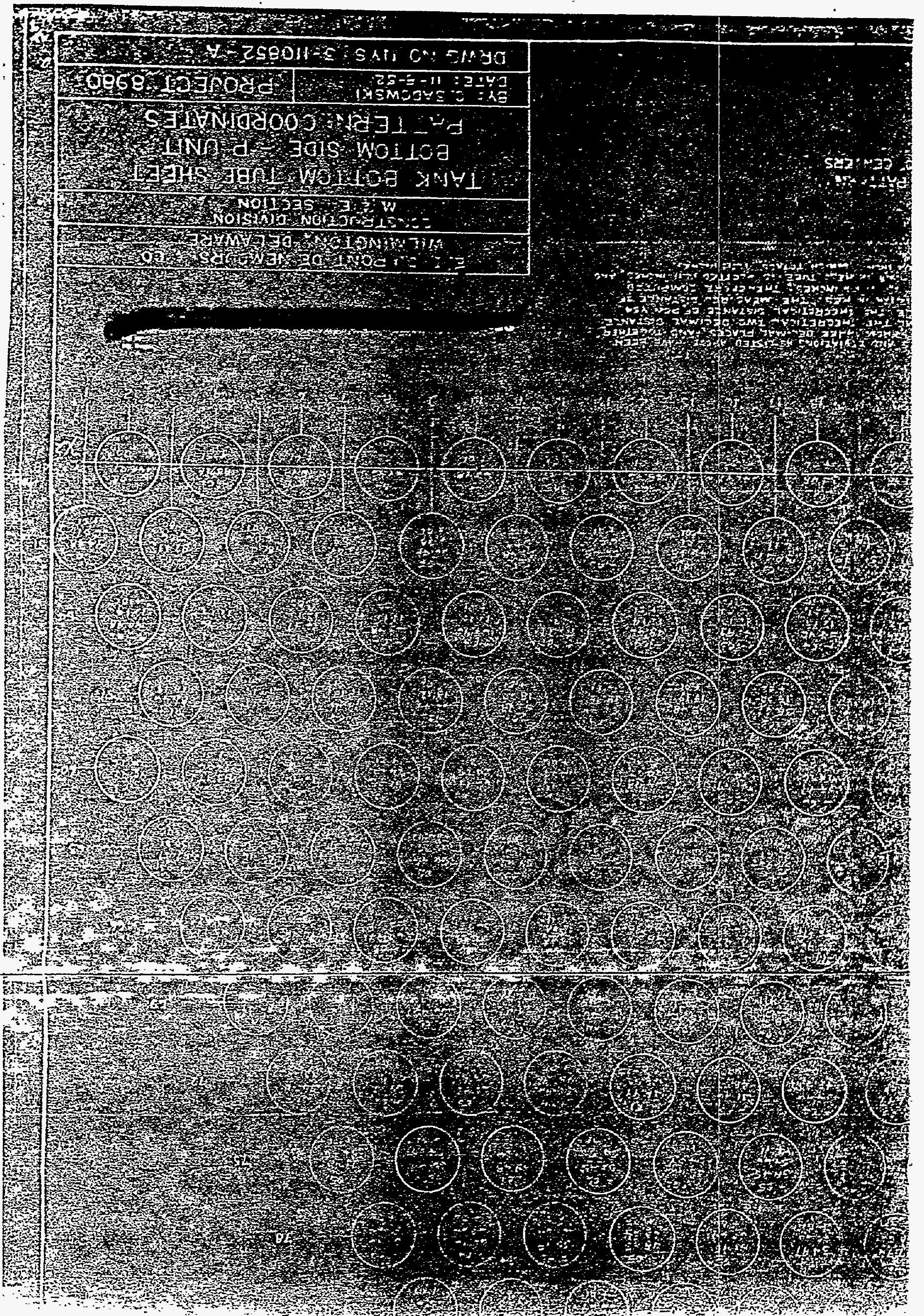




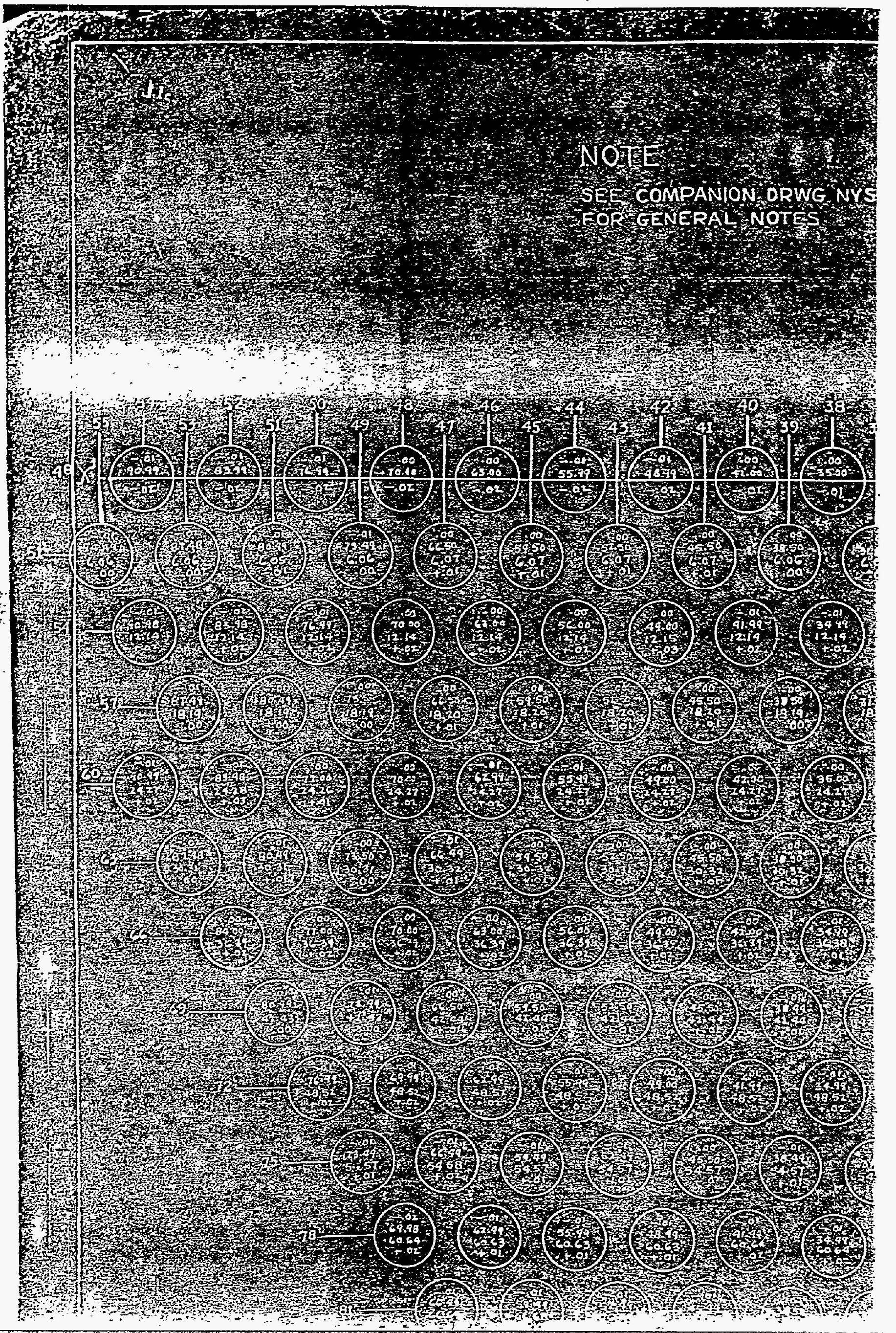



(6) $(26)$

tit

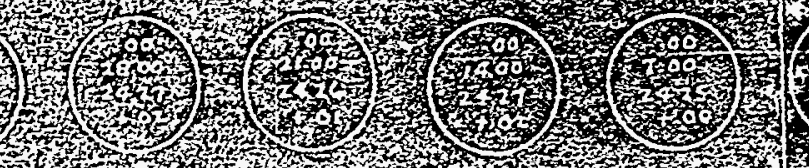

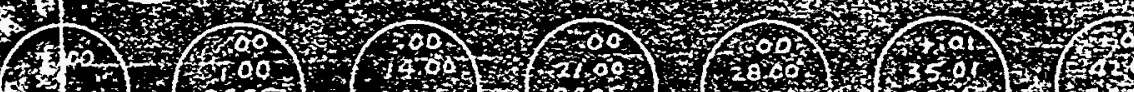
1.00)

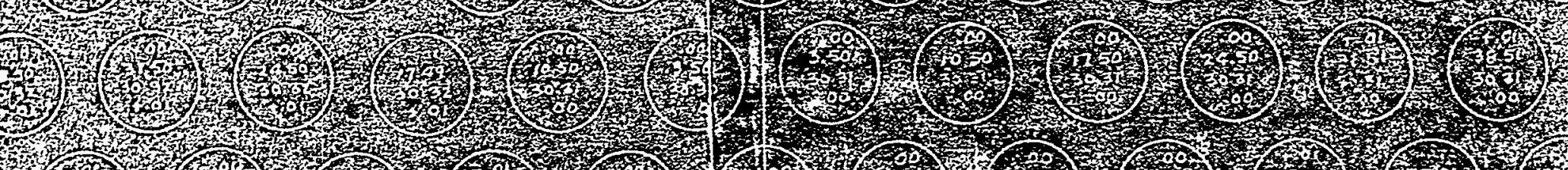

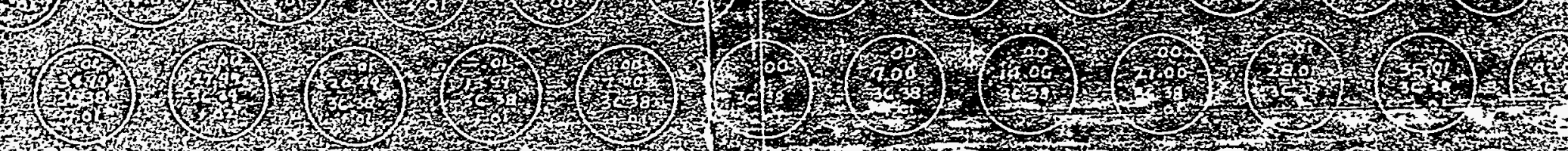
(2) (6) (2) 


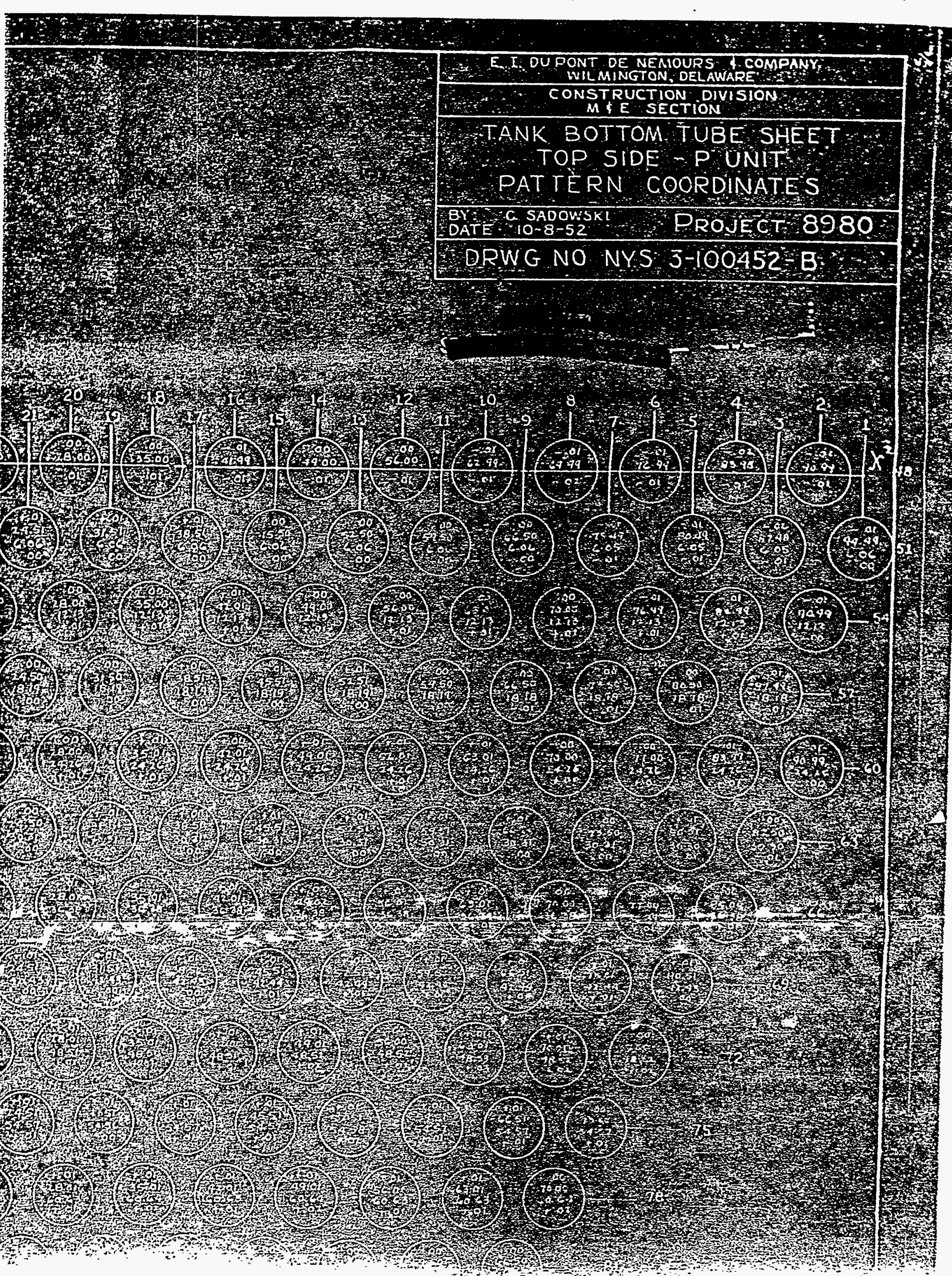




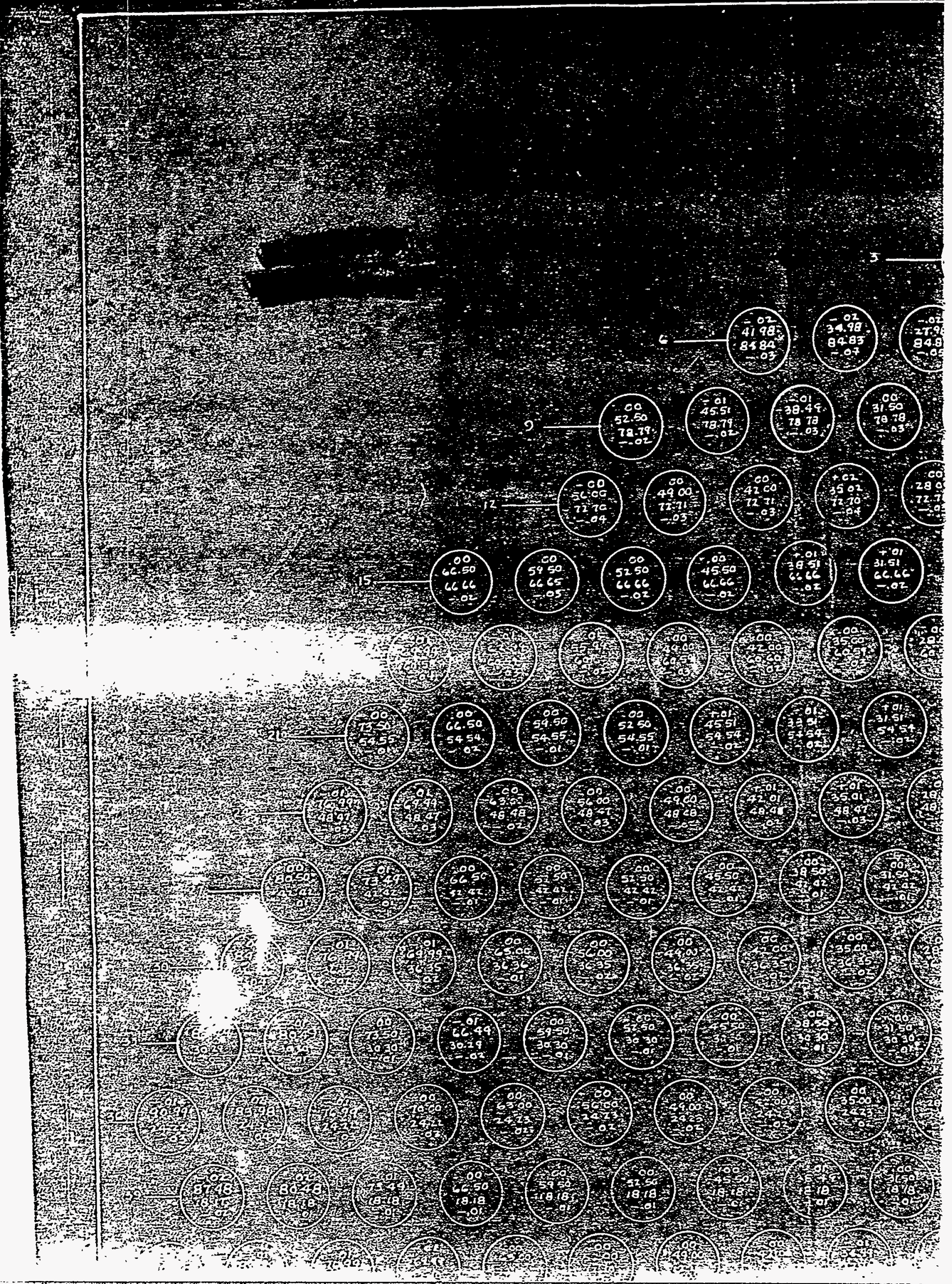


M. (2)

(3)

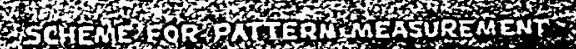

H
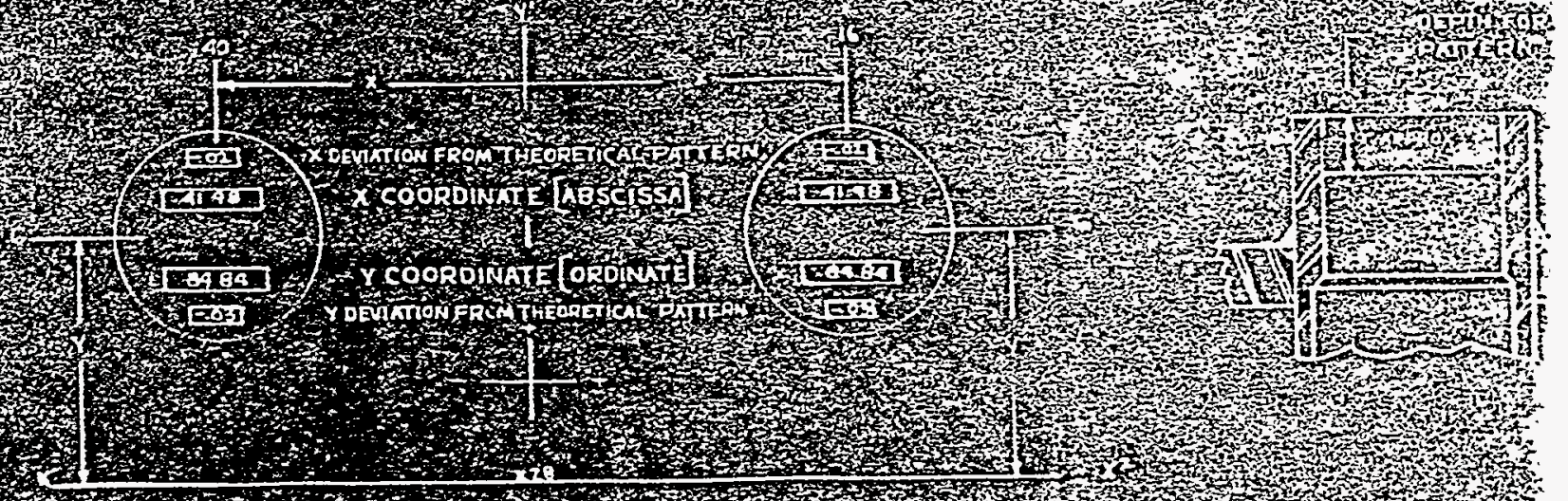
$6 y+4$

$? a^{2}$

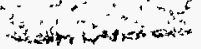

EXHIBIT

EESULPS OF PATTERN COORDIMATSS TAKEN ON TOF

AND BOTTOF SIDES OF TIH: "L" BOTTOR. TUBE SHEET ASSENBLY. 


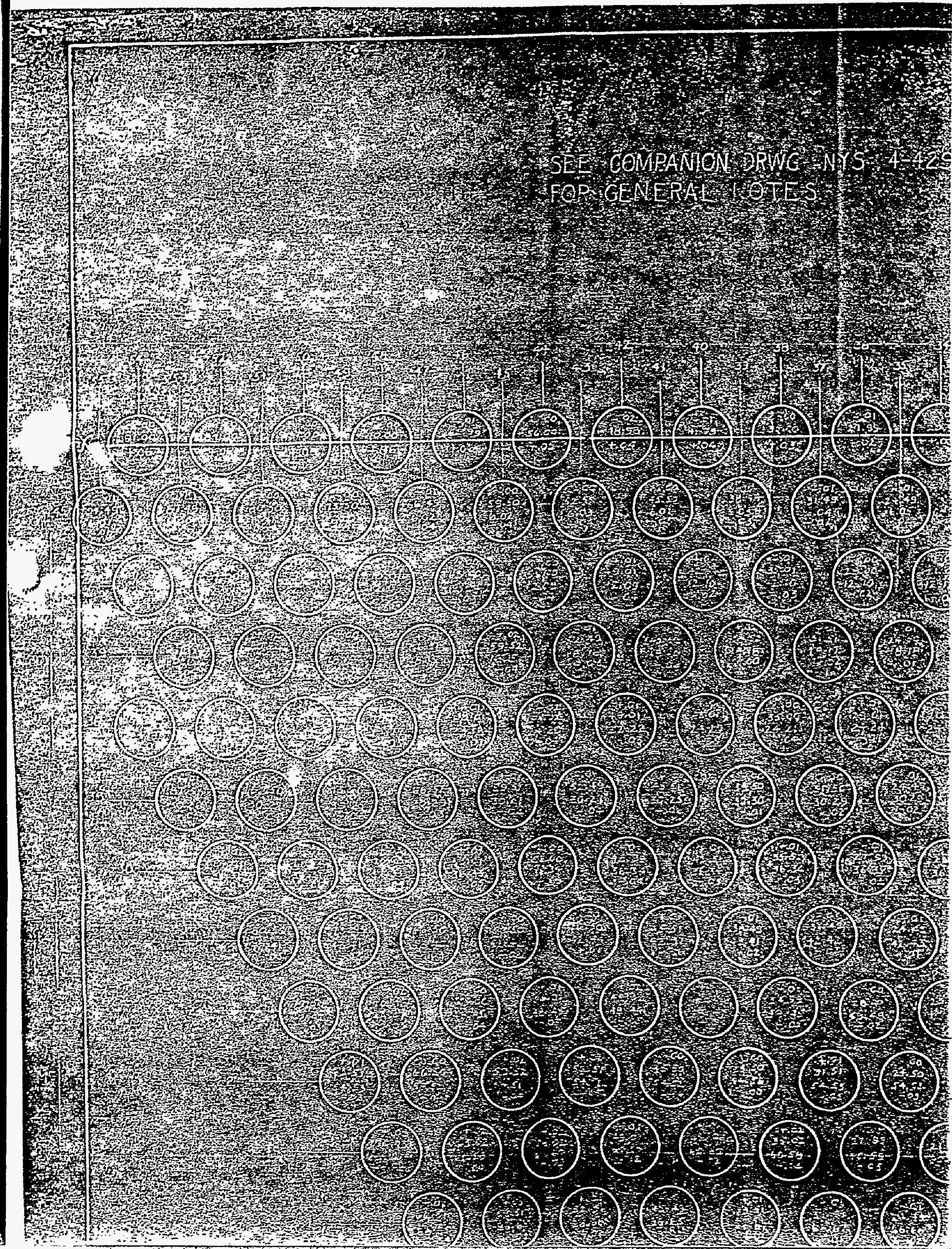




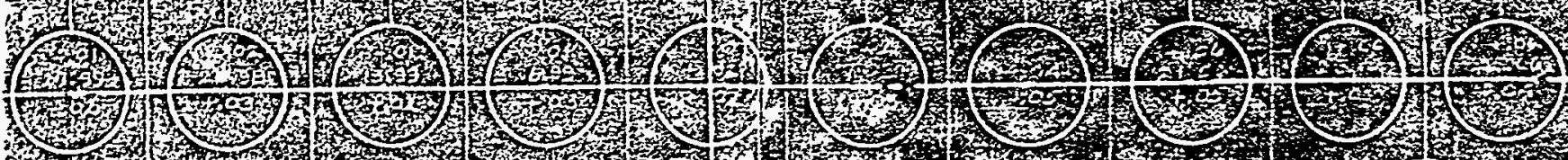




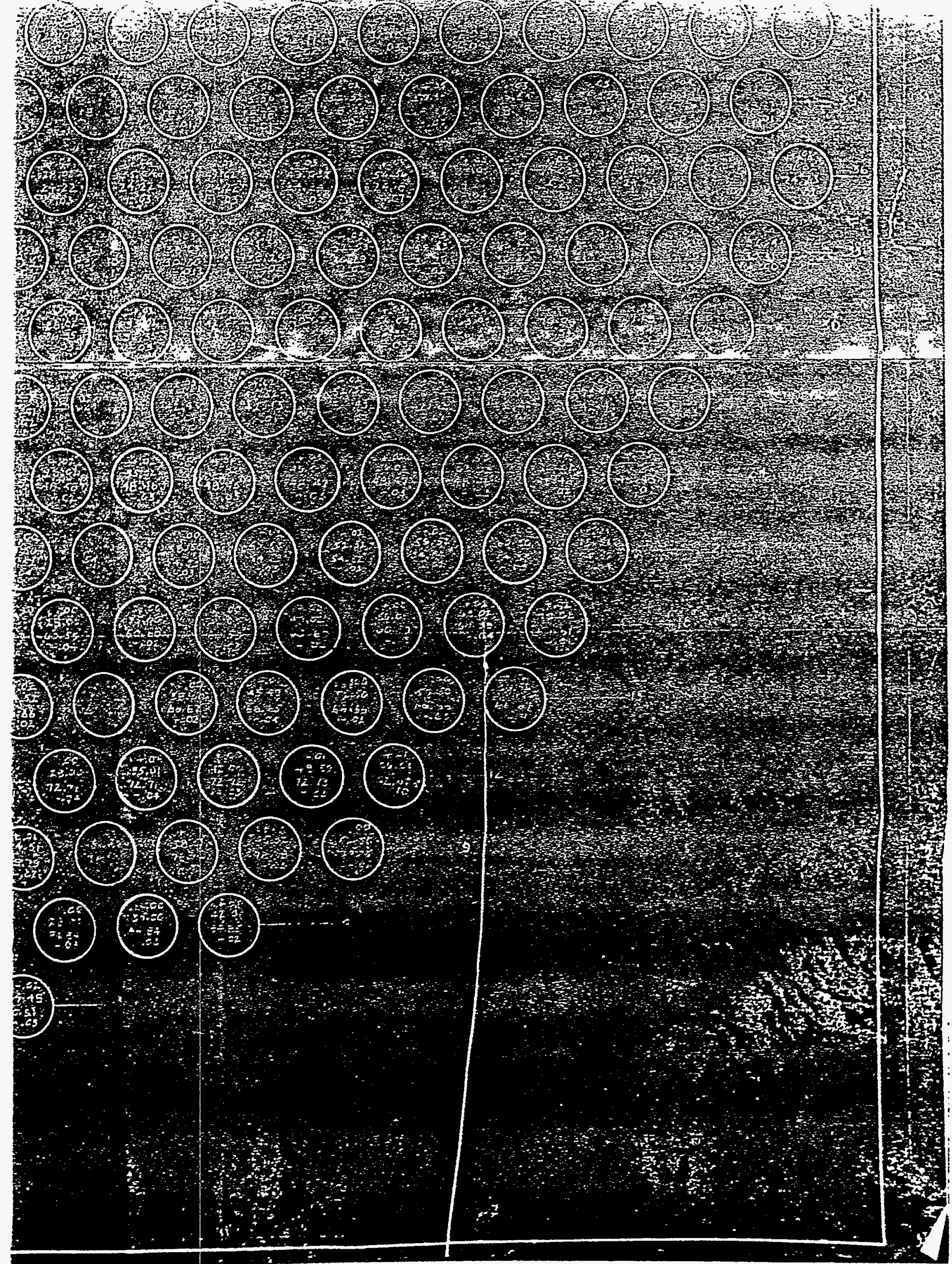




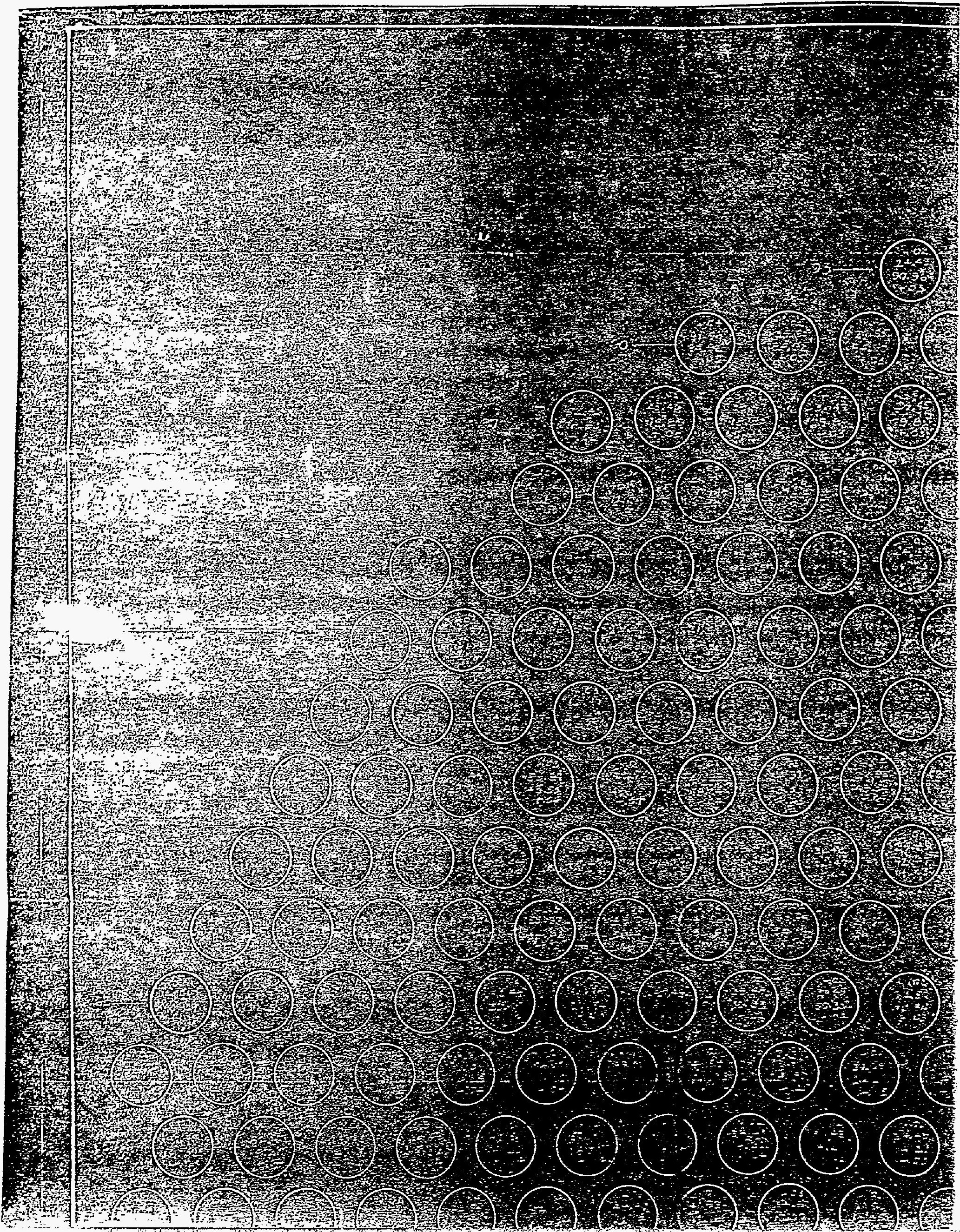




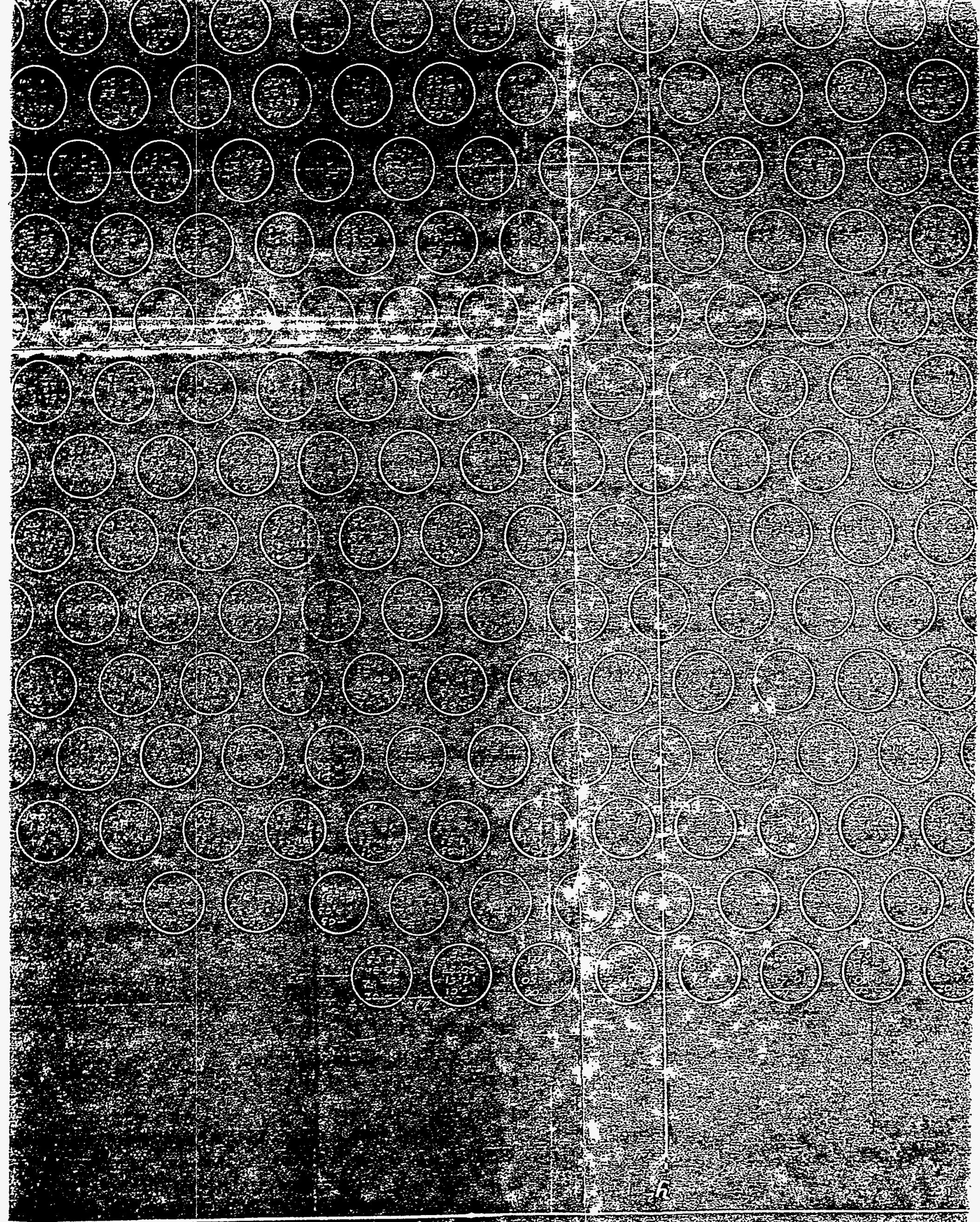


$\rightarrow$ ing ot

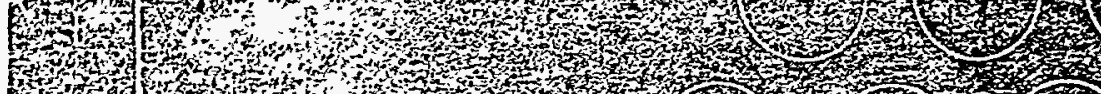

s. 


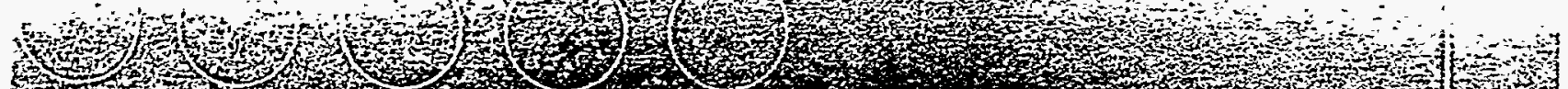

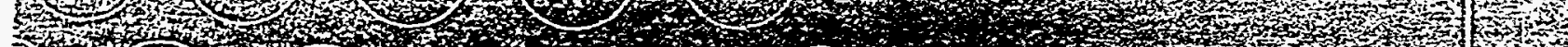

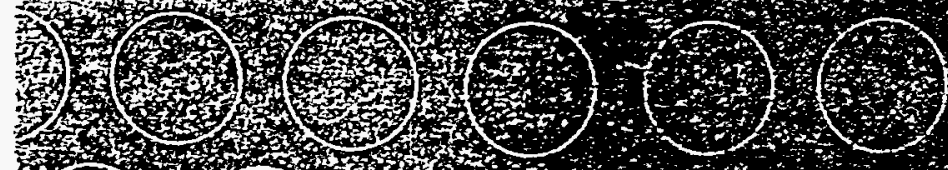

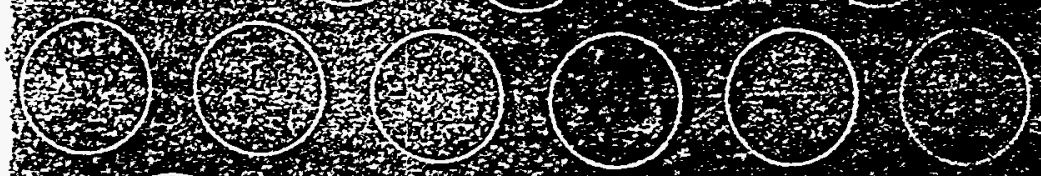

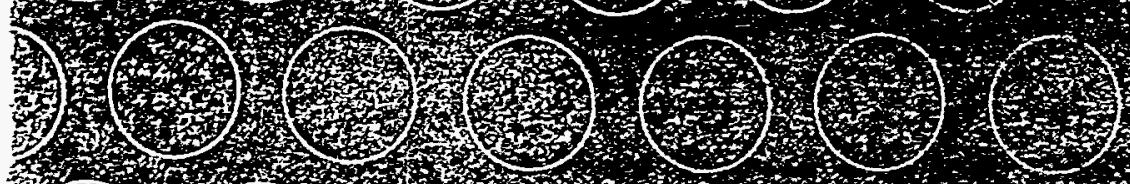

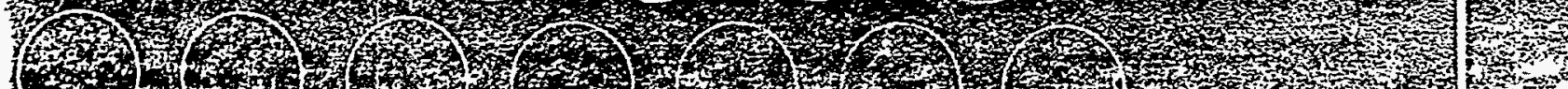

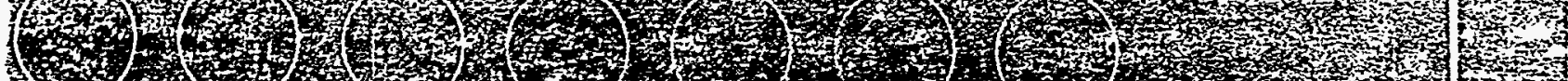

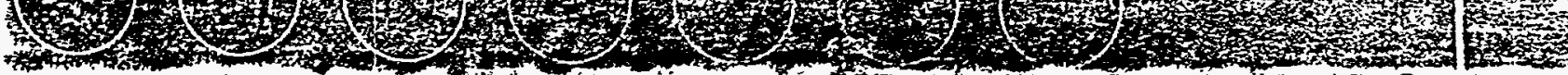
活, -

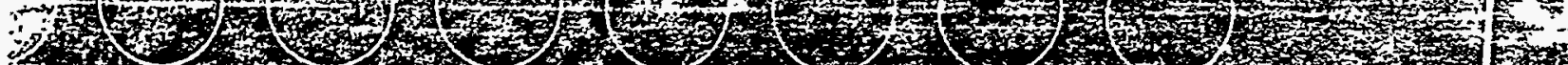

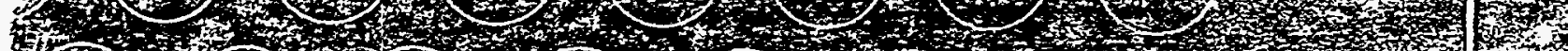

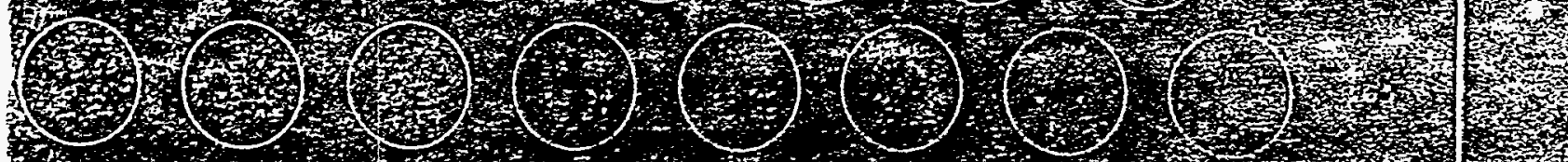
(3) $(3)(-3)(-3)$ (3) (3) (3) (3) $(3)$ DOOOOOOOO

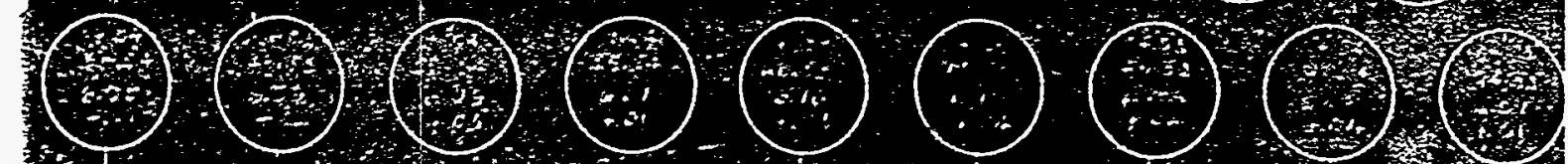

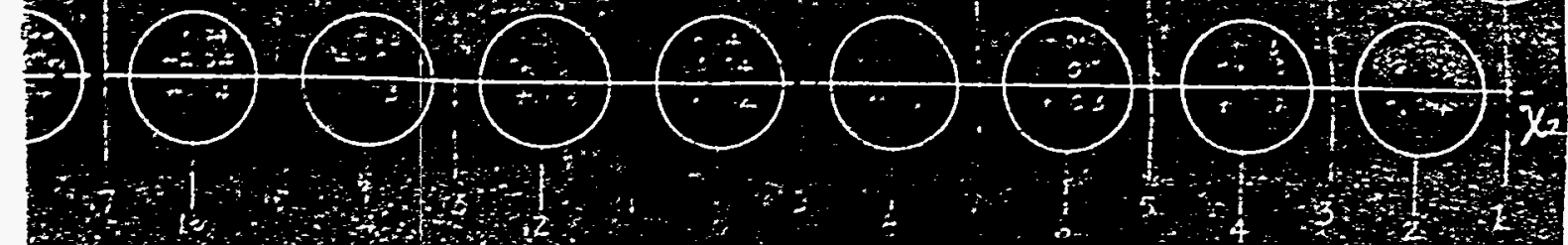

\begin{tabular}{|c|}
\hline 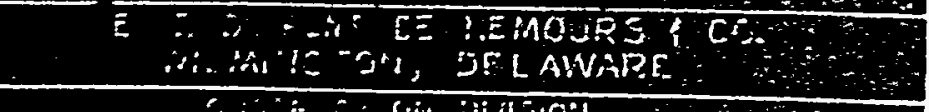 \\
\hline$\therefore$ in \\
\hline 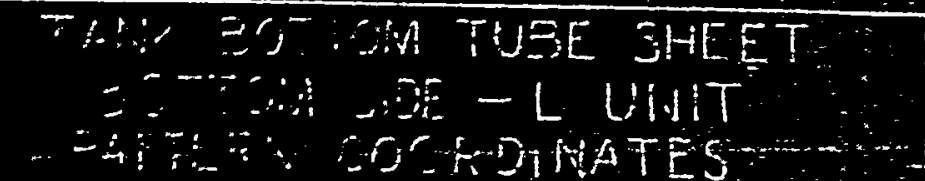 \\
\hline PACAÉt 9920 \\
\hline 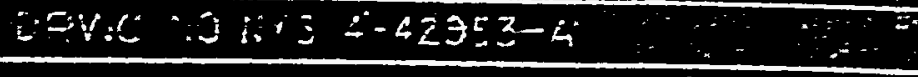 \\
\hline
\end{tabular}


SFE COMPANION DRAWING NYS 4-4 FOR GENERAL NOTES

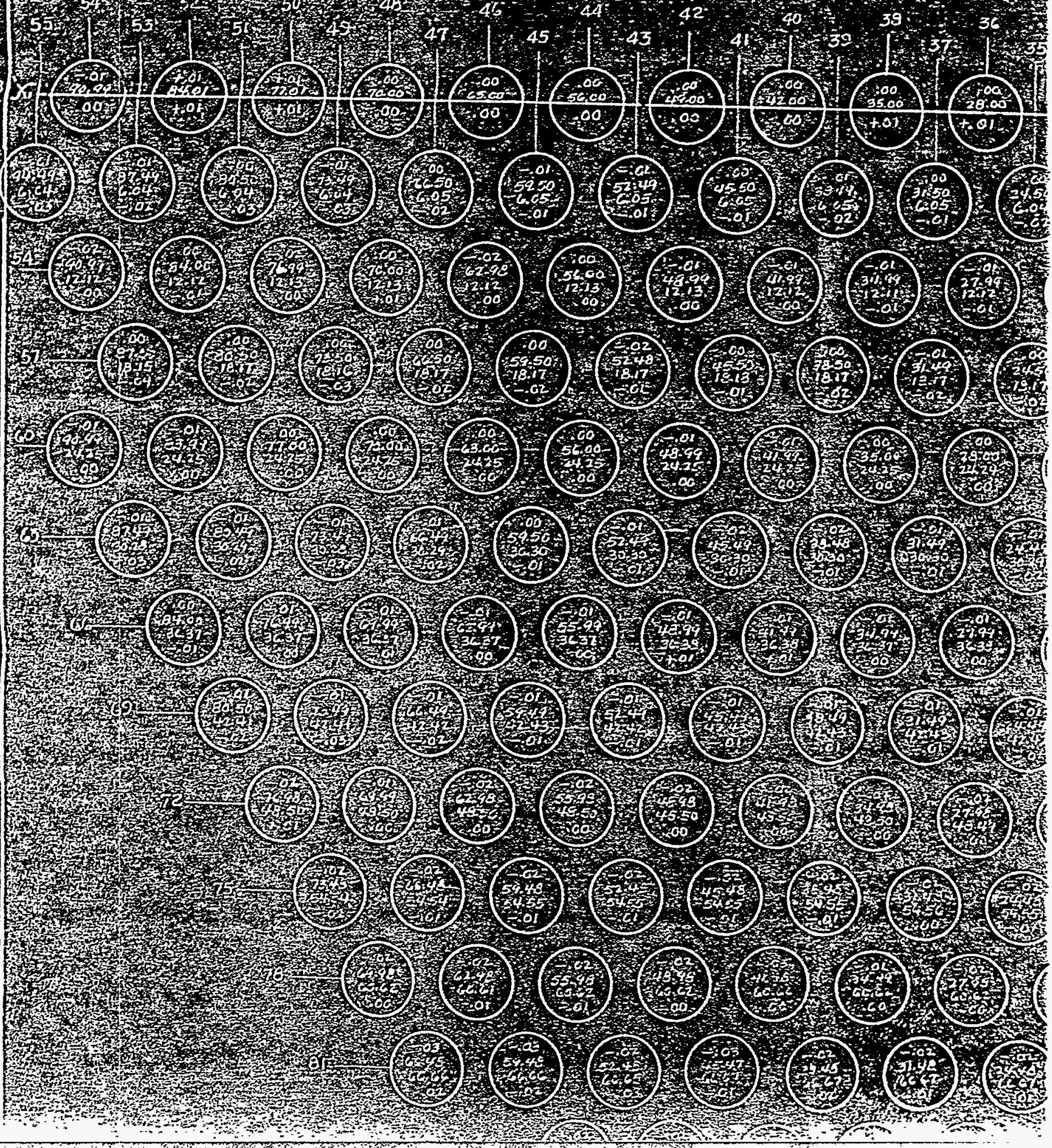




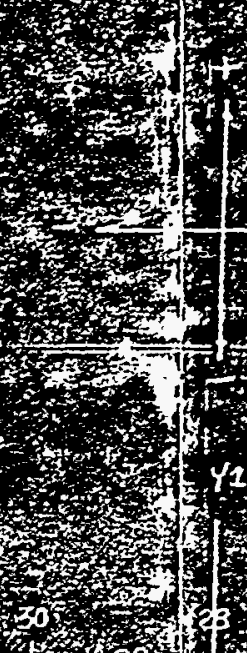

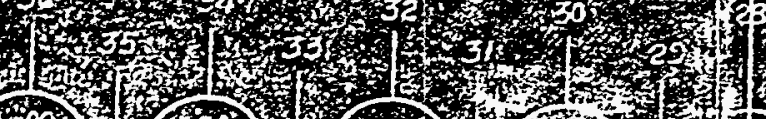

(2) (2)

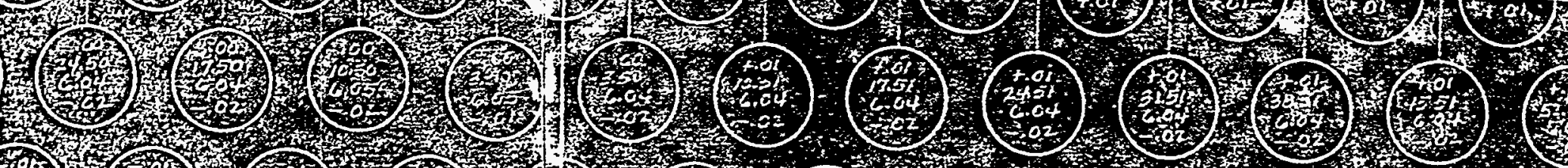

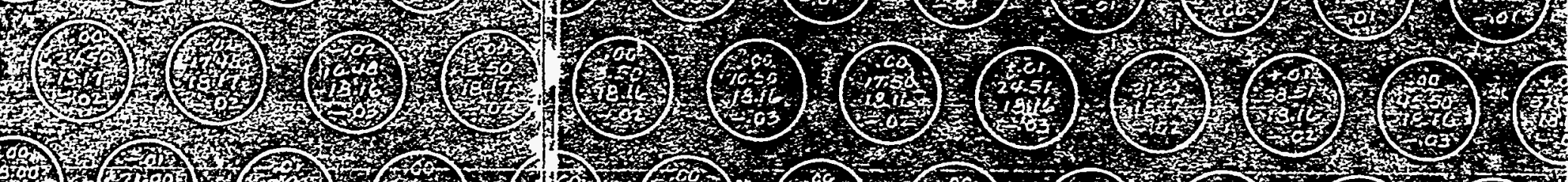

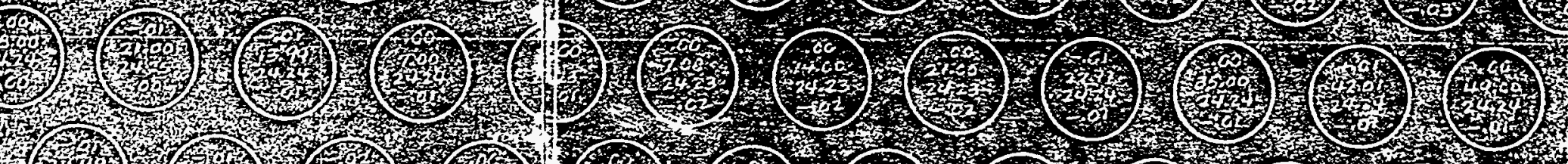

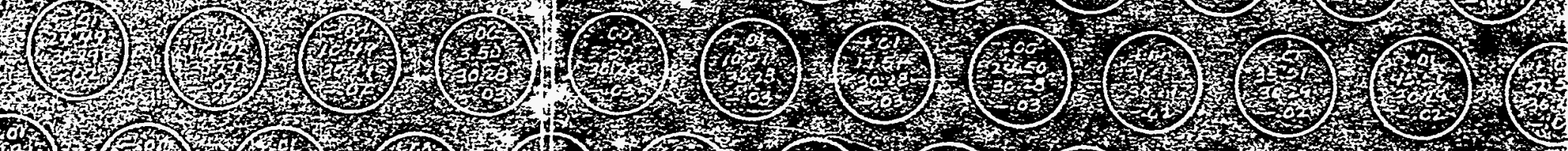

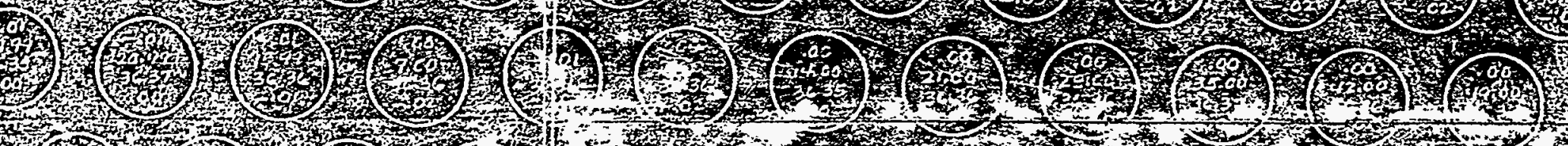

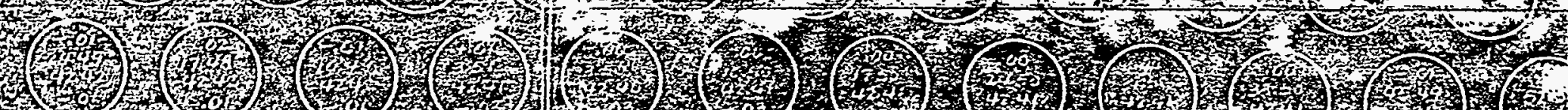
(r.)

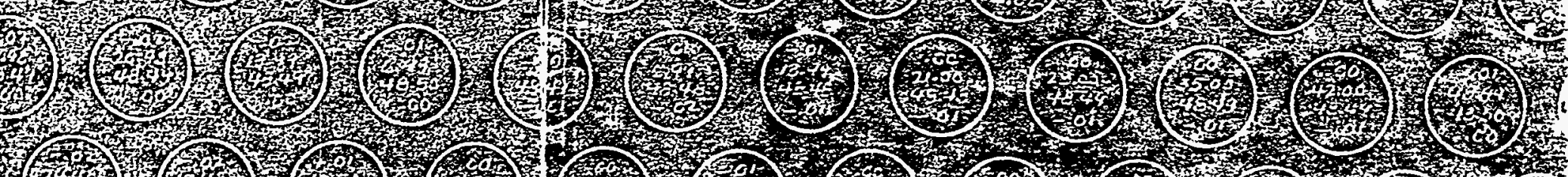
(4) (2) 


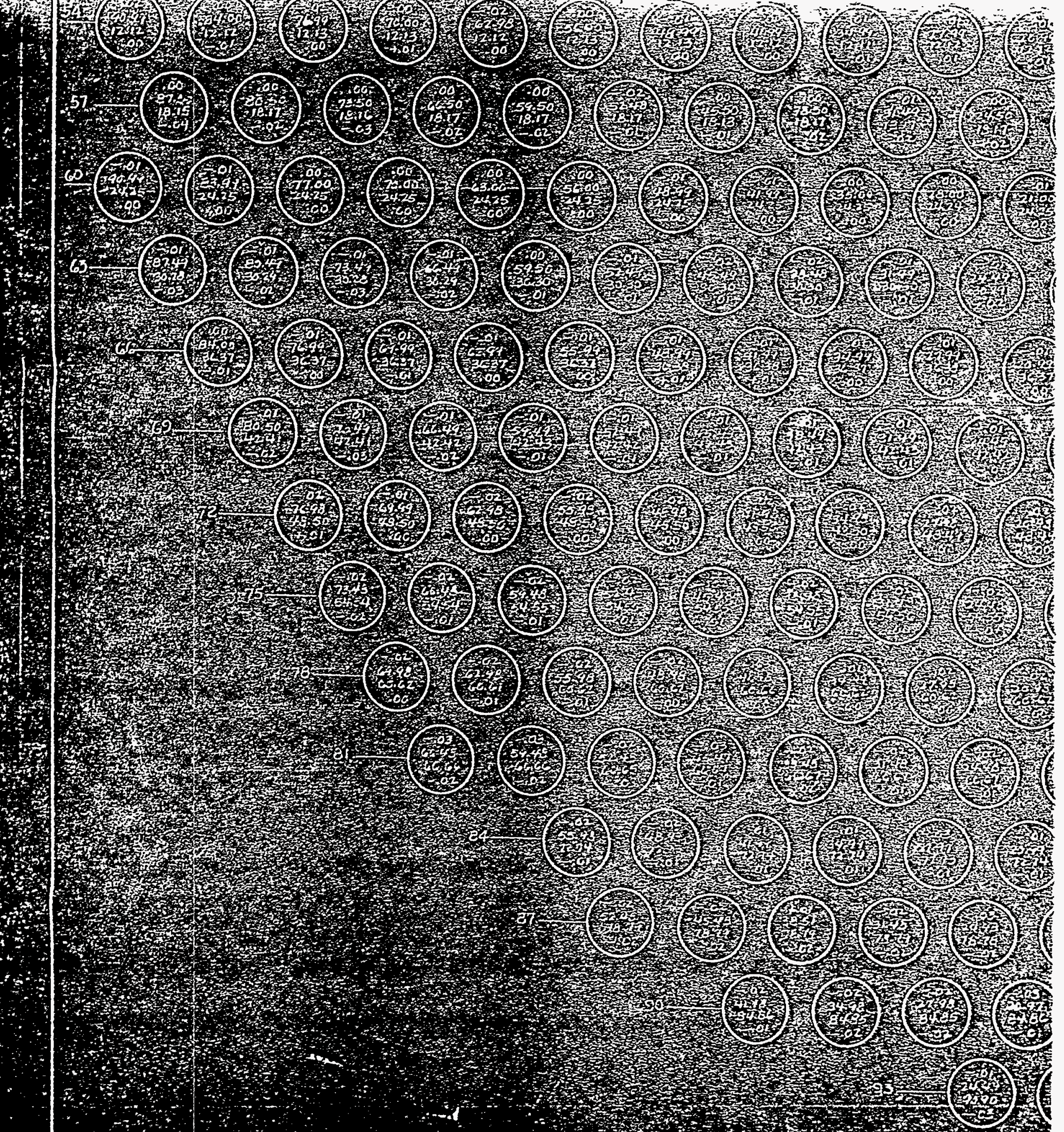




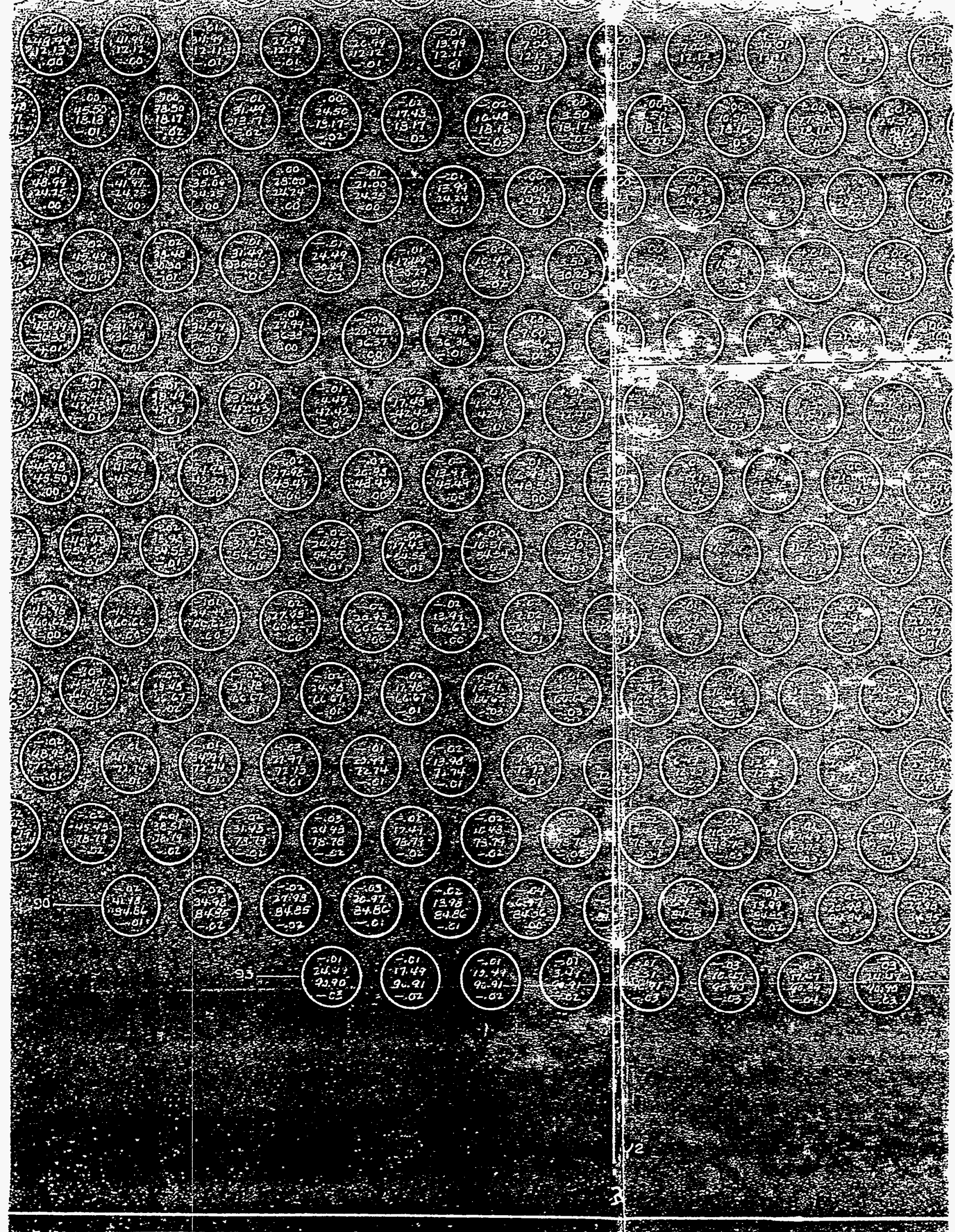




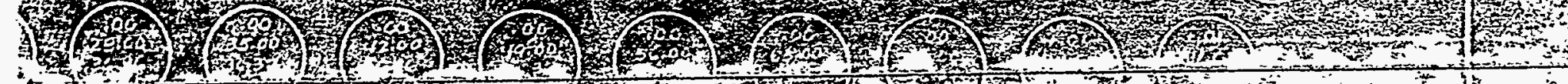

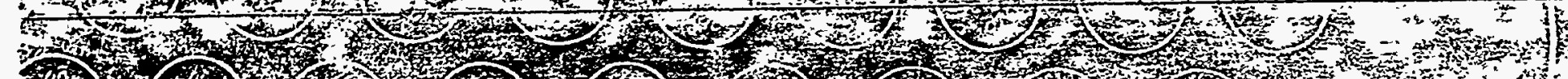

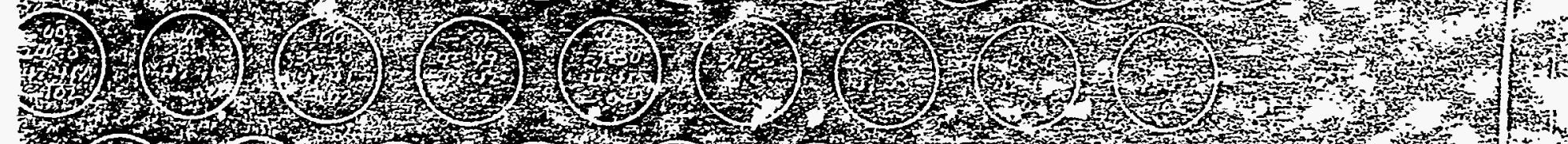
13.7. (6) (6) (6) (7).

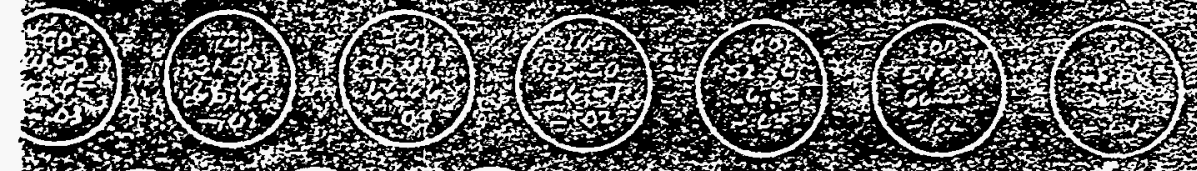
26) 20.6) 垔

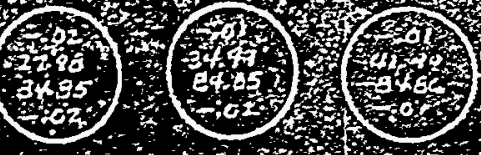




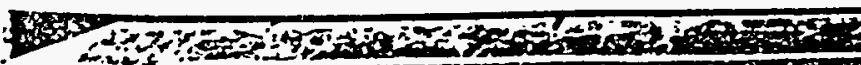

in

i fos

is

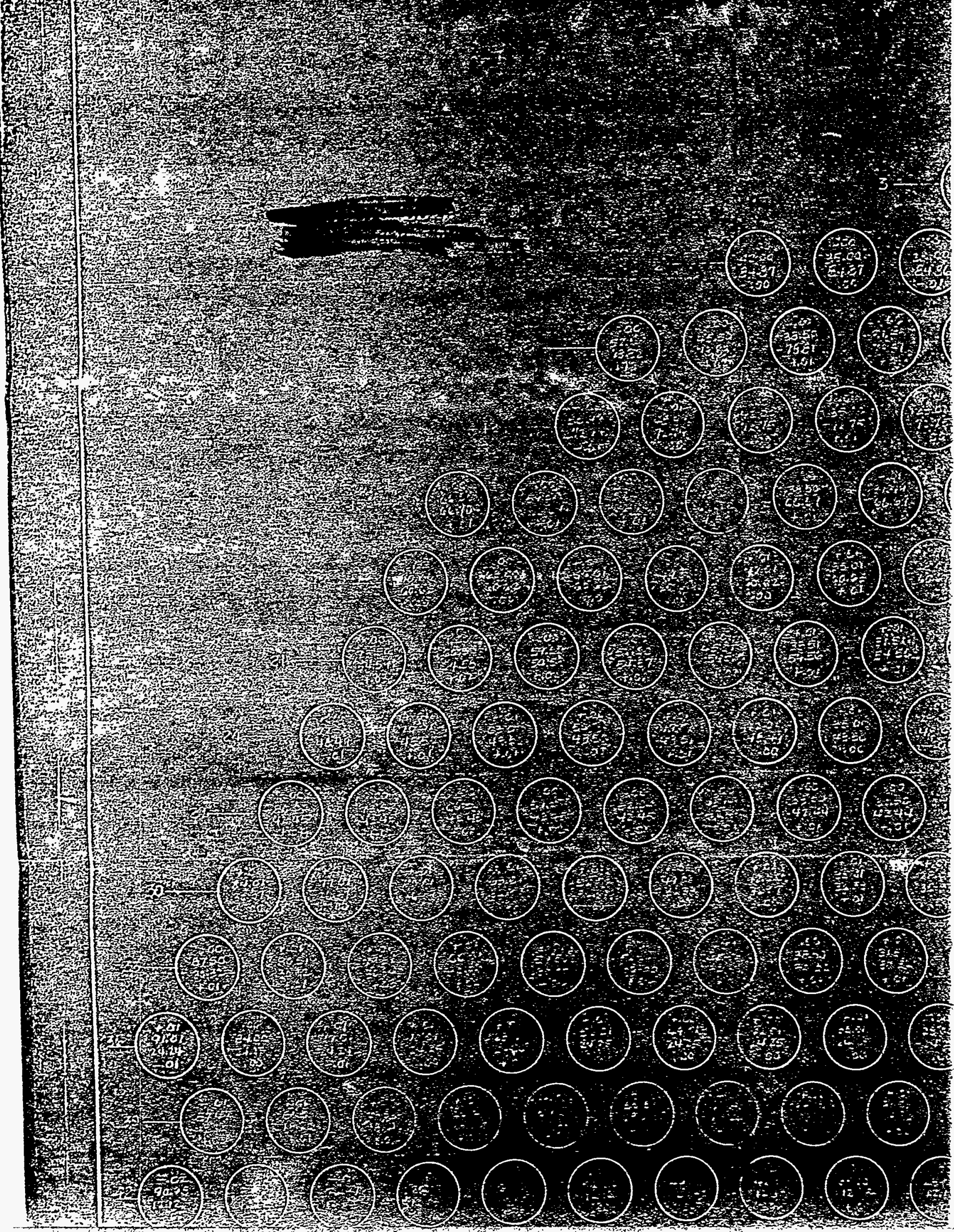




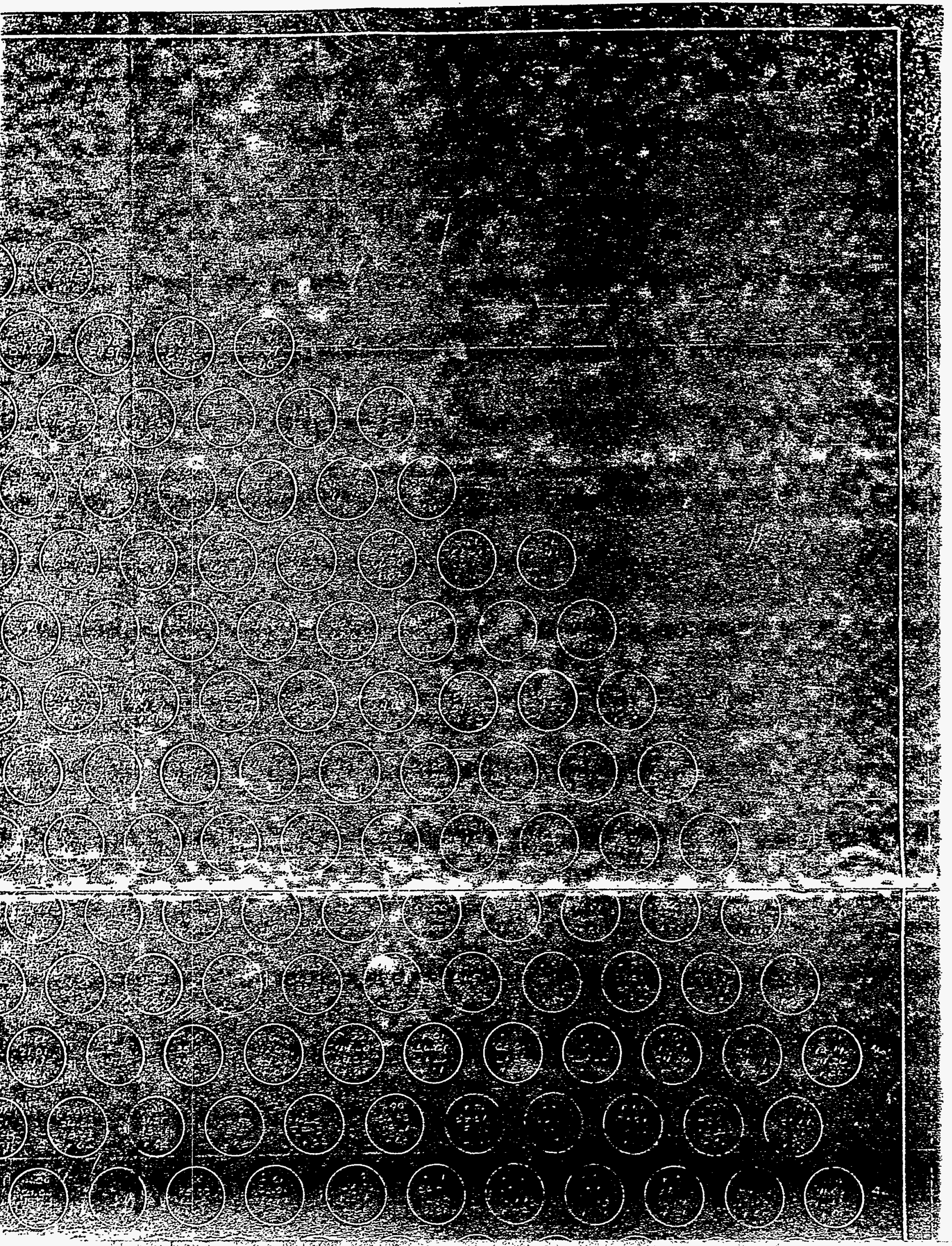




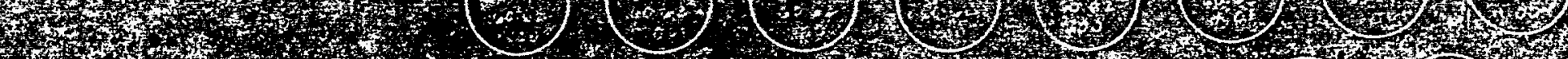
676 f 19.

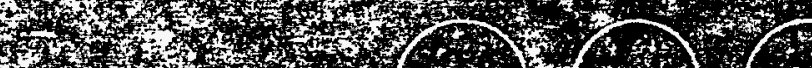

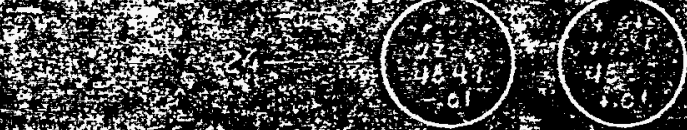

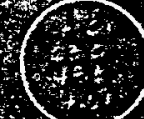

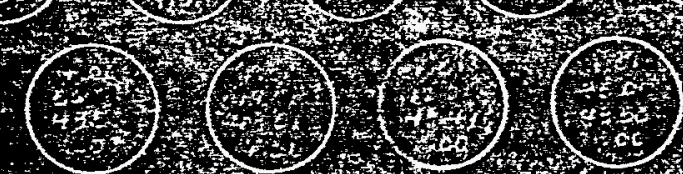

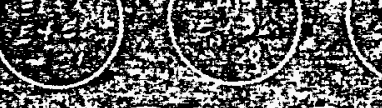

政

,

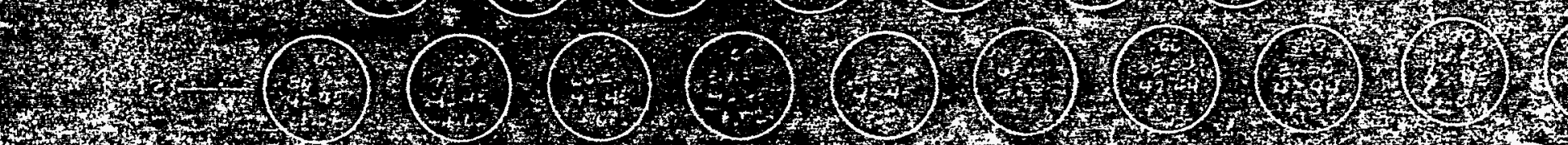

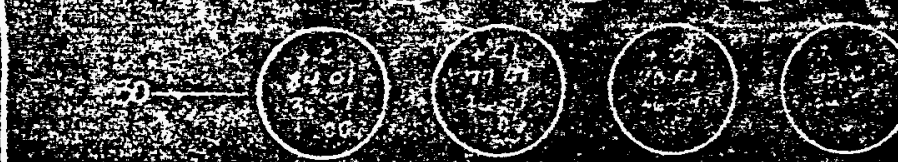
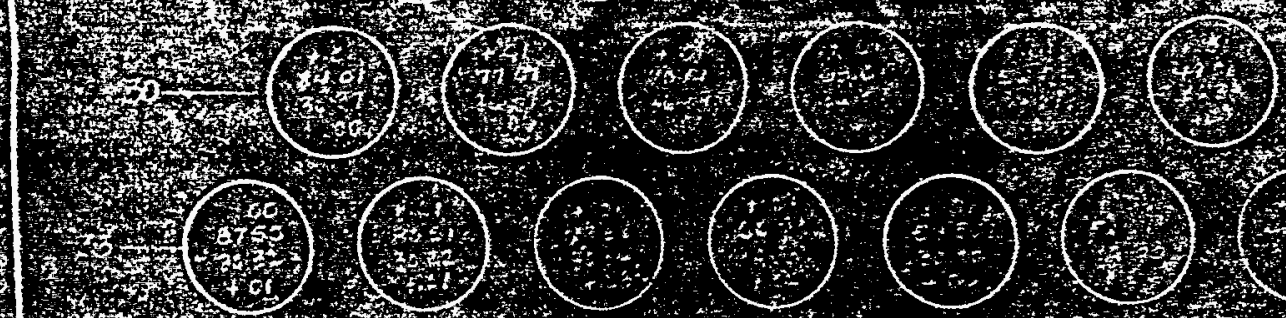

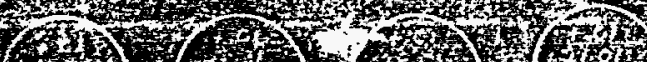

\section{$304040 \times 20$}

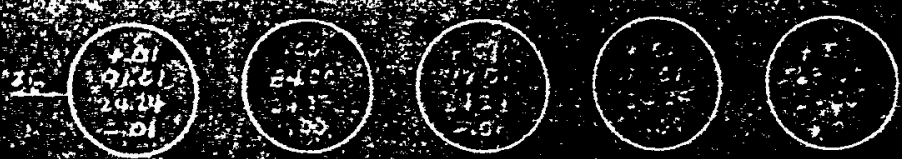

$x-x^{2}+3$

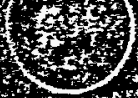

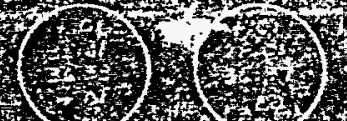

$4\left(\begin{array}{c}3 \\ 3 \\ 2\end{array}\right.$

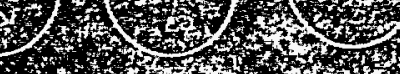

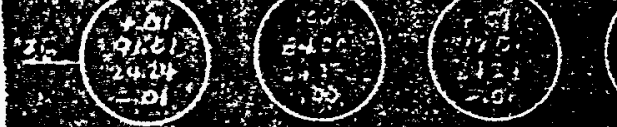

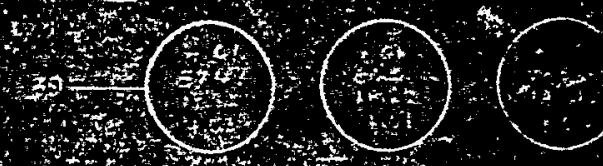

$4=\left(\begin{array}{c}-102 \\ 10.12 \\ -6\end{array}\right.$

45
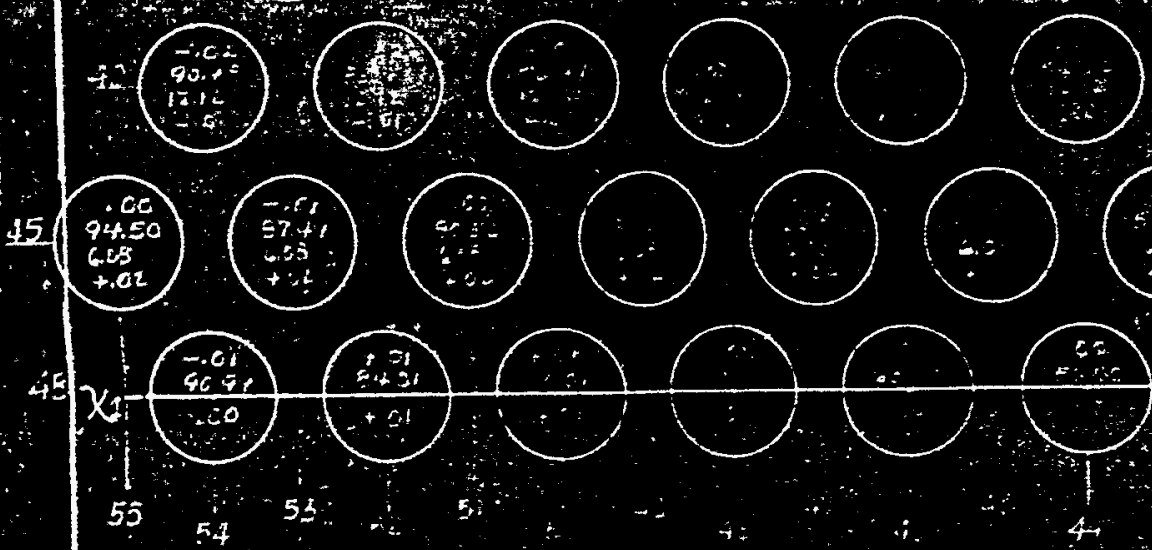

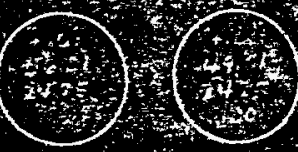

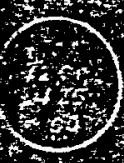

$(5$

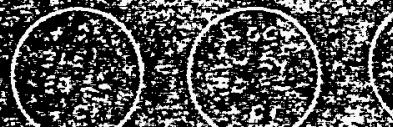

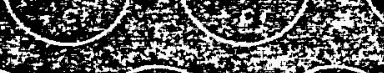

FAT

SH:B?
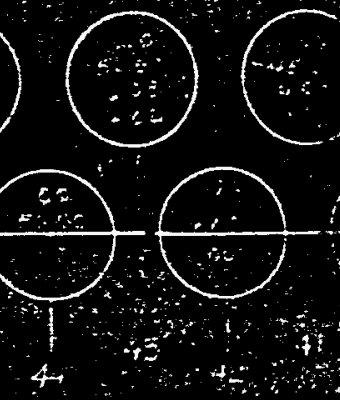

4
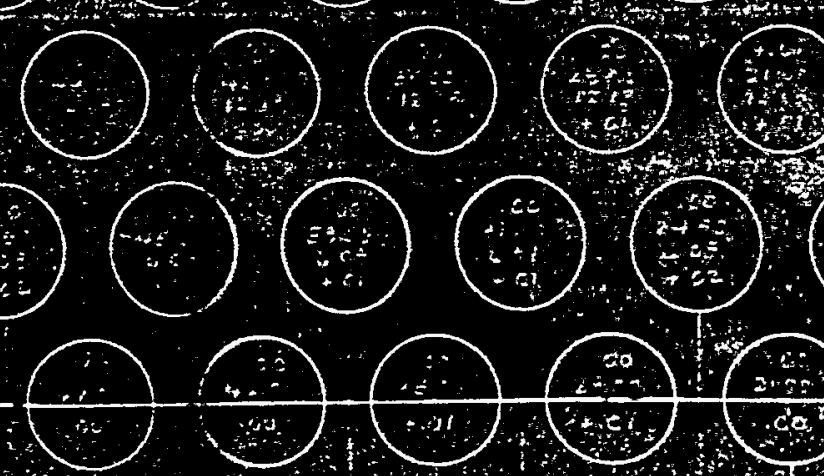

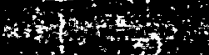

$+4$
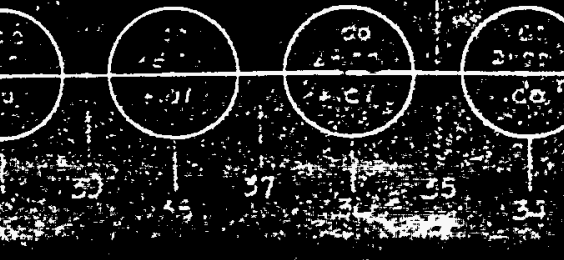


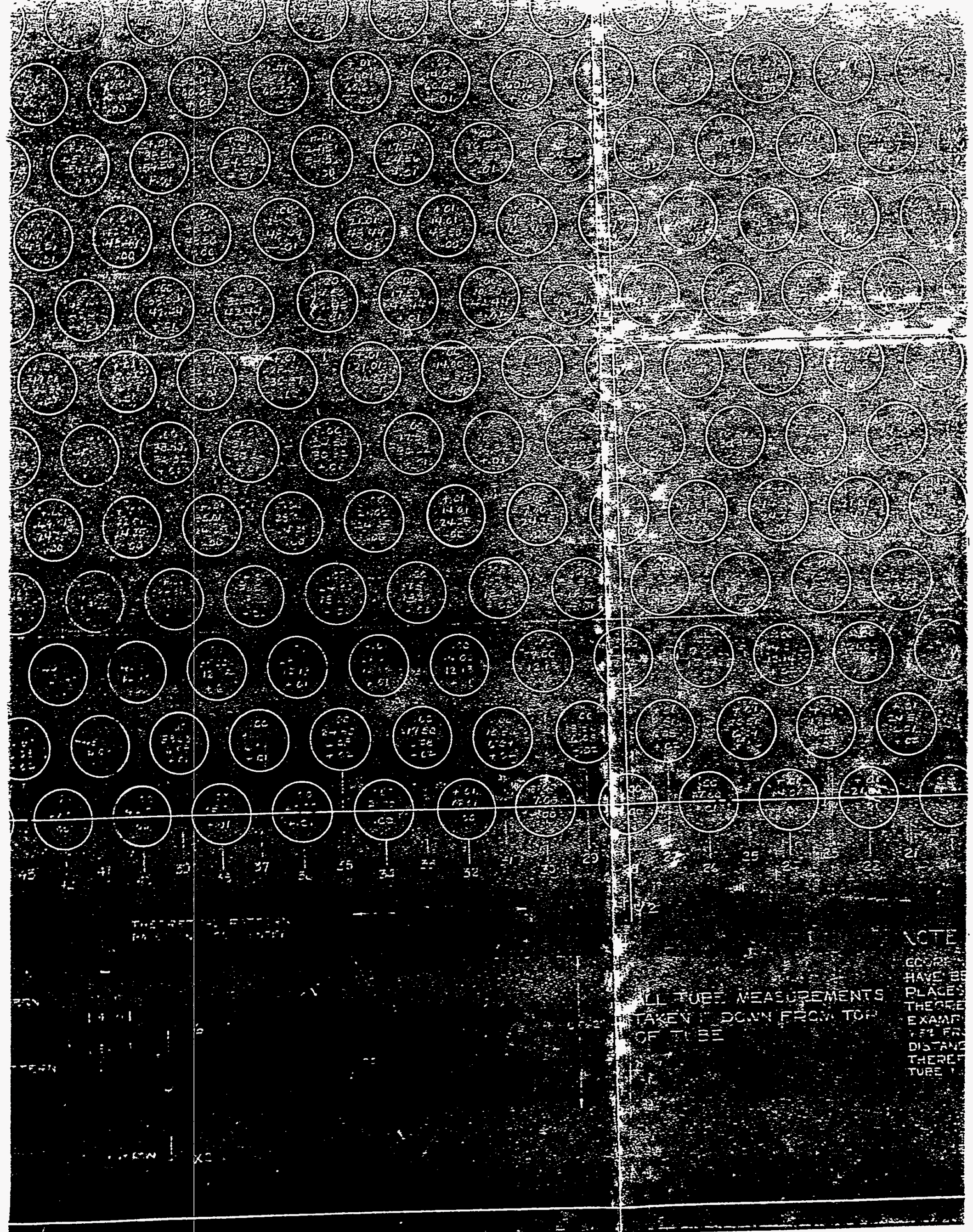




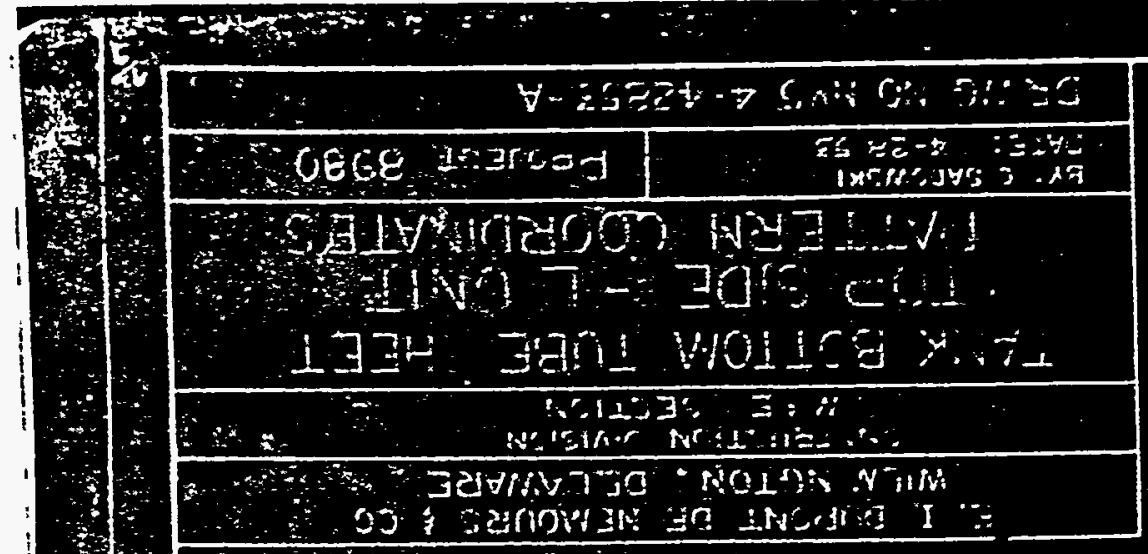

and

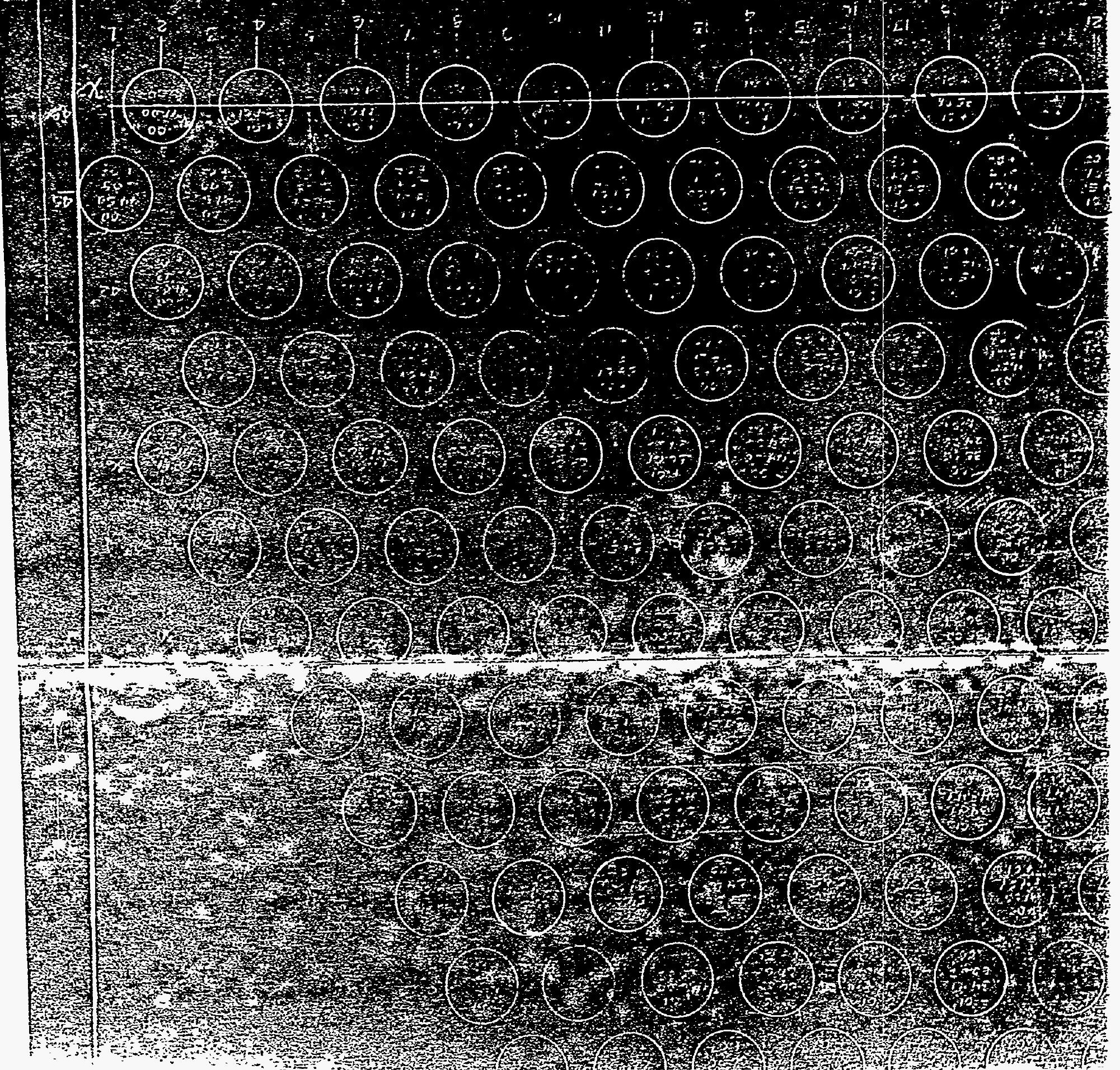


cleaned the interior of the unit. The cleaning procedure established for this unit was formulated in a meeting hield and Dowell Inc. The primary purpose of this meetinghas

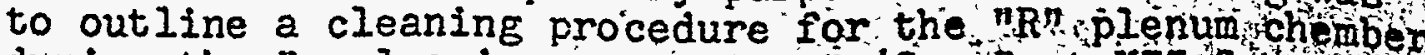
during the "recleaning operations" (See Part VII Section) item $15 \mathrm{~A}-(5)$ of this manual for resume of this problen which were currently under way in the shop to salvago this unit. Sence at this time no definite procedure for cleaning any sub-assembly had been establit shed it itwas decided to include a cleaning precedure for rnt bottom tube sheet and top tube sheet in the overalloleang program. However, due to the urgency of eleangh to the problem encountered on the $\mathrm{n}_{\mathrm{P}} \mathrm{p}$ Tenum chamber no deflat step by step cleaning procedure was outlined fo $x^{2}$ he th bottom tube sheet. In lieu of this the cleans proceare outlined for the "R" plenum chamber was used as $\mathrm{g}$ guffo for the cleaning of the " ${ }^{n}{ }^{n}$ bottom tube sheet and also the top tube sheet.

Essentially, internal cleaning of the thin bot tom tube sheet was the same as the "R plenumonamboncept for the methods incorporated 1 the handing and gett ing the cleaning solution into and out of the unit for

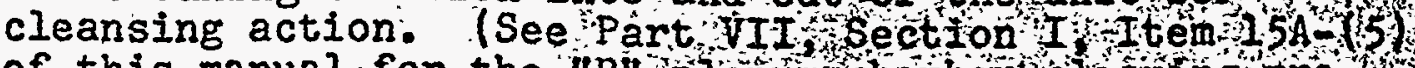
of this manual for the "rin penum chanber cleaning procedure).

A resume of the internal chemlal cieaning performed on the " ${ }_{R}$ " bottom tube sheet was as follow ring filling cradle was assembled on the thit thd nedest ary pipe connections were made on un th wass then moxed

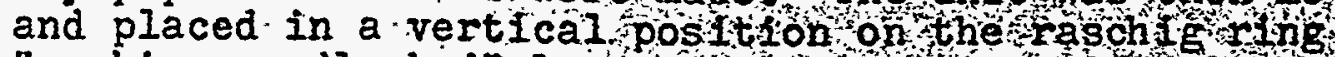
"rocking cradle bed" located next to a washing pit on th hot detergent supplied by Bowell wa sumped into the unit with hot detergent the solution on the nsta was in agitated for one-háf of an hourthrough ofr lines connected to the raschig $\mathrm{rng}$ inspection orts. These inspection ports were located anow the botto hallo of the unit in the wrapper plates of Pelatively, spealing inth

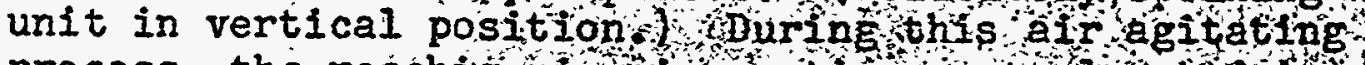
process, the raschig rng inspection ports 10 cated la wrapper plates around the tophalf of the undt fere opened thus allowing the hot deterent to be forced out through the ports under the alr agtating pressure the detergent remaining in the unit was draned through to of openngs in the wrapper plates $100 a t e d i n t h e$ bottom hal of o the unit while in a ventical position the unit whs the filled with warm distilled water for the bottomstad and allowed to overflow through the rashy ritue nspectlon ports located in the wrapper plates around the top hat of the runit. This rinsing acton was cont nuedrot 15 minutes. The noveriowing foperation was dscont nuted and with the unit stili completely folit of warmalstilfed water, it was air agitated for approxintely one hal hour. With in three minutes after atroteding thount was drained by opening up al1 port foles in the botom half of the unit During the draining opentino the unit was rocked in the cradle bed untilthe unit completely 
drained. The draining operation was completed in 45 minutes.

The interior of the unit was then visually examined by du Pont Inspectors. This examination consisted of viping clean paper towels on the inside surfaces of the unit. A1l paper towels revealed dark smudge marks; some black, others dark red. The unit was rejected by the du Pont Inspection Depertment on this basis; however, the Design Division reviewed the results and accepted the unit as being clean based on the supposition that the grime noted on the paper tovils was not detrimental to the operation of the unit.

(2) Establishing $X$ and $Y$ Centerlines on Top and Bottom Side of the Bottom Tube Sheet

After cleaning the unit, $X$ and $Y$ centerlines were re-established on the top side of the unit. The method used for establishing these lines was similar to that described in Part II-A, Section 13. After this, the assembly was leveled using the Vild NIII Precision Level and target. (See Part III, II-J, for use of instrument in leveling of units.) Next, the $X$ and $Y$ centerlines on the top side were transferred to the bottom side of the unit using the pictorially ililustrates how the transfer of $X$ and $Y$ axes vas accomplished.

The unit was then turned bottom side up and a 18. straight edge laid along the $X$ axes. The straight edge was then aligned to coincide with the two points previously transferred to the two tubes at the extreme ends of the $X$ axis. A line was then scribed along the bottom ends of the tubes using the face of the straight edge as a guide. Before moving the straight edge, measurements were taken from the face of the straight edge to the inside diameter of each tube located on the $X$ axis (row $Y 48$ ). (See photo serial \#53 in Part II-A, Section 13.) The straight edge was removed and the bore diameter of each tube was taken in the same direction using a standard dial indicator bore gage and ring gage. Next, the straight edge was laid along the $Y$ axis (row $\times 28)^{\prime}$ and the above procedure repeated. The measurements takention the tube bores were used in tube pattern calculations for determining the location of a tube with respect to the $Z$ and $Y$ axes.

B. "p" Unit

(1) Dowell Cleaning

Prior to loading raschig rings in the bottom tube sheet, Dowell Inc. of Wilmington, Delaware, chemically cleaned the interior of the unit. Cleaning of this unit. was similar to that performed on the "R" bottom tube sheet, except for minor changes in the length of air agitation time and the number of times the unit was rinsed 


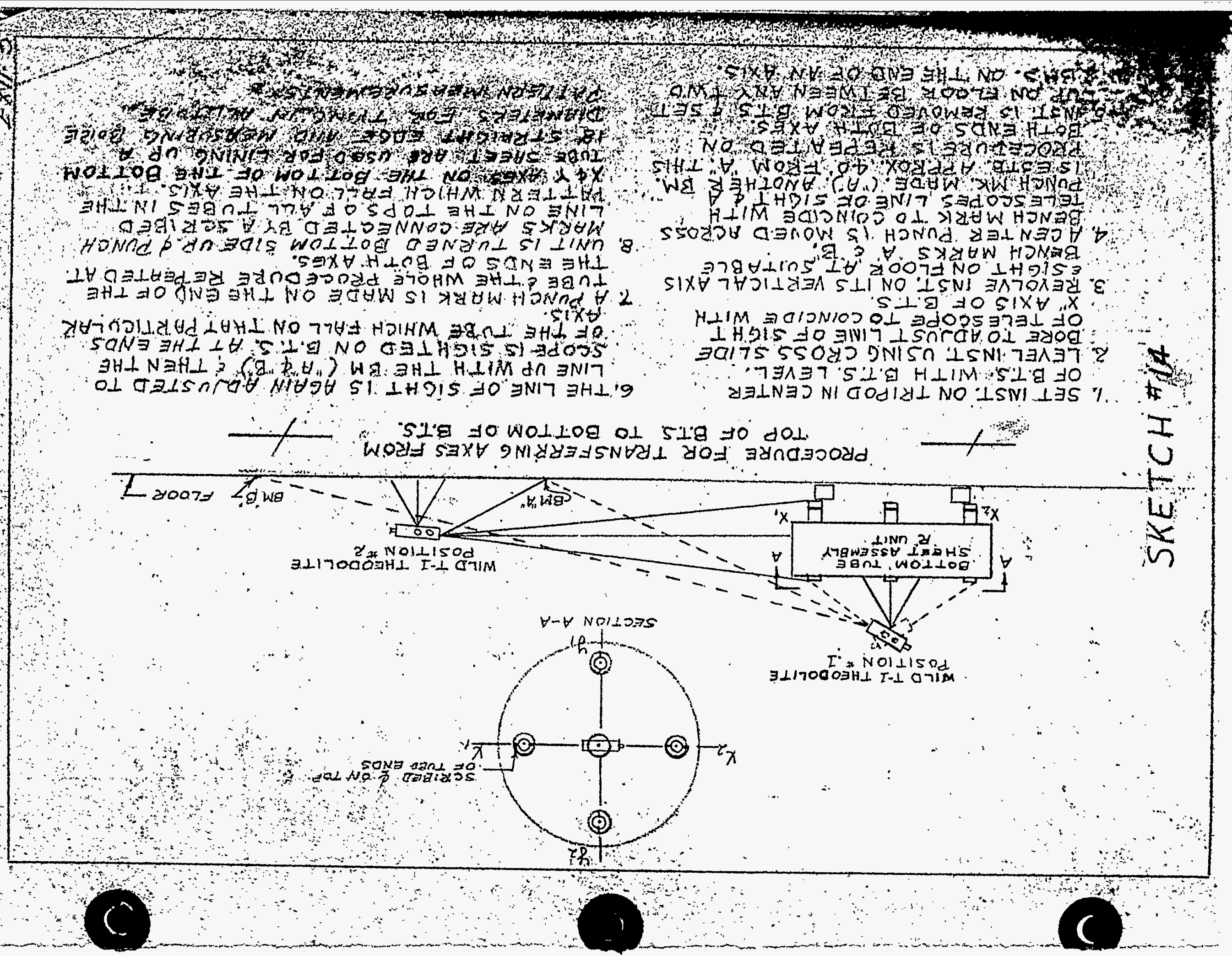


A resume of the internal chemical cleaning performed on the "p" bottom tube sheet assembly was as follows: The raschig ring filling cradle was assembled on the unit and necessary pipe connections were made. The unft was then moved and placed in a vertical position on the raschig ring "rocking cradle bed" . located next to a washing pit. A hot detergent supplied by Dowell was pumped into the unit until it was fuli. After filling the unit with hot detergent, the solution on the inside was air agitated for $2^{\frac{1}{2}}$ hours through alr. ines connected to the raschig ring inspection ports. These inspection ports were located around the bottoin half of the unit in the wrapper plates. (Relatively speaking with unit in vertical position.) During this air agitating process, the raschig ring inspection ports located in wrapper plates around the top haif of the unit were opened, thus allowlng hot detergent to be forced out through the ports under the as agitating presure. The detergent remaining in the unit was drained through two $4^{\text {n }}$ valve openings located in the bottom half of the unit while in a vertical position. After draining the detergent from the assembly, it was filled with warm rinse water and agitated by rotating the assembly as the rinse water was drained through the two 4 valve
openings. The unit was rocked in the cradle bod until the unit completely drained. The above rinsing procedure was repeated two more times, and the unit was inspected internally for cleaniliness. The inspection procedure consisted of a visual inspection of the interior through the $2^{n}$ inspection ports and rubbing cotton swabs over in the inner plate surfaces through the two 4" valve openings. The interior of the assembly was found clean and accepted for rasch $1 \mathrm{~g}$ ring loading.

(2) Establishing $X$ and $Y$ Centerlines on The Top and Bottom Sides of the Bottom Tube Sheet.

This inspection was performed in a similar manner to that described in section $16 \mathrm{~A}-(2)$ of this manual.

C. "L" Unit

(1) Sandblasting Top SIde of Unit and Wrapper Plates

The top side and wrapper plates were sandblasted with iron-free silica sand to remove all surface fomix impurities and weld oxidation from the exterior surfaces ltop and wrapper plates only. "Bottom side was not sandblasted) prior to final visual weld inspections and pressure tests. Since hydrostatic and freon testing follows the sandblasting operation, all openings in the bottom tube sheet were sealed with equipment sultable for both operations.

Before sandblasting this unit, approximately 15 ps1 of air was introduced into the interior to prevent fine grit from entering the ssembly. After the sandblasting operation, looso sand and dust was biown off 
using air hose.

Generally, all sandblasting was done outside the shop with the unit resting on a railroad flatcar; however, in the case of the "I" bottom tube sheet weather conditions did not permit this; therefore, the unit was sandblasted under the conical shaped hood used for the drying operation inside the building.

To prepare the bottom tube sheet for sandblasting, the unit was placed top side up on four (4) cast iron pedestals approximately $3^{\prime}$ high under the conical shaped hood used for drying. AIl large tubes and instrument lead tubes were blanked off with wood caps of suitable size on both top and bottom ends of the tubes. Wiood caps were held in place with a long $3 / 8^{\prime \prime}$ diameter rod threaded on both ends for $3 / 8^{n}$ nuts, which were tightened on both ends to hold the caps tight. The two $8^{n} \times 8^{n}$ main loading ports were sealed with $1 / 2^{\prime \prime}$ thick solid lap patch plates $(\mathrm{S} / \mathrm{S})$.

The 2t" diameter inlet and outlet openings in the wrapper plates were sealed with $1 / 2 "$ lap patch plates which were drilled and tapped for 1/2" pipe plugs (for testing purposes). AlI $2^{n}$ filling and inspection ports were sealed with a shoulder head screw plug and rubber ring gaskets. A retaining groove was machined in the screw type plug to hold the rubber gasket. The ten instrument wells were capped using S/S pipe plugs. All other machined surfaces were protected with cloth back masking tepe.

After the unit had been completely sealed off as described above and placed under the conical shaped drying hood, the top side and wrapper plates were sandblasted. Upon completion of the sandblasting operation, du Pont Inspectors visually inspected the unit for cleanliness and performed ferroxyl test at random to determine if the areas sandblasted vere iron free. All tests and visual inspections proved satisfactory and the unit was released for further fabrication.

(2) Establishing $X$ and $Y$ Centerlines on Top and Bottom Sides of Bottom Tube Sheet and Verticality Readings.

After sanablasting the "L" bottom tube sheet assembly, the unit was placed (top side up) on suitable cast iron pedestals; five (5) around the outer periphery of the unit and one in the middle to equally support the weight of the unit. Next, the unit was leveled using the fild NIII Precision Level and target. (See Part III, II-J for use of instrument in leveling of units). When the unit was level within approximately .008"t to .010", $X$ and $Y$ centerlines were established on the top side in a similar manner to that described in Part II-A, Section 13. After establishing the $X$ axis, and with a $18^{\prime}$ straight edge coinciding with the $X$ axis, measurements from the face of the straight edge to the I.D. of tubes on this axis were taken in an identical manner to that 
pictorially illustrated in photo serial $\frac{11}{15} 53$, Part II. Also, bore diameters of these tubes were measured using a standard dial indicator bore gage in the same direction as those measurements taken from the $18^{\prime}$ straight edge. The above procedure was repeated on the $Y$ axis. Both sets of treasurements were later used in calculating the position of laree tubes in the tube pattern with respect to both the $X$ and $Y$ axes. For a discussion on pattern coordinate calculations, see Part III, II-G.

After $X$ and $Y$ axes were established on the top side of the unit, these axes were transferred to the bottom side of the unit in a similar manner to that shown in Sketch 114 . The unit was turned bottom side up and a $18^{\prime}$ straight edge was lined up with the transferred $X$ axis, Next, measurements from the face of the straight edge to the I.D. of tubes on this axis were taken as described above. Then, bore diameters were measured in a similar manner to that also described above. Likewise all measurements taken on the bottom side were later used in calculating the positions of large tubes on the bottom side as discussed above.

The unit was then turned top side up and re-leveled using the ild NIII Precision Level and target. After the unit was leveled, verticalities of those tubes in the spider web tube pattern were taken and recorded. For results of this inspection see Sketch $\frac{\| 1}{715}$. The tubes in the "spider web" tube pattern have already been established in the past as being representative of all tubes in a unit. The verticality readings were then analyzed by du Pont inspectors to determine if tube verticality tolerance was being maintained after the unit was leveled. Verticality readings shown in sketch \#15 were outside this limit, they were considered satisfactory by the du Pont Inspection Department and accepted.

(3) Dowell Cleaning

Internal Dowell cleaning of the "L" bottom tube sheet was performed in a similar manner to that described in section $16 \mathrm{~B}-(1)$ of this manual.

After cleaning, a visual inspection was made on the interior by looking thru two $5^{\text {n }}$ pipe nipples using a flasklight. Samples for visual examination were taken by rubbing clean paper towels on those areas accessible by hand thru the $5^{n}$ openings and not visible by eye. All samples taken and visual examinations made thru these two openings indicated no foreign material was present on the interior surfaces of the unit. Other visual inspections were made by looking thru the $2 "$ inspection ports with the aid of a flashlight. Inspection ports were located in wrapper plates in a semi-symetrical pattern around the outer perimeter of the unit. AII inspections exhibited a satisfactory surface cleanliness, although a slight residue of detergent was noted on some 


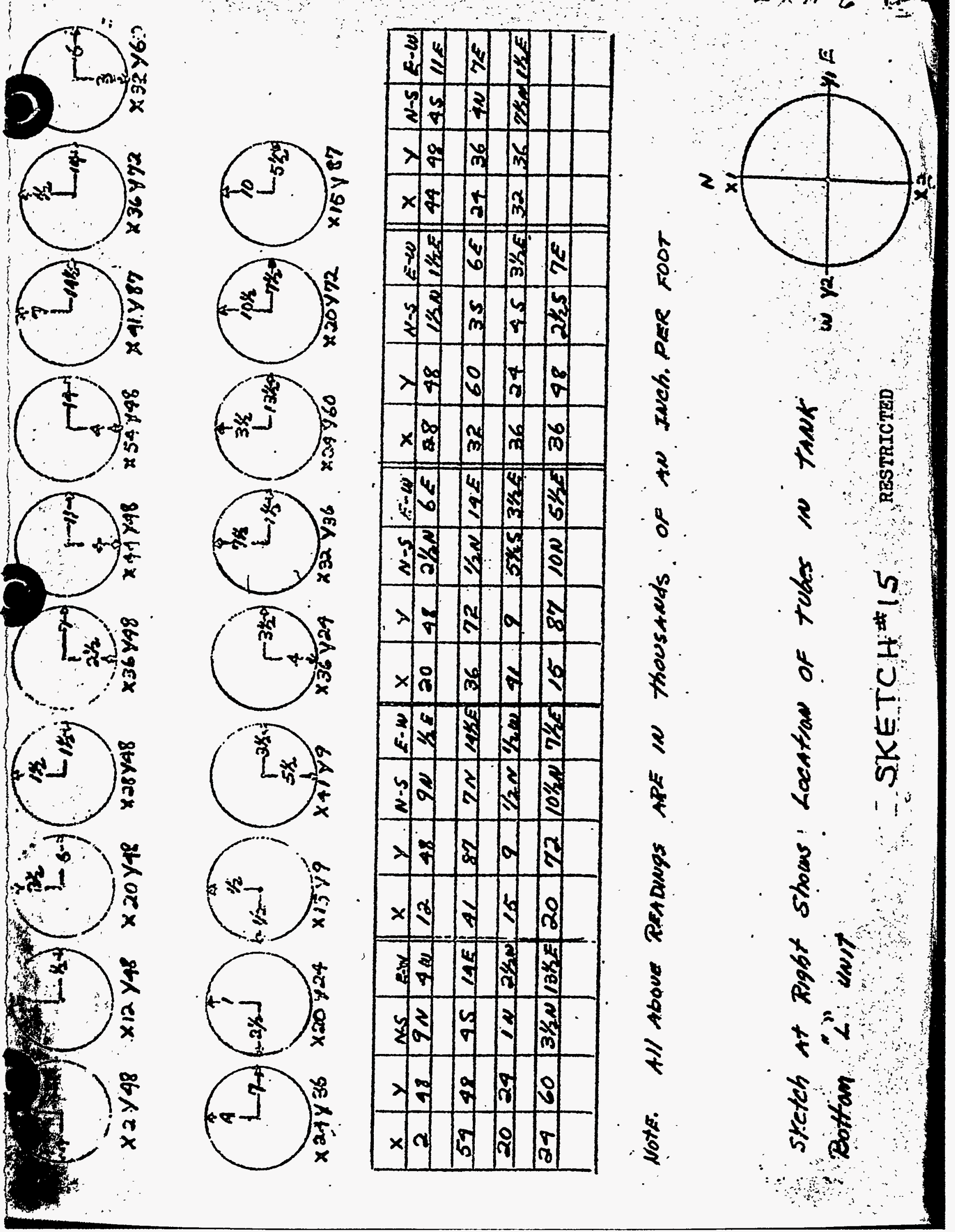


tubes. This gave the appearance of a white powder-like substance; however, this was not considered detrimental to the operation of the unit and was accepted by the du Pont Inspection Department. All other visual and mechanical examinations indicated that the unit was clean and the assembly was released for internal drying prior to loading of raschig rings.

\section{(4) Internal Drying of Unit Prior to Loading Raschig Rings}

For the internal drying procedure and the inspections performed by du Pont inspectors during this operation on the "L" bottom tube sheet, refer to Part VII, Section I, item 16C-(20).

\section{Raschig Ring Loading Inspections}

A. "R" Unit

A heavy loading cradle was designed and built by New York Ship to handle the top tube sheet and tank bottom assemblies for raschig ring loading during fabrication of the NYX unit. This same loading cradle was used to handle the unit during loading of raschig rings in the " $\mathrm{R}^{\text {" bottom }}$ tube sheet. Part II-B, Section 14 describes the equipment used, and also illustrates pictorially the raschig ring loading methods.

The "in" bottom tube sheet assembly was loaded with raschig rings in accordance with the filler loading procedure and filler loading cleanliness procedure established by the Design Division and later adopted for subsequent units. Hollowing this procedure, approximately 64 tons of raschig rings were loaded into the " $\mathrm{k}$ " bottom tube sheet. Du Pont inspectors observed all loading steps in the loading operation. Before loading rings they were visually inspected to see that no foreign matter was present and that the rings were clean. After all loading was completed, the loading port plugs were screwed in tight and later welded with the unit in a horizontal position.

The assembly was moved from the loading cradle bed and placed top side up. During the handling operations, raschig rings settled in the unit and it was necessary to add additional rings while the unit was in a horizontal position. This was done by opening auxiliary loading ports nearest the top side of the unit in wrapper plates and jetting additional rings into the unit. A spedial air jetting gun fabricated by New York Ship was used to blow the raschig rings into the unit. This operation was witnessed by a du Pont inspector.

After each auxiliary loading port was filled completely with raschig rings, plugs were screwed in the wrapper plates and then welded. AII " $A$ " and "B" filling port plug welding was then chipped, dressed and then visually inspected by du Pont inspectors for soundness and quality. This completed the raschig ring loading operation and the unit was released for further fabrication. 
1. heavy loading cradle was designed and built by New York Ship to handle the top tube sheet and bottom tube sheet assemblies for raschig ring loading during fabrication of the RYX unit. This same loading cradle was used to handle the unit during loading of raschig rings in the "P" bottom tube sheet. Part II-B, Section 14 describes the equiprent used, and also illustrates pictorially the raschig ring loading methods.

The "pn bottom tube sheet was loaded with raschig rings in accordance with the filler loading procedure and filler loading cleanliness procedure established by Design for the NYX unit and later aciopted for subsequent units. Following this procedure a total of 61 tons, $1,4851 \mathrm{bs}$. or raschig rings were loaded into this unit.

The following is a resume of the loading operations as observed by a du Pont inspector. The unit was set in a vertical position and loading was done at first through two main loading ports. After each of the first 3 loading cycles of 10 tons each, the urit was rotated $45^{\circ}$ right and left 3 times.

At this time inspectors discovered metal chips in a raschig ring container. A conference was held between New York Ship and du Pont and the chips examined. It was concluded by all that the chips found in the container was of no serious consequence.

The loading procedure was resumed and the fourth filling cycle of 4 tons, the fifth filling cycle of 5 tons, the sixth filling cycle of 10 tons and all other filling cycles that followed ( 9 filling cycles in ali) were completed by rotating unit as described above. The loading of unit with raschig rings was done with a stainless steel hopper. Faschig rings were dumped from cardboard containers into a stainless steel hopper. (AIl rings. were checked for cleanliness by inspectors before rings were dumped into hoppers.) The hoppers, with 1 -ton of raschig rings in them, were lifted by crane to loading ports of unit. Unloading of hoppers was done through:a valve controlled funnel-like extension on the hoppers. After main loading ports were filled to capacity, loading was continued by hand through " $A$ " and " $B$ " ports until they were filled to capacity. When loading was completed (In vertical position), the loading port plugs were screwed in tight and later. welded with the unit in a horizontal. position.

The assembly was noved from the loading cradle bed and placed top side up. During the handling operations; raschig rings settled in the unit and it was necessary to" add additional ririgs while the unit was in a horizontal position: This was done by opening auxiliary loading ports nearest the top side of the unit in wrapper plates and jetting adjitional rings into the unit. A special air jetting gun fabricated by New York Ship was used to blow the raschig rings into the unit. This operation was 
witnessed by a du Pont inspector.

After each auxiliary loading port was filled completely with raschig rings, plugs were screwed in the wrapper plates and then welded. AII "in" and "B" fllling port plug welding was chipped, dressed and visually inspected by du Pont inspectors for soundness and quality. This completed the raschig ring loading operation and the unit was released for further fabrication.

c. "L" Unit

Loading of the " $L$ " bottom tube sheet with raschig rings was performed in a similar manner to that described in Sections $17 \mathrm{~A}$ and $\mathrm{B}$ of this manual. No discrepancies were encountered.

A total of $321 \frac{1}{2}$ boxes of raschig rings weighting approximately 38 lbs per box, or approximately 51 tons, 170 Ibs. was loaded into this unit. The entire loading operation was witnessed by the du Pont Inspection Department and accepted as being satisfactory.

Just prior to loading raschig rings, the bottom side of the bottom tube sheet was sandblasted in a similar manner to that described in section $16 \mathrm{C}-(1)$ of this manual.

ifter sandblasting the unit was acid washed on the bottom side, visually inspected and found satisfactory.

18. Inspection of 8" Schedule $5 \mathrm{~S}$ Split Pipe kielded to Periphery of Bottom Tube Sheet.

A. "R" Unit

After completing the raschig ring loading operation, the bottor tube sheet was placed in a horizontal position (top side up on suitable cast iron pedestals) and leveled by du Pont inspectors using the Wild liII Precision Level and target. Preparations were then made by New York Ship for assembling and welding two half round $8 "$ schedule $5 \mathrm{~S}$ pipe sections to the periphery of the bottom tube sheet assembly. (See du Pont drawing 130947 for location of split pipe)

Before assembling and welding the half round sections to the unit, the butt welded joints in the piping were $x$-rayed 100\%, radiographs examined by du Pont inspectors, and necessary repairs made. Next, each section was acid washed, ferroxyl tested and accepted by du Pont inspectors. Also, two half tee pipe connections were fabricated for the top and bottom circumferential pipe sections. One half tee pipe connection served as a inlet connector for the circumferential piping located nearest the bottom side of the unit. The other served as a outlet connector for the circumferential piping located nearest the top side of the unit. The butt welded joints that make up each of the two half tee pipe connections were visually inspected for cracks, porosity, undercutting and other mechanical defects. Repairs were made and then the butt joints were $x$-rayed $100 \%$. 
The half round pipe sections and half tee pipe connectors were assembled to the unit and welded using automatic aircomatic hand welding machines. After all welding was completed, a visual inspection was made to determine the soundness and quality of welding. Defects such as porosity, undercutting, cracks and other mechanical defects were chipped out, rewelded, ground smoth and re-inspected.. After all repairs were made, the job was accepted subject to a final freon and hydrostatic test at a later date.

B. "pn Unit

Tabrication and inspection of 8 split circumferential pipe welded to the pertphery of the "pn bottom tube sheet was similar to that performed on "I" bottom tiabe sheet, except as follows:

(1) New York ship requested that the 8 in schedule $5 \mathrm{~s}$ split pipe (-109" wall thickness) be changed to 8 " schedule IOS (148" wall thickness) Design Division granted this request based on the following facts reported to them thy the duont Inspection Department:

a. Difficulty in working and handing material due to thin thickness

b. Weld burn through frequent ly experienced in joining pipe segments together for making the transverses butt weld joint. In addition much difficulty was experienced by New York Ship in getting the quality of weid to pass u-68 Code requirements. See Drg: 5-2 presented herewith

(2) Dy cheking of top and bottom jilet we joing solft pipe to circumference of unit was incorporated on this assembly. For dy-cheking procedure, see part il, SectLon I, 1 tem $14 \mathrm{~B}-(6)$

(3) Hyarostatic and freontesting of the on spi cit ciumer ential piping and results are coveredin section $14 \mathrm{~B}-(2)$ rand $(3)$

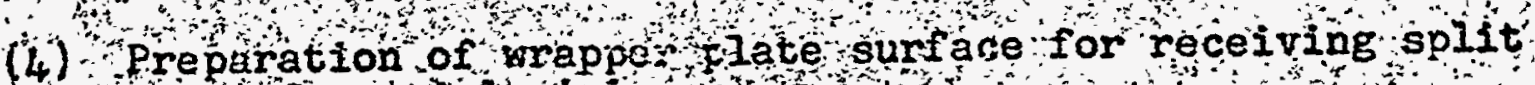
circumferential piping

Prio to assembling and welang of the spist circumferential piping to the per 1 phery ot the $B$ s $s$ assembly the location of the pipe ras iald out on the wapper plates to suit drawing dimensions Next the areo enclosed by the piping as defined by layout lines was ground to remove any iroh inclusions and all other mech anical defects present in the wrapper plate surfaces After thi the ground areas were acta washed by New Iork Ship and then ferroxy 1 tested by the du Pont Inspection Department Those areas that indicated the presence bof free iron were re-ground and then cleaned with Safe-Tee Solvent $(F, 0.128)$ AIl contaminated areas were referroxyl tested and found satisfactory for assembling and welding the split eccumerential piping to the unit. 


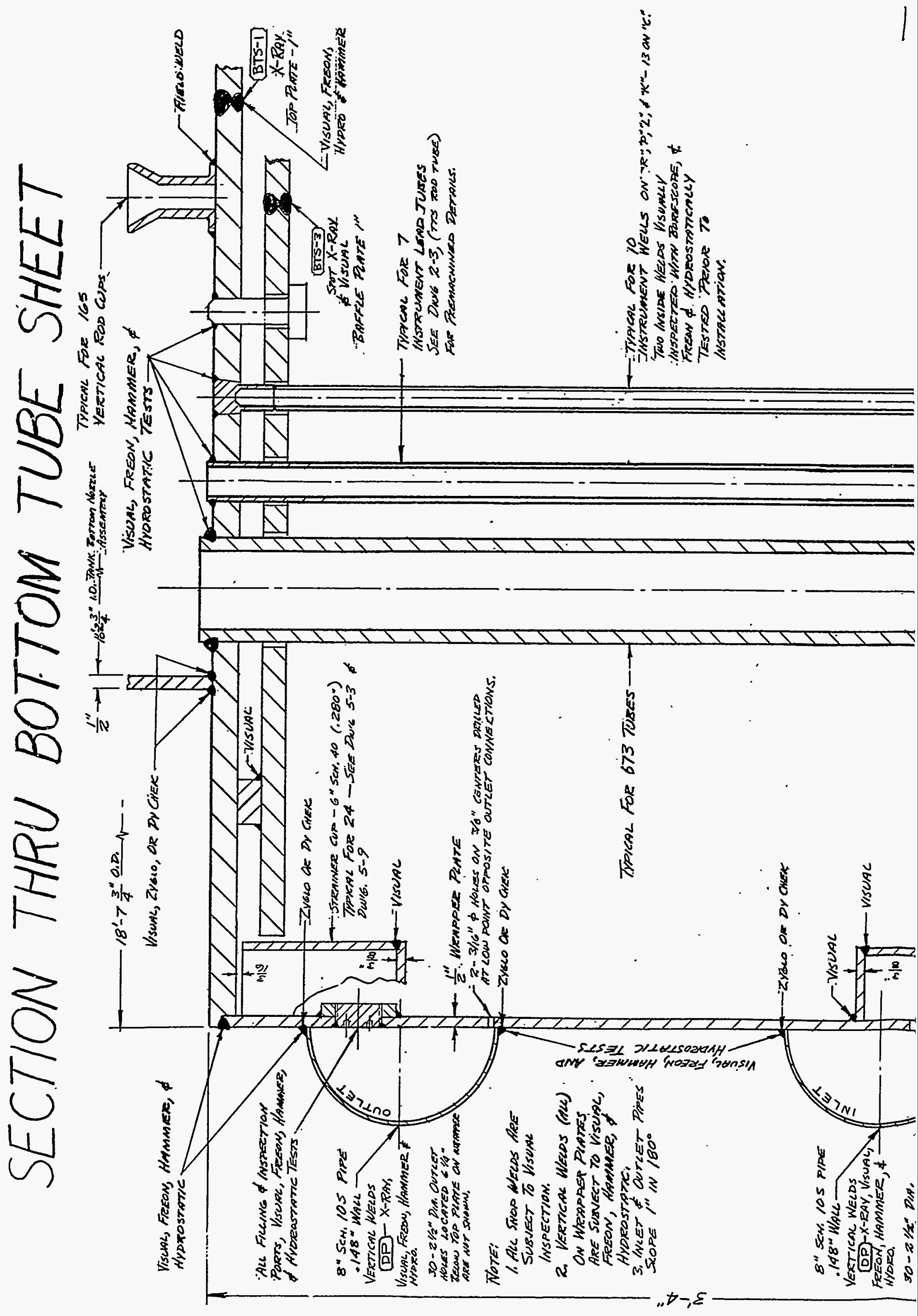




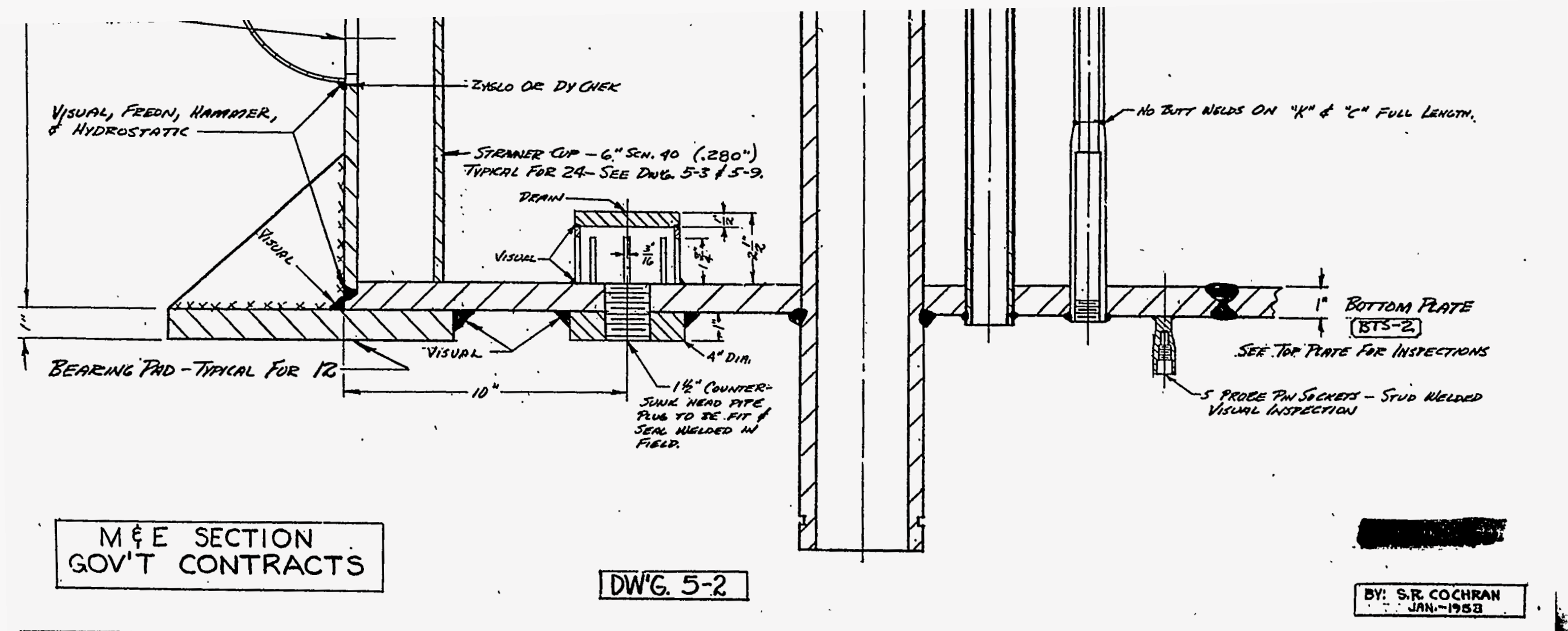


C. "L" Unit

Fabrication and inspection of $8^{n}$ schedule $10 S$ split circumferential pipe welded to the periphery of the "L" bottom tube sheet was similar to those performed on the "p" bottom tube sheet except as follows:

(1) Changes in belding Procedure

a. Secondary Argon Gas Shield

The top and bottom circumferential pipe sections (iil 132960) were fabricated, assembled and welded to the "L" bottom tube sheet using the welding procedure adopted for the "P" unit; however, an additional step was added to the latter and "Ln, "K" and "C" split pipe welding procedures. This step consisted of introducing argon gas into the interior of the split pipe sections at a pressure of $10 \mathrm{H} / \mathrm{cu}$ ft after the pipe had been fit and tack welded to the unit. This argon pressure was maintained for one hour, then reduced to 5if/cu ft. and all welding fully completed using hand operated aircomatic welding machines.

The purpose for introducing argon gas into the interior of each pipe section and holding it there during final welding operations was to provide an interral or secondary gas shield to prevent oxidation of weld metal on the inside. Otherwise, weld metal that works its way to the inside during the final welding operation without the inert gas shield would be exposed to air with weld oxidation resulting. Oxidation causes pitting, porosity and other mechanical defects which cannot be repaired due to inaccessibility. (See BwE. 5-2)

The introduction of argon gas at a pressure of 10 if $/ \mathrm{cu}$ ft and holding it at this pressure for one hour was necessary in order to insure that a homogenous nixture of the gas displaced nearly all oxygen. Fit-up of the split pipe and tack relding to hold it in place for final welding was a "metal to metal" joint between the unit and pipe with only a slight seepage of gas taking place when subjected to the argon pressure. Since it was only necessary to maintain a pressure slightly above atmospheric pressure to keep outside air from entering, the argon gas pressure was reduced to $5 \mathrm{H} / \mathrm{cu} \mathrm{ft}$. to eliminate unnecessary escapage of gas.

b. Weld Freparation Change From Fillet To Butt Field.

On "il" and "p" units the weld preparation for joining the split pipe edges to the unit for final welding was cut square and then fillet welded to the circumference of the bottom tube sheet as shown in Sketch fil 16. Anember of the du Pont Inspection Department recognized that the quality of welding was 
being sacrificed due to the above method of weld preparation on the split pipe edges for the "p" B.T.S. Also, it was found by welding samples of the split pipe to a $1^{\prime \prime}$ thick $S / S$ plate that full weld penetration was not being maintained.

As a result of the above findings, it was suggested by liew York Ship's welding engineer that a $70^{\circ}$ bevel (weld preparation) be chipped on the top edge of the split pipe and a $45^{\circ}$ bevel be chipped on the bottom edge. These weld preparation bevels were determined experimentally by New York Ship's welding

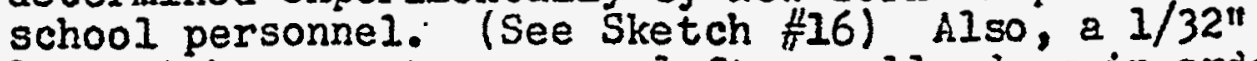
land with no root gap was left on all edges in order that"metal to metal" contact between the split pipe and unit be maintained for sealing off the argon gas during final welding operations as explained in Section (I) above.

The above weld preparation change from fillet weld to butt weld vias incorporated into the fabrication procedure for " $k$ " and "L" units.

(2) Split Pipe and Half-tee Hall Thickness Check

Starting with the "L" bottom tube sheets split circumferential piping, it was decided by the du Pont Inspection Department to check wall thickness of all 8" schedule los pipe (.148" thick), at the transverse butt weld joints after all welding repairs, grinding, etc., were completed, and before assembling and butt welding the split pipe to the bottom tube sheet assembly. In addition, a spot check was made on all pipe to see that wall thickness was not less than $0.125^{\circ}$. Yeasurements were taken using a $12^{\prime \prime}$ outside micrometer with a dial indicetor affixed to the micrometer spindle at one end of the frame. Clamped to the other end of the micrometer frame was a $1 / l_{t} "$ steel rod. The dial indicator was set by placing a $2^{\prime \prime}$ block $0.1875^{\prime \prime}$ thick between the dial indicator plunger and the $1 / 4 "$ steel rod tip. In this manner the dial indicator was set to read deviations plus or minus from the basic setting of $0.1875^{\prime \prime}$. The section of pipe to be checked was "sandwiched" between the pre-set dial indicator and $1 / 4$ " rod tip with both indicator and $1 / 4 "$ rod perpendicular to the pipe. Iith the $12^{\prime \prime}$ micrometer frame in this position, the device was moved in a zig-zag manner over the surface of the pipe and thickness read directly in .001". In measuring the thickness of a transverse butt weld joint (one/section of pipe before velding to B.T.S.), the micrometer frame was positioned at the Held in a similar manner described above and thickness measurements of all points $1 / 2$ " each side of the butt reld was checked. All of the above thickness checks vere performed on the split circumferential piping for the "L" and " $K$ " bottom tube sheet assemblies. Final results indicated that the pipe was a minimum of .125" thick which was acceptable to the du Pont Inspection Department. 
In addition to thickness checks made on the split pipe, these same measurements were repeated on the two half-tee pipe connectors before assembling and welding to the B.T.S. assembly. (See du Pont drawing Vi3290 for location) However, the minimum wall thickness for the half-tee connectors was set at $.157^{\prime \prime}$. All thickness measurements made on the two tees for the "L" B.T.S. indicated that resilts ranged between. .186" and. .I9g" which was satisfactory.

All of the above thickness checks were made after $x$-raying and making all necessary repairs on the split circumferential piping and half-tee pipe connectors. After this, the pieces were released for welding to the bottom tube sheet assembly.

(3) Hydrostatic and Freon Test

Hydrostatic and freon testing of the $8 "$ split circumferential piping and half-tee connectors is covered in section $14 \mathrm{C}$ of this manual. For other inspections performed on the split circumferential piping, see Dwg. 5-2 in Section 18B of this manul.

(4) Checking Slope of Split Circunferential Piping and Location of Half-tees with llespect to "Y" Axis

Inspection of the split circumferential pipe slope and location of half-tees with respect to the "Y" axis is covered in Exhibit $/ 16$ presented herewith.

19. Aligntrent of Tank Bottom Kozzle Assembly on Top Side of Bottom Tube Sheet.

\&. "ij" Unit

The tank bottom nozzle assembly was fabricated as a unit before fitting and yelding to the bottom tube sheet. Dwg. 5-5 illustrates pictorially all inspection made on this assembly.

Prior to fitting and welding the nozzle assembly to the bottom tube sheet, du Pont inspectors performed several jobs which aided New York Ship in lining up the assembly for welding.

As discussed in Section $16 \hbar-(2)$ of this manuzl, $X$ and $Y$ centerlines were established on the top side of the bottom tube sheet and then "wrapped" around the unit. From the se lines liew York Ship trammed $60^{\circ}$ lines on the unit to correspond to each of the six nozzle centerlines on the nozzle assembly. The tank bottom nozzle assembly was superimposed on top of the bottom tube sheet and its nozzle radial centerlines $\left(6 \notin 60^{\circ}\right)$ were matched to the six trammed $60^{\circ}$ radial centerlines on the bottom tube sheet. After liew York Ship aligned the nozzle assembly, it was fillet welded to the unit. Next, du Pont Inspectors made preparations to transfer the $X$ and $Y$ axes to the top outside edge of the nozzle assembly to be used later for lofting in of the main 


\section{EXHIBIT H 16}

CHECKING SCOPE OF SPLIT CIRCUHFERENTIAL PIPING AND LOCATION OF HALF-TEES UITH RESPECT TO "Y" AXIS. 
E. I..DU PONT DE NaMQURS \& $C O$, INC。 penstruction Division

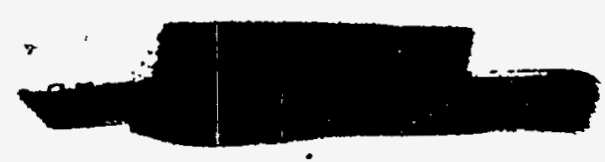

Report Number 514-1

CC: H. W. Gosney, F.P.M.

R. K. Mason-D.A.Hauser-SRP 13

R. K. Mason-W.P.Duncan-SRP

H. L. Bunker - J.G.Brewer

J. G. Brewer

H. B. Gage

F. C. Breuninger

S. R. Cochran (2)

R. H. Barto - NYS (3)

J. B. Johnson - File

June 12, 1953

New York Ship - Camden, No J.

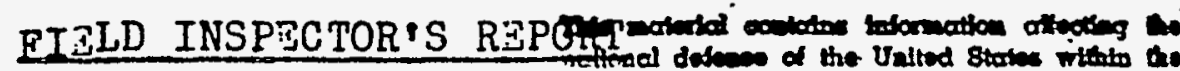

TO C. J. VEITH - M \& E FILE ir v. ug of the englonoge lows. Thto 18, U.S.C.

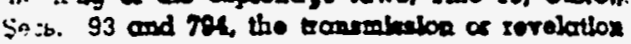
FROM H. Dahlke - H. Neicen

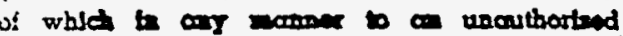

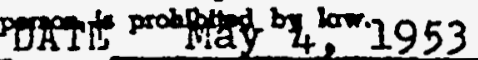

PROJECT NO. 8980 PLANT Savannah River ORDER NO. AXC $-167 \frac{1}{2}$ RQUIPMENT Tank Bottom - Half Round EQ.PC.NO。 $153-\mathrm{L}$ DRAHING NOS. $W-132760 R .18$ JOB RATING

KNDOR New York Shipbuilding Corp. LOCATION Camden, N. Jo

\section{Inspection made $5 / 4 / 53$}

3cope: To check the slope of the half rounds as per specifications of drawing (slope $I^{\prime \prime}$ in 180 from inlet or outlet conn.). Also to check orientation of tees with respect to $Y$ axis with 50 ' steel tape.

Procedure: The distance from top plate to center of top half round was checked at the outlet conn., $180^{\circ}$ from this point, and at several other points. The distance at the outlet was $8 "$ and $180^{\circ}$ from here it was $9^{n}$. The same procedure was used on bottom; measuring from bottom plate to lower edge of bottom half round. The distance at the inlet conn. was $13^{n}$ and at $180^{\circ}$ from this it was $12^{n}$. The slope was uniform between these points.

The top tee was 4'10:" off the $Y_{2}$ axis toward the $X_{1}$ axis and the bottom tee was 4'10-9/16" off the $\mathrm{Y}_{1}$ axis toward the $\mathrm{X}_{2}$ axis.

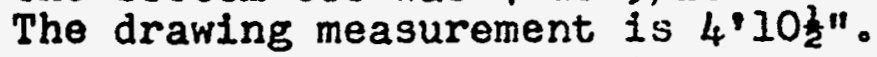

Note: All of the above measurements were considered acceptable.

Iniw

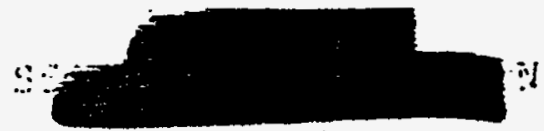




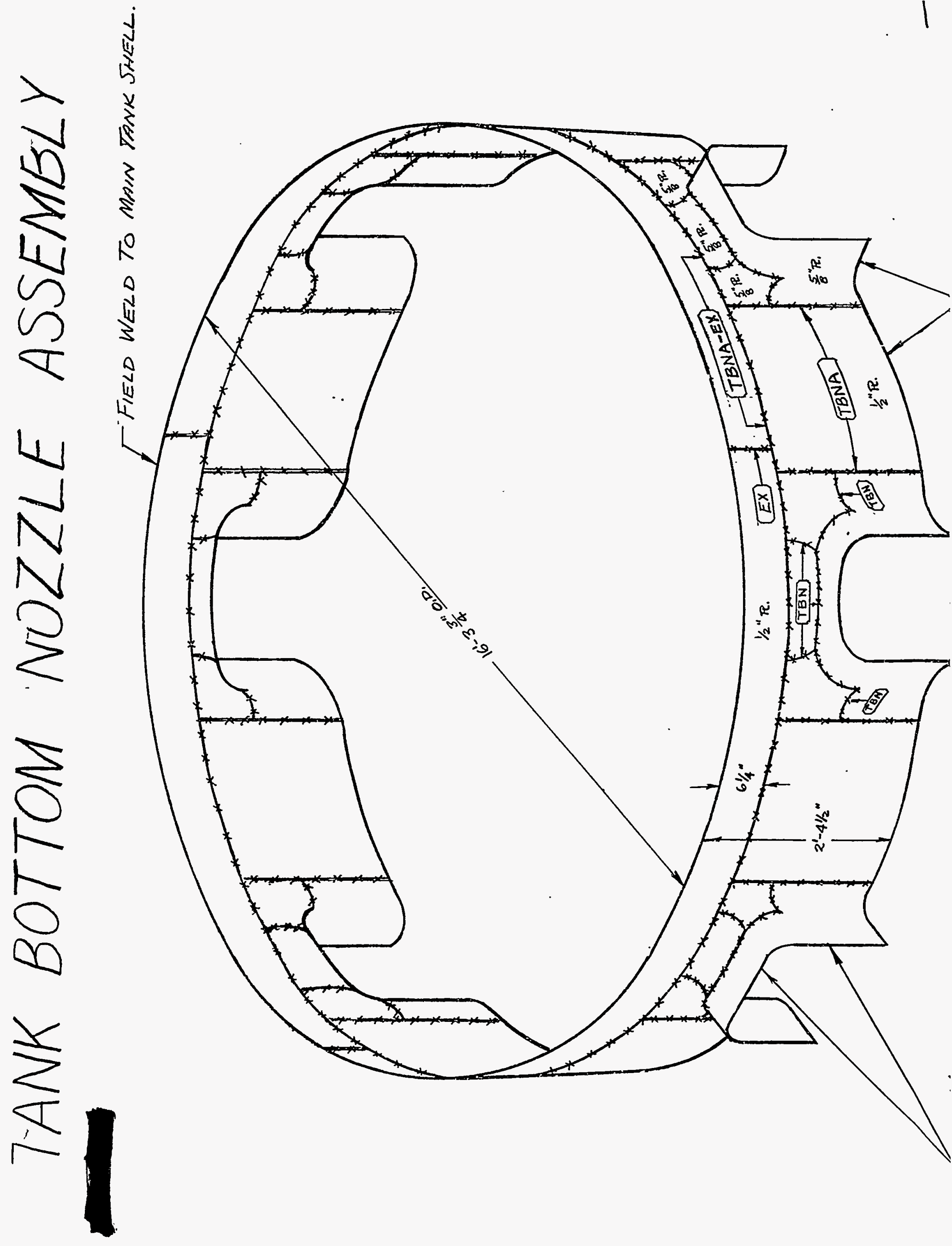


$\frac{1}{4}$

它崖

\begin{tabular}{l}
4 \\
$i$ \\
10 \\
0 \\
$\vdots$ \\
3 \\
\hline
\end{tabular}

ㄴ.

है

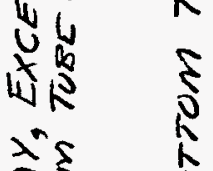

रह

15
$+\infty$

文

त व

วิ

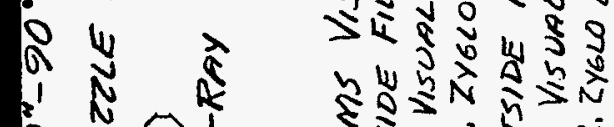

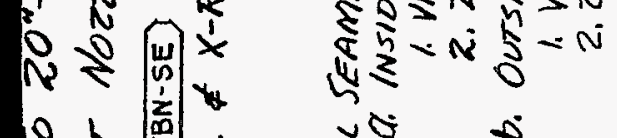




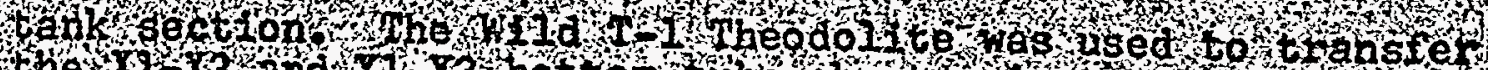

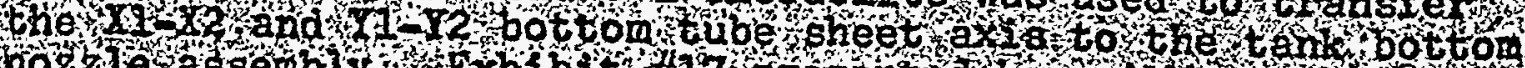

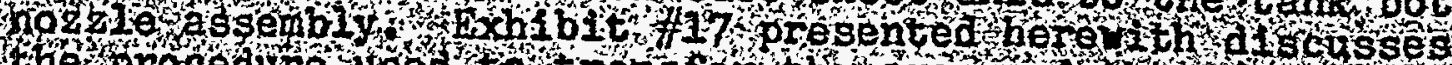

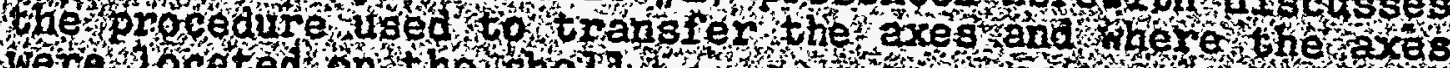

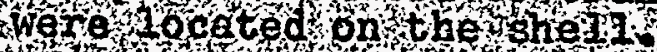

B.

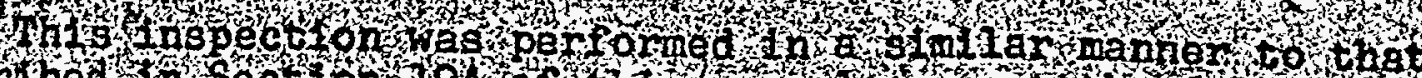

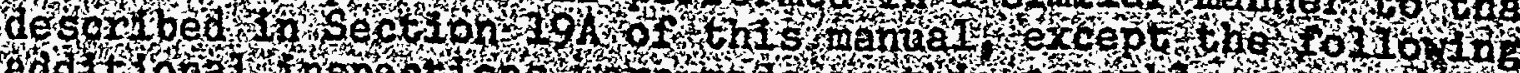

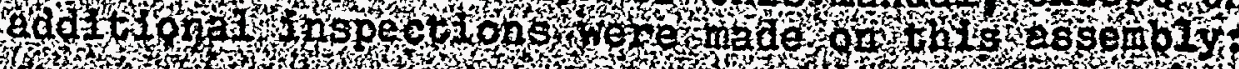

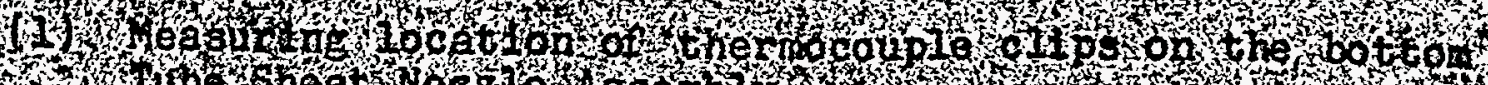

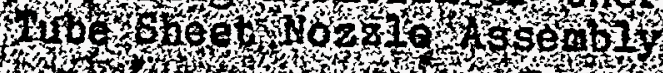

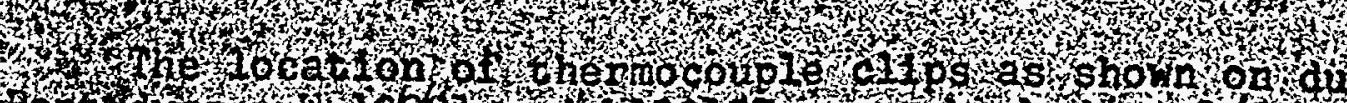

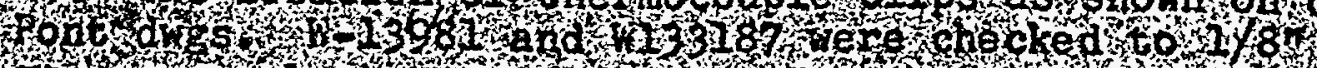

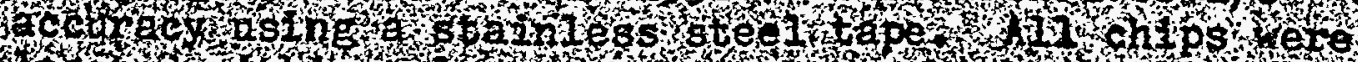

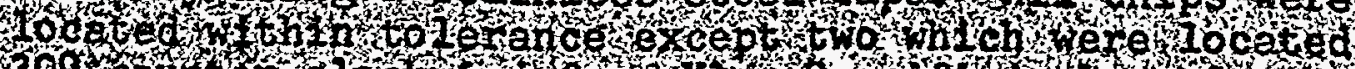

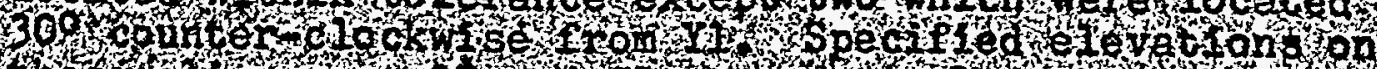

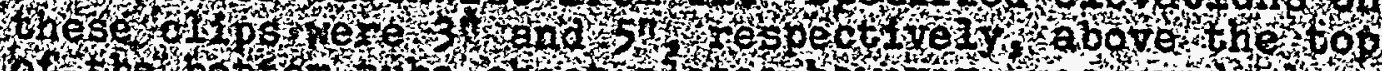

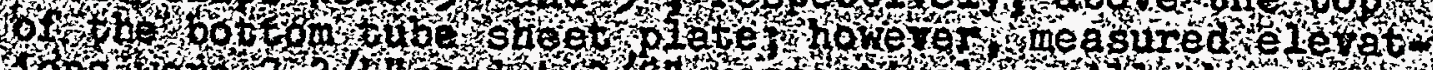

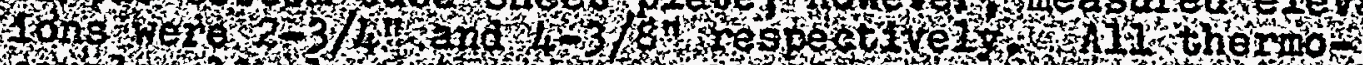

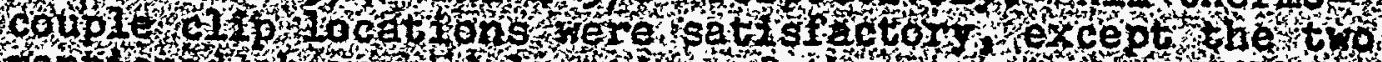

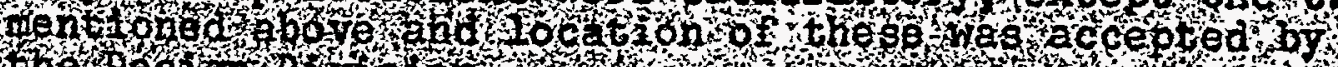

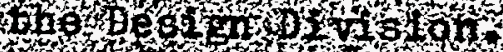

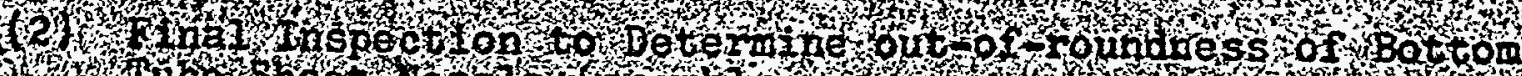

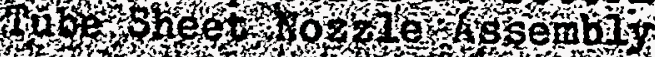

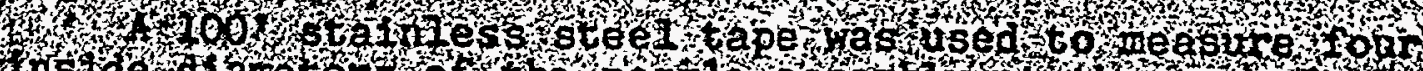

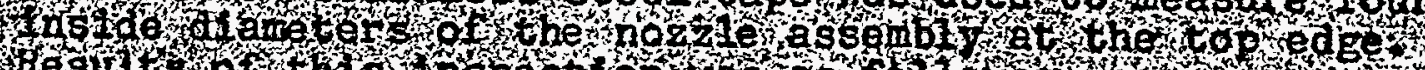

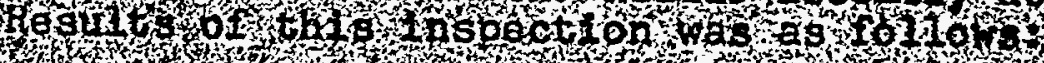

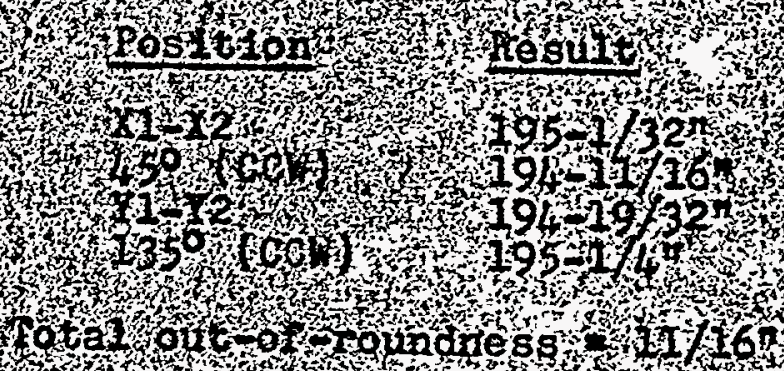

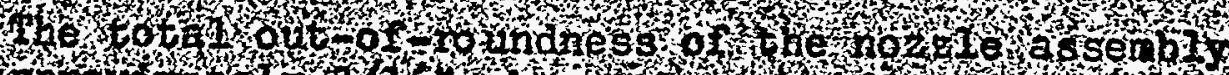

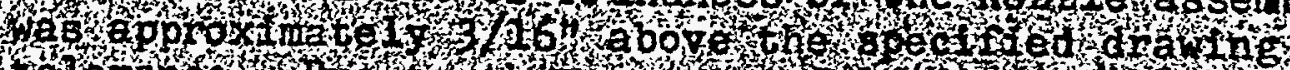

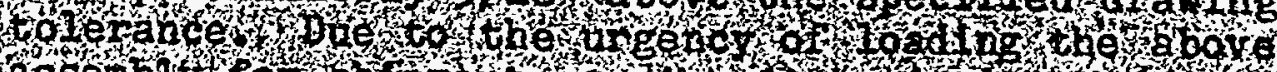

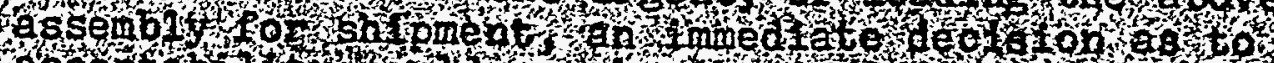

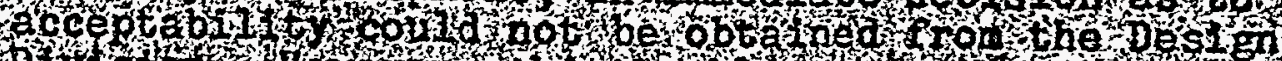

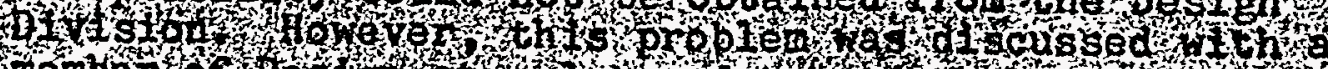

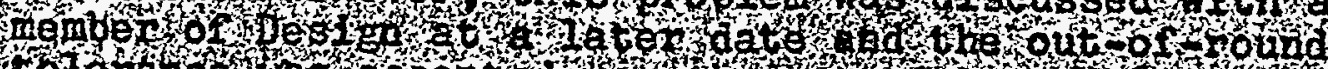

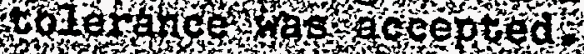

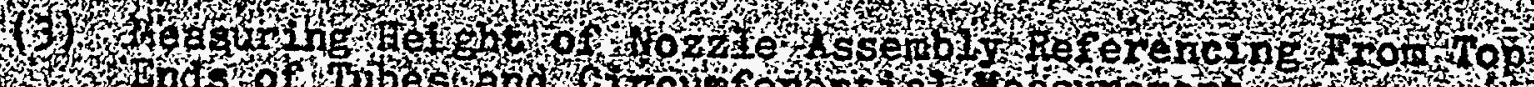

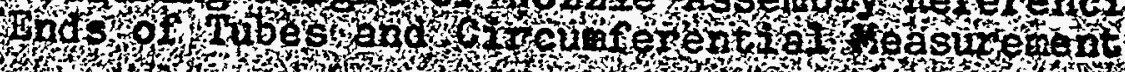

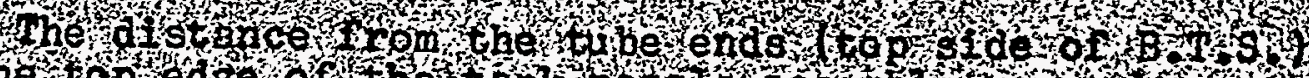

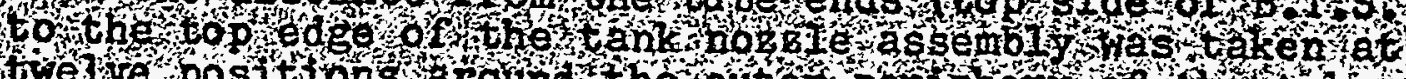

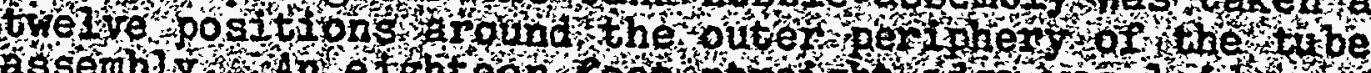

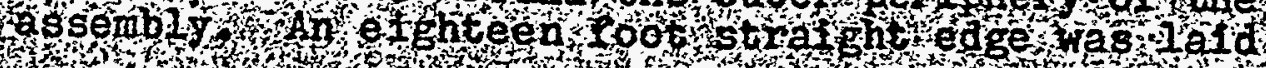





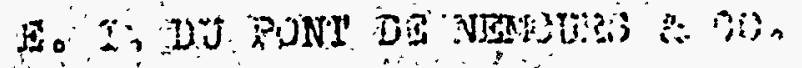

CONSTRUCTION DIVISION

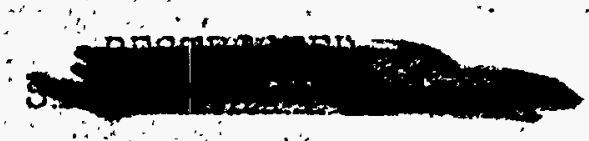

leport Number $13 I-R$

$C C: C \cdot E_{\circ}$ Buckley, F.P.M०

R.K. Mason, F.P.M.-SRP (3)

HoL. Bunker - J.G. Brewer

J.G. Brewer

H.B. Gage

F.C. Breuninger

A.H. Hughes

$\rightarrow C . W_{0}$ Dunn - F1lev

July 17, 1952

New York Ship - Camden, No. J:

$16^{6}$

TO

c.joVEITH - M \& E FILE

FROM

GRAHAMI O MIKELAIT

PROJECT NO 8980 PLANT SAVANNAH RIVER

EQUIPMENT TANK BOTTOM TUBE SHEET

DRAWING NO.

$W-130947$

VENDOR

NEW YORR SHIFBUILDING CORP:

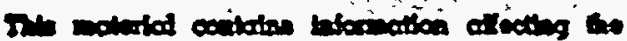

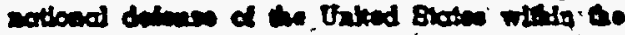

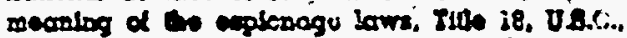

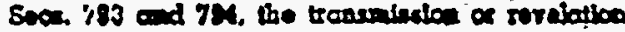

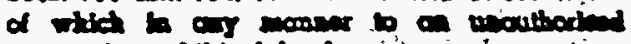

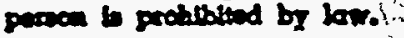

DATE JULY 13,1952

ORDER NO. AXC-167t

E2.PC.NO。 153-R

JOB RATING

LOCATION CAMDEN, NaJ。

Scope: Transfer of X1-X2, Y1-Y2 axes to tank shell section above tank bottom nozzles for tank shell alignment and assembly.

Procedure: At each of four areas opposite the ends of the axes, three (3) points were set on the inside and three (3) points on the outside of the shell section at approximately In $^{n}, 2^{n}$ and $33^{\prime \prime}$ below the edge where the shell section and main tank sheli w1II be jolned." Polnts are outlined inside stenclled letter "o"'s and Eij. are encircled with blue layout paint. (Paint is very soluble in alcohol.)

Procedure, which was contrary to that originally established in Memo \#165 to A.H. Hughes from C.H. Dunn, was governed by existing conditions and was as follows:

i. Instrument (WIld TI.Theodolite) was set up on the tank bottom tube sheet axis at the extreme end opposite area on tank shell section to which the axis was to be transferrid:

2." Instrument was walked-in on the axis and points were optical transferred to the shell section. Position of the instrument was checked by plunging and reversing it. 


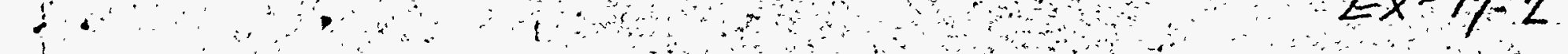

FIELD INSPECTOR'S REPORT

FROM GRAHAM - MIKELAIT
PAOE 2 OF 2

JULY 17.1952

3. Polnts on inside of sheli vire got by diroct obserpation

40 Polnts on the outs1da of the shall were set by allgning the uppor half of clamped stras ght adgo which wasiplaced on the outside of the shell Aftor the upper half of the stralght edge was ilghted and cilpricd by the Inttrimont. I Ino was scribed a long the stralght odgo Points rere then set in the center of the pcribed IIne. The points of th1s latter Ifne are bolloved to be as accurato as those set by direct observation.

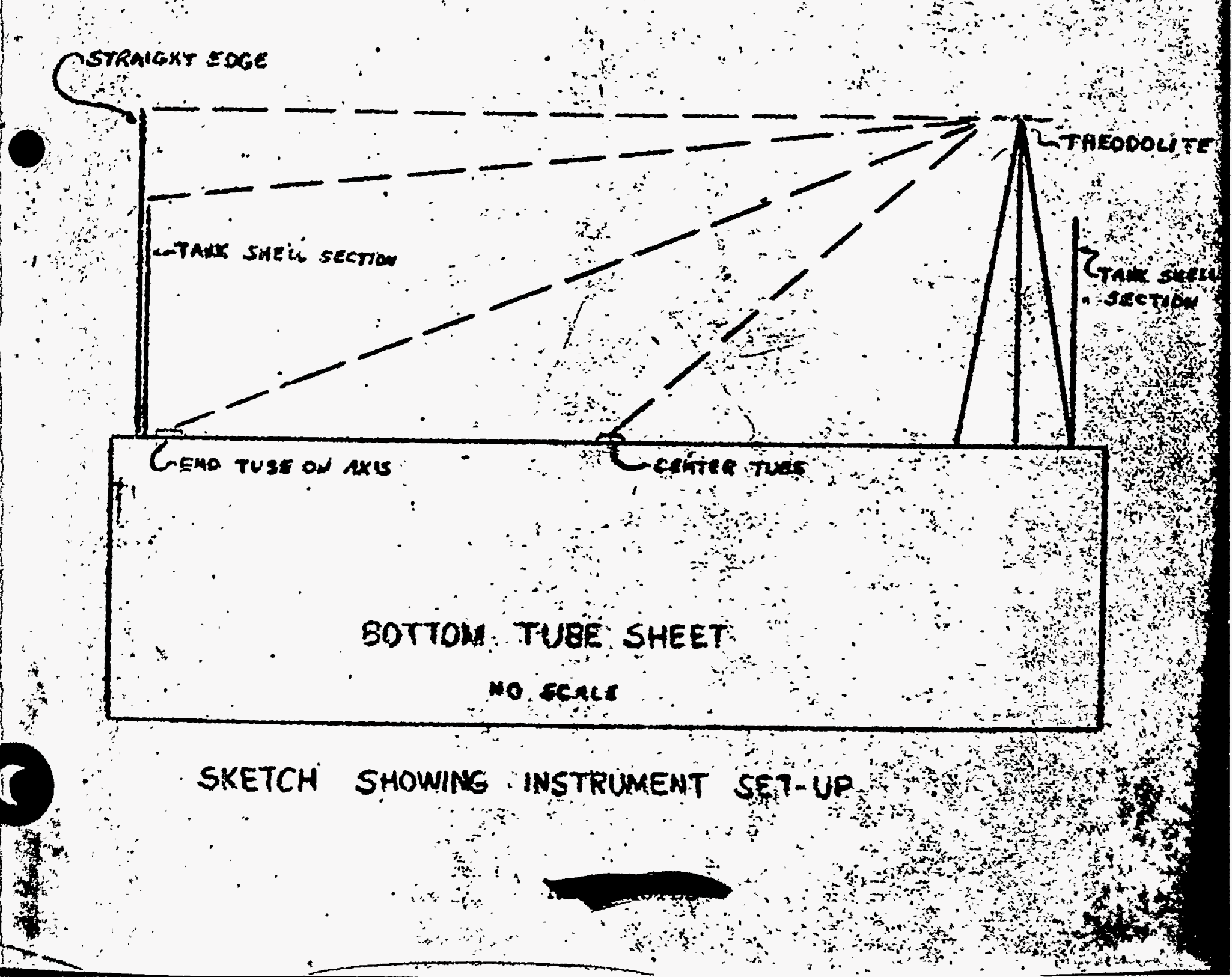


across the top of the tank nozzle assembly at the twelve positions to be measured. Vertical distances between the bottom edge of the straight edge and the top ends of the tubes were taken with a $3^{\prime}$ scale graduated in $1 / 32^{\prime \prime}$. The points measured were taken at the middle of each nozzle and half-way between each nozzle.

Results of this inspection were as follows:

\begin{tabular}{|c|c|c|}
\hline Fosition & Nozzle \#t & Dimension \\
\hline $\begin{array}{l}1 \\
1 \frac{1}{2} \\
2 \\
2 \frac{1}{2} \\
3 \\
3 \frac{1}{2} \\
4 \\
4 \frac{2}{2} \\
5 \\
5 \frac{1}{2} \\
6 \\
6 \frac{1}{2}\end{array}$ & $\begin{array}{l}1 \\
\frac{1}{2} \\
\frac{3}{4} \\
4 \\
\frac{5}{5} \\
\frac{6}{6}\end{array}$ & $\begin{array}{l}28-5 / 32^{n} \\
28-1 / 8^{n} \\
28-3 / 16^{n} \\
28-3 / 32^{\prime \prime} \\
28-3 / 32^{n} \\
28-1 / 16^{\prime \prime} \\
28-3 / 16^{n} \\
28-1 / 8^{n} \\
28-5 / 32^{\prime \prime} \\
28-3 / 32^{n} \\
28-5 / 32^{\prime \prime} \\
28-3 / 32^{n}\end{array}$ \\
\hline
\end{tabular}

Drawing dimension was $28^{\prime \prime}$. The actual dimension ranged between $28-1 / 16^{*}$ to $28-3 / 16^{\prime \prime}$. The above dimensions were final and accepted by du Pont Inspection Department.

Next, the outside circumference of the nozzle assembly was measured using $1001 \mathrm{~S} / \mathrm{S}$ tape graduated in $1 / 16^{\prime \prime}$. This measurement was taken approximately $1^{\prime \prime}$ below the top edge of the nozzle assembly. Final circumference me asurement was recorded and $51:-31 / 8 "$ which was accepted by the du Pont Inspection Department.

c. "L" Unit

All measurements and inspections performed on the " $L "$ bottom tube sheet nozzle assembly were similar to those discussed in Sections $19 \mathrm{~A}$ and $\mathrm{B}$ of this manual. Final results. were satisfactory and accepted by the du Pont Inspection Department. Additional measurements taken on the nozzle assembly during main tank aligning operations are discussed in Part VII, Section IV.

20. Welding Inspection and $z y-g l o$ Testing of Fillet lield Joining Nozzle Assembly to Bottom Tube Sheet

A. "R" Unit

After the nozzle assembly was welded to the top side of the bottom tube sheet, both sides of the double fillet welded joint between the two components were ground smooth and then visually inspected. Weld defects such as cracks, porosity, undercutting and other mechanical imperfections were chipped or ground out and then re-welded (if necessary), re-inspected and accepted. DWg. 5-I show's pictorially where these inspections and repairs were made. 

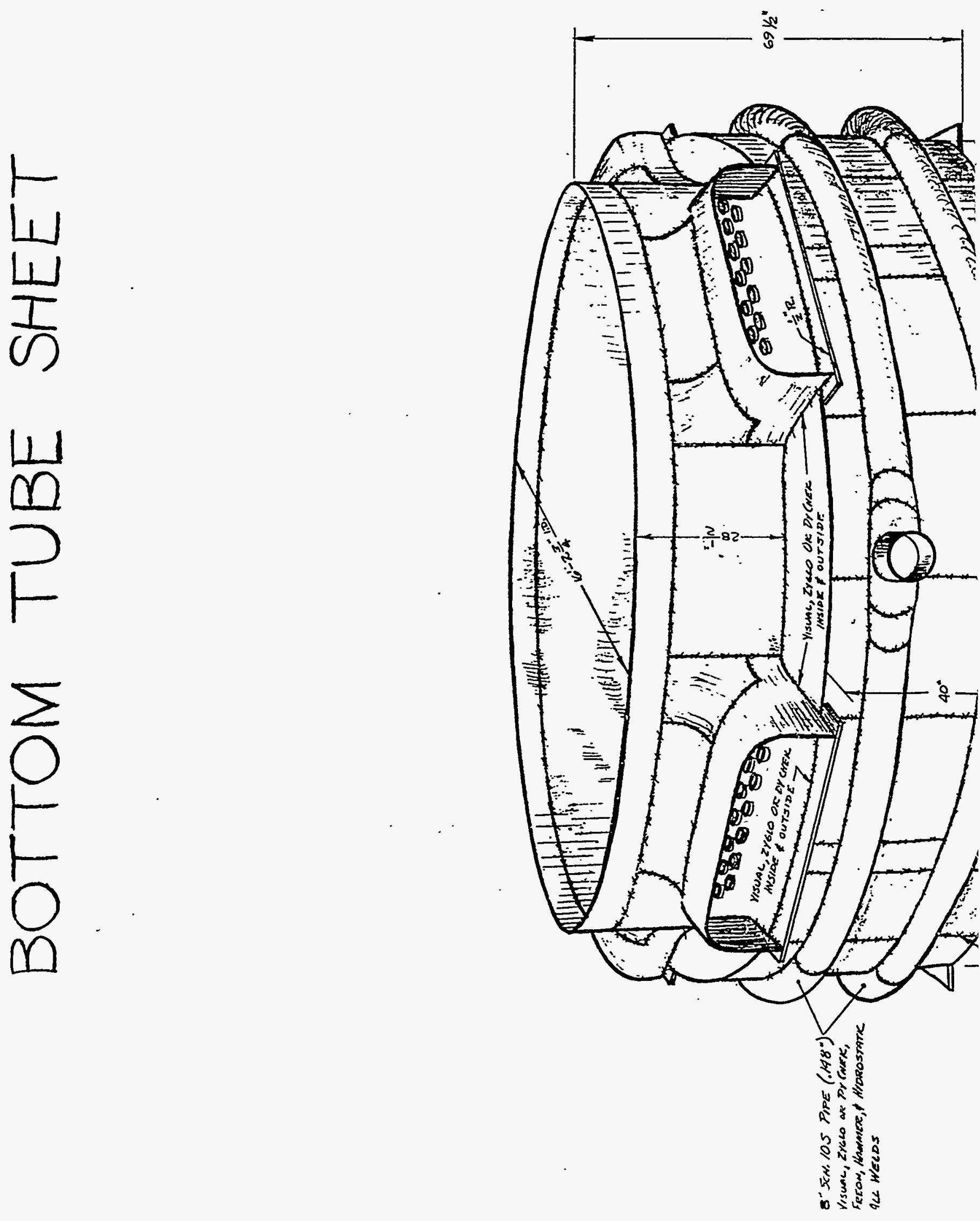


$$
1
$$


Next, the double fillet welded joint was zy-glo tested in a similar manner described in Section $14 \mathrm{~h}-(3)$ a of this manual. Any cracks or imperfections found were chipped or ground out and re-welded there necessary. Final inspection revealed that all welding was of a sound rature and quality and accepted as being satisfactory.

B. "p" Unit

This inspection was performed in a similar manner to that described in Section $20 \mathrm{~A}$ of this manual.

C. "L" Unit

Inspection of the fillet weld joining the bottom tube sheet nozzle assembly was performed in a similax manner to that described in Section $20 \mathrm{~A}$ of this manual. However, in lieu of the zy-glo test, the dy-chek method was employed to check the quality of welding joining the above two components. For the procedure followed when the dy-chek method of inspecting welds is employed, see Part VII, Section I, item 14C-(9).

21. Veasurements and Inspections After Loading haschig Rings and helding Bottom Tube Sheet Nozzle Assembly to Unit

A. "Rn" Unit

(1) Profile keasurements

ifter loading raschig rings into the unit, a profile in three directions across the top side tube ends was taken to determine if additional weight of raschig rings deflected the tube end plare. The profile was taken using a $18 '$ straight edge and feeler gages. No appreciable distortion resulted.

(2) Inspection of $20^{\prime \prime}-90^{\circ}$ Tank Outlet Nozzle Elbows

a. Inspections Performed Before

After fabricating six $20^{n}-90^{\circ}$ tank out let nozzle elbows, all weld seams were visually inspected for cracks, porosity, undercutting and other mechanical defects. Hecessary repairs were made, and then the nozzle elbows were released for $x$-raying (See Dwg. 5-6).

The above weld seams were $x$-rayed $100 \%$, repairs made and then re-x-rayed.

Next, the six nozzle elbows were acid washed to remove "free iron" and other foreign material present on the nozzle surfaces. After this the nozzle elbows were ferroxyl tested by du Pont inspectors and accepted for welding to the bottom tube sheet nozzle assembly.

b. Inspections Performed After Helding liozzle to Bottom Tube Sheet Nozzle Assembly 


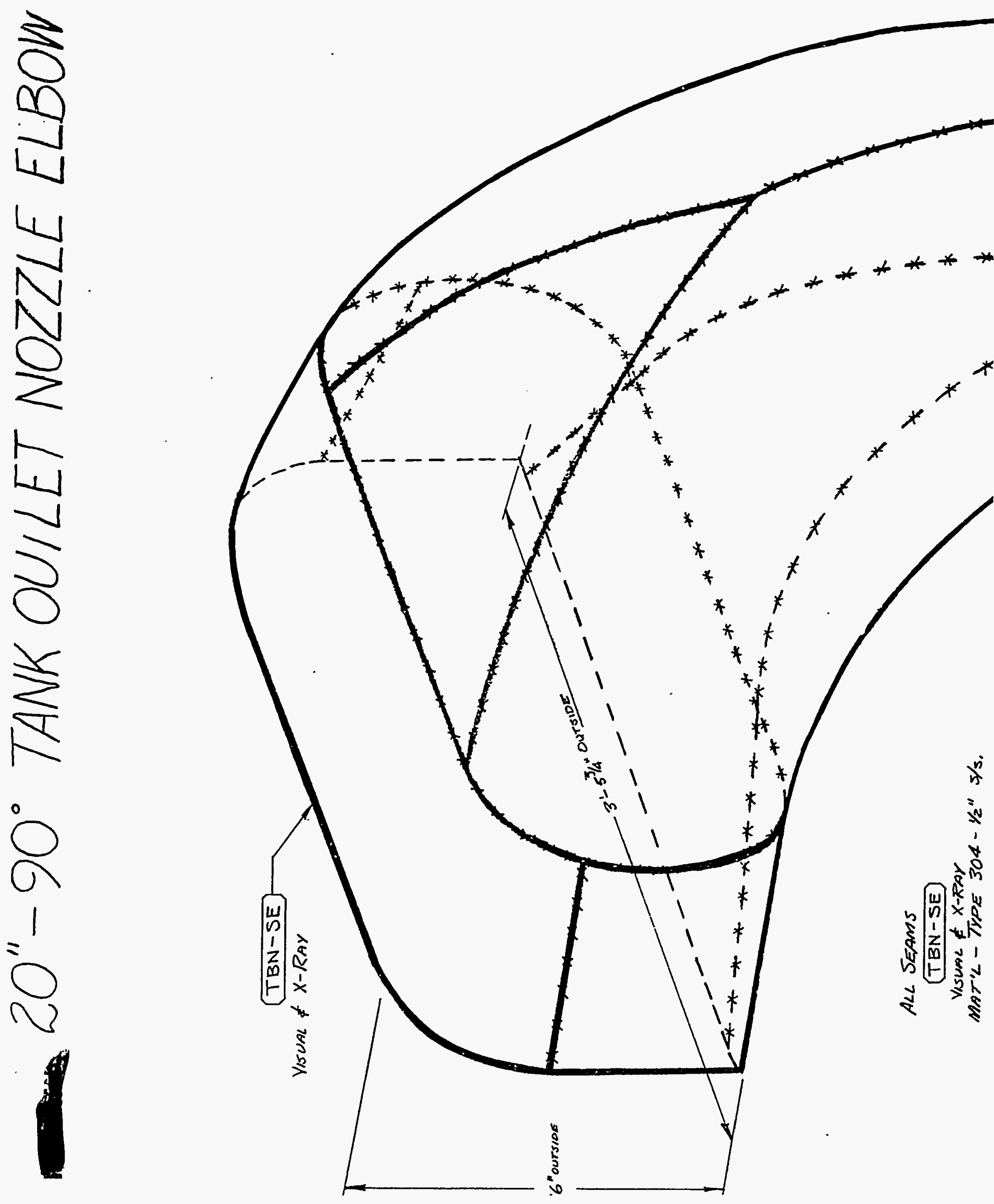


Six $20^{\prime \prime}-90^{\circ}$ tank outlet nozzle elbows were welded to the bottom tube sheet nozzle assembly. After grinding and dressing the butt welds joining the nozzle elbows to the nozzle assembly, they were inspected $v 1 s u a l l y$ for cracks, porosity, undercutting and other mechanical defects. Repairs were made and: then the butt welded joints were $x$-rayed $100 \%$ repalrs made, re-x-rayed and passed as being satisfactory

c. Air test and final freonctest for detection of leaks at tube welds and at fillet welds joining 8n $^{n}$ split. circumferential piping to B.T.S.

To prepare the " $R$ " bottom tube sheet for freon testing, it was given an air-soap test by. llew York Ship personnel after welding the " $"$ ". spitt circunferintial piping to the unit.

Two stainless steel blanks were cut, fit, and welded to the half pipe tees. All openings were no sealed off. These blanks were fitted with pipe connections for supplying air into the unit and also for "bleeding" the unit after the air test. A special threaded pipe with pressure gage attached was coupled to one of the pipe connections located in the Tee blank. Compressed filtered air was pumped into the bottom tube sheet to raise the internal air pressure to $35 \mathrm{psi}$. With the aid of a standard type paint brush, a soap-glycerine water solution was applfed to ali weld surfaces. Thirteen leaks nere found in the fillet welding joining the 81 split pipe fo the wrapper plates. All negative areas were marked for weld repair. The pressure was released and these areas in welding where the leaks occurred were chipped out, dressed, re-welded and ground smooth.

The unit was again subjected to the alr test, and all weld surfaces checked with soap glycerine." solution revealed that all repairs were satisfactory. No other leaks were found and the unit was considered air tight and released for further testing.

Next, twenty pounds (by weight) of freon fitio was introduced into the interior of the urit and then the internal pressure was increased to $35 \mathrm{psi} w 1 \mathrm{th}$ air. This condition was held for one hour before proceding with the test. All tube welding $8 \%$ splt pipe fillet and butt welding, and wrapper plate butt welds were tested for possible leaks using a generat Electric Type "H" Halide Detector set on mediun isent sitivity. Photo serial \#240 in Part PII Section paragraph 14B-(5) illustrates the use of this thsto ment. No leaks were detected and the unit was accepted.

d. Final Hydrostatic Test

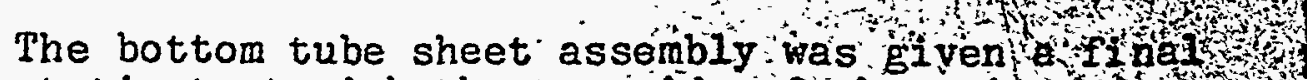
hydrostatic test with the top side of the unituph wh 
The unit was resting on four sets of pedestals approximately $6^{\prime}$ high to allow workmen and inspectors to walk underneath the unit during the test. While in this position, the unit was shiamed on one side

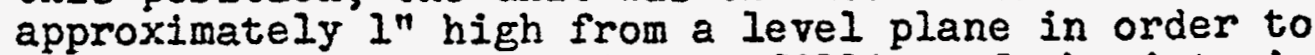
properly vent the unit during filling of the interior with distilled water. After the unit was filled with distilled water, the internal pressure was raised to

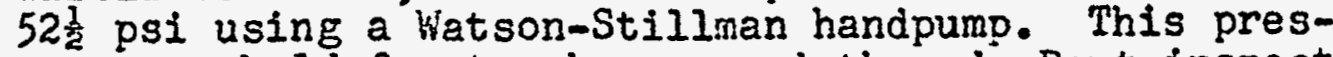
sure was held for two hours, and then du Pont inspectors checked all tube welding, " $^{\prime \prime}$ split circumferential fillet and butt welding for possible le akage. No leaks were found in this final hydrostatic test and the unit was accepted as being watertight.

B. "p" Unit

(1) Profile Measurements

This inspection was performed in a similar manner to that described in section $21 k-(1)$ of this manual. Results of this inspection indicated no appreciable distortion resulted after filling the unit with raschig rings.

(2) Inspection of $20^{\prime \prime}-90^{\circ}$ Tank Outlet Nozzle Elbows

3. Inspections Before Bielding to Nozzle Assembly

These inspections were performed in a similar manner to that described in Section $21 \mathrm{~A}-(2)$ of this manual except as follows: As shown in photo serial \#124 presented herewith, du Pont inspectors performed dy-chek tests on the edges of $21120^{n}-90^{0}$ elbows to determine if cracks or laminations were present in the edges of the nozzle. Defects found were chipped out, re-welded using the metalic-arc welding process, ground, and re-inspected. AII six $20^{\prime \prime}-90^{\circ}$ elbows for "P" B.T.S. were checked in this manner. This same inspection was performed on "L" B.T.S.

b. Inspections Performed After Helding Nozzles to Bottom Tube sheet Nozzle Assembly.

These inspections were performed in a similar manner to those discussed in Section $2 \mathrm{IA}-(2) \mathrm{b}$ of this manual. All results were satisfactory.

(3) Hiotion lieasurement Pad Inspections

Three motion measurement pads were located and welded to the top edge of wrapper plates on the outer periphery of the unit $120^{\circ}$ apart. To these pads were bolted stellited plates with a 40 Rockwell minimum hardness "C" scale. (See du Pont drawing W131395-Kev. 18). These were checked with a straight edge across the tops of the tubes and a precision square held across the face of the pads to see that they were perpendicular to the plane of the tube faces. The surface was checked with a profilometer and the hardness was checked by New York Ship's 


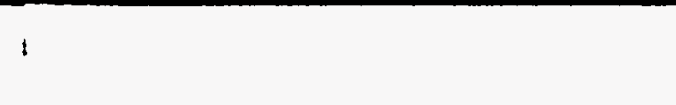

Serial Number 124

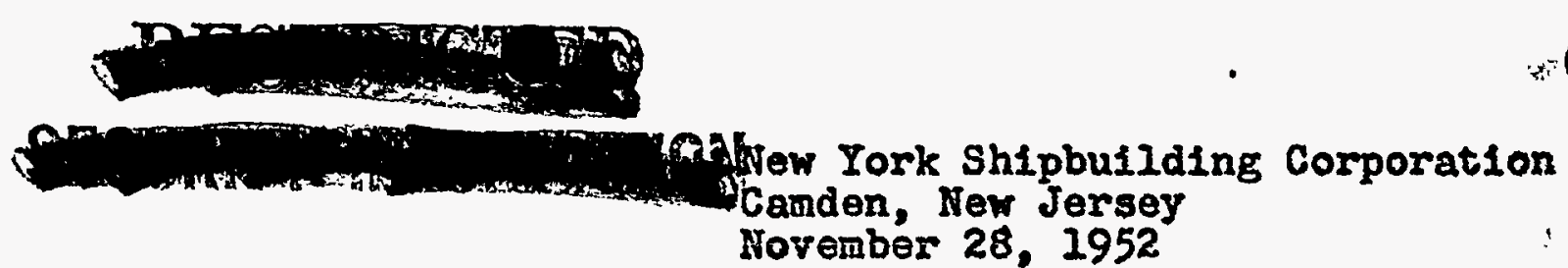

\section{PROJECT 8980 - SAVANNAH RIVER, PLANT}

This view shows a du Pont inspector performing

a dy-chek on the edge of a "p" unit tank bottom noszle. Test is run to determine if cracks or laminations are present in the edge of the nosxle.

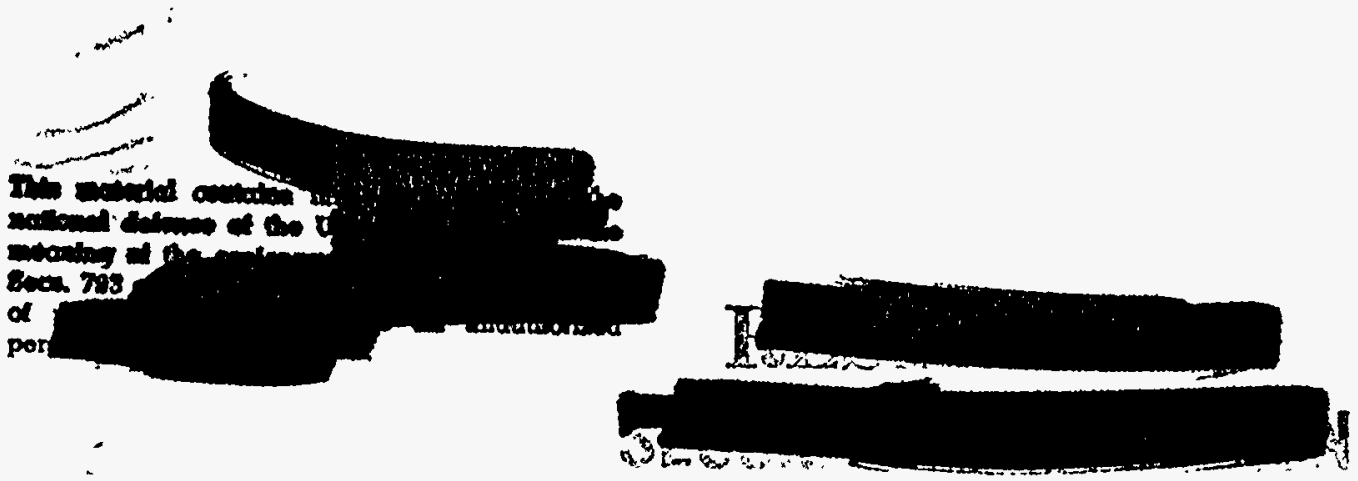




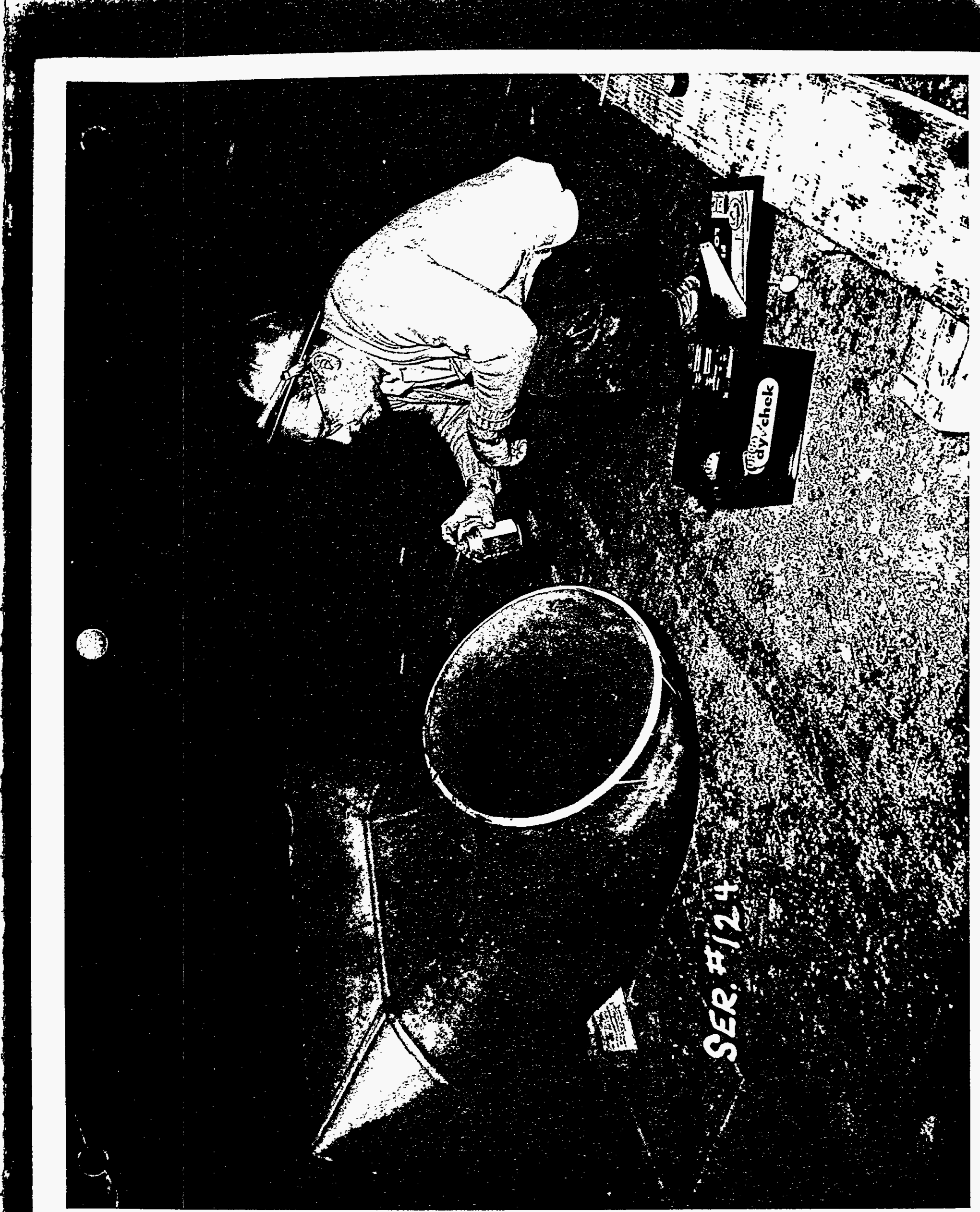




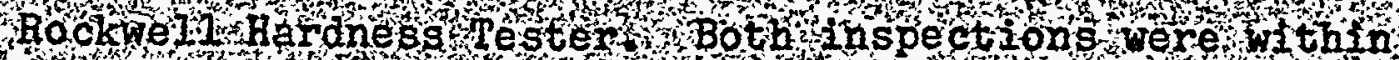

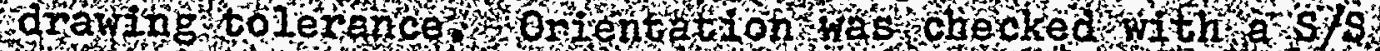

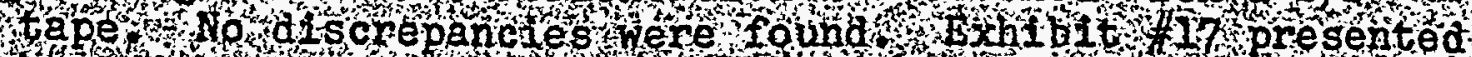

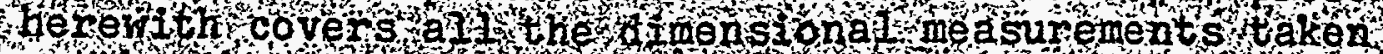

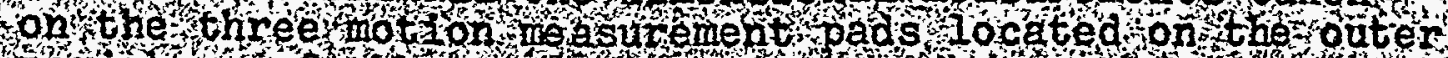
periphey on the whits

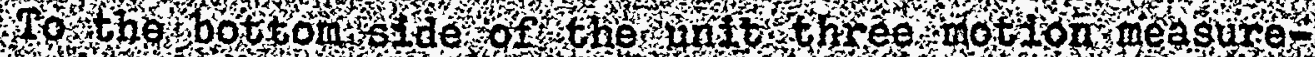

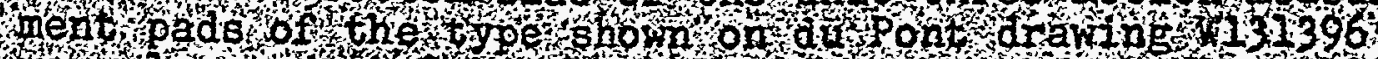

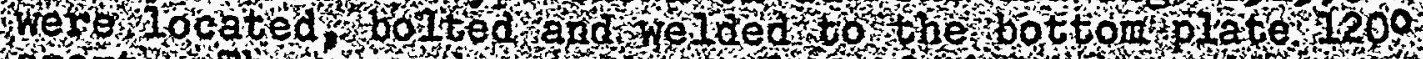

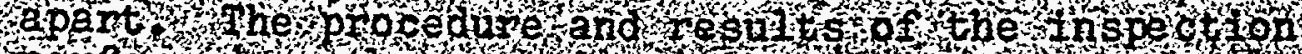

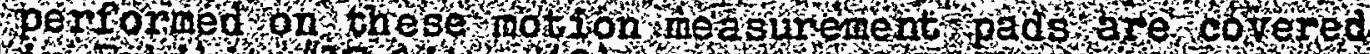

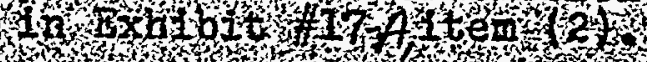

6 .

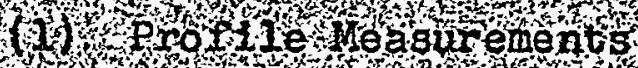

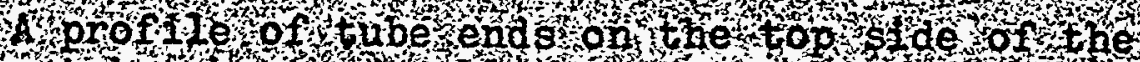

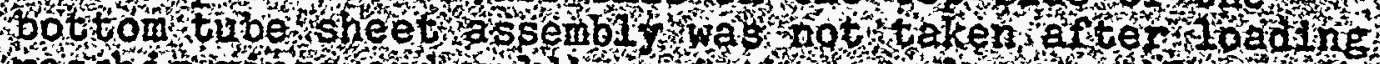

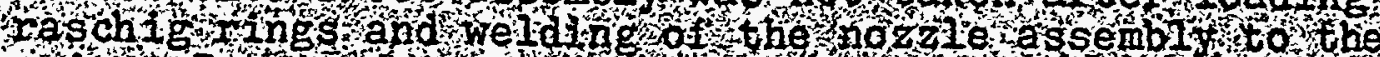

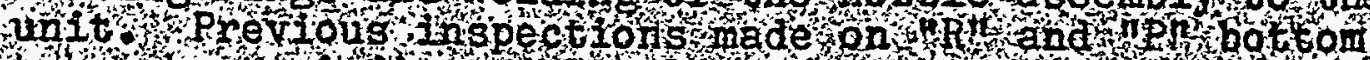

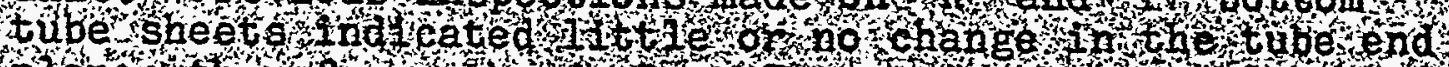

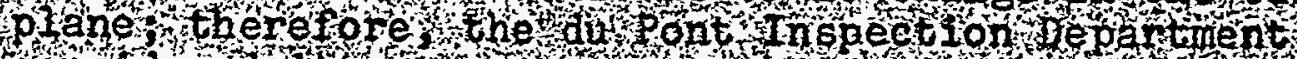

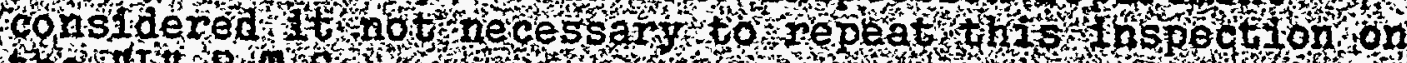
tuenditos 4 is

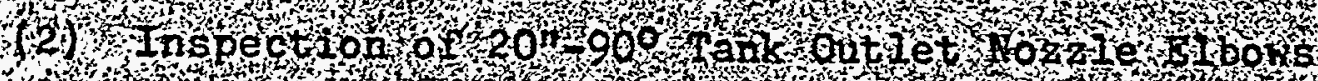

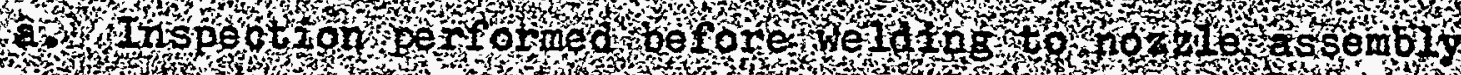

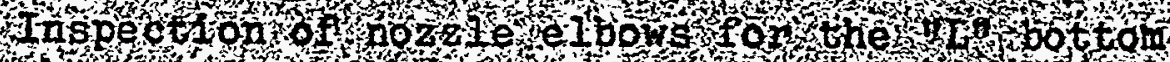

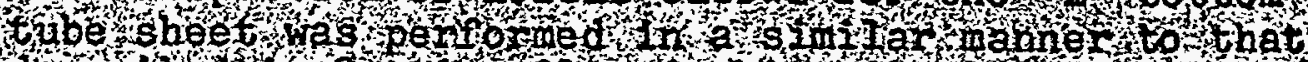

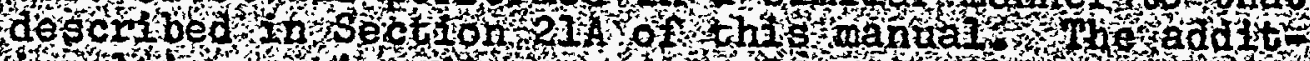

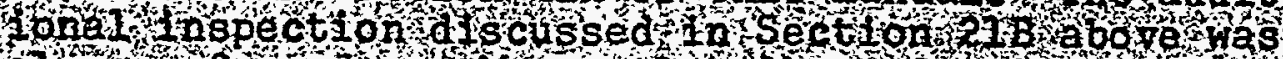

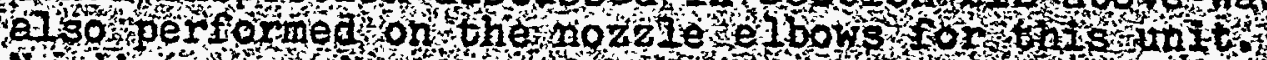

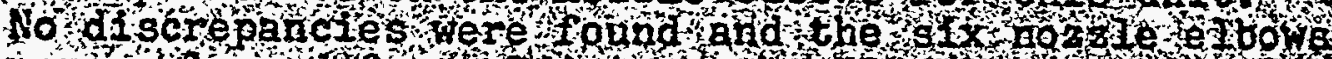

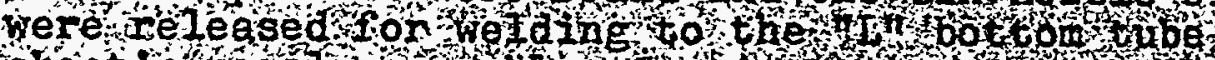

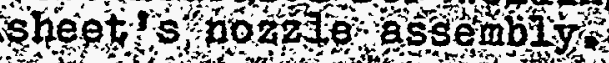

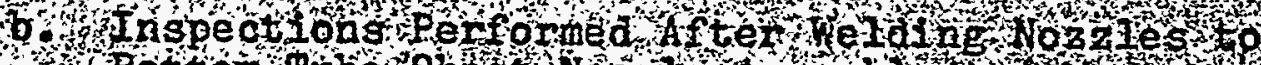

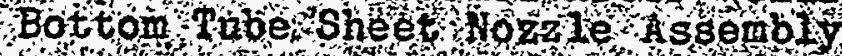

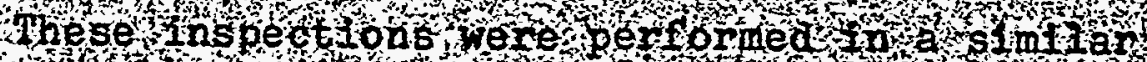

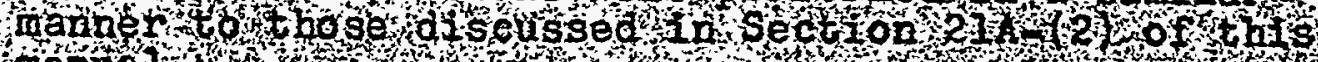
hiandal

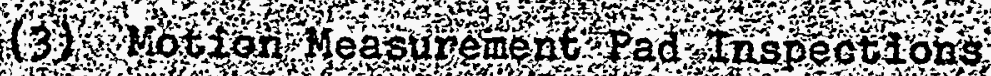

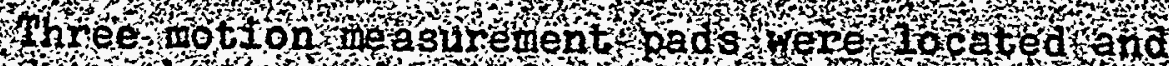

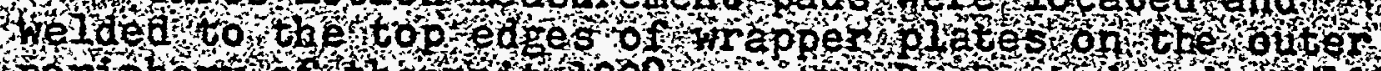

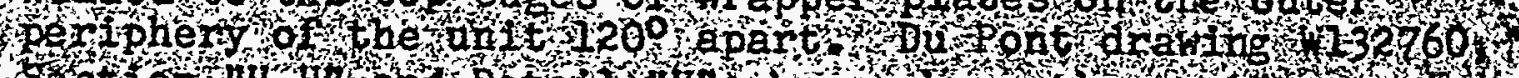

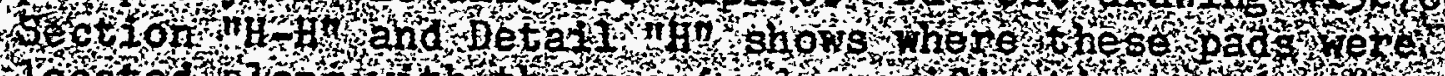

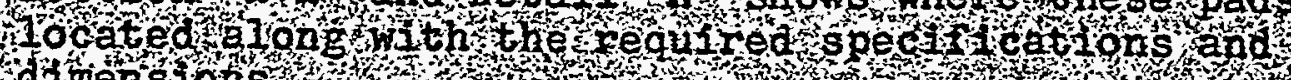

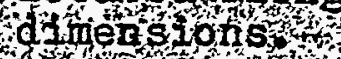

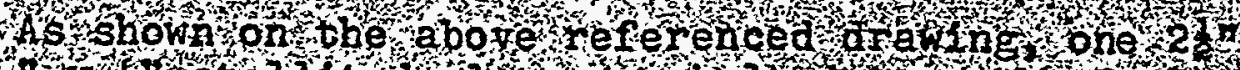

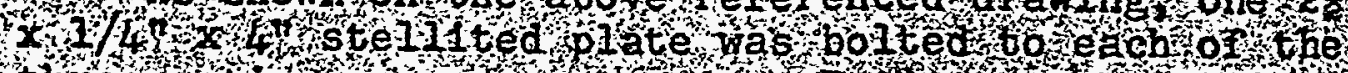

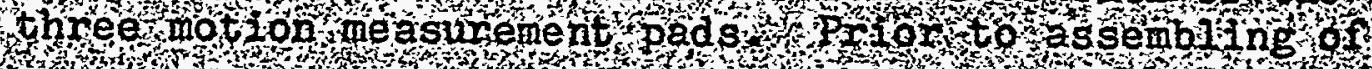




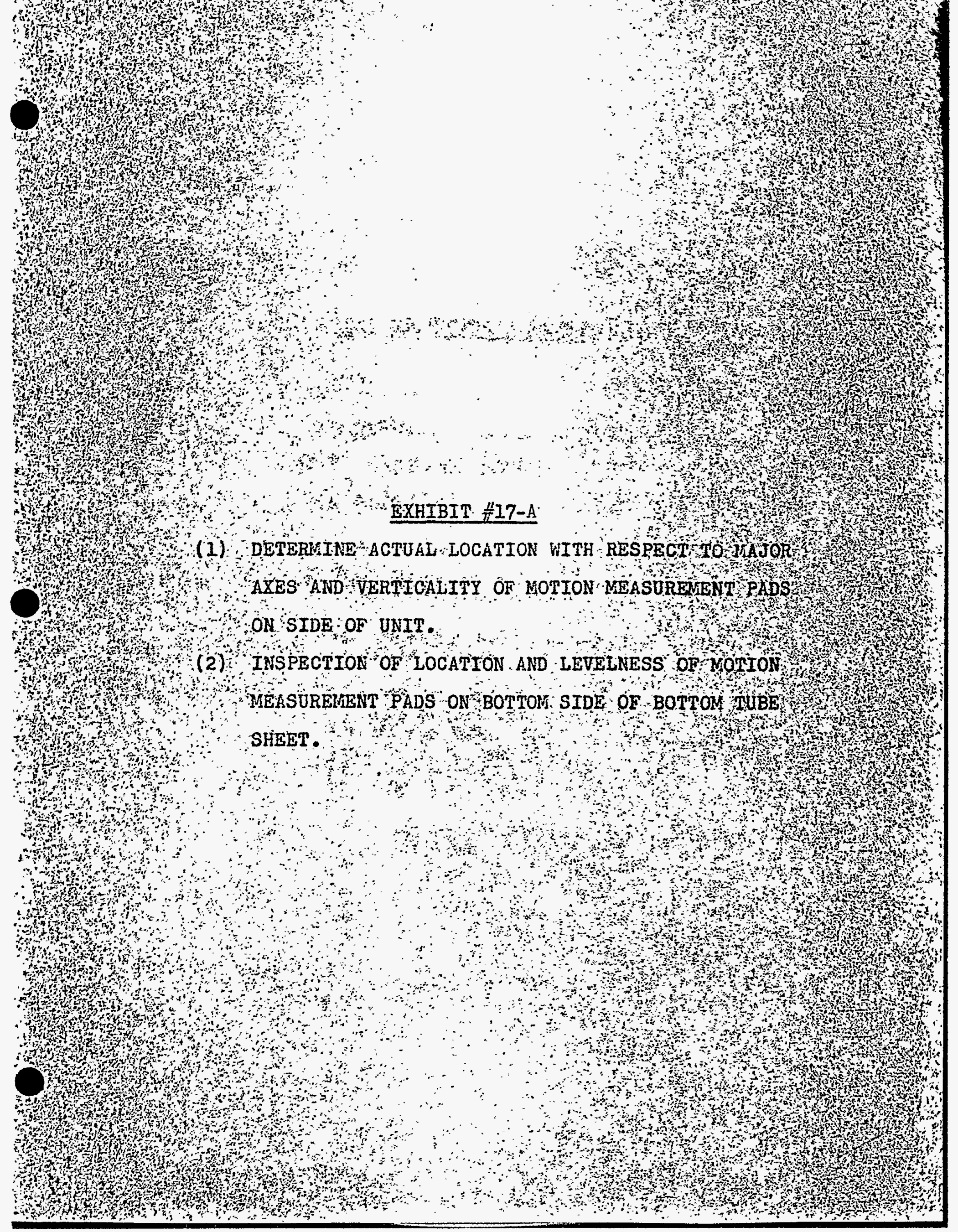


Bu I. DU POMYS DE NEMOURS \& CO,, INC. Construction Division

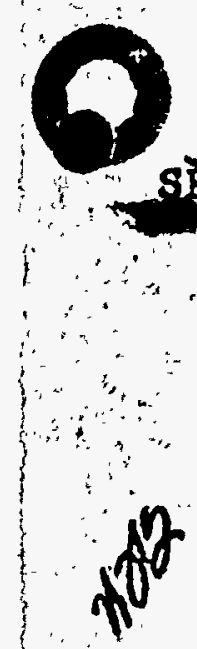

Report Number $287-P$

CC: H. W. Gosney Fo. P.

R. K. Mason, F.P.M.SAP (3)

H. L. Bunkar -J.G. Brewer

J. G. Brewer

H. B. 'Gage

7. C. Breuninger

R. H. Potts

J. B. Johnson - FIle

October 29, 1952

New York Ship - Camden jis.

\section{FIELD INSPECTOR'S REPORT}

TO

C. J. VEITH - H \& E FILE

Brou

R. B. Chaney - R. W. Mease

PROJECT NO.

8980

PLANT Savanneh RIver

DATE October 29, 1952

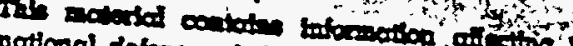

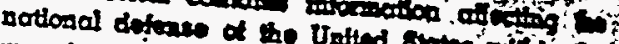

meconiog of the explocone lan suth whith

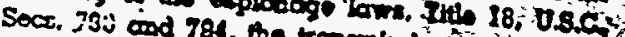

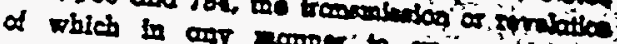

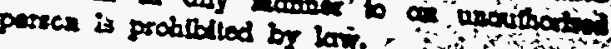

BPUIPHENT

Tank Bottom Tube Sheet

DRAWING MOS. $W-131395$ EQ.PC.NO. $153-\mathrm{P}$ ORDER NO. AXC-1671 JOB RATING $+3$

\section{VBWDOR New Iork Shipbuilding Corporation} LOCATION Camden, N.J.:

Scope:

Procedure:

To determine actual location with respect to the major axes and

1. Location - Bach pad ras measured using a tape (S.S. DuPont extended around the shell from a major axis to the edge of the pad. The pad was measured and $a$ centerline to centerline measurement calculatedo The tape measure was then converted to. degreis us: ing .032" (of circumference) = one (1) minute of

2. Verticality - Each pad was-checked with a box level calibratod In $.001^{n / 9 n}$ and converted to .001" $/ 12^{n}$. Pads are

Results: 1. Location - See attached sketch.

2. Verticality - No. $1-.000^{n} / 12^{n}$

No. $2-.001^{n} / 12^{n}$

No. 3 - .002" $/ 12^{n}$

The location and verticality of each pad was acceptable" 
Wonk BoHom

$10 / 28 / 52$

workotion of Motion

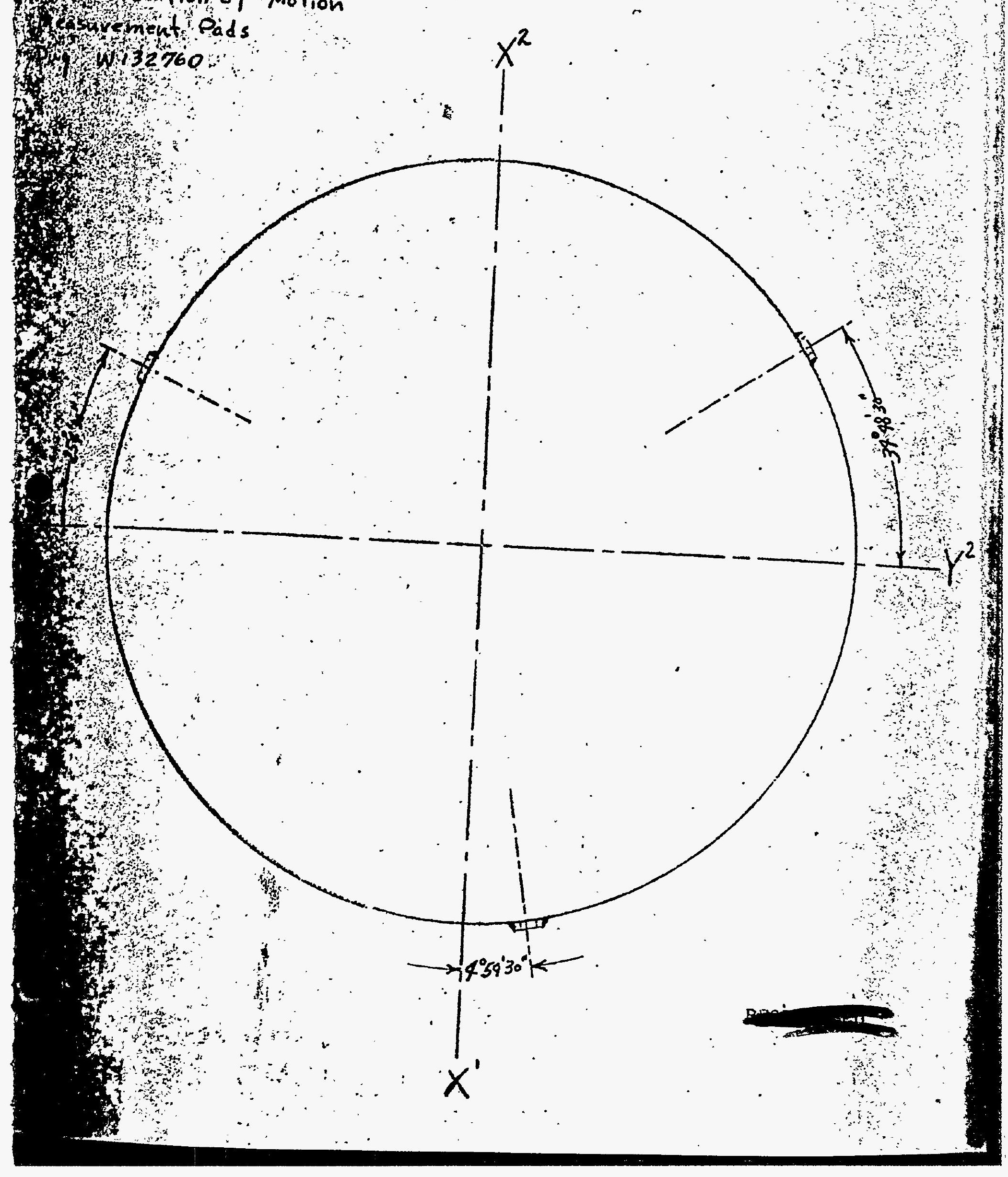


E. I, DU PONT DE NGHOURS \& $\mathrm{CO}$. , INC.

Report Number $294-\mathrm{P}$.

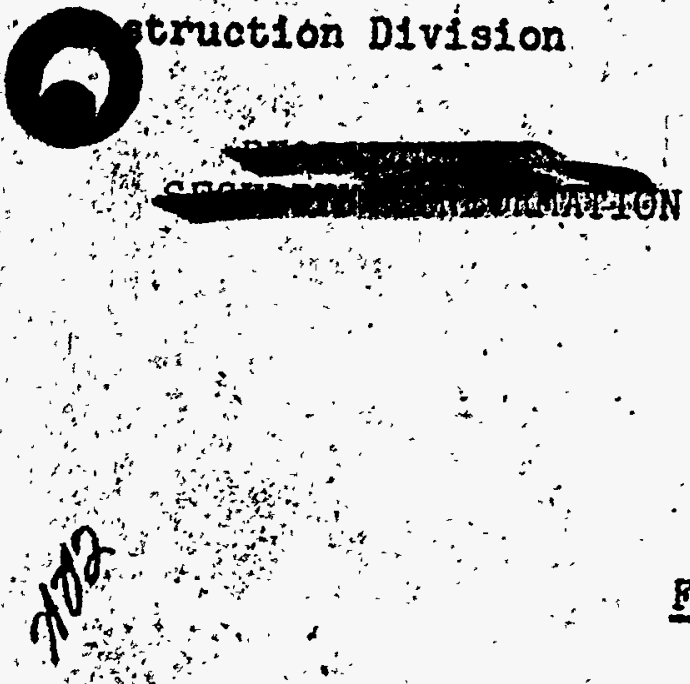

CC: H. W. Cosney, P.P.M:

R. X. Mason, B.P.M. -SRP (3)

H. L. Bunker - J.Q. Brewar

J.: G. Brew̃er

H. B. Gage

F. C. Breuningar

R. H. Potts (2)

J. B. Johnson - File

November 3,1952

Now York Ship - Camden, N.J.

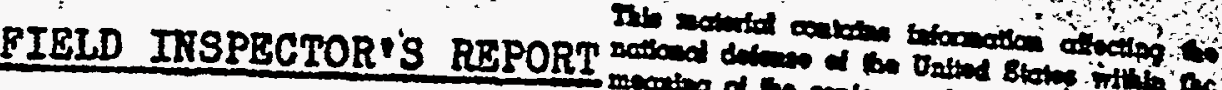

TO C. J. VEITH $-M \&$ E PILE

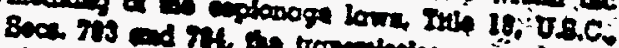

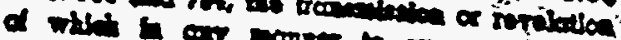

mone an probutind by kiv.

FROM Dó Mo Leland - R: Ro Baker ; . DATE

PROJECT NO.: 8980 PLANT " Savannah River

EQUIPMENT Tank Bottom Tube Sheet ORDER TO.

October 28, 1952

DRAWING NOS.

W-132396

BQ.PG.EO.

AXC-1672

Dorakring NOS.

YiNDOR NeW Tork Shipbullaing Corporation - LOCATION

JOB RATING

153-P

Scope:

Inspection of location and levelness of motion measurement pade

Procedure:

A combination square and a level were used to check location and

Resuitso:

The pads were located properly with respect to the axes.

The distances-from the $0 . D$. of the tube sheet to the center line of pads are shown on attached sheot.

\section{Level is as follows:}

Pad on Yl axis was out of level .0015n per foot

Pad near XI

. Pad near X2." $n$ " $n$ n .0025n $n \ldots n$

Note: The location and levelness of these pads were satisfactory.

Imis

tttach.

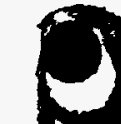




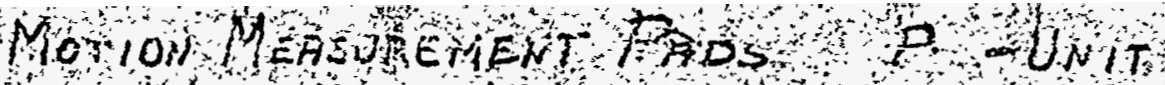

W-132763
$W$

$$
W-132763
$$

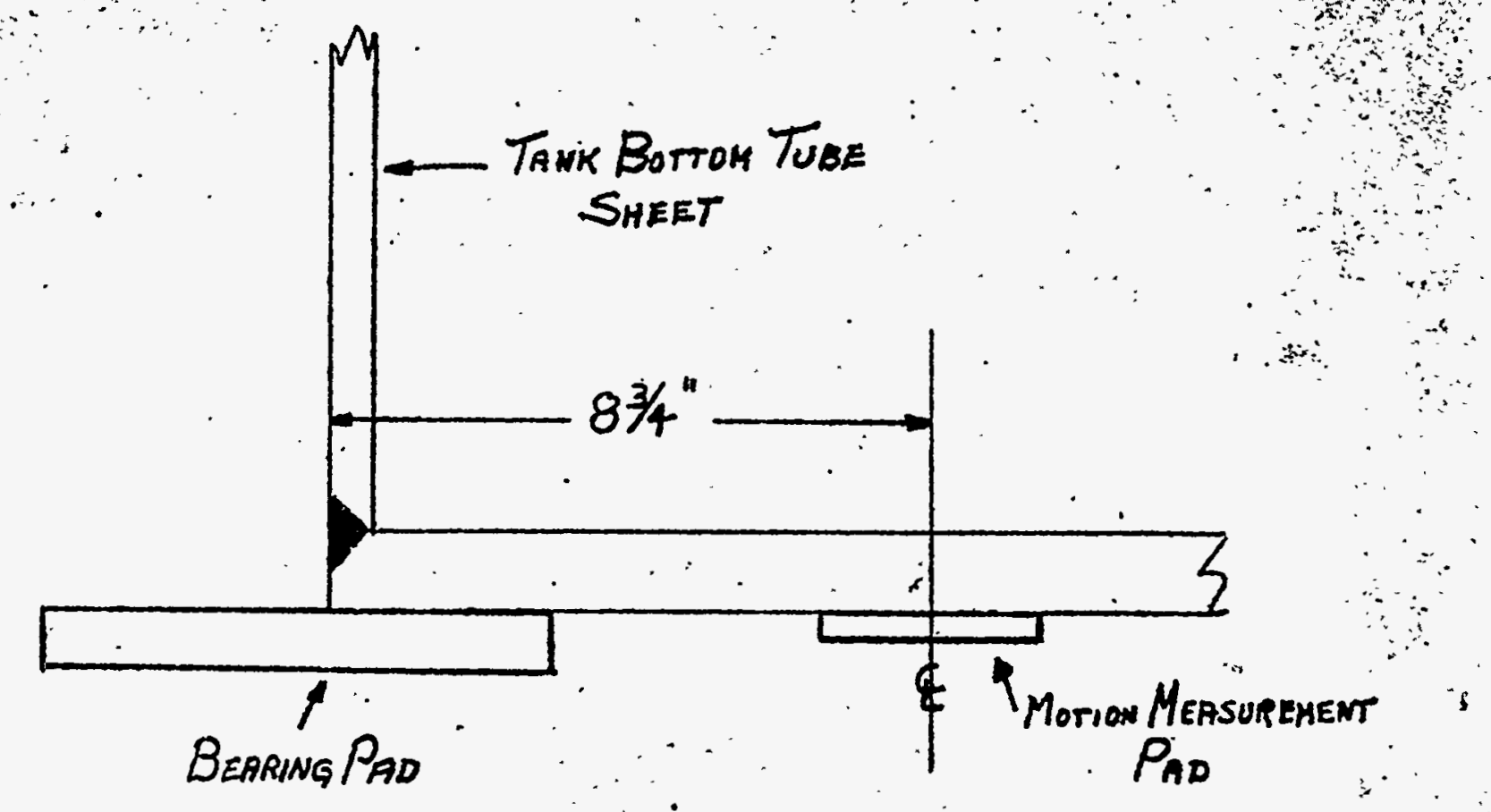

Pad ON YI axis Measured $87 \%$

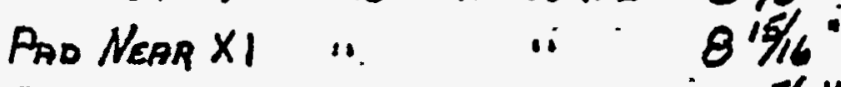

PAD. "X2 ". " $81 \% 16^{\prime \prime}$ 
the stellited plates to the unit, each of othe three plates were checked for Rockwell hardness hus inish and flatness. The hardness was checked on $\mathrm{New}$ or $\mathrm{sh}$ sols Rockwell Hardness Tester Hardness was found to be Rockwell C-43 to 51 which was acceptable to the di 3 ont Inspection Department, RhS finIsh was cheked ifths profilometer and results indicated the f $1 \mathrm{~h}$ ish to be

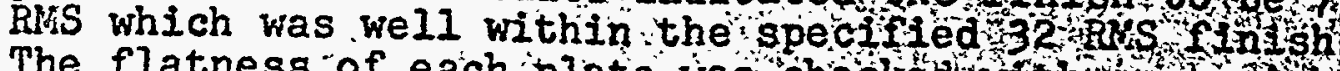
The flatness of each plate łas checked wh hatstal

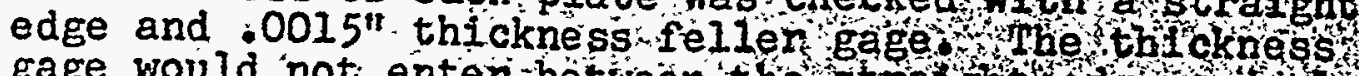

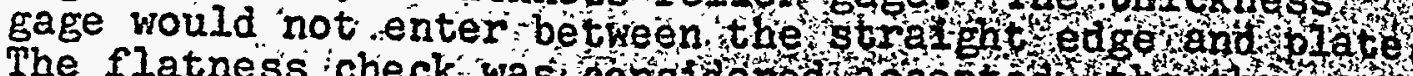

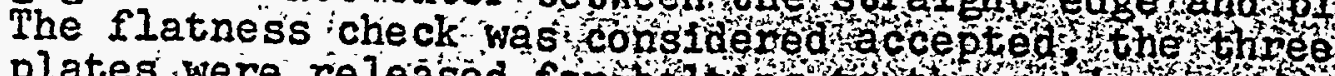
plates were releásed for bolting tho thotonghang

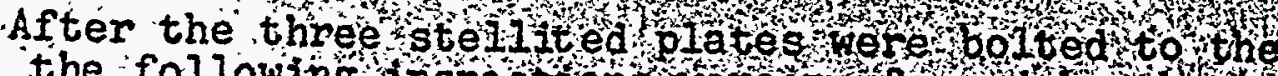

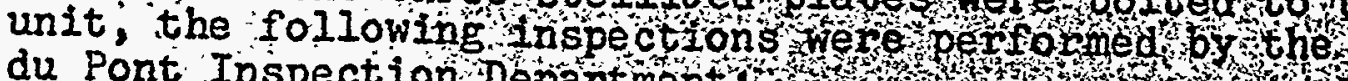
du Pont Inspection Department?

a. Orientation of Blocks

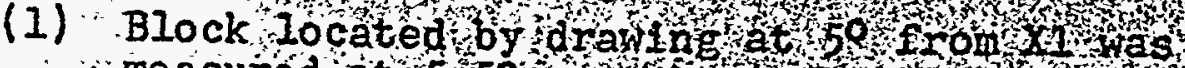
measured at 550

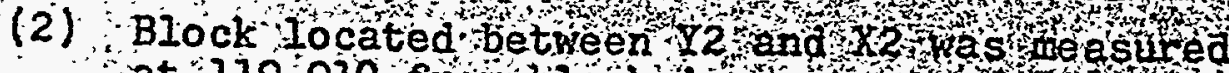
at 119.910 from block in part os

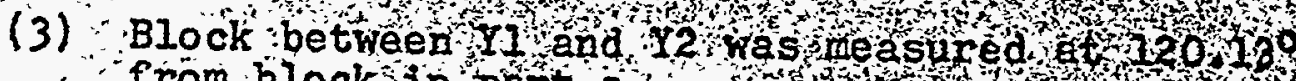
from block in part

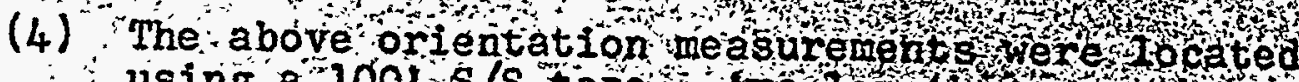

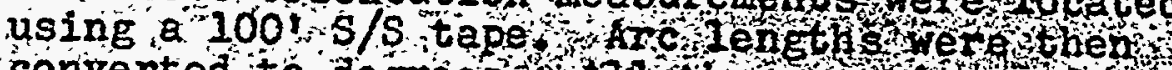

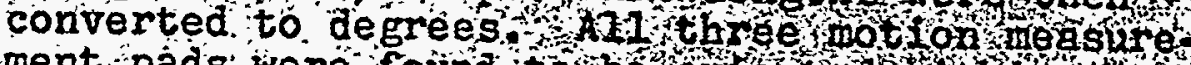
ment pads were found to beyor thed by th tolerance

(5) Size of Blocks

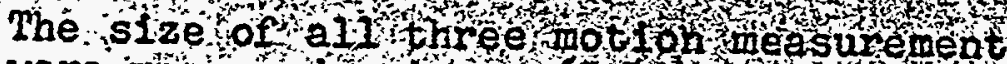

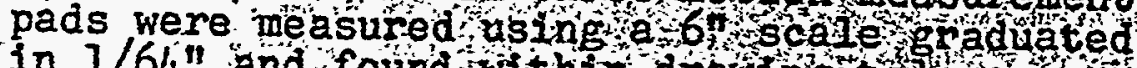

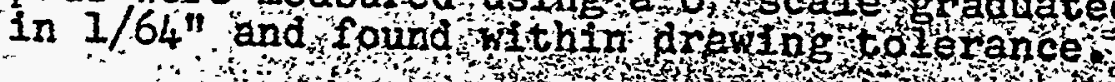

\section{(6). Field Compiaint}

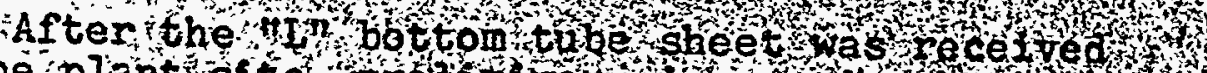

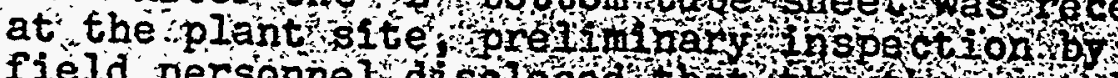

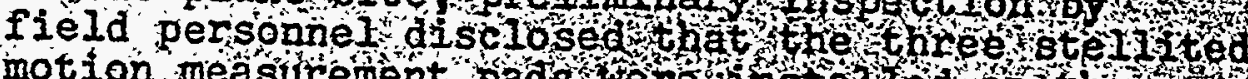

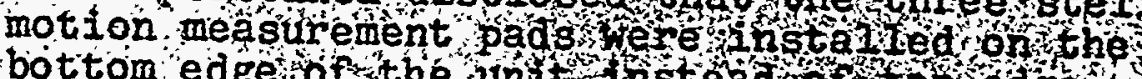
bottom edge of the unt th stad of top ofges

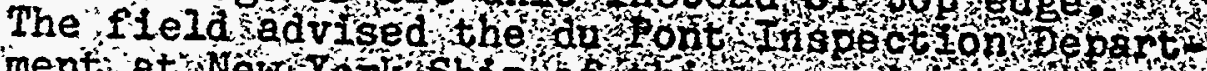

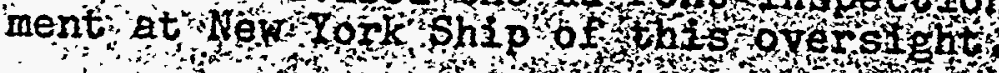

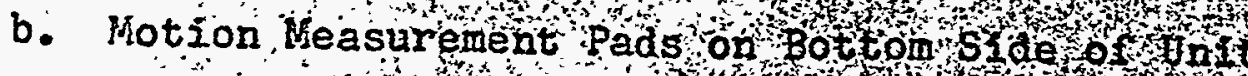

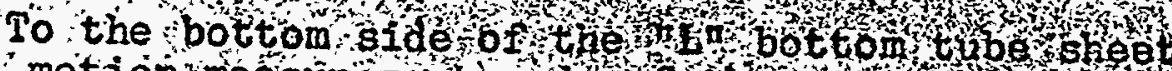
three motion nésurement pad of the type shoht on

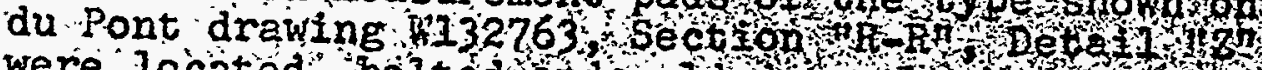
were located" bolted and we Ided tothe bottom pla te 1200 aparta After the three blocks pekem al shed 
machined and prior to assembling to the unit, they were checked dimensionally using a $6^{n}$ scale graduated in $1 / 64^{n}$ and found within tolerance.

Next, the three blocks were then located, bolted and welded to the bottom side of the bottom tube sheet. Inspection of location and levelness of motion measurement pads after assembling to the unit were similar to those discussed in Section 21B, Exhibit 非7-A, item 2. The location and levelness of these blocks were satis- factory and accepted by the du Pont Inspection Department.

22. Bearing Pad Inspection and Discrepancies

A. "rRn Unit

(1) Bearing Pad Hole Discrepancies

As shown on du Pont drawing W-130949 and $1-131265$, twelve bearing pads were located and welded $30^{\circ}$ apart on the bottom side of the unit. Into each of the bearing pads two elongated, tapered holes were milled. During the process of machining these holes in the bearing pads, numerous problems were encountered due to the original method of machining tried. In order to clarify the problem encountered, a step-by-step procedure covering the old and new method of machining and the steps taken to rectify the situation encountered on the $R^{\text {n }}$ botom tube sheet will be discussed in outline form as follows:

(a) Bearing pad holes on NYX bottom tube sheet were changed from round holes to elongated, tapered holes

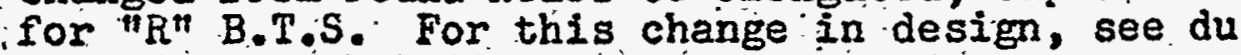
Pont drawing W-130949.

(b) Bearing pad centerlines (radial with respect to center of B.T.S.) were established using the large jig that was used for locating the same hole locations in the NYX BTS bearing pads. A template was made and used for layout of elongated bearing pad holes. This template was adjusted to the centerline of each bearing pad and elongation of holes scribed and center punched.

(c) Unit was set and leveled on cast iron padestals and elongated holes were milled in bearing pads using portable "Versa Milis.".

(d) Du pont inspectors examined the finished machined job and noted that the holes were not with in tolerance $V$ isual inspe ction revealed that on all bear ing pad holes milled there was evidence of itTool chattert on the wall of the holes, which was outside the layout Innes Also, no taper had been allowed for:

(e) In view of this problem lt wás decided by New York Ship to drill out holes to a larger diameter and counter-bore holes (from top side) approximately 


\section{Page 72}

$1 / 8^{n}$ deep for insertion of a shoulder head bushing. These shoulder head bushings had an elongated, tapered bushing milled in the to finish size. This method of repair was agreed to by the du Pont Inspection Department with Design Division's concurrence and twenty-four bushings were fabricated (two/bearing pads).

(f) New bearing pad holes were laid out from existing centerlines on bearing pads.

(g) \& small jig was made to clamp to the face of the bearing pad which lined its bushed holes up with layout of bearing pad holes.

(h) Round holes were drilled and reamed.

(i) A large field jig was set on bearing pads, lined up with centerlines and bearing pad holes scribed. to jig. This jig was later sent to the plant site for locating, drilling and tapping holes in the units foundation.

(j) Twenty-four shoulder head bushings (round 0.0 . and elongated, tapered I.D.) were press fit into the bearing pads. Care was taken to insure that elongated holes in shoulder head bushings were held parallel to the bearing pad centerline. A dummy plug that fit elongated, tapered holes in the bearing pad bushings had a flat strip across its face about 10" long for aligning the bushings (in bearing pad) to the bearing pad centerline. When bushings were in line, they were drilled, taped, and dowelled.

(k) Du Pont inspectors checked all work concurrent with New York Ship's personnel and found the job to be satisfactory.

\section{(2) Repair of Damaged Bearing Pad Face}

During the process of handing the bottom tube sheet, one edge of a bearing pad located $30^{\circ}$ off the X2 axis was hit and slightly bent. Du Pont inspectors measured the amount of distortion using feeler gages and a small straight edge. In sketch fly the lines $P-P, R-F$, centerlines, $H_{-}-H_{1}$, and $N-N$, show the position of the straight edge and maximum clearances. AII clearances were to point marked.

The New York Ship mechanics repaired the damaged bearing pad, and re-inspection by du Pont inspectors in a similar manner to that discussed above was performed. Results indicated the bearing pad surface was " $.005^{\prime \prime}$ with in the plane of tube ends and was. $90^{\circ}$ with the centerline of the large tubes. The repair job was accepted as being satisfactory and the unit was released for further fabrication. 


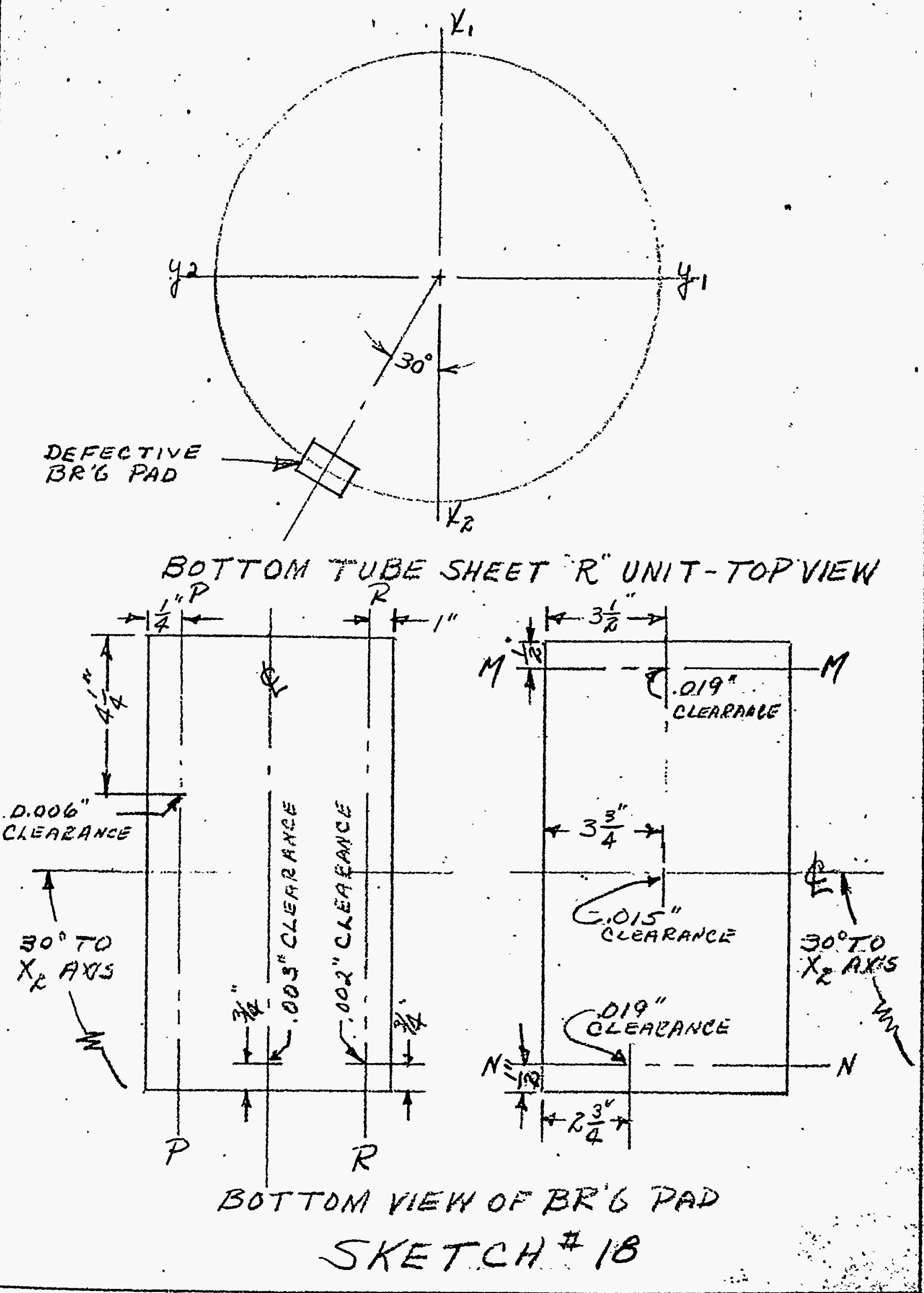


(1) Bearing Pad Hole plscrepancles

The sume discrepandes found on the twelve bottom tubs sheet bearing pads there encountered

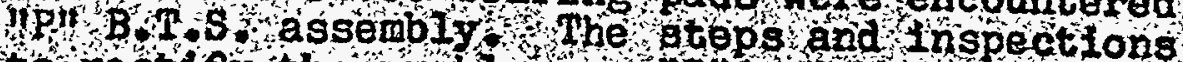
to rectify the problem on inp unlt were similar taken on the "RT B.T.S. assembi this problem, see section $22 \mathrm{~A}$ (1) see du pont drantng -131396 .

\section{c. oningint}

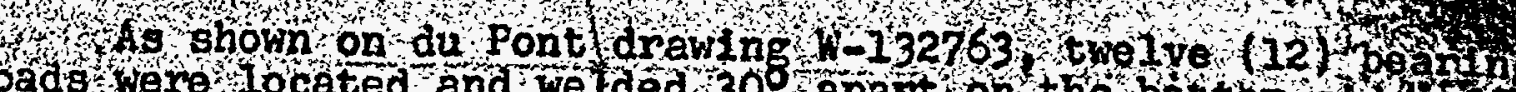

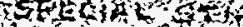

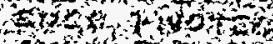

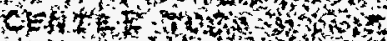
pada Were located and we lad 30 apart on the bottom 3 Ide the und The aesign of the bearin pads for this unt the sonowhat alf ferent from those fabricated for tho nhe and bottom tube sheets - By referrinsto drawing 13094 and tho ebove referenced drawing the se a f forences can 6 oreadily sedn This design change cane bbout as a result of the dis crepancies encountered dur ing naching of bearlng pads ing inanual.

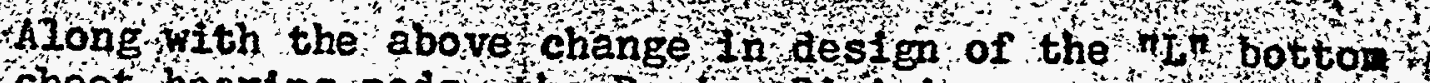
tube sheet bearing pads the Desfon ofviston requested that the following tolerances be closely od ared to by Wer to ok $+\%$

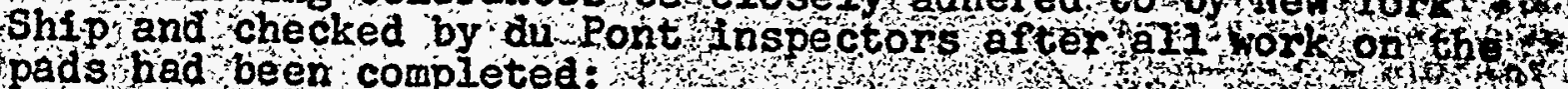
pads had been compléted:

(1) The 5 tong gufde surfaces shall be parallel to the

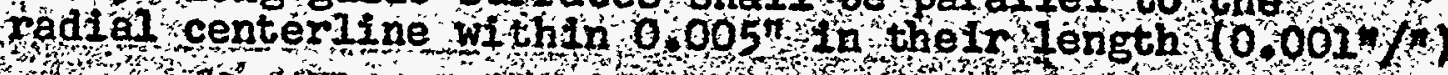

$(2)$ the centeriline of the $10 \mathrm{w}$ wate section of the bearing pad pinal be within $18 \%$ one side or the other of the radia 1 centerline on which $1 \mathrm{t}$ should fell.

(3) If the necesstty to da chine the oulde surfaces for parallelism to the centerline-arises after welding tho pads the $102^{\prime \prime}$ dimensfon nay be reduced to a minitun or 10-3/d . The se tolerances were assumed gifficient by pesign to counteract any welding distortion or possible error In lit-up.

To comply with tho abova bearing pa speciflcations

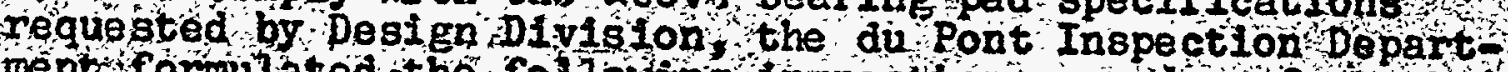
ment formulated the fol 10 ong inspecton procedure for satting and checking the bearing pads

(1) Wf ter the bearing pads have been inst alied and foced of

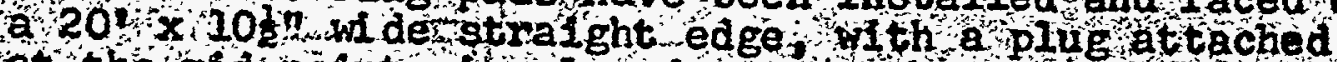
at the mid-point, 15 placedacross the unit pivoting In the center tube (Sessetch (19)

(2) The stralght edge tay be rotated so that the hldpolnt

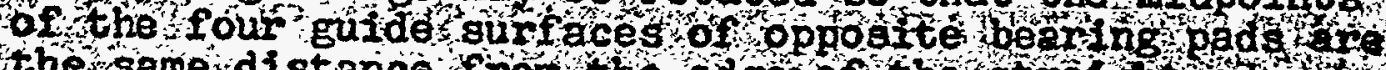

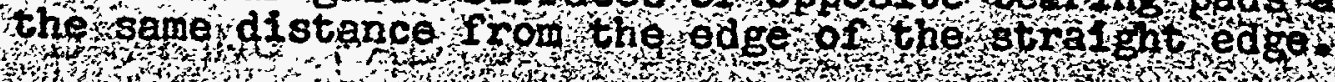




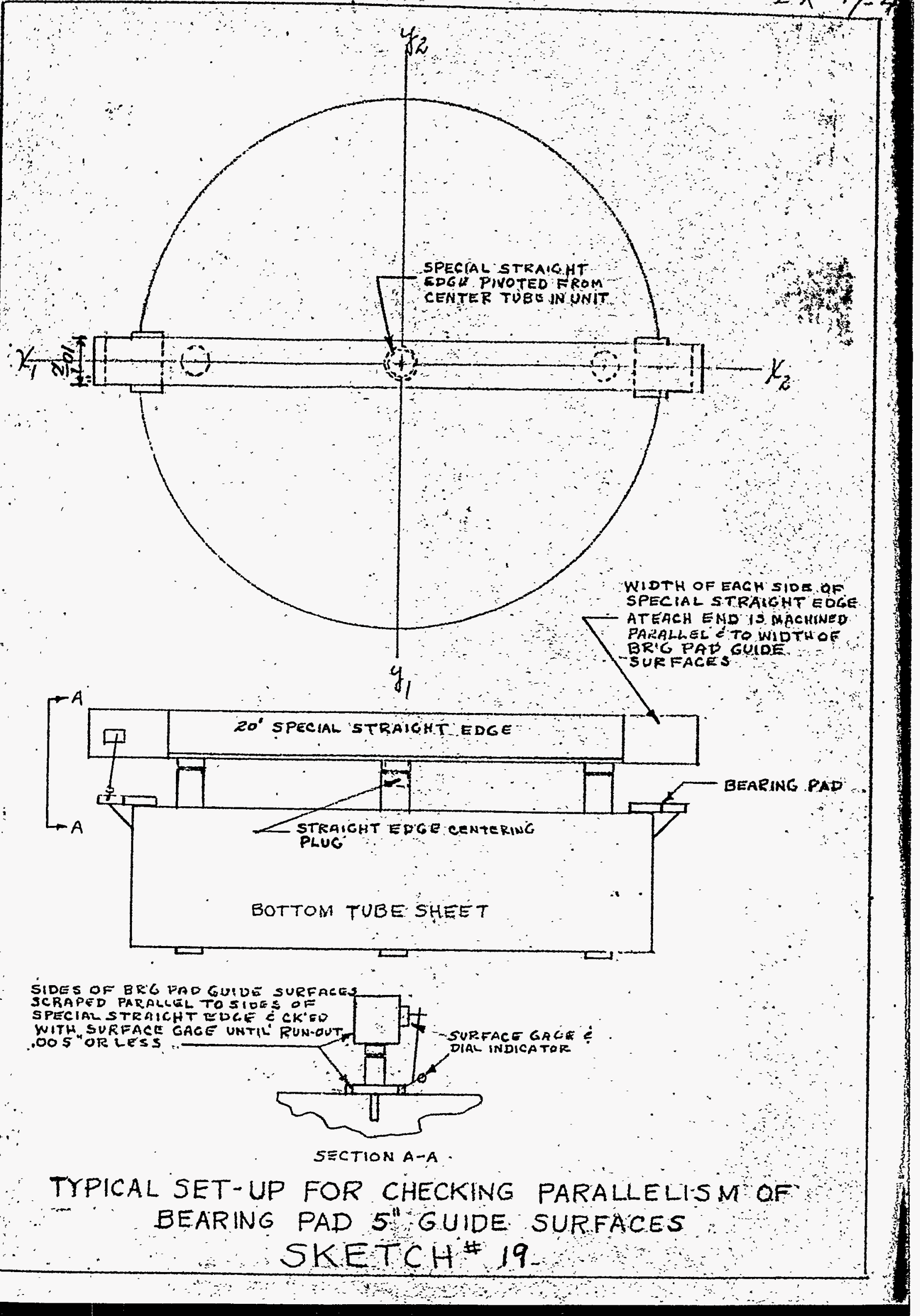


(3) None of the mid-points of these' four guide surfaces can be more than 1/8n from the edge of the straight. edge.

(4) The four guide surfaces are then finished parallel to the edges of the straight edge within $0.005^{\text {t }}$ over their entire length $\left(0.001{ }^{n / 7}\right)$

Following the above outlined procedure, the 20 stralght edge was laid parallel to the centerline of the tube bundle, and then using a surface block and dial indicator the runout on the $5^{n}$ guide surfaces were checked. Sketch 19 plctorially 11lustrates in detail how this inspection was performed. The other 10 remaining pads were Inspected in a similar manner. The sides of all bearing pads checkea on the "L bottom tube shet were found to be less than ooj In/in/5ino ln length and were accepted.

\section{Orfentation and diametrical location of the 12 bearing} pads were measured using a 50 stainless steel tape AlI other bearing pad dimensions were measured with a $6^{n}$ scale graduated in $1 / 64^{\mathrm{n}}$ : For results of the above inspections, see DR, No. 6353-9 presented herewith

A resume of all other measurements made on the 12 bearing pads is covered in Section 120 of this manual.

23. Rod Cups

A. Un unit

As shown on du Pont drawing D110129, one hundred sixtyfive (165) rod cups were required for the "n" bottom tube sheet. The se rod cups were to be cast from type 304 stainless steel (.08C Max.): A pattern of the rod cups ras made by New York Ship and sent to an out side foundry for casting. Rod cups were cast and then shipped to New York Ship. Upon receipt of rod cups, they were inspected by du Pont inspectors for quantity and then released to hew York Ship for finishing operations. All rod cups were ground and dressed on the outside, and then the bore, taper bore and length were mâchined to size and dressed.

Rod cups were acid washed, ferroxyl tested at random, and then visually and dimensionelity inspected. The outside diameters were measured using $1-2^{n}$ and $2-3^{n}$ outside micrometers. Inside diameters were me asured using $a$ telescope gage and I-2" outside micrometers. Al1 other dimensions were scaled using a $6^{\text {n }}$ machinist rule. Ninor flaws and cavities were found in the finished rod cups, particularly in the rod cup base legs. These defects were ground out spot welded and dressed. Repaired rod cups were re-acid washed; inspected and found satisfactory.

It was decided at this time that welding of rod cups to the top side of the bottom tube sheet would be done in the field rather than at New York Ship. This decision was based on the fact that rod cups welded to the unit at New York Ship would probably be bent or broken loose from the unit during 


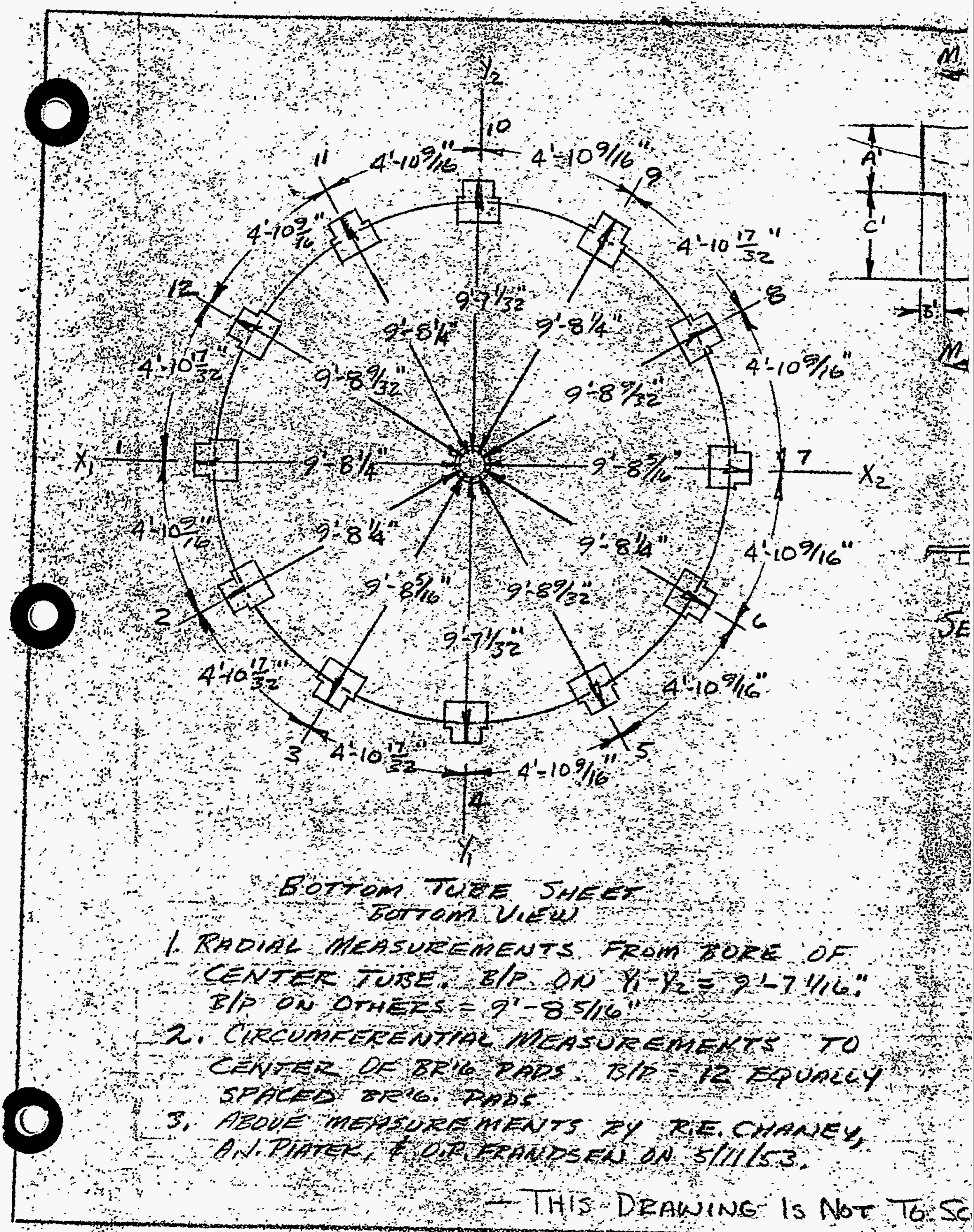




\section{Page 75}

handling operations before the unit was shipped. The finished rod cups were boxed and stored and later shipped to the field along with the main unit.

B. "P" Unit

Inspection of rod cups for the "P" bottom tube sheet was performed in a similar manner to that described in Section $23 \mathrm{~A}$ of this manual.

c." "L" Unit

Inspection of rod cups for the "L" bottom tube sheet was performed in a sinilar manner to that described in Section $23 \mathrm{~A}$ of this manual.

24. Inspection of Split Retaining lings and Flanges for the Bottom Tube Sheet Large Tubes

f. "lit Unit

As show on du Pont drawing D112637, six hundred and seventy-three (673) split retaining rings and flanges were required for the " $R^{\text {r }}$ bottom tube sheet. All machining and welding of split retaining rings and fianges was done by New York Ship and the finished parts submitted to the du Pont Inspection Department for final inspection. The discussion to follow will deal with the old anc new type methods employed by inspectors for checking the machined parts and the discrepancies encountered and how they were rectified.

During the inspection of the split retaining rings for the "ii" B.T.S., it was found through concurrent inspection that the rings shrunk out-of-round after the four studs were welded. It became necessary for New York Ship to fit the split retaining rings to B.T.S. scrap tubes to check the outof - roundness. They were trued up by hammering, and then refitted to the tube for re-checking. This was repeated until all rings rotated freely on the tube. The rings vere re-fitted for inspection in the same manner. This same method was used for checking split retaining rings for the "P" B.T.S.

The split flange assemblies for the " B.T.S. were spot checked dimensionally using a $6^{\prime \prime}$ scale graudated in $1 / 64^{n}$. In all cases this inspection proved satisfactory.

In the course of time, a du Pont Inspector noted that the above method of checking split retaining rings was time consuming, and costly and in addition, the scrap B.T.S. tubes used for checking were not of maximum diameter, so it was possible that the rirgs would be tight on some of the B.T.S. tubes.

It was suggested by the inspector that a new method for checking the rings to be used, and after trying the new method, it was incorporated into the du Pont inspection procedure. This new method consisted of fitting the split rings to a functional plug gage which eliminated having to remove the 
bolts to take the rings apart for fitting. The counter-bores of the rings were fitted over the end of a scrap tube for hammering to "round up" the ring from weld shrinkage without removing the bolts. The plug gage had a top diameter of $3.725^{\prime \prime}$ to gage for free rotation on the maximum diameter of th.e groove in the tube; a bottom diameter of $3.940^{\prime \prime}$ to gage for free rotation on the maximum $0 . D$. of the tube and $0.206^{\prime \prime}$ shoulder between the two diameters to gage (by sight and feel) for free rotation in the minimum slot width on $a$ tube. The quality of fitting and inspecting was improved because the plug gage represants the maximum diameters and minimum slot width which was not obtainable on a scrap tube. The tolerances allowed this plug gage were below drawing requirements, but was acceptable per the technical inspection group. This new method of inspectirg split retaining rings was incorporated into the du Pont irspection procedure on "L", " $K "$, and "C" B.T.S.

iffter the split retaining rings and flanges were visually and dimensionally inspected, they were acid washed, ferroxyl tested, and boxed for shipping to the plant site.

Upor receipt of the rings and flanges at the Javannah ilver ilant, and after the "l:" bottom tube sheet had been set in place, split retaining rings and flanges were assembled to the bottom end of each large tube in the unit. Dwg. 2-5 presented herevith illustrates pictorially how a split retainer ring and flange vas installed on the bottom end of a la rge tube. During the assembling operation four $7 / 16^{\prime \prime}-14 k \mathrm{C}-2$ castilated hexagon nuts were used to clamp the "simulated insert" in tho bottom end of a large tube. shen tightening up the split flange the threads were not long enough and the nut froze on the body of the stud. This condition was not noted in the field, and as a result the studs were twisted off at the weld in an effort to tighten the flarges. The field concluded that the weld joining the studs to the retainer rinE was not sound and notified the du Pont Inspection Department of the above discrepancy. Tests were then performed by du Pont inspectors at New York Ship to determine how much torque was required to break the stud weld loose, and also to further study the soundness of the welded joint. riesults of this test indicated that the studs were properly kelded to withstand the test torque applied. From this test it was concluded that the threaded studs vere not long enough to securely clamr the "simulated insert" in the bottom tube sheet large tubes.

The above problem was rectified on "F", "L", "K" and " $C$ " by lengtrenirg the thread to $11 / 8 "$ on each of the four retainer ring studs, thus lessenine the possiblilty of nuts freezing to the stud body (when tightening) and breaking the weld joining the stud to the retainer ring.

B. "ip" Unit

Inspection performed on split retainer rings and flanges for this units is discussed in section $24 \dot{A}$ of this manual. 


\section{SPLIT RETAINING RING \& FLANGE}
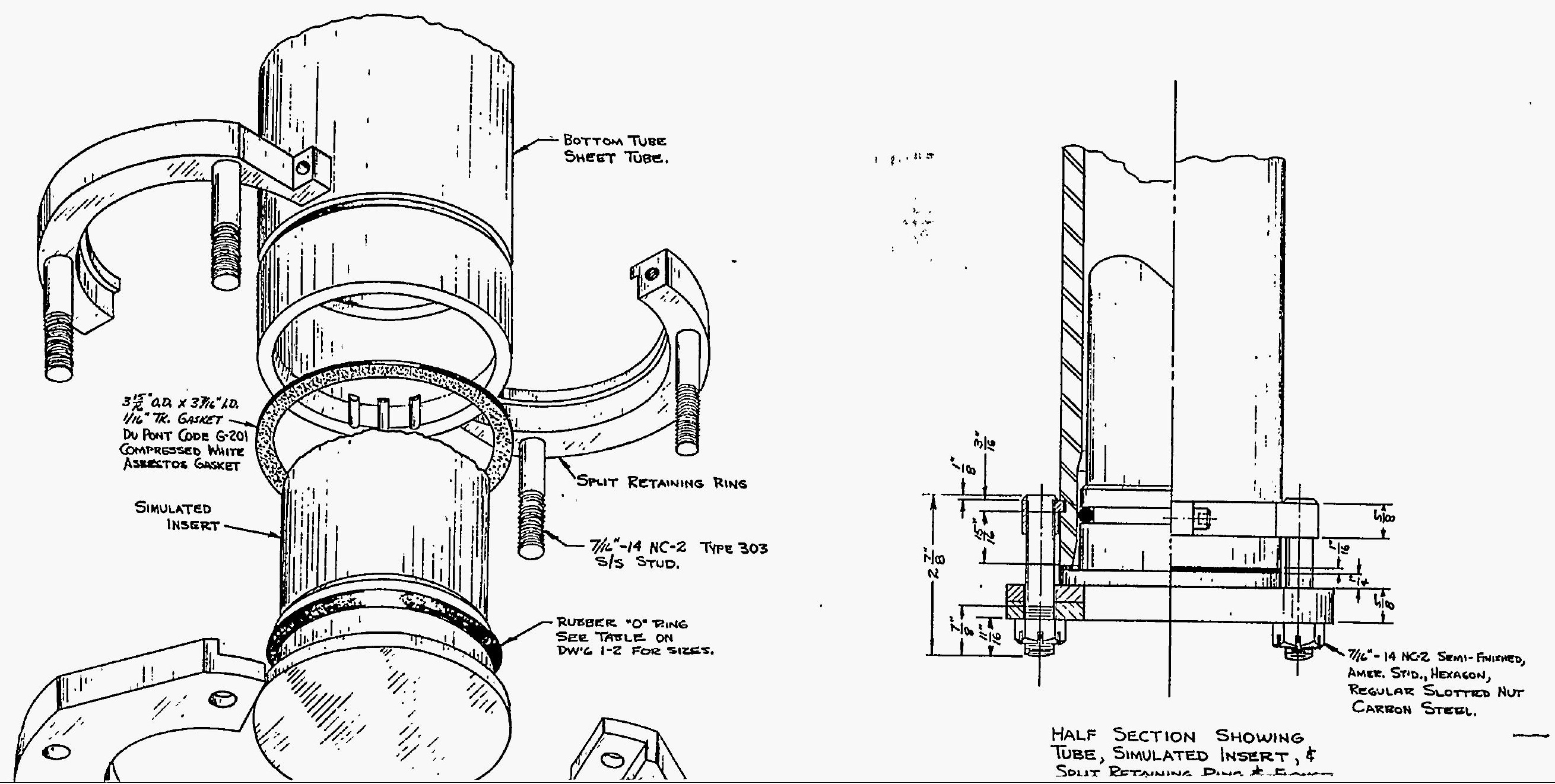


$$
\text { l }
$$


The inspections performed on split retainer rings and flanges for the "L" bottom tube sheet vas performed in a similar manner to that discussed in Section $24 \mathrm{~A}$ of this manual. In addition, a jetail analysis of the actual inspection of the split retainer rings and flanges for "L" unit is presented herewith as Exhibit \#18.

25. Nozzle Muff Assemblies

A. $" R^{n}$ Unit

As shown in Dwg. 5-7 and 5-8 presented herewith, six nozzle muff assemblies were required for the " $R^{n}$ bottom tube sheet nozzle assembly.

Waterial required for the fifty-four (54) muff leaf plates ( $9 /$ nozzle) were inspected for laminations and other surface imperfections. Necessary repairs were made and then they were ferroxyl tested before releasing for fabrication. Kuff plates were laid out, formed and machined to drawing size. The finished machined muff plates were then grouped in assemblies ( $9 /$ nozzle) for the six bottom tube sheet nozzles and identified by a code number stenciled on the plate. The upper, center, and lower muff plates which required keyways were laid out and milled to size. Next, spacer bars, sleeves, dowel pins, keys, etc., were fabricated and machined to size. All component parts were then grouped and fit to their respective positions. The three top keys were located, ground and fit to the top inside of each bottom tube sheet nozzle. The top muff plates were then used as a jig for locating the final position of the three keys to the top inside of each bottom tube sheet nozzle. After positioning the muff plates to align the three (3) keys on the top inside of each nozzle, they were inspected for proper clearance by du Pont inspectors and approved. The keys were then tack welded. The upper muff leaf plates were renoved from each of the six nozzles and all keys were fully welded and dressed. All welding was then visually inspected by du Pont insnectors for porosity, undercutting, cracks, and other nechanical defects. "ecessary repairs were made, re-inspected and accepted.

Since the shipping date was near, and in order to expedite the completion on the "L" bottom tube sheet assembly to meet this date, it was decided that the three keys located on the top flate of the unit in each nozzle section would be located, fit and welded in the field.

The six nozzle muff assemblies were ther sandblasted, acid tiashed, and ferroxyl tested by du Pont inspectors. All muff assemblies were accepted and boxed for shipment to the field where final assembling to the $\mathrm{B}$.T.S. nozzles, fitting of center and taper drive keys was to be accomplished.

To assist in the location, fitting and welding of muff keys on the top plate of the "R" B.T.S., and final assembling of nozzle muffs into the unit in the field, a representative from liew York Ship's Boiler Shop visited the Savannah River 


\section{EXHIBIT $\# 18$}

INSPECTION OF SPLIT RETAINING RINGS AND

FLANGES FOR THE "L" BOTTOR TUBE SHEET ASSEr BLY 
E. T. DU PONT DE NEMOUFS \&C CO, INC. Construction Division
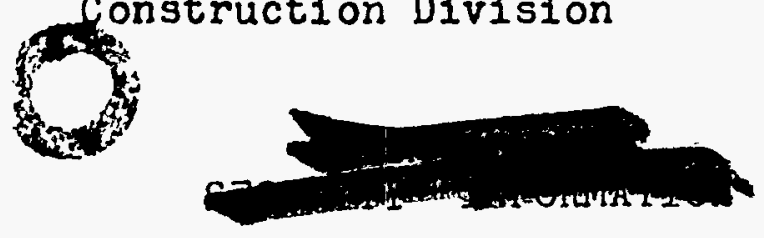

की

TO C. J. VEITH - N \& E FIIT

FROM D. J. Smathers \& H. i. Laughlin

PROJECT NO. $8980^{\circ}$ PLANT Savannah RIver ZQUIPMENT BTS Split Retaining Rings DRAWING NOS. $D-112846$

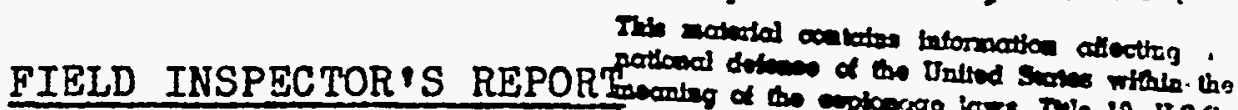
June 11, 1953 New York Ship - Camden, N. J. .

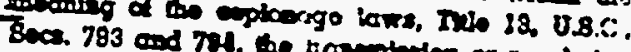

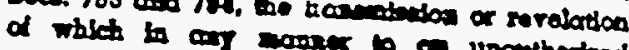
parson is probilatiod by kaw.

DATE Nay 29, 1953

$\int_{\text {Cope: }}^{\text {NDOR New York Shipbuilding Corp. LOCATION Camden, N. J. }}$

Procedure: After final machining and fitting, the rings were inspected for size with a co-axial functional plug gage $\left(3.940^{n} \mathrm{dia}\right.$. $x 1 / 2^{n}$ long and $3.725^{\prime \prime}$ dia. $x .206^{\prime \prime}$ long, the .206" being the shoulder depth between the two diameters): This plug permitted a tighter fit on the tube than the drawing tolerances would permit, but this was acceptable per Nir. A. A. Arthur (Design) and Mr. R.V. Graham (Technical Inspector).

Results: About $90 \%$ of the rings were found to be satisfactory and the remaining rings were corrected until the following conditions were met:

1. The lerge plug would start into the bottom of the counterbore.

2. The small plug would seat in the bore from the top side and the end of the plug would extend flush with the shoulder (by finger feel) or into the counterbore. This eliminated the possibility that the ring could bind in the slot width of a tube.

3. The cap screws were tight。

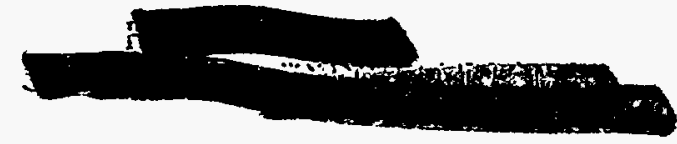




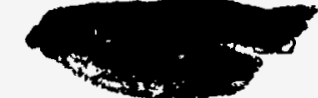

ILD INSPECTOR'S REPORT

bK: . Smathers/Laughin
Page 2 of 2

Report Number 512-2L

It was noticed that a large percentage of the rings had sharp buris on the I.D.'s at the joints which could possibly scratch the tube or foul the joint. It was planned to file these burrs when the rings were split for cleaning. About $50 \%$ of the rings were in lefts" and $50 \%$ were "rights"; that is, the stud-welds and counterbores were on the opposite sides of the rings to that sho:n on the drawing. This difference was considered umimportant by Mr. A. A. Arthur and Mir. R. V. Graham.

Two rings were scrapped because the counterbore was too small. The rings were split, wired together in pairs, and cleaned with FO. 128 solvent and then passivated to remove the oxides from the stud welds. The rings were visually inspected for cleanliness and were accepted.

The burrs at the I.D.'s of the joints were filed and visually spot-checked and accepted.

All dimensions except bore sizes and lengths (which were plug checked) were scale-measured and found within drawing tolerances.

After the rings were screwed together for shipping, $50 \%$ were spot checked by fitting them to the plug gage. It was noticed that a very small percentage of the screw threads were tight and about 10 rings of the 315 checked fitted very tight to the plug gage, but this was considered satisfactory and 670 rings were shipped to Savannah River.

jix hundred eighty (680) split flanges were visually inspected after passivation and were found to be clean and free from burrs. These flanges were scale measured (spot check) and found to meet drawing requirements. They were shipped to Savannah.River.

Vote: Approximately $10 \%$ of each of the split flanges and retaining rings were ferroxyl tested after passivation and no free iron was evident. On this basis all flanges and rings were accepted.

mw 


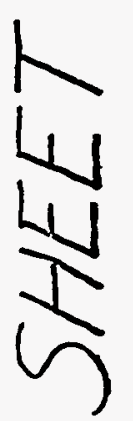

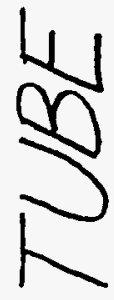
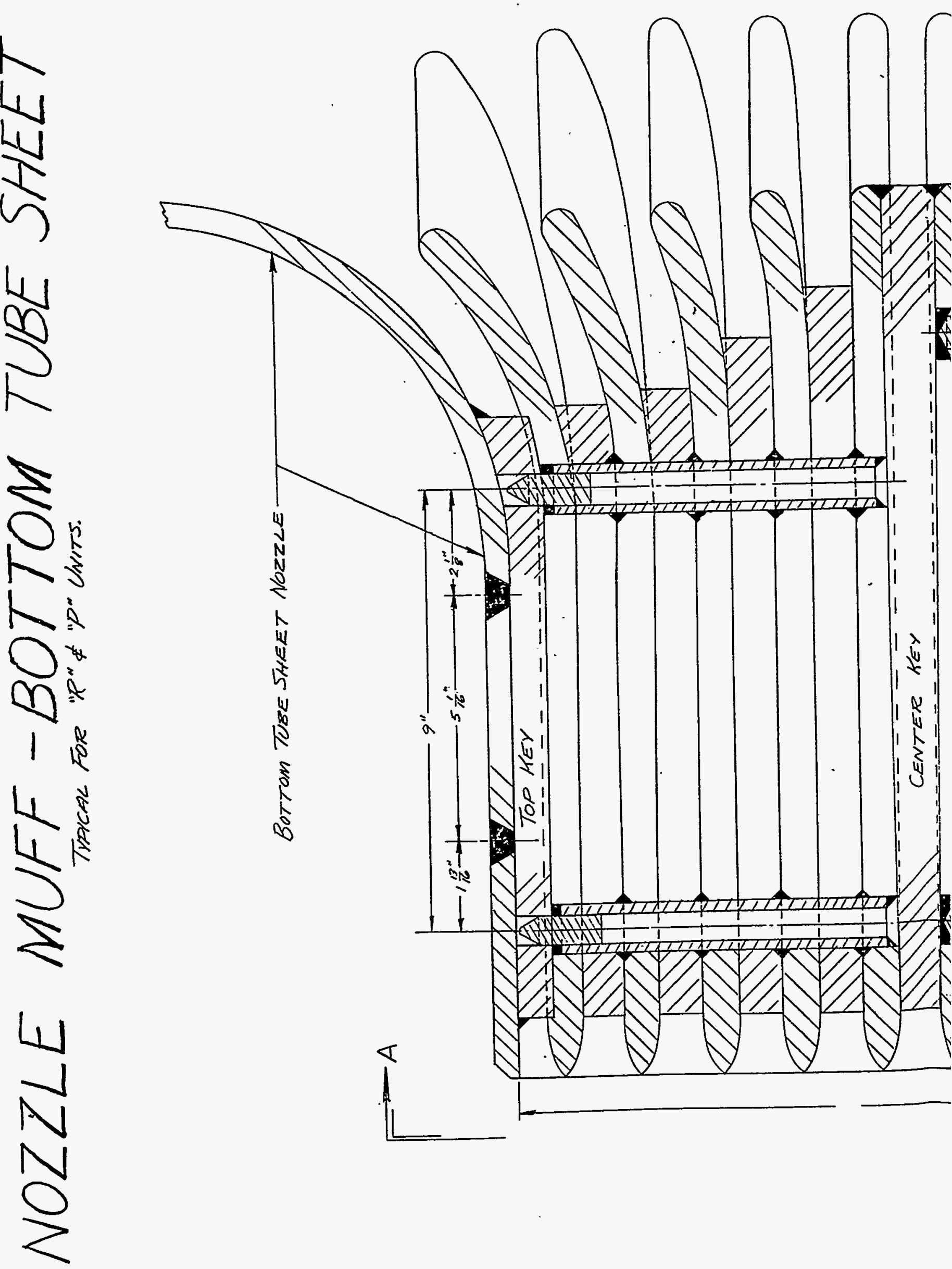

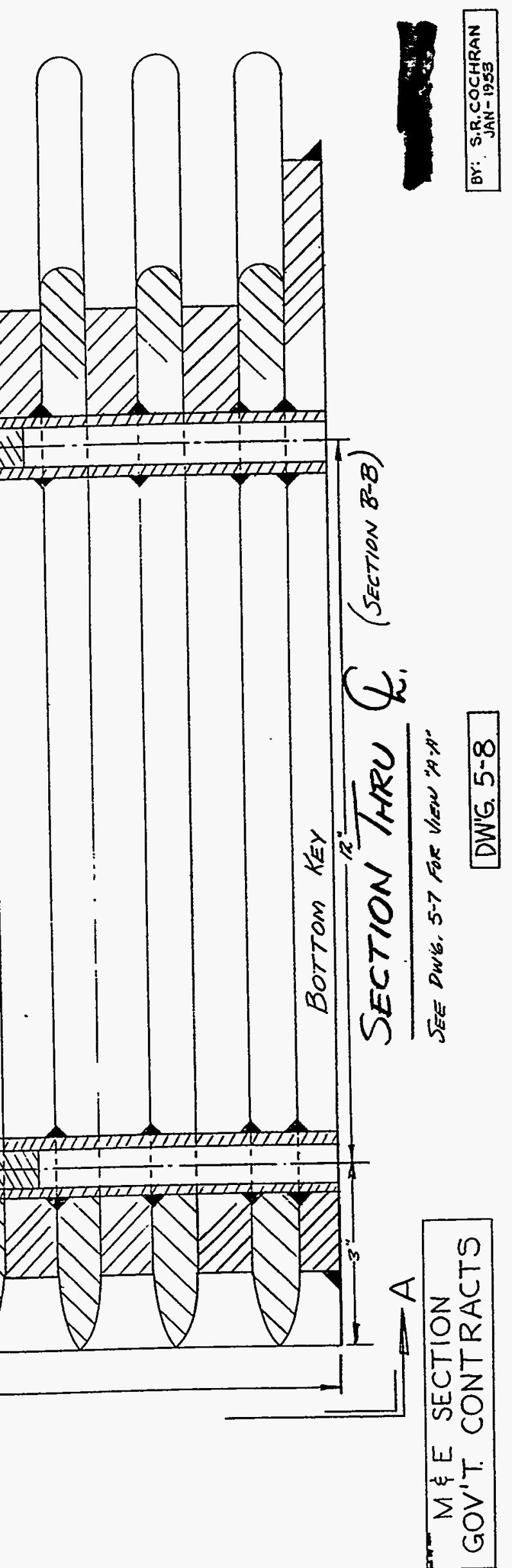
Project to supervise the final nozzle muff assembling operations.

B. "P" Unit

The fabrication and inspection of the six nozzle muff assemblies for the "P" B.T.S. nozzle assembly was similar to that performed on the " $R$ " B.T.S. described in Section $25 \dot{A}$ above except as follows: In addition to visual inspection of muff keys welded to the top inside section of each nozzle, they were also dy-cheked to further ascertain the quality of welding. Necessary repairs were made, key welding re-inspected and accepted by the du Pont Inspection Department. AIso, on this unit the three keys located on the top plate of the unit in each nozzle section were not fit and welded at New York Ship. This work was left for the field to complete. To assist in the location, fitting and welding of muff keys on the top plate of the "pn B.T.S., and final assembling of nozzle nuffs into the unit in the field, a representative from New York Ship's Boiler Shop visited the SRP to supervise the final nozzle assembling operations.

C. "L" Unit

The design of the six nozzle muff assemblies for the "L" bottom tube sheet was somewhat different from "R" and "P". By referring to DWg's. 5-10 and 5-8, these differences can be readily seen. lievertheless, the fabrication and inspection of the muff assemblies for " $L$ " was essentiallYthe same as that performed on the "l!" and "p" units, with one exception: The three keys located on the top plate of the " $\mathrm{L}$ " B.T.S. In each nozzle section were fit and their positions center-punched for later re-setting and welding in the field. The locations of the three keys in each of the six nozzles were visually and dimensionally checked by inspectors during the lay-out operations performed by liew York Ship personnel and found satisfactory.

Prior to final dimensional inspections on the muff assemblies, a preliminary dimensional inspection revealed that the vendor had drilled 1 1/64" diameter sleeve holes in details $D 114662-\mathrm{A}, \mathrm{R}, \mathrm{K}$, and $\mathrm{H}_{\mathrm{K}}$ on $9^{\prime \prime}$ centers instead of $12^{\prime \prime}$ centers as specified on draviing D114662 (also, see drawing 1133304-RO). A plug vith beveled edges was welded into sleeve hole drilled in wrong location, and a new sleeve hole was drilled in the proper location. The plug welds were then ground flush with the plate surface. AII welding was visually inspected for soundness and quality and then dy-cheked to further ascertain the intergrity of the welding. All inspections were satisfactory and accepted by the du Pont Inspection Department.

The upper sections of each muff assembly were fit into the nozzle assembly before welding the latter to the top side of the B.T.S. The fitting of each nozzle muff bottom assembly was waived in order to "Ioft-in" the main tank section in the time remaining before the proposed shipping date. 


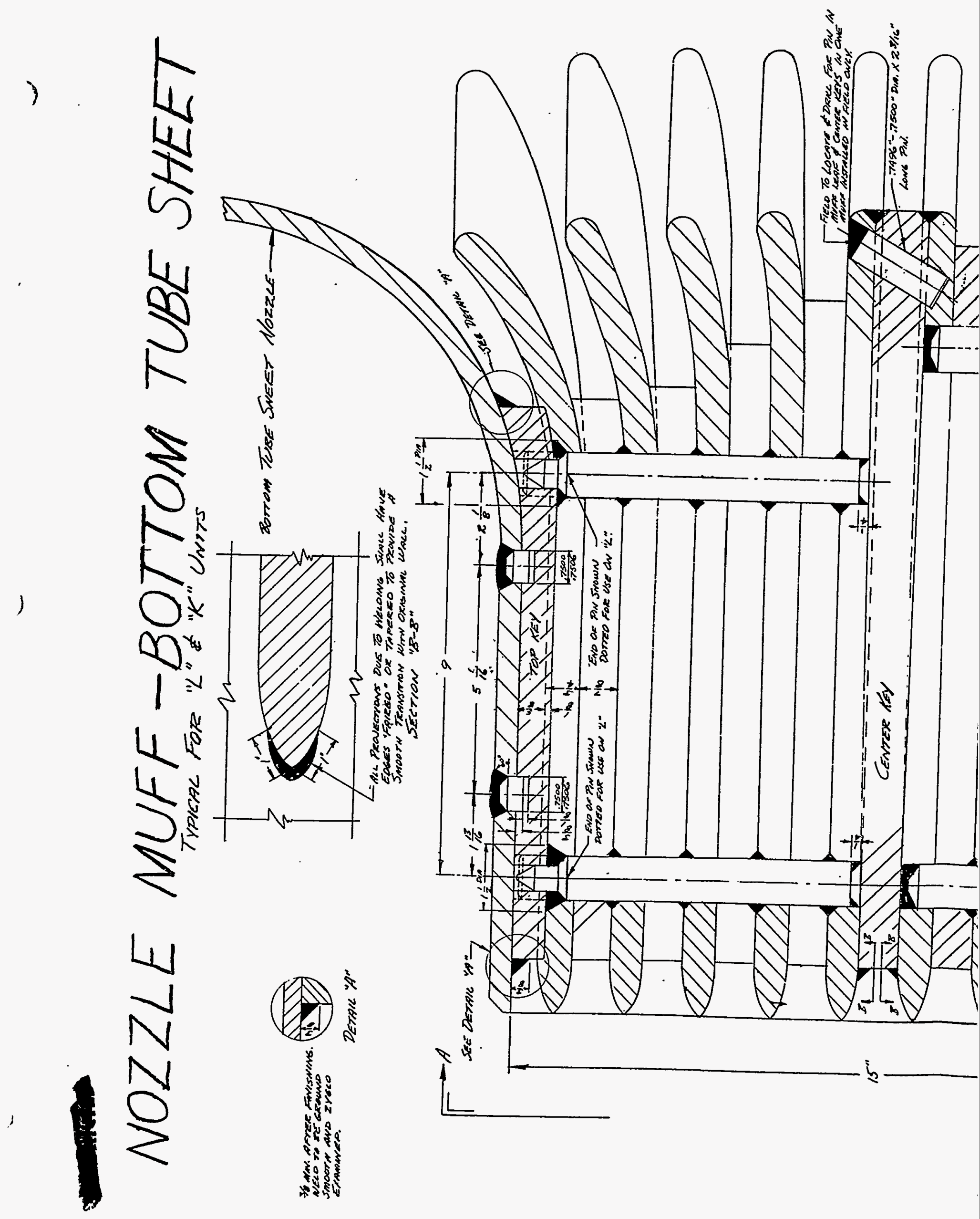




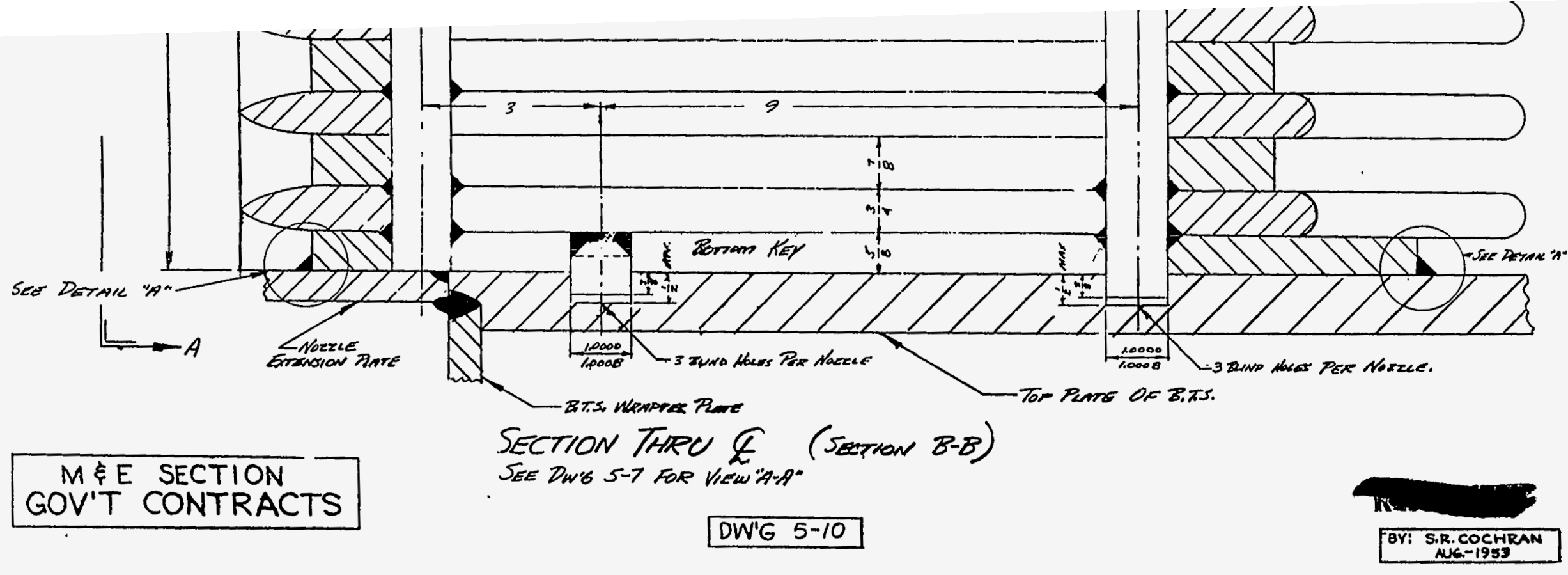


H.L almenszonal inspections confirmed that machining was within tolerance; welding and fit-up was satisfactory except as described above. Wuff assemblies were then sandblasted, acid washed and ferroxyl tested by du Pont inspectors. All six muff assemblies were accepted and boxed for shipment to the field where final assembling to the B.T.S. was to be performed by field personnel.

ifter the "L" bottom tube sheet had been received at $S R P$ and when the field was ready to assemble nozzle muff asseablies into the unit, a representative from New York Ship's Boiler Shop again visited the plant site to supervise and assist in nozzle muff assembling operations.

26. lieat iumbering System ( 111 Units)

On January 6,1953 , a visit was made to NYS by a member of the Savannah Fiver Plant AED. The purpose of his visit was to request that the Operations Group be furnished with chemical analysis and physical properties of each piece of steel used in the fabrication of the units at NiS.

Previous to this time no such record had been kept. However, when an incoming shipment of steel was inspected by du Pont inspectors at liYs the heat numbers yere made a part of the inspection reports. In addition, it was possible to tie in the shop bills of material with purchase orders, and thus obtain heat numbers and analyses either from NYS files or by requesting this information from the vendors. In some cases involving small quantities of steel the information was not available. In most instances physical properties were unobtainable since they were furnished only on request at the time of ordering.

Before this request was made by SHP, it had not been the prictice at NYS to transfer heat numbers when a piece of steel was cut. The heat number transfer procedure was immediately instituted and has been followed since by lys persornel with close check by the du Pont Inspection Dept. Since the "ij" unit and the tank bottom of the "p" unit had already been shipped to the field, it was, of course, physically impossible to transfer heat numbers on the se units.' On the units in fabrication at that time, the Inspection Dept. visually examined each piece of steel possible for lisat numbers. This was a double check on the inforration ascerticined from dills of material and purchase orders. The latter source vias not foolproof, since material purchased for one part of the unit irould possible be used in another part for purposes of expedicrcy. Hoirever, this rarely happened.

In the case of smaller pieces used in fabrication, it was normally the procedure to use cuttings from larger pieces of the same gauge material which bad beer originally ordered oversize just for such a purpose. It was impossible to determine the heat numbers of these "cuttings" that were used prior to the time the transfer of heat numbers vas initiated.

The rough tubing for the tube bundles was purchased from various vendors and then shipped to numerous other vendors for pre-machining. Due to the Ereat amount of handing and intermixing involved, it would have oeen useless to attempt to pin 
down the heat number of each specific tube. The Operations group was so informed and agreed that the heat numbers of tubes would not be supplied.

The above is a general picture of the heat numbering system. is for the individual units, the following is the status of the heat records:

$$
\text { "kn" Unit: }
$$

The heat numbers, chemical analyses and in some cases the physical characteristics of $99 \%$ of the steel in the unit have been accumulated and tabulated and forwarded to S.F.P. In the tabulation, the unit was broken down into main assemblies, subassemblies and individual pieces of the subassemblies by name. The pertinent drawing number was recorded and also remarks if required. A typical entry in the record would be as follows:

$$
\begin{aligned}
& \text { MAIN TANK AND ZNCLOSURE - "R" UNIT } \\
& \text { E. P. } 105 R-A X C 167 \frac{1}{2}
\end{aligned}
$$

\begin{tabular}{|c|c|c|c|c|c|c|c|c|}
\hline$P$ & $s$ & $S i$ & $N I$ & $\mathrm{Cr}$ & Yield in ${ }^{2}$ & Tensile in 2 & Elong $2^{\prime \prime}$ & Remarks \\
\hline .026 & .013 & .58 & 9.28 & 18.34 & 41,800 & 82,300 & 60 & \\
\hline
\end{tabular}

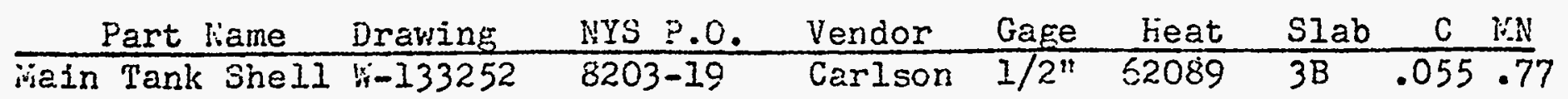

a. Upper Section

"P" Unit

Same as " "is"

"L" Unit

Same as " $n$ " and "p"

27. Final Inspection of Urit and Shipping Cear Installation

A. "

The top side of the botton tube sheet was jitted with air to remove all loose material present. Next, the top side of the tube sheet and the inside of the 3.T.S. nozzle assembly was acid washed and then rinsed with clean city water. Ferroxyl tests were performed at random to determine if any "free iron" was present on the surfaces of the unit.

All tube bores were swabbed out usinE F.0. 128 (Fine Organicg) and then followed up with a clean dry cloth to retaove the excess F.0. 128 and any grime left in the tube bores. it visual inspection was made by du pont inspectors and then wood plugs with an o-ring fitted to its diameter was inserted 
into the bottom and top of all large tubes. These were similar in design to those shown in Sketch $\pi 38$ in part VII, Section 1 items 15 thru 16. is visual inspection was again made to determine if all large tubes were plugged on the top and bottom ends. All inspections proved satisfactory. Then liew York Ship bolted an aluminum disc to each side of the large tube pattern to serve as a protective covering for the tube ends. Handling gear was installed and then the entire unit was "pillow-cased" with canvas and laced on the outer periphery and made ready for shipping. (See photo serial it71)

The "i" bottom tube sheet was shipped by tus boat and barge from New York Ship on August 2,1952 , to the Savannah liver Plant located in the state of South Carolina.

B. "P" Unit

Final inspection of the unit prior to shipping to the field was performed in a similar manner to that described in Section $26 \dot{*}$ of this manual.

The "p" bottom tube sheet assembly was shipped by tug boat and barge from liew York Ship on November 1, 1952, to the Savannah kiver Plant located in the state of South Carolina.

C. "L" Unit

Exterior cleaning of the bottom tube sheet prior to shipping was omitted at vendor's plant because of lack of time due to shipoing date and other fabrication operations. Hovever, the following cleaning operations were performed during the latter stages of fabrication: Prior to welding the 8" half-round distribution (inlet and outiet) pipes to the bottom tube sheet, the wrapper plates were cleaned with a solution of F.0. 128 (Fine Organics Saf-Tee Solvent) and then acid washed. I ferroxyl test indicated that cleaning was satisfactory. The interior surfaces of the $8^{\prime \prime}$ half-rounds were cleaned, acid washed, ferroxyl tested and the 8 " pipes welded to the assembly.

After welding of the 8" half-round pipes, a freon and hydrostatic test was made on the assembly. Both tests indicated sound velds throughout the assembly after minor repairs.

The haif-rounds were cleared (internally) just prior to testing with a vacuum cleaner with 30 feet of hose in order to renove any metal or foreign matter. ns the assembly was being filled with water for the hydrostatic test, water was permitted to flow through I ${ }^{2}$ " fitting in the top half of outlet tee cover for fifteen ininutes to provide a cleaning action. That is, water was forced from assembly through the half-rounds and drained out through the I 1 " opening whose top side was flush with the top surface of the tee. The outlet pipe was cleaned in this manner.

Shipping plugs with O-rings fitted to the diameter were not put in large tubes prior to shipping. It was found during repairing bottom land bores the insertion and removal of these 


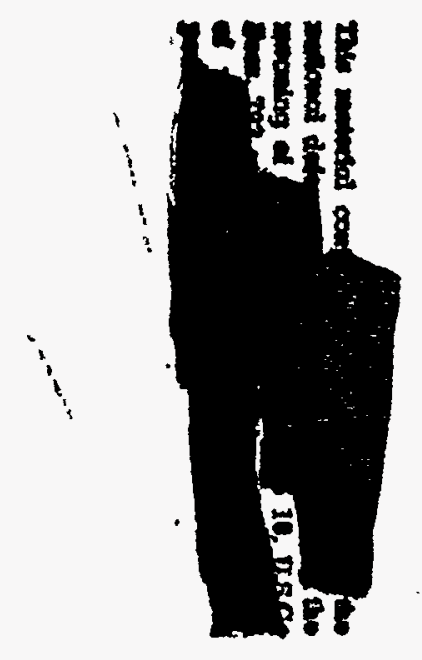

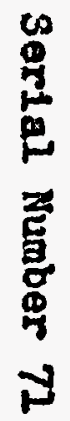

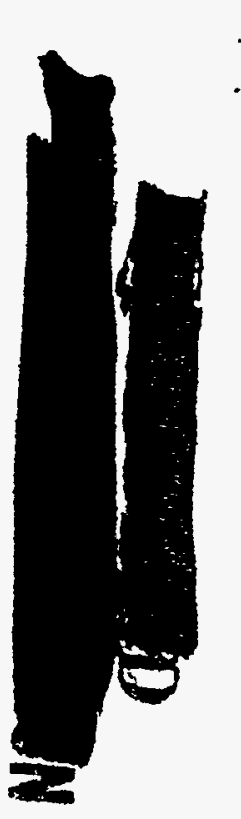

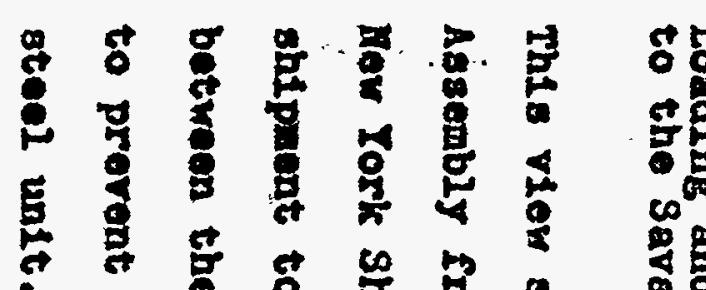
8 8 \% 8 \%

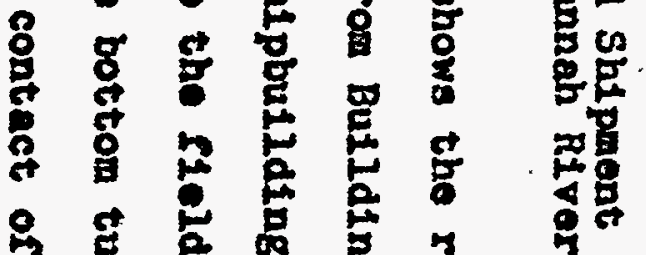

$\because 8009$

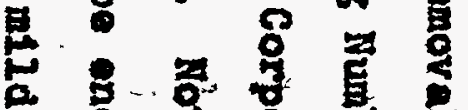

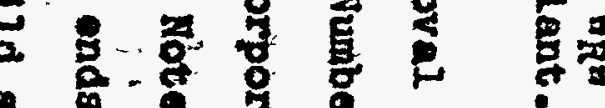

+ 8 \&

↔

兽

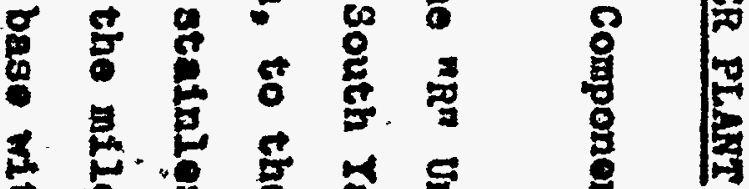

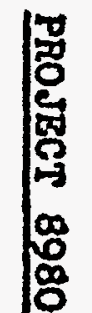

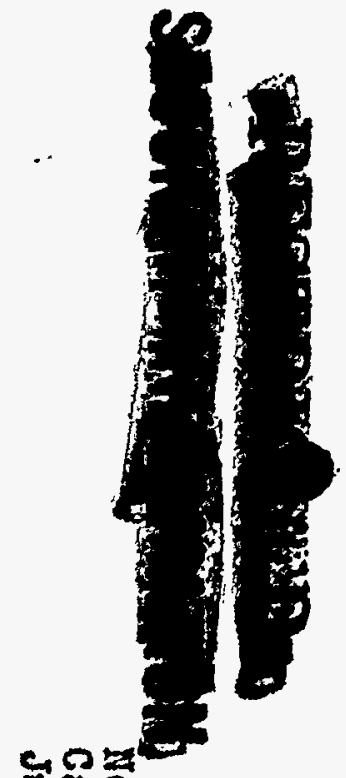

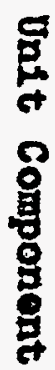

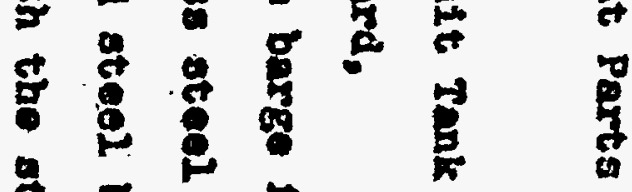

兽

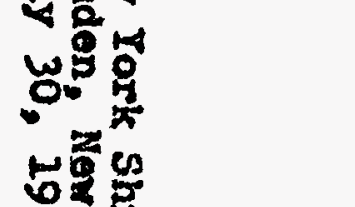

象里

N̦ts

罚

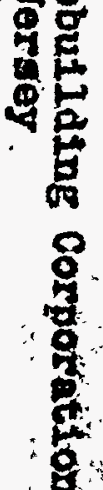




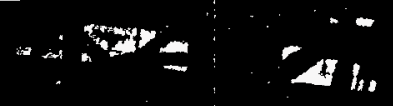

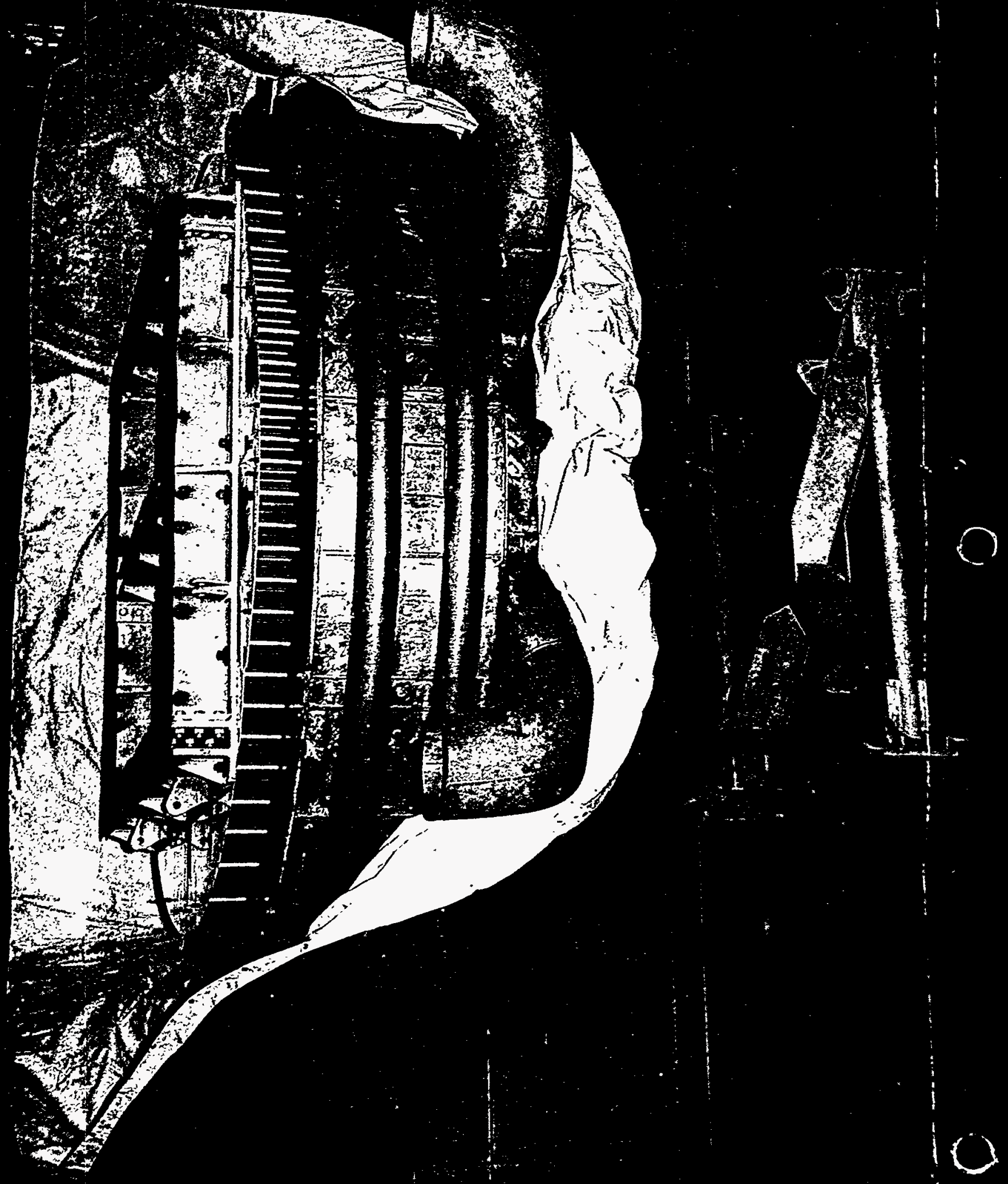


wooden plugs marred the surface finish in spots, and in most cases damaged the tubes 0 -ring seating zone.

A large aluminum disc was bolted to each side of the tube pattern to serve as a protective covering for the tube ends. handling gear was installed and then the entire unit was "pillowcased" with canvas and laced on the outer periphery and made ready for shipcing. (See photo serial $\frac{\|}{\hbar} 7 I$ )

The " $L$ " bottom tube sheet was shipped by tug boet and barge on June 3,1953 , to the Savannah kiver Plant located in the state of South Carolina. 

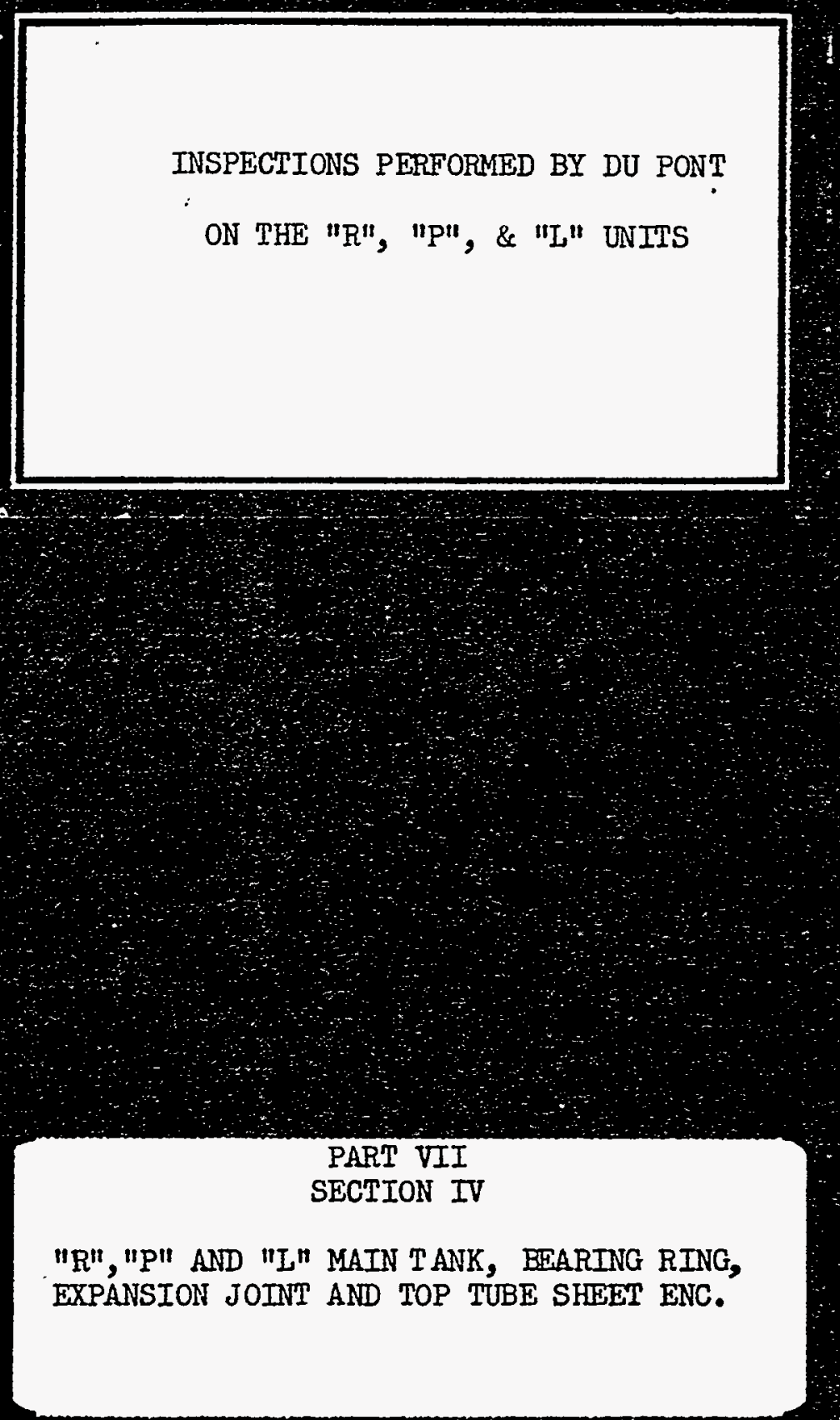
(6)

$$
\begin{gathered}
\text { REPORT } \\
\text { OF }
\end{gathered}
$$

MATERIAL \& EQUIPMENT

$$
\text { SECTION'S }
$$$$
\text { ACTIVITIES }
$$

AT

\section{NEW YORK SHIPBUILDING CORP. \\ DURING FABRICATION \\ OF}

AXC 1671/2.

STARTING MAY 18, 1951

PART VII - SECTION IV

BY: JAMES RAY STEWART

MAY 28, 1954 
PAIR VII - SBCTS ON IV - INSPECTIC:SS PERTORMBD BI IU PCIT OI "R", "P" AND "L"

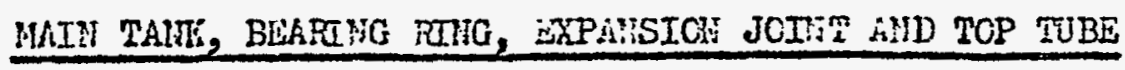

SHLET EICLOSURE

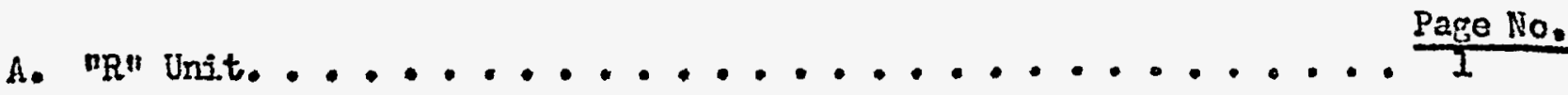

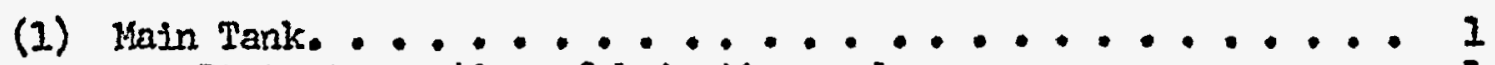

a. Plate inspection, fabrication and x-ray. ........ I

b. Tank out-of-roundness. ................. 2

c. Inspections after grindin and acid washing. ...... 2

(2) Inspection of Eearing Ring, ispansion Joint and Top Tube

Sheet Enclosure ...................... 3

2. Bearing ring . . . . . . ......... 3

b. Tank expension joint and welding to bearing ring... ... 4

c. Tinal machining of tank expansion joint and

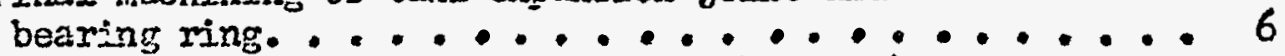

d. Fabrication and inspection of top tube sheet

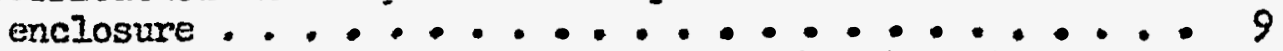

e. Welding of top tube sheet enclosure to bearing ring

and expansion joint asserably. ............. 12

f. Mrchining of seal ring ............... 15

g. Fitting and weloing of expansion joint to

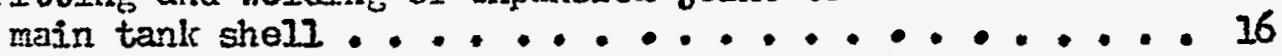

h. Orientation and fitarp of main tank and enclosure

to bottom tube sheet nozzle section......... 17

B. "p" Unit. ......................... 18

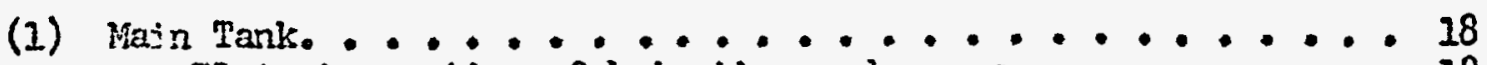

a. Plate inspection, fabrication and x-ray. ....... 18

1 Plate arrangement and fabrication sequence ..... 18

2 Radiograph inspections............. 19

b. Tank out-of-roundness. .............. 19

c. Inspections after grincing and aciei tashing. ..... I9

(2) Inspection of bearing ring, expansion joint, and top tube

sheet enclosure ................... 19

a. Bearing ring .................... 19

b. Tank expansion joint and welding to bearing ring ... 19

c. Final machining of tank expansion joint and.

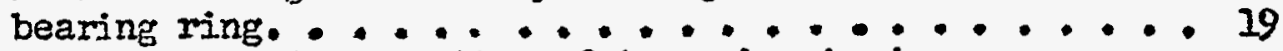

d. Fabrication and inspection of top tube sheet

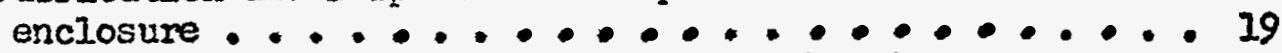

e. ticling of top tube sheet enclosura to bearing

ring and expansjon joint assembly .......... 20

f. Machining of seal ring ............... 20

g. Fitting and relling of expansion joint to main tank shell ................. 20

h. Problems and difficulties encountered on the

"pl main tank assambly. ................. 21

i. Remajnint inspections performed on the rain tank

pricr to shipping ................. 24 
c. "II" Unit. ............................. 26

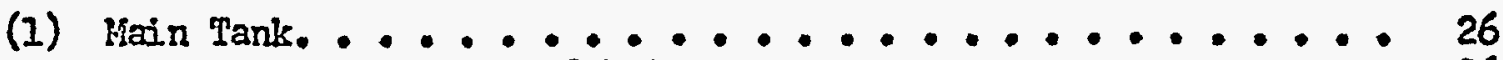

a. Plate Inspection, fabrication and x-ray. ....... 26

b. Tank out-of-roundness. ............... 26

c. Inspections after grinding and acid washing. ...... 26

(2) Inspection of Bearing Bing, Expansion Joint and Top Tube

Sheet inclosure ...................... 27

a. Bearing ring and expansion joint ............ 27

b: Fabrication changes and inspection of new baaring ring and expansion joint fö "I" Unit ......... 27

c. Remaining inspections performod on the "L" main

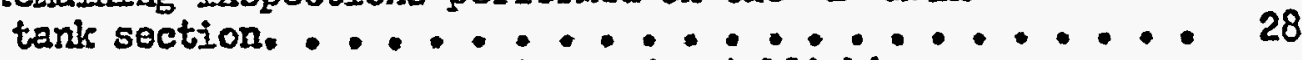

d. Revisions to weld inspection and establishing centerlines on the "I" and "K" main tank, top tube sheet enclosure and bottom tube sheet nozzle section with results presented for "L" unit 
1. Dwg. 6-5

2. Sketch $\# 8$

3. Ing. $6-3$

4. Dwg. 6-4

5. Sketch \#9

6. Dwg. 6-2

7.Dwg. 6-1

8. Sketch 10

9. Sketch \#1I

10. Exhibit $\# 6$

11. Exhibit \#7

12. Sketch \#12

13. Sketch \#13

14. Sketch tif 14

15. Sketch $\# 15$

16. Sketch 16

17. Dwg. 6-6

18. Exhibit \#18

19. Sketch $\frac{117}{6}$

20. Exhibit fito

21. Drig. 6-7

22. Sketch $\frac{418}{4}$

23. Sketch $\# 19$
- liain Tank ShelI "R"

- Section of Bearing Ring Shbwing biachining Before Welding Tk. \& Expansion Ring

- Section Showing Expansion Rine Joined to Top Tube Bheet Enclosure \& hain Tank

- Expansion Ring \& Bearing Ring

- Section Thru Expansion Joint

- Top Tube Sheet Enclosure - Sections

- Top Tube Sheet Enclosure

- Section of Seal Ring

- Layout for Supporting Br'g Ring Ass'y \& Tank Bnclosure During Velding

- Report Number 123-R, BI'E. Ring \& Exp. Ring

- Bearing Ring

- Setup for Transferring Centerlines from Br'g Ring to Outside of Tank Enclosure

- Rearing Ring - Expansion Joint - Tank Shell Assembiy

- Tank Enclosure, Bearing Ring \& Tank Shell

- Leveling Bottom Tube Sheet Assembly in Preparation for Lofting in of ifn. Tank

- Orientation \& Fitup of MAlNi Tank \& Inclosure to Bottom Tube Sheet

- Main Tank Shell "P"

- Visual, Ki-ray and Dy-chek Inspection of All . Felds on the "pn Unit Tank Assembly

-, Hethod for Locating Defect in Welding Usin $\mathrm{X}$-ray Film

* Expansion Joint Thickness He: surements by Audi-gage Wethod

- kain Tank SheII "I"

- "L" Tank Shell

- "L" Tank Shell 
24. Sketch \#20

25. Exhibit AII

26. Durg. Ho. $6353-4$

27. Dwg. No. 6353-5

28. Dwg. No. 6353-6

29. Dwg. No. 6353-I

30. Dwg. No. 6353-2

31. Dwg. No. 6353-3

32. Sketch $\frac{\| t}{t} 2 I$

33. Dnrog. civo. 6353-8

34. Dwig. No. 6353-7
- "L" Tank Shell

- Sunmaxy of Heat Treating " $L$ " and "K" Expansion Joint Segments

- "L" Unit Bearing King Leasurements

- "I" Unit Bearing Ring Indexing Device iveasurements

- "L" Jnit Bearing Ring - Bearing Pad Cutout Details

- "I" Unit laiain Tank - Top Shell Diameter ifeasurements

- "I" Unit liain Tank - Top SheIl Orientation of Nozzles \& Lifting Iug Cutouts

- "L" Unit Kain Tank - Top ShelI Heasurements of Iifting Lag Cutouts

- Neasuring for Strain in axpansion Joint

- "L" Unit Tank \& Bottom Tube Sheet Vertical Dinensions

- "L" Unit Main Tank Diameter Keasuements 
The following list covers all du pont prints pertaining to fabrication relcased to the $F$ \& Group located at New York Shipbuildini Corp.

This list was prepared from existing drawing filles at the latter location on larch 27, 1954. For reference purposes and convenience, drawings are listed by sub-assembly, drawing number, title and revision number.

A. "R" Unit

\begin{tabular}{|c|c|c|}
\hline Drawing & ritie & Revision fi \\
\hline$\cdot-1312104$ & Yain Tank Top Shell - Plan \& Section Arrgt. & 0 \\
\hline$\forall-1312125$ & Jain Tanir Shell - Section of Detajls Arrgt. & 17 \\
\hline$w-131735$ & Wozzle Iruff - Plan \& Section Arrgt. & 0 \\
\hline$D-112625$ & $20^{\prime \prime}-90^{\circ}$ Tank outlet Bivor & 0 \\
\hline Im-114hil & Nozzle Musf & 0 \\
\hline
\end{tabular}

B. "p" unit

Drawing if

$x-131519$

i -231542

$W-131543$

if -131564

W-131,981

W-133187

$w-132530$

$j-132536$

D-1]2727

$5-114474$ itie

Revision ff

Main Tank Top Shell - Sections \& Details Arryt.

Mąn Tank Shell \& Eearing Fing - Plan of Sections Arrgt.

Hain Tank top shell - Plan of Sections Arrgt.

Hain Tank Eottom Beaxing Plates - Plan \& retails 3 Arrgt.

Tanti rall Thermocouples - Arret., plan a section 12

Tank ball Themocouples - Arrgt. Sections - Sheet2. 5

Tank Botton Tube Shect Hozzle Kuff - Plan (Sec- 0 tions Arrgt.)

Tani: Botton Tube Sheet Hozzle huff - Plan (Sections Arrgt.)

1

20"1-90 tank outlet nozzle elbork

0

Nozzle murf for tank botton tube sheet 
C. "L" Unit

Drawing

itile

Revision it

W-133138

Main Tank Lottom Pearins Plates PIan \&

0 Detail Arrgt.

W -133252

Main Tank Shell \& Eearing Ring Plan \& Sections

7

i -133266

Wain Tani Top Shell Plan \& Sections Arrgt.

1

Yi- 133270

Main Tank Top Shell sections \& Datails Arrgt.

10

i -133272

Main Tani Top Eearing Ring Eearing Supports Plan

9 \& sections Amgt.

$6-1.33303$

Tank Eotton Tube Sheet Nozele Cross \& Section Arrgt.

$W-1.33304$

Tank Botton tube sheet noz

$n=133879$

Tank wall thermocouples arrgt. Plan \& sections sheet H1.

$1-133880$

Tank wall thermocouples arrgt. Sections sheet $; 25$

$D-172875$

$20^{\prime \prime}-90^{\circ}$ Tank outlet Hozzle El ton 


\section{PARI VII - SECTION IV}

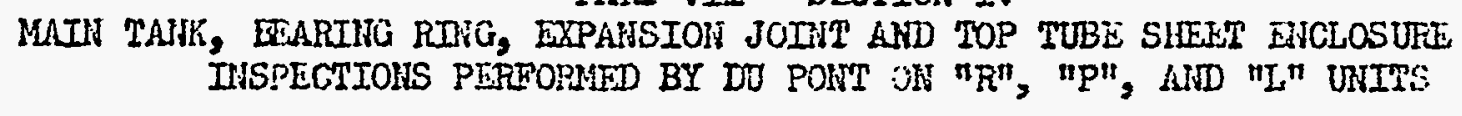

A. "R" Unit

(1) Main Tank

a. Plate Inspection, Fabrication and $\mathrm{X}$-ray

The type 304 stainless ateel material for the tank vas inspected for surface condition, imbeddediron, mechanical defects and dimensions. All plates were checked with a majnet to determine if the material was austenitic. Ferroxyl tests were performed at random to determine if any free iron was imbedied. Free iron found was renoved by grinding. All material was accepted after minor repairs and released for falrication.

The tank was rade up in the Hat in two bali-sections for later rolling on a set of 15 it. horizontal roll. (see Drg. 6-5). The plates were then set together and fitted in two half sectious vith allowance for trink to be full on length. This was necessary since weldin: of the expansion joint and bottom tube sheet nozzle edge causes shrinkage. The "A" and "B" halves were fit and welced as shown in Dag. 6-5. Before rolling, each half section joint was ground and tiren visually inspected for porosity, undercutting, cracks, and other meclianical defects. Repairs were made and then the joints were $x \rightarrow r a y e d$ in the flat. Riadiographs were examined by du Pont inspectors and repairs made wilere necessary.

The tank differed from $N Y K$ in that it was shorter in height because of the acidition added to lengthen the lottom tribe sheet nozzle assembly and the incorporation of a ner type expansion joint.

After the two half sections were $x$-rayed and accepted, the two half sections were rolied. The weight of the plate being rolled vas held in position and moved as required by tro balancing biams and two overhead cranes. (See photo serial filsh in Part II). During rolling the plate curvature was progressively checked with a radius template. hiter rollini each half-section was set with the botton edges on a level slab. Final curvature was obtiined by hamering with wooden mallets.

The two halves were then fitted to a rild wrought steel form made up of three drating size rings (spiciers) bolted together on strinisers. (see photo serial $f 67$ in Part II). The two half-sections were held to the jig with a cable and turn buckle around tine mid-section of the tank for fitting the first vertical butt. After this the closing vertical butt was draw together, 

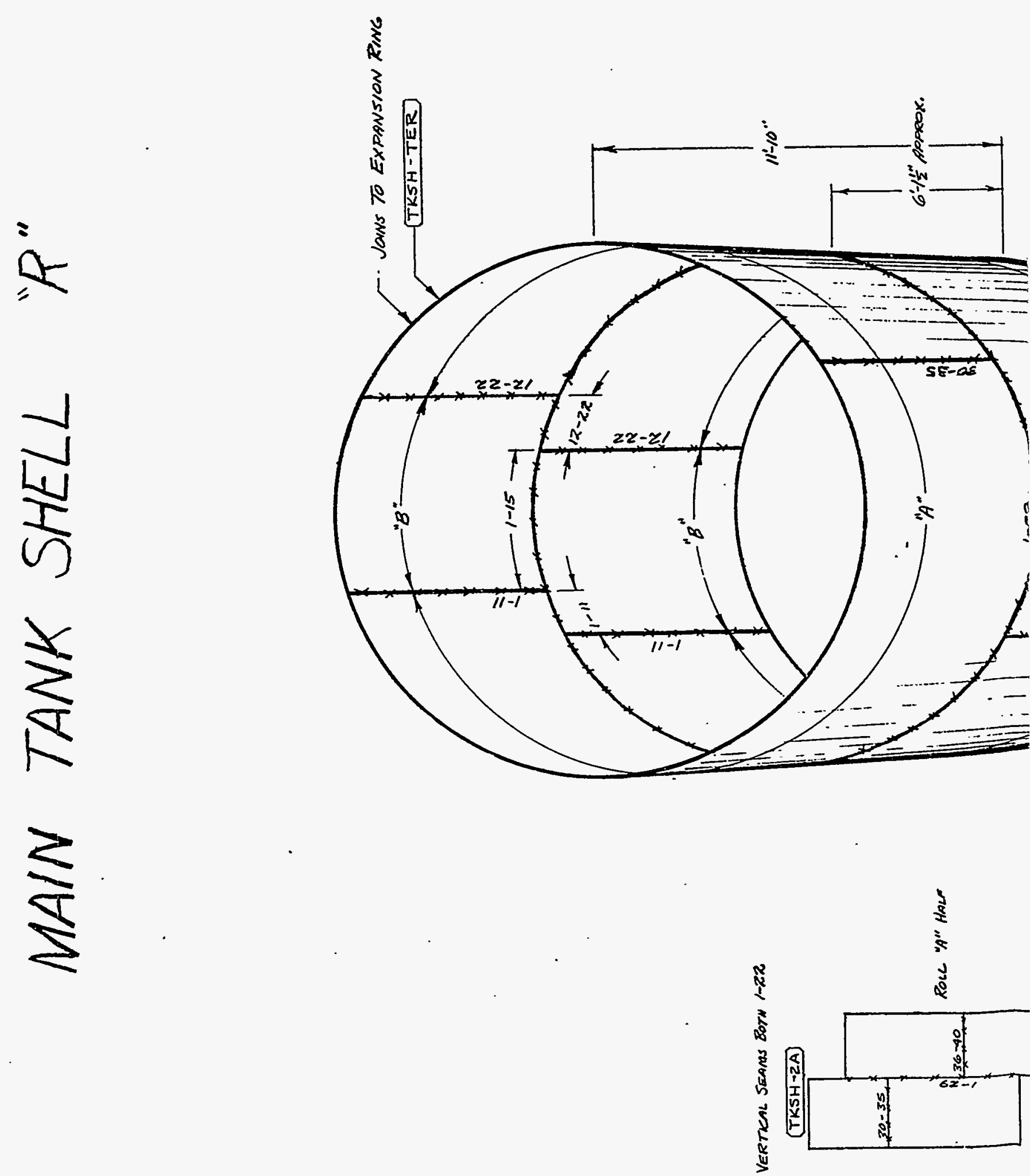


$\left[\begin{array}{cc}0 \\ 0 \\ < & 3 \\ -1 & m \\ 0 & m \\ 0 & m \\ z & m \\ -1 & 1 \\ 70 & 0 \\ D & z \\ n & \\ -1 \\ c\end{array}\right.$

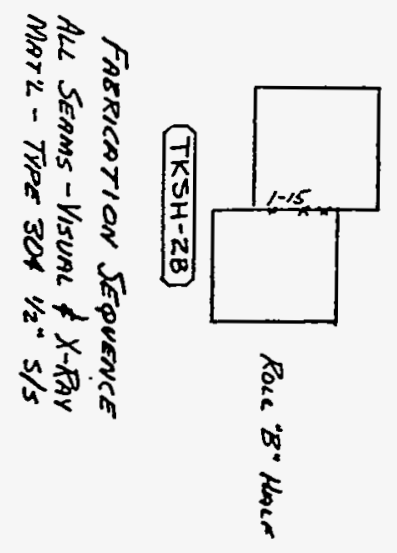

\begin{tabular}{l}
0 \\
0 \\
0 \\
0 \\
1 \\
0 \\
\hline
\end{tabular}
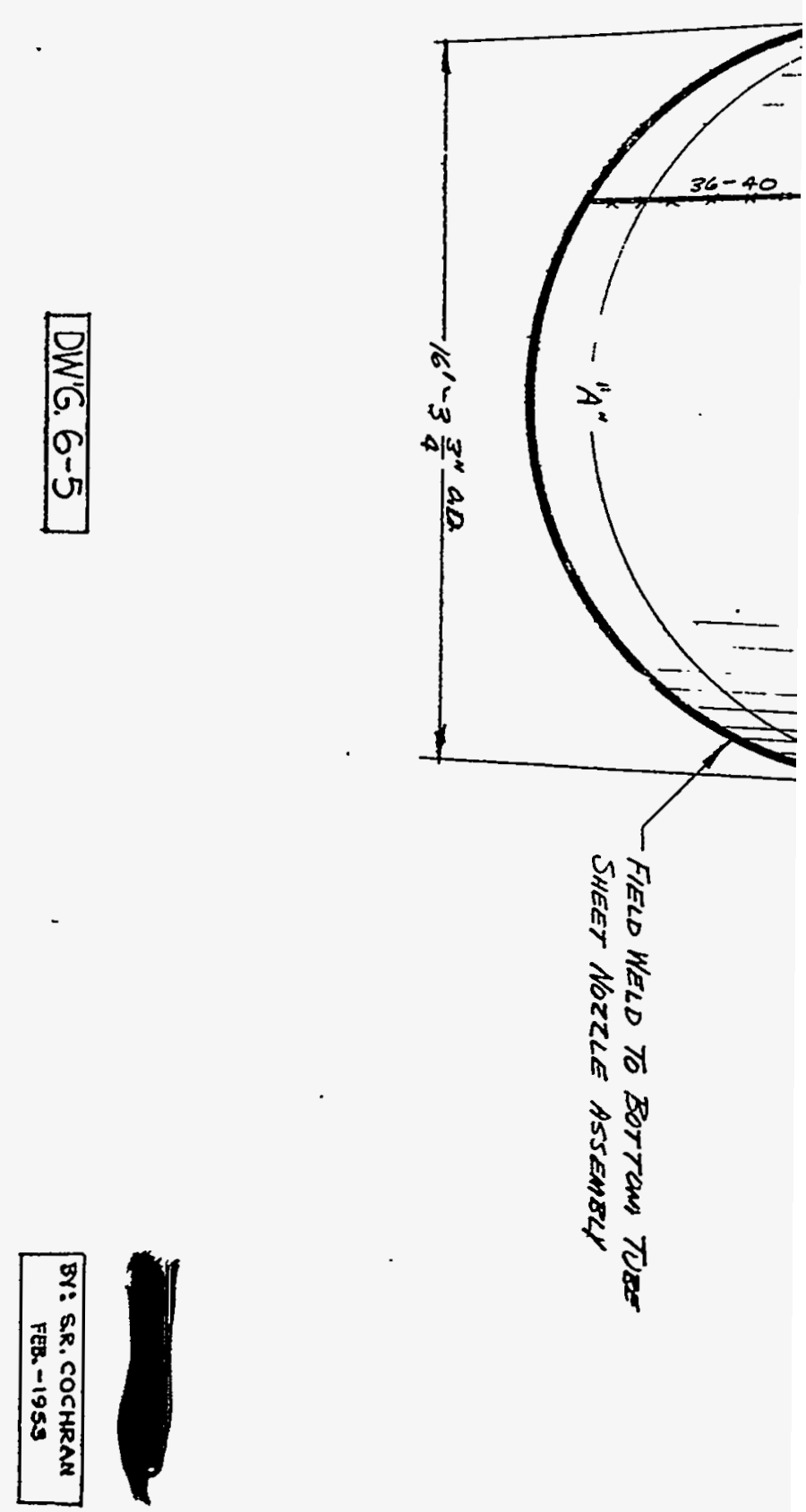
fitted and tack welded. The tank was then set on a set of thin rollers for all welding in a down-hand position. (See photo serial i250 in part II). The lower seam was step-welded from inside the tank using manual Aircomatic method adapted for this job. After each weld pass, they were chipped and dressed. After the lower sean was fully welded on the inside, the tank was rotated $180^{\circ}$ and tine same operation repeated on the otiner sear. The lower sean root bead which was now in the up position was back chipped from the outside, wire brushed, cleaned with solvent, and tnen fully welded from the outside in a downanci position according to the established welding procedure. The tank was again rotated $180^{\circ}$ to bring the other seam on top for bacis chipping, cleaning, and welding. After all welding was completed, the two weld seams were ground flush and then the two vertical seams were $x$-rayed 100\%. Radiographs were examined by du Pont inspectors and necessary repairs ade. The circunferential weld previously $x$-rayed in the flat was not re-x-rayed after rolling.

The main tank shell was ground all over to remove iron imbedded in tine plate surface, and then preparations were made for locating and welding thermocouple clips to tire outside of the tank shell. Thernocouple clips were machined, dressed, fit and welded to the main tank. Welciing was visually inspected and approved. Locations of the themocouple clips were measured using a 61 tape referencing from the jojor axes and found to be within specified tolerances.

b. Tank out rof-roundness

Before weldinis the rain tank to the expansion joint, and with tre "sijicer jig" removed, prelininary measurements on the I.D. of the tank vere taken to determine out-os-roundness. Keasurements were taken with a 16 pin gage set to a predetermined length using a steel tape graduated in 1/16". "seasure ients were taken at three elevations on the I.D. of tine tank in the $X$ and $Y$ directions: namely, (I) top (2) middle and (3) bottom. Also, tine height of the tank has measured at four positions ( $90^{\circ}$ to each other), usin a stainless steel tape graduated in $1 / 16 "$. These cirmensions were 21 within drawing tolerance.

Final neasurements were also taken on the tank aiter welding to tine top tube sheet enclosure assembly in a similar manner to that descrived above. These final dimensions were all within the required tolerance.

c. Inspections After Grinding and Acid Washing

The "spider jig" was removed from insice the tank and preparations were made for acid washing the insice and outside; however, after removing the $j i \mathrm{~g}$, it was noted that the area where the three mild steel forming rings were peessed against the tank shell, 
the rings had left deposits of Iree iron imbedded in the tank shell surface. Before proceeding with the acid washing operation, the Iron imbaddedin the inside shell surface was removed by gxinding Next the inside and outside surfaces of the tank shell were acid washed to remove any addition limbedded iron, dirt, scale, and weld stioke. The inside of the tank was then inspected

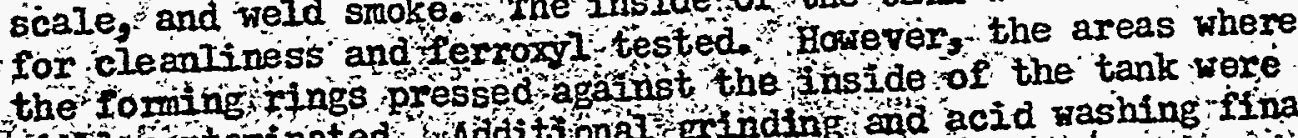

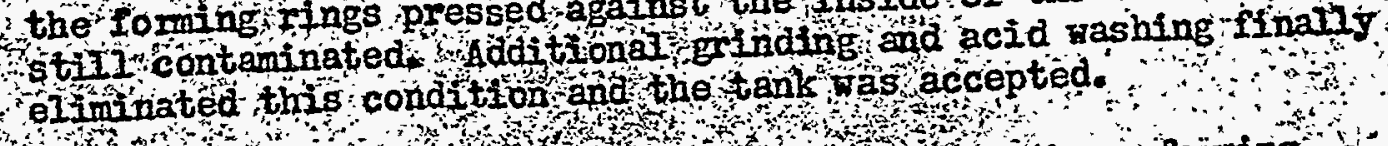

In the meantine ut was decided to rowe the forning

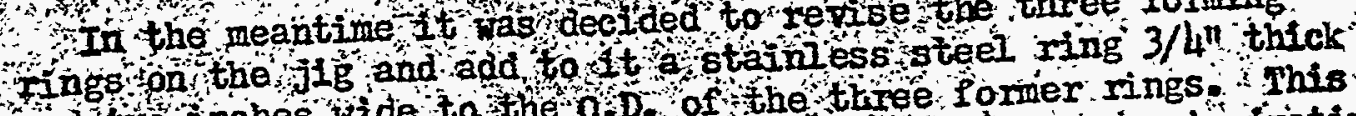

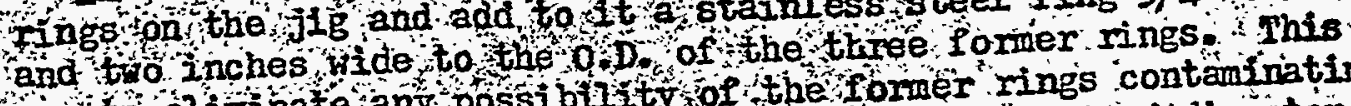
swas to eliminate an possibirty of the former rings contaminating the tank ohel a stantess steel fing of the required diameter was welded to each of the three forming fings . Fach forming

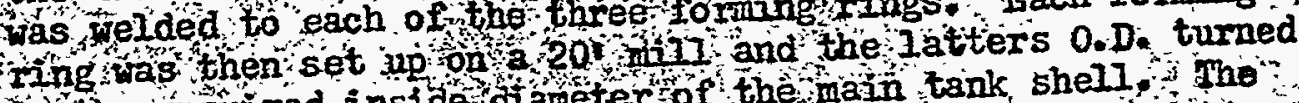
to the regured inside dareter of the main tank shell addition of the stainless stee rings to the min tank spider jig former rings was a so Incorporated joto the top tube sheet

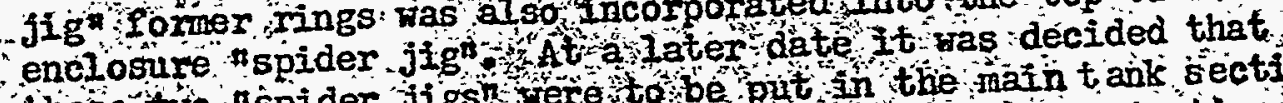

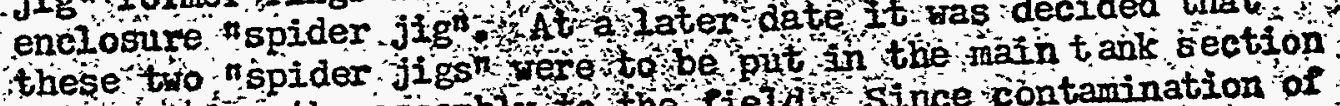
for shipping the assembly talhe fold since fontamination of the main tank shell and toptubo sheotenclosure could not be tolerated after fina cleaning ine adjtion of the stainess steel rings to the 0.D.ofthe fomer oungsin the tro jigs justified

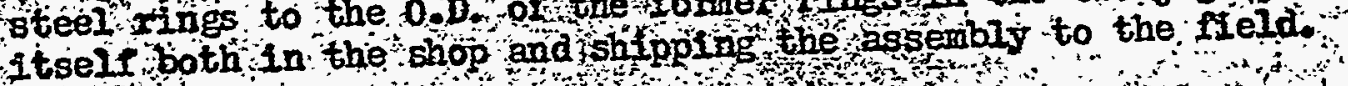

Atself both In the

(2) Inspection of Bearing Ring

Bearing Ring :

Spe baring ring segsents were burned rom 3 thick type

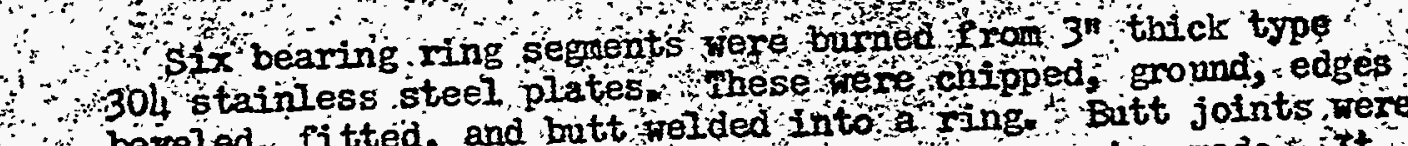

berelod, fitted, and butt weided into jang bitt joints were -rayed, radiographs examined and necessary repairs made

wijl for rough machining puring rough machining, 3/26n thick ness was left on both top and botton of ring for final machining (following assembly of bearing - ring to tank expansion joint).

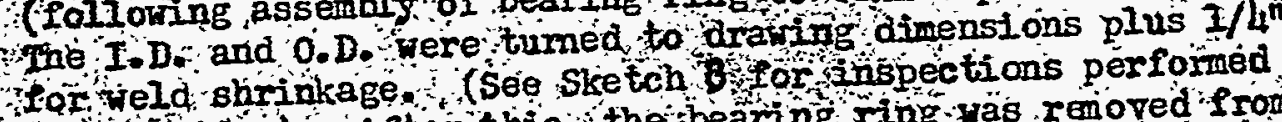

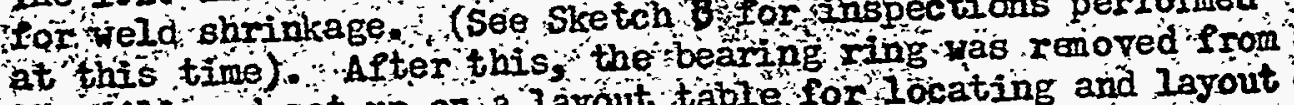
the mill and set up on a layout tabie, for locating and layout of 12 bearng slots or cut onts on the botton face of the bearing Iring. Tor Iocation of bearing sots se du pont drawing 130953. After-1aying put the bearing slots the bearing ring was set up on a fydrotel Hiling Kachline for rough miling of the 12 slots. Next, the bearing ring ras remoted from the mill and preparations made for weiding the bearing nng extens jon to the bearing ring

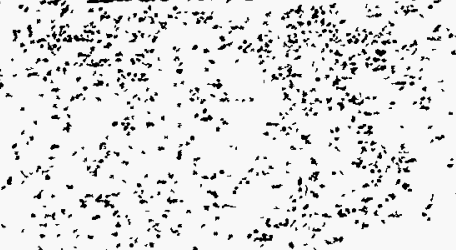

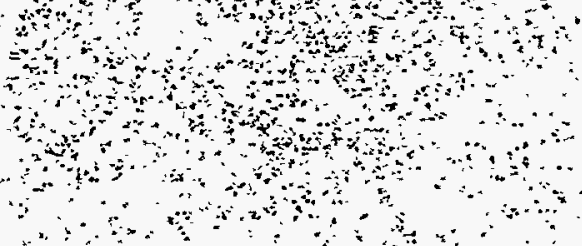




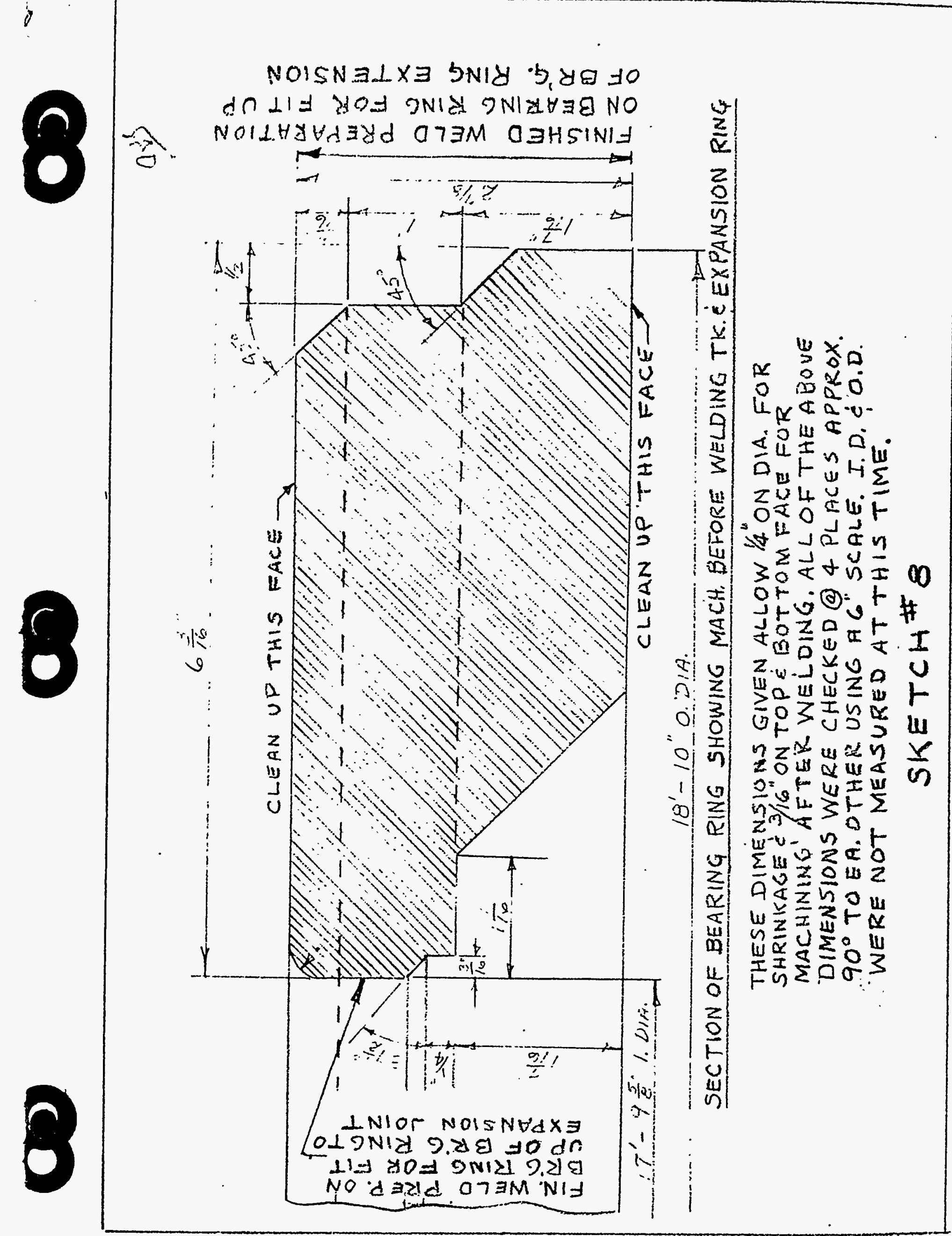


Prior to fit-up and welding to bearing ring, the extension was macie up in four sections, rolled and butt welded to form a rin. All butt joints were $x$-rayed. Fadio sraphs were examined uy du pont inspectors and where necessary repairs were made. Excess material was left on top of extension for final machining (following assemuly to tank expansion joint). The bottom edget of the extension was bevel ed for weld preparation joining it to the $0 . D$. of the bearing ring. The bearing ring was clampec to a platen and the extenston assembled and tack welced to the $0 . D$. The bearing rin was removed from the platen and set up on a welding positioner in order that all welcing be done in the downhand position. The outside circumferential joint joinin; the bottom edge of the extension to the bearine ring bas butt welced according to the procedure adapted for this job. After tilis, tile bearing ring was removed from the veloing positioner and clamped to a platen for fillet welcing the inner side of the extension to the bearing ring. (See DWE. 6-3 for view of beariñ rinj and extension). Next, the fillet Feld anc outside circumferential weld were ground arld tinen visually inspected for craciss, porosity, uncercutting, and other mechanical defects. Necessary repass were mede and then the inside fillet weld was zy山glo tested to further ascertain the qualito of welaing. joditional repairs were mace and all welding was accepted. The outsicie circumferential weld did not require $2 y$ islo testinz per cu yont specifications.

Finally, the vertical butts in the bearing ring were re-x-rayed for final dispositiou. Radiographs were inspected by du Pont inspectors and where necessary, repairs were made. Ho other work was performed on the bearing ring until the expansion joint and top tube sheet enclosure were coinjleted. The following sections cover the final machining and inspection of the beariñ ring.

b. Tank Expansion Joint and Helciing to Bearin: Rin:

The " $R$ " unit expansion joint was different from the desinn of the WYX. The diffirence can be seen by referring to Dhg. 6-4 presented herewith and to Sketch 18 in Part II.

Six expension joint sections were formed fro. 3/16" tuick 304 stainlesi steel using ham ners and flatters against a die. racil of these main sections were contoureci on the outsicie and inside edges to form an inside and outside $90^{\circ}$ bend. Io tine top and bottom edges lip pieces (full in width) were formed, fittec and welded to each of the six main segments. After fabricating and welding the six main segments (each consisting of three pieces), the horizontal butt welds dere ground flush with the 3/16" thick plate surface on botin sides.

An assembling ana handling jig had been fabricated for positioning and hol din? the six expansion joint se jnents to the correct ciameter wilile fitting and welding the vertical joints to fom tire compiete expansion joint. The six segments were fit to tire jis by chipping the butt joints to form the complete expansion joint or ring. Care was taken to stager the horizontal raciial welds in tire expansion joint ritin respect to the vertical welds. The butt joints were tiren leveled 


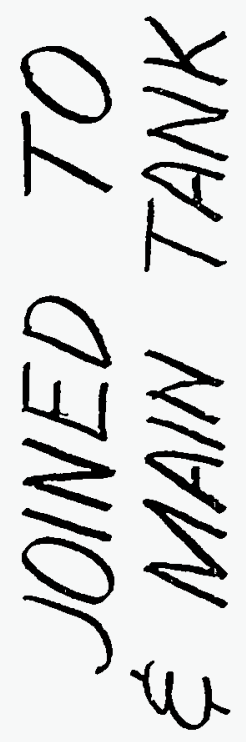

造
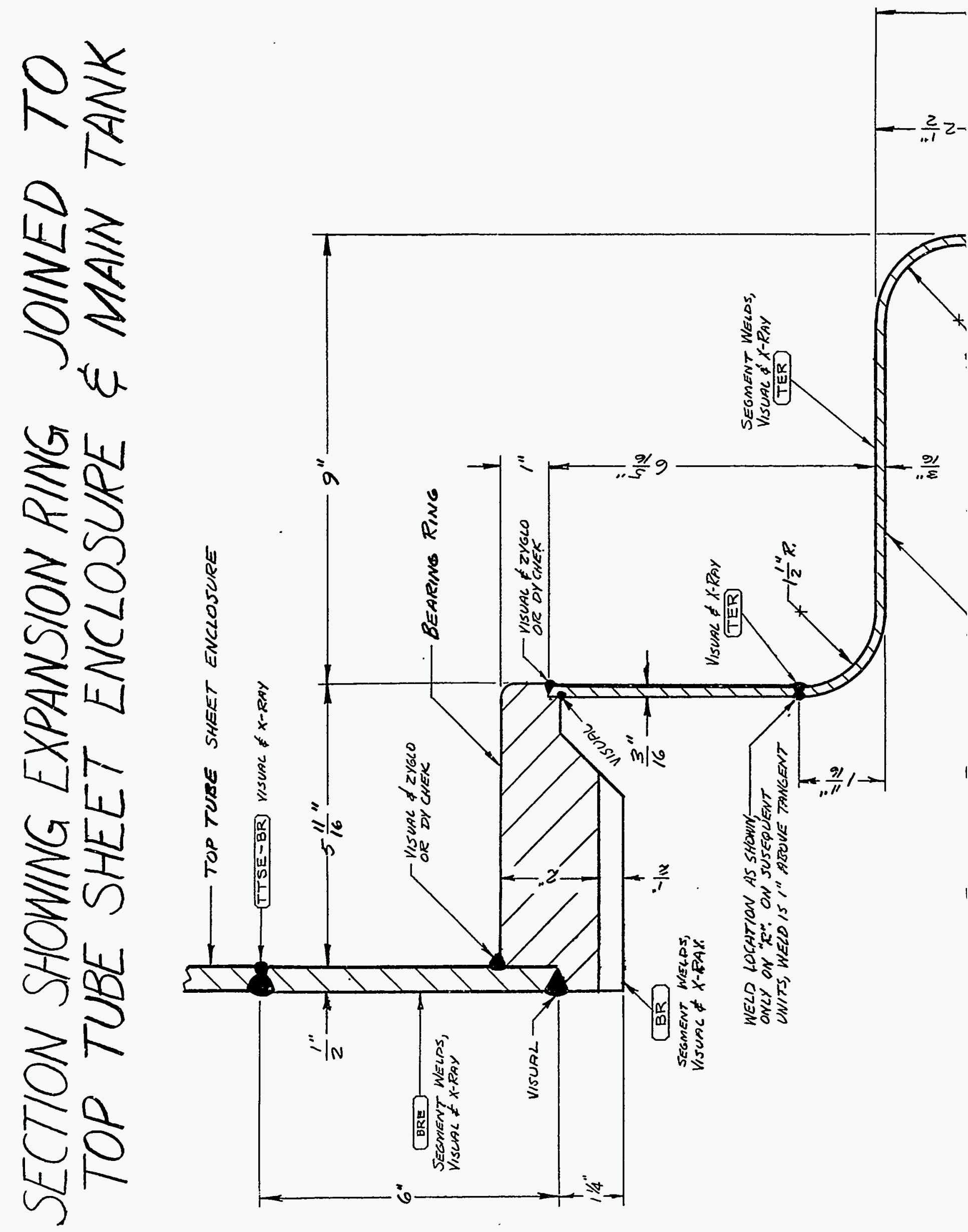


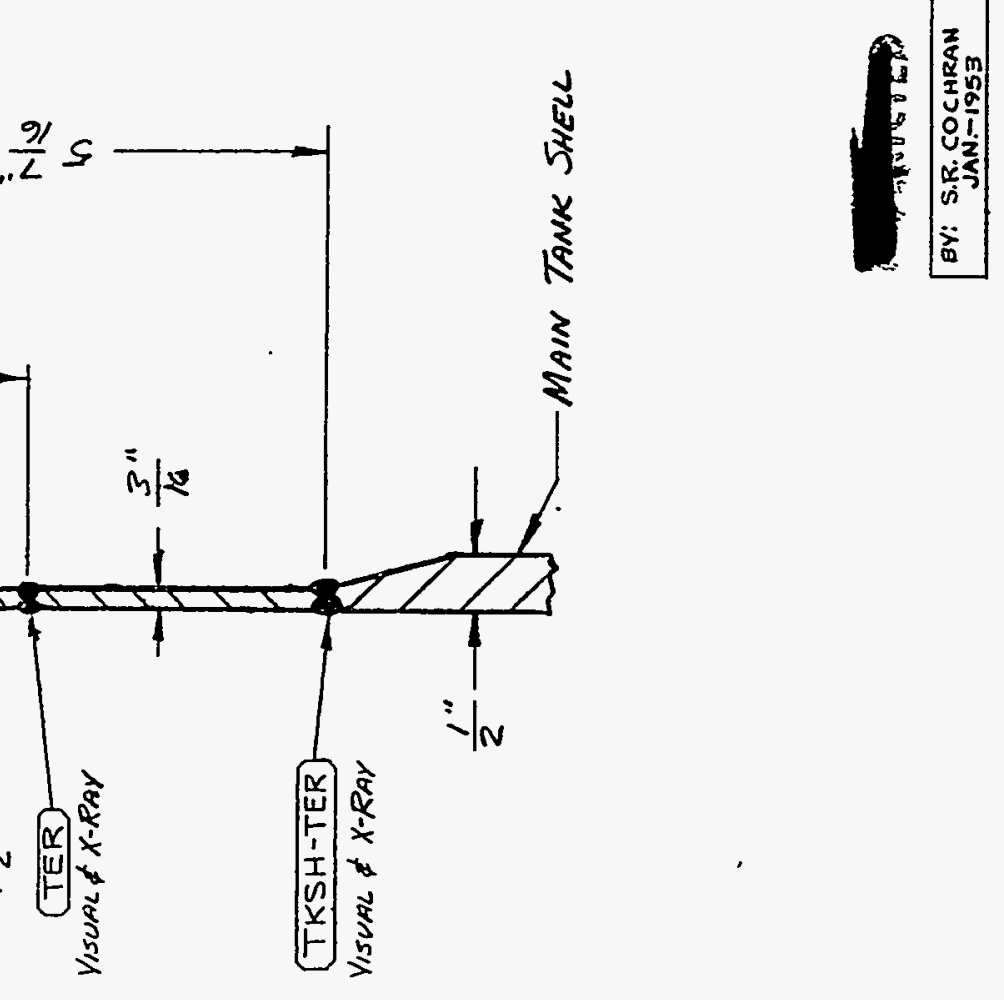

\begin{tabular}{|c|}
$m$ \\
1 \\
0 \\
0 \\
$\vdots$ \\
\hline
\end{tabular}

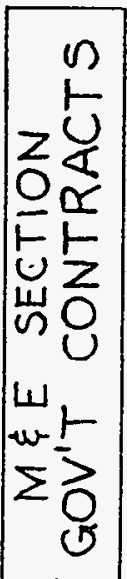



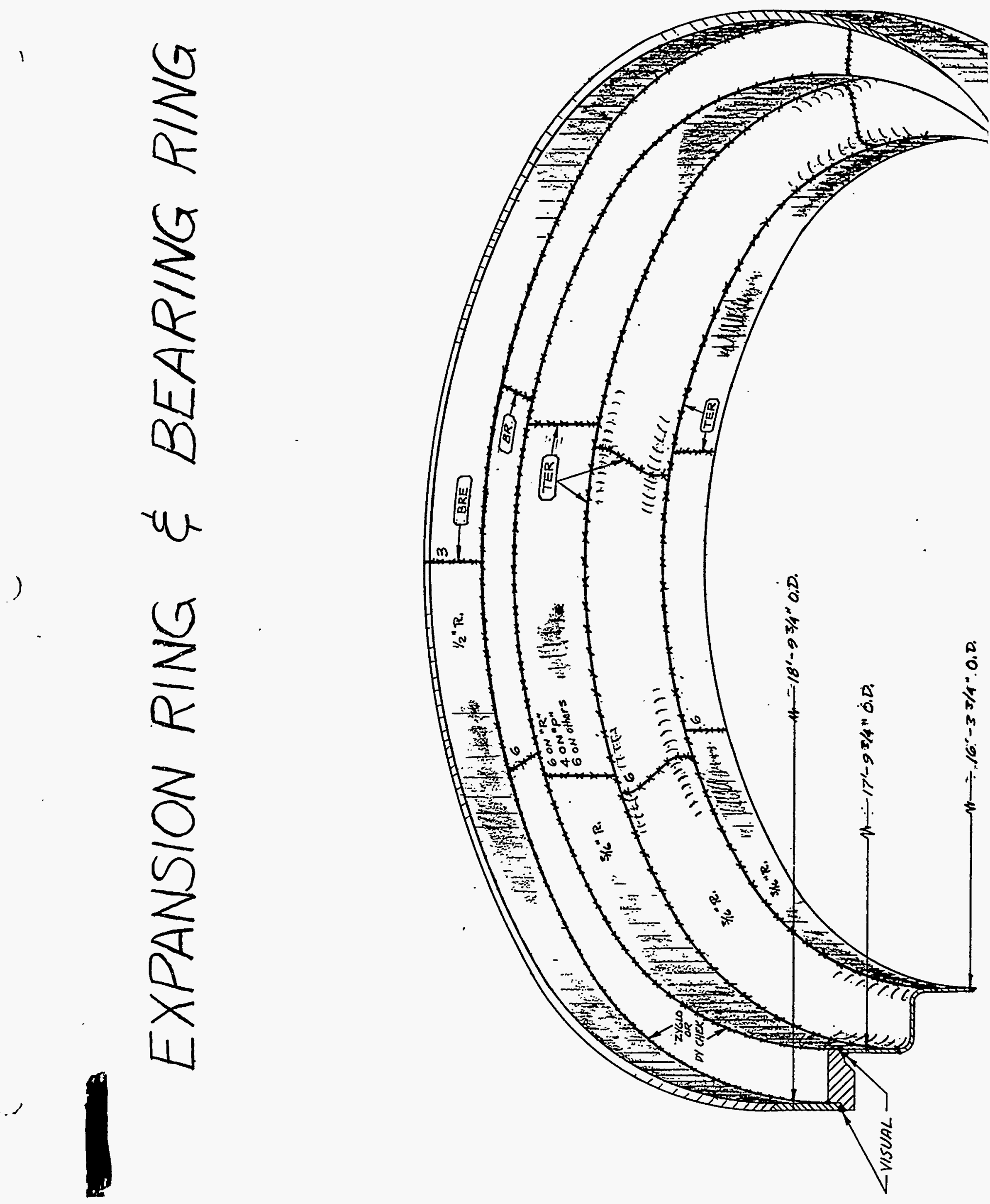
for welding, backing strips cut, fit and tack welded to each vertical joint.

With the complete expansion joint segnents now fitted and clamped to the assembling and handling jig, the entire assembly was bolted to a velding positioner in order for all welding to be dore in the downinand position. All welding was completed, backing strips chipped of $f$, and then all vertical butt joints were ground flusi with the plate surface on both sides of the weld. All buttwelding was visually inspected by du Pont inspectors for porosity, cracks, undercutting and other mechanical defects. Necessary repairs were made, re-inspected and accepted. All horizontal and butt wel ds vere then $x$-rayed $100 \%$. Radiographs were examined by du Pont inspectors and repairs made where necessary. Defects found were removed by chipping and then rewelding using metallic acid welding process and coated $304 \mathrm{~S} / \mathrm{S}$ rods. All repaired areas bere ground smooth and then $x$-rayed. (NOTE: expansion joint was raised slightly out of the jig for $x$-raying butt welded joints)

The expansion joint was re-clamped to the asembling and handling $j i g$ and preparations were made for machining the top edge joining the latier to the bearing ring. (The botton edge is machined to size after welding expansion joint to bearing ring.) The expansion joint was moved and set up on a 201 boring mill for this operation. After the assembly was set up on the rill by New Yoris Ship mechanics, the top edge of the expansion joint iras machined to size and beveled for welding to the bearing ring. Before leaving the mill, this dimension was checked at random around the circumference of the expansion joint by du Pont inspectors. Referring to Sketch \#9, the specified finished machined dimension was $65 / 16$ " from the top side of the expansion joint mid-section to the top edge of the weld preparation. This dimension was checked using a machinist combination square graduated in $1 / 64 "$. Also, the distance from the mid-section segment to the bottom edge of the expansion joint was checked in a similar manner to determine if enough metal was left for final machining after weloing to bearing ring at a later date. (See 5ketch \#9) All dimensions proved satisfactory, and the expansion joint was released for welding to the bearing ring.

The bearing ring was placed on a level platen bottom-side-up and clamped in place. Next, the expansion joint, which was clamped in the assembling and handling jig, was turned bottomside-up and positioned over the bearing ring. The top edge (now in downhand position) was. then fit and tack relded to the bore of the bearing ring. The assembly was then moved and bolted to a welding positioner for welding the inside joint between bearing ring and expansion joint in a downhand position. After all welding was completed on the inside, the joint was ground flush and then inspected for cracks, porosity, unciercutting and other mechanical defects. Necessary repairs were made and then the 


\section{SECTION THRU EXPANSION JOINT}

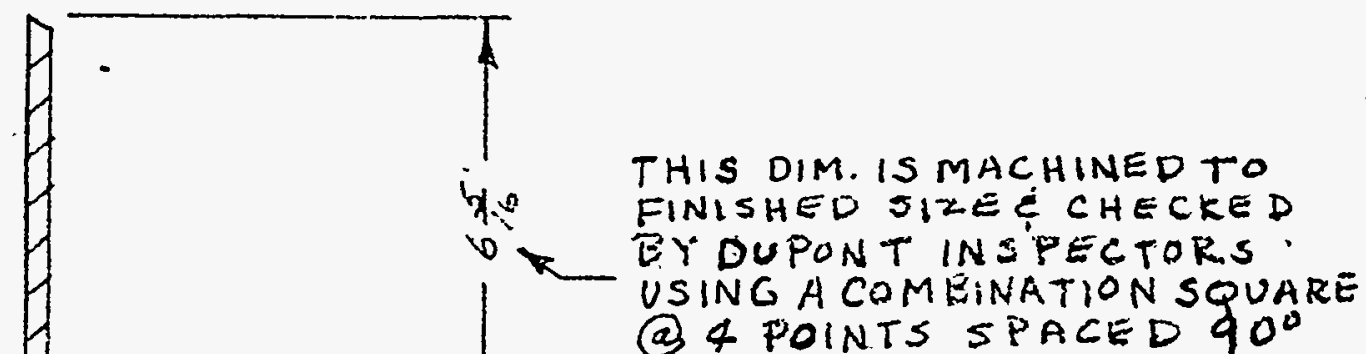

INTS APART.

THIS EDGE IS MACH. TO DW'G. DIM. AFTER WELDING EXPANSION

THIS DIM.CK'ED@RANDUM TO DETERMINE IF ENOUGH METAL ISLEFT FOR FINAL MACH. AFTER WELDING EXPANSION JOINT TO ER'G RING JOIN.T TO BEARING RING, SEE SECTION "C",

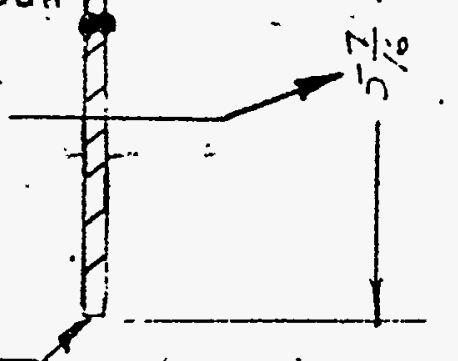


Inside foint was $z y-$ glo tested to furtiner ascertain the quality of welding. Additional $r$ epairs were made, re-inspected and accepted by the du Pont Inspection Departinent.

The assemily was moved from the welding positioner, placed on a level platen, and clamped in place with the botton side up. With the assenbly in this position, a fillet bead was made on the outside joining the expansion joint to the bearing ring. After velding, the outside circumferential fillet weld was ground and tiren visually inspected for cracks, porosity, undercutting and otiner mechanical defects. Hecessary repairs were made, reinspected and accepted. The expansion joint and bearing ring was now welded into an assembly as shown pictorially in Irig. 6-4 presented heresith.

\section{c Pinal Machining of Tank Expansion Joint and Bearing Ring}

The cearing ring and expansion joint assembly was made ready to set lottom sicie up on a 201 boring mill vitiz the assembling and handing $j i g$ assemiled to hold it in shape. before placing the bearing ring and expansion joint asserbly on the 20 boring mill, twelve cast iron pedestals were positioned around the outer periphery of the mill table to correspond to each of the bearing ring cutouts on the bottom side of the bearing ring. The tops of these cast iron pedestals vere then machined to a plane. Thrse pedestals were purposely staggered in this manner in order to cuplicate the actual set-up of the asserbly when installed at the plant site. The assembly was positioned and clamped in place by fies York Ship.mechanics, and preparations were made for machining the bottom side of the bearinis ring to finish size. As shown in sketch $7 / 6,3 / 16 "$ was left on this side after rough machining for final machining at this time. The bottom side of the bearing ring was rachined to size and then checked by du pont inspectors using a conkination square graduated in 1/64". The cistance fian the finished machined bottom side of the bearing ring to the outside edige of the expansion joint mid-section was measured and found to be $5^{n} t 1 / 32^{\prime \prime}$. (See Dwg. 6-3 for location of this measurenent). The bearing ring finisin was tiren checked using a profillometer and found to be 32 nus or less which met the specified finish requirement. Next, the botton edge of the expansion joint was nachined square and to drawin: size for iater fitting and beveling of weld preparition for joining it to the main tank section. This dimension was measured using a combination square and found to be within drawing tolerance. (Seesketch $\$ 9$ )

Next, the bearing ring and expansion joint assembly was turned top side up for machining the top side of the bearing ring and bearing ring extension; howerer, during turning of the assembly, a cast iron support biock used to support the assendly on the mill slipped and siightly bent the lower edge of the expansion joint. The bent portion was re-contoured by Hew York Ship mechanics using wooden mallets and flatteners. After straightening, the repaired area was inspected by du Pont inspectors and found satisfactory. 
Wh the top side of the assembly up, the botton side bi the bearing ring was positioned on cast iron pedestals claraped and staggered to the mill table in order to support the bearing ring at each of the 12 bearing cutouts rough machined in the botton side of the ring. (See paragraph $I$ above) As shown in sketch $78,3 / 16^{\prime \prime}$ was left on the top side after rough machining for final machining at this time. The top side of the bearing ring was then machined to size. The inside fillet weld joining bearlng ring extension to the bearing ring was radiused and blended in by machining. Next, the bearing ring extension was. In inished machined to size. Before renoving the bearing ring and expansion joint assembly from the 20 boring mill, the folloling moasurements were made by au Pont inspectors:

(1) The finish (Ris) ras checked on the top side of the bearing ring using a profilometer. Results indicated that the finish was 32 FUS micro-inches or Iess which met required du Pont specifications.

(2) The outside diameter and circumference of the bearing ring extension were checked. These measurewents vere taken near the top edge of the extension to determine if fit-up of bearing ring extension to the top tube sheet enclosure will be satisfactory. The $0 . D$. measurement was taken across the assembly in three positions equally spaced using a stainless stuel top grachated In $1 / 16^{n}$. The circunferential neasurement was taken using a special stainless steel tape graduated to read the actual diameter (average) of the bearing ring extension when placed arouni the girth. $\Delta 11$ measurements Indicated that satisfactory fit-up could be accorplished between the bearing ring extension and botton edge of the top tube sheet enclosure. Results were recorded and given to Ner York Ship.

(3) The same measurements listed in (2) aoove were repeated on the bottom edge of the top tube sheet enclosure to verify fit-up tetween the latter and bearing ring extenst.on. (See Drg, 6-3)

(4) Circumference of bearing ring was measured using a special stainless steel tape gracuated to read the average diameter to the nearest $1 / 16^{n}$.

(5) Inside diameter of bearing ring was measured at $0^{\circ}$, $45^{\circ}, 90^{\circ}$, and $135^{\circ}$ using a pre-set pin gage of suitable length.

(6) The $511 / 16$ " dimension across top surface of bearing ring was checked. (See Dwg. 6-3) This was measured using a 6" seale. .

(7) Thickness of bearing ring between each of the twelve bearing pad cutouts on the botton side of the bearing ring was checked (Drasing thickness - $2 \frac{2^{n}}{2}$; see Drg. 6-3). This measurement was taken using a 18 " "C" micrometer frame witi a dial indicator attached to a 
adjustable spindle for recording thickness to the nearest .001". Tinis gage was pre-set using a standard pin gage of suitable length.

(8) The distance from the bottom surface of bearing ring to weld preparation on bottom edge of expansion joint (Drawing size - $10 \frac{3}{4}$ ) was checked with a 12" scale graduated in 1/64".

(9) The distance erom top surface of bearing ring to weld preparation on botton edge of expansion joint was measured using a small straight edge and combination square. (Drawing size - $123 / 4^{\prime \prime}$; see Dag. 6-3)

(10) The distance from the top 5 urface of bearing ring to the top of the mid-section in the expansion joint was taken at 12 locations equally spaced around the periphery of the assembly (draning size - 75/16"; see Iwg. 6-8)

(11) The 0.D. and circumference of the expansion joint edge tiat fitis to the top edge of the maintank was checked in a similar manner outlined in item (2) above.

(12) At this time New York Ship lay out men established and scribed $X$ and $Y$ axes on the bearing ring assembly: Iu Pont inspectors re-tramed these lines in an identiéaj:-inaner used by Now York Ship to deternine if axes were $90^{\circ}$ apart and in their correct position. slso, the accuracy of the axes transferred to the Inside and outside of the bearing ring was checked.

All of the above measurenents were found satisfactory by the cu vont Inspection Department and the assembly was released for furtiver macilning

Three indexing slots Here leyed out $120^{\circ}$ apart. on the top side of the bearing Iing by New York Sintp layout men. (See du Font, drawing W-130953 for Iocation and layout of three Indexing slots). The asseribily was then set up on a hydrotel milling machine and the three indexing gxoover machined to draving sizes. The slots were then inspected for size, orientation and diametral location. orientation and diametral lociticns were taken using a stainless steel tape graduated in $I_{1}^{\prime} 16^{\prime \prime}$. and referencing $P$ xom the preylously established $X$ and $I$ axes. The length, width and depth of each slot was measured using a $6^{n}$ scale grado" uated in $1 / 64 n$.

The above measurements were satisfactory and the assenbly was turned bottom side up for finlsh machining the twelve rough machined bearing pad cut-outs on the bottom side of the bearing ring. The twelve bearing 
cut-outs were machined to drawing size, dressed, and then the assembly was released to the du Pont Inspection Departisent for Inspection. The following inspections were performed on each of the twelve bearins pad slots:

(1) Machined surfaces of slot were checked for finish (RuS) using a profilometer. All nacinined surfaces required 125 Rits micro-inch finish.

(2) Depth of the two "steps" in the slots wasschecked using a pair of depth micrometers. All measuments were referenced iran the bearing ring face (top side). These iteasurements were held within $t .005 n$.

(3) Orientation of each bearing pad slot was checked with respect to each other referencing from the $X$ and $Y$ axes. These measurementsuere taken using a stainless steel tape graduated in $1 / 16 "$ and estimated to the nearest $1 / 64^{\prime \prime}$. For location of bearing pad slots with respect to the $X$ and $Y$ axes, see du Pont drawing W-130953.

(4) All other measurements were cheched with a 6" scale graduated in $1 / 64^{\prime \prime}$.

The above measurements proved satfsfactory and the assembly was released for fitting and welding to the top tube sheet enclosure.

d. Fabrication and Inspection of Top Tube Sheet Enclosure

The type 304 stainless steel material for the top tico sheet enclosure was inspected for surface concition, enbedded iron, nechanical defects, and dimensions. Bli plates were checked with a magnet to determine if the raterial was austentic structure. Ferroxyl tests were performed at random on the plates to determine if any free iron was imbedded in the surface. Any indicition of free iron was removec by grinding. $A l l$ material inspected sas accepted after minor repairs and released for top tube sheet encloida fabrication.

Two plates were flame cut, chipped, machinew and rolled to make up the top tube sheet enclosure shell. Excessinaterial was left on the top and bottom edges for final machining. The rolled half shell

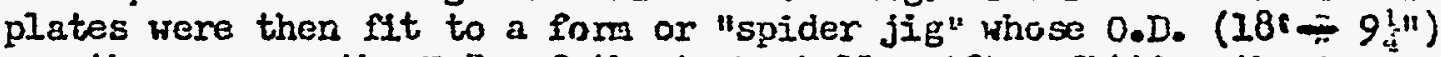
was the eame as the I.D. of the tank shell. After fitting the two plate sections to the "spider jig", the two vertical seams were tack weldec. For view of top tube shect enclosure shell, see Irg. 6-2.

Next, four lifting lug openings were laid out on the top portion of the shell. These openings were cut and chipped to layout. (see Darg. 6-2 for view of lifting lug cutout in enclosure shell). For location of top tube sheet lifting Ius cut-outs, see Drg. 6-I. In axidition, two overnlow pockets and two nozzle openings were laid out on the shell. These were cut and chipped to lajout. (See Ding. $0-2$, section E-B and C-C). 


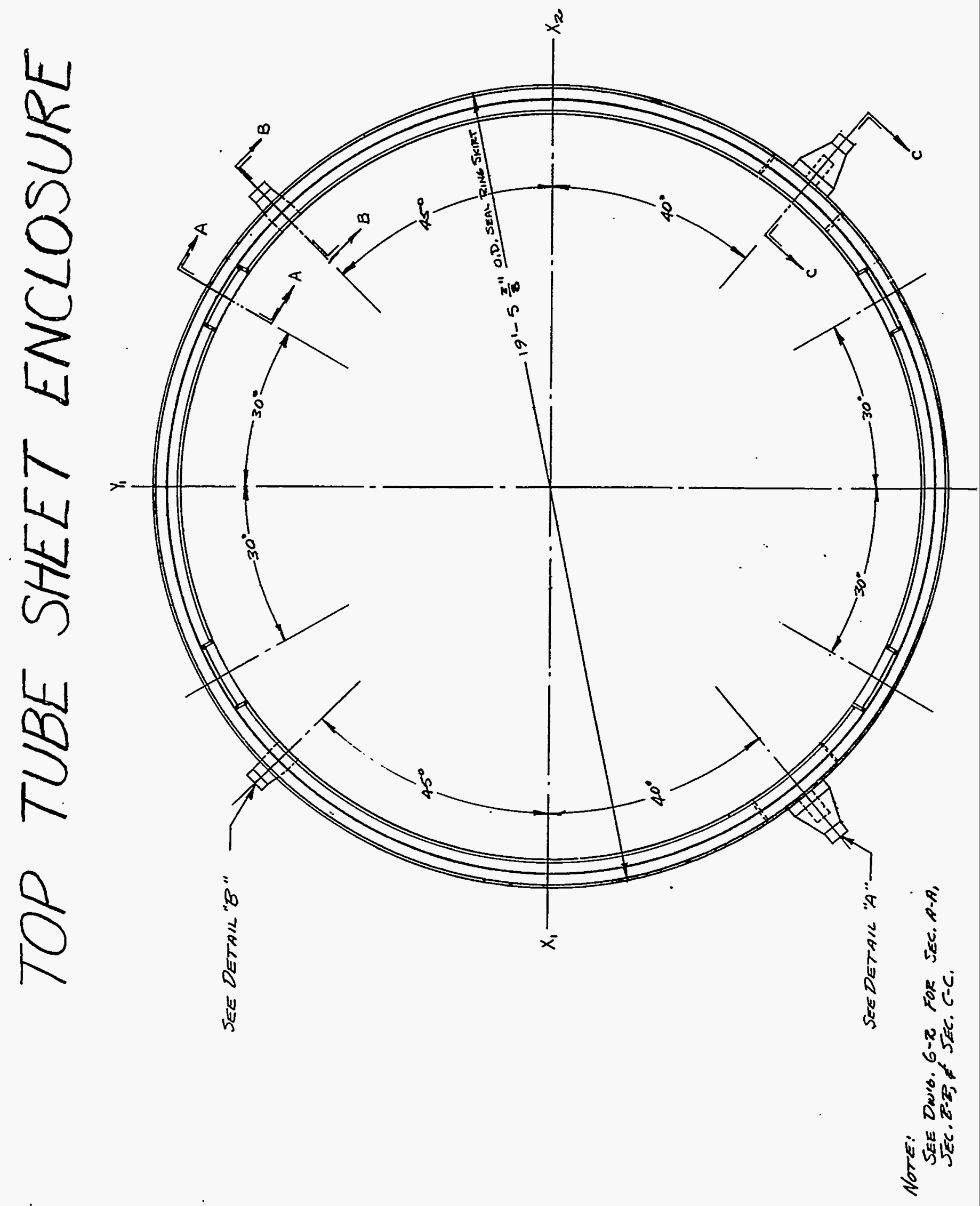



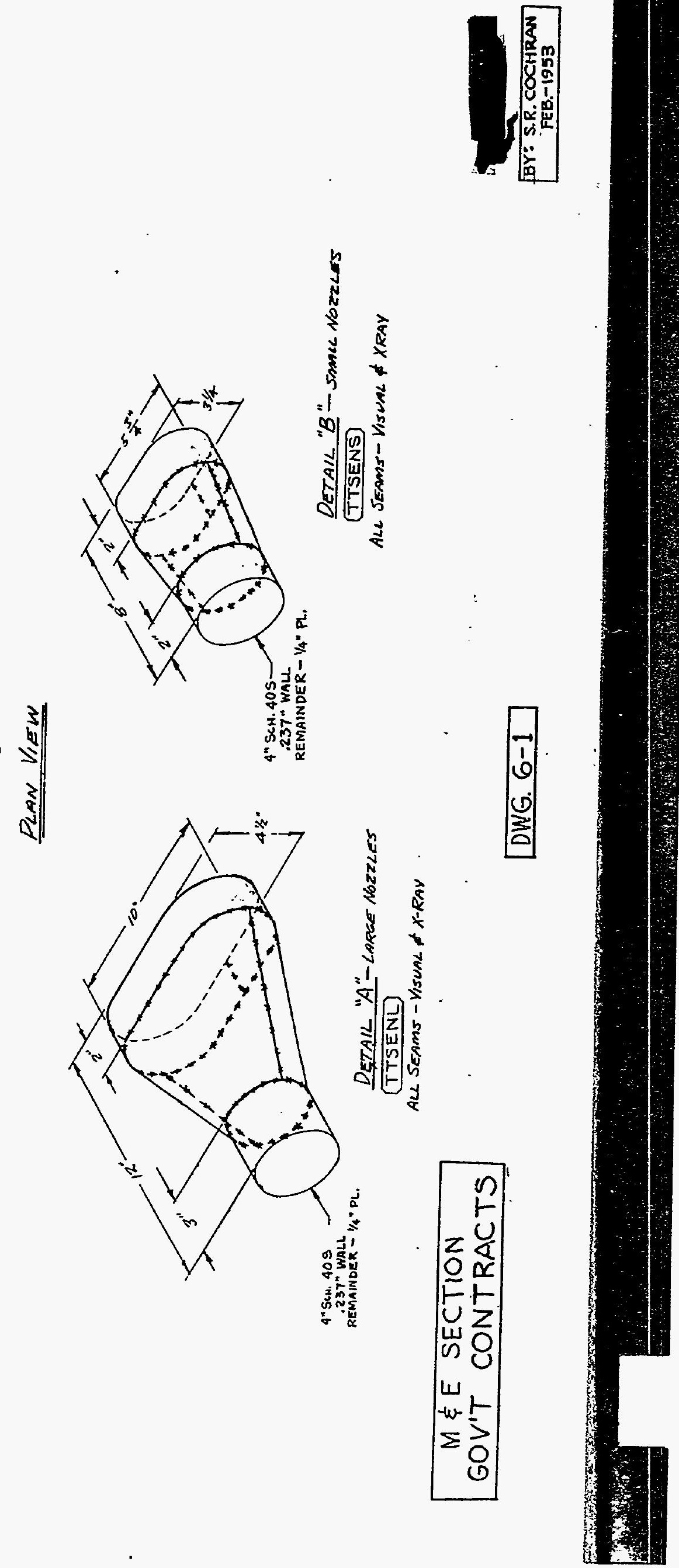
Four Iffting Iug assembles and tro overflow pockets were lald out on plate, pieces cut, fitted, and welded to form "pocket assomblies," Tro large nozzles and two mall nozzles were laid out from developed templates, material cut, formed to template and welded with pipe sections to form the four nozzles. (For isonotric vien of large and amall nozqles, aee $\mathrm{Drg}$. 6-I, details "A" and "B". For sectional view of larse and small nozales, see Drg, 6-2, sections $B-B$ and $C-C$ ). All welding on the inside and outside of the four nozzles were ground and then visualiy inspected for cracks, porosity undercuttiug and other mechanical defects. Hecessary repaixs were made, re-inspected and released for $x$-raying. No and necessary repairs made. lext, the nozziles were sandblasted; acld washed and ferroxyl tested. 111 inspections proved aatiofactory and the nogzles vere released for assembling to the top tube sheet enclosure.

The four lifting lug assemblies were fit and tack welded In their proper position. Also, the two overflow pocket assemblies were fit and tack weidedin place.

The top tube gheet enclosure was then bolted to an 18 : reloing position in order that all welaing be done in a downhand position. : Tack welds were chipped, wire brushed, and ground as required, and all joints were manually "aircomatic" step welded accoxding to the welding procedure adapted for this job. During the above operations, a visual inspection by du Pont inspectors was maintialnd to insure quality in welding.

After all weliking had beencompleted, it was ground and then visually inspected. Dng. 6-2 illustrates pictorially where all visualy insuections were nade. Cracks, porosity, undercutting and other mechanical defects were chipped or ground out of the defective welding, re-inspected and accepted. (Howtí No dy-cheking or $2 y$-glowing of welding as shorm in Dwg. 6-2 was performed on " $R$ ITS enclosure. This was started on "p" and subsequent units). Next, the two vertical shell seams were $x$-rayed, radiographs eximined and necessary repairs made.

The top thibe sheet enclosure was renoved from the welding positioner and placed on a level platen until the seal ring was fabricated. The following paragraphs cover this pirase of fabrication and inspection.

Before the seal ring was laid out and fabricated to size, the circunference of the top tube sheet enclosure was measured to determine what size to machine the bore of the seal ring. 
Thts measurement was taken just below the large and small nozzle cutouts using a special tape to read the 0.D. of the sboll when wrapped around the shell circumforence. This $0 . D$. was recorded and given to a New York Ship machinist for borlng the seal ring to size for fitting and welding around the $0 . D$. of the enclosure shell.

Six lengths of $2 \frac{1}{2} \times 4^{n}$ bar stock were chipped on the ends for double vee butt joints. A section was made by clamping ami fitting tro lengths to a level platen and butt welding the two together. Two additional sections were made in a similar manner. All welding was done using mamal Aircamatic welding machines. After this, the butt joint in each of the three sections was chipred, ground, and weld defects repaired. The three sections were then heated to a chexry red and formed to a sen-circular layout using moon vars and pins on a Pumace slab. After forming the sections, the curvature was checked with a radius template. Next, both butt joints on one section were chipped and then clamped to layout on a slab. The two other sections were fit to layout in a similar manner.

After fitting the three sections to form a ring, the three doulle vee butt joints were welded using manual Airconatic selding machines. Tho butt joints vere chipped, ground and then $x$-rayed. Radiographs were examined by du pont inspectors and necessary repains made. It was then recontoured, flatteried and set up on the 201 boring mill for rough machining. The $0 . D$. of the seal ring was machined $\frac{11}{4}$ full on diameter to allow additional metal for shrinkage caused fran welding the gasket retaining bar to the $0 . D$. of the ring at a later tine. Next, the inside fillet weid preparation on the top edge of the seal ring (where the gasket retainer bar was to be walded) was finished rachined to size. Also, the fillet welc preparation on the opposite edge of seal ring (where the ring was welded to the 0.D. of the top tube sheet enclosure) was machined to finish size. Held preparations on the top edge of the seal ring were machined to drawing sizes at this time in order to insure that a full 1/4" fillet weld would be left after finish machining the top face of the seal ring. (See Sketch 10 ) The seal ring was then removed from the 201 boxing mill and set aside until the gasket retainer bar was fabricated.

Four segments were fomed from plate, fitted, and welded to make up the gasket retainer bar. Tho 


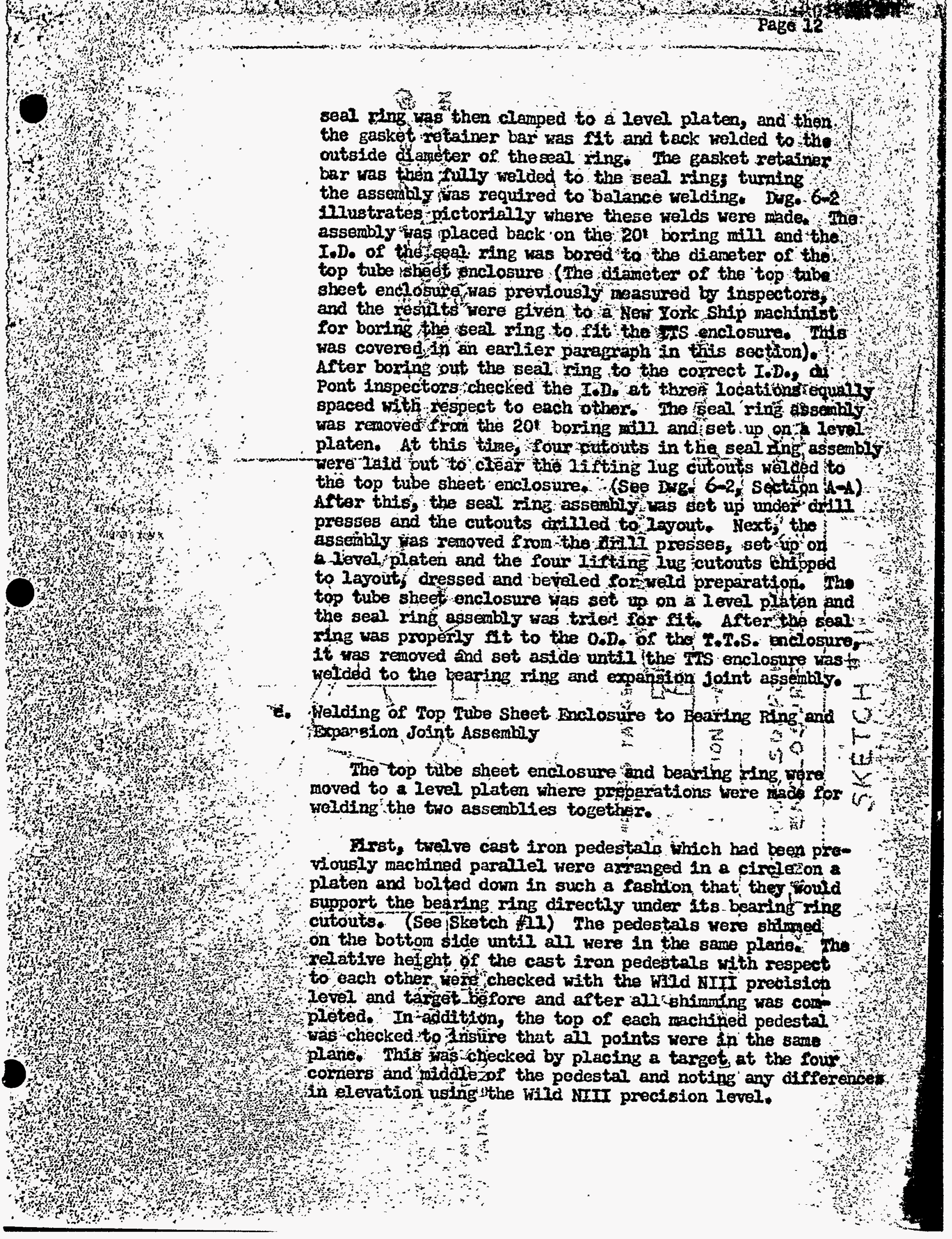




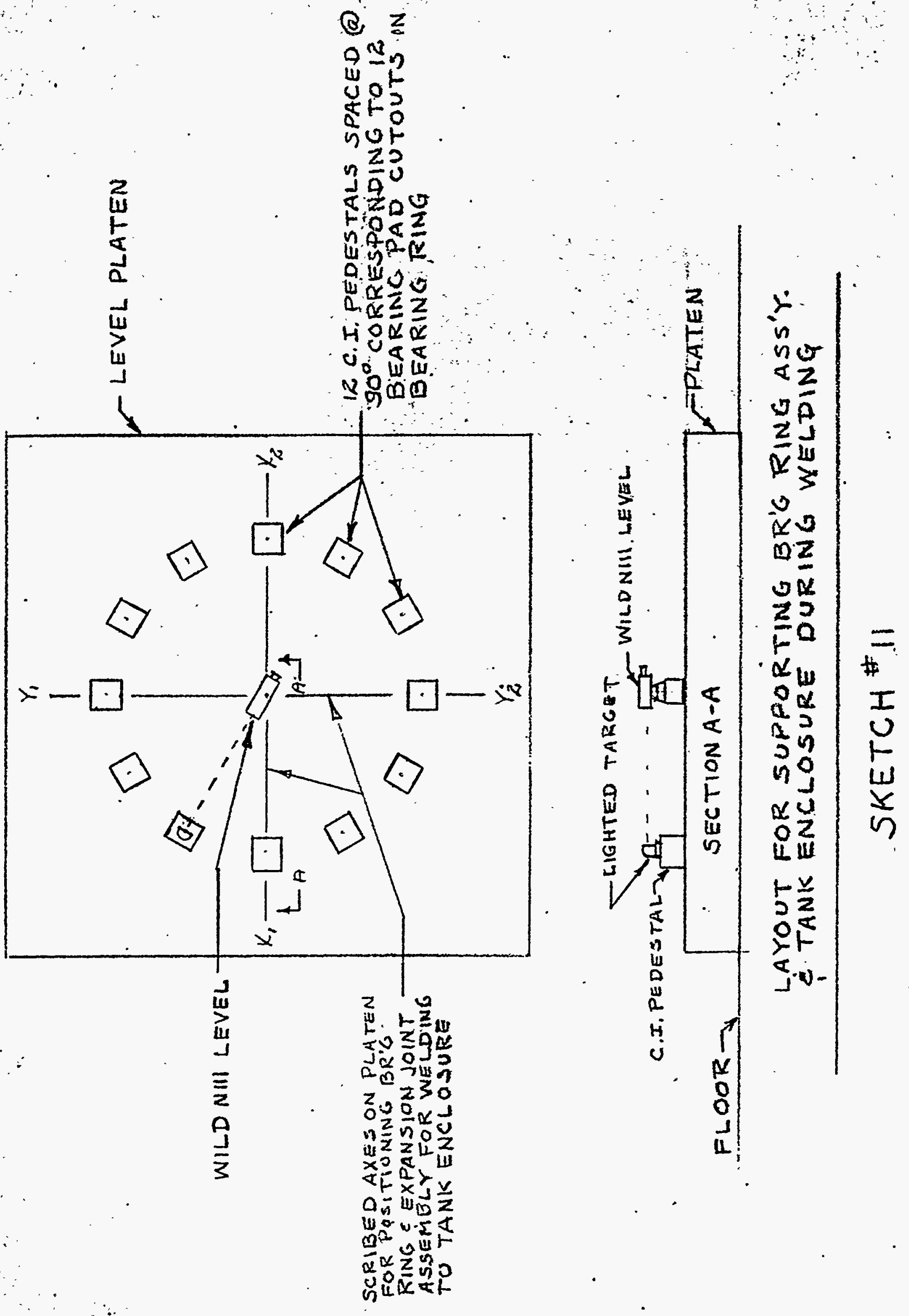


After the twelve pedestala nere leveled, the bearing ring and cxpansion joint assembly was placed (top side uv) on the pedestals and the $X$ and $I$ centerline on the latter matched to a sinilar set of axes seribed on the platen. Hen this aligment vas satisfied, the bearing ring was clamped in position. Rext, the top tube sheet enclosure was lowered in position and its $X$ and $I$ axes (previously established by Nis for alignent purposes oniy) were mitched to a similar set of axes on the bear. ing ring and extension. After this, the top tuive sheet enclosure was locked in position to the bearing ring with welded stainless steel clips. The Ths enclosuro seal ring was then lowered in position and set parallel and to its correct height from the baaring ming. Next, it was tack welded to the circunference of the tank enclosure shell.

The bottan edge of the top tube sheet enclosure was tack welced to the bearing ring extension. Before fully welding this joint, the following inspections were made by du pont inspectors:

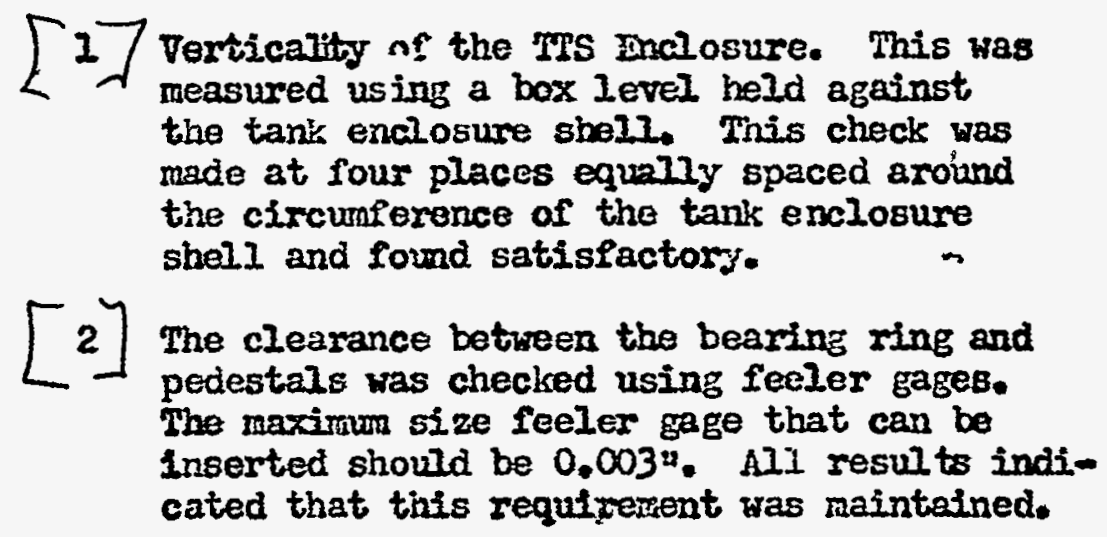

The joint between the bearing ring extension and bottors edge of the tank exclosure shell was fully velded. After this, onother check with the W17d NIII precision level was made. The instrument was set up in the midale of the tank enclosure shell and level readings were taken. Readings were taken at 12 points on the top side of the bearing ring. These trelve points were directly over the areas where the bearing ring was resting on the 12 cast iron pedestals. All measurements indicated that the top face of the bearing ring was still in the required plane.

The butt weld where the bearing ring extension and bottom edge of the tank enclosure shell join was dressed, $x$-rayed, radiographs exarined and repairs made. In addition, the distance from horizontal vel is on bearing ring 
and horizontal and vertical welds on expansion ring to bearing pad slots in bearing ring were measured. (See Exhibit 6 for resiats)

Hext, the height of the seal ring was checked referencing from the top surface of tho bearing ring and it was found to be $3 / 32^{n}$. low the tack welds joining it to the Ths enclosure were chipped loose and the ring was positioned and leveled to its correct hojght rith respect to the bearing

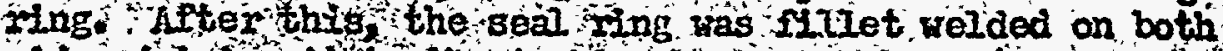
sides foinjig tet to the tank anclosire shell. (see Drig 6-2, Section $\mathrm{B}-\mathrm{B}$ - I or Iccation of circunferential equet velos)

After 17 welaing was completed the following inspec toons were egain mo eated

[1] Whe Jevel of tho bearing fing ras checked at the designated if points with the assembly unclamped from the plater.

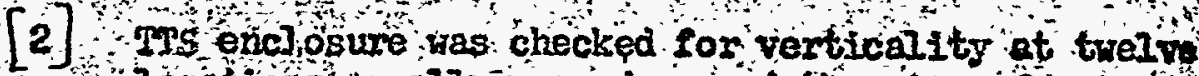
Iocations equaliy spaced around the circumerence of the kank enclosure using a box Ievel.

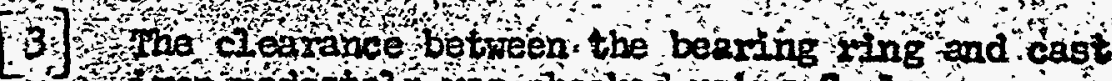
tophedestal was phecke using reeler gageg.

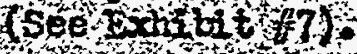

The folloing iola inspeptons were made after welding the ofaring to the tank enciosice shell.

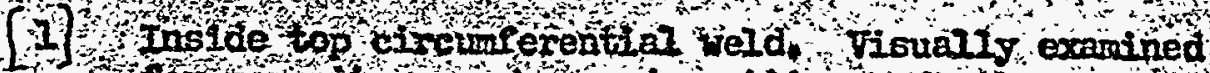
of poxosity, oracks undercutting and other Wechant cal defects pinal condition of reld as ilded wh th some prinding to remove defects. t.

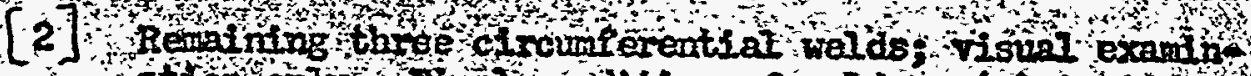
ation onjy alnal conation of relds (a) Inside

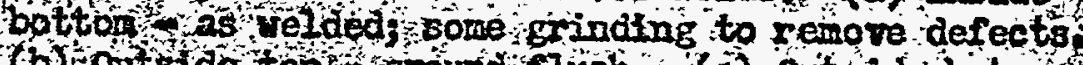

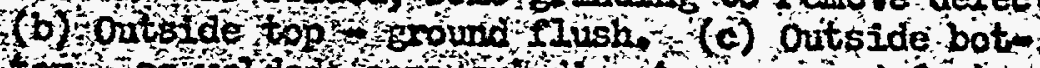

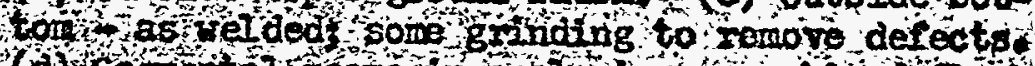

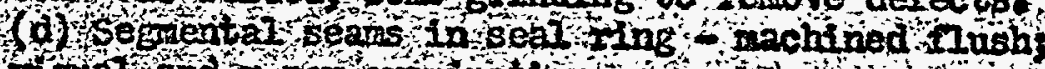

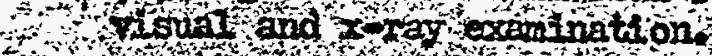

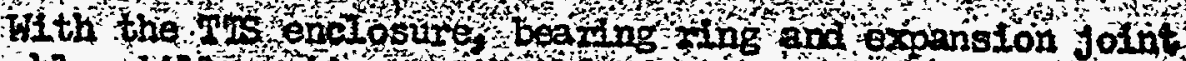

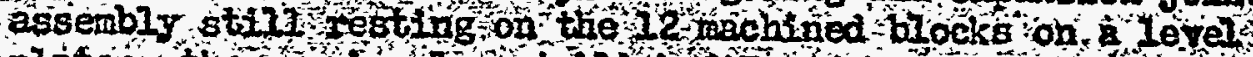
platen the prevolos ly established X ana I axes on thobear Ing ring wete tansfarma to tho outside of the assomiy.

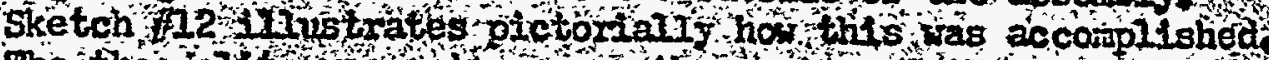

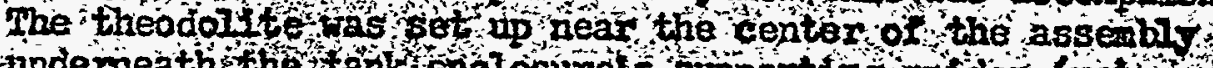
anderneath the tank onclosuxe s oupporting spider fnot

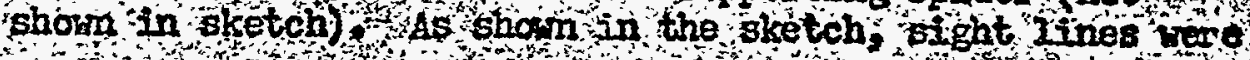


EXHIBIT 76

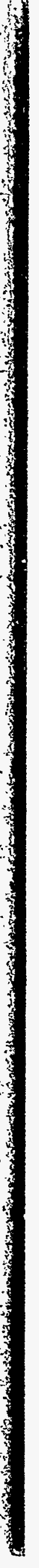


E. I. DU PONT DE NEMOURS \& CO, INC. Construction Division

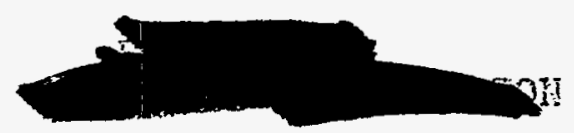

Report Number 123-R

$C C: C \circ E_{0}$ Buckley, F。P.M。

R. Ko Mason, FoPoly。 S SRP i 3

Ho I. Bunker o JoG。 Brewer

J. Go Brewer

Ho Bo Gage

$\mathrm{F}$ 。 Co Breuninger

A. Ho Hughes

C. W。 Dunn

File

July 11, 1952

New York Ship - Camden, NoJ。

$n^{2}$

FIELD INSPECTOR'S REPORT

To C. Jo VEITH - 1 \& E FILE

FROM Ao Jo Piatek - C. H. Hej.st DATE July 9, 1952

PROJECT NO. 8980 PLANT Savannah River ORDER NO. AXC-167? EQUIPMENT Bearing Ring and Expansion Ring EQ.PC。NO $250=\AA$

DRAWING NOS, Vo130953 JOB RATING INDOR. New York Shipbuilding Corporation LOCATION Camden, No Jo

Scope: To reasure the distance from horizontal welds on bearing ring and horizontral and yertical telds on expansion ring to bearing pad slots in bearing ring. Measurements taken July 9,1952 ?.

Procedure: Measurements were taken with an 8 fto steol tape. Tho distance, the horizontal weld is from the slot, is a chord neasurement taken from outer edge of weld so the outer edge of the center of the bearing pad sloto The distances, the horizontal and vertical Welds on expansion ring are from the slots are ARC measurements taken on the outer circumiterence of bearing ring. from welds to center of slots。

Rosults: Results on attrached sheet.

$2 m w$

Attach。

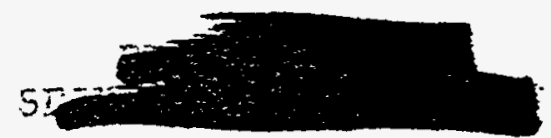




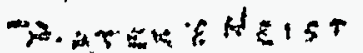

To

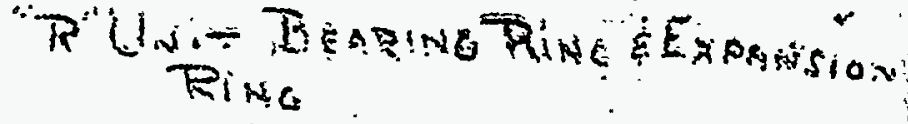

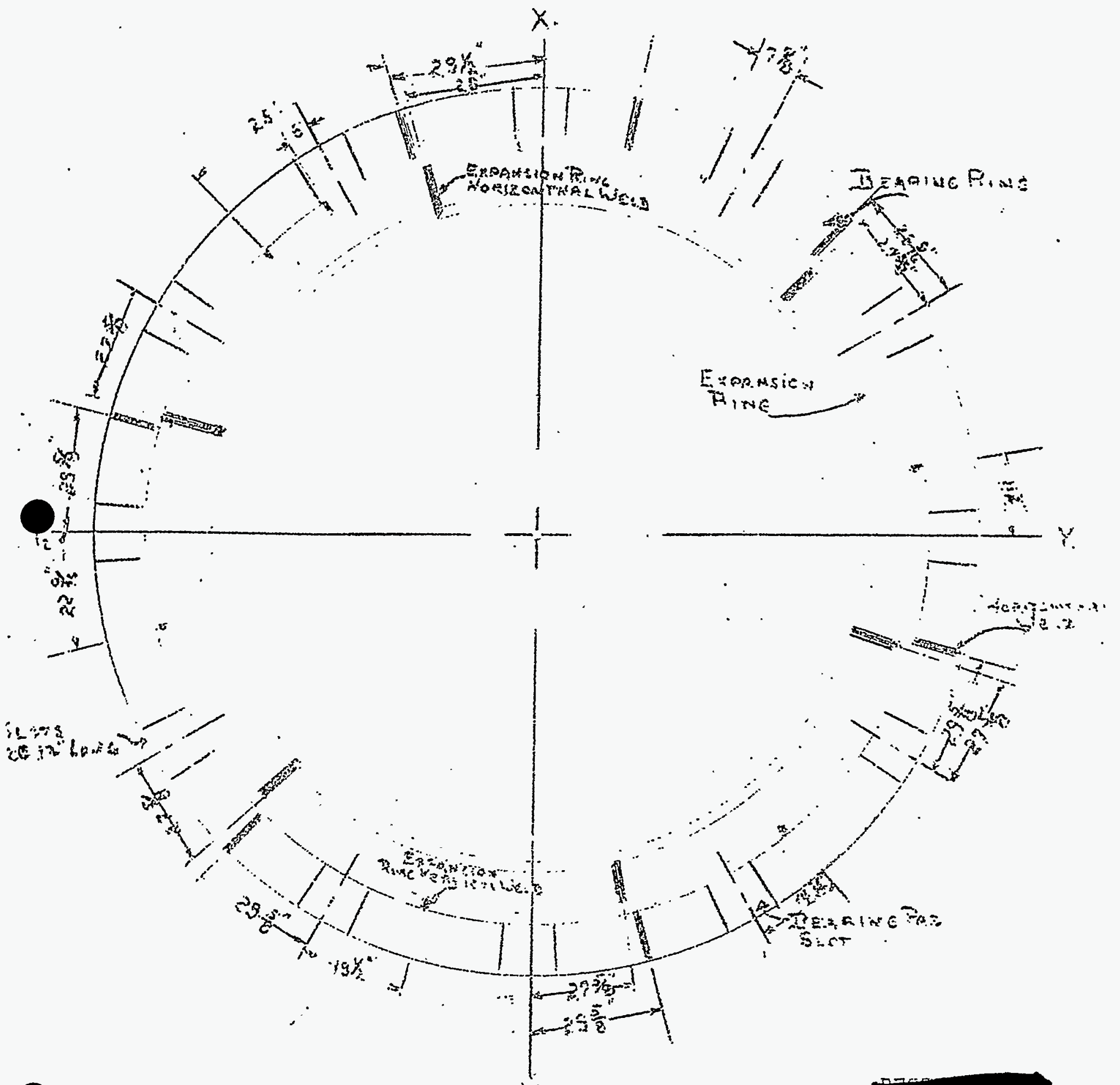

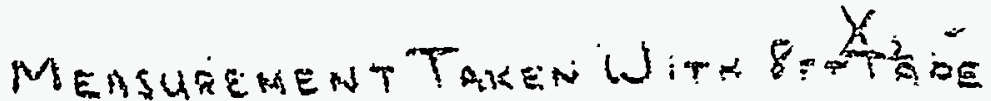

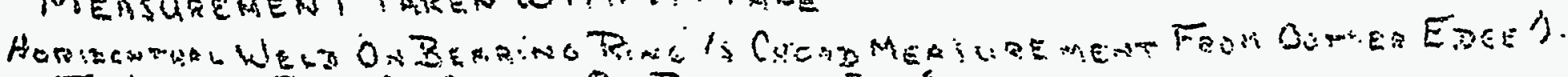

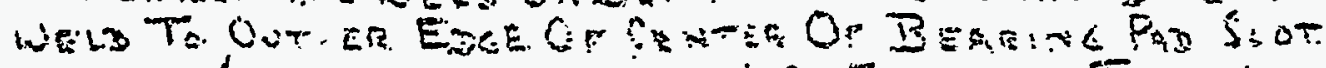

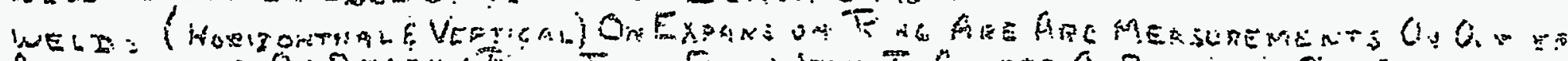

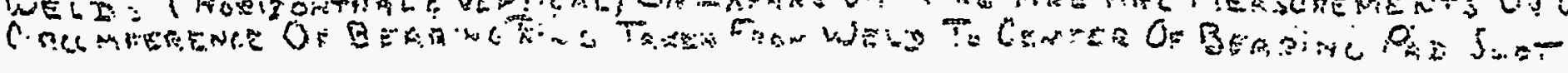




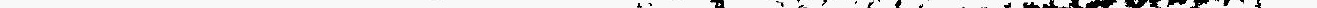




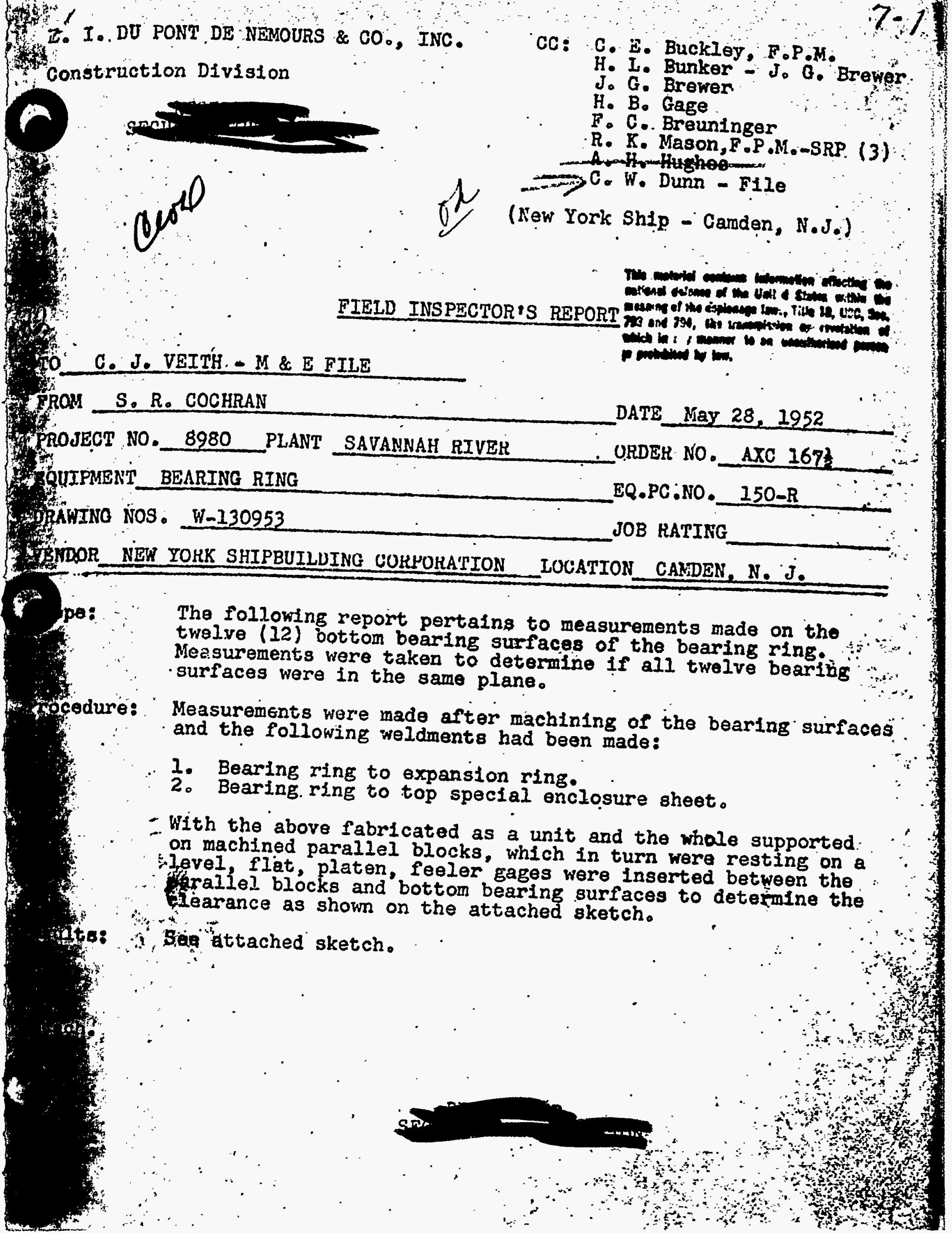




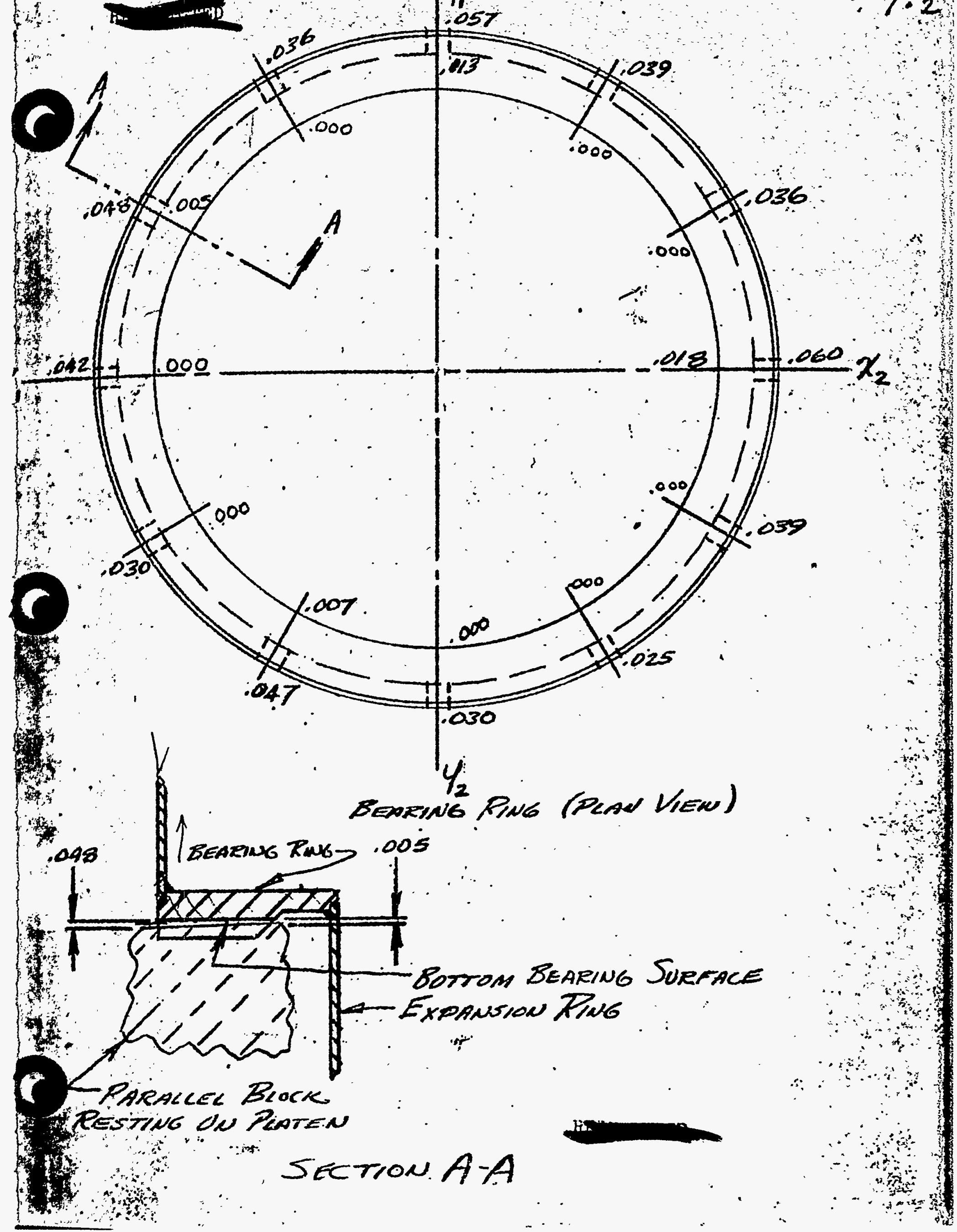




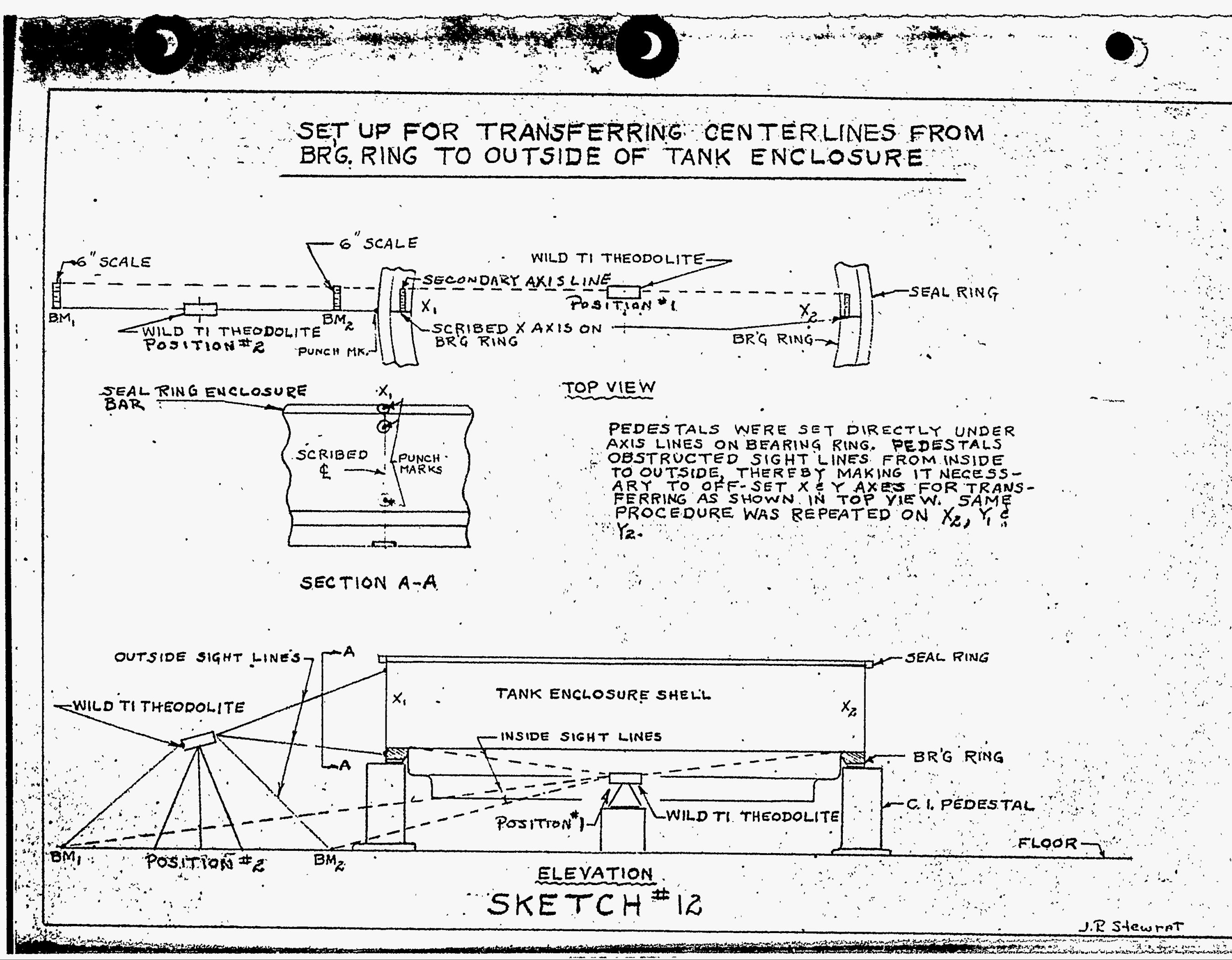




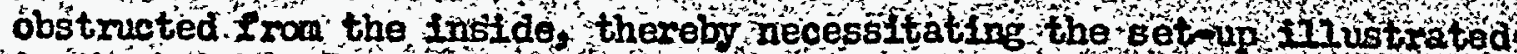

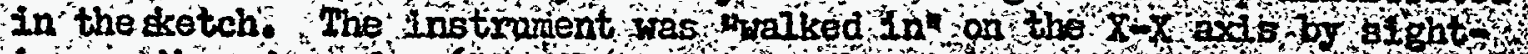
Ing on the edge of a 6 scale and then piunging the ths twinent and

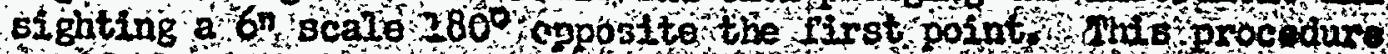

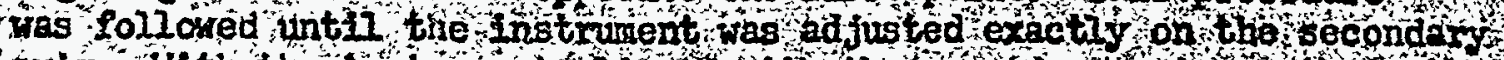

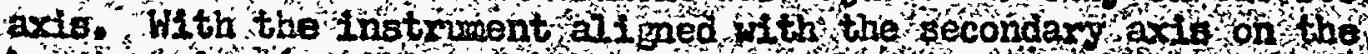

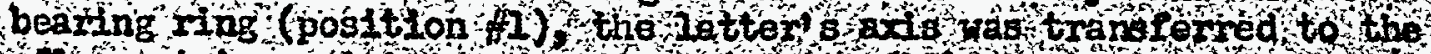

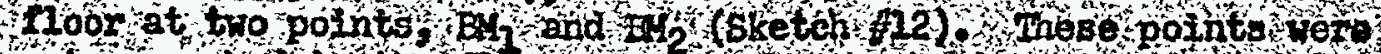

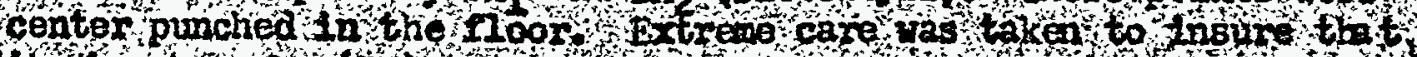

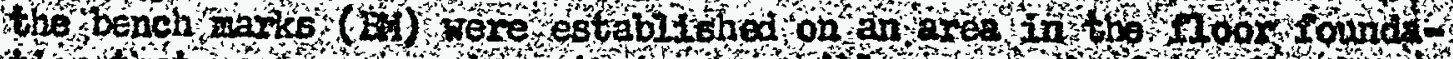

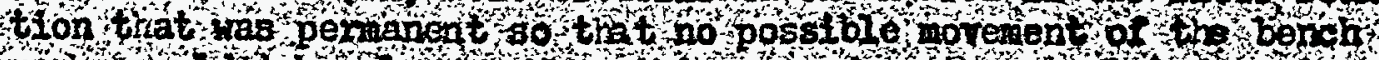

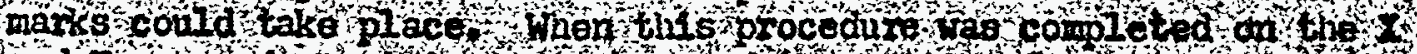

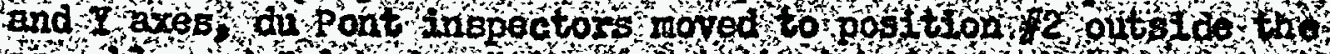

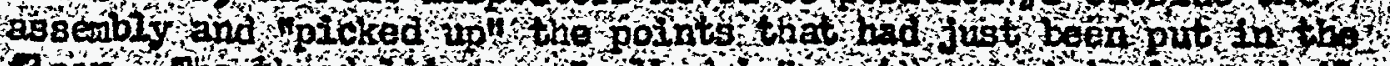

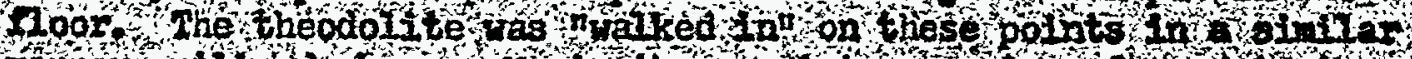

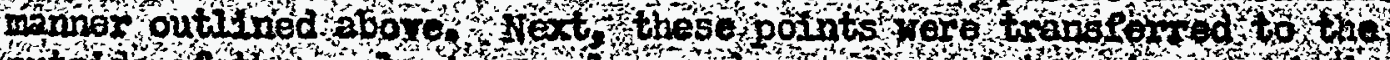

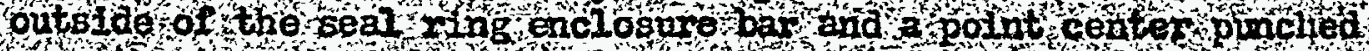

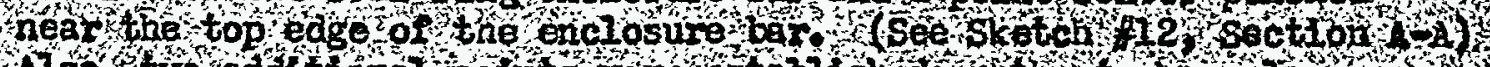

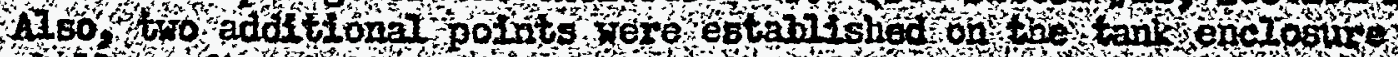

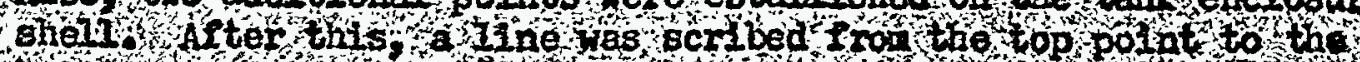

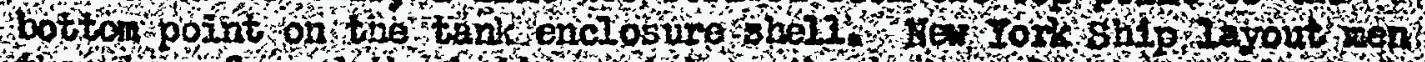

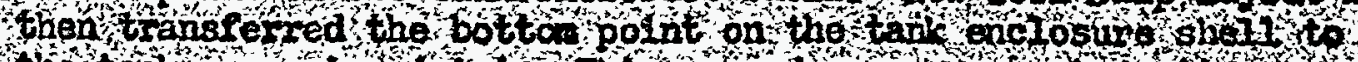

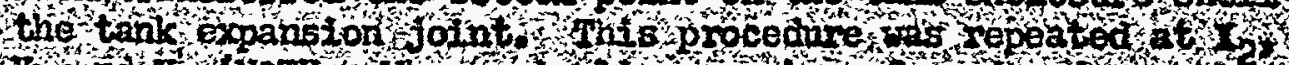

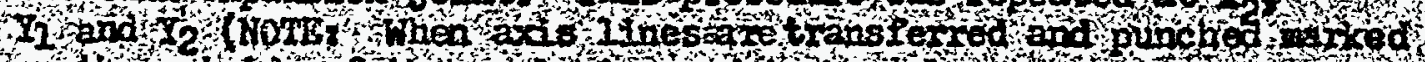

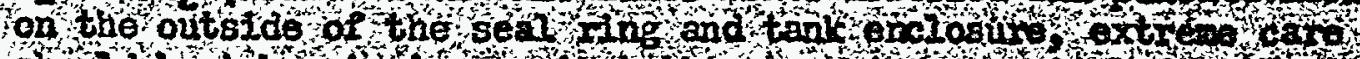

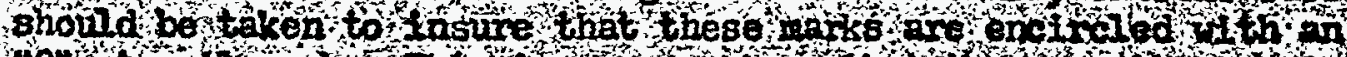

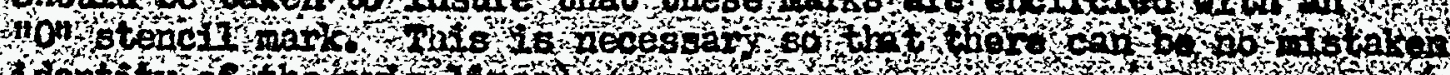

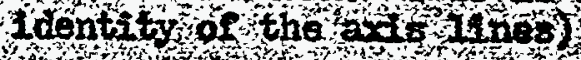

\section{Hachining of seal phs}

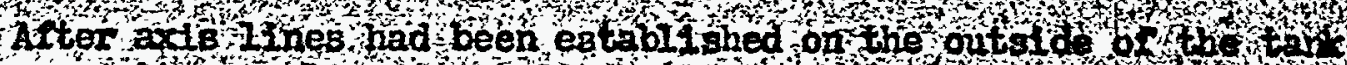

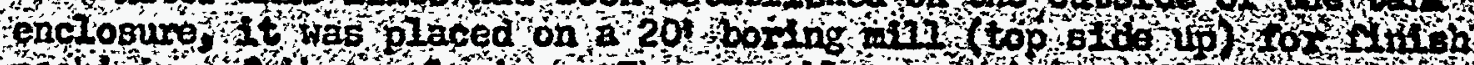

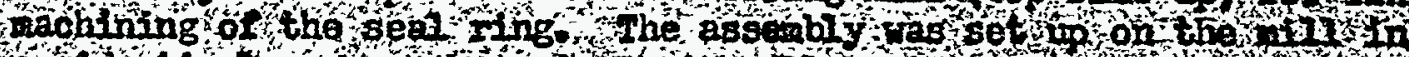

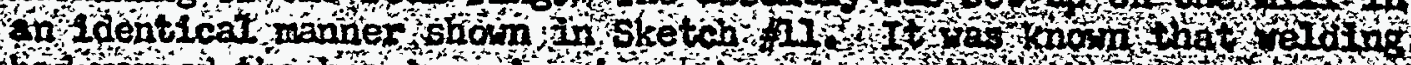

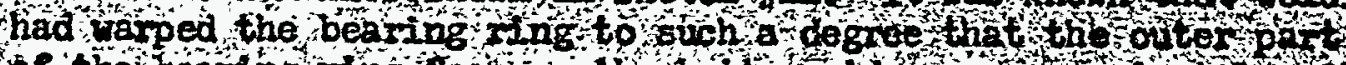

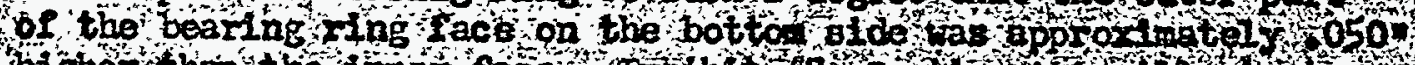

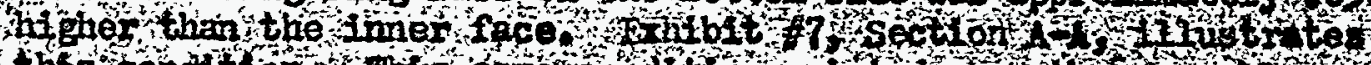

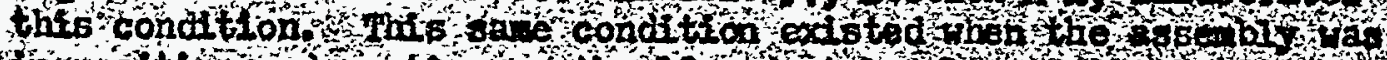

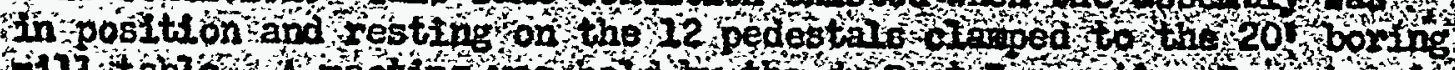

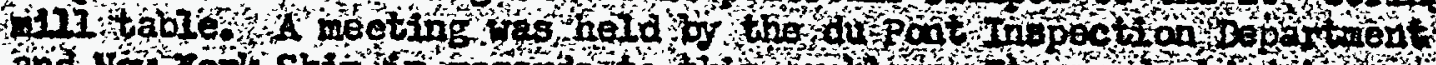

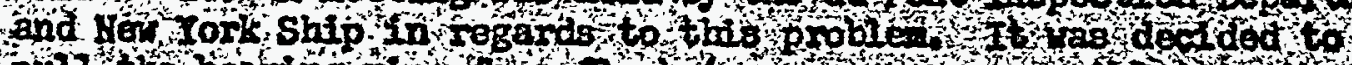

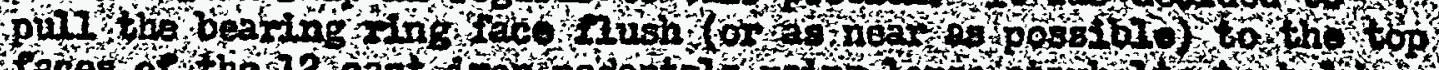

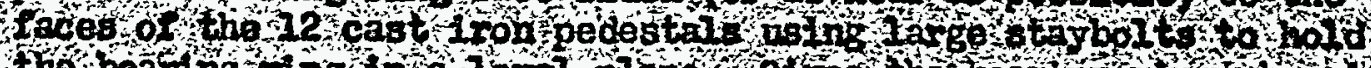

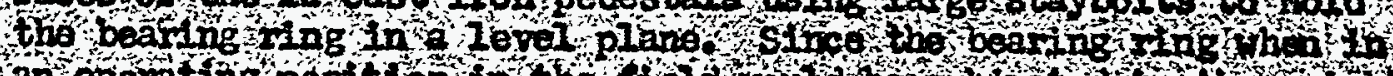

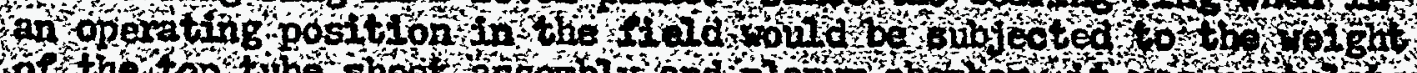

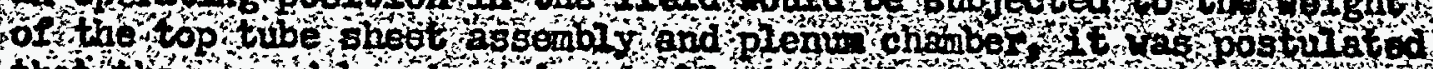

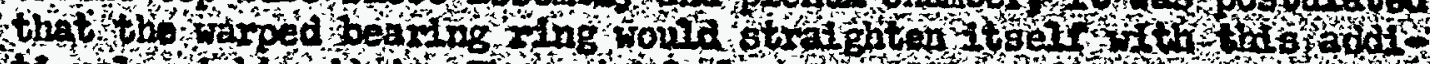

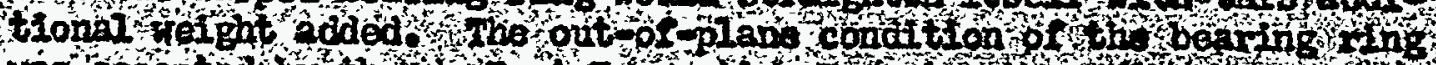

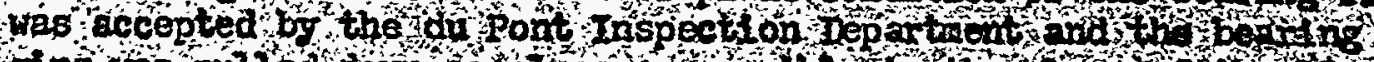

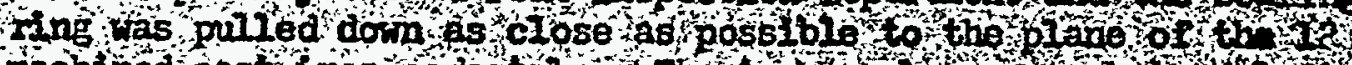

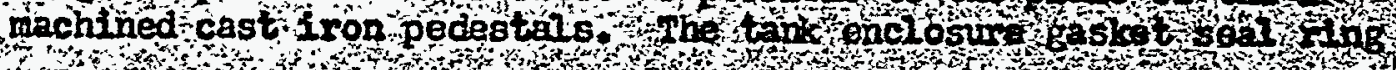


ires nachined to drawing size, After pachining the dinenstons gho on in sketch \#13 were checked by du pont inspectors and accepted.

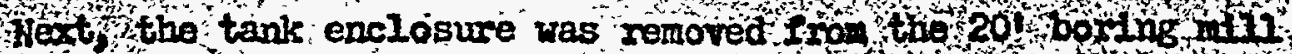

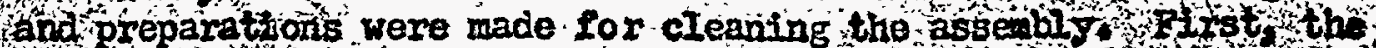

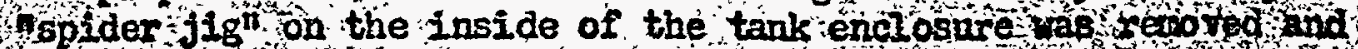

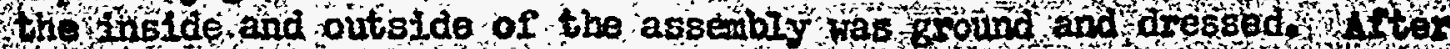

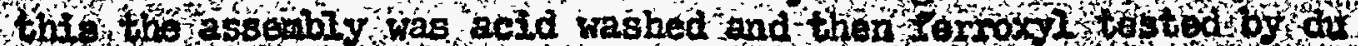
pont inspectora some places in the burface of the enciosure wer Iound to have Iron Incluslons and other riechanical de fects othese Bpots vere re-ground, acid weshed, re-inspedted, forroxyl tested and

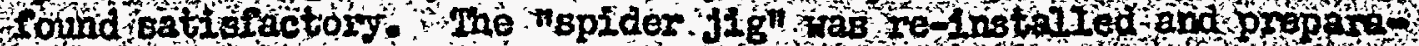

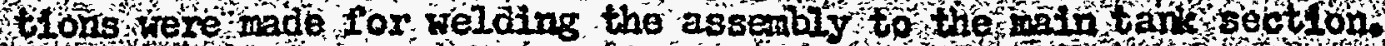

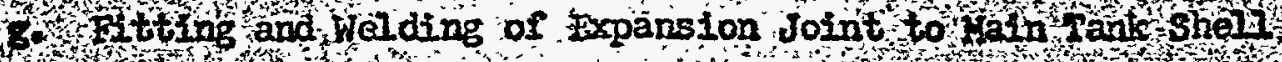

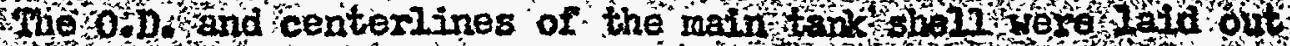

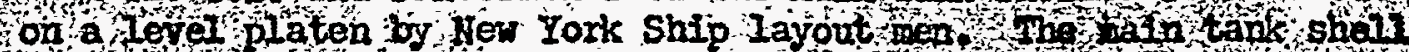

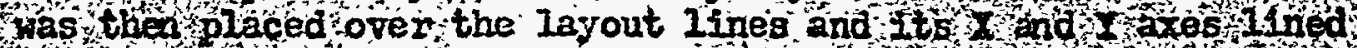

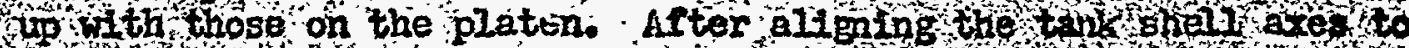
cokrespond"to platen axes, elght stainiess, steel bidoks vero tach

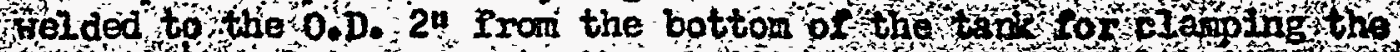
tonk to the platen wext, the position of the vol teat butto or

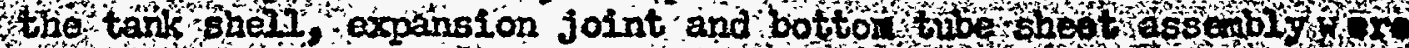

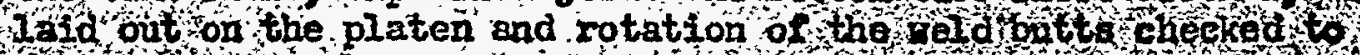

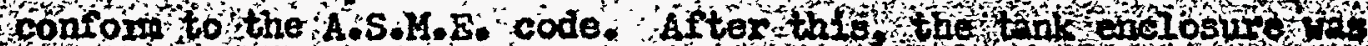

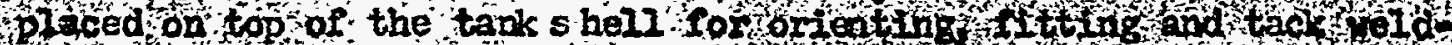
Ing of the expansion joint to the tank gholl to top edgo of the of

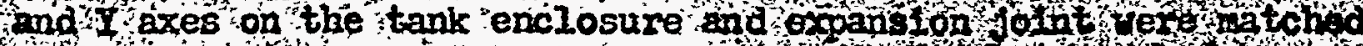

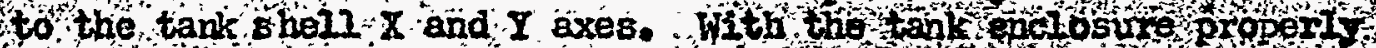

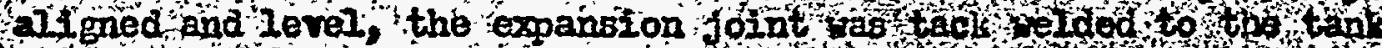

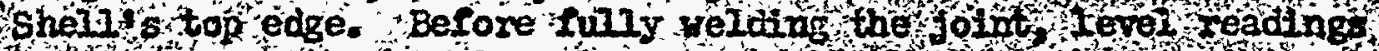
were taken on the bearing ring as preylow y lescribed in this sec-

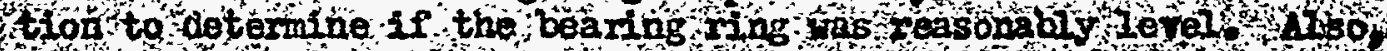
the distance from the bottail side of the thal re beaning ing gatost

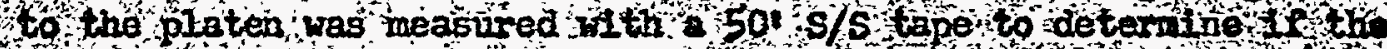

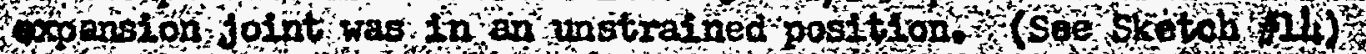

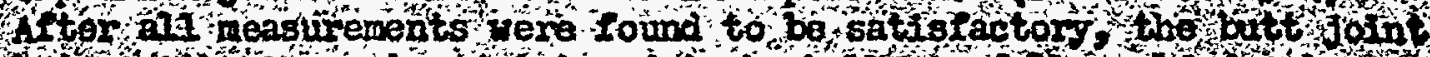

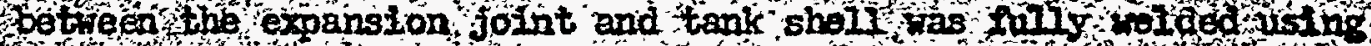

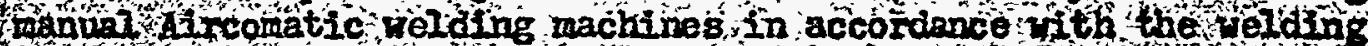
proceduro adated for this job atl welding on the Inside and out side

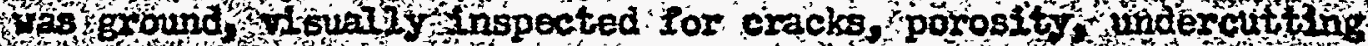

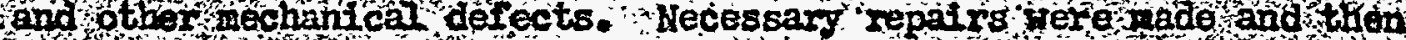

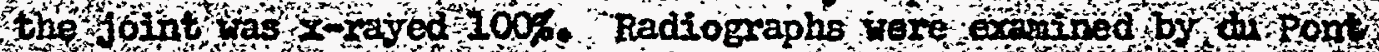
Inspectors and hecessazy repairs ade.

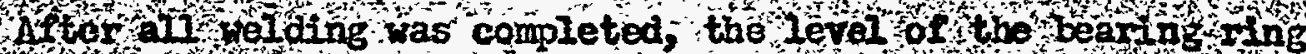
Tas a ga in check a to determine if it had moved as a wesint of rald Ing oflo o the distance from the 12 bearing sing cutotits to tho 


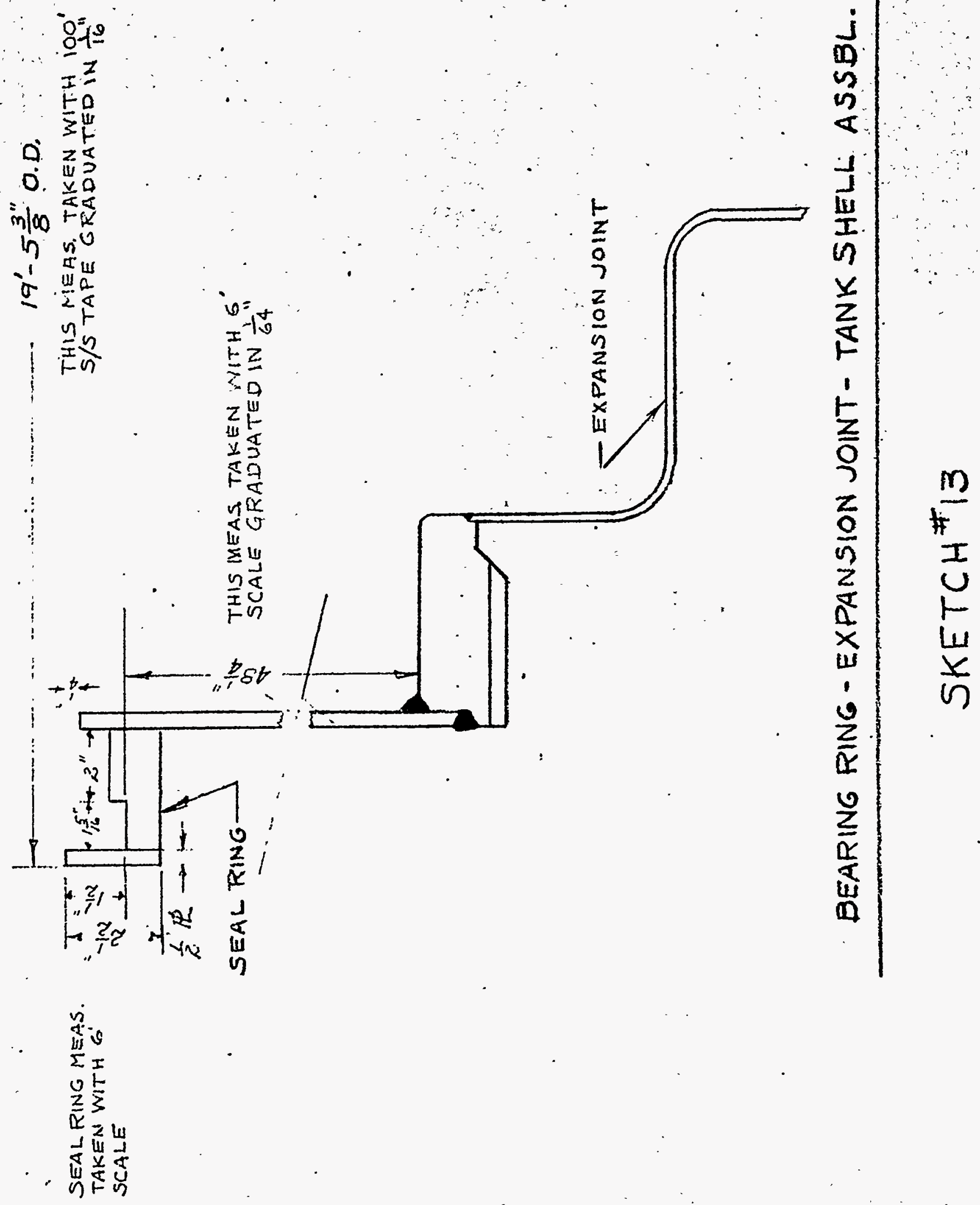




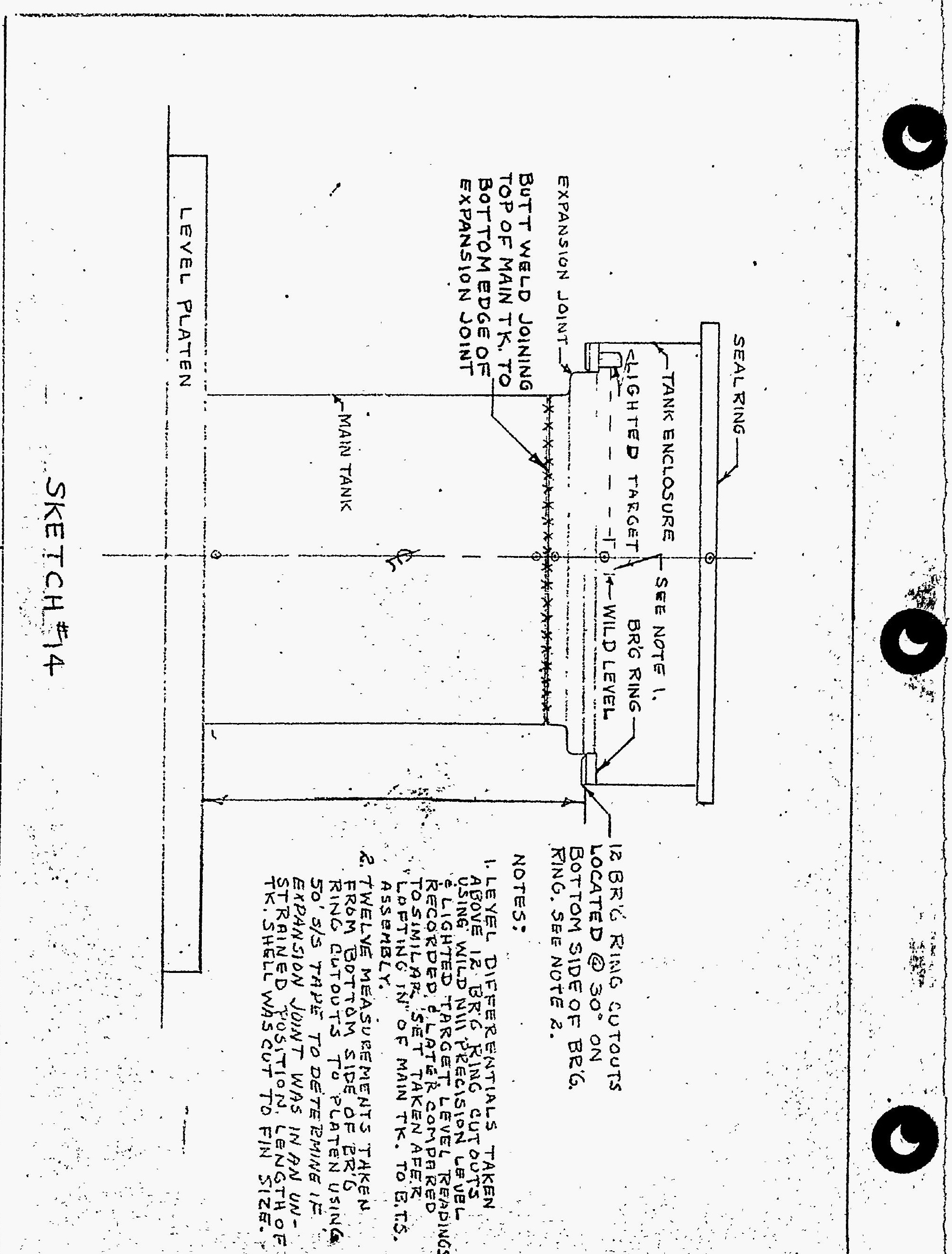


platen was again checked to determine if the proper tank shell elevation was still maintained and if the bearing ring was in an unstrained position. The above level differentials taken on the bearing ring and the distances taped from the bearing ring cutouts to the platen were recorded and later used for fitting and leveling up the assembly to the bottom tube sheet. The assembly was then released for fitting to the botton tube sheet assembly.

h. Orlentation and Fit-up of Kain Tank and Enclosure to Bottom Tube Shoet

The bottoin tube sheet assembiy was leveled nithin 0.008 using the Wild UIII precision level and lighted target. (See pait III-IIJ) Sketch II 5 iliustrates pictorfally how this was accomplished. Next, the tank shell assembly was positioned over the bottom tube sheet and the $X$ and $I$ axes on the bearing ring expanston jolnt, and tank shell were matched to the $X$ and $Y$ axes scribed on the tank bottom nozzle assembly. (See Slsetch fI6) (See Part VII; section III, item 19). This was accomplished by rotating the main tank clocksise or counterclocksise until the two sets of axes colncided. After the two sets of axes were properly matched, the wild level was used to check the level differentials on the inside top face of the bearing ring. This was accomplished in a similar manner 111ustrated in Sketch ill. (See Section A-(I)e of this manual) Level differentials were adjusted to correspond to those discussed in sketch fl. These level differentials were adjusted by use of a spider frame nounted on the inside of the tank shell Ior vertical adjustment, After Ievel differential readings were closely duplicated, the expansion joint was considered to be in an unstrained condition. Then the distance from the 12 bearing ring cutouts to the bottom edge of the tank shell (where fileld weld was to be made) iras measured using a 501 s/S tape graduated in 1/16". (See Sketch 116). To these measurements allowance for weld shrinkage and root opening were added to obtuin the drawing diviension. The tank sholl was then scribed around the circunference using a scribe and surface gage "riding" on the tank bottom nozzle assembly where the fleld butt weld was to be made. The botton edge of the main tank was then chipped to layout and the two assenblies batted together. Next, the $X$ and $Y$ axes located on the bearing ring were lined up with tho $X$ and $Y$ azes scribed on the botton tube sheet using four plumb bobs, (one at the extremity of each axis). After adjusting the bearing ring axes to colncide with the bottom tube sheet axes, clesrance at the butt joint joining the main tank shell and tank nozzle assembly was checked using" feeler gages. Clearance betiveen the joint was found to vary: between $.000^{\prime \prime}$ and $.025^{\prime \prime}$ wich was acceptable. However, during the course of changing shifts, the four plumb bobs suspended 

from the bearing ring and coinciding with the bottom tube axes were accidentally moved, thus destroying the alimment check cotween the two assemblies. Since the verticality of the tanir shell, ifinal bearing ring level readings and overall elevation measurements had not been taken, it was decided to use the Wild $I$ theodolite for final tank alignnent operations in liev of re-establishing the location of the four plumb bobs.

The first problem was to establish bench marks (Ba) on the floor for use in aligning the Wild $M I$ theodolite on the $X$ and $Y$ axes. (See Sketch f16) To accomplish this, the theodolite was set up on the $X_{7}$ side of the assembly. Next, a mercury plumb bob, suspended on a piece of piano wire, was passed thru a large tube on the $X_{2}$ side of the unit and aligned to the $X$ axis. The instruments line of sight was adjusted to line up with the piano wire and scribed $X$ axis line on the wrapper.plates (PT. "A") The theodolites line of sight now coincided with the botton tube sheet's "X" axis. $B M_{1}$ and $\mathrm{KH}_{2}$ were then established on the $\mathrm{X}_{2}$ side of the unit in the floor as shown in Sketch $\mathrm{HI}_{1} 6 . \mathrm{BM}_{3}$ and $\mathrm{BLf}_{4}$ were established in a similar manner. The theodolite wes moved to the $Y_{2}$ side of the assenbly and the above procedure repeated. (For detail use of the Wild TI theodolite, see part III-II K). As shown in Sketch 176, the theodolite was returmed to the ${ }_{n}$ side of the unit, "walked in" on ER3, ERL, and PT "An. Then the velticality of the scribed $E$ on the enclosure, scribed $E$ on tank and scribed $\ell$ on the nozzle assembly were checked for vertical alignment by sishting thru the instrument. This procedure was repeated on the three other ares, orienting the tank assembly where necessary, urtil nll centerlines were plumb and coincided with each other. After this, the bearing ring was ajain checked at the twelve bearing pad cutouts using the kild NIII IEvel and lighted target in a manner previously described in this section. Finally, measurements were again taken at $\mathrm{H} 3, \mathrm{H} 2$ and $\mathrm{HI}$ (sketch 176 ) using a 50 ' S/S tape graduated in I/16". All measurements were vithin drawing tolerance and accepted. This completed all measurements taken curing and after lofting in of the main tank assembly to the bottom tube sheet. The main tank assembly was removed from the bottom tube sheet and made ready for shipping to the plant site.

B. "pn Unit

(1) Main Tank

a. Plate Inspection, Fabrication and X-ray

The fabrication, machining and inspection of the "Pn main tank shell was similar to that discussed in section $A(1)-a$ of this manual, except as follows:

$[I]$ Plate Arrangement and Fabrication Sequence

The main tank shell was fabricated from four $\frac{1}{2}$ thick type 304 stainless steel plates. For fabrication sequence, see D.g. 6-6 presented herewith. 

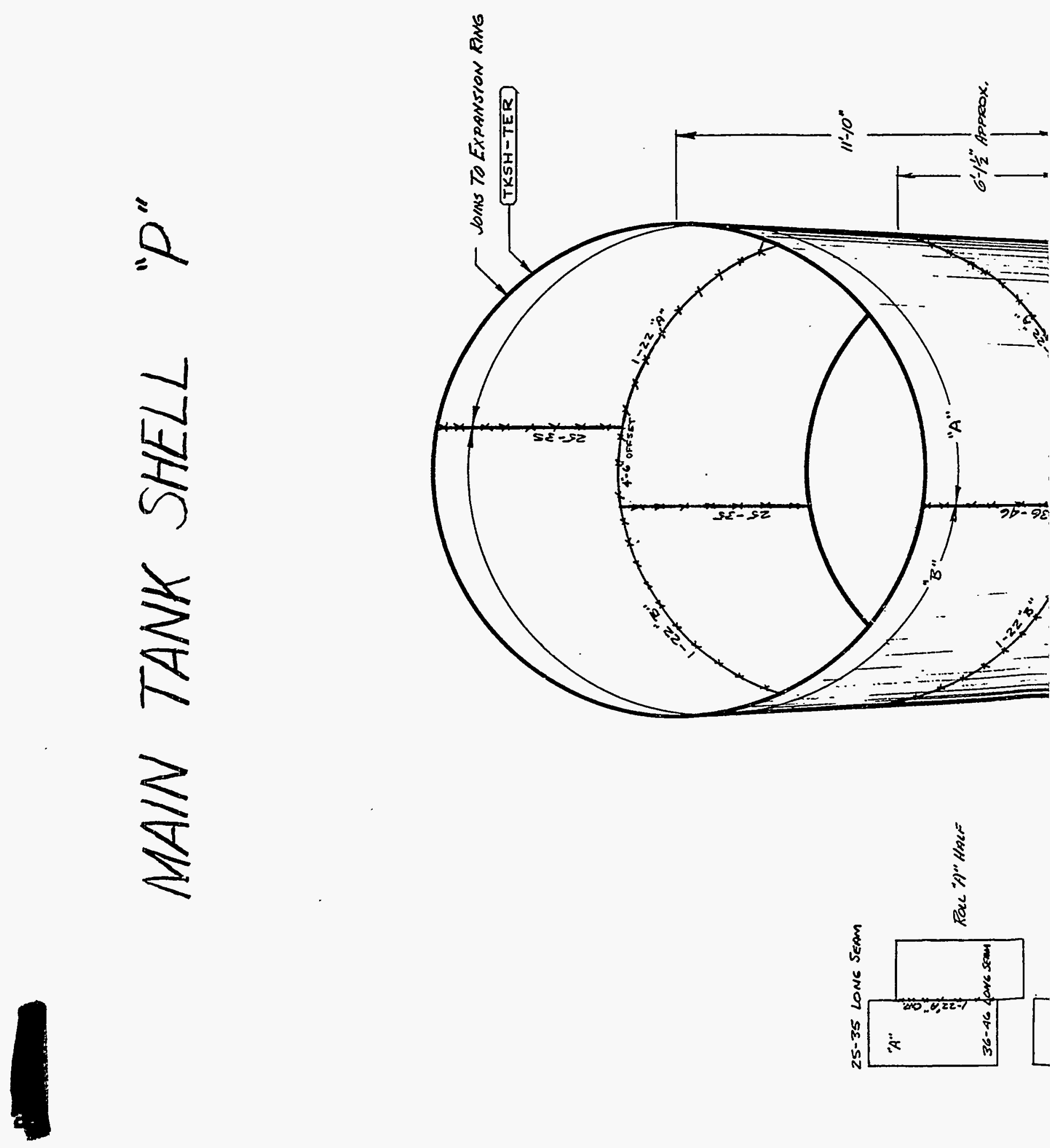
5

N

ई

th

10 แ

जै है

娄
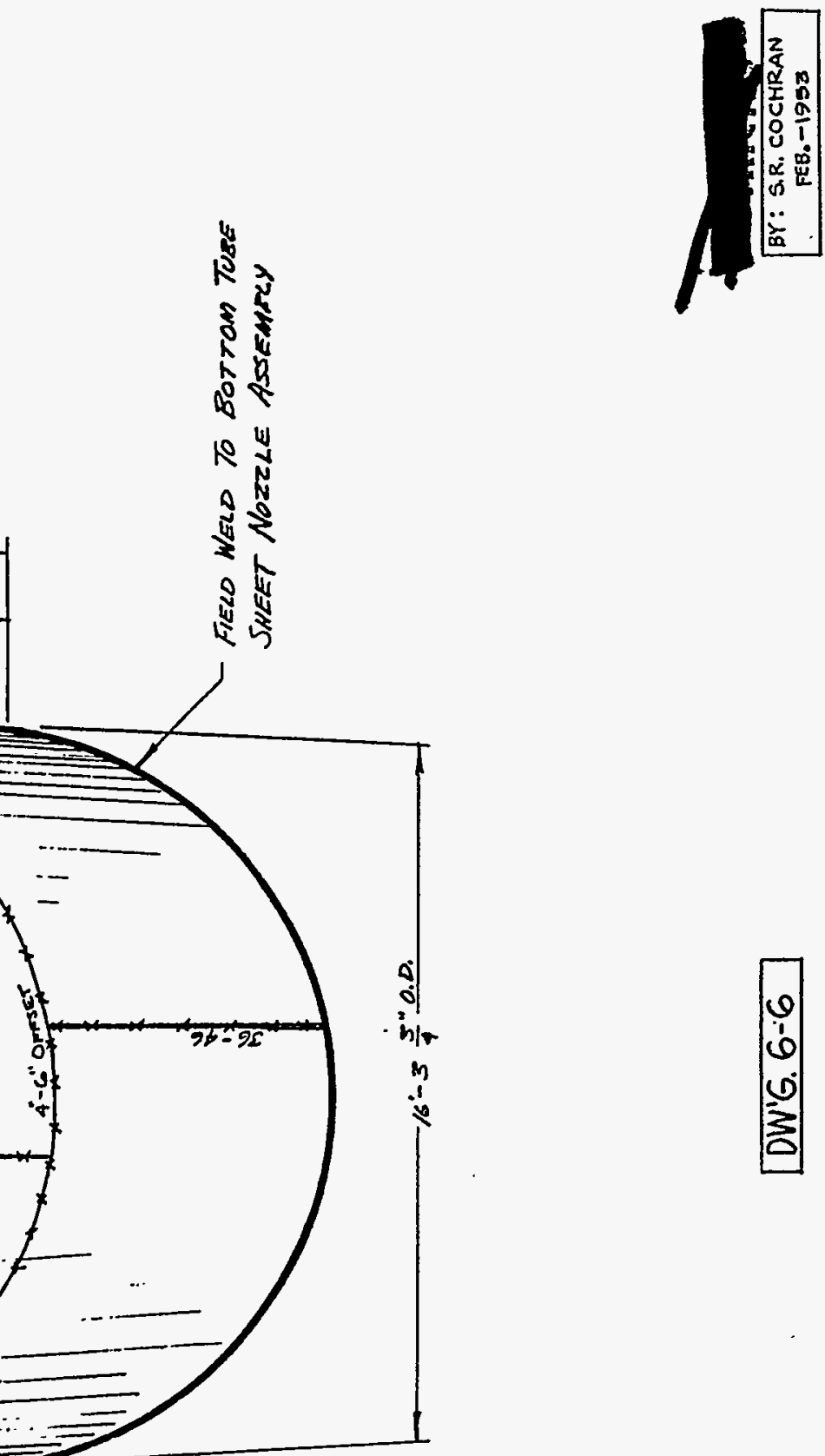

\begin{tabular}{l}
0 \\
1 \\
0 \\
0 \\
\hdashline \\
\hdashline
\end{tabular}
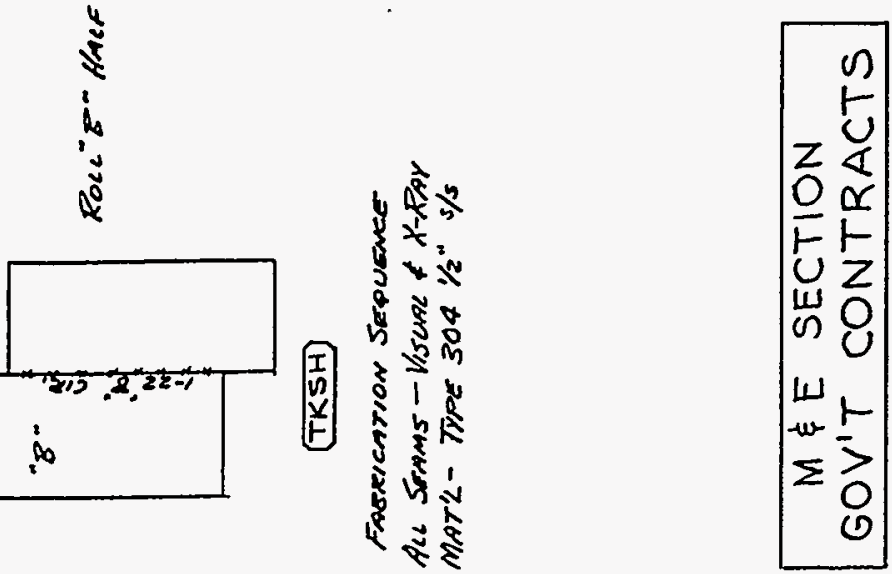


\section{[2] Radiograph Inspections}

It was discorered by the du Pont Inspection Department that New York Ship $x$-rayed butt welded joints in "R" tank shell's two half-sections before folling the plates to form the tank. These radiographs were pressnted to du Pont as final pictures. Since $x$-raying butt welded joints in the flat and before rolling did not represent the final condition of welding, and in addition, did comform to U-68 code requirements, it was requested that all final $x$-raying be done after the tank half-section plates were rolled and butt welded together to fom the main tank shell.

Fexiork Ship complied with the above request and $x$-rayed all "P" tank welciing after the shell had been fabricated. This change in $x$-ray technique was immediately incorporated into the tank fabrication procedure for "L", "K" and "C" Units.

b. Wank out-or-Roundness

Same as Section A (1)-b of this manual.

c. Inspections After Grinding and Acid Washing

Same as section $A(I)-c$ of this manual.

(2) Inspection of Bearing Ring, Expension Joint, and Top Tube Sheet Enclosure

a. Eearing Ring

Fabrication, machining and inspection of the npt bearing ring was performed in a similar manner to that described in section $A(2)-a$ of this manual. No major problems were encountered at this stage of fabrication.

b. Tank lixpansion Joint and Welding to Bearing Ring

Pabrication, machining and inspection of the "p" tank expansion joint and welding it to the bearing ring was performed in a similar manner to that described in section $A(2)-b$ of this manual. No major problems were encountered at this stage of fabrication.

c. Final Kiachining of Tank Expansion Joint and Eearing Ring

This machining operation and the inspections performed were similar to that discussed in section $A(2)-C$ of this manual. Ho major problems were encountered at this stage of fabrication.

d. Fabrication and Inspection of Top Tube Sheet Enclosure

All inspections performed during and after fabricating and machining the top tube sheet enclosure were similar to that discussed in Section $A(2)$-d of this manual, except as follows: Design Division 
requested that the following inspections be performed on the "p" top tube sheet enclosure and on all sub-assemblies of the "K", "L," and "C" units.

1 Apply zy-glo or dy-chek inspection to all important weld seams which cannot be $x$-rayed or pressure tested. Design classified all important welds whose failure would p rmit leakage and those subjected to possible hydraulic vibiration. Typleal of those welds not requiring $z y-g l o$ or dy-cheking are welds attaching external motion measurement pads.

2 Grind smooth all welds exposed to the process muids. This is desired to help maintain cleanliness standards and to aid inspection of welds. This does not mean that all such welds must be ground flush with the surface. In all cases care must be exercised to avoid "thinning" the metal on each side of the weld.

The above several inspection speciflcations were added to obtain further assurance of weld soundness in the fabricated units.

Dwg. 6-2 presented in section A(2)-d of this manual pictorially iiiustrates where $\mathrm{Zy}$-glo or Dy-cheking was performed on the "P" top tube sheet enclosure. Exhibit \#IE presented herewith covers the the results of this inspection along with other visual, $x$-ray and miscellaneous inspections performed on the "P" unit tank assembly prior to shipping.

e. Welding of Top Tube Sheet Enclosure to Bearing Ring and Expansion Joint Assembly

The welding of the top tube sheet enclosure to bearing ring and expansion joint assembly was done in a similar manner to that described in section A(2)-e of this manual. Ho major problems were encountered at this atage of fabrication.

f. Machining of Seal Fing

The machining of the top tube sheet's seal ring was done in a similar manner to that described in section $A(2)-f$ of this manual. No major problems were encountered at this stage of fabrication.

g. Fitting and Velding of Expansion Joint to Kain Tank Shell

This operation was performed in a similar manner to that described in section $A(2)-g$ of $t$ iis manual. Inspection concurrent and after welding of the expansion joint to the main tank shell was also similar to those discussed in the above referenced section. Exhibit $/ 19$ presented herewith summarizes the dimensions taken on this assembly which affect field assembly at the construction site. 


\section{EXHIBIT 428}

VISUAL, $X$-RAY AND DY-CHEX INSPECTION OF AIL VELLS ON THE "PN UNIT TAMK ASSEMBLT 
E. Ic DU PONT DE NENOURS \& $\mathrm{CO}$. INC。 Construction Division

(i)

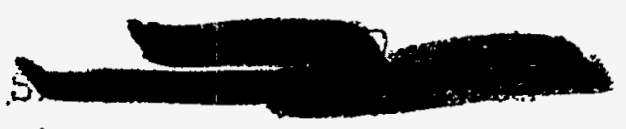

Report Number 392-P

CC: HoW. Gosney, F.P.H.

$R_{0} K_{0}$ Mason=K。R. Leifermann Savannah River Plant (3)

$H_{0} I_{0}$ Bunker $\approx J_{0} G$ G Brewer

$J_{0} G_{0}$ Brewer

H. B. Gage

F。 Co Breuninger

S。R。 Cochran (2)

$J_{0}$ Bo johnson = File

$\mathrm{R}$. H. Potts

January $19,2.953$

Nev York ship - Cainden, No Jo

tid

FIELD IHSPECTOR'S REFORT

TO

$C_{0} J_{0}$ VEITH (2)

FROM

H. E. Dills

DATE January 10,1953

PROJECT 8980 PLANE Sayannah River

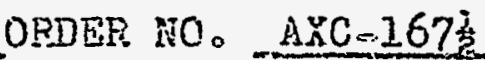

EQUIPRAENT Tanit Assembly $E Q . P C \cdot N O$ 。 $250=9$

DRAWING NOS. $40131542=H-131543$ JOB RATIPG

C ENDOR New York Shipoullding Corporation LOCATION

Camden, No Jo

Thi3 report covers the visual, $\mathrm{x}$ ray and dy-cheli inspection of all welds on the "P" Unit Tank Assembly which.includes the Top Tube Sheet Enclosure, Bearing Ring, Expansion Ring, and Tenk Shell. This inspection was conpleted and the assenbly tas shipped unfinished on January 15,1953 at the request of Construction Division Hanagenent.

All welds were visually inspected for soundness, undercuis, everi crown contour on the outstab of $1 / 2^{78}$ material and slush with parent metal

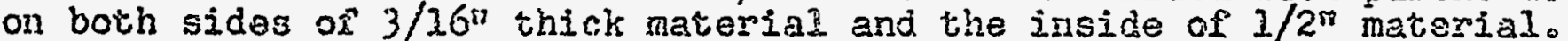

All inside welds that are subjected to prassure and are not rorrayed were inspected ror superee defects such as ciocks, pin holes, etc. by using the dyochek inethod. This dyochek method consists of the following steps:

(1) A red dye is applied to the surfsce of weld which penetrates any cracks or holes that are in the weld.

(2) Dya is cleaned of leaving a deposit uf dye in any cracks or holes in the weld.

(3) Appiy a white developer to the cleaned suriace and allow it to dry. Any defects will then show up through this white developer as red Ines or spots. A few defects were found, repzirec and rechecked. These welds were ther accepled as sound and $f^{\prime}$ ree of surface defects. 
Al] butt welds, both vertical and circumferential. were jwayed according to the AoSoH.E. Boiler Code for 1949, PE2, U.68. These $\mathrm{X}$-rays were examined for defects and found aceeptable with the exception of the three circumferencial and sixteen $(36)$ vertical seams on the expansion ring. There are a total of sixty $(60)$ filns on the expansiori ring that require weld repair. In all cases defocts consist of a single spor or several spots per film.

The defects on these sixty $(50)$ ilims were cifcled with ink and also conments were witten for each film. Thase defectis were located on the expansion ring and marked on the outside surface mith prussian blue. Surface defects were circled while aubsurface defects vere marked with a solfd line. The defects in the expansion ring to tank sheli seam and films 40-4.1, $10-11,11-12,940 X$, and $75-76$ on the other seans are not located or marked on the expensiori ring surface dus to the fact that repajrs were made just prior to sinpping and the filins were not availabie for erasination until. aster the assembly had been loaded for shipment. For further information concerning keld identivicetion and defects see atsachmers.

Films covering expansion ring, bearing wing extenston to top tube sherti enclosure, and exparision rine to tank will be brought to the Savannah River Project along with coment sheets by a representative of ithe $\mathrm{M} \& \mathrm{E}$ Section. He will assist in the location of defocts and secting of the tank。

After the expansion ring was assembled, suriace fissures were dis

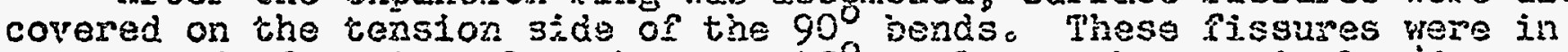
groups and of varjous lengths at a $45^{\circ}$ angls to the veroical and wer'e approxtinately $005 \pi$ deep. These fissures were renoyed by polishing the surface with 50 and 150 grite exery paper. The condition mas examined by $J_{0} A_{0}$ Colilins, jo $\hat{G}_{0}$ Eretraz and $j_{c} B_{0}$ Johnson and considered ecceptable.

The distortion in the exparsion wing, particulerly at tire yertical

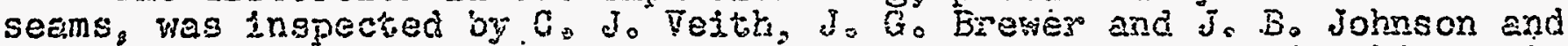
accepted. This distortion took place during the rocess of tield repalr. It is of graduel contour and blencs whis the orighing expansion ring contour leaving no sharp corsers. To remove this distorion would have meant additional cold woriking of tre meterial accompanied by stretchirg anci thinnirg of the utetel.

A separate report wil be issued describing thiskness check of expangion ring by the Augi - Gage Methoc.

\footnotetext{
Imw

Cattach。
} 
$\because)$

Number or No. of films No. of films

Welä Seam

Identification

films accepted rejected

Top Tube Sheet

TTSE-3

Enclosure vertical 1 thru 6

6

6

0

Top Tube Sheet

TTSR3-BR3

Enclosure to bearo

1. thru 51

51

52

0

ing ring exiension

Large Hozzles

AII Welds

Small Nozzles

A1l Welds

Seal Ring

Sogmental Seams

Bearing Ring

Segraental Seams

hain Tani Shell

Circumferential

Main Tank ShelI

Vertical

Bearing Ring

Extension Vertical

Expanston Ring

Top Circumferential i-lis

Expansion Ring Bottom

C.ircumserential
RRE?

$3=\pi$
$3 \rightarrow \pi$

TTSENLL 01
TTSERL3
TTSENI2

TTSENS

TESR3

1 thru 6

$\mathrm{BR} 3$

1 thru 6

TKSH3A 11022

THSH3B $1=22$

TISH3

$25=4.6$

TPR 3
IDL.
TER?

$49-92$
13

13

26

26

0

6

6

6

6

0

44

22

22

0

3

3

0

48

27

23

ss

27

37 
O

Number of No. of films Noo of films Held Sean Identification films accopsod jojected

Expansion Ring
Verticals
Top Section
Center Section

TER3

$4^{-}$

2

2

$930 \mathrm{z}, 94 . \mathrm{X}_{8}$

$95 \rightarrow X^{2} \& 96-\bar{X}$

TER3

6

0

6

$1030 \mathrm{X}, 1.04 \times \mathrm{X}$ $1050 \times, 206=x$ $107-X \& 208-X$

Botton Section TER3

\section{6}

5

1.

These appear only on circumferential boston sean film

Expension Ring to Tank Shelı

TRSH3-TER 3

44

31

13

1 thru 44 


\section{EXHIBIT \#19}

SUMLARY OF DIREISIOHS MEASURED ON THE "P" UNIT PLENOR CILASBER, TOP TUBE SHEET, BOTTOY TUBE SHEET AHD NAIIS TANK ASSEMBLY 
E. I. DU FONT DE NEMOURS \&. CO, INO. Construction Division

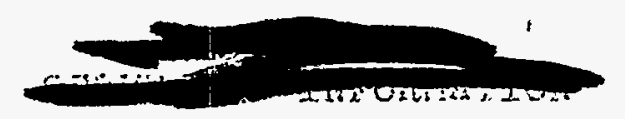

$p^{2}$
Report. Number $482=P$

CC: Ho Wo Gosney, FoP.M.

$\mathrm{R}$. $\mathrm{X}$. hasor $\mathrm{D}$. A. Hauser Savannah River Plant (3)

$R$. K. Mason - E.M.Vassi SRP

$H_{0} I_{0}$ Bunker \& $J_{0} G_{0}$ Brewer

J. G. Brewer

H. B。 Gage

F. C. Breuninger

S. R. Cochran (2)

R。 H。 Bart,o $=$ INYS (3)

Apri1 27, 1953

New York Ship - Camoien, NoJ。

\section{FIELD INSPECTOR'S REPORT}

TO C. J. VEITH $=M \& E$ EILE

FROM S. $R_{0}$ Cochran DATE january 16,1953

PROJECT NO 8980 PLANT Savannah River

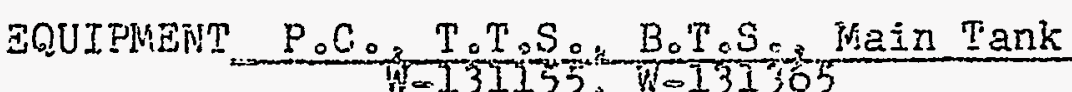
DRANTNG NOS. $W-131395, W=1.31543$ ORDEF HO: $A X C=167$ ? $155 \%, 154$, EQ.PC。HO。 $1539,150 \%$ JOB RATING

C TERDOR hew York Shipbuilding Corp. LOCATION Camcien, Ho do

This report summarizes dimensions measured on subject equipment which affect field assemb?y at construction site.

Irspections were made by du Font inspecion dum various phases of fabrication at vendor"s plant.

Most of the inspections listed herein are covered by previous field inspection reports: therepun numberous references will be noted. (This is to enable one to obtein more speeific details as to procedura and ruethod of inspection if recessity warrants such actions!

A. FJenum Chamber isee skstoch $/ i$ !

1. Langth of tubes

a. Dimension: hì

b. Number of meăsurements made:

Thirtyone on tubes on outer periphery of tube srea.

$c$ : Measurements ware nade by I. Ho Mergenthajer on $12=10=52$ using $24^{\text {th }}$ verrier caligers. 


\section{FROM S.R。 Cochran}

2. Distance from bottom edge of hood to bottom race of tubes.

a. Dimension: $\mathrm{h}_{2}$

b. Number of measurements made:

Eight $-\mathrm{lat}_{1}, \mathrm{X}_{2}, \mathrm{Y}_{1}, \mathrm{Y}_{2}$ and at diameters $45^{\circ} \mathrm{CW}$ \& $\mathrm{CCN}$ from $x$ axis

co Measurements were made on $12 / 5 / 52$ by. Lo W. Mergenthaler.

3. Outside diameter or botton edge of hood.

a. Dimension: $n_{4}$

$\mathrm{b}$. This weasuremènt will be made at a later date as present stage of fabrication will not permit this measurements. Refer to zeoort numbar is $5 \mathrm{I}$. 9 .)

B. Top Tubo shet (see sketch \#i)

1. Distance from botrom edge of bearsing pads to top race of tubes.

a. Dimension: $\mathrm{h}_{3}$

b. Number of measurenents made:

C

One at each bearing pad.

c. Reference Report Wumber 2014:F

2. Outside disanters of top tube sheet

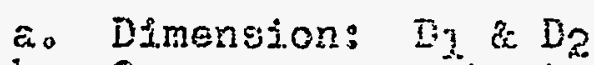

b. One msasuremont at each devation made. Diameters were celculated from circumsersence measuremenis.

co Heasurenchts veine made on $2 / 9 / 53$, by D. Jo Snathers using a

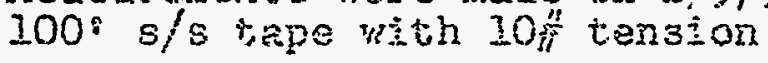

Note: Actukl diameter moasurements to detcmine out $=0$-roundness,

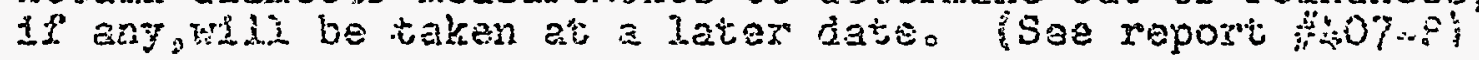

3. Outside dianoters at top edge of ifiting lives.

2. Dimengion: D3

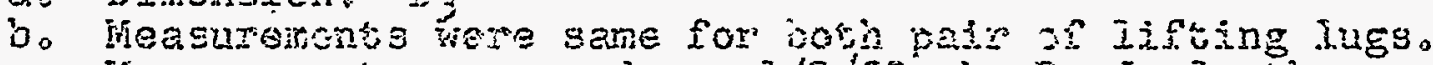

co Measurement wea $100^{\mathrm{s}} \mathrm{s} / \mathrm{s}$ tape wis lof teneion。 
C. Boctom Tube Sheet (see sketch \#2)

1. Instde diameters of tank bottom nozzle assembly at field weld preparation.

8. Dimension: $D_{1}, D_{2}, D_{3}, \& D_{4}$.

b. Reference Report Numbar 320\%?

2. Outside circunference of tank botłom nozzle assembly at 2 below. field weld preparation.

a. Dimension: $C_{\text {I }}$

b. Reference Report Number 352-P

3. Distance from top face of tubes to top edge of field veld preparacion.

2. Dimension: hy

bo. Twelve neasurements were made as shown

co Reference Report Humber 34TaP

4o Distance from ooctiom surface of bearing pad to top face of subes.

a. Dimension: h2

b. Twelte measurements made as shown

c. Reference Reqort Number 1950P

5. Length of tubes

a. Dimension: $h_{3}$

b. Raforence Report kumber $195 \times \mathrm{P}$

D. Main Tank (soe skeicin \#3)

1. Distance from seal surface of saal xing to top surface of bearing ring.

a. Dimension: $h_{1}$

b. Reierence Reporic itumber 397-P

2. Inside diameters and outside cizcumference of Main Tank bottom section

2. Dimenston: $D_{1} D_{2}, D_{38}$ \& $C_{1}$

b. Reference Report Number $34 I=$ ? 
( $\therefore$ Main Tank - Top Secrion (see sketch 能)

3. Various diameters

2. Reîerence report number 396 co

F. Main Tank o Botton Section (see sketch \#5)

I. Various elevations

2. Ref $\in$ rence report number $398 \% P$

$1 \mathrm{mw}$

atrach。 5

O 


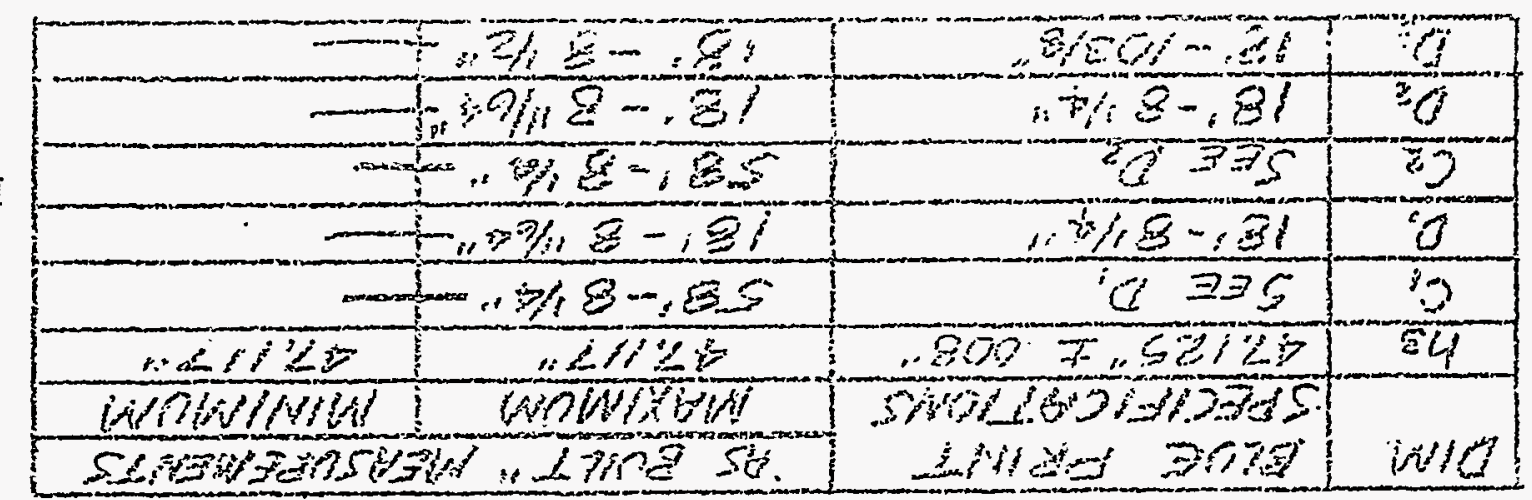

sont sens arbs

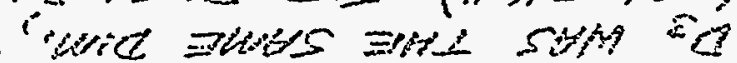
ดว

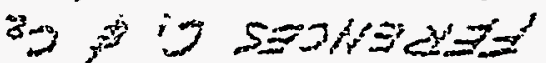

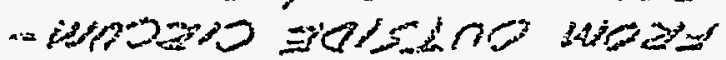

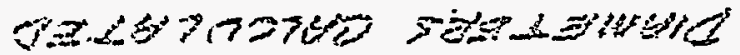

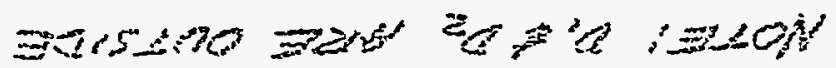

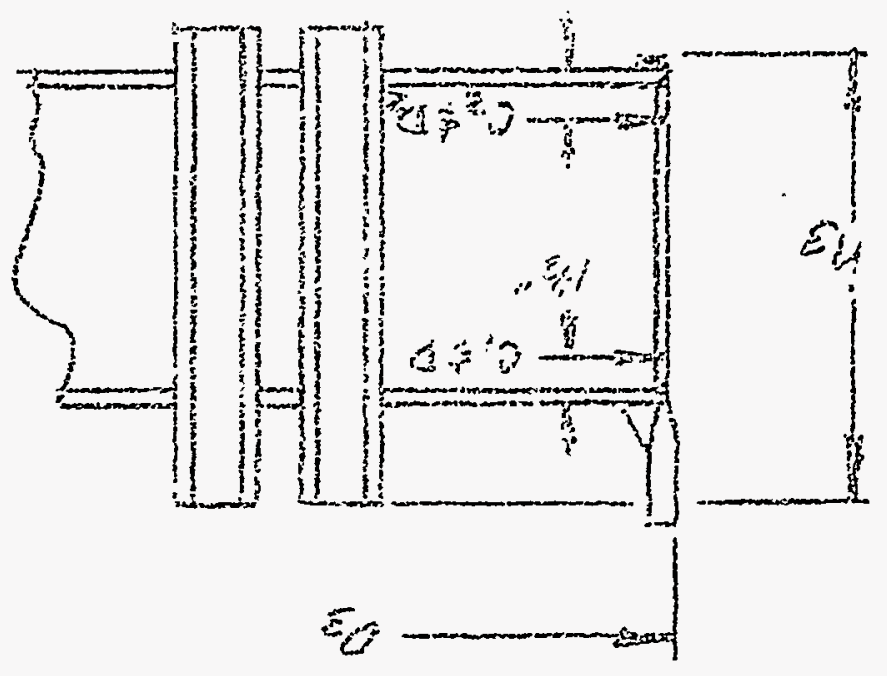

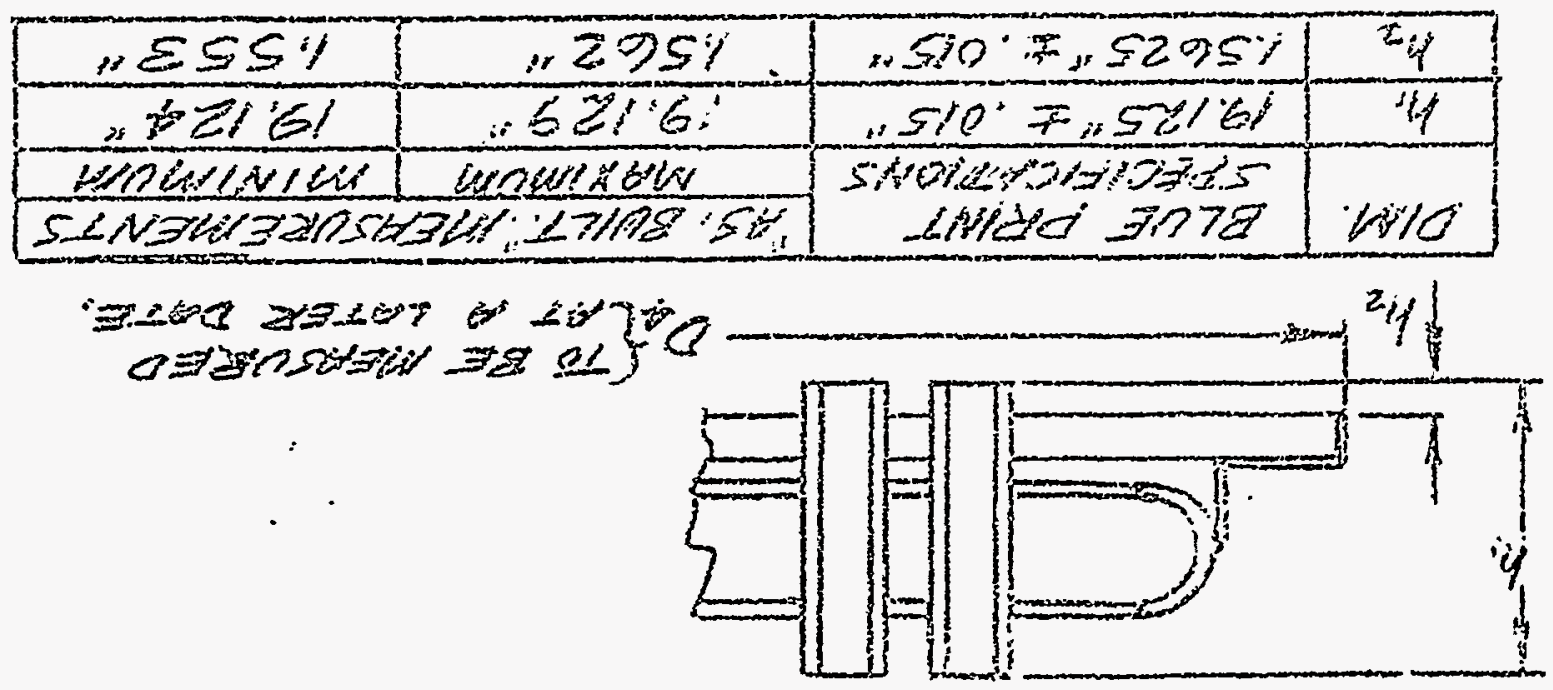

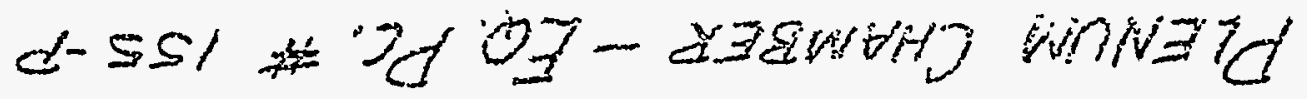




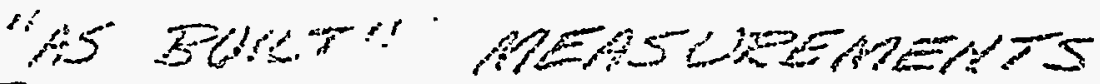

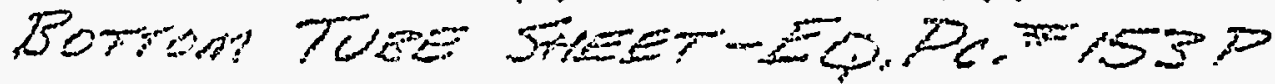

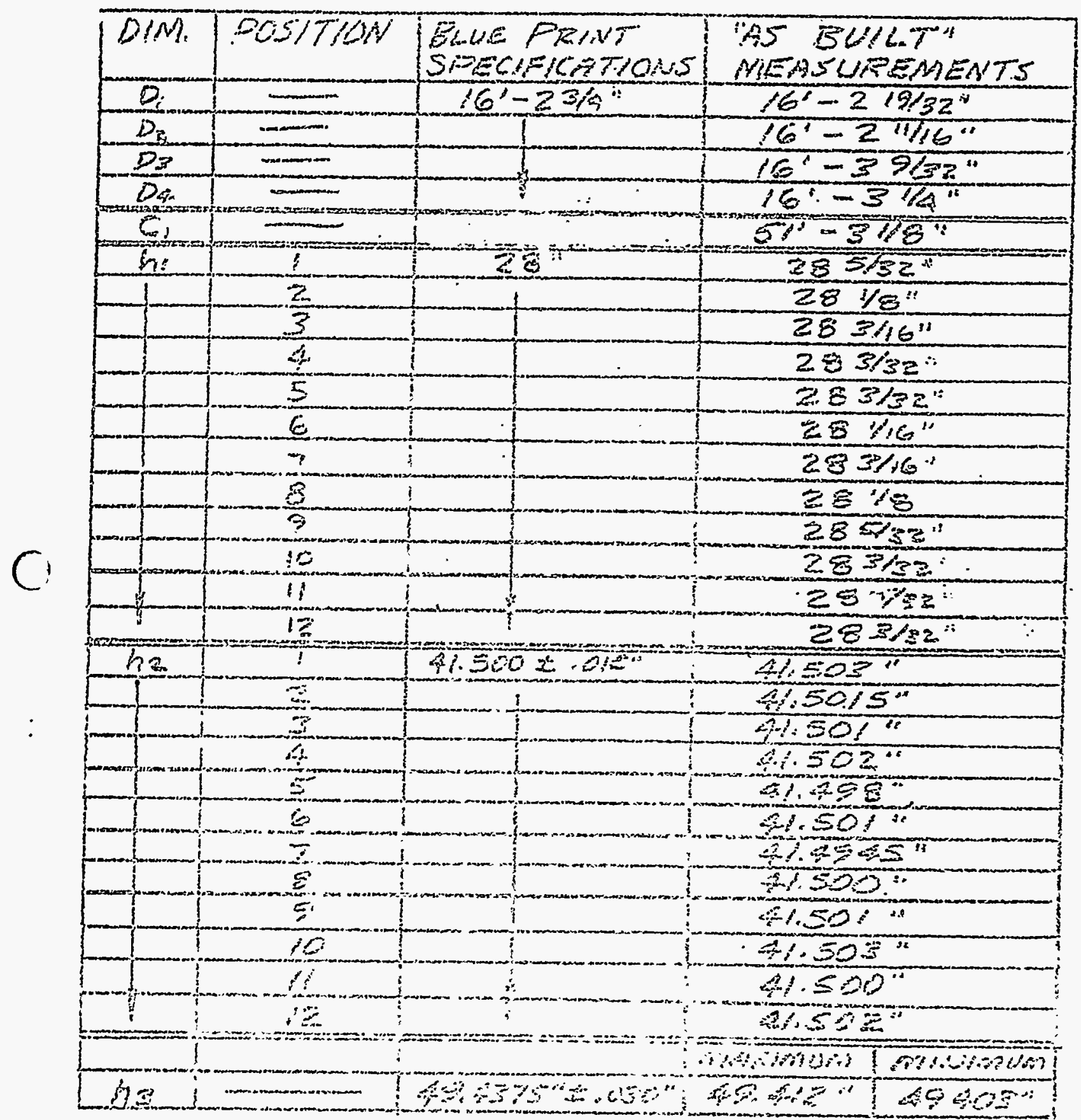

5 WEDES:

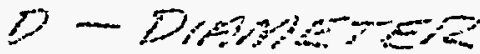

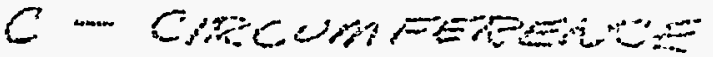

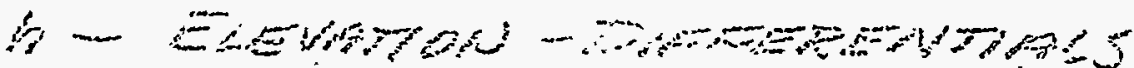




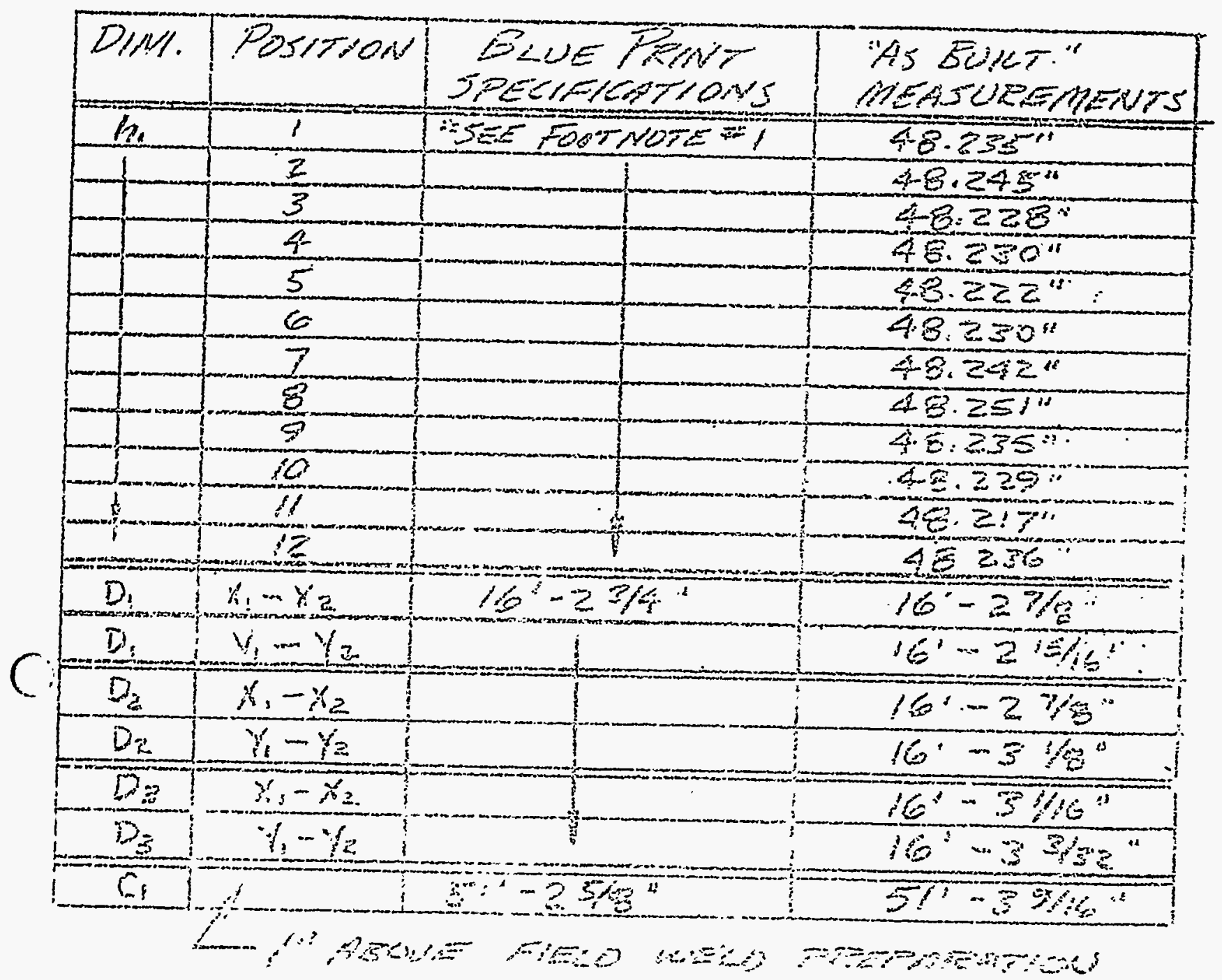

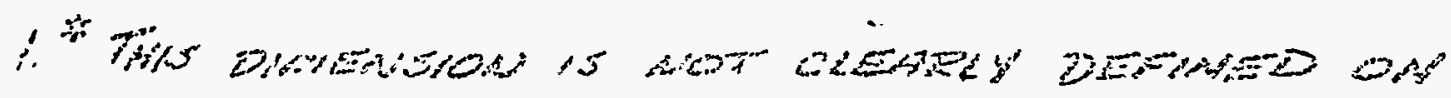

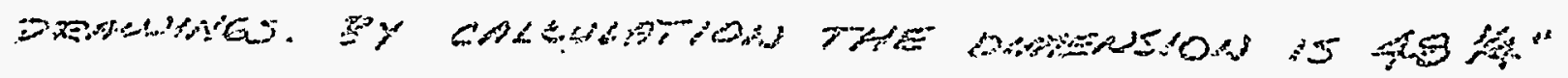



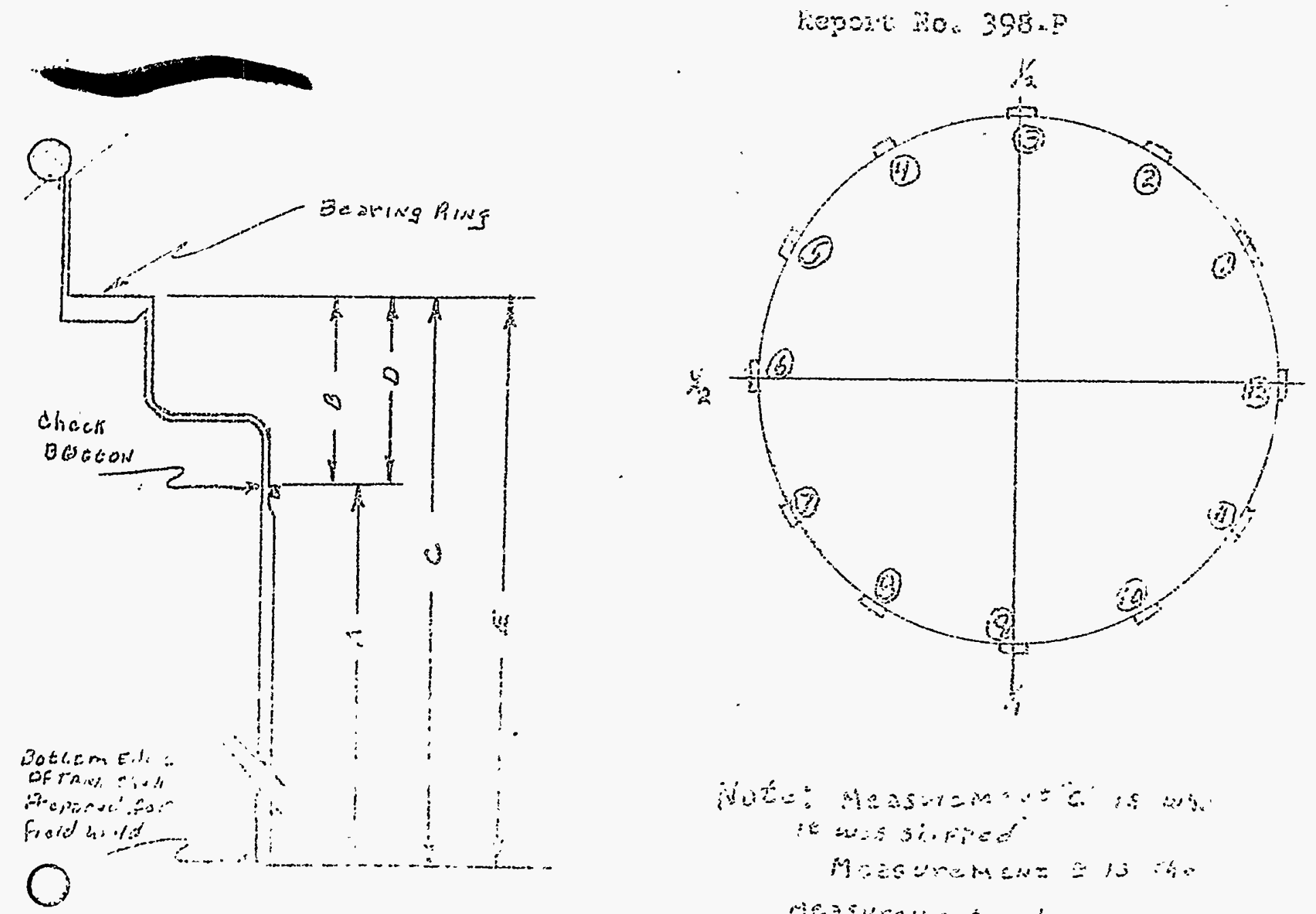

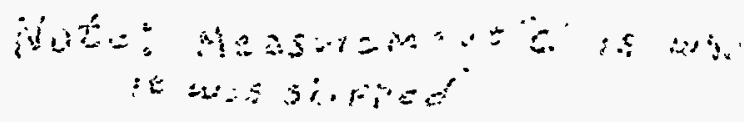

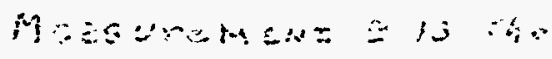

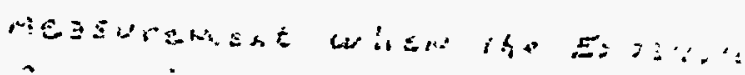
A a

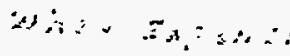
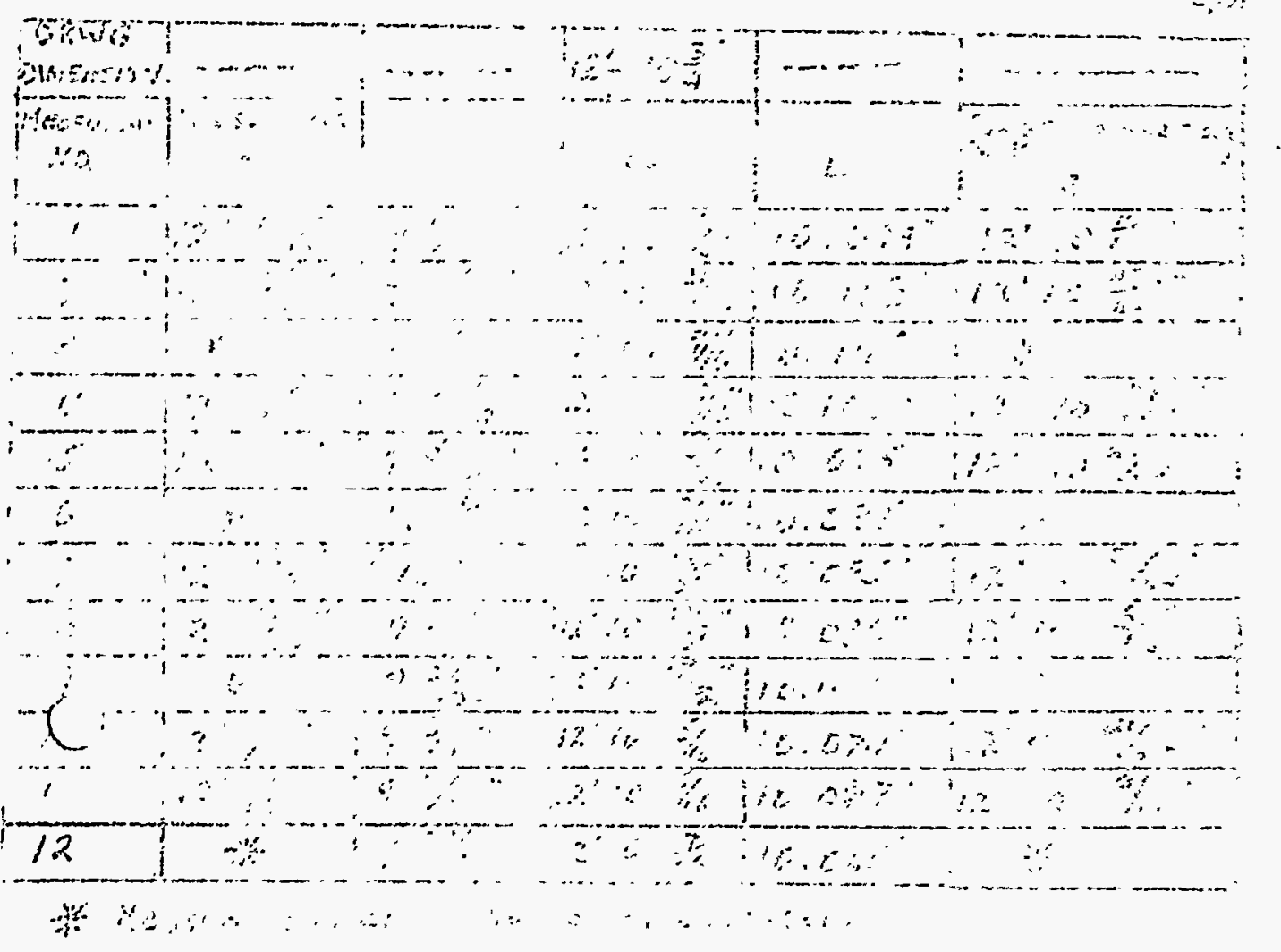


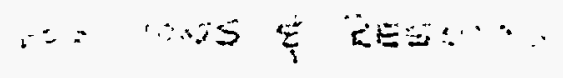

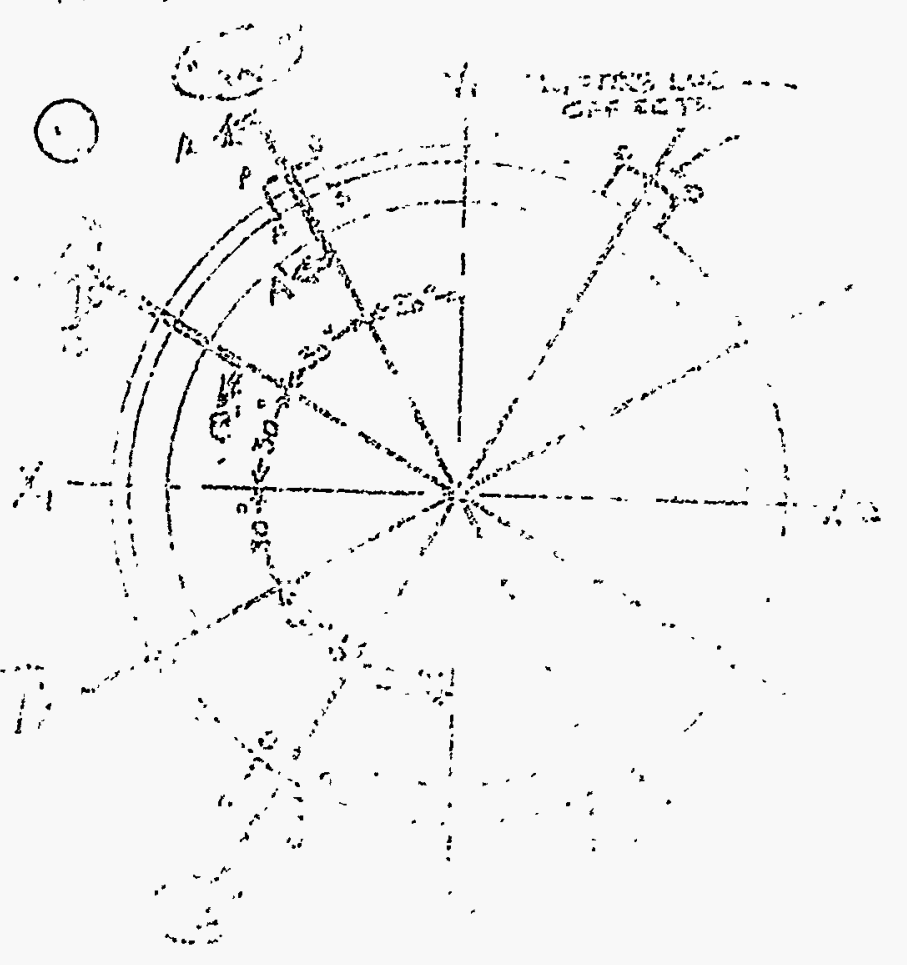

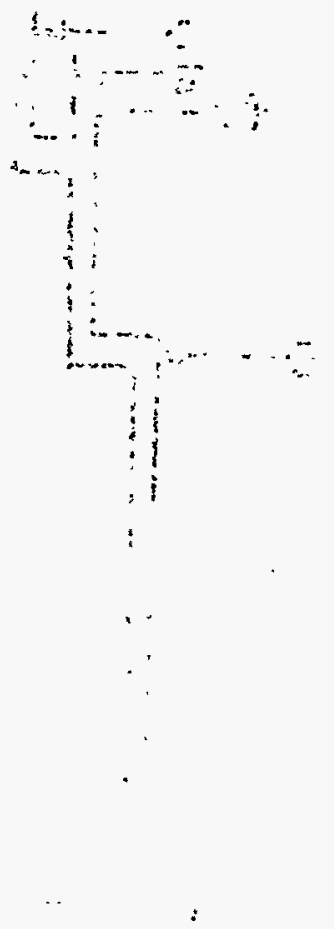

$\therefore \quad \therefore \because \therefore \quad \therefore \quad \therefore \quad \therefore \quad \therefore \quad \therefore$

$\therefore$ apde

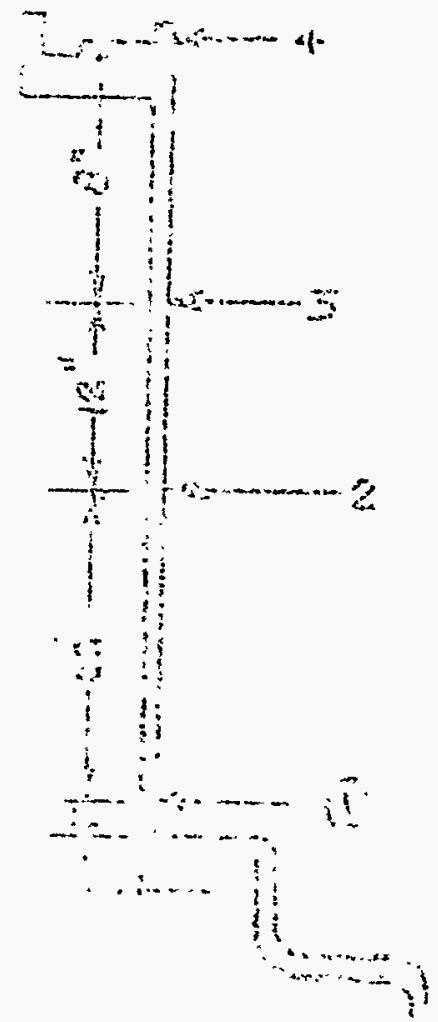

C;

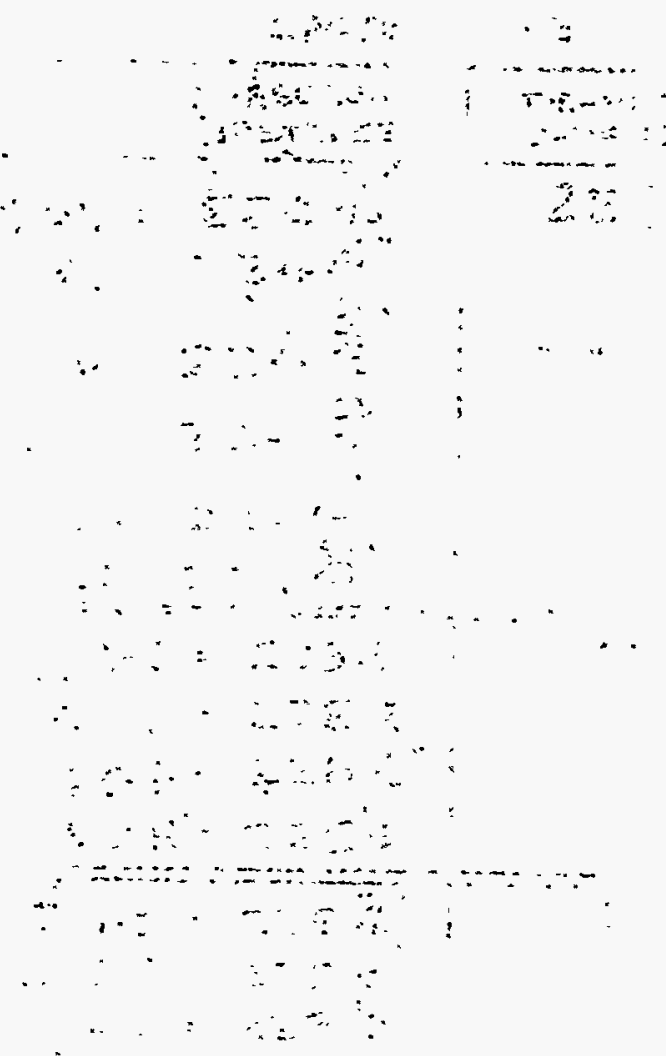

( 
h. Problems and Difficulties Encountered on the "pn fain Tank Assembiy

During the final stages of fabricating and inspecting the "p" main tank assembly, field complaints were received pertaining to defects in "R" Unit's expansion joint. As a result of field difficulties, the $x$-ray technique and fabrication methods used on the "p" main tank were re-studied and in several cases improved

A chronological discussion of the field complaints and correctifo action taken at $\mathrm{Hew}$ York Ship appears in the following paragraphs.

A report from the field stated that the "Rn Unit's expansion joint had seven (7) small cracks in parent metal perpendicular.to upper Eirth veld on the expansion joint itself. During the field hydrostatic test, two (2) of these seven (7) cracks leaked, The defects in the expansion joint were evident after re-examination of the radiographs; however, they were originaliy interpreted by dit Pont inspection rersonnel at New York ship as lead marks and accepted Further investigation by the du Pont Inspection Department lead the to belleve that these cracks were caused from the forming dies used to fabricate the sepnents of the expansion joint. The foring ais used to form the "R" and "p" expansion joints had originaijy beentised to fabricate the KIYX expansion joint. The original die (for HXX)

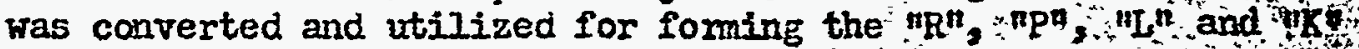
expansion joint segments; however, in order to use the or ighnal expansion joint dies, a skixt plate had to be removed The skikt plate was cut off, but New York Ship didn't fill in depressfons on the edges and smootin in the working segment areas on the dies When the expansion joint segments for "R" were foried, it "was postuifaited that these rough edges in the skirt plate caused cracks fordid in the expansion jointi parent metal perpendicular to the uppe glinth weld durins the process of hamering (cold) the expansion joint is shape.

As a result of the above field complaint, the following steps were taken by the du Pont Inspection Department to alleviate the re-occurrence of the above problem on "L" and "K" unit expansfon and to apply these steps wherever possible to the "p" main tank before shipping to the field.

[I] The expansion joint forming dies were completely resortipd by filling in all cepressions in the sklrt plate pnd grind ing all sharp comers to a smooth contour. The divs ivero

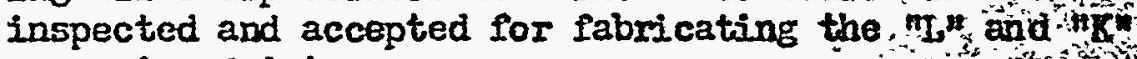
expansion joints.

[2] Fine grain x-ray filn was substituted for coarse grain ofitits

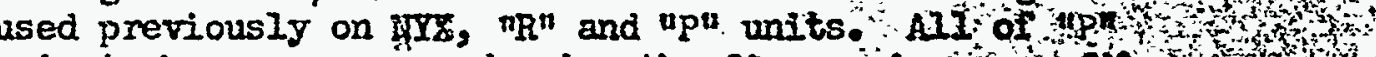
main tank was rem-rayed using the fine grain xray. Plifint

[3] A new $x$-ray film reading procedure established for tiph tant

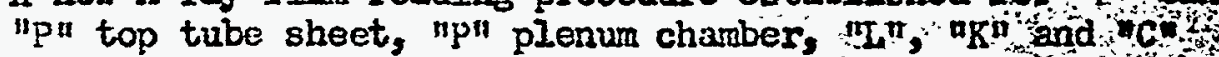
units. The $x$-ray film reading procedure was as follófs 
(a) $\Lambda 11$ welds must be inspected visually prior to $x$-ray for defects and surface condition, and repairs made. This produces better pictures and saves $x$-ray time and film.

(b) Filn too dark for adequate vision on viewer must be examined on the intensifier. Film too light for interpretation must be retaken.

(c) Look at entire film-not just weld area-you are looking for defects in parent metal, too.

(d) Take advantage of film overlap on consecutive pictures and film overlap at joint intersections for identical images; this may help separate $x$-ray technique defects from work defects.

(e) Images Resulting from Condition of Work:

1. Porosity

6. Incomplete penetration

2. 5 lag inclusions or tungsten inclusions 7. Grinder or chipplng

3. Undercuts

4. Cracks

5. Lack of fusion

8. Excessive weld crown

9. Thinning of base metal

10. Weld splatter

(f) Junages Resulting from $X-r a y$ Technique:

1. Scratches \& abrasions

2. Water marks

3. Color contrast

4. Static marks

5. Penetrameter \& identification letters

6. Lead $s$ intensifying marks

(g) On those defects that cannot be interpreted, the film is taken to weld joint for location of affected area and physical examination of weld.

(h) If visual examination shows nothing, another $x$-ray is taken for comparison of one filn against the other for similar markings.

(i) Chip out and reweld if same marks appear.

(j) Chip out and reweld all defects icientified as beyond code acceptibility.

(k) Ee-x-ray repairs

(1) Reading of film and repair of defects by New York Ship is to be done before filn is presented to du Pont for final examination.

(m) All film is to be read by at least two inspectors at different times. Radiograph inspection is to be confined only to shift leaders and supervisurs.

(n) Du Pont is to examine oniy x-rays representing final condition of plate and welds (forming, grinding, etc., all done) 
(0) X-ray lederer in du Pont Inspection Department established for better control over visual examination and $x$-raying. of welding.

(D) Purchasea $x$-ray viewer and $x$-ray intensifier. $X$-ray vieuer to be first used for examining all radiographs. Suspicious defects that don't show up too clearly on $x$-ray viewer are to be reexamined on $x$-ray intensifier for final disposition.

(q) For easiex location of defects in welds that showed on $x$-ray film, holder mubers were established so that steel stencil numbers in parent metal were not covered by the holder number." This method allowed the steel numbers that were stamped in the parent metal near the weld seam that was $x$-rayed to show clearly on the film; therefore, when defects shored on the film, they could be easily located on the assembly by matching these numbers on the film to corresponding steel stenciled numbers stanped in area $x$-rayed. (See Sketch $\$ 17$ )

$[4]$ Preparation of Heided Joints Prior to $x$-ray

The following procedure for preparation of welded joints prior to $x-r a y$ was incorporated into the fabrication sequence for " "K", and "C" Units:

(a) Prelininary $X-r a y$

Where it is desirable to check welds for sajor defects prior to furtiner working such as rolling of plate assembly that has been selded Mat or expansion ring joints, etc.; preliminary $x-$ ray " . is to be made in as welded condition or with rough grind onis.

(b) Final X-ray

Flat butts - where finished joints are to be ground flush, kond line is to be removed or ground, so no bond line can be found by feeling with hand. Visual inspection to be taken for. undercut, gouge maris, grind mariss, etce, and repairs to be made. If straightening is to be done, it should be made at tilis tine. All centerpounch marks in the expansion ring are to be ground out, welded and ground flush. Exceptionally deep center punch marks in any, thickness of plate are to be repaired.

Where butts are not to be ground flush, reinforcement is to be 1/32" to 1/6", uniform and smooth. Grind high spots as required and buils up low spots. Where multiple bead finish.is used, bead: Iines are to be ground out to improve $x$-ray interpretation,

Where weld metal is too high to grind and chipping is done to Nush welds, enough metal is to be left on to insure ripped area from chipping to be ground out. 


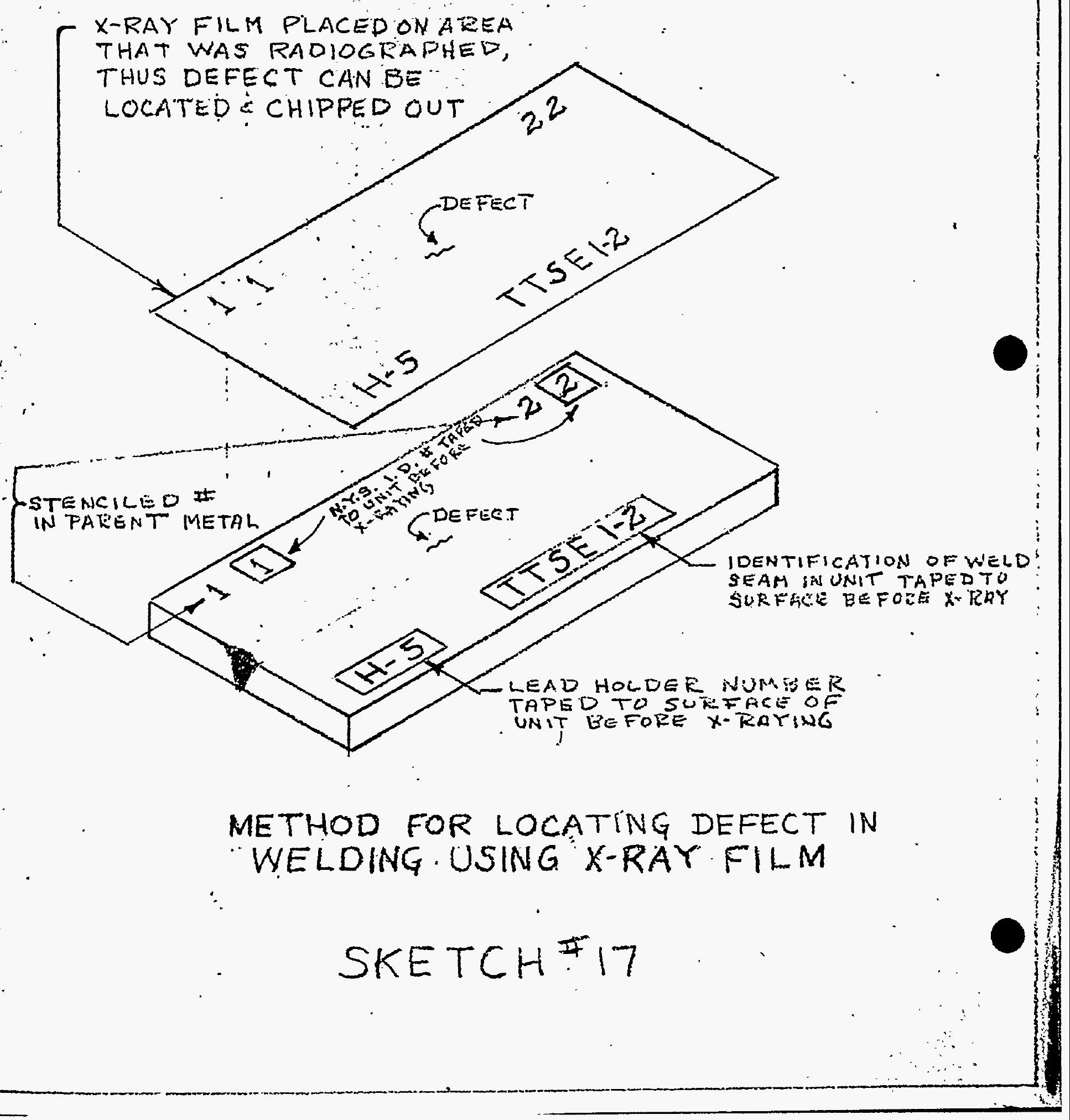


Whefe one-sided welds into backing strips are used, backing strip is to be removed (where possible) and chipped out to good clean metal, if necessary, welded and ground smoott. The side on winich the backing strip is - is to be held flush. Any differential in thickness of plates to run on opposite side.

All grinding to be done perpendicular to welded joints where possible.

"Th" or fillet welds that require $2 \mathrm{y}-\mathrm{glo}$, to be ground smooth and slightly radiused, so cross section is not smaller than designed fillet size. other fililets to have uniform contour.

Where welding is cone on irregular contours and different thickness plates, welds are to be blended to give best possible appearance.

Where possible and practical, sandblast prior to surface examination and $x$-ray. This is to de done after all repairs are made.

Unit to be $x$-rayed, to be checked by Dept. 46 fitter and welded supervision prior to release to rept. 19 for examination and $x$-ray.

When ready for final $\mathrm{x}$-ray, as determined by WYS, du. Pont inspectors to make visual examination for approval of surface.

[5] Tank Expanion Joint: Eefore flnal x-ray, grind welds Flush and polish entire joint to approximately 7 li finish. This applies to "P" and subsequent units.

[6]

Grind smooth and zy-glo or dy-chek the upper weld joining the expansion joint to the bearing ring. This applies to "p" and subsequent units.

[7] Anneal 6 segments of expansion joint after forming but before welding together. This applies only to $\mathrm{L}_{\mathrm{L}} \mathrm{n}$ and $\mathrm{nK}^{\mathrm{n}}$ units.

1. Remaining Inspections Performed on the "g" Main Tank Prior to Shippirg

As a result of the change over from coarse grain $x$-ray film to fine grain film, the entire "p" main tank assembly was re-x-rayed using fine grain $x-r a y$ film. Most of the major defects were found to exist in the expansion joint. linose in the main tank shell were minor and repaired here at New York Ship. 
After all $x$-raying was completed, surface fissures were discovered on tne tension side of the $90^{\circ}$ bends in the expansion joint. These fissures were in groups and of various lengths at a $45^{\circ}$ angle to the vertical and were approximately $0.005^{\prime \prime}$ deep. These fissures were removed by polishing the surface with 50 and 150 rit emery paper. This condition was examined after repair and accepted by members of Design Division and the du Pont Inspection Department.

After all grinding and weld repairs were completed on the expansion joint, it was decided to check tne thickness of the joint to deteraine hos much "tiinning" of the material resulted after the grinding operation. Since no mechanical method of measuring the expansion joint thickness after it had been assembled into the main tank was feasible, it was necessary to have it checked electronically using an "Audi-gage". A representative of Branson Instrunents, Inc., Stanford, Conn., was called in to perform the job.

The scope, procedure and results of this inspecition is presented herewith as Bxhibit thlo.

During the time that the surface fissures were being repaired, extensive weld repair work to the expansion joint vas under way. Inert gas shielded arc welding, $\theta_{.} g_{*}$, "Heli-are*, on the main tank and its parts were used to repair defects in welding on tinis sub-assembly. Erperience obtained during part of the repair welding on the "P" main tank expansion joint proted the superiority of coated electrode metal-arc welding for work of this kind on light gauge stainless steel.

A significant advantage of the coated electrode metal-arc metiod as used for repair velding lies in the fact that the heat input is less than imolved in "Heli-arc", hence less shrinkage and distortion occurs.

As a result of the above problem and the use of coated electrode metal-arc welcing, the Design Division granted permission to use t.lis type rod in the repair of expansion joints and in repair of tube-to-tube sheet velds.

As the shipping date of Naverber 1, 1952, for "pn bottom tube shest and "p" main tank epproached, it became apparent that "p" tanik would not be ready due to the considerable amount of welding repairs necessary on the expansion joint. Also, the "p" main tank assembly had not been "lofted in" to the "p" botton tube sheet at Hew York Ship because of the atove welding prollem. Therefore, the following decisions were made and followed to expedite the completion and shipment of the aforerentioned units to the field. 
EXHIBIT ZIO $\cdots$

EXPAISION JOINT THICKNESS IEASUREMENTS SY AJDI-GAGE WETIOD 
E。 z. DU PONT DE ITBOURS \& $\mathrm{CO}$, IISC, Regort Number 395 0 P

Consticliction Division

$i$
CC: Ho Wo Gosney, F.P.H。

R. Ko Mason, - KoR。 Leifermann

Savannah River glant (6)

Ho I. Eunkex \& J. G。 Bretver

Jo Go Brewer

H. B. Gage

F.C. Breuninger

S. R. Cochran (2)

R. H. Potts

J. Bo Johnson - File

January 20, 1953

flew York Ship - Canden, No Jo

nip

FIEID IHSPECTOE'S REPORT

TO

C. Jo VEITH $=$ R \& E FIIE (2)

FRON

Vo Jo Jaughiala

DATE.

January 16,1953

PEOJECT ROO 8980 PJAITI

Sargingah River ORRER nO. AXCo $16 \%$

EQUTFMEAT

Expension Rsug EQ.PC.HOO $2150+5$

PRHENG ROS. yol $31.5 \% 2$ JOB RATING

VENDOR New York Shjpbijlajis Corgoration IOCATIOY

Canden, $\mathrm{N}_{0} \mathrm{~J}_{0}$

Scope:

This report corers the thichness check on the above unit expansion ringo Tiris chect was made on 106 to 207053

Procedure:

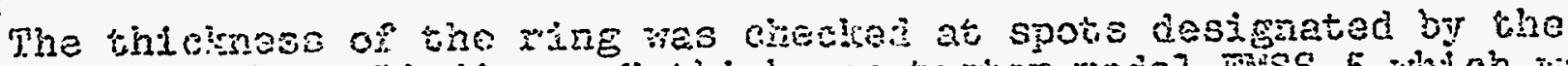

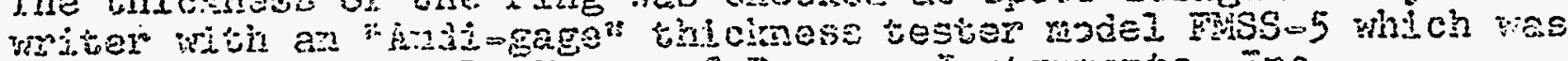
opezated by ix,

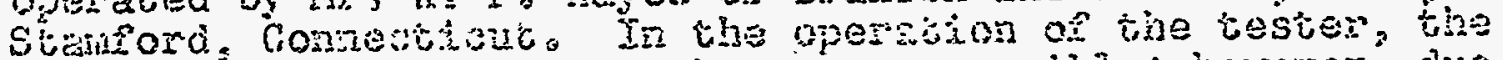

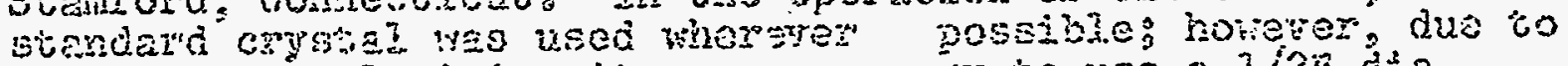

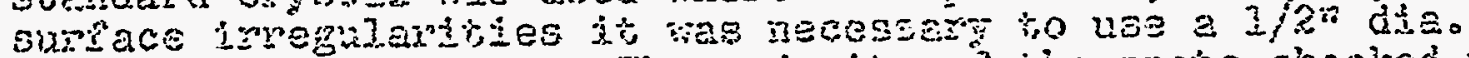

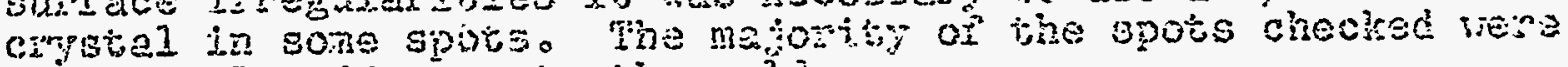

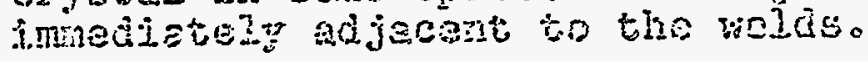

Ro:3].t.s:

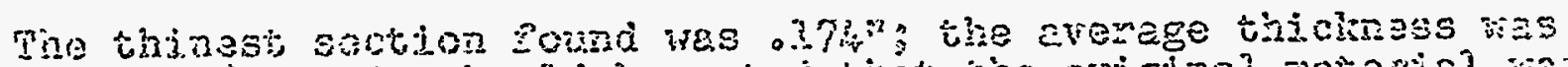

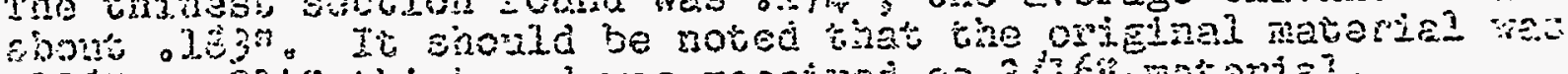

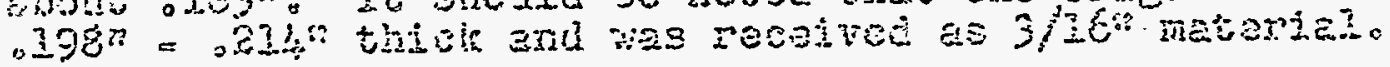

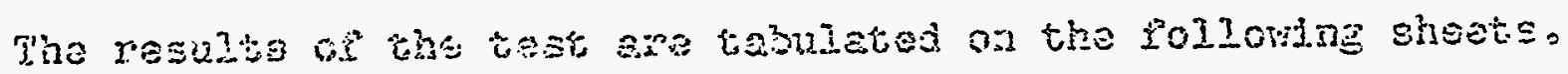

Inlir

attach。

$$
\text { ! }
$$

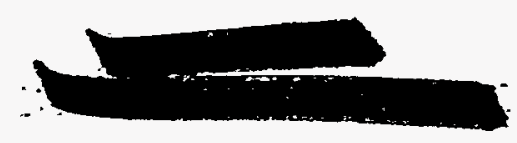


ITEM THSPECTOS:S REROR:?

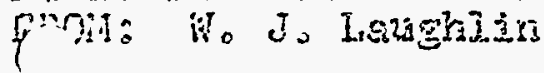

Report Number 395 $\circ$

Page 2 of 4

Column I denotes location of check located on Page

Colum 2 denotes thickness in $0007^{\text {s }}$

\begin{tabular}{|c|c|c|c|c|c|c|c|c|c|c|c|}
\hline 2 & 2 & 1 & 2 & 1 & 2 & 1 & 2 & $I$ & 2 & 2 & 2 \\
\hline $\begin{array}{l}1 \\
2 \\
3 \\
4 \\
5 \\
6 \\
7 \\
8 \\
9 \\
10 \\
31 \\
12 \\
13 \\
14 \\
15 \\
16 \\
17 \\
18 \\
19 \\
20 \\
23 \\
25 \\
23 \\
21 \\
25 \\
26\end{array}$ & 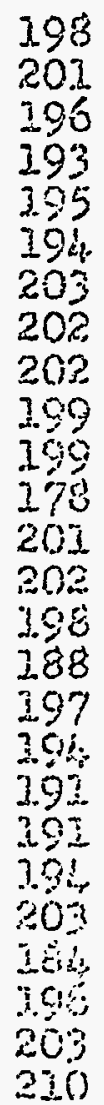 & $\begin{array}{l}27 \\
28 \\
29 \\
30 \\
33 \\
32 \\
33 \\
34 \\
35 \\
36 \\
37 \\
30 \\
39 \\
20 \\
42 \\
48 \\
43 \\
480 \\
45 \\
46 \\
4.7 \\
48 \\
49 \\
50 \\
53 \\
53\end{array}$ & $\begin{array}{l}199 \\
196 \\
194 \\
202 \\
194 \\
134 \\
204 \\
200 \\
199 \\
197 \\
194 \\
194 \\
190 \\
189 \\
194 \\
194 \\
1907 \\
190 \\
196 \\
394 \\
390 \\
193 \\
179 \\
169 \\
204 \\
196\end{array}$ & $\begin{array}{l}53 \\
54 \\
55 \\
55 \\
57 \\
58 \\
59 \\
60 \\
61 \\
62 \\
63 \\
64 \\
65 \\
66 \\
67 \\
88 \\
69 \\
70 \\
71 \\
72 \\
73 \\
74 \\
73 \\
70 \\
79 \\
73\end{array}$ & 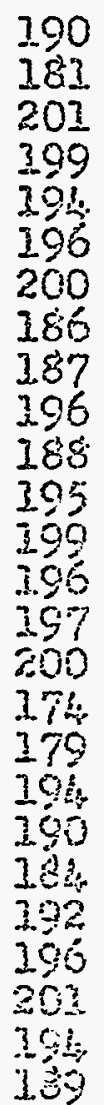 & 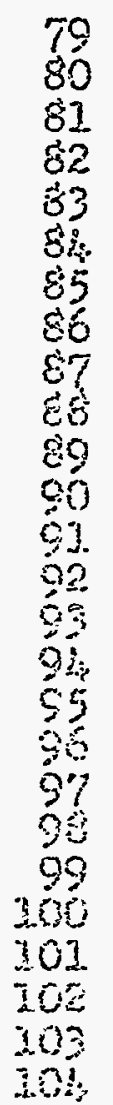 & 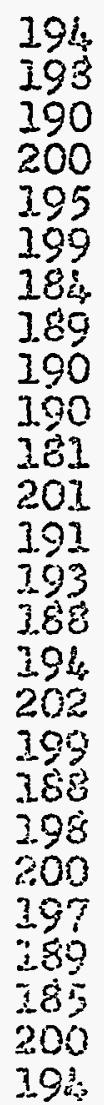 & 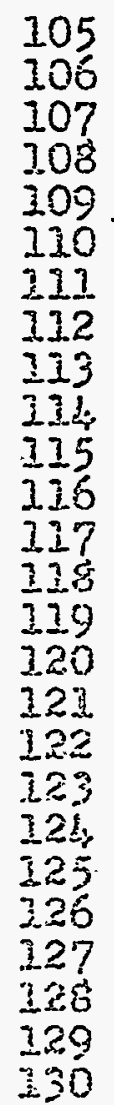 & $\begin{array}{l}189 \\
195 \\
199 \\
200 \\
186 \\
194 \\
192 \\
201 \\
194 \\
183 \\
191 \\
192 \\
197 \\
194 \\
181 \\
196 \\
197 \\
198 \\
194 \\
193 \\
193 \\
193 \\
196 \\
186 \\
190 \\
290 \\
186\end{array}$ & $\begin{array}{l}131 \\
132 \\
133 \\
134 \\
135 \\
135 \\
137 \\
138 \\
139 \\
140 \\
141 \\
142 \\
143 \\
144 \\
145 \\
345 \\
147 \\
318 \\
149 \\
150 \\
151 \\
152 \\
152 \\
153 \\
154 \\
135 \\
350\end{array}$ & $\begin{array}{l}192 \\
202 \\
192 \\
202 \\
207 \\
202 \\
203 \\
203 \\
209 \\
107 \\
189 \\
189 \\
183 \\
198 \\
202 \\
201 \\
195 \\
104 \\
192 \\
105 \\
200 \\
182 \\
208 \\
206 \\
207 \\
201\end{array}$ \\
\hline
\end{tabular}


(- Colum 1 denotes Jocation of check Iocated on Page 4 Columin 2 denotes thichress in .00j"

\begin{tabular}{|c|c|c|c|c|c|c|c|c|c|c|c|}
\hline 1 & 2 & 1 & 2 & 3 & 2 & $I$ & 2 & 1 & 2 & 2 & 2 \\
\hline $\begin{array}{l}157 \\
158 \\
159 \\
160 \\
361 \\
162 \\
163 \\
164 \\
165 \\
166 \\
167 \\
368 \\
169 \\
170 \\
171\end{array}$ & $\begin{array}{l}194 \\
193 \\
180 \\
184 \\
203 \\
394 \\
184 \\
201 \\
194 \\
200 \\
207 \\
194 \\
202 \\
190 \\
289\end{array}$ & $\begin{array}{l}173 \\
173 \\
174 \\
175 \\
176 \\
177 \\
375 \\
179 \\
180 \\
181 \\
182 \\
183 \\
184 \\
383 \\
180\end{array}$ & $\begin{array}{l}206 \\
192 \\
200 \\
192 \\
280 \\
180 \\
101 \\
180 \\
187 \\
205 \\
201 \\
214 \\
201 \\
202 \\
190\end{array}$ & $\begin{array}{l}187 \\
188 \\
189 \\
190 \\
191 \\
192 \\
199 \\
394 \\
195 \\
196 \\
1907 \\
1998 \\
190 \\
200 \\
201\end{array}$ & $\begin{array}{l}208 \\
206 \\
211 \\
207 \\
207 \\
189 \\
201 \\
202 \\
202 \\
204 \\
203 \\
203 \\
199 \\
192 \\
189\end{array}$ & $\begin{array}{l}202 \\
203 \\
204 \\
205 \\
205 \\
207 \\
208 \\
209 \\
210 \\
211 \\
212 \\
213 \\
214 \\
215 \\
216\end{array}$ & $\begin{array}{l}206 \\
207 \\
200 \\
209 \\
207 \\
181 \\
201 \\
197 \\
190 \\
199 \\
196 \\
1902 \\
206 \\
192 \\
198\end{array}$ & $\begin{array}{l}217 \\
235 \\
219 \\
220 \\
221 \\
222 \\
223 \\
224 \\
225 \\
226 \\
227 \\
2280 \\
229 \\
230 \\
231 \\
232 \\
233 \\
234 \\
235 \\
236\end{array}$ & $\begin{array}{l}191 \\
1880 \\
201 \\
196 \\
186 \\
294 \\
201 \\
1880 \\
186 \\
198 \\
194 \\
207 \\
196 \\
190 \\
204 \\
396 \\
204 \\
200 \\
202 \\
198\end{array}$ & $\begin{array}{l}237 \\
233 \\
239 \\
240 \\
241 \\
242 \\
243 \\
243 \\
24.5 \\
245 \\
246 \\
247 \\
24,8 \\
249 \\
250 \\
251 \\
252 \\
253 \\
254 \\
255\end{array}$ & $\begin{array}{l}202 \\
199 \\
196 \\
188 \\
201 \\
194 \\
192 \\
188 \\
194 \\
200 \\
192 \\
190 \\
201 \\
203 \\
191 \\
384 \\
201 \\
180 \\
204\end{array}$ \\
\hline
\end{tabular}




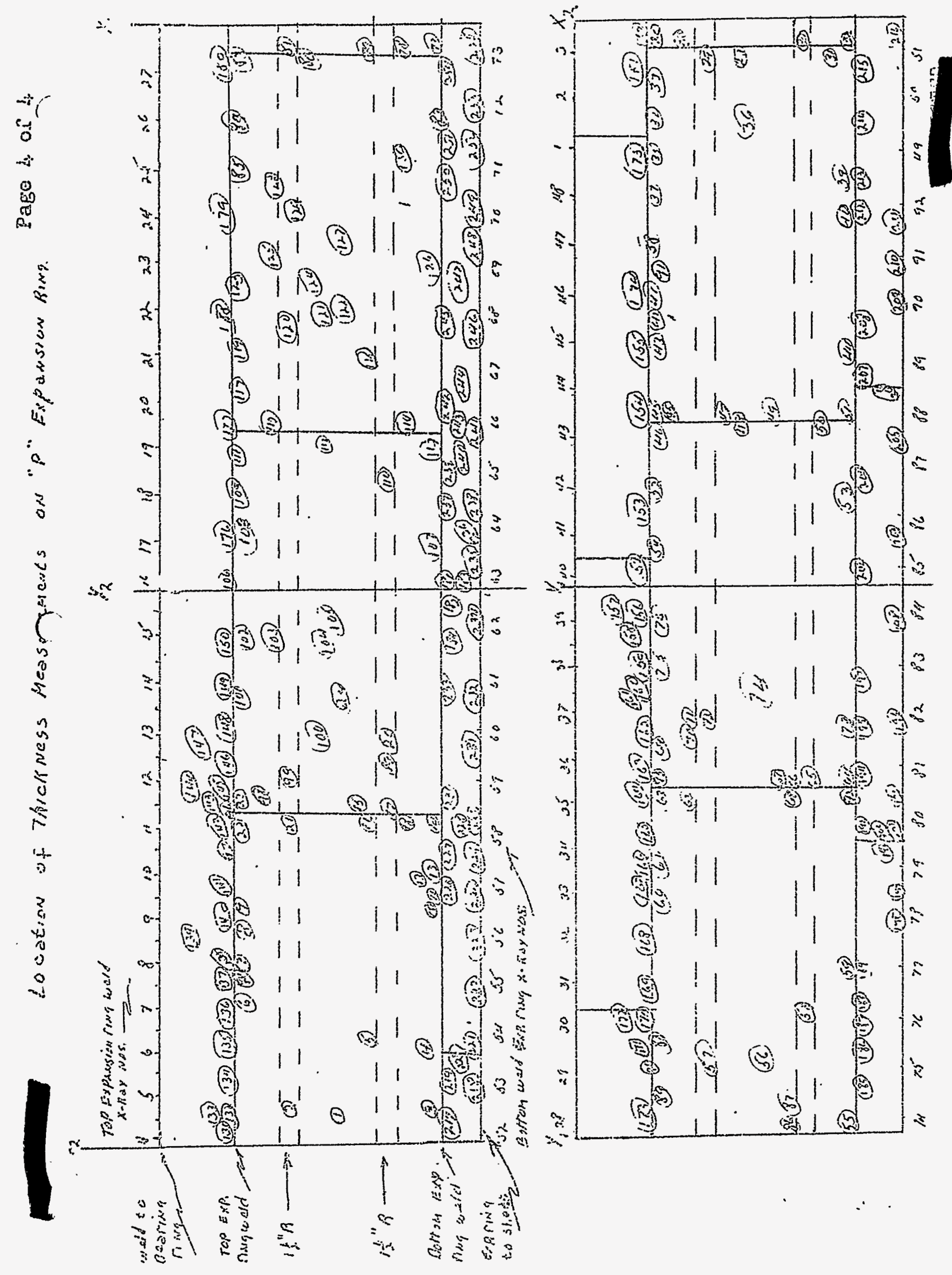


[1] All repairs not made to the expansion joint at New York Ship were cone at the plant site. X-ray filin showng cefects in expansi on joint welding was marked on the film at NIS for easy location at the field site for making the necessary repairs. To assist the field in locating the defects in the expansion joint, a du port inspector was sent to SES with the marked film.

[2]

Also, a New York Ship representative accompanied the inspector to SRP to assist the inspector and field personnel in the lofting in of the "i:" main tank section. The decision was made to loft in the "l:" main tank to the bottom tube sheet at the plant site based on the fact that time remaining before tre shipping date could not be utilized to. perfon this operation.

C. "L" Unit

(1) Krain Tank

a. Plate Inspection, Fabrication and X-ray

Same as section $B(I)$-a of this manual, except for fabrication sequence, see Lw. 6-7 presented herewith.

b. Tank out-of--Foundiness

Same as jection $\mathrm{D}(1)-\mathrm{L}$ or this manual except as follows:

Durin" hardling the "I" main tank shell was dropped in Illdg. 3 causing sicht damage to the shell plates. Sketcnes 718 , fil9 and H20 show where caved in spots and dents occurred. All cave in spote and dents were taken out by using a 450 ton cold press and large wooden hamers. As shown in sketch \#18, one scar was vielded and ground smooth.

After all repair work was completed, the welding in the imnediate vicinity of daraged areas were re-x-rayed and necessary repairs made. In addition, the top and bottom circunference measurements were re-taken and Iound satisfactory. Sketch iflg lists the results.

All repairs to the tank were successful, and it was released for further fabrication.

c. Inspections After Grinding and hlcid Washing

Sarne as section $A(I)-C$ of this manual. 

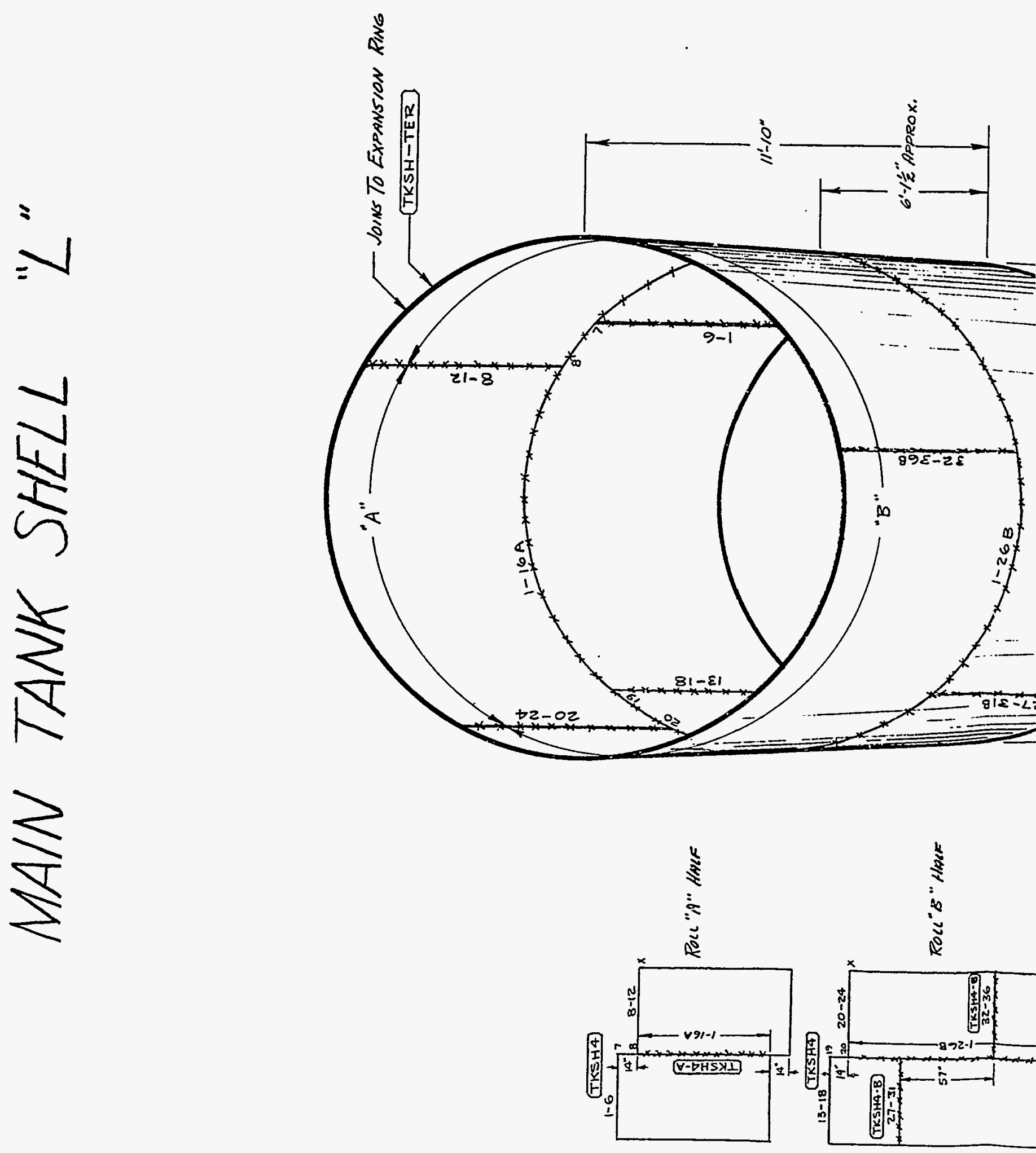


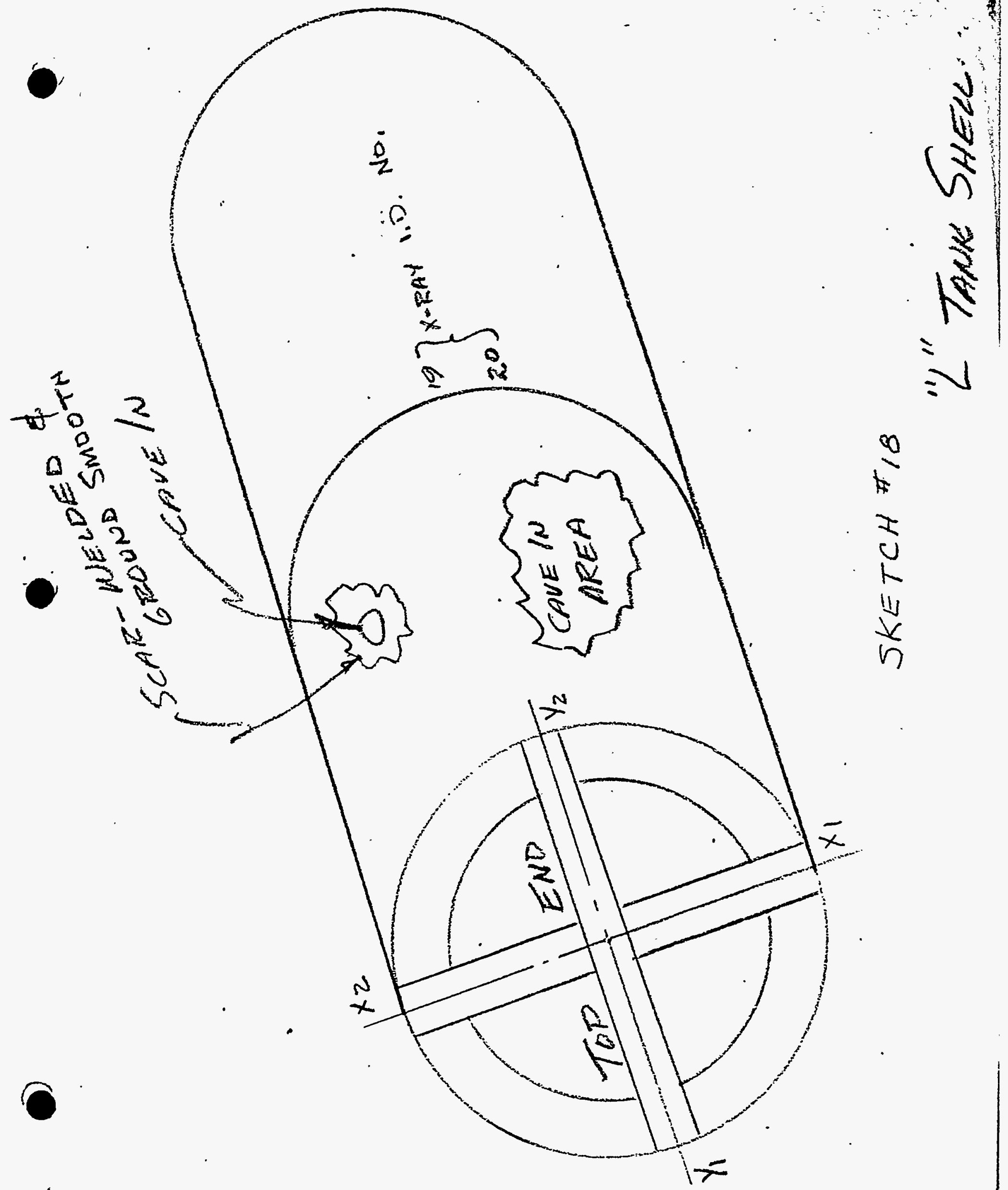




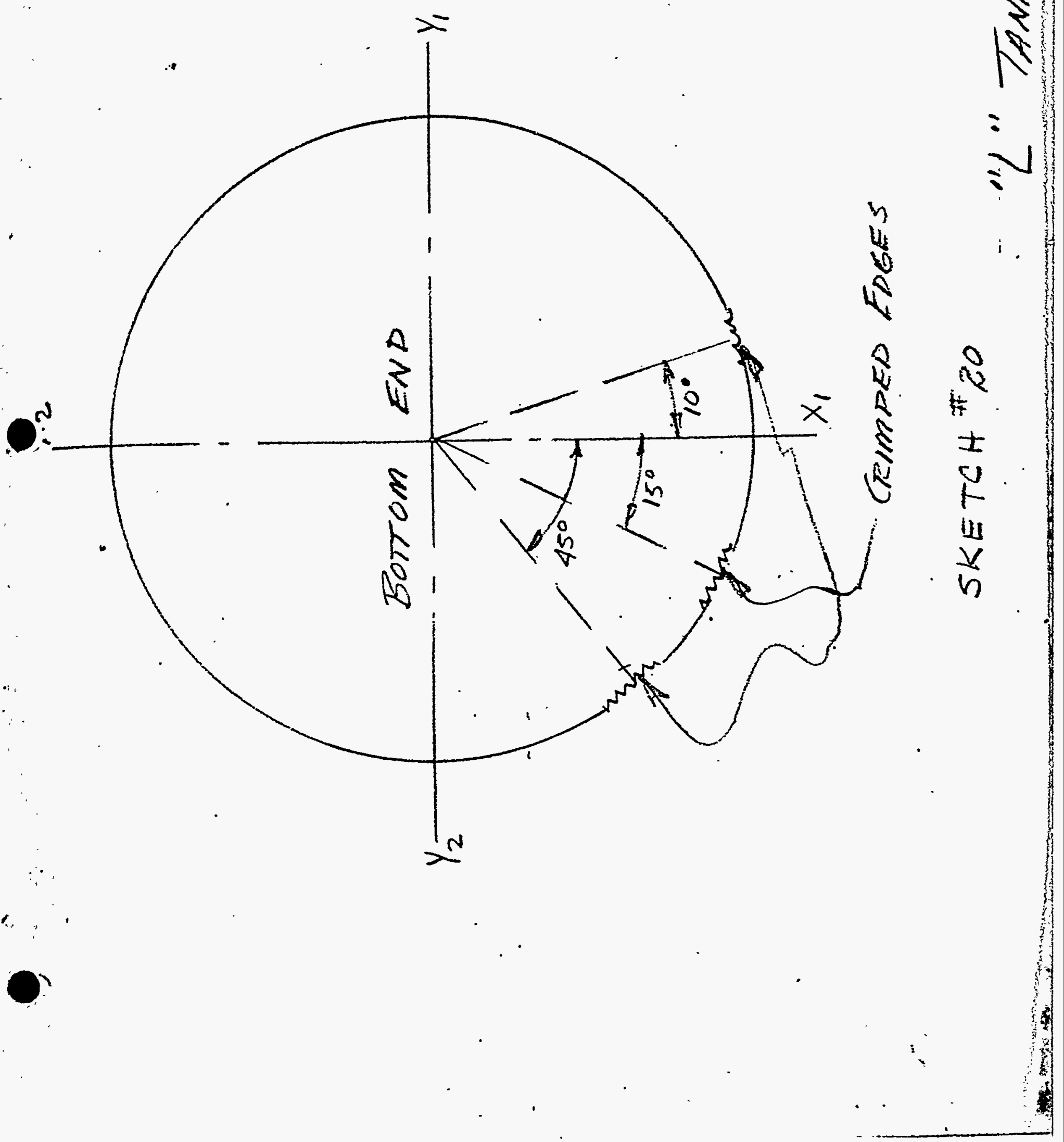


(2) Inspection of Bearing Ring, Expansion Joint and Top Tube sheet Enclosure

a. Bearing Ring and Expansion Joint

The bearing ring and expansion joint vere fabricated, welded together and machined to rough dimensions in a similar manner described in section (2) $a$ and $b$ of this manual.

However, at this stage of fabrication, field complaints on the "B" expansion joint prompted the du Pont Inspection Department to establish a new fabrication procedure for "L", "K" and "C" Units discussed in Section $B(2)-h$ of this manual. Sincd "L" unit's expansion joint had all ready been fabricated before the revisions were made, the only revision that could be incorporated into the "I" expansion joint assembly at this atage of fabrication was re-x-raying of all welding - using fine grain film in lieu of coarse grain previously used on this unit. All welding in the "I" expansion joint was re-x-rayed using fine grain film and radiographs examined in accordance with the new film reading procedure outlined in Section $B(2)-h$ of this manual. Upon examining the radiographs, it was found that too many defects in the "I." expansion joint welding were present to justify repairing. It was agreed by all parties concerned that if these weld repairs were made the expansion joint would be warped from welding heat to such a degree that it could not be satisfactorily used in a process unit. Eased on this supposition, it was agreed by Design Division, du Pont Inspection Department and New York Ship to serap the "I," bearing ring and expansion joint assembly and fabricate a new one for this unit.

b. Fabrication Changes and Inspection of New Bearing Fing and Expansion Joint for "I" Unit

The fabrication, machining and inspection of the new bearing ring and expansion joint was similar to that discuassed in section $A(2)$, except the following changes in fabrication and inspection methods were made on this unit and also "K" Jnit.

[1] Welding specifications were revised to permit manual metallic arc welding on process units in the following cases:

(a) All welds in the "I," and $n_{2} n$ expansion joint

(b) Joint between expansion joint and bearing ring.

(c) Joint between expansion ring and main tank. 
(d) All welds on the top tube shoet lifting lug hoods ( I, $\mathrm{K}$ and $\mathrm{C}$ )

(e) Butt welds in the botton tube sheet 8 " half round pipes ( $I, X$ and $C$ )

(f) Joint between 8" half round pipes and the bottom tube sheet wrapper

[2] In making of new expansion joint for "L" and "K "Units, segment butt welds were aligned. See Dwg. 6-4 presented herewith in Section $A(2) B$.

[3] All six expansion joint segnents for "In" and " $K^{\prime \prime}$ Jnits, were annealed after foming but before welding together. Exhibit 111 presented herewith is a sumary of heat treating of expansion joint segments after cold forming to final shape and completion of major welding.

[4] Before annealing all expansion joint segments for "I" and " $\mathrm{K}^{\prime \prime}$ were $\mathrm{X}$-rayed and majority of repairs made. After annealing segments were sandblasted, acid washed and then re-x-rayed and minor repairs made.

$[5]$ Before final $\mathrm{x}-\mathrm{ray}$, all welds in the six segments (I \& $\mathrm{K}$ ) were ground flush to remove the bond line and the entire joint polished to approximately a fl finish. Concurrently with the grinding operations, a du Pont Inspector checked the thicimass of the expansion joint segments using a tubular micrometer fitted with a dial indicator in the standard method of indicator usage. The indicator was set to zero using a $.187^{\prime \prime}$ standard. linimun thickness of expansion joint segments was $0.166^{\prime \prime}$. These measurements were taken in a zig-zag manner across the weld ( $1 / 2^{n}$ on each side) and the lowest readings were recorded. All readings were above $.166^{n}$ on both " $L "$ and " $K$ " expansion joints and accepted.

[6] After butt welcing the six segments to form the expansion joint, the vertical welds were checked for thickness in a similar manner described in part 5 above. All measurements were acceptable.

[7] AII other revisions made to the "L" and " $K$ " expansion joints not mentioned above are covered in section $s(2)-h$ of this manual.

C. Remaining Inspections Performed on the "น" Kain Tank Section

The remaining inspections performed on the "L" main tank section after fabricating and machining a new bearing ring and expansion joint for this unit was similar to that previously discussed in section $A(2)$ and including revisions discussed in 
EXXIBIT fFII

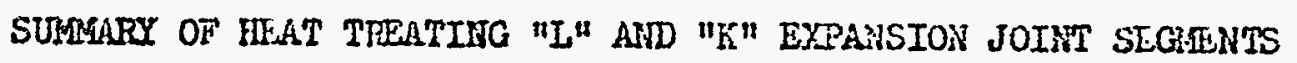


I. I: DU PONT DE NEMOURS \& CO., TNC. Şonstruction Division
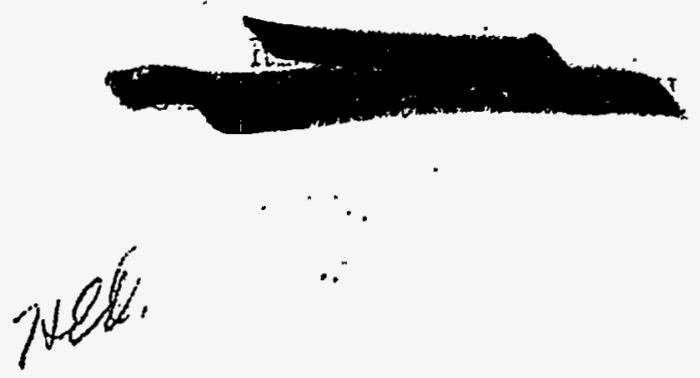

CC: J. B. Johnson

R. K. Mason-D.A.Hauser-osRP

$R_{*} \cdot I_{0}$ Mason-J.D.Cook-SiP

H. I. Bunker-J。G。Brewer

J. G. Brewer

H. B. Gage

F. C. Breuninger

I. J. Carroll

R. H. Barto - NXS (3) File.

October 29, 1953

New York Ship - Camden; N.J.

FIEID INSPECTOR'S REPORT

TO C. J. VEITH $=$ M \& E FILE

I'ROMI S. R. Cochran DATE JuIY 7,1953

PROJECT NO. 8980 PIANT Savannah River.ORDER NO. ARC-267弯 BQUIPWANT Eypansion Ring Sogmants EQPC.NO. I50-I \& 150-K DRAWING NOS. W-133252 REV.7 \& W-133628 ReV.9 jOB RATINC

CNENDOR New York Shigbuilding Coro. IOCATION Camden. IN Jo

This is a sumnary of heat treating of expansion ring segments after cold forming to final shape and completion of majos welding.

The segmente were heat treated by the following procedure:

J. Furnace was greheated to a temperature of $600^{\circ} \mathrm{F}$ to $1000^{\circ} \mathrm{F}$. (Temprature of pre-heat varied for indjvicual heat treating operations orex above range.)

2. Segmerte were heated to $1950^{\circ} \mathrm{g}$ to $2050^{\circ} \mathrm{z}$ at approximateis $300^{\circ}$ per hour.

3. Sezrunts were tress heid for 15 minutes at ebove teroperature.

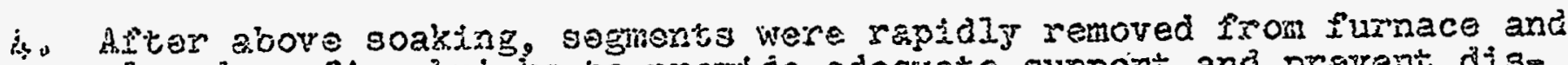
placed on sire tricks co provlde adequate support and pravest distortion during coojline. Segments ware air cooled to a black color within 2 minutes âter removal fron furnace.

Finrnace used ir heat treating bporation is $18^{\prime}$ long by $15^{\circ}$ wide by L, nigh with an arch siaped ceiling, arched ovor the 15 width. Three burners are equaliy spaced on one side orer the is langth at an elevation of 18\%. The furnace is befiled in the center along the ifo length with 2

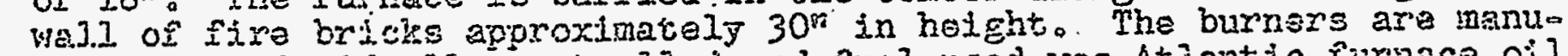
alijy and jndividualiy controlled and fuel used ws Atiantic rurnace oil. medjum waighto 
Temperature measuring device used, was a Brown \& Sharpe, portable, 4 point recording potentiometer, calibrated and used with chromel-alumel thermocouple leads. Two thermocouple leads were welded to each end of each segments were stress relieved.

The following segments used in "L" \& " ${ }^{n}$ unit expansion rings and identified by $x-r a y$ stencil numbers listed were heat treated on the following dates:

1. Segments TER 5-2 and TER 5-4 were heat treated on 2/14/53. J. B. Johnson and $R_{0} V_{0}$ Graham witnessed the heat treatmento Segment TER 504 was located on the burner side of the furnace. The furnace. was prenheated to $1000 \%$ and 3 hours 10 min. later a temperature of $2000^{\circ} \mathrm{F}$ was reached. This is a rate of temperature increase of $316^{\circ} \mathrm{F}$ per hour. Segments were held for 15 min. at $2000^{\circ}$, removed fron furnace and air cooled to a black color within 2 minutes.

No appreciable distortion vas present.

2. Segments TER 503 and TER 505 were heat treated on $2 / 18 / 53$. J. $B_{0}$ Johnson and $R_{0} V_{0}$ Graham witnessed the heat treatment. Segment TER 5-3 was located on the burner side of the furnace. The furnace was preoheated to $900^{\circ} \mathrm{F}$ and 3 hours later an average temperature of $1950^{\circ} \mathrm{F}$ was reached. This is a rate of temperature increase of $350^{\circ} \mathrm{F}$ per hour. Segments were held for 20 minutes at $1950^{\circ}$ F, renoved from furnance and air cooled to $a$ black color within 2 minutes. No appreciable distortion occurred.

3. Segments TER 501 and $5-6$ were heat treated on $2 / 28 / 53$. J. 3. Johnson and R. V. Graham witnessed the heat treatment. Segment TrR 506 was locateg on the burner side of the furnace. The furnace was preaheatod to $800^{\mathrm{F}}$ and 3 hours 20 min. later a temperature of $1900^{\circ} \mathrm{F}$ was reached. This is 2 ate of temperature increase of $330 \mathrm{~F}$ per hour. Segnents were held 5 or 17 mino at $1900^{\circ}$, removed from furnace and air cooled to a black color vitibin 2 minutes. Ho distortion occurred.

4. Segments TER 6al and 605 wre hsat ireated on 3/14/53. J. B. Johnson and $E_{0} V$.Graham ritnessed the heat ireatment. Segment TER 6-I was on the burner side of the curnace. The eurnace was pre-heated to $1050 \%$ and 3 hours later a tomperature oi $7950^{\circ}$ was reached. This is a rats of temperature increase of $300 \mathrm{~F}$ per hour. Segments were held at $1050^{\circ}$ F ror 15 min., removed from furnace and air cooled to a black color in 2 min. No distortion occurred.

5. Segments TER $6-3$ and $6-4$ were heat treated on $3 / 28 / 53$. MoH.Scholes witnessed the heat treatment. Segment TER $6-3$ was on the burner side of the furnace. The furnace was pre-heated to $800^{\circ} \mathrm{F}$ and 4 hours later a temperature of $1950^{\circ} \mathrm{F}$ was reached. This is a rate of temper ature increase of $288^{\circ} \mathrm{F}$ per hour. Segments were held at $1950^{\circ} \mathrm{F}$ for I5 min., removed from furnace and air cooled to a black color within 3 mino No distortion occurred. 
FROM: $\quad S * R$. Cochrar

6. Sogments TER $6-2$ and 6.6 vere heat treated on $4 / 25 / 53$. MoH.Scholes witnessed the heat treatment. Segment TER 6-2 was on the burner side of the furnace. The furnace was pre-heated to $900 \mathrm{~F}$ and $3 \mathrm{hr}$, $40 \mathrm{~min}$. leter a temporature of $1975^{\circ} \mathrm{F}$ was reached. This is a rate of temperature increase of $329^{\circ} \mathrm{F}$ per hour. Segments were held at $1975^{\circ} \mathrm{F}$ for $15 \mathrm{~min}$, removed from furnace and air cooled to a black color vithin 2 min. No distortion occurred.

7. Segments TER $6 \times 3$ and 6.7 were heat treated on 5/9/53. M.H.Scholes witnossed the heat treatment. Segment TER 6-3. was on the burner side of furnace. The furnace was pise-heated to $800 \mathrm{~F}$ and $4 \mathrm{hr}, 30$ min. Iater-a temperature of $2000^{\circ} \mathrm{F}$ was reached Rate of temperature Increase: $267^{\circ} \mathrm{F}$ per hour. Segments wore held at $2000^{\circ} \mathrm{F}$ for 15 min. removed from furnace and air cooled to a black color within 2 min. No discortion occurred.

The following segments were used on "I" unit:

$$
\text { TER } \begin{aligned}
& 5-2 \\
& 503 \\
& 5-4
\end{aligned}
$$

TER 5-5

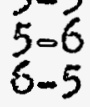

Che following segments were ussd on wrenit:

$\begin{array}{rr}\text { TER } 6-4 & \text { TER } 6-7 \\ 6-2 & 6-1 \\ 6-6 & 5-1\end{array}$

Segment TER 6oj tras scrapped。

Furnace charts are on file for all seguents. 
Section $B(2)-h$ of this manual, except as follows: Since the addition of numerous changes in fabrication affected the procedure originally followed for establishins centerIines and the inspection of welds on the "R" and "p" main tank section, the original inspection procedure had to be revised for performing these additional operations on "I" and "K" main tank sections.

This procedure appears in the following section and is intended to incorporate all revisions and experience gained on "R", "pu, "L" and "K" main tank sections with results presented only for the "L" unit. The original procedure discussed for "R" (Section $A$ ) remains the same for all units except for revisions that appear in the following section.

d. Revisions to Held Inspection and Istablishing Centerlines on the "L" and " $K$ " Kain Tank, Top Tube sheet Enclosure and bottan Tube Sneet Nozzle Section with pesults :resented for "L" Unit

[1] Rough Machine Eearing Ring

All inspections perforned at this stage of fabrication were similar to those discussed in Section (2)a of this manual.

[2] Machine Held Preparation on Top of Completely welded Expansion Joint

Inspectors checked the distance from botton edge to top edize of expansion joint in four places. This inspection is pictorially illustrated in sketch 19 , section $A(2)-b$ of this mamal.

[3] Weld Bearing Ring Extension to Bearing Fing

The following weld inspections were added; (See DWE. 6-3, section $A(2)-a$ ).

Inside Weld - Visual examination and dy-chek testing of entire circumference in as welded condition with preliminary grinding done was performed to insure good dy-cheli result s. After machining the top side of the bearing ring to size, dy-chek inspection was performed again because during machining it was necessary to radius the inside weld to clean up on the diameter of the beiring ring.

Outside jeld * Final condition of weld visually examined. come grinciin. was necessary to remove questionable defects. 
Vertical Seams - Visual and X-ray examination Iinal condition of weldinlush inside; some Erinding on outside to rerrove questionable defects.

\section{[4]}

Weld Fxpansion Joint to Bearing Ring

The following weld inspections were adcied: (See Deg. $6-3$, section $A(2)-a$ )

Inside - Tisual and dy-chek examination of wold. Final condition of weld - ground flush.

Outside - Visual inspection. Final condition of weld - as welded with some grinding to remove questionable defects.

[5] Final Hachining of Tank Expansion Joint and Eearing king

All inspections performed were same as discussed in Section A(2) -c of this manual, except as follows:

After the welding operations described above [4] were completed and inspected, a check was made to insure that the vendor scribed a line to the proper diameter on the top surface of the bearing ring so that during machining enough of the bearing ring was machined to insure proper fit of the T.T.S.E., but no more weld than absolutely necessary was removed joining bearing ring extension to bearing ring.

Final results obtained on the "t." Unit bearing ring are covered in drawings 6353-4, 6353-5 and 6353-6 presented herewith. As stated above, these measurements were taken in a similar manner described in section $A(2) \rightarrow c$ of this manuil. All results were acceptable.

[6] Fabrication and Inspection of Top Tute Sheet Enclosure

Al1 inspections performed on the "I" top tube sheet enclosure were similar to those discussed in section $A(2)$-d of this manual, except as follows: The original three nozzles (Ietail " Section $A(2)-d$ ) were scrapped due to excessive weld repairs. Hew ones were fabricated, inspected and accepted.

Drawing nurivers 6353-1, 6353-2, and 6353-3 presented herewith cover al 1 dimensional inspections taken on this submassenbly. 


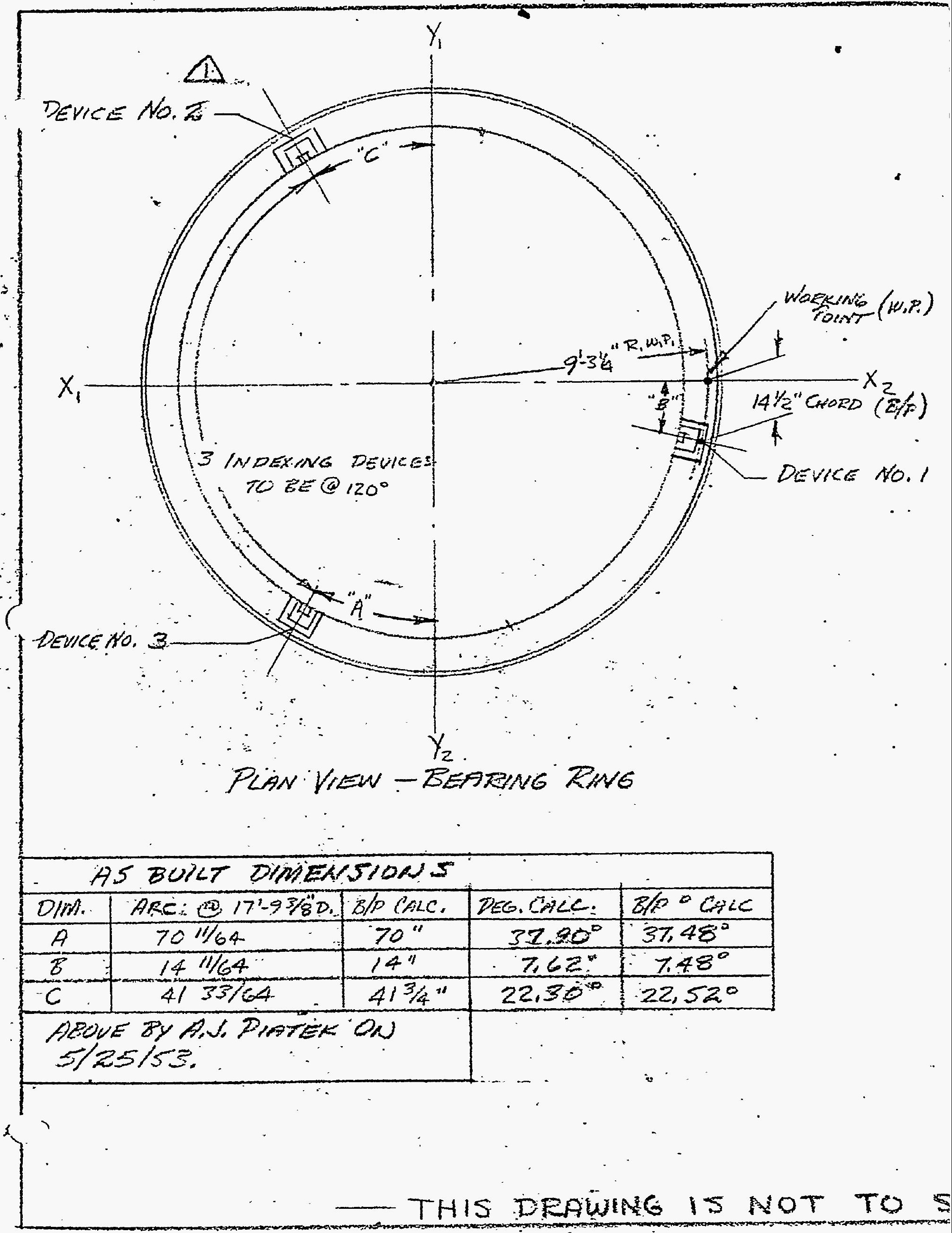




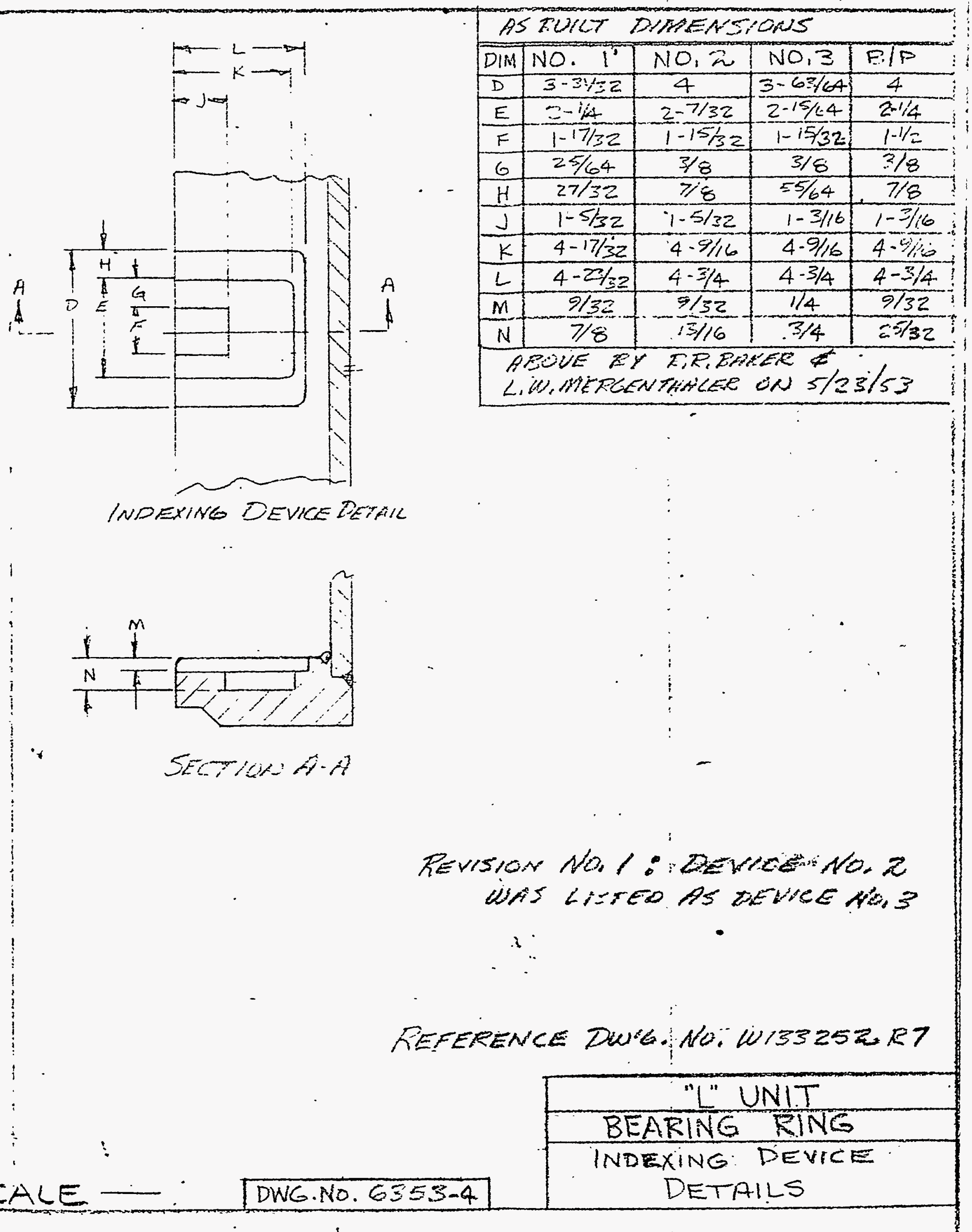




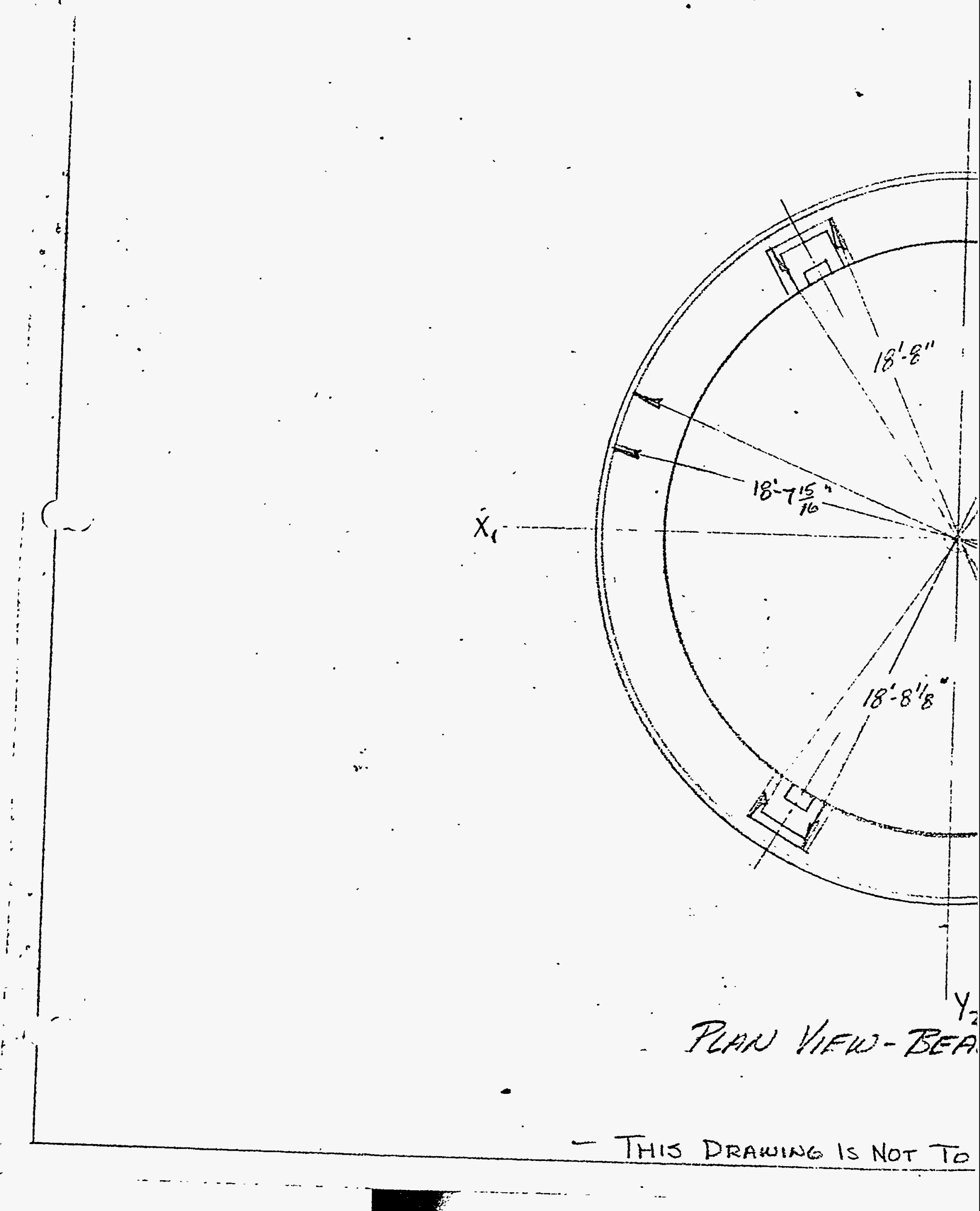




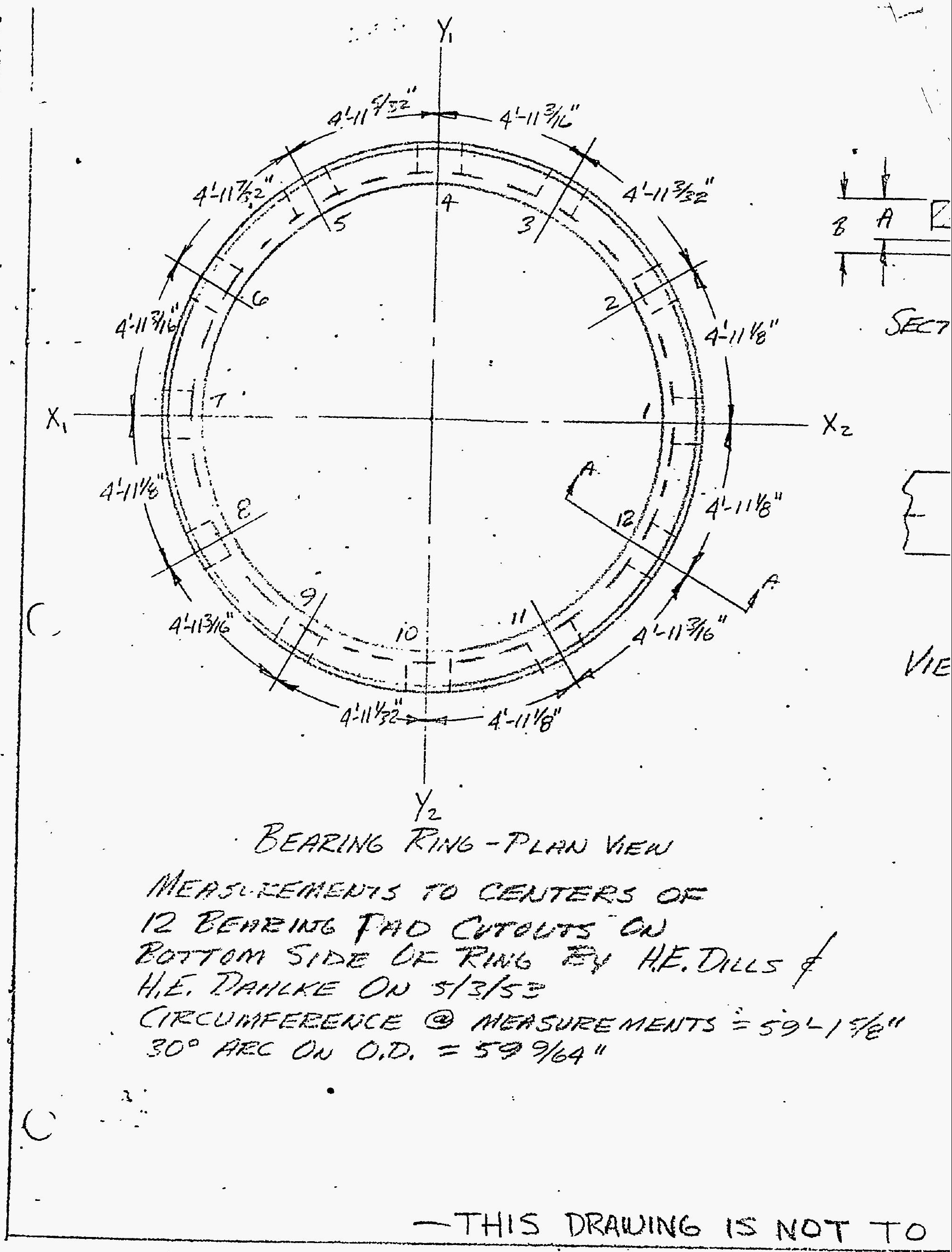




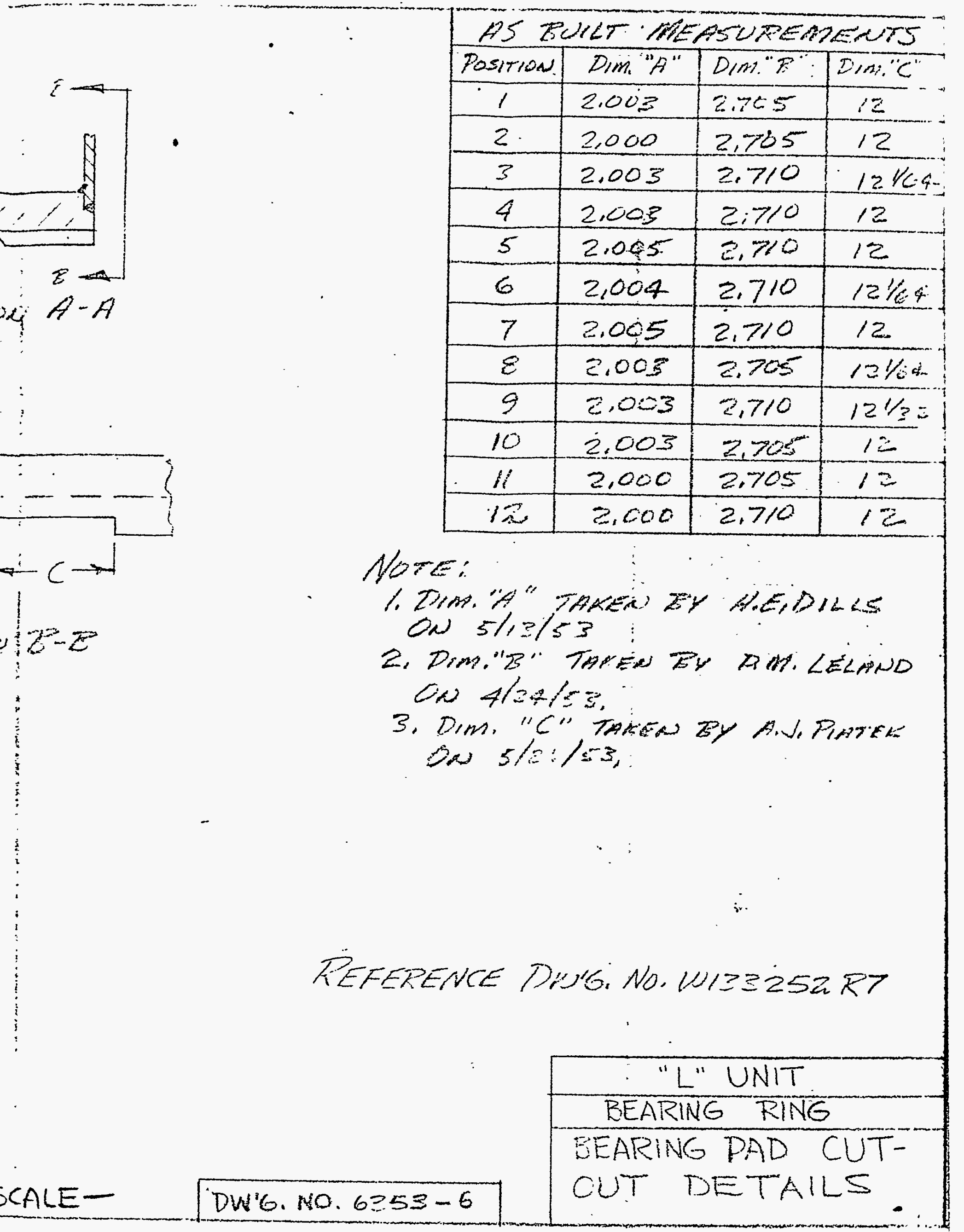




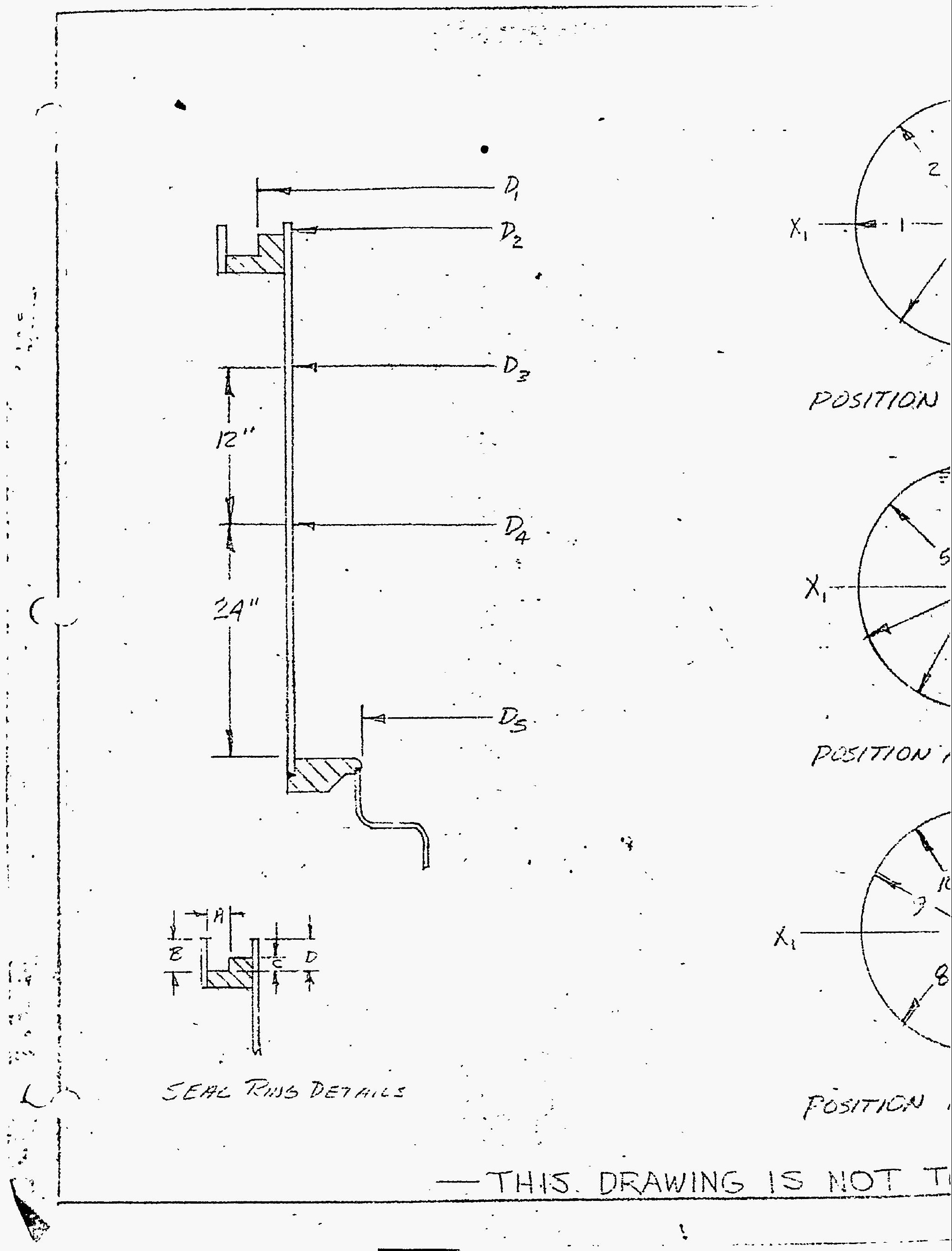




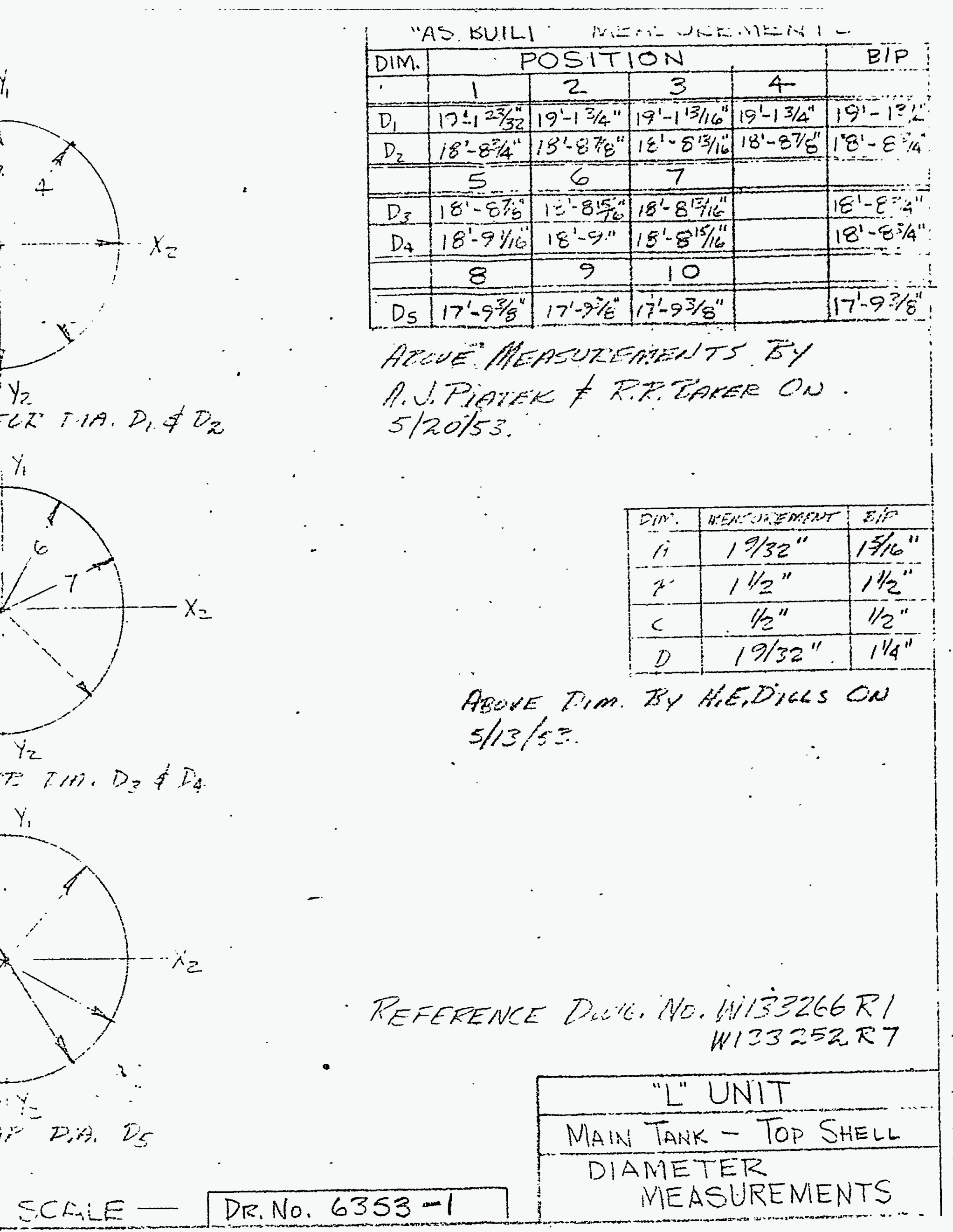




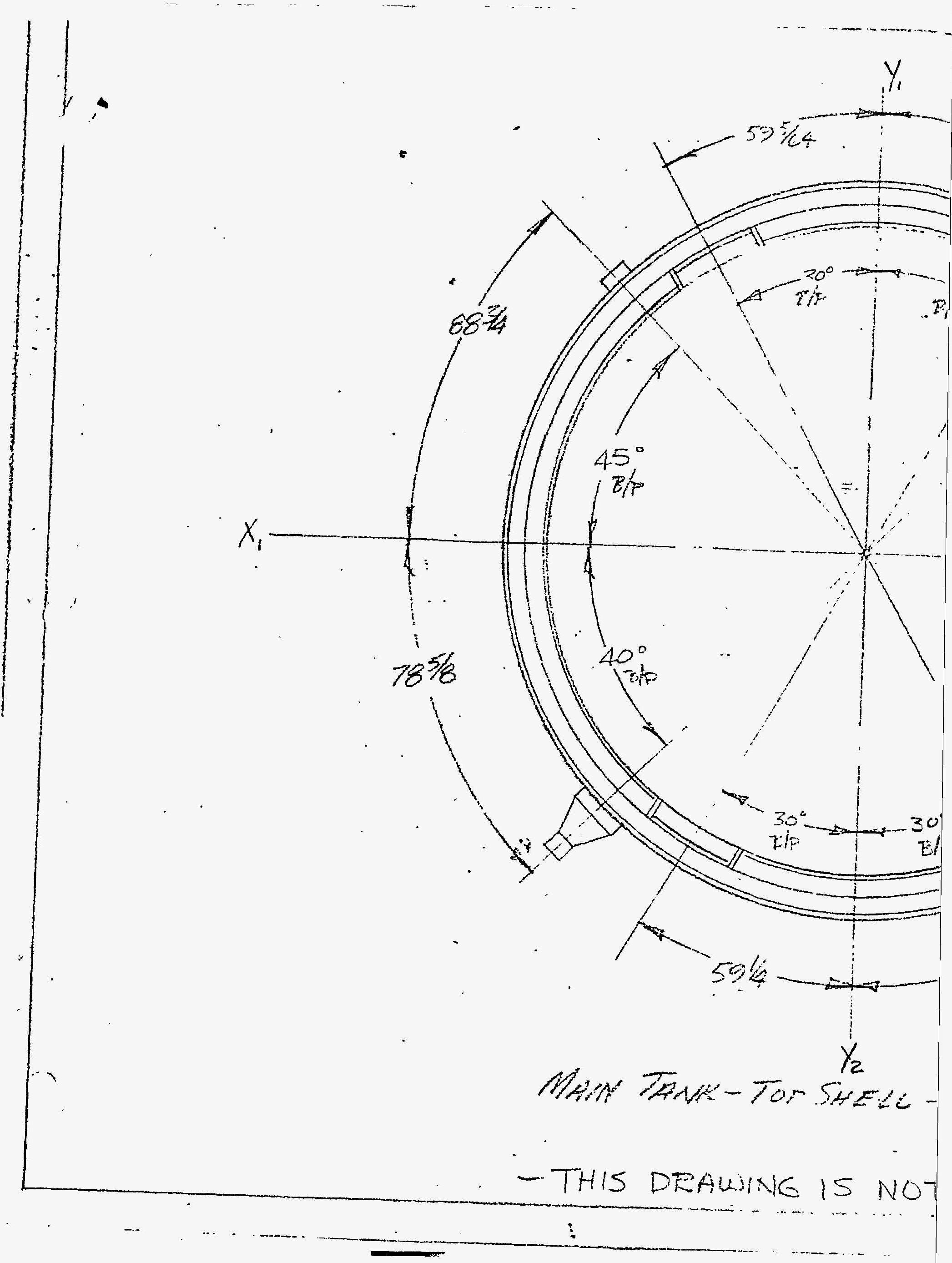




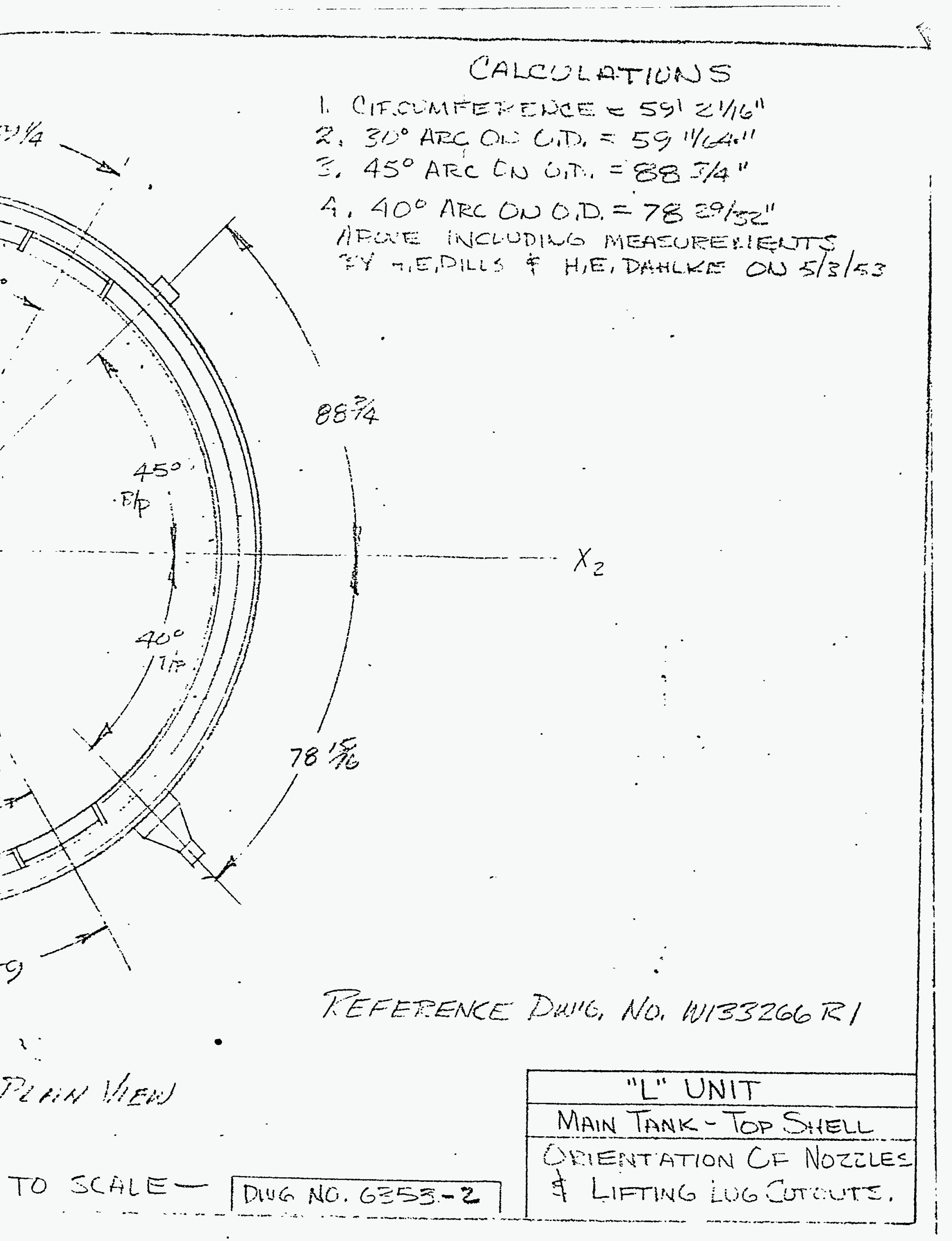




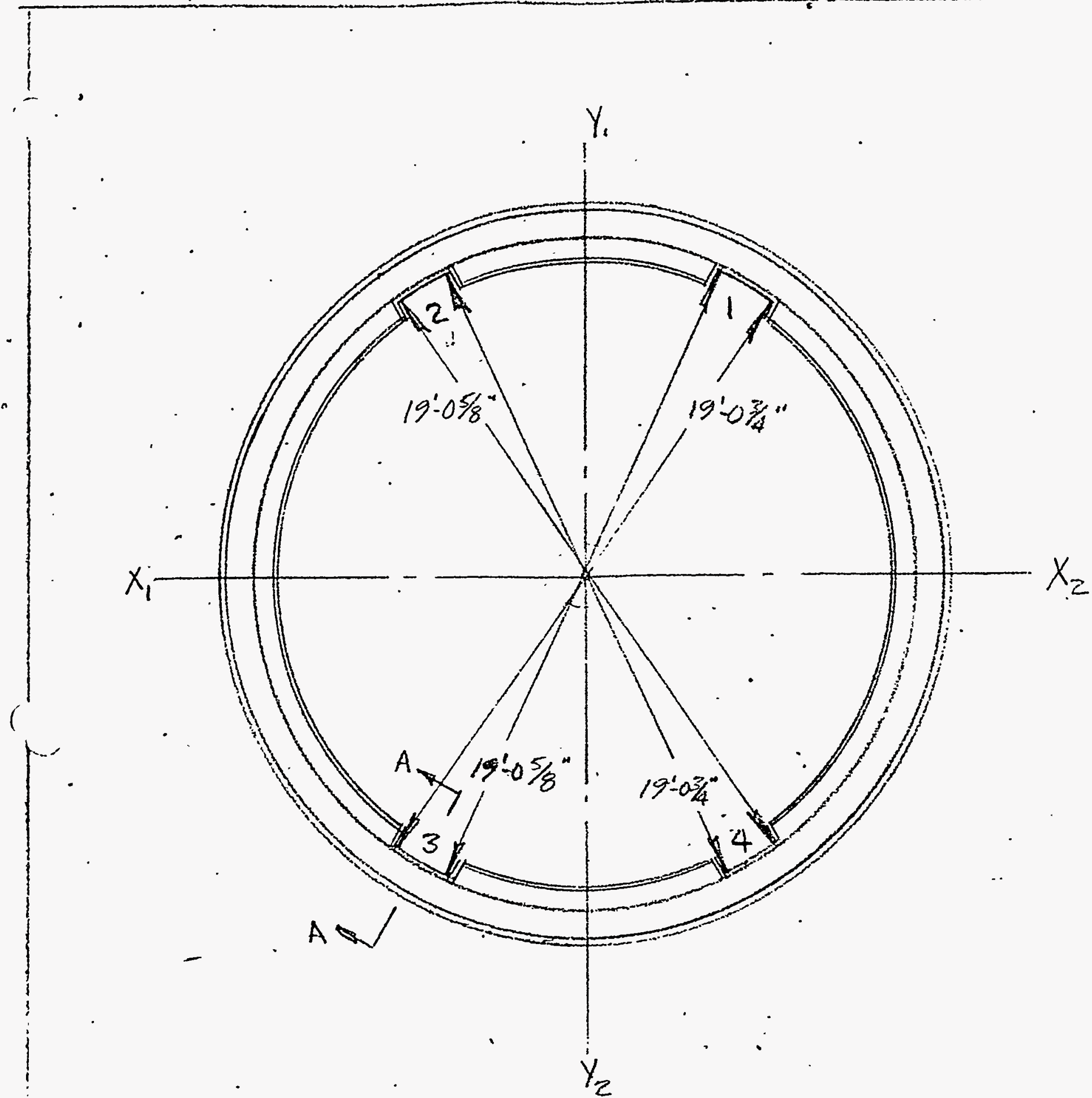

DIAMETER MEASUREMENTS CF

- LIFTING LUG CUTOUTS

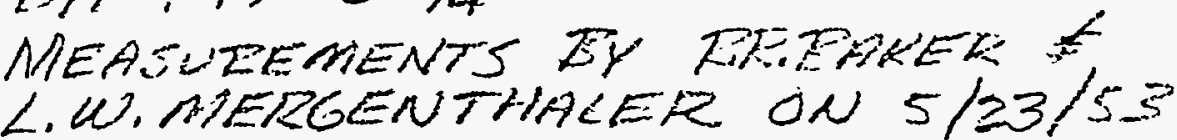

- THIS DRAWING IS WOT 

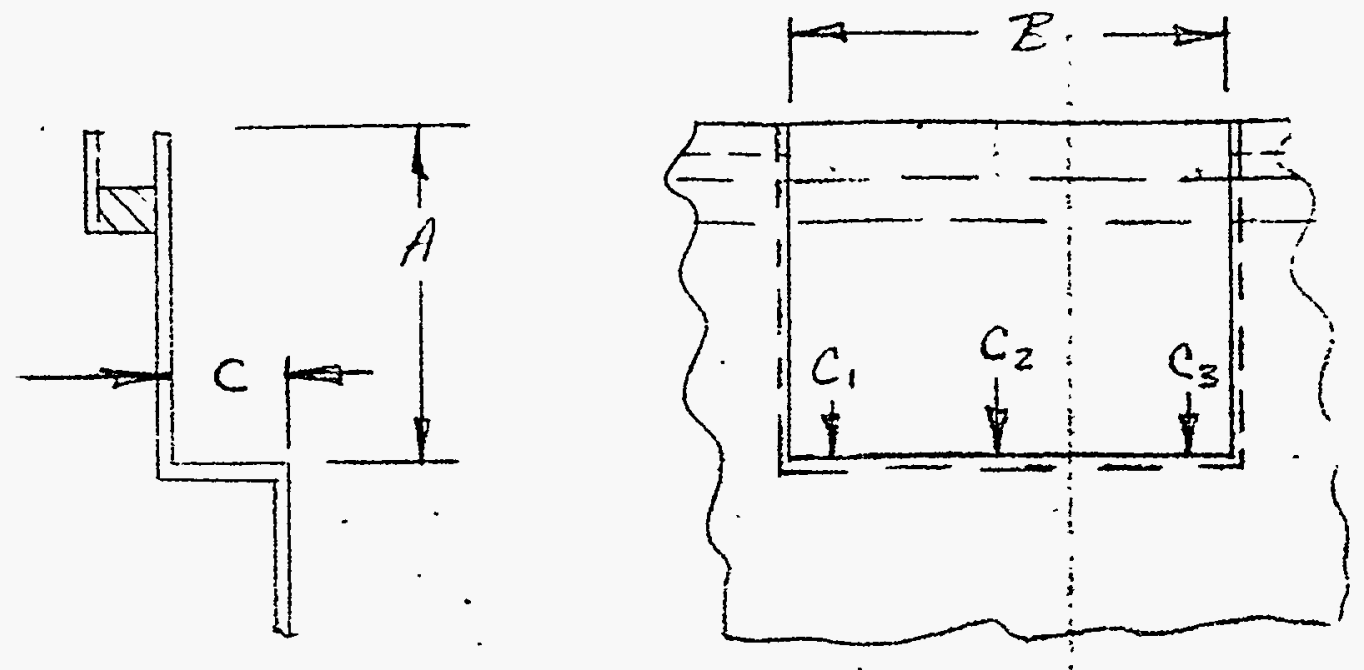

SECTION AA

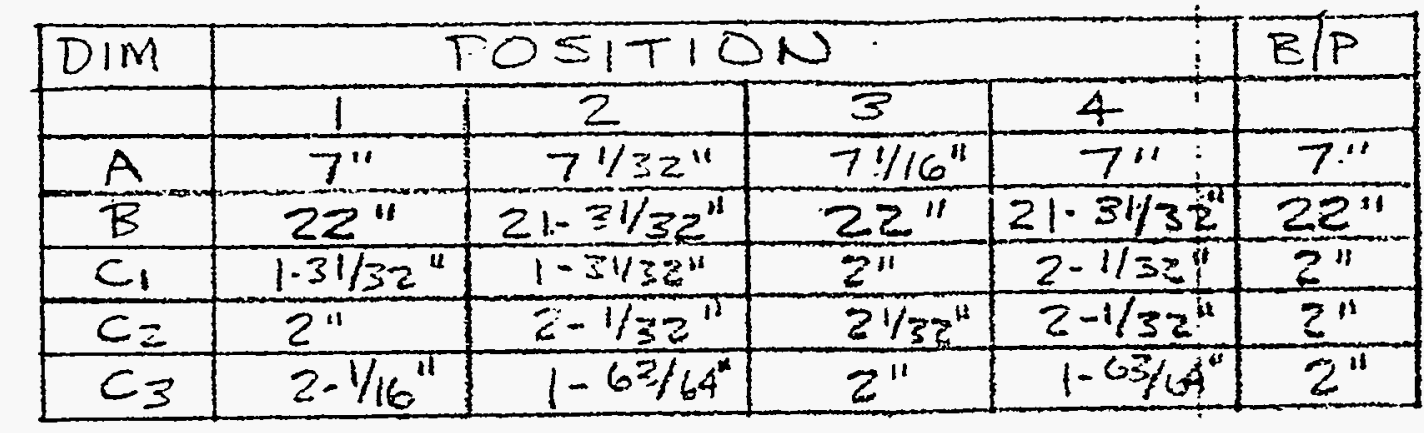

A ROVE MEASUREMENTS BY RE. TAKER LU. MEREENTTHALER ON $5 / 3 S / S$ S.

REFERENCE DR. NO, WIS3266 Ell

\begin{tabular}{|c|}
\hline "L" UNIT \\
\hline MAIN TANK -TOP SHELL \\
\hline MEASUREMENTS OF \\
LIFTING LUG CUTOUTS
\end{tabular}


[7] Helding of Top Tube sheet Enclosure to Bearing Fing and Expansion Joint issembly

The fabrication and inspections performed at this stage of fabrication vere similar to that described in section $A(2)-e$ oxcept as follows:

After machining the seal ring on the top tube sheet enclosure, the entire assembly was moved to a level platen and set on $40 "$ high pedestals and leveled. When the unit was set up, inspectors checked the position of the four peciestals located near the extremities of the $X$ and $Y$ axes to see that they did not fall on the and axis pointsasid obstruct the line of sight of the theodolite. (Thts occurred on the "R" assembly and is discussed in section $A(2)-e$ of this manual). The transferming of centerlines was performed in a similar manner pictorially illustrated in sketch $\# 12$, Section $A(2)-g$ of this manual, except it was not necessary to off-set the theodolite on "L" and "I" units because the 40" high peciestals were positioned so as not to obstruct the instruments line of sight.

Following the above mentioned set-up, the vendor's personnel velded four reference buttons on each of the four axes. The assembly was supported as shown in sketch 721 in order that the expansion ring was in an unstrained position. After taking the micrometer redcing (sketch \#21) from the reference button to the spirit level, the inspector stenciled an "on mark on the button at the point measured, and also scribed lines on the bearing ring for relocation of the spirit level at a later time. These measurements were checked three times in order for the inspector to Le sure that this method was exact. These measurements were duplicated when the expansion joint was joineduto the tank shell, thereby verifying that the exparioiun joint was still in an unstrained position.

$[8]$

Fitting and Welding Expansion Joint to Tanik Shell

The fitting and welding of the expansion joint to the tank shell and inspections performed were done in a similar nanner pictorialiy illustrated in Sketch fll 4 , Section (2)-i of this manual, except an additional inspection was performed on " $L$ " and "kn" units and was as follows:

After the expansion joint was tacked to the main tank shell and level readings on the bearing ring were taken, measurements from the top face of the bearing ring to each of the four reference 


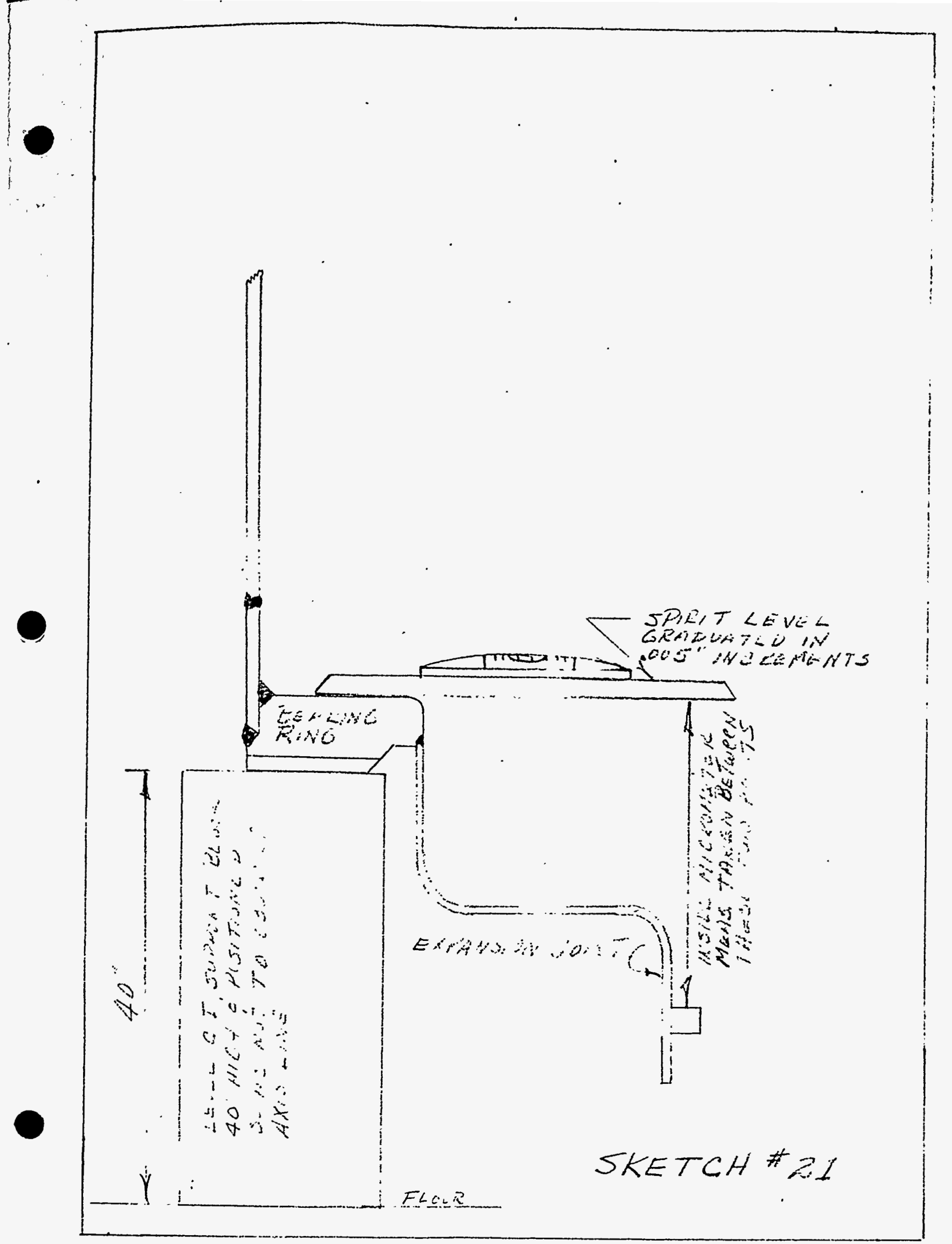


buttons welded to the expansion joint were agoin taken in a similar sanner described in item [7] above. This was deemed necessary in orcier to determine if the expansion joint was stili in an unstrained position.

- If reference measurements taken in [7] deviate considerably from measurements taken after tack welding the expansion joint to the tank shell, the expansive joint is in a strained position. If this condition exists, the readings are made to compare to reference measurements by adjusting the spider web gear inside the main tank assembly until readings are ouplicated within a few thousandths of reference measurements.

[9] Transfer of Axes from Eottom Tube Sinect to Nozale Section

In order to assist the field construction force to assembly and set up units at the plant site, $x$ and $Y$ axes previously established on the "L" (or "K") were transferred to the botton of the bottom tube sheet and to the inside and outside of the cottom tube shect nozzle section at a point approximately I" below the prepared welding edge on the nozzle assembly. Transfer of centeriines was done with the aid of the wild II theodolite. This was accomplished by "waliong" the theodolite in on the estabished centerlines, transferring these lines to the floor, and then setting up the instrument on the established floor points. These points were picked up from the floor in a similar manner to that shown in sketch 424 , part VII, Section III, and projected back: to the outside of the nozzle assembly, BTS wrapper plates and the botton ends of the extreme tubes located on the $X$ and $Y$ dxes. Ihese points ware then used for lofting in the main section described in the next section.

[10] Orientation and Fit-up of the fiain Tank and inclosure to the Bottom rube sheet rozzle section

With the bottom tube sineet leveI within .008", the "I" main tark shell and enclosure wis placed on the bottom tube sheet nouzle assembly with the aid of an overhead crane. The theodolite was then set-up and on the flor points established at the extreme ends of ine of the axis. (see sketch $f_{126}$, Section $A(2)-h$ which pictorially illustrates where the theodolite wis first placed). After adjusting the instrument to coincicie with the floor points, the instrument's line of sight was projected from the bottom tube sheet centerline points to the centerlines on the top tule sheet enclosure. The enclosure 
and main tank were then rotated until all axis lines on this side coincided. These axis lines were checked on all four sides of the tank shell in a similar manner to that pictorialiy illustrated in Sketch 16 referenced above.

Following the above procedure, the bearing ring was leveled and the expansion joint adjusted (if necessary) until the bearing ring was level and in an unstrained position. This adjusting of the bearing ring sometimes causes mo ement of the entire tank shell so the theodolite was set up again and all tank centerlines checked for being coincident as described above.

After the assembly met the above requirements, the distance from the bearing ring to the tops of bottom tube sheet tubes was checked at positions $x_{1}$, $X_{2}, I_{2}$ and $Y_{2}$. This Has measured $b_{s}$ placing a straight edge on the bearing ring and taping the distance between the face of the straight edge and tube ends with a $100 \mathrm{ft}$. stainless ste 1 tape graduated in 1/16". Timenion "C" on Dr. No. 6353-8 presented herewith illustrates pictorially where these measurements vere tikane and the results obtained.

If these measurements are long, the main tank is removed and the excess metal is chipped from the top edge of the nozzle assembly. After this the main tank is again put back on the nozzle assembly and the entire procedure discussed above is repeated. The measurements from the bearing ring to bottom tube sheet tubes are again taken and if they within a tolerance of to $-1 / 32^{\prime \prime}$, these measurements are accepteu.

Finally, measurements from the 12 bearing ring cutouts to the bottom of each botton tube sheet bearing pad yere taken using a level and 100' stainless steel tape graduated in $1 / 16^{\circ}$.

Results of the a bove inspections are covered in Dr. No. 6353-8 presented herewith anci were acceptable.

Befure renoving the maintank section from the botton tube sheet, diameter measurements were taken on the assembly. The method used was similar to that described in section $A(I)-b$ of this manual.

Final results of tank diameter measurements are shown on Dr. No. 6353-7 presented herewith.

The main $t$ ank was accepted, removed from the bottom tube sheet assembly and prepared for shipmentto the Savannah River Plant located in the state of South Carolina. 


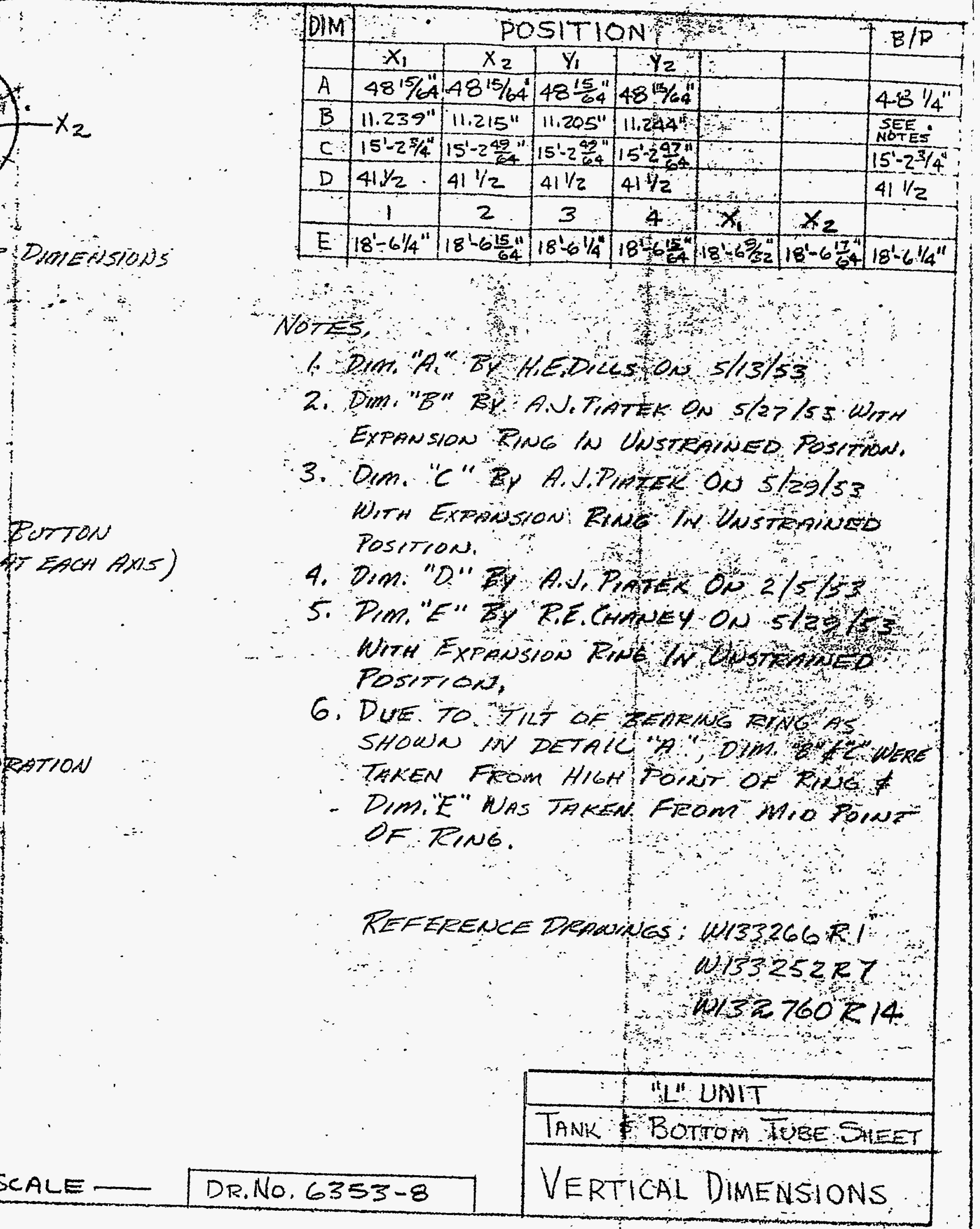




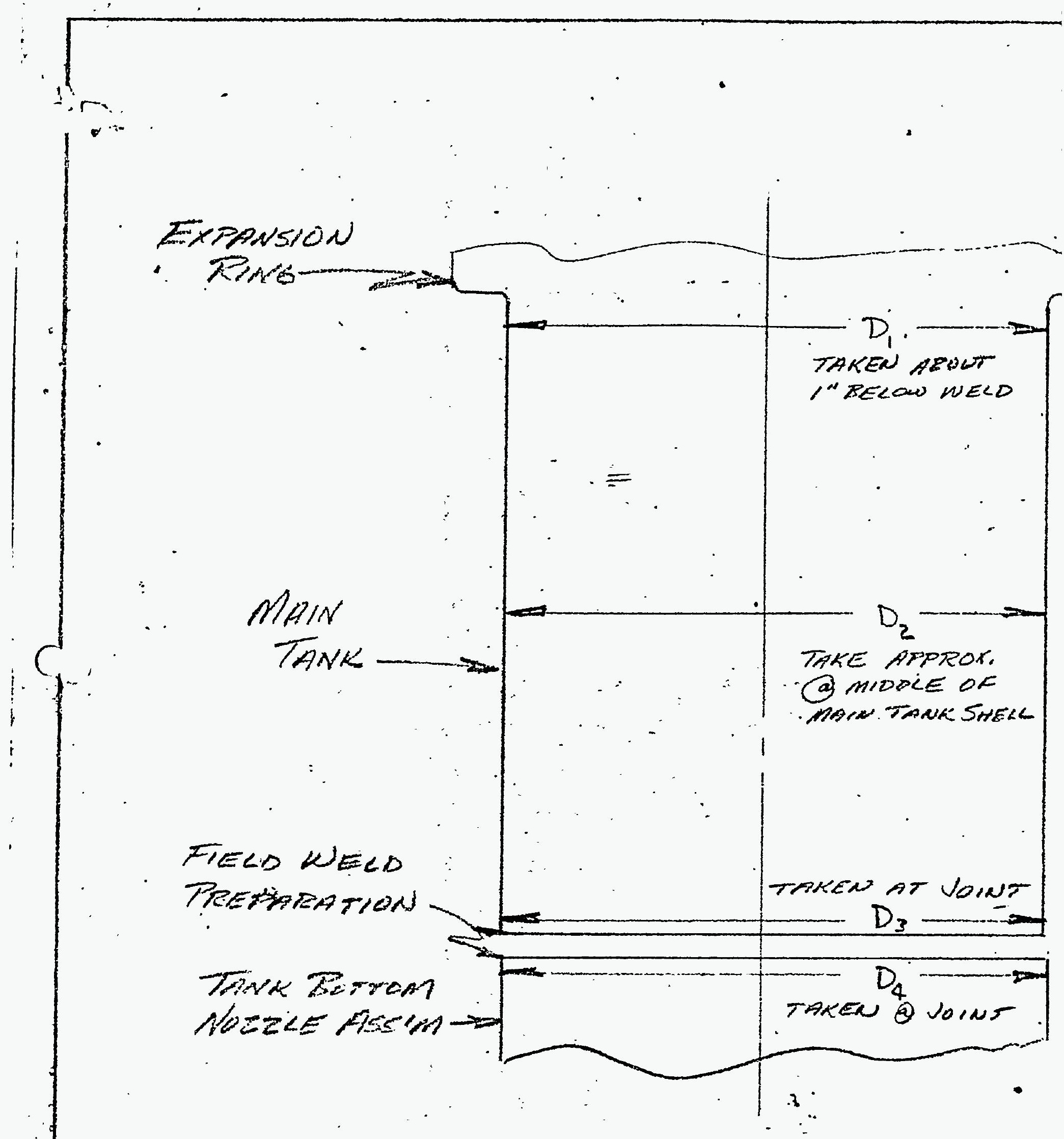

- This Drawing is Not To 


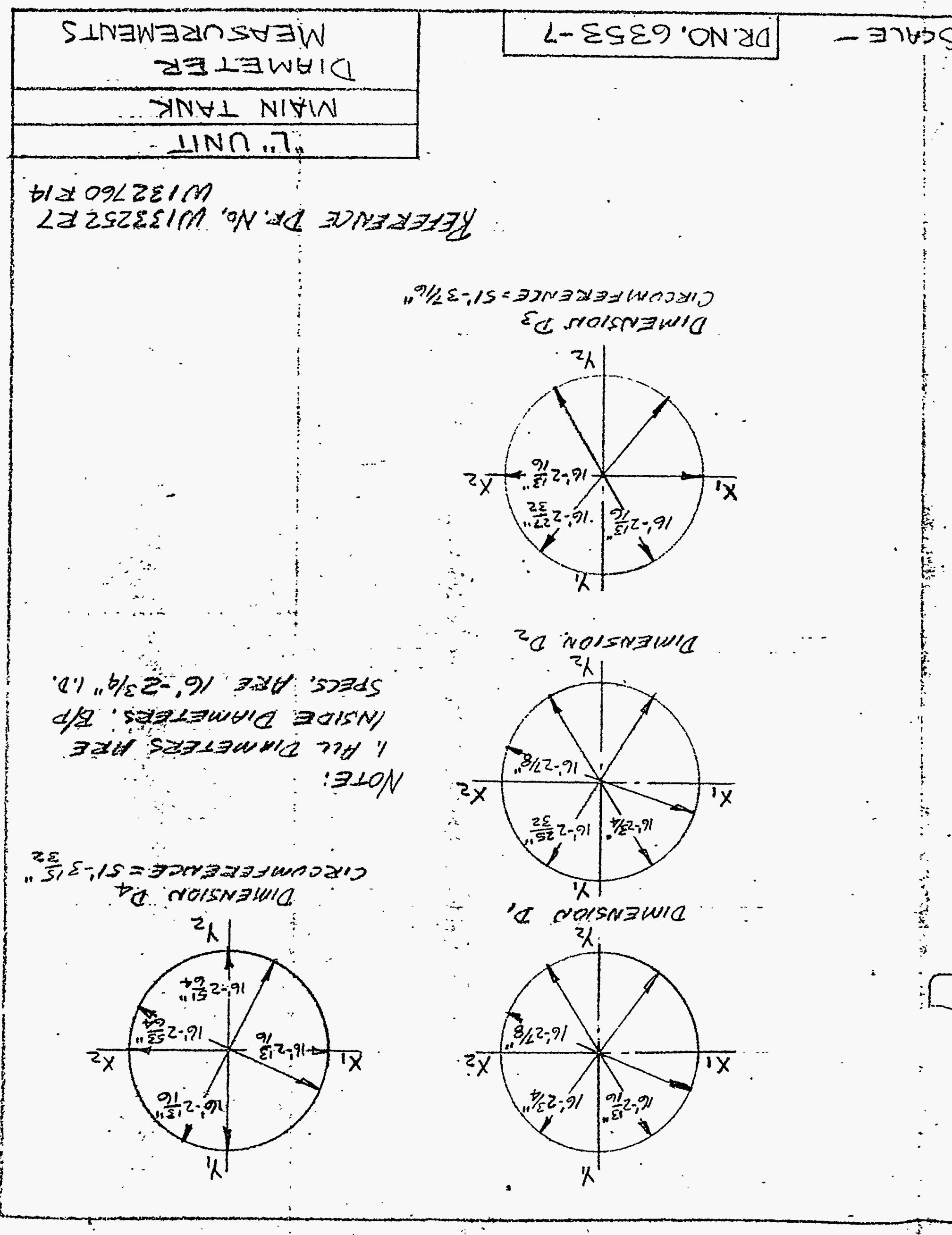

